\title{
Site $\mathrm{C}^{0011^{1}}$
}

\author{
Expedition 322 Scientists $^{2}$
}

\section{Chapter contents}

Background and objectives.......... 1

Operations................... 2

Lithology .................4

Structural geology. .............. 11

Biostratigraphy ................ 13

Paleomagnetism ................ 14

Physical properties .............. 20

Inorganic geochemistry . . . . . . . . 23

Organic geochemistry. ............ 26

Microbiology .................. 28

Downhole measurements... . . . . . . . . . 28

Logging and core-log-seismic integration . . . 29

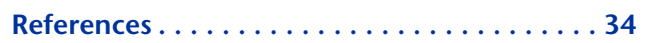

Figures..................... 38

Tables....................... 120

${ }^{1}$ Expedition 322 Scientists, 2010. Site C0011. In Saito, S., Underwood, M.B., Kubo, Y., and the Expedition 322 Scientists, Proc. IODP, 322: Tokyo (Integrated Ocean Drilling Program Management International, Inc.).

doi:10.2204/iodp.proc.322.103.2010

'Expedition 322 Scientists' addresses.

\section{Background and objectives}

Integrated Ocean Drilling Program (IODP) Site C0011 (proposed Site NT1-07) was the primary site for IODP Expedition 322 (Saito et al., 2009). The site is located in the Shikoku Basin on the northwest flank of a prominent basement high (Kashinosaki Knoll) that was constructed on the subducting Philippine Sea plate (Fig. F1). The primary purpose of drilling at this location was to recover a complete section of sedimentary strata and uppermost igneous basement, thereby characterizing the subduction inputs to the Nankai Trough. Analysis of seismic reflection data just prior to drilling indicated a depth to basement of $~ 1050$ meters below seafloor (mbsf). This estimate of total sediment thickness is considerably less than the value used in the Scientific Prospectus $(1200 \mathrm{~m}$ thick). The adjustment was made after making refinements to the acoustic velocity model following successful acquisition of loggingwhile-drilling (LWD) data during the final days of IODP Expedition 319. The availability of LWD data was a major benefit for scientific productivity during Expedition 322 by guiding both operations and scientific interpretations. For example, the coring plan was modified to begin sampling at $340 \mathrm{~m}$ core depth below seafloor (CSF) rather than the original position of $400 \mathrm{~m} \mathrm{CSF}$, and plans to deploy the sediment temperature-pressure (SET-P) tool for in situ pressure measurements were adjusted to target the most favorable intervals on the logs.

By recovering a complete suite of cores and LWD logs from Site C0011, the Expedition 322 scientists expected to help answer the following questions:

1. How does the physical hydrogeology of the Shikoku Basin respond to variations in primary lithologic architecture and basement structure?

2. How do fluids in the igneous basement affect subduction processes?

3. How have system-wide patterns of sediment dispersal affected composition within the Shikoku Basin, particularly on the northeast side of the fossil spreading ridge (Kinan seamount chain)?

4. Which factor(s) inherited from the Shikoku Basin control(s) the décollement's position near the toe of the Nankai accretionary prism, as well as the location of ramps and flats and mechanical behavior throughout?

5. Does the plate boundary fault, near its updip limit of seismicity, shift its position from a sediment/sediment interface 
(stable sliding) to the sediment/basalt interface (stick-slip)? If so, what are the causes?

Answers to these questions will require data from multiple drilling sites and expeditions and will contribute to the success of the Nankai Trough Seismogenic Zone Experiment (NanTroSEIZE) in many important ways. Fundamentally, the results from Expedition 322 will document initial conditions within presubduction equivalents of the seismogenic zone.

\section{Operations}

Expedition 322 began at $0000 \mathrm{~h}$ on 1 September 2009 during the port call at Yokkaichi, Japan. The science party boarded the D/V Chikyu in the morning hours, and an initial science meeting was held. A prespud meeting with ship crew was held the next day. See Table T1 for a breakdown of general coring operations.

Before the start of Expedition 322, LWD and measurement-while-drilling (MWD) data were collected in Hole C0011A during the contingency days at the end of Expedition 319. As a part of across-expedition collaboration within NanTroSEIZE, data interpretation of the LWD/MWD was carried out mainly during Expedition 322 by its shipboard scientists. Therefore, we start this section with the Expedition 319 LWD/ MWD operations.

\section{Hole C0011A (Expedition 319)}

Schlumberger engineers and technicians prepared the Schlumberger LWD and MWD tools for assembly prior to drilling Hole C0011A (target depth = as deep as possible or $900 \mathrm{mbsf}$, water depth $=4049 \mathrm{~m}$ ). Because the water depth was too great for remotely operated vehicle placement of transponders, the six transponders were dropped from the drillship and all were dropped by $0400 \mathrm{~h}$ on 26 August. At $0845 \mathrm{~h}$ on 26 August, the $12^{1 / 4}$ inch bit LWD/MWD bottomhole assembly (BHA) (Table T2) was run into the hole, and a calibration check was conducted between the Big Head transducers on the ship and the transponders on the seafloor. At $1900 \mathrm{~h}$ on $26 \mathrm{Au}-$ gust, a prespud meeting was held to determine target depth (determined as $900 \mathrm{~m}$ LWD depth below seafloor [LSF]), jet-in program, and conditions for stopping drilling. Spud-in of Hole C0011A was achieved at $2239 \mathrm{~h}$ on 26 August, and the mudline (i.e., water depth) was confirmed to be $4049 \mathrm{~m}$ by MWD gamma ray measurement. After jetting in to $41 \mathrm{~m}$ drilling depth below seafloor (DSF), drilling the 121/4 inch hole commenced. There were short wiper trips and sweeps to maintain good borehole condition and to prevent the BHA from getting stuck in the hole. Total depth (TD) (952 m LSF) was reached at $2359 \mathrm{~h}$ on
29 August, spotted $121 \mathrm{~m}^{3}$ of $1.30 \mathrm{~g} / \mathrm{cm}^{3}$ kill mud, and began pulling out of the hole. The BHA reached the surface at $1300 \mathrm{~h}$ on 30 August, and the tools were laid down for LWD data recovery. Meanwhile, the Chikyu moved to the rendezvous point for the supply ship, the Kaiko, to load and backload cargo for Expedition 322.

\section{Transit}

The Chikyu departed the port of Yokkaichi at $1600 \mathrm{~h}$ on 4 September 2009 . After $\sim 130 \mathrm{nmi}$ of transit, the Chikyu arrived at drill Site C0011 at $1100 \mathrm{~h}$ on 5 September. We carried out underwater television (UWTV) free fall for torsion release and spaced out the inner barrel assembly.

\section{Hole C0011B}

We started running into the hole with the $105 / 8$ inch rotary core barrel (RCB) BHA at $2230 \mathrm{~h}$ on 5 September. The center bit was dropped at $1000 \mathrm{~h}$ on $6 \mathrm{Sep}-$ tember, and then we spudded Hole C0011B at $1700 \mathrm{~h}$ after the replacement of a leaking wash pipe. UWTV was not used because of bad sea conditions, which created uncertainty in the depth of the mudline. It was decided that removing the guide horn for UWTV deployment was more risky than the lack of UWTV. Water depth at the site was set as $4077 \mathrm{~m}$ drilling depth below rig floor (DRF) (4048.7 m DSF), based on the gamma ray log data of Expedition 319 Hole C0011A.

We continued drilling to $4367 \mathrm{~m}$ DRF. Rate of penetration (ROP) was controlled at $30 \mathrm{~m} / \mathrm{h}$ and was $17.6 \mathrm{~m} / \mathrm{h}$ including the pipe connection. Hi-Vis gel was pumped at every two stands. At $1015 \mathrm{~h}$ on $7 \mathrm{Sep}-$ tember, a leak was found in the wash pipe and it was replaced. At $1700 \mathrm{~h}$, the drain hose of the core line wiper was replaced and drilling operations resumed. We reached $4417 \mathrm{~m}$ DRF (340 m DSF) at $1945 \mathrm{~h}$.

The center bit assembly was retrieved at a second attempt at $0030 \mathrm{~h}$ on 8 September. RCB core was cut from $4417 \mathrm{~m}$ DRF under heave of $1.5 \mathrm{~m}$. Core 322C0011B-1R was recovered on deck at $0258 \mathrm{~h}$. The core liner was jammed inside the inner barrel and was removed with a high-pressure pump. The hole was swept out with $10 \mathrm{~m}^{3}$ of Hi-Vis gel while removing core liner. The $2.2 \mathrm{~m}$ long recovered core was heavily disturbed because of a twisted core liner.

We were unable to continue sinker bar operations because of high winds ( $>20 \mathrm{~m} / \mathrm{s})$. We decided to wait on weather (WOW) as of $0515 \mathrm{~h}$. The drill bit was pulled up to $50 \mathrm{~m}$ DSF. Operations resumed at $1300 \mathrm{~h}$ once the wind speed decreased to $<18 \mathrm{~m} / \mathrm{s}$. Before resuming RCB coring, test runs of SET-P and UWTV were carried out. The SET-P tool with colleted 
delivery system (CDS) was run through the drill pipe and held $30 \mathrm{~s}$ without drilling mud circulation at 1000 and $2000 \mathrm{~m}$ DRF. The tool was retrieved and the data showed successful results of water pressure measurements. Then, a UWTV test run was carried out from 1645 to $0600 \mathrm{~h}$ on 9 September.

RCB coring operations resumed at $0800 \mathrm{~h}$. After running into the hole bottom, Core 322-C0011B-2R was cut from $4426.5 \mathrm{~m}$ DRF at $1100 \mathrm{~h}$ and recovered on deck at $1315 \mathrm{~h}$. The recovered core was $1.3 \mathrm{~m}$ long with $13.7 \%$ recovery. Core $322-\mathrm{C} 0011 \mathrm{~B}-3 \mathrm{R}$ was cored by a $6.0 \mathrm{~m}$ advance for space-out. The $6.26 \mathrm{~m}$ of core was on deck at $1623 \mathrm{~h}$ with $104.3 \%$ recovery. Core 322-C0011B-4R was recovered on deck after a second attempt at $2337 \mathrm{~h}$. The recovered core was $3.55 \mathrm{~m}$ long.

Coring continued smoothly on 10 September. Eight cores were cut and recovered from Core 322-C0011B$5 \mathrm{R}$ at $0235 \mathrm{~h}$ through $12 \mathrm{R}$ at $2324 \mathrm{~h}$. Core recovery averaged $69.7 \%$ through the day. Hi-Vis mud was pumped to clean the hole between each coring operation.

Core 322-C0011B-13R was cut from $4527.5 \mathrm{~m}$ DRF at $0015 \mathrm{~h}$ on 11 September but was not recovered until $0857 \mathrm{~h}$. The core line winch cable was tangled at $160 \mathrm{~m} \mathrm{DRF}$, and coring operations were suspended until $0700 \mathrm{~h}$. Core 322-C0011B-14R was on deck at $1148 \mathrm{~h}$ and recovery was $5.78 \mathrm{~m}$.

Core 322-C0011B-15R was cut from $4546.5 \mathrm{~m}$ DRF at $1247 \mathrm{~h}$, but core jamming was suspected when the ROP decreased at $4553.8 \mathrm{~m}$ DRF. Coring was stopped after a $7.3 \mathrm{~m}$ advance and retrieval of the inner barrel was attempted. After two unsuccessful latching attempts, the core line was changed from aft to forward. The third attempt was also unsuccessful. The sinker bar was retrieved without the inner barrel, and a shear pin of the retrieving tool was found broken.

Core 322-C0011B-15R was finally retrieved on deck at $1204 \mathrm{~h}$ on 12 September. The fourth attempt without a line wiper worked, and the core barrel was successfully caught. The recovered core was $7.36 \mathrm{~m}$ long from a $7.3 \mathrm{~m}$ advance. After reaming down to the hole bottom and pumping $10 \mathrm{~m}^{3}$ of Hi-Vis gel, the inner barrel was dropped at $1330 \mathrm{~h}$ and coring of Core 322-C0011B-16R was started.

Drilling of Core 322-C0011B-16R was stopped after a $2.3 \mathrm{~m}$ advance because of a drop in ROP. The core was on deck at $1641 \mathrm{~h}$ and $1.98 \mathrm{~m}$ of core was recovered. Core 322-C0011B-17R was another short $2.4 \mathrm{~m}$ advance. Coring was stopped because of a drilling break. Only a few pieces of mudstone/sandstone were recovered at $2045 \mathrm{~h}$.

On 13 September, seven cores from Core 322C0011B-18R through 24R were recovered. Core 322-
C0011B-18R was no recovery after a full $9.5 \mathrm{~m}$ advance. Core 322-C0011B-19R was stopped after a $7.5 \mathrm{~m}$ advance because of slow ROP and was on deck at $0545 \mathrm{~h}$ with $100 \%$ recovery. Core $322-\mathrm{C} 0011 \mathrm{~B}-20 \mathrm{R}$ was on deck at $0930 \mathrm{~h}$ after a $3.1 \mathrm{~m}$ advance. Coring was stopped because of unsteady pump pressure from $4576 \mathrm{~m}$ DRF. The recovered core was $0.58 \mathrm{~m}$ long. Cores 322-C0011B-21R and 23R were good recovery (>90\%), But Core 322-C0011B-22R recovered only $0.23 \mathrm{~m}$ of material in the core catcher. Core 322-C0011B-24R was on deck at $2351 \mathrm{~h}$ and $5.21 \mathrm{~m}$ of core was recovered.

On 14 September, five cores from Core 322-C0011B$25 \mathrm{R}$ through $29 \mathrm{R}$ were recovered. Coring of Core 322-C0011B-28R was stopped because of a drop in ROP and abnormal pressure observed at $4649.7 \mathrm{~m}$ DRF. Core 322-C0011B-29R was on deck at $1725 \mathrm{~h}$ and only $0.3 \mathrm{~m}$ of fragments was found in the core catcher.

The center bit assembly was dropped for cleaning inside the pipe and bit. Then, after checking pump pressure of circulation, coring operations resumed at $0100 \mathrm{~h}$ on 15 September. Core 322-C0011B-30R was on deck at $0410 \mathrm{~h}$, and $4.01 \mathrm{~m}$ of core was recovered from a $6.1 \mathrm{~m}$ advance. After reaming from 4625 to $4663 \mathrm{~m}$ DRF, Core 322-C0011B-31R was on deck at $0827 \mathrm{~h}$. Relatively good core recovery continued until Core 322-C0011B-39R, except for Core 322-C0011B$34 \mathrm{R}$, which ended up with $0.32 \mathrm{~m}$ of material.

On 16 September, SET-P measurement was planned after coring $8.5 \mathrm{~m}$ of Core 322-C0011B-40R. This was to deploy the SET-P tool at $680.5 \mathrm{~m}$ DSF, targeting an inferred sandy layer identified in the LWD log. Core 322-C0011B-40R, however, hit a hard layer and $4.92 \mathrm{~m}$ of core was recovered from a $6.5 \mathrm{~m}$ advance. The remaining $2.0 \mathrm{~m}$ was cored as Core 322-C0011B$41 \mathrm{R}$ in order to determine lithology before planned SET-P measurement.

Core 322-C0011B-41R was on deck at $1730 \mathrm{~h}$, and $0.25 \mathrm{~m}$ of calcareous concretion was recovered in the core catcher and several pebbles of hard mudstone were found in the bottom of the core. The lithology was not what we expected around this interval and was obviously not suitable for the SET-P experiment. We attempted another short $(4.5 \mathrm{~m})$ core (322C0011B-42R). Core 322-C0011B-42R was on deck at $2108 \mathrm{~h}$, and $3.64 \mathrm{~m}$ of softer mudstone was recovered.

Because we were uncertain in depth determination without good correlation between LWD and multisensor core logger (MSCL) data, it was unclear whether we had overshot the target sand layer or were still above it. We continued to attempt to identify a key bed for SET-P deployment by another short (4 m) core (322-C0011B-43R). 
Core 322-C0011B-43R was on deck at $0438 \mathrm{~h}$ on 17 September after the fourth attempt to catch the inner barrel. The recovered core was $8.49 \mathrm{~m}$ and $>200 \%$ recovery. At a first sight, the lithology looked like a thick sand layer sandwiched by mudstone in the top $2 \mathrm{~m}$ and the bottom. But the bed turned out to be fragmented material such as drill cuttings/ debris in the hole bottom.

Having spent more than the $12 \mathrm{~h}$ allocated to this experiment in our operations plan, we decided to cancel our SET-P deployment. We canceled a second run planned at $\sim 900$ mbsf as well because the deployment would have been more difficult in deeper sections without a clear target.

After this decision, RCB coring operations resumed. Cores 322-C0011B-44R and 45R were good recovery (>8 m), but Core 322-C0011B-46R was a short $3.5 \mathrm{~m}$ advance because of low penetration and high torque, and $1.79 \mathrm{~m}$ of core was recovered.

RCB coring continued on 18 September but the recovered core was not as good as expected in rough sea conditions under the influence of an approaching typhoon. Core 322-C0011B-48R contained rounded pebble-size mudstone, which was suspected to be caving/cuttings material. Core 322-C0011B$49 \mathrm{R}$ was on deck at $1100 \mathrm{~h}$, but the plastic liner was found damaged and jammed in the inner barrel. Recovery of material at the rig floor was finished at $1345 \mathrm{~h}$. The recovered core was $6.68 \mathrm{~m}$ long from a $7.9 \mathrm{~m}$ advance. Core 322-C0011B-50R was on deck at $1745 \mathrm{~h}$, but core quality was again not good. We decided to clean the bit and the hole and WOW before continuing coring.

After hole and bit cleaning was completed, the drill bit was pulled up to $~ 50$ m DSF for WOW. Advisory status continued until $1800 \mathrm{~h}$ on 19 September because of average wind speed $>18 \mathrm{~m} / \mathrm{s}$. Operations resumed at $2200 \mathrm{~h}$, and Core 322-C0011B-51R was cored from $757 \mathrm{~m}$ DSF and was on deck at $1100 \mathrm{~h}$ on 20 September. The recovered core was $10.15 \mathrm{~m}$ long. Core $322-C 0011 \mathrm{~B}-52 \mathrm{R}$ was on deck at $1744 \mathrm{~h}$. Another $10.15 \mathrm{~m}$ of core was recovered after a second try of catching the inner barrel. Core 322-C0011B53R was on deck at $2207 \mathrm{~h}$, but a drop in penetration resulted in short $3.7 \mathrm{~m}$ advances.

On 21 September, Cores 322-C0011B-54R and 55R were forced to be short $8.8 \mathrm{~m}$ and $7.3 \mathrm{~m}$ advances, respectively. After Core 322-C0011B-55R, coring was skipped because of the slow penetration and poor quality, and we drilled with the center bit assembly from 4863.3 to $4921 \mathrm{~m} \mathrm{DRF}(57.7 \mathrm{~m})$.

Coring operations resumed at $0000 \mathrm{~h}$ on 22 September. Core 322-C0011B-56R was on deck at $0404 \mathrm{~h}$, and $2.53 \mathrm{~m}$ of core was recovered from a $2.4 \mathrm{~m}$ ad- vance. Core 322-C0011B-57R was on deck at $0937 \mathrm{~h}$, and $6.93 \mathrm{~m}$ of core was recovered. Core 322-C0011B$58 \mathrm{R}$ was on deck at $1545 \mathrm{~h}$, and $9.89 \mathrm{~m}$ of core was recovered in relatively good condition. Core 322C0011B-59R was on deck at $2146 \mathrm{~h}$, and $3.73 \mathrm{~m}$ of core was recovered from an $8.6 \mathrm{~m}$ advance.

Core 322-C0011B-60R was on deck at $0215 \mathrm{~h}$ on 23 September, and $0.15 \mathrm{~m}$ of material was recovered from a short $2.0 \mathrm{~m}$ advance because of low ROP. It was decided to wash down several more tens of meters after recovery of the next core. However, Core 322-C0011B-61R was not recovered until $1249 \mathrm{~h}$, even with a $5.0 \mathrm{~m}$ advance, and only $5 \mathrm{~cm}$ of material was recovered. The Co-Chief Scientists decided to finish operations at this site and move to the next site. Kill mud (100 $\mathrm{m}^{3}$ of $\left.1.3 \mathrm{SG}\right)$ was spotted, and we started pulling out of the hole at $1730 \mathrm{~h}$. The TD of Hole C0011B was $4958.0 \mathrm{~m}$ DRF (881.0 m DSF). Upon retrieval, the drill bit was shown to be heavily damaged with most of its cutting teeth missing.

Retrieval of transponders started in the morning of 24 September and finished before $1830 \mathrm{~h}$. The ship moved to proposed Site NT1-01A and set transponders.

\section{Lithology}

At Site C0011, five lithologic units were identified on the basis of sediment composition, sediment texture, and sedimentary structures (Fig. F2; Table T3):

Unit I: 0-340 m CSF (bottom = Section 322C0011B-1R-1, $0 \mathrm{~cm}$ ),

Unit II: 340-479.06 m CSF (bottom = Section 322C0011B-17R-CC, $6 \mathrm{~cm}$ ),

Unit III: 479.06-673.98 m CSF (bottom = Section 322-C0011B-40R-2, $58 \mathrm{~cm}$ ),

Unit IV: 673.98-849.95 m CSF (bottom = Section 322-C0011B-57R-3, $73 \mathrm{~cm}$ ), and

Unit V: 849.95-876.05 m CSF (bottom = Section 322-C0011B-61R-CC, $5 \mathrm{~cm}$ ).

\section{Lithologic Unit I (upper Shikoku Basin)}

Interval: not cored

Depth: 0-340 m CSF

Age: Holocene-late Miocene ( 0-7.6 Ma)

Lithologic Unit I is defined from LWD and seismic data (see "Logging and core-log-seismic integration") as extending from the seafloor to $340 \mathrm{~m} \mathrm{CSF}$ (Section 322-C0011B-1R-1, $0 \mathrm{~cm}$ ). The age of the uppermost part of Unit II indicates that Unit I ranges from Holocene to late Miocene ( 0-7.6 Ma). Judging from the LWD data and correlation to other Ocean Drilling Program (ODP) sites in this region, Unit I is probably composed of silty clay(stone) with rare intercalation of volcanic ash layers. 


\section{Lithologic Unit II (middle Shikoku Basin)}

Interval: Sections 322-C0011B-1R-1, $0 \mathrm{~cm}$, through 17R-CC, $6 \mathrm{~cm}$

Depth: 340-479.06 m CSF

Age: late Miocene (>7.6-9.1 Ma)

Lithologic Unit II (middle Shikoku Basin) is $139.06 \mathrm{~m}$ thick and extends from 340 to 479.06 m CSF (Fig. F2; Table T3). The dominant lithology is green-gray silty claystone, which alternates with medium- to thickbedded volcaniclastic and tuffaceous sandstone interbedded with dark gray clayey siltstone. The green-gray silty claystones appear to be the "background sedimentation" and typically occur as intensely bioturbated intervals from centimeters to several meters thick (Fig. F3A). Within the silty claystone intervals, dark green claystone layers are typically $<0.5 \mathrm{~cm}$ thick, and, where bioturbation has not obscured their presence to the naked eye, they are commonly spaced $5-10 \mathrm{~cm}$ apart. Partly based on LWD data (see "Logging and core-log-seismic integration"), the tuffaceous sandstones occur in intervals $2-10 \mathrm{~m}$ thick (Fig. F4). The tuffaceous sandstone beds commonly range from granular to fine-grained sandstone, and they are typically normally graded with plane-parallel lamination (Fig. F3B).

Smear slide estimates show that the tuffaceous sandstones are composed of $>25 \%$ pyroclasts, with magmatic minerals showing relative abundances of plagioclase $>$ pyroxene $>$ amphibole. The volcanic glass appears very fresh, with pumiceous glass as the dominant component. The siliciclastic component of the sandstone is mainly fragments of reworked chert, altered tuff fragments, siltstone, and sandstone.

Interbeds of volcaniclastic sandstone, silty claystone, and siltstone characterize the lower part of lithologic Unit II. The silty claystone typically occurs as intensely bioturbated intervals from centimeters to several meters thick. The first sandstone with estimates of $<25 \%$ pyroclasts occurs at $435.99 \mathrm{~m}$ CSF (smear slide data from Section 322-C0011B-11R-5, $75 \mathrm{~cm}$ ). The volcaniclastic sandstones occur in packets 2-4 $\mathrm{m}$ thick (based on the LWD data; see "Logging and core-log-seismic integration") and are typically normally graded and show gradational contacts into dark gray siltstone. The dark gray clayey siltstone also occurs as discrete beds that are typically $0.1-1 \mathrm{~m}$ thick (Fig. F5) and display minimal amounts of bioturbation.

The volcaniclastic sandstones include both volcaniclastic and terrigenous siliciclastic grains. Smear slide estimates show $>25 \%$ volcaniclastic grains and $<25 \%$ pyroclastic grains. These sandstones have a large amount of minerals, with relative abundances of plagioclase $>$ pyroxene $>$ quartz $>$ amphibole. The estimated quartz content is typically between $2 \%$ and $6 \%$, most of which is chert. Additionally, there are large amounts of sedimentary lithic grains, mainly as reworked siltstone, sandstone, and chert grains. In the lower part of lithologic Unit II, volcaniclastic components decrease below an estimated $25 \%$ of the total grain population. The lower part of lithologic Unit II has the first occurrence of diopside in Section 322-C0011B-5R-3, $63 \mathrm{~cm}$ (as an accessory mineral, <1\%), but from Section 322-C0011B-7R-6, $39.5 \mathrm{~cm}$, diopside is relatively common (up to $3 \%$ ). From Core 322-C0011B-7R, the volcanic glass appears altered, and there is a mixture of mafic and felsic glass shards.

Unit II also contains a chaotic deposit that is $10.29 \mathrm{~m}$ thick, extending from 400.86 to $411.15 \mathrm{~m}$ CSF (Sections 322-C0011B-7R-CC, $16.5 \mathrm{~cm}$, through 8R-7, $92 \mathrm{~cm}$ ). This deposit is composed of disaggregated pieces of volcaniclastic sandstone and bioturbated silty claystone that show tight to isoclinal folding, thinning and attenuation of original bedding, and subhorizontal small-scale faults with a normal (extensional) sense of displacement in the uppermost part (Fig. F6). Apparently, an in situ volcanic sandstone bed, immediately underlain and overlain by chaotic deposits, is at 405.29-406.01 m CSF (interval 322-C0011B-8R-3, 70-142 cm). Given the sediment deformation in the adjacent deposits, it seems most likely that this bed is also part of the chaotic deposit. An alternative interpretation is that two thinner chaotic units are separated by a single volcaniclastic sandstone bed.

Figure F7 and smear slides (see "Site C0011 smear slides" in "Core descriptions") show the total volcaniclastic components for Unit II, and Figure F8 shows representative photomicrographs from the smear slides. These results were obtained by point counting (200 points). Pyroclast abundance was used to define the first occurrence of tuffaceous sandstone. Overall, sedimentary lithic fragments are more abundant in the lower part of lithologic Unit II (Fig. F7).

\section{Lithologic Unit III (lower Shikoku basin)}

Interval: Sections 322-C0011B-17R-CC, $6 \mathrm{~cm}$, through 40R-2, $58 \mathrm{~cm}$

Depth: 479.06-673.98 m CSF

Age: middle Miocene ( 9.1-12.3 Ma)

Lithologic Unit III is $194.92 \mathrm{~m}$ thick and starts at $479.06 \mathrm{~m}$ CSF, immediately below an unusual tightly cemented terrigenous sandstone, and ends with the first appearance of dark gray clayey siltstone at $673.98 \mathrm{~m}$ CSF. Unit III is characterized by bioturbated silty claystone. Zoophycos isp., Phycosiphon incertum, and Chondrites isp. are common in the silty 
claystone, and the intensity of bioturbation mostly corresponds to bioturbation Index 5 (see the "Methods" chapter). Unit III contains minor amounts of dark gray silty claystone and lime mudstone (Fig. F9). Unit III also contains dark green layers, typically $<0.5 \mathrm{~cm}$ thick with variable spacing, but as repetitive as one every $5-10 \mathrm{~cm}$. These dark green layers are intensely bioturbated and contain altered mafic glass, silica, and plagioclase. The off white-colored lime mudstone lithology is rich in altered nannofossils. A cemented, laminated carbonate layer (very poor recovery) is present at interval $322-\mathrm{C} 0011 \mathrm{~B}-44 \mathrm{R}-1$, 0 $61 \mathrm{~cm}$. Minor amounts of ocher-colored burrows occur throughout Unit III. Although nannofossils are rare in parts of Unit III, some burrows contain nannofossils. Small amounts of pyrite are also present, with a few pieces up to $2 \mathrm{~mm}$ in diameter.

A thin chaotic deposit was identified at 570.91$571.42 \mathrm{~m}$ CSF (Section 322-C0011B-28R-3, 92-143 cm). Possible creep structures are recognized at intervals 322-C0011B-21R-6, 50-54 cm; 26R-5, 44-46 cm; and 31R-3, 111-116 cm (see "Structural geology").

Smear slide estimates for Unit III show relatively low amounts of quartz, accessory minerals (i.e., all other minerals except clay minerals), and volcaniclastic components. Within Unit III, there is an overall uphole increase then decrease in the amount of feldspar, with a maximum estimated value near $575 \mathrm{~m}$ CSF (Fig. F10; "Site C0011 smear slides" in "Core descriptions").

\section{Lithologic Unit IV (lower Shikoku Basin)}

Interval: Sections 322-C0011B-40R-2, $58 \mathrm{~cm}$, through $57 \mathrm{R}-3,73 \mathrm{~cm}$

Depth: 673.98-849.95 m CSF

Age: middle Miocene ( 12.3-14.0 Ma)

The top of lithologic Unit IV is gradational from Unit III, at $673.98 \mathrm{~m} \mathrm{CSF}$, starting with the first core recovery of clayey siltstone. The base of Unit IV is placed at $849.95 \mathrm{~m} \mathrm{CSF}$, above the first appearance of tuff. Although the overall core recovery statistic in Unit IV was $\sim 86 \%$, much of the section is unsampled in the $56.7 \mathrm{~m}$ thick washdown interval between 786.3 and $844.0 \mathrm{~m} \mathrm{CSF}$.

Unit IV is characterized by alternations of silty claystone, clayey siltstone, and normally graded sandstone (Fig. F11). The clayey siltstone typically occurs in beds 5-60 $\mathrm{cm}$ thick (Fig. F4), mainly with sharp bases, diffuse plane-parallel lamination in the lower parts, and normal grading into silty claystone at the top. Bioturbation in the clay-bearing siltstone is slight to moderate, compared with the intense bioturbation observed in the silty claystone. We interpret these deposits as muddy turbidites. The sharp-based, normally graded sandstones are $10-80 \mathrm{~cm}$ thick and typically show plane-parallel lamination. The sandstones commonly contain small, disseminated wood fragments $<5 \mathrm{~mm}$ in diameter. Dark-colored anastomosing, millimeter-scale deformation bands occur at the base of some clayey siltstone beds (see "Structural geology").

Smear slide estimates show that the clay-bearing siltstones in Unit IV have a larger terrigenous component than hemipelagic deposits in Unit III, with more abundant detrital quartz (Fig. F10; see "Site C0011 smear slides" in "Core descriptions"). Most quartz grains show undulose extinction. Also more abundant are grains of polycrystalline quartz and vein quartz (with chlorite inclusions as rhipidolith chlorite). Metamorphic rock fragments are also typical (i.e., sericite-quartz intergrowths) and characteristic of low-grade metamorphic terranes.

\section{Lithologic Unit V (lower Shikoku Basin)}

Interval: Sections 322-C0011B-57R-3, $73 \mathrm{~cm}$, through 61R-CC, $5 \mathrm{~cm}$

Depth: 849.95-876.05 m CSF

Age: middle Miocene ( $\geq 14.0 \mathrm{Ma})$

Lithologic Unit V starts at $849.95 \mathrm{~m} \mathrm{CSF}$ and extends to $876.05 \mathrm{~m} \mathrm{CSF}$ at the premature termination depth of Hole C0011B. The Unit IV/V boundary is at Section 322-C0011B-57R-3, $73 \mathrm{~cm}$, with the first appearance of tuff. The integrated age-depth model gives an age of $14.0 \mathrm{Ma}$ at the lithologic unit boundary (see "Paleomagnetism").

The main lithology in Unit V is tuffaceous sandy siltstone, with minor amounts of silty claystone and tuff (Fig. F12). The beds of tuffaceous sandy siltstone show normal grading, load structures, flame structures, and current-ripple lamination in their uppermost parts (Fig. F12).

Smear slide estimates show background mud sedimentation with $10 \%-40 \%$ glass and the tuffs containing $60 \%-80 \%$ glass, juvenile minerals, and minor amounts of pelagic sediments (claystone, chert, and siltstone grains). Within Unit V, there is a marked increase in the feldspar content (Fig. F10; "Site C0011 smear slides" in "Core descriptions"). Most of the tuffs show considerable alteration of the primary mineral components, also expressed in the occurrence of zeolites (e.g., analcime and clinoptilolite). The glass components appear to be derived from highly evolved, explosive volcanism. Mafic volcanic components are minor. Lithification of the tuffs has resulted from an increase in diagenetic carbonate cement and zeolites.

\section{X-ray diffraction analyses}

For Hole C0011B, the results of X-ray diffraction (XRD) analyses of bulk sediment samples are shown 
in Figure F13 and Table T4. In Unit II, XRD analyses of the bulk samples show that calcite is low throughout (up to $\sim 6 \%$, but typically $<0.5 \%$ ). Quartz appears fairly uniform $(\sim 15 \%)$ throughout the entire Unit II but with a slight increase toward the bottom (from $\sim 13 \%$ to $\sim 19 \%)$. Clay mineral content scatters in the upper part of Unit II (from $~ 90 \%$ to $40 \%$ ) and is approximately constant in the lower part of Unit II ( 64\%). Feldspar shows a minimal increase downhole in Unit II and is typically 13\%-14\%; outlying high values in the upper and lower part of Unit II exceed $30 \%$. The feldspar and clay mineral content are inversely correlated. This is probably a grain-size effect with more feldspar in the sand-size fraction.

Throughout Unit III, there are no significant variations in bulk mineralogy, with an average of $68 \%$ total clay minerals, $17 \%$ quartz, $12 \%$ feldspar, and $2 \%$ calcite. Departures from this typical composition are associated with thin beds of lime mudstone and calcareous claystone, which naturally show elevated relative percentages of calcite.

In Unit IV, quartz values range from $0.1 \%$ to $39 \%$, with an average of $18 \%$. Feldspar content varies between $1 \%$ and $40 \%$, with an average of $12 \%$. Quartz and feldspar show similar variations, with a negative shift between 758.40 and $762.55 \mathrm{~m}$ CSF (Sections 322-C0011B-52R-2, $11 \mathrm{~cm}$, through 52R-5, $34 \mathrm{~cm}$ ) but increasing below $774.68 \mathrm{~m}$ CSF (Section 322C0011B-54R-5, $44 \mathrm{~cm}$ ) because of grain-size effects. Clay mineral content averages 64\%. Quartz and clay mineral content are inversely correlated. Calcite values are low $(<0.5 \%)$, except for several scattered samples of calcareous claystone.

In Unit $\mathrm{V}$, clay mineral content decreases from $73 \%$ to $47 \%$, with an average of $61 \%$. However, quartz and feldspar content increase from $8 \%$ to $40 \%$ and $11 \%$ to $23 \%$, respectively, with average values of $23 \%$ and $15 \%$, respectively. In Unit V, calcite values were below detection limits.

XRD analyses of tuff samples from Unit V show the presence of zeolites, which corroborates the presence of analcime in smear slides. Zeolites include undifferentiated clinoptilolite/heulandite and analcime (Fig. F14). Also, there are considerable amounts of authigenic smectite in the altered tuffs.

\section{X-ray fluorescence analyses}

In order to characterize compositional trends with depth and/or lithologic characteristics of the sediments from Hole C0011B, X-ray fluorescence (XRF) analysis was undertaken for 96 samples, which sampled all of the cored units (Fig. F15; Table T5). The analyzed sediments span a relatively small range of major element composition, compatible with a dom- inant crustal composition (both high $\mathrm{SiO}_{2}$ and $\mathrm{Al}_{2} \mathrm{O}_{3}$, Fig. F15A).

With depth, $\mathrm{Al}_{2} \mathrm{O}_{3}$ content (Fig. F15B) appears to decrease throughout the upper part of Unit II and appears constant in the lower part of Unit II and in Unit III. These variations reflect variations of clay mineral proportions as seen in XRD analyses (see "Xray diffraction analyses"). Unit IV and V sediments have variable $\mathrm{Al}_{2} \mathrm{O}_{3}$ composition.

Sodium content has local maxima in Unit II and V sediments (up to $4.43 \mathrm{wt} \%$, Fig. F15C) but shows an overall uphole increasing trend. Differentiating between lithologic units (Fig. F15D) shows that volcanic components result in higher $\mathrm{Na}_{2} \mathrm{O}$ content, compatible with the higher amount of feldspar observed in these sediments (see "X-ray diffraction analyses"). $\mathrm{Na}_{2} \mathrm{O}$ content (Fig. F15D), together with $\mathrm{MgO}$ and $\mathrm{K}_{2} \mathrm{O}$ (not shown) in the silty claystones, shows an uphole increasing trend. This is probably related to dilution by silica from quartz minerals as seen in the slightly increasing trend with depth in XRD analyses (see "X-ray diffraction analyses").

$\mathrm{K}_{2} \mathrm{O}$ content (Fig. F15E) is variable throughout Hole C0011B. Most of this variability can be explained by carbonate- and volcaniclastic-rich sediments, but the silty claystones also have a large scatter in values, which may be related to the presence of different types of clay minerals (e.g., illite). In Unit II, the sediments that include a volcanic component appear to have a smaller $\mathrm{K}_{2} \mathrm{O}$ content $\left(\mathrm{K}_{2} \mathrm{O}\right.$ from 1.07 to $2.16 \mathrm{wt} \%)$ compared with the sediments that include a volcanic component in Unit $\mathrm{V}\left(\mathrm{K}_{2} \mathrm{O}\right.$ from 1.23 to $3.68 \mathrm{wt} \%)$. This difference could be related to different volcanic sources and/or the chemical evolution of a single source.

The few lime mudstones that were analyzed have very high concentrations of both $\mathrm{P}_{2} \mathrm{O}_{5}$ and $\mathrm{MnO}$ (up to 8.4 and $11.2 \mathrm{wt} \%$, respectively, Fig. F15F). The high $\mathrm{P}_{2} \mathrm{O}_{5}$ content in the carbonate samples is probably related to the presence of authigenic apatite $\left(\mathrm{Ca}_{5}\left[\mathrm{PO}_{4}\right]_{3}[\mathrm{~F}, \mathrm{Cl}, \mathrm{OH}]\right)$. The $\mathrm{MnO}$ content can be explained by the presence of rhodochrosite $\left(\mathrm{MnCO}_{3}\right)$. Rhodochrosite is typical of anoxic environments and is indicative of geochemical conditions where ferric iron oxides usually dissolve (Canfield et al., 1992).

\section{Interpretation of lithologies and lithofacies at Site $\mathrm{C0011}$}

At Site C0011, six major lithologies are recognized (silty claystone, clayey siltstone, tuffaceous sandstone, volcaniclastic sandstone, sandstone, and volcanic ash/tuff) together with several minor lithologies such as tuffaceous siltstone, calcareous claystone, 
lime mudstones, and chaotic deposits. These lithologies compose four broad "lithofacies:" hemipelagic, turbidite, chaotic deposits, and tuff.

The hemipelagic lithofacies is composed mostly of silty claystone. Green-gray silty claystone is the dominant lithology throughout Site C0011. This lithology is intensely bioturbated and commonly intercalated with green silty claystone layers $(<1 \mathrm{~cm}$ thick). We interpret the lithofacies to represent the background sedimentation from suspended sediment. The approximately constant rate of sediment accumulation supports this interpretation (see "Sediment accumulation rates at Site C0011"). Minor lithologies, such as calcareous claystone and lime mudstone, contributed through high concentrations of nannofossils, although some such carbonates were probably produced by diagenesis.

Coarser grained lithologies (clayey siltstone, tuffaceous sandstone, volcaniclastic sandstone, and sandstone) all show sharp-based beds, normal grading, and plane-parallel lamination. Such features are typical in turbidites, and, therefore, we interpret these deposits as the products of sediment gravity flows, most likely from turbidity currents. Together, we group these lithologies into the turbidite lithofacies. The tuffaceous turbidity currents may have been triggered either by submarine slides or flow transformations from subaerial pyroclastic flows entering the ocean (e.g., Stow et al., 1998; Freundt, 2003; Freundt and Schmincke, 1998; Trofimovs et al., 2006) (Fig. F16). Terrigenous sand may have been deposited from turbidity currents that originated by flow transformations from debris flows or sediment slides (e.g., Felix and Peakall, 2006), hyperpycnal flow (Mulder and Syvitski, 1995), continuous breaching of an unconsolidated sand cliff (Mastbergen and Van Den Berg, 2003), mobilization of sand by storm waves, storm-surge ebb currents, or a seismic trigger. The clay-bearing siltstone also shows characteristic features of turbidites, such as normal grading and lamination, and they are less bioturbated than the hemipelagic lithofacies. The siltstone commonly overlies turbiditic sandstone with a gradational contact, and, therefore, it was probably deposited as muddy turbidites from the finest grain-size fraction.

The tuffaceous and volcaniclastic turbidites contain small amounts of terrigenous clasts. This suggests reworking of older sedimentary strata, the source of which remains unclear. The longevity and distance traveled by turbidity currents is derived from selfsustaining flow (i.e., the process by which the erosion of sediment from the bed increases current density) and, therefore, the downstream pull of gravity (Pantin, 1979; Parker, 1982). It is, therefore, reasonable to expect natural turbidity currents to develop from relatively weak initial upstream conditions (Naruse et al., 2008). Many of the sandstones at Site C0011 are mixtures of pyroclastic and terrigenous siliciclastic material, so this self-sustaining process can help explain the composition of turbiditic deposits.

Chaotic deposits occur in both Units II and III. The chaotic deposits of Unit II formed either during long-distance transport in cohesive debris flows or more locally as sediment slides (e.g., along the inner margins of submarine channels). The presence of coarse-grained sandstone injection features within the chaotic deposits, together with the presence of small-scale, near-horizontal normal faults at the top, favors an origin that was relatively close to Site C0011. The rotation of more steeply dipping faults during the final stages of sediment slumping and sliding, for example, could have led to liquefaction and fluidization. Together, these deposits constitute the chaotic lithofacies.

The tuffs in Unit $\mathrm{V}$ are interpreted as air fall pyroclastic deposits because they contain $>75 \%$ glass shards, show normal grading, and are texturally well sorted. These deposits, with hemipelagic interbeds, form the tuff lithofacies.

\section{Sediment accumulation rates at Site $\mathbf{C 0 0 1 1}$}

Sediment accumulation rates for the hemipelagic and the turbiditic deposits at Site C0011 were compared. The hemipelagic accumulation rate appears to have changed abruptly in the middle of Unit III (Fig. F17C). Units II and IV are characterized by high sediment accumulation rates for the turbiditic deposits (Fig. F17B). To define turbidite accumulation rates, the thickness ratio between the hemipelagites (silty claystone, calcareous mudstone, and lime mudstone) and turbidites (sandstone, tuffaceous sandstone, volcaniclastic sandstone, and clayey siltstone) was measured in each core (Fig. F17A). Then, the cumulative thickness of the hemipelagic and turbiditic deposits was calculated on the basis of the thickness ratio and core length. Next, the cumulative thickness of the turbiditic deposit was plotted against that of the hemipelagic deposit (Fig. F17B). Although most cores were not $100 \%$ recovery, as an approximation, the thickness ratio between two lithofacies was assumed to be constant within each core. Cores showing low recovery rates $(<15 \%)$ were excluded from this analysis, and their data were linearly interpolated with respect to data in adjacent cores. Cores of sand-prone intervals (Units II and IV) mostly showed $>70 \%$ recovery rate, so this approximation has little effect on our analysis. This approximation also appears to have a minimal effect on the analysis of lowrecovery rate cores because the LWD data suggest that these cores were mostly obtained from intervals 
of monotonous hemipelagic deposits. The only exception that could not be estimated well by this approximation is the wash down interval of Unit IV (786.3-844.0 $\mathrm{m}$ CSF). As there are only two agecontrol points, both within and below the wash down interval, the possible error introduced in our analysis in the wash down interval could be large. Thus, if we exclude all data obtained below the wash down interval, the conclusions about the sediment accumulation rate are robust.

Sediment accumulation rates for the hemipelagic and turbiditic deposits were calculated on the basis of paleontologic and magnetostratigraphic data (see "Paleomagnetism"), using a least-squares fit and a central difference method with a length of two cores (Fig. F17B). The results of this analysis suggest that the sediment accumulation rate for the hemipelagic deposits was constant $(7.7 \mathrm{~cm} / \mathrm{k}$.y. $)$ from Unit V to the lower part of Unit III. Near the middle part of Unit III, there appears to have been a significant decrease to $3.9 \mathrm{~cm} / \mathrm{k} . y$. (Fig. F17C), which is maintained through Unit II. This significant decrease in the sediment accumulation rate for the hemipelagites, along with the observed changes in magnetic properties recorded for the same depth interval at Site C0011 (see "Physical properties"), suggests the possibility of some fundamental paleoenvironmental change at Site C0011. Also, our analysis shows that the sediment accumulation rate for the turbidites in Units II and IV averaged $\sim 1-1.2 \mathrm{~m}$ of turbidite per $1 \mathrm{~m}$ of hemipelagic deposition. The sediment accumulation rate of the turbidites, therefore, was $\sim 3.9-4.7 \mathrm{~cm} / \mathrm{k} . y$. , for a hemipelagic sediment accumulation rate of $\sim 3.9 \mathrm{~cm} / \mathrm{k}$.y. Unit III is characterized by a near-zero sediment accumulation rate of turbidites (Fig. F17B).

\section{Paleogeography and sediment provenance at Site $\mathrm{C} 0011$}

Kashinosaki Knoll is located $\sim 100 \mathrm{~km}$ southeast of the Kii Peninsula and is $\sim 150-200 \mathrm{~km}$ west of the Izu-Bonin arc. Figure F18 shows the calculated locations of Hole C0011B from its present position backtracked to its position at $\sim 12 \mathrm{Ma}$ (Unit V), based on estimated plate convergence rates (0-4 Ma: $4 \mathrm{~cm} / \mathrm{y}$ to the northwest; 4-12 Ma: $0.9 \mathrm{~cm} / \mathrm{y}$ to the northnorthwest) (Kimura et al., 2005). From these rates, we interpret the initial location of Site C0011, for deposition of Unit V, as $\sim 350 \mathrm{~km}$ south of its present position.

During deposition of the entire section cored at Site C0011, the site's distance from the Izu-Bonin arc would have been similar with respect to the current geographic location ( 150-200 km), and, therefore, sediment gravity flows could have transported volcanic/pyroclastic material from the Izu-Bonin arc over such distances. Also, at 7-12 Ma, Site C0011 was located $\sim 200 \mathrm{~km}$ south of southwest Japan, making this a possible additional sediment source. In addition, there were probably locally active volcanic seamounts within the Shikoku Basin at that time. The terrigenous sediments of Unit IV represent the distal parts of a submarine fan, possibly sourced from sedimentary and metasedimentary terranes in the Outer Zone of southwest Japan.

Age-dating and geochemical analysis of the igneous rocks from southwest Japan, integrated with the tectonic development of Japan and the Philippine Sea plate, suggests the following history of volcanic activity (Fig. F19) (Kimura et al., 2005):

Stage I: initial rifting of the Sea of Japan (25-17 Ma), Stage II: opening of the Sea of Japan (17-12 Ma),

Stage III: late Tertiary volcanic arc (12-4 Ma), and

Stage IV: late Pliocene-Holocene volcanic arc (4$0 \mathrm{Ma})$.

${ }^{40} \mathrm{Ar} /{ }^{39} \mathrm{Ar}$ dates of volcanic rocks from the seamount chains in the northern part of the Shikoku Basin show that volcanism began at $\sim 17 \mathrm{Ma}$ (Ishizuka et al., 2003), slightly predating the cessation of Shikoku Basin (backarc basin) spreading at $15 \mathrm{Ma}$ (Okino et al., 1994, 1999) and the opening of the Sea of Japan, waxing in intensity at $12 \mathrm{Ma}$, and continuing until 3 Ma. Magmatism migrated eastward through backarc knolls to the intra-arc rift zone (Ishizuka et al., 2003). After $7 \mathrm{Ma}$, volcanism became active along the entire Izu-Bonin seamount chains, both in the western seamounts and backarc knoll zone (Ishizuka et al., 1998).

The crest of Kashinosaki Knoll is located $10 \mathrm{~km}$ south of Site C0011. Differences in the magnetic and gravity anomalies over the Kashinosaki Knoll and the Zenisu Ridge, together with seismic reflection data, suggest that the knoll is unlikely to be the westward extension of the Zenisu Ridge and that the north-dipping thrust fault underlying the Zenisu Ridge does not continue westward under the knoll as previously proposed (Le Pichon et al., 1987; Lallemant et al., 1989). Seismic depth Section ODKM-22 crosses the summit of the Kashinosaki Knoll in the vicinity of IODP Sites C0011 and C0012 and shows thinning of the lower and middle Shikoku Basin sediments onto this basement high (Ike et al., 2008a); this seismic interval corresponds to Units III, IV, and $\mathrm{V}$ at Site C0011. Units IV and V thin considerably toward the knoll. It appears that much of the hemipelagic Unit III passively draped the knoll; however, the Kashinosaki Knoll retained some bathymetric relief during that phase of hemipelagic deposition.

Petrographic trends interpreted from the smear slide data (Fig. F10) are consistent with a change from an 
essentially inactive and dissected volcanic island arc that was being reworked into deep water (Unit IV and the lower part of Unit II) to an active volcanic arc (upper part of Unit II). Unit V ( 14 Ma) accumulated on the rough seafloor topography created earlier by seamount volcanism. Those strata are dominated by felsic volcanic grains, derived from either the IzuBonin or southwest Japan arc. At that time ( 14 Ma), there was considerable magmatic activity in the southwest Japan arc (e.g., the anomalous near-trench igneous activity as seen in granite emplacement during the middle Miocene in Kii Peninsula) (Hoshi et al., 2007, and references therein).

Unit IV (lower Shikoku Basin; 14-12 Ma) comprises fine-grained, terrigenous turbidites, containing locally abundant woody material together with low-grade metamorphic grains, all suggesting a provenance from the Outer Zone of southwest Japan. Unit III is almost exclusively hemipelagic deposits, probably from several sources, including the Izu-Bonin arc, southwest Japan arc, and seamounts within the Shikoku Basin. The seismic character of Unit III is essentially a sheetlike "drape" that thins over the Kashinosaki Knoll. The abrupt change in the sediment accumulation rate in Unit III at $\sim 11$ Ma coincides with the cessation of voluminous forearc volcanism at $\sim 11 \mathrm{Ma}$. Although there are various ways to explain this change in the sediment accumulation rate, one possibility is that sediment influx slowed down as anomalous near-trench volcanism in the main source area for sediment was supplanted by forearc cooling (the transition from Stage II to Stage III of Kimura et al., 2005) (Fig. F19).

On the basis of the stratigraphy at Site C0011 and the seismic and LWD character, we interpret Unit II (middle Shikoku Basin) as the distal facies of a submarine fan (with both shallow channel and more sheetlike subenvironments) developed on the Shikoku Basin plain. The present-day topography of the Shikoku Basin shows the presence of backarc en echelon seamounts, consisting of four cross-chains in the northern part of the Izu-Bonin backarc (Machida et al., 2008). Such cross-chains would act to laterally confine sediment gravity flow deposits from relatively restricted geographic segments of the Izu-Bonin arc. Development of elongated feeder systems (canyons and channels) to very irregularly shaped submarine fans on the Shikoku Basin plain would enhance prospects for greater sediment accumulations further west in the Shikoku Basin. Additionally, submarine canyons along the Izu-Bonin arc (as is the present case) would tend to act as the principal sediment transport paths for redepositing sediment into deep water between these cross-chains. We envision a similar topography for the Shikoku Basin during deposition of Unit II.

\section{Comparison between Site C0011 and nearby ODP/IODP sites}

We recognize five lithologic units at Site C0011 and tentatively correlate these with lithostratigraphic units at ODP Sites 808, 1173, 1174, and 1177 (Table T6).

Unit I of Site C0011 is probably equivalent to the upper Shikoku Basin facies at Sites 808 (Subunit IVA), 1173 (Unit II), 1174 (Unit III), and 1177 (Unit I) (Table T6). Seismic profiling suggests no trench-wedge facies at Site C0011. Although Unit I at Site C0011 was drilled without coring, the LWD data of Hole C0011A imply that this unit is composed mainly of hemipelagic deposits with possible intercalation of thin ash layers, which are similar to the lithologies in the upper Shikoku Basin facies at Sites 808, 1173, 1174 , and 1177. Judging from the age at the uppermost interval of Unit II, the bottom of Unit I is $\sim 7.6 \mathrm{Ma}$, which is older than the maximum age of the upper Shikoku Basin facies at previous sites.

Unit II of Site C0011, with abundant sandstone turbidites, has no equivalent of comparable age at previous ODP sites (Table T6). In spite of the common occurrence of volcanic sandstone turbidites, we did not find unequivocal tuff beds formed by ash fall in this unit. Together with its Miocene age (7.69.1 Ma), it is reasonable to define a new stratigraphic interval for the Shikoku Basin. We therefore designate Unit II as the "middle Shikoku Basin" facies. Age-equivalent strata of the lower Shikoku Basin facies at nearby ODP sites do not contain volcanicrich sandstone turbidites.

Unit III of Site C0011 is equivalent in lithology to the lower Shikoku Basin hemipelagic facies at Sites 808 (Unit IVB), 1173 (Unit III), 1174 (Unit IV), and 1177 (Unit II) (Table T6), but its age is older (9.1$12.2 \mathrm{Ma}$ ). Unit III is characterized by monotonous hemipelagic deposits with thin green layers (color banding), which is common lithology in the lower Shikoku Basin facies of all correlative ODP sites in the Nankai Trough. At Site 1177, similar thin, dark green layers in mudstone were described in the hemipelagic silty claystone. The colors, in part, reflect variations in the content of clay minerals (Shipboard Scientific Party, 2001b). Generally, the upper boundary of the lower Shikoku Basin facies is assigned to the bottom of the last distinct ash layer in the upper Shikoku Basin facies, although this is also influenced by a diagenetic transition from unaltered to heavily altered ash layers (Moore, Taira, Klaus, et al., 2001). Unit III of Site C0011 contains no distinct tuff layer, so it seems reasonable using facies criteria to consider this unit as the youngest part of the lower Shikoku Basin facies.

Unit IV of Site C0011 probably correlates in both facies and age with the lower Shikoku Basin turbidite 
facies of Site 1177 (Unit III) (Table T6). Abundant muddy and sandy turbidites suggest that this unit was deposited in the submarine fan system. The lower Shikoku turbidite facies of Site 1177 contains four packets of sandy turbidites. The gravity flow deposits contain abundant quartz, sedimentary and metasedimentary lithic fragments, and woody organic matter, indicating their terrigenous origin. These features are similar to the finer grained turbidites in Unit IV of Site C0011. Site 1173, which is located along the Kinan Seamounts between Sites 1177 and C0011, does not contain a Miocene turbidite facies. Thus, Unit III of Site 1177 and Unit IV of Site C0011 may represent independent submarine fan systems separated by a basement high.

Unit V of Site C0011 is composed of volcaniclastic deposits, such as tuff and tuffaceous silty claystone, and is equivalent to the volcaniclastic facies observed in Sites 808, 1174, 1173, and 1177 (Table T6). The volcaniclastic facies are widely distributed as deposits covering the basement rocks in the Nankai Trough (Unit V of Sites 808 and 1174; Unit IV of Sites 1173 and 1177), and their maximum age increases with distance from the Kinan Seamounts. Unit V of Site C0011 is $\sim 14 \mathrm{Ma}$ in age, which also matches the age of volcaniclastic deposits in the Muroto transect area.

\section{Structural geology}

Structures observed at Site C0011 are sparse and subtle (as expected for subduction input sediments) in common with those observed at Sites 1173 and 1177 (reference sites for the Nankai accretionary prism off Cape Muroto and Cape Ashizuri, respectively). Although bedding is generally recognizable throughout Hole C0011B, highly bioturbated hemipelagic sediments often prevented actual surface measurement. Structural data measured on cores are given in C0011_STRUCT_DATA.XLS in STRUCTUR in "Supplementary material." Where possible, planar structures were corrected to true geographic coordinates using shipboard paleomagnetic data. The distribution of planar structures and lithologic divisions with depth are shown in Figure F20. The main structural features encountered in Hole C0011B are subhorizontal bedding attitudes and fault distribution such that layer-parallel faults are found at shallow depths and high-angle faults are found at greater depths.

\section{Bedding}

Bedding planes dip almost horizontal or $10^{\circ}-20^{\circ}$, and faults that are parallel to bedding planes characterize the structure in Hole C0011B. Bedding in lith- ologic Unit III is scattered between $0^{\circ}$ and $30^{\circ}$, whereas bedding dips in Units II, IV, and V are concentrated below $20^{\circ}$. High-angle bedding planes are distributed only in the interval corresponding to the chaotic deposits in Core 322-C0011B-8R and Section 28R-2 (Fig. F20). Planar structures were reoriented to the geographic coordinate system using paleomagnetic data listed in Table T7. Poles of bedding and faults cluster around the subhorizontal inclination (Fig. F21). Cylindrical best fit of the bedding pole indicates a weak distribution along the north-northwest-south-southeast, perpendicular to the trench axis. These structural data of bedding planes correspond reasonably well with the data deduced from LWD image analysis (Fig. F22). These data indicate the bedding inclination was controlled by trenchwarddipping bathymetric slopes on the seaward side of the trench.

Sandstone layers display a lighter color under X-ray computed tomography (CT) exposure (Fig. F23A) because of their higher bulk density than the mudstone layers. X-ray CT images, therefore, are useful for distinguishing lithology even if the lithologic boundary is not clear using conventional observation methods. However, it tends to be difficult to detect bioturbation in the greenish clay-rich layers that contain strong bioturbation, probably because of the small difference in bulk density or chemical composition both within and outside the burrows. Boundaries between different lithologies, such as silty claystone, clayey siltstone, and sandstone, are distinct in X-ray CT images (Fig. F23), which indicates a difference in their bulk densities. In some cases, however, sandstone and silty claystone or clayey siltstone do not show significant differences in X-ray CT images (e.g., Fig. F24). These exceptions should always be considered for whole-round sampling or lithologic evaluation before splitting.

\section{Deformation structures}

\section{Layer-parallel faults}

Although small-scale healed faults with high-angle dips are present, most faults in lithologic Units II and III are characterized by healed faults with layerparallel attitudes (Figs. F20, F25). These faults are characterized by higher bulk density under X-ray CT image observation (Fig. F26), which is indicative of shear-induced compaction. No such faults were observed in Units IV and V.

Although layer-parallel faults were not reported at Sites 1173 and 1177, healed faults with high-angle dips were reported (Moore, Taira, Klaus, et al., 2001). Layer-parallel faults are well identified in the late Miocene-Pliocene accretionary complex and PliocenePleistocene cover sediments in the Miura Peninsula, 
central Japan (e.g., Yamamoto et al., 2005). Similar structures are also reported from the toe of the Nankai accretionary complex, off Muroto, at Sites 808 and 1174 (Maltman et al., 1993; Ujiie et al., 2004). These analogs from ancient and modern accretionary complexes and cover sediments formed soon after sedimentation (the primary stage of deformation history).

\section{High-angle faults and fractures}

High-angle faults and fractures dipping $45^{\circ}-70^{\circ}$ developed in lithologic Units III, IV, and V (Fig. F20). They exhibit brittle deformation features without gouge or CT value variation (Fig. F27). The faults contain striations inferred to be slickenlines on the fault surface, which is indicative of dip-slip movement. These faults apparently correspond with a normal fault system because the dip angles are too high to make thrust faults in such a stable sedimentary basin. Also, burrows or layers cut by these faults indicate normal displacement (Fig. F27). Although healed high-angle faults were reported at Sites 1173 and 1177, faults in Hole C0011B have not been healed, apparently because of the difference in sediment physical properties during deformation.

Although variations in dip angle correspond well to LWD image data, the distribution pattern is different. Core observation revealed that the high-angle faults/fractures were distributed deeper than $580 \mathrm{~m}$ CSF to at least $881 \mathrm{~m} \mathrm{CSF} \mathrm{(TD),} \mathrm{whereas} \mathrm{LWD} \mathrm{image}$ analysis shows the distribution between 150 and $700 \mathrm{~m}$ LSF. This difference might be caused by poor core recovery in the shallower interval and lower quality borehole images in the deeper section.

\section{Bioturbated dark deformation bands}

Although layer-parallel faults commonly accompany very thin deformation bands $(\sim 1-2 \mathrm{~mm})$, some of them have thick $(>1 \mathrm{~cm})$, dark deformation bands (Fig. F28). These deformation bands are filled with well-sorted, fine, dark material and have some round clasts of silty claystone. These apparent clasts are burrows, which connect to the upper adjacent layer in X-ray CT images. These bioturbated claystones were also reported at Site 1173 during ODP Leg 190 (Moore, Taira, Klaus, et al., 2001). The band that occurs at interval 322-C0011B-31R-3, 100-117 cm (Fig. F28C), accompanies a much darker, thin layer at its bottom, which indicates shear flow. The dark matrix has a slightly less dense CT signature than the host rock. These deformation structures indicate submarine soft-sediment sliding or creep in a shallow enough subsurface to be bioturbated. These deformation bands disappear in lithologic Units IV and V.

\section{Veins}

Mineral-filled veins are observed only below $762 \mathrm{~m}$ CSF and are composed mostly of calcite (Fig. F29). Although at least five mineral-filled veins were identified in Hole C0011B, they are quite rare at Sites 1173 and 1177 (only one mineral-filled vein was identified from Site 1173). The calcite veins form dogteeth texture, though some are partly fragmented. On the basis of the striation that was recognized on the outside veins and this fragmented occurrence, the vein minerals are thought to have crystallized along faults, and some faults appear to show repeated movement, as indicated by different phases of crystal growth.

\section{Interpretation}

In general, the deformation structures observed in Hole C0011B correspond with lateral extension and vertical compaction. Layer-parallel faults and the bioturbated dark deformation bands exposed only in lithologic Units II and III likely formed by softsediment creep soon after sedimentation. The disappearance of these structures in the lower part of the hole (Units IV and V) implies that there was no cause of further deformation (e.g., seafloor tilting) after or during the deposition of Units IV and V. High-angle faults/fractures exposed in Units III, IV, and $V$ developed at a later stage because they exhibit brittle deformation features. Although attitudes of faults/fractures were reoriented to the geographic coordinate system using paleomagnetic data, the restored data are limited and scattered. Additional reliable postcruise paleomagnetic data are required to evaluate the stress conditions.

Documentation of the structures in Hole C0011B provides a further important structural datum against which we can compare more highly deformed sites within the prism. The scientific results obtained from this subduction input site will help scientists recognize structures at other sites that are the result of deformation within the accretionary prism.

\section{Drilling-induced deformation}

RCB coring induced syndrilling fractures. In addition to visual observation, X-ray CT images were used extensively for the evaluation of drilling-induced deformation.

Syndrilling fractures are commonly observed in Xray CT images as noncompleted cracks. Nevertheless, the cracks fully propagate after splitting (Fig. F30). A jigsaw-puzzle fracture in which pieces are reconstructible with similar uneven plane indicates in situ deformation without displacement (Fig. F31). The fracture that has a linear plane but shows bending at 
the rim of the core also has the same nature as other jigsaw-puzzle fractures.

Drilling-induced conjugate faults typically occur in a convex shape (Fig. F30). A possible explanation is that during drilling, a fracture is generated at the contact of the drill bit in the bottom of the borehole and propagates upward into the core with a certain angle that is constrained by the angle of internal friction.

Cuttings (the scrapings of sediments or rocks during drilling) sometimes strayed into the core liner in significant amounts, even though they are usually washed out through the outside drill pipe. Core 322C0011B-43R, which records $224 \%$ of recovery, was filled with cuttings in the bottom $4.38 \mathrm{~m}$ (from Section 322-C0011B-43R-5, $64 \mathrm{~cm}$, through 43R-CC, $17.5 \mathrm{~cm}$; Fig. F32). Subtracting the cuttings, Core 322 -C0011B-43R recovery becomes $114.5 \%$. Wellsorted coarse angular fragments can superficially be mistaken for a sandy layer. In Sections 322-C0011B$48 \mathrm{R}-5$ and 48R-6, a grading of poorly sorted round cuttings was observed (Fig. F33). Those cuttings are uniformly composed of adjacent silty claystone. They appear similar or less dense than the claystone in X-ray CT images, which may be a result of higher porosity. Using X-ray CT images, cuttings are distinguished from sandstone, which usually has higher bulk density than clayey siltstone (see Fig. F23). Round vesicles are also a unique feature of cuttings-filled cores (Fig. F32). The size of cuttings varies from millimeters to centimeters. Fragments are either angular (in Core 322-C0011B-43R, Fig. F32) or round (in Core 48R, Fig. F33).

\section{Biostratigraphy}

Preliminary shipboard analysis of the core catcher and additional samples from Cores 322-C0011B-1R through $61 \mathrm{R}$ reveals assemblages of calcareous nannofossils and planktonic foraminifers (Tables T8, T9). Biostratigraphic datums were mainly derived from coccoliths (Fig. F34). According to these datum events, the composite of Hole C0011B has a middlelate Miocene age.

Floral and faunal assemblages of planktonic organisms provide some insight into paleoceanographic conditions. Species abundance is generally common to rare. In the late Miocene, sediments contain warmwater genera such as the calcareous nannofossil genus Discoaster.

\section{Calcareous nannofossils}

Preliminary examination of all core catcher samples from Hole C0011B obtained moderately to poorly preserved nannofossils, which occur in common abundance in most of the samples, and species diversity is comparatively high. However, severe dissolution occurred, leading to barren or very poor occurrence of coccoliths in some intervals (Table T8). Most of the zonal markers of Martini's zonation (1971) and Raffi et al. (2006) were identified in the sedimentary sequence. The nannofossils that occurred in Hole C0011B are listed in Table T8, and correlations between the hole and the biostratigraphy are shown in Figure F34 and Table T10.

Discoaster quinqueramus and Discoaster berggrenii, which indicate upper Miocene Zone NN11 (5.598.52 Ma), were found in Samples 322-C0011B-1R-CC through 9R-CC. The paracme beginning (PB) (Raffi et al., 2006) of Reticulofenestra pseudoumbilicus $(8.78 \mathrm{Ma})$ was also identified in Samples 322C0011B-9R-CC and 10R-CC. Discoaster hamatus, which appears between 10.541 and $9.56 \mathrm{Ma}$ and is contrasted to Zone NN9, was found in Samples 322C0011B-21R-CC through 24R-CC. The first occurrence (FO) of Catinaster coalitus, which shows the bottom of Zone NN8 (10.88 Ma), was recognized between Samples 322-C0011B-25R-5, 8-10 cm, and 26R-7, $103 \mathrm{~cm}$. Samples 322-C0011B-26R-7, $10 \mathrm{~cm}$, through 37R-CC are characterized by the sporadic occurrence of Discoaster kugleri and Coccolithus miopelagicus, which reveals that the intervals are assigned to Zone NN7 (between 10.88 and $11.90 \mathrm{Ma}$ ). Cyclicargolithus floridanus indicates the upper part of Zone NN6 (12.037 Ma) and was found below Sample 322C0011B-39R-5, 43-43.5 cm. Therefore, the middle/ late Miocene boundary is situated between Samples 322-C0011B-37R-CC and 38R-3, $127 \mathrm{~cm}$. Sphenolithus heteromorphus disappeared at the Zone NN5/ NN6 boundary (13.532-13.654 Ma) in the middle part of the middle Miocene, which lies between Samples 322-C0011B-53R-CC and 57R-CC. Eight nannofossil datums in Hole C0011B (from the FO of $D$. berggrenii to the last occurrence [LO] of $S$. heteromorphus) were at much higher levels compared to Sites 1173 and 1177. Calcareous nannofossil results for Hole C0011B and Sites 1173 and 1177 show biostratigraphic changes from the middle-late Miocene. However, calcareous nannofossil assemblages at Sites 1173 and 1177 were affected by both strong overgrowth and etching (Shipboard Scientific Party, 2001a). Better correlation of each datum event and the correct position of datum events require postcruise studies on additional samples from these core sections.

\section{Planktonic foraminifers}

Preliminary analyses of all core catcher samples from Cores 322-C0011B-1R through 61R and a few additional samples were examined on board the ship. 
Planktonic foraminifer fossils occurred in poor abundance with moderate to good preservation. Hole C0011B sediment samples have shown the planktonic foraminifer assemblages are barren to very rare in abundance in an almost consecutive number of intervals (Table T9).

Three biohorizons and datum events were noted from Hole C0011B (Table T9). The upper part of Unit II characterizes two biohorizons from core catcher Samples 322-C0011B-6R-CC, 7.5-12.5 cm, and 7RCC, $11.5-16.5 \mathrm{~cm}$, with the FO of Truncorotalia crassaformis and LO of Globoturborotalita nepenthes. The third and last biohorizon occurred during the upper part of Unit IV and was recognized by the LO of Catapsydrax dissimilis. A better evaluation of the rare availability and the correct position of datum events require postcruise studies on additional samples from the core sections.

\section{Sedimentation rate}

The sedimentation rate of calcareous nannofossils in Hole C0011B, which is categorized by three sections, is shown in Figure F35. The sedimentation rate for Unit II to the upper part of Unit III (421-497 m CSF) has been calculated at $\sim 9.05 \mathrm{~cm} / \mathrm{k}$.y. In contrast, the sedimentation rate of the upper to middle part of Unit III (497-537 m CSF) decreased to $4.31 \mathrm{~cm} / \mathrm{k} . \mathrm{y}$. Below $537 \mathrm{~m} \mathrm{CSF}$, the sedimentation rate remained stable and increased to $9.02 \mathrm{~cm} / \mathrm{k} . \mathrm{y}$. from the lower part of Unit III to Unit IV.

\section{Paleomagnetism}

Because of the unavailability of the Chikyu's cryogenic magnetometer (see "Paleomagnetism" in the "Methods" chapter), regular whole-round core pass-through magnetic measurements of core sections could not be carried out for Expedition 322 . Thus, shipboard paleomagnetic studies for Site C0011 consisted of only natural remanent magnetization (NRM) and discrete sample progressive demagnetization measurements with Chikyu's spinner magnetometer and alternating-field (AF) demagnetizer. Paleomagnetic cubes or minicores were stepwise AF demagnetized to evaluate the directional stability and coercivity spectrum of each sample. We analyzed the results in Zijderveld diagrams (Zijderveld, 1967) and calculated the characteristic remanent magnetization (ChRM) direction using principal component analysis (Kirschvink, 1980). Volume magnetic susceptibility of these discrete samples was measured after AF demagnetization measurements with the Kappabridge KLY 3. The Königsberger ratio, which is defined as the ratio of remanent magnetization to induced magnetization in Earth's magnetic field, was also determined for the measured samples. Two samples were taken next to the samples used for AF demagnetization and subjected to progressive thermal demagnetization to determine their unblocking temperatures and magnetic carriers, as well as to compare whether thermal demagnetization is better than the $\mathrm{AF}$ technique in removing drilling-induced remanent magnetization (DIRM) and viscous remanent magnetization (VRM) and isolating primary components. In addition, four specimens, which went through $\mathrm{AF}$ demagnetization experiments, were given an isothermal remanent magnetization (IRM) in the laboratory with the pulse magnetizer MMPM 10 before being subjected to thermal demagnetization to identify magnetic minerals.

\section{NRM, magnetic susceptibility, and Königsberger ratio}

\section{NRM and magnetic susceptibility}

Paleomagnetic data obtained at Site C0011 exhibit significant variations in demagnetization behavior among the various lithologies recovered. The most significant variations in NRM intensity and susceptibility for discrete samples from Site C0011 are well correlated with lithology (Fig. F36). For example, tuffaceous sandstone and volcaniclastic sandstone layers in lithologic Unit II and the upper part of lithologic Unit III (from $~ 340$ to $410 \mathrm{~m} \mathrm{CSF}$ ) have the highest NRM intensity (with a mean of $\sim 270 \mathrm{~mA} / \mathrm{m}$ ). From 410 to $510 \mathrm{~m}$ CSF (middle part of Unit II and upper part of Unit III), NRM intensity averages $\sim 4 \mathrm{~mA} / \mathrm{m}$ except for a few discrete peaks of higher NRM values in some depth intervals (e.g., at around 413, 435, 447, 464, and $477 \mathrm{~m} \mathrm{CSF}$ ), which can be tied directly to a visible presence of volcaniclastic and tuffaceous sandstone in these regions (see "Lithology"). In the middle part of Unit III, paleomagnetic measurements also indicate that intensity tends to increase at $530 \mathrm{~m}$ CSF and then gradually decrease at $570 \mathrm{~m} \mathrm{CSF}$, forming a broad NRM intensity high peak (averaging $\sim 30 \mathrm{~mA} / \mathrm{m}$ ). This intensity peak appears to coincide with changes in the hemipelagic sedimentation rate and $P$-wave velocity trend at this depth interval (see "Lithology" and "Physical properties"). From $570 \mathrm{~m}$ CSF to the bottom of lithologic Unit IV, NRM intensity consistently exhibits lower values $(\sim 4 \mathrm{~mA} / \mathrm{m})$. On the other hand, tuff and tuffaceous silt/claystone throughout lithologic Unit $\mathrm{V}$ have higher NRM intensity values (mean of $\sim 30 \mathrm{~mA} / \mathrm{m}$ ).

Magnetic susceptibility variations generally parallel NRM intensity variations (Fig. F36). Magnetic susceptibility values are generally $\sim 3.3 \times 10^{-4}$ SI for muddy turbidites but significantly higher $\left(>1 \times 10^{-3}\right.$ 
SI) for volcaniclastic sandstone layers. Four sharp increases in magnetic susceptibility are present at approximately 361, 377, 407, and $480 \mathrm{~m}$ CSF (base of lithologic Unit II). The variation in susceptibility is most likely caused by variations in the magnetic mineral type or magnetic mineral content in the depth ranges where volcanic ashes were observed.

\section{Paleomagnetic stability tests}

Remanent magnetization of discrete samples was investigated using stepwise AF or thermal demagnetization techniques in order to extract the primary component of magnetizations acquired at the time of deposition. Figure F37 illustrates the magnetic stability behavior of several representative samples from various lithologic units. Figure F37A (Sample 322-C0011B-4R-1, 72-74 cm) and F37B (Sample 7R-1, $118-120 \mathrm{~cm}$ ) shows examples of normal polarity and reversed polarity intervals, giving confidential results for polarity determination. The behavior demonstrates the removal of nearly vertical downward DIRM after AF demagnetization at $10 \mathrm{mT}$ and the isolation of a stable component of magnetization that univectorially decays toward the origin of the vector plots (Zijderveld, 1967).

An example of the demagnetization behavior of a sample (322-C0011B-15R-4, 96-98 cm) during thermal demagnetization is illustrated in Figure F37C. A secondary component of magnetization was removed at low temperatures $\left(200^{\circ} \mathrm{C}\right)$, and the ChRM component, having higher unblocking temperatures, could be identified by heating the sample up to $400^{\circ} \mathrm{C}$. Figure F37D illustrates the $\mathrm{AF}$ demagnetization behavior of a sample (322-C0011B-15R-4, 99$101 \mathrm{~cm}$ ) just below the sample demagnetized by the thermal technique mentioned above. The same drilling overprint and ChRM components are easily revealed by AF demagnetization above $10 \mathrm{mT}$. The response of ChRM to AF and thermal demagnetization suggests that ChRM in most samples might be carried by fine (i.e., single-domain to pseudosingledomain), low-Ti titanomagnetite grains. Several muddy turbidite samples from lithologic Unit IV (Sample 322-C0011B-49R-7, 74-76 cm, $735.67 \mathrm{~m}$ CSF), however, exhibit very high coercivity (>180 mT) during AF demagnetization (Fig. F37E), suggesting that hematite might exist in these samples as well. The inclination values of ChRM components in each unit are slightly higher than the expected inclination for the site $\left(52.2^{\circ}\right.$ for normal polarity or $-52.2^{\circ}$ for reversed polarity). This higher inclination may be an indication of the incomplete removal of DIRM by AF demagnetization. Although the ChRM inclination is higher, it suggests that ChRM might be the primary magnetization acquired when sediments were deposited. ChRM components were extracted from most of the samples by fitting linear regression lines with least-squares minimization of Kirschvink (1980).

\section{Drilling-induced remanent magnetization}

The most common property during demagnetization experiments on Site C0011 samples is a pervasive remagnetization (overprint) imparted by the coring process, which is characterized by NRM inclinations that are strongly biased toward vertical (toward $+90^{\circ}$ ) in all cores (Fig. F36; black circles). In most cases, this steep downward component of magnetization imparted by the coring process can be easily removed by $10 \mathrm{mT}$ AF demagnetization (Fig. F38). Thus, the vector components of DIRM were calculated by subtracting NRM after AF demagnetization at $10 \mathrm{mT}\left(\mathrm{NRM}_{10 \mathrm{mT}}\right)$ from NRM before demagnetization $\left(\mathrm{NRM}_{0 \mathrm{mT}}\right)$ and projected on an equal area plot (Fig. F38). Indeed, the component calculated for 100 samples taken from lithologic Unit II has a very steep mean inclination $\left(\right.$ declination $=-176^{\circ}$, inclination $=$ $87.5^{\circ}$, and $\alpha_{95}=1.1^{\circ}$ ). Although inclination is very steep and difficult to distinguish from the vertical direction, declination close to $180^{\circ}$ may indicate that the magnetization is slightly inward of the core.

To further clarify the nature of DIRM and try to increase the quality of paleomagnetic results by removing the outer part of the core, a standard paleomagnetic minicore sample (322-C0011B-7R6, $11-13 \mathrm{~cm}, 398.38 \mathrm{~m} \mathrm{CSF}$ ) was sliced into three specimens, and each specimen was AF demagnetized separately (Fig. F39). It is expected that this remagnetization affects the external portions of the cores most severely, presumably because the outside of the core is physically closer to the magnetized core barrel. Figure F39A, F39B, and F39C displays the demagnetization behavior for these three specimens. Although apparent differences in DIRM component inclinations cannot be readily observed on vector endpoint diagrams, the inclination after AF demagnetization at $10 \mathrm{mT}$ was slightly improved from bottom to top (Fig. F39D; blue circles). However, inclination calculated by linear fitting (Fig. F39D; green circles) are mostly the same from top to bottom. DIRM intensity was reduced only slightly from bottom (outer part) to middle and top part (Fig. F39E; red circles). These results suggest that remagnetization may come mostly from the rotation/vibration of the core barrel in the presence of a strong magnetic field but not by friction between the core and drill bit and has more or less uniform effects on the core sections. Thus, the mechanism of DIRM for rotary coring is different from that for piston coring accompanying significant deformation of sediment, which can be reduced in the center of the core (Acton et al., 2002). 
To understand the source of the strong magnetic field, the magnetic field of the drill bit was measured after the termination of drilling in Hole C0011B, which was lower than Earth's magnetic field (less than $\sim 0.5 \mathrm{G}$ ). This may indicate that the magnetic field produced by the core barrel and/or BHA is strong enough to magnetize the sediments/rocks during drilling.

Although this DIRM is not a welcome feature in isolating the characteristic component of magnetization, its steep positive inclinations do serve as a useful check for whether or not shipboard paleomagnetic samples were inverted by human errors during either collecting or measuring processes. Using this information, we have successfully identified and recovered several such errors for cores from Hole C0011B. This feature was also applied to several small blocks of rocks partially eroded by the drilling process where up/down directions were not completely sure and successfully identified the polarity of magnetization.

We also noticed that certain lithologies are more susceptible to this overprint, and neither AF nor thermal demagnetization can be effective in removing the DIRM. As shown in Figure F40, the DIRM persisted to at least $40 \mathrm{mT}$ AF demagnetization on the silty sandstone Sample 322-C0011B-16R-1, $35-37 \mathrm{~cm}$, and to as high as $600^{\circ} \mathrm{C}$ temperature treatment on the accompanying Sample 16R-1, 38$40 \mathrm{~cm}$. No ChRM component could be identified from these two samples or from an additional sample in this core. Shipboard smear slide observations on this core (interval 322-C0011B-16R-3, $4 \mathrm{~cm}$ ) revealed an abundance of pyroxene in these silty sandstone samples (see "Site C0011 smear slides" in "Core descriptions"). In addition, considerable abundance of barite was observed for the same smear slide, which is very unusual throughout the site. It is not clear whether the mineral assemblage in these samples facilitated the complete remagnetization or if a different core barrel with stronger magnetization was used to retrieve Core 322-C0011B-16R.

\section{Königsberger ratio}

The Königsberger $(Q)$ ratio is defined as the ratio of remanent magnetization to the induced magnetization in Earth's magnetic field. In general, the Königsberger ratio is used as a measure of stability to indicate a rock's capability of maintaining a stable remanence relative to the induced magnetization. The magnetic field value of 50,000 nT $(39.79 \mathrm{~A} / \mathrm{m})$, which is close to the current total field value of the International Geomagnetic Reference Field at Site C0011 (45,351 nT), was used to calculate the Königsberger ratio for rock samples at Site C0011:

$$
Q=J_{\mathrm{nrm}} /\left(K_{\mathrm{m}} \times \mathrm{H}\right)
$$

where

$$
\begin{aligned}
& \mathrm{H}=\text { local geomagnetic field }(\mathrm{A} / \mathrm{m}), \\
& K_{\mathrm{m}}=\text { bulk susceptibility }(\mathrm{SI}), \text { and } \\
& J_{\mathrm{nrm}}=\text { NRM intensity }(\mathrm{A} / \mathrm{m}) .
\end{aligned}
$$

In order to detect the effect of the DIRM to $Q$ ratio determination, we calculate $Q$ ratio in the following two ways: (1) using DIRM, which can be estimated by subtracting $\mathrm{NRM}_{10 \mathrm{mT}}$ from $\mathrm{NRM}_{0 \mathrm{mT}}$ assuming most of the DIRM was essentially removed after AF demagnetization to $10 \mathrm{mT}$, and (2) $\mathrm{NRM}_{10 \mathrm{mT}}$. As shown in Figure F36 (last column), the large decrease in $Q$ ratios between $N M_{0 m T}-N_{10 m T}$ (blue symbols) and $\mathrm{NRM}_{10 \mathrm{mT}}$ (red symbols) demonstrates the existence of the pervasive DIRM imparted to these cores. In general, results show that $Q$ ratios of the majority of samples after AF demagnetization at $10 \mathrm{mT}$ (red symbols) are less than unity, suggesting that in situ total magnetization of the sediments contains dominantly induced magnetization. Furthermore, the large $Q$ ratio values of various sandstone layers (triangles and rectangles) in Figure F36 are the results of DIRM, as evidenced by the same $Q$ ratio values between these sandstone layers and mudstone after AF demagnetization to $10 \mathrm{mT}$ (Fig. F36; last column, red symbols). The low-coercivity magnetic minerals in various sandstone layers carry an unstable remanence that is more susceptible to an external magnetic field, with exceptions for sandstone samples in Unit II ( 360 m CSF) and Unit IV ( 730 $\mathrm{m}$ CSF) that do not show this behavior. Instead, the $Q$ ratio values after AF demagnetization at $10 \mathrm{mT}$ for these sandstones are more scattered. It is also notable that the $Q$ ratio for $\mathrm{NRM}_{0 \mathrm{mT}}-$ $\mathrm{NRM}_{10 \mathrm{mT}}$ (blue symbols) shows a broad peak between 520 and $560 \mathrm{~m} \mathrm{CSF}$ where NRM intensity is high, indicating different magnetic mineralogy.

\section{Polarity sequence and magnetostratigraphy}

Because of the rotary technique used for drilling, relative rotation frequently occurs between different segments of sediment within the core. Consequently, the magnetic polarity has been assigned on the basis of the stable remanent magnetization inclination. As Site C0011 is situated at a moderate latitude in the Northern Hemisphere, positive (downward directed) inclinations are taken to signify normal polarity, and negative (upward directed) inclinations signify reversed polarity.

We used ChRM inclinations from discrete measurements to define magnetic polarity sequences for Site C0011. Because of incomplete recovery and extensive whole-round sampling of core sections, continuous magnetic polarity sequences from Hole C0011B 
could not be completed. Nevertheless, several important polarity boundaries were discerned on the basis of changes in the sign of inclinations of paleomagnetic samples, which constitute magnetostratigraphic records for Hole C0011B (Fig. F36; polarity column between inclination and intensity). Each of the major polarity zones is defined by continuity or dominance of the same polarity.

The most diagnostic feature in the paleomagnetic data obtained for Hole C0011B is that some changes in magnetic polarity can be correlated with changes in biostratigraphic zonations. For example, core sections between 394.69 and $452.54 \mathrm{~m}$ CSF (Sections 322-C0011B-7R-1, 118-120 cm, through 13R-2, $64 \mathrm{~cm}$ ) show dominantly reversed polarity. Biostratigraphic Zone NN11a/NN10b with well-defined FO Discoaster berggrenii events (Zone NN11a/NN10 boundary) is also placed at this interval (see "Biostratigraphy"), suggesting the reversed polarity should correlate with Chron C4r (8.108-8.769 Ma). Shipboard biostratigraphic data also suggest that sediments within 495.49-557.73 m CSF are older than 9.61 Ma but younger than 10.81 Ma (see "Biostratigraphy"). This information suggests that the observed long normal polarity interval between 507.90 and 564.89 m CSF (Sections 322-C00011B-21R-7, $81 \mathrm{~cm}$, through 28R-1, $40 \mathrm{~cm}$ ) should correspond to the normal polarity Chron C5n.2n (9.99-11.04 Ma). This match is definite because Chron C5n.2n is the only long normal chron of this particular age. Furthermore, biostratigraphic data suggest that sediments between 653 and $667 \mathrm{~m} \mathrm{CSF}$ in Unit IV may be 11.88-12.04 Ma in age (see "Biostratigraphy"). This information suggests that the relatively well defined record of the normal/reversed polarity boundary at $695 \mathrm{~m} \mathrm{CSF}$ should correspond to the end of Chron C5An.2r (12.41 Ma).

An unexpected result generated from our preliminary study is the identification of what appears to be a magnetic excursion zone from 865.5 to $866.2 \mathrm{~m}$ CSF in lithologic Unit V (corresponding to Sections 322-C0011B-58R-8, $86 \mathrm{~cm}$, through 59R-1, $78 \mathrm{~cm}$ ). Magnetic polarity changes from normal to reversed and then back to normal within an interval of only $0.7 \mathrm{~m}$ (Fig. F41). NRM intensity also changes significantly in this zone. On the other hand, magnetic susceptibility does not show a major change through the depth interval, indicating that the magnetic mineral does not change significantly within the depth interval. In addition, this $0.7 \mathrm{~m}$ layer of tuffaceous sandstone displays contorted laminae because of soft-sediment folding. Thus, the apparent switch in magnetic polarity is probably an artifact of the folding.

\section{Integrated age model and sedimentation rates for Hole C0011B}

Paleomagnetic and biostratigraphic datum events are summarized in Table T11, and the main features of the magnetostratigraphic interpretation along with the inferred biostratigraphic zones at Site C0011 are presented in Figure F42. It is clear from this compilation that the paleomagnetic and paleontological age determinations for the late Miocene sequence in Hole C0011B are compatible, but the resolution of the paleomagnetic data is significantly greater. This allows a more precise determination of sedimentation rates and better definition of the times during which significant changes in sedimentation rate occurred.

Late Miocene sediments cored in Hole C0011B yielded a pilot magnetic polarity stratigraphy (Fig. F42A), from which preliminary sedimentation rates can be calculated. Major geomagnetic chrons and biostratigraphic zonal boundaries for Hole C0011B are shown in Figure F42B. If correct, these calibration points allow the determination of sedimentation accumulation rate values and assignment of "absolute" ages to the lithologic unit boundaries identified in Hole C0011B. Figure F42A summarizes the results inferred from magnetostratigraphic data alone: Unit II was deposited between 7.6 and 9.1 Ma. The paleomagnetically inferred mean sediment accumulation rate for Unit II is $9.5 \mathrm{~cm} / \mathrm{k}$.y. This average includes both hemipelagic setting and rapid gravity flow events. Unit III was deposited between 9.1 and $12.3 \mathrm{Ma}$. The magnetostratigraphic record infers a relatively slow sediment accumulation rate $(2.7 \mathrm{~cm} / \mathrm{k} . \mathrm{y}$.) for the upper part of Unit III (between 480 and $520 \mathrm{~m}$ $\mathrm{CSF})$ and an increased rate $(6.3 \mathrm{~cm} / \mathrm{k} . \mathrm{y}$.) for the lower part of Unit III. Unit IV was deposited between 12.3 and 13.9 Ma with a mean sediment accumulation rate of $11.0 \mathrm{~cm} / \mathrm{k} . \mathrm{y}$.

On the other hand, if we combine both biostratigraphic and paleomagnetic data to create an integrated age model, the results are slightly modified as shown in Figure F42B. The mean sediment accumulation rate is $9.4 \mathrm{~cm} / \mathrm{k} . \mathrm{y}$. for Unit II and $9.5 \mathrm{~cm} / \mathrm{k} . \mathrm{y}$. for Units III-V except for $480-540 \mathrm{~m} \mathrm{CSF}$, where the sedimentation rate is only $4.0 \mathrm{~cm} / \mathrm{k} . \mathrm{y}$. The timescale of nannofossil biostratigraphy used for Expedition 322 and throughout the NanTroSEIZE is based on Raffi et al. (2006), which is calibrated relative to the astronomically tuned geomagnetic polarity timescale used for the magnetostratigraphy of Expedition 322 (ATNTS2004; Lourens et al., 2004). Thus, it is natural to conduct the combined analysis using both magnetostratigraphy and nannofossil stratigraphy on sedimentation rates and age models. The number of stratigraphic datum events are 11 for 
magnetostratigraphy and 7 for nannofossil stratigraphy, which are comparable. Thus, for the combined analysis, equal weights are put on each data point. Because three linearly aligned segments could readily be recognized on the diagram, the slope of each segment was calculated by least-squares fitting with a line. The robustness of the fitting was tested by moving the boundary between the second $(\sim 10$ $\mathrm{Ma}$ ) and third (oldest) segments for slope calculation one or two data points back and forth. The age showing change in sedimentation rates moves only between 10.7 and $11.3 \mathrm{Ma}$ (centered at $11 \mathrm{Ma}$ ). Thus, it can be concluded that the change in sedimentation rate in the middle of Unit III happened at around $11 \mathrm{Ma}$ with an uncertainty of $\pm \sim 0.3 \mathrm{Ma}$. Improvements to precision need to be conducted including the error of each datum in combination with the uncertainty of recognition of magnetostratigraphy and nannofossils.

Lithologic equivalents of Units II-V of the lower Shikoku Basin facies have been recovered in other drilling transects of the Nankai Trough area (Moore, Taira, Klaus, et al., 2001). For the Muroto transect, Sites 808 and 1174 (inside of the trench) and 1173 (outside of the trench) give sedimentation rates of $3.2,3.5$, and $2.7 \mathrm{~cm} / \mathrm{k} . \mathrm{y}$., respectively for the lower Shikoku Basin facies deposits. These values are slightly lower than, but comparable to, the sedimentation rates we derived for the upper part of Unit III at Site C0011 (4.0 cm/k.y.). In general, they show significant changes in sedimentation rates at $\sim 11$ Ma (Sites 808 and 1174) or $\sim 13$ Ma (Site 1173). This can also be correlated with the change in sedimentation rate at $11 \mathrm{Ma}$ for Site C0011. However, Site 1173, which is comparable to Site C0011, gives a slightly older age. On the other hand, Site 1177, situated outside of the trench of the Ashizuri transect, gives a comparable sedimentation rate of $2.8 \mathrm{~cm} / \mathrm{k} . \mathrm{y}$. Sedimentation rate estimated from magnetostratigraphy at Site 1177 shows a slight downward increase at $\sim 7 \mathrm{Ma}$, which is potentially associated with the change in the lower Shikoku Basin from hemipelagic facies to turbidite facies.

\section{Paleomagnetic reorientation of the cores}

Paleomagnetic declinations were used extensively for reorienting cored material. Table T7 lists the paleomagnetic directions used for reorienting coherent blocks cored by RCB for structural parameters relative to the geographic coordinate system (see "Structural geology"). Although clockwise rotation of $\sim 30^{\circ}$ is expected for the Shikoku Basin between 5 and 15 Ma according to Sdrolias et al. (2004), we assumed that cored material did not experience significant rotation relative to the geographic frame after deposition. Further analysis to detect reliable magne- tization components by distinguishing both VRM and primary remanent magnetization could be conducted by using a superconducting quantum interference device magnetometer in combination with $\mathrm{AF}$ and thermal demagnetizations in shore-based studies.

\section{Rock magnetic characterization at Site C0011}

\section{Self-reversal of IRM of tuffaceous sandstone}

In an attempt to characterize magnetic minerals in tuffaceous sandstone and silty claystone samples, thermal demagnetization of composite IRM experiments were conducted according to procedures by Lowrie (1990). During the experiments, the unusual nature of self-reversal of IRM was observed for two samples taken from tuffaceous sandstones (Samples 322-C0011B-3R-4, 8-10 cm, and 6R-1, 34-36 cm) in lithologic Unit II. Figure F43A (blue) shows the behavior of Sample 322-C0011B-3R-4, 8-10 cm, during the IRM acquisition experiment. Magnetization was imparted in $+z(1 ;+2.9 \mathrm{~T}),+y(2 ;+0.4 \mathrm{~T})$ and $+x$ $(3 ;+0.12 \mathrm{~T})$ axes successively, but the acquired magnetization directions are always in the opposite directions of the applied field. Directions for Sample 322-C0011B-6R-1, 34-36 cm (silty claystone), showed normal magnetization acquisition behavior in the directions of the magnetizing field (Fig. F43A [red]). Afterward, stepwise thermal demagnetization was conducted and the polarity of the $x$ magnetization component (0.12 T: low-coercivity component) changed from negative to positive at temperatures between $400^{\circ}$ and $450^{\circ} \mathrm{C}$ (Fig. F43B). Sample 322C0011B-6R-1, 34-36 cm, taken from silty claystone, showed different but still anomalous behavior during heating. All three magnetization components for Sample 322-C0011B-6R-1, 34-36 cm, show shift from positive to negative between $450^{\circ}$ and $500^{\circ} \mathrm{C}$ (Fig. F43C). Demagnetization behavior on heating lower than $450^{\circ} \mathrm{C}$ (Fig. F43D) shows unblocking temperatures of $\sim 350^{\circ} \mathrm{C}$ for low- $(0.12 \mathrm{~T})$ and medium$(0.4 \mathrm{~T})$ coercivity components.

Considering the source of the reversal of IRM for tuffaceous sandstones, we need to perform additional experiments on shore. However, we may possibly associate the phenomena with the self-reversal of thermoremanent magnetization for hemoilmenite-bearing pumices such as those from the Haruna Volcano (Nagata et al., 1951). There is also documentation of the reversal of IRM for a pyrrhotite crystal during the increase in magnetic field strength (Zapletal, 1992). Although we cannot tell what kind of magnetic mineral is showing the reversed IRM described above, exchange coupling such as that reported for lamellar magnetism of titanohematite with ilmenite 
exsolution (Fabian et al., 2008) may have played a role. The strange behavior observed for silty claystone samples may also be an indication of similar exchange coupling of the volcaniclastic material included in the sediment sample but in combination with other magnetic minerals contained in normal silty claystone.

\section{Anisotropy of magnetic susceptibility}

For limited samples taken from tuffaceous/volcaniclastic sandstone layers and sand/silty sandstone layers of Hole C0011B, anisotropy of magnetic susceptibility (AMS) was measured with the Kappabridge KLY 3S but only after AF demagnetization. The difference in AMS before and after AF demagnetization is checked with two representative samples from silty sandstone and silty claystone. Figure F44A shows the difference in AMS before (small symbols) and after (large symbols) AF demagnetization for Samples 322-C0011B12R-5, 15-17 cm (blue; silty sandstone), and 12R-7, 9-11 cm (green; silty claystone). No significant difference is shown before and after AF demagnetization for $K_{\min }$ of silty sandstone. For the silty claystone sample, $K_{\min }$ does not show any significant changes, whereas $K_{\text {int }}$ and $K_{\max }$ exhibit a detectable difference. However, considering the relatively large 95\% confidence angles for $K_{\text {int }}$ and $K_{\min }$ along this plane $\left(25^{\circ} \sim 26^{\circ}\right)$, the difference is actually not very significant. Both of these samples show $K_{\text {min }}$ axes close to the vertical direction, indicating the preservation of primary fabric of sediments. Figure F44B shows the difference in shape parameter (T) and anisotropy degree $\left(\mathrm{P}^{\prime}\right)$ for the two samples. The silty sandstone sample did not show significant change before and after AF demagnetization, whereas the silty claystone sample shows slight change after AF demagnetization toward less anisotropic fabric and a shift from oblate to prolate. Mean volume magnetic susceptibility showed only minor changes through demagnetization from $5.008 \times 10^{-4}$ to $5.040 \times 10^{-4}$ SI for silty sandstone and from $2.771 \times 10^{-4}$ to $2.700 \times 10^{-4} \mathrm{SI}$ for silty claystone. Although it was recommended to perform AMS measurements before AF demagnetization (e.g., Jordanova et al., 2007), we conclude that we can use AMS after demagnetization on sandstone or silty sandstone layers encountered at this site.

Figure F44C shows the AMS results measured on tuffaceous/volcaniclastic sandstones (blue) and silty sandstones (red) for Unit II. $K_{\min }$ inclination is $>60^{\circ}$; however, it is $<60^{\circ}$ for tuffaceous sandstones and volcaniclastic sandstones where magnetic susceptibility is high. These horizons correspond to the prolate shape of the ellipsoid (negative values of shape parameter). The anisotropy degree also changes with the shape parameter. This evidence suggests that there is a mechanism leading to the development of lineation for tuffaceous sandstones and volcaniclastic sandstones where high magnetic susceptibility is observed, which might be related to the formation of these layers. For sandstones, shape parameter is positive indicating the oblate shape of the ellipsoid and $K_{\min }$ inclination is steeper than $60^{\circ}$. These lines of fact delineate that the sedimentary fabric is mostly preserved for the measured sandstones.

\section{Cross-check of magnetic susceptibility measurements}

Along the MSCL track, whole-round magnetic susceptibility was measured continuously using a loop sensor with an $80 \mathrm{~mm}$ aperture diameter (see "Physical properties"). As we obtained reliable magnetic susceptibility by measurements on discrete shipboard paleomagnetic samples (cubes or minicores) with the Kappabridge, we conducted a cross-check of volume magnetic susceptibility measured with the MSCL and Kappabridge. Figure F45A shows volume magnetic susceptibility measured with the Kappabridge (blue circles) along with those measured with the MSCL loop sensor (solid line). The MSCL values show significantly lower values compared with those measured with the Kappabridge. The raw value (MS) of the MSCL is used to calculate the corrected volume magnetic susceptibility (CMS) value according to the following formula written in the instruction manual:

$$
\begin{gathered}
\mathrm{CMS}=\mathrm{MS} / f(t) \\
f(t)=4.8566 t^{2}-3.0163 t+0.6448
\end{gathered}
$$

where

$$
\begin{aligned}
t= & X / L D, \\
X= & \text { diameter of core (liner thickness subtracted), } \\
& \text { and } \\
\mathrm{LD}= & \text { loop aperture diameter }(80 \mathrm{~mm}) .
\end{aligned}
$$

Throughout Expedition 322, LD = $80 \mathrm{~mm}$ (aperture diameter of the loop sensor) was used for the calculation of volume magnetic susceptibility (CMS values). Figure F45B shows the correlation between CMS values and the magnetic susceptibility measured with the Kappabridge. CMS values are systematically lower than the values with the Kappabridge, which may indicate that there are significant spaces between liner and core materials. Although the discrepancy might be explained by the smaller diameter of the real core $(\sim 60 \mathrm{~mm})$ compared with the inner diameter of the core liner $(66 \mathrm{~mm})$, which can be observed on the cross section of X-ray CT scan images, proper calibration with the reliable 
standard material might better be conducted in the future.

\section{Physical properties}

The goal of physical property measurements in Hole C0011B was to provide high-resolution data on the bulk physical properties and their downhole variations. Measurements included natural gamma radiation, gamma ray attenuation (GRA) density, electrical resistivity, magnetic susceptibility, thermal conductivity, moisture and density (MAD) properties (bulk and grain density, porosity, and water content), and $P$-wave velocity (see "Physical properties" in the "Methods" chapter). All physical property measurements were made after cores had been imaged by X-ray $\mathrm{CT}$ and had equilibrated to room temperature $\left(\sim 20^{\circ} \mathrm{C}\right)$. Whole-round multisensor core logger (MSCL-W) data were collected on whole-round sections to define natural gamma radiation, GRA density, noncontact resistivity, magnetic susceptibility, and $P$-wave velocity. Thermal conductivity was measured using either a full-space needle probe method on wholeround cores or a half-space line source method on working halves of cores. The half-space method was used on sediments below $365 \mathrm{~m}$ CSF because the needle probe could not be inserted into lithified sediment. MAD analyses were performed on discrete samples collected from the working halves and cluster samples taken adjacent to whole-round samples. Sample cubes cut from working halves were used to measure $P$-wave velocity and electrical resistivity in the $x-, y$-, and $z$-directions (see Fig. F17 in the "Methods" chapter).

\section{MSCL-W}

\section{GRA density}

GRA density generally and gradually increases with depth through lithologic Units II, III, and IV (Fig. F46). Calculated density values range from 0.86 to $0.95 \mathrm{~g} / \mathrm{cm}^{3}$ over the cored interval. Subtle increases and decreases in density occur throughout Unit II and a slightly higher density unit occurs from 620 to $638 \mathrm{~m}$ CSF. High-density intervals exist in Unit IV and in the lower section of Unit III. These GRA density data are not representative of formation bulk density because the cores are smaller than the inner diameter of the core liner. The presence of air around the core creates low-density artifacts.

\section{Natural gamma radiation}

Natural gamma radiation increases downhole through Unit II and into Unit III and then remains approximately constant through Units III, IV, and V with the exception of the upper portion of Unit IV (Fig. F46). Natural gamma radiation averages 22.6 counts per second (cps) in the upper portion of Unit II, $33.7 \mathrm{cps}$ in the lower portion of Unit II, $44.6 \mathrm{cps}$ in Unit III, $43.5 \mathrm{cps}$ in Unit IV, and $40.7 \mathrm{cps}$ in Unit V. These variations are consistent with LWD data that are interpreted to represent decreasing sand content with depth through Units II and III (Fig. F47). Natural gamma radiation also shows a step increase from Units II to III consistent with a lithologic change downhole to sediments dominated by hemipelagic mudstone. Unit IV begins with an increase in natural gamma radiation followed by a decrease to a near-constant average value. Natural gamma radiation in Unit $\mathrm{V}$ has a decreasing trend. These data proved valuable for identifying correlatable intervals between Holes C0011A and C0011B (see "Logging and core-log-seismic integration") and linking the gamma ray response to lithologic character (see "Lithology").

\section{Magnetic susceptibility}

Magnetic susceptibility appears to decrease downhole, ranging from $8.9 \times 10^{-5} \mathrm{CMS}$ to $1393 \times 10^{-5} \mathrm{CMS}$ within the upper portion of Unit II and $3.0 \times 10^{-5}$ to $806.0 \times 10^{-5} \mathrm{CMS}$ within the lower portion of Unit II, whereas the maximum magnetic susceptibility within Unit III is $127.5 \times 10^{-5} \mathrm{CMS}$ (Fig. F46). Spikes of high magnetic susceptibility in Unit II correlate with tuffaceous and volcaniclastic sandstones (Figs. F2, F3, F4), thus relating magnetic susceptibility to grain size and sediment composition. Two distinct magnetic susceptibility zones exist within Unit III: above $616 \mathrm{~m}$ CSF resistivity is variable with a slight downhole increase; however, a small step decrease occurs at $616 \mathrm{~m} \mathrm{CSF}$, and through the rest of Unit III, magnetic susceptibility is constant (Fig. F46). This shift in magnetic susceptibility coincides with a change in the rate of hemipelagic sediment accumulation from 7.7 to $3.9 \mathrm{~cm} / \mathrm{k} . y$. (Fig. F16) and may also correspond to a change in clay mineralogy. Unit IV begins with a peak and an increase in magnetic susceptibility, below which it decreases to levels similar to those measured in the lower portion of Unit III (Fig. F46).

\section{Electrical resistivity}

Electrical resistivity is generally low, with $>90 \%$ of the values throughout Hole C0011B $<5 \Omega \mathrm{m}$, but locally high-resistivity layers, up to $60.4 \Omega \mathrm{m}$, are present (Fig. F46). Throughout Hole C0011B, resistivity varies greatly; at times variations correlate with LWD data from Hole C0011A and provide ties from cores to logs (see "Logging and core-log-seismic integration"). Usually variations in electrical resistivity cor- 
relate with variations in natural gamma radiation, providing additional information on lithologic variability (Fig. F46).

\section{P-wave velocity}

Anomalously low $P$-wave velocity data were recorded throughout Hole C0011B with the MSCL-W P-wave system. This likely results from insufficient transmission of compressional waves between transducers. This was caused by cores that across sediment cores, which did not completely fill the core liner.

\section{MAD measurements}

MAD measurements in Hole C0011B provide a detailed characterization of grain density, bulk density, porosity, void ratio, and water content. All MAD data are provided in Tables T12 and T13 and are summarized below.

\section{Bulk and grain density}

Bulk density of mudstone and sandstone discrete samples increases downhole as anticipated from increasing overburden and normal consolidation (Tables T12, T13). Mudstone bulk density ranges from 1.54 to $2.55 \mathrm{~g} / \mathrm{cm}^{3}$, whereas sandstone bulk density ranges from 1.39 to $2.19 \mathrm{~g} / \mathrm{cm}^{3}$ (Fig. F48A). Mudstone and sandstone bulk density increases slightly with depth in Unit II (Fig. F48A). The Unit II/III transition has a small but abrupt local increase in bulk density followed by a gradual increase in bulk density through lithologic Unit IV. Grain density has an average of 2.67 and $2.61 \mathrm{~g} / \mathrm{cm}^{3}$ for mudstone and sandstone, respectively. The spread in grain density is unusually large, $2.02-2.99 \mathrm{~g} / \mathrm{cm}^{3}$ for mudstone grains and $2.11-2.99 \mathrm{~g} / \mathrm{cm}^{3}$ for sandstone grains; however, average values are consistent and representative of siliciclastic grain densities. Some of the bulk and grain density scatter is probably due to faulty pycnometer measurements, and some of the bulk density scatter is due to drilling disturbance.

\section{Porosity}

Calculated porosity values decrease with depth as anticipated from normal consolidation (Fig. F48B). To characterize the porosity behavior, we employ a porosity-effective stress model (e.g., Rubey and Hubbert, 1959):

$$
\phi=\phi_{\mathrm{o}} \mathrm{e}^{-\beta \sigma_{v}^{\prime}}
$$

where

$$
\begin{aligned}
& \phi_{o}=\text { reference porosity, } \\
& \beta=\text { bulk compressibility, and }
\end{aligned}
$$

$$
\begin{aligned}
\sigma_{v}^{\prime}= & \text { effective vertical stress determined by inte- } \\
& \text { grating the bulk density data and assuming } \\
& \text { hydrostatic fluid pressure. }
\end{aligned}
$$

A regression of the mudstone porosity-effective stress data yields bulk compressibility of $0.0731 / \mathrm{MPa}$ and reference porosity of 0.61 . In general, the porosity model matches observations (Fig. F48B). Lithologic Unit II above $440 \mathrm{~m}$ CSF has slightly higher porosity than the modeled porosity. Possible causes for this deviation are higher sand content and/or the presence of cement, both of which decrease compressibility. Observed and modeled porosities are in general agreement from 440 to $720 \mathrm{~m} \mathrm{CSF}$ and below $740 \mathrm{~m}$ CSF. From 720 to $740 \mathrm{~m}$ CSF the model overpredicts the measured porosity, suggesting either overconsolidation of the interval or locally enhanced compression. The interpretation of subdued porosity loss above $440 \mathrm{~m}$ CSF, followed by a transition to normal consolidation below is similar to trends observed at Sites 1173 (at 343 mbsf) and 1177 (at 400 mbsf). The interpreted transition in Hole C0011B is far less clear than at Sites 1173 and 1177. This apparent transition is harder to identify because of several possible influences: (1) mudstones in Hole C0011B have lower compressibility than those at Sites 1173 and 1177 (Spinelli et al., 2007), (2) the transition occurs deeper in Hole C0011B, and (3) data from Hole C0011B have greater scatter. Because the mudstones in Hole C0011B are stiffer and experienced a higher stress prior to the apparent preservation of porosity, we expect the porosity shift to be less pronounced than if the transition occurred in shallower, more compressible sediments (e.g., Sites 1173 and 1177).

Sandstone porosity at Site C0011 does not exhibit a consistent trend but ranges from 0.30 to 0.78 (Fig. F48B; Table T13). The porosity of sand-rich units is harder to evaluate accurately with standard MAD methods because of enhanced drainage and evaporation.

\section{Shear strength}

No shear strength measurements were made below $340 \mathrm{~m}$ CSF because the sediment is too stiff for reliable measurements.

\section{Anisotropy of $\boldsymbol{P}$-wave velocity and electrical resistivity}

$P$-wave velocity and electrical resistivity were measured on discrete cube samples cut from working halves. Measurements were made in three directions orthogonal to the $x-, y$-, and $z$-axes of the core reference (see Fig. F17 in the "Methods" chapter). For both $P$-wave velocity and electrical resistivity, the horizontal-plane anisotropy $\left(a_{\mathrm{VPhor}}, a_{\text {phor }}\right)$ and verticalplane anisotropy $\left(a_{\mathrm{VPvert}}, a_{\text {pvert }}\right)$ were calculated (see "Physical properties" in the "Methods" chapter). 
Velocity is highly varied from 1600 to $2300 \mathrm{~m} / \mathrm{s}$ (Table T14). There are no definitive trends between 340 and $440 \mathrm{~m}$ CSF. Below $440 \mathrm{~m}$ CSF, velocity gradually increases with depth (Figs. F48C, F49). Within lithologic Unit III, two velocity trends exist: velocity increases from the top of Unit III to $575 \mathrm{~m} \mathrm{CSF}$, and the velocity gradient is constant from $575 \mathrm{~m}$ CSF to the base of Unit III. Velocity then increases through Unit IV to Unit V; however, the data have significant scatter.

Vertical-plane anisotropy of velocity $\left(a_{\text {VPvert }}\right)$ (see "Physical properties" in the "Methods" chapter) is generally positive, indicating average horizontal velocity is greater than vertical velocity (Fig. F49). A transition from no vertical-plane anisotropy (isotropic) to positive vertical-plane anisotropy may exist near $440 \mathrm{~m}$ CSF; however, significant scatter in the data obscures the trend. Horizontal-plane anisotropy $\left(a_{\mathrm{VPhor}}\right)$ varies widely between $-10 \%$ and $7 \%$, and it fluctuates around $0 \%$ from Unit II through Unit V. Velocity data tend to have less scatter with increasing depth, which is perhaps related to more competent sediments facilitating increased sample integrity. In contrast, velocity anisotropy data appear to suffer significantly from core disturbance (e.g., fluid-filled microfractures); scatter in the $P$-wave anisotropy data likely reflects variable degrees (and/or orientation) of drilling disturbance.

A velocity-porosity relationship is developed with measured $P$-wave velocity and nearest neighbor ( $<66 \mathrm{~cm}$ offset) porosity data (Fig. F50). For comparison to the observations, empirical relationships for $P$-wave velocity versus porosity from (1) global compilations for "normal" and "high" consolidation sediment (Erickson and Jarrard, 1998) and (2) Shikoku Basin sediments (Hoffman and Tobin, 2004) are plotted. The global compilations provide loose upper and lower bounds for the expected relationship between velocity and porosity. The trend reported for Shikoku Basin sediments is

$$
\begin{gathered}
V_{\mathrm{P}}=0.746+0.532 \phi+\left\{0.305 /\left[(\phi+0.124)^{2}+0.051\right]\right\} \\
+0.61\left(v_{\mathrm{sh}}-1.123\right) X_{1}
\end{gathered}
$$

where

$$
\begin{aligned}
& V_{\mathrm{P}}=P \text {-wave velocity, } \\
& \phi=\text { porosity, } \\
& V_{\text {sh }}=\operatorname{shale} \text { fraction }(0.32), \text { and } \\
& X_{1}=\tanh \left[40\left(\phi-\phi_{c}\right)\right]-\left|\tanh \left[40\left(\phi-\phi_{c}\right)\right]\right|,
\end{aligned}
$$

where critical porosity $\left(\phi_{c}\right)$ is 0.295 (Hoffman and Tobin, 2004). Many of the values from Hole C0011B lie within the velocity model bounds (Fig. F50). Some of the samples, however, are faster than predicted by the velocity model, especially for samples with porosity $>55 \%$.
Electrical resistivity measured on cube samples varies from 2.0 to $12.0 \Omega \mathrm{m}$ (Table T15; Fig. F51). In most cases, vertical resistivity is greater than horizontal (see "Physical properties" in the "Methods" chapter), with anisotropy becoming more negative downhole. In Unit II electrical resistivity is approximately constant in the vertical plane and decreases slightly with depth in the horizontal plane (Fig. F51); however, the data have significant scatter. Similar to the $P$-wave velocity measurements, electrical resistivity determinations are particularly sensitive to the amount of disturbance and orientation of drilling-induced, fluid-filled microfractures. Additionally, electrical resistivity is very sensitive to sample saturation and evaporation of water. In Units III-IV, resistivity appears to increase slightly with depth, likely resulting from decreased porosity with depth. Scatter in the data obscures any definitive trend. The general downhole trend of resistivity anisotropy becoming more negative is probably controlled by the alignment and flattening of pores caused by consolidation and grain reorientation.

\section{Thermal conductivity}

Thermal conductivity measurements were conducted with the needle probe on whole-round samples $(<365 \mathrm{~m} \mathrm{CSF})$ and with the half-space probe on split core samples (>365 m CSF). Thermal conductivity values vary between 0.98 and $1.77 \mathrm{~W} /(\mathrm{m} \cdot \mathrm{K}$ ) (Table T16; Fig. F48D). Thermal conductivity of sand-rich layers ranges from 1.11 to $1.75 \mathrm{~W} /(\mathrm{m} \cdot \mathrm{K})$. In Unit II, thermal conductivity slightly increases with depth. From the lower portion of Unit II through the upper $\sim 50 \mathrm{~m}$ of Unit III, thermal conductivity increases steeply in response to porosity loss. In the lower portion of Unit III, thermal conductivity slightly decreases with depth; this may result from an increasing number of drilling-induced cracks in the core. Thermal conductivity increases in Units IV and V but has significant scatter. The correlation between thermal conductivity and porosity is shown in Figure F52. The relationship for Site C0011 sediments is consistent with sediment grain thermal conductivity ranging from 2.1 to $3.4 \mathrm{~W} /(\mathrm{m} \cdot \mathrm{K})$ and centered at $2.6 \mathrm{~W} /(\mathrm{m} \cdot \mathrm{K})$ (a typical value for hemipelagic sediment).

\section{Comparison with Site 1177}

The location of Site C0011 is physiographically similar to the location of Site 1177 . Both are $\sim 20 \mathrm{~km}$ seaward of the Nankai Trough and $>100 \mathrm{~km}$ off the axis of the Kinan seamount chain. We compare some of the general trends in sediment physical properties between the two sites. At Site 1177, the upper Shikoku Basin facies has nearly constant porosity, and $P$-wave velocity gradually increases with depth 
through this interval (Fig. F53). In the $\sim 100 \mathrm{~m}$ below the upper Shikoku Basin facies at Site 1177, porosity decreases with depth dramatically and $P$-wave velocity increases with depth along a steeper trend than in the upper Shikoku Basin facies. $P$-wave anisotropy is nearly zero in the upper Shikoku Basin facies. In the lower Shikoku Basin facies, $P$-waves travel faster in the horizontal direction than vertical. At $\sim 440 \mathrm{~m}$ CSF in Hole C0011B, transitions in sediment physical properties, such as those observed at Site 1177, are less obvious (Figs. F48, F53). However, drillinginduced core disturbance at Site C0011 obscures details in trends (see "Core quality and physical properties"). There appear to be shifts in trends of porosity, $P$-wave velocity, and $P$-wave velocity anisotropy consistent with those at Site 1177 (Fig. F53). The general trends are consistent with shallower sediment having an open framework of randomly oriented sediment grains. Consolidation of deeper sediment has caused porosity loss and horizontal alignment of platey, clay-sized particles. The consolidation trends of mudstones, however, are different between Hole C0011B and Site 1177. Bulk compressibility $(\beta=0.0731 / \mathrm{MPa})$ for mudstone in Hole C0011B is $\sim 80 \%$ of the bulk compressibility at Site 1177 . This difference in compressibility may relate to variations in grain shape, grain size distribution, mineralogy, and/or grain fabric between sites.

\section{Core quality and physical properties}

Multiple drilling and coring processes affected core quality in a negative way, which had adverse effects on data quality from bulk physical property measurements. Decreased core diameter from overwashing during RCB coring produced cores that did not fill the core liner, resulting in a significant amount of air and water between the core and the liner. This resulted in calculated values that are not representative of in situ conditions (e.g., low GRA density); measurements are made assuming the core liner is filled with sediment. Advanced processing, integrating Xray CT images for absolute core diameter, could be applied to MSCL-W data to account for the smaller core diameter. In addition, a large number of cores had microscale cracks and fractures induced by drilling, coring, and/or the core recovery process. Some of these features were distinct on the X-ray CT images and in half-round cores (Fig. F54). While physical property sampling made efforts to avoid regions that had visibly identifiable cracks, the data indicate that disturbance is pervasive through most of the cored interval in Hole C0011B. This disturbance is evidenced by the high variability in MAD bulk density and porosity, which have a broader-than-normal (Hole C0011B versus Site 1177) variability based on the general mud-dominated sediments (Fig. F53).
The significant variation in velocity measured on cube samples, in comparison to Site 1177 (Fig. F53), also suggests microcracks yielding low velocity on samples. The thermal conductivity decrease with decreasing porosity (Fig. F48) also confirms small, water-filled fractures in competent material, resulting in a measured thermal conductivity that is lower than in situ thermal conductivity. Side-by-side comparison of split core photographs and X-ray CT images (Fig. F54) shows that not all macroscopic fractures are imaged by X-ray CT (assuming the core splitting process introduces few macroscopic fractures relative to the coring process). Similarly, not all cracks are identifiable in hand samples. Thus, wholeround samples are likely more impacted by drilling disturbance than is evident from X-ray CT images. The presence of small fractures in whole-round samples could introduce artificial anisotropy in permeability and seismic velocity or they could act as planes of weakness in deformation tests. These potential artifacts must be considered in postexpedition geotechnical studies. Even in the presence of disturbance effects, it is possible to interpret general downhole trends and interunit trends. Detailed interpretation of localized changes in physical properties is less reliable because of coring-related disturbance.

\section{Inorganic geochemistry}

The main geochemical objective at Site C0011, located seaward of the trench, was to document the variations in interstitial water chemical composition. Such data may be used to elucidate the origins, volume, and nature of fluid and chemical transport and the fluid-rock interactions that may affect the state and geotechnical properties of the strata at the décollement and their evolution after subduction. A total of 46 interstitial water samples were squeezed from selected whole-round sections for chemical and isotopic analyses. Samples depths ranged from 360.0 to $867.5 \mathrm{~m} \mathrm{CSF}$. One sample per core was collected when possible. Because of poor core recovery and/or intense disturbance, no samples of interstitial water were recovered from Cores 322-C0011B-1R, 2R, 17R, 18R, 20R, 22R, 29R, 34R, 41R, 46R, 49R, 50R, 54R, $60 \mathrm{R}$, and 61R.

\section{Fluid recovery and contamination}

To obtain enough interstitial water for shipboard and shore-based analyses, 30 to $40 \mathrm{~cm}$ long sections were squeezed in Unit II (340-479.60 m CSF). Longer sections (50 to $56 \mathrm{~cm}$ in length) were collected for interstitial water extraction in Units III-V (below $479.60 \mathrm{~m}$ CSF, starting at Core 322-C0011B-17R) because these sediments are more consolidated. The interstitial water volumes, which were recovered from 
whole-round sections by squeezing at a maximum pressure of $25,000 \mathrm{psi}$, are presented as a function of depth in Figure F55. A drastic change in interstitial water recovery occurs between Units II and III. Interstitial water volume ranges from 7.5 to $82.5 \mathrm{~mL}$ between 359.61 and $478.21 \mathrm{~m}$ CSF (Cores 322C0011B-3R through 16R). The higher recovered volumes correspond to sandy lithologies. Below a tightly cemented terrigenous sandstone, from which no interstitial waters were recovered (Cores 322C0011B-17R and 18R at 479.0 and $481.4 \mathrm{~m}$ CSF, respectively), the average interstitial water volume fell to $7 \pm 5 \mathrm{~mL}$, even after increasing the whole-round section length by $25 \%$. Because of the lithified nature of the formation at this site and technical problems during coring operations, many of the cores were very disturbed. Removing the outer layers of these highly fractured and friable samples was not always possible; thus, many interstitial water samples are contaminated with drilling fluid (Figs. F55, F56). We began coring operations in Hole C0011B at $340 \mathrm{~m} \mathrm{CSF}$, and thus, we did not sample the sulfatemethane transition (SMT) zone; however, we can assume that this transition lies well above our shallowest sample and use the sulfate concentration to identify and quantify contamination as indicated in "Inorganic geochemistry" in the "Methods" chapter. The degree of drilling fluid contamination of the highly disturbed samples reaches 30\% (Fig. F55); we chose to discard all data from samples in which contamination is $>15 \%$. There is no apparent correlation between the degree of contamination and volume of interstitial water recovered (Fig. F55).

Interstitial water data collected at Site C0011 are listed in Table T17. In addition, in Table T18 we list sulfate-corrected data, which represent the composition of the interstitial water corrected for drilling fluid contamination. In these samples, contamination ranges from $2 \%$ to $14 \%$, with the higher values $(>10 \%)$ corresponding to disturbed, friable samples that were hard to clean properly. The sulfatecorrected data are illustrated in Figures F57 and F58. These contamination-corrected distributions reflect the combined effects of organic matter diagenesis, hydration and dehydration reactions, precipitation of authigenic phases, and alteration of volcanogenic sediments and oceanic basement.

\section{Biogeochemical processes}

Because the upper $340 \mathrm{~m}$ of this site was not cored, we do not have information on the shallow diagenetic processes. Data from sites drilled on this margin during Leg 190 (Shipboard Scientific Party, 2001b) and IODP Expeditions 315 and 316 (Tobin et al., 2009) show that the base of the sulfate reducing zone occurs in the upper $20 \mathrm{~m} \mathrm{CSF}$. The observed ammonium and phosphate distributions at Site C0011 (Fig. F57) reflect the production of these metabolites at shallower sections than those drilled, although the actual production and consumption pathways cannot be defined at this site. Alkalinity is also probably produced in the shallower sections, and the observed low values reflect consumption by authigenic carbonate formation (Fig. F57).

\section{Halogen concentration ( $\mathrm{Cl}$ and $\mathrm{Br}$ )}

In the cored section recovered from Site C0011, Cl concentration generally decreases from $\sim 550 \mathrm{mM}$ to values that are $\sim 7 \%$ lower than those of seawater. This freshening trend is superficially consistent with that observed at ODP Site 1177, drilled seaward of the deformation front in the Ashizuri transect during Leg 190 (Fig. F59). In general, some possible causes for the freshening include dehydration of smectite at depth and $\mathrm{Cl}$ uptake into an authigenic hydrous phase. As originally postulated for the profiles observed at Site 1177 (Shipboard Scientific Party, 2001b), hydration of volcanic ash layers combined with dehydration reactions may have contributed to the observed $\mathrm{Cl}$ variability. But subsequent shorebased analyses of clay minerals and numerical modeling of thermal conditions and diagenetic reaction progress (Steurer and Underwood, 2003; Saffer et al., 2008; Saffer and McKiernan, 2009) indicate that the freshened interstitial water at Site 1177 originates from greater depth arcward; fluid migration updip probably occurred along highly permeable sand beds. This possibility also exists at Site C0011. Chlorinity increases in the deeper sections of Hole C0011B (below $700 \mathrm{~m} \mathrm{CSF}$ ), and this trend is probably the result of hydration reactions during basement alteration and diffusional exchange with a more seawater-like fluid in the basalt (see "Inorganic geochemistry" in the "Site C0012" chapter). There is no significant variability in the $\mathrm{Br} / \mathrm{Cl}$ ratio downcore, but observed values (1.6 to $1.8 \mathrm{mmol} /$ mol) (Fig. F57) are slightly higher than seawater.

\section{Chemical changes due to alteration of volcaniclastics}

The dominant lithology in Unit II is an alternation of green-gray silty claystone and medium- to thickbedded volcaniclastic and tuffaceous sandstone. To evaluate the chemical exchange due to volcanic glass alteration, we consider here the alteration of anorthite, one of the major and most reactive mineralogical constituents of glass. Dissolution of anorthite leads to a release of calcium, aluminum, and silica to the interstitial water following Reaction 1 . The presence of magnesium and potassium in the interstitial water 
permits the precipitation of montmorillonite-(Ca, $\mathrm{Mg}, \mathrm{K})$, a dioctahedral smectite, as a secondary mineral as described by Reaction 2. By combining anorthite dissolution and montmorillonite precipitation and assuming that aluminium is not mobilized, we can write the overall chemical Reaction 3.

$$
\begin{gathered}
\mathrm{CaAl}_{2}\left(\mathrm{SiO}_{4}\right)_{2}+8 \mathrm{H}^{+}= \\
\mathrm{Ca}^{2+}+2 \mathrm{Al}^{3+}+2 \mathrm{H}_{4} \mathrm{SiO}_{2(\mathrm{aq})} . \\
4 \mathrm{H}_{4} \mathrm{SiO}_{2(\mathrm{aq})}+1.67 \mathrm{Al}^{3+}+(0.33+x) \mathrm{Mg}^{2+}+(2 y) \mathrm{K}^{+} \\
+(0.165-x-y) \mathrm{Ca}^{2+}=\left(\mathrm{Ca}_{0.165-x-y} \mathrm{Mg}_{\mathrm{x}}, \mathrm{K}_{2 \mathrm{y}}\right) \\
\mathrm{Mg}_{0.33} \mathrm{Al}_{1.67} \mathrm{Si}_{4} \mathrm{O}_{10}(\mathrm{OH})_{2} . \\
\text { Anorthite }+2.8 \mathrm{H}_{4} \mathrm{SiO}_{2(\mathrm{aq})}+(0.33+x) \mathrm{Mg}^{2+} \\
+(2 y) \mathrm{K}^{+}= \\
\text {montmorillonite- }(\mathrm{Ca}, \mathrm{Mg}, \mathrm{K}) \\
+(0.8+x+y) \mathrm{Ca}^{2+} .
\end{gathered}
$$

In basaltic glass, olivine and pyroxene alteration will provide extra aqueous silica for montmorillonite precipitation. Thus, the expected effect of anorthite alteration, and more generally of volcanic glass, will be an uptake of magnesium and potassium from interstitial water and a release of calcium. These changes are common in ash-bearing sediments (e.g., Gieskes et al., 1990) as well as in deep formations where exchanges with underlying basement rocks are known to occur (e.g., Lawrence and Gieskes, 1981). It is worth noting that interstitial water from Site C0011 bears a significantly more extensive alteration fingerprint (Fig. F59) than that from Site 1177, with almost complete removal of potassium and magnesium below $400 \mathrm{~m}$ CSF. The observed concomitant change in dissolved silica suggests that ash alteration is also controlling the silica profile. Alternatively, the silica distribution may reflect temperature-dependent opal diagenesis as postulated for Sites 1173 and 1177 by Spinelli et al. (2007).

In an attempt to elucidate these equilibria, we performed calculations of the interstitial water saturation state using the PhreeqcI software package (Parkhust and Appelo, 1999) and integrated Lawrence Livermore National Laboratory database, "thermo.com.V8.R.230" (Johnson et al., 1992), using values for pure end-members of mineral phases and assuming temperatures of $5^{\circ}$ and $25^{\circ} \mathrm{C}$. The results shown in Figure F60 are a first-order approximation of the thermodynamic equilibrium and do not include any kinetic effects. The results for the formation of montmorillonite illustrate supersaturation of this mineral above $400 \mathrm{~m} \mathrm{CSF}$ and an envelope of values that approximate equilibrium at depths $>400 \mathrm{~m} \mathrm{CSF}$, suggesting that this reaction controls the distribution of silica, potassium, and magnesium in interstitial water. The resulting removal of potassium from interstitial water observed at this site raises the question of the source of potassium for smectite to illite conversion, even after this sediment sequence is deeply buried and warmed to sufficiently high temperatures.

Dissolved calcium values at Site C0011 are much higher than those measured at Site 1177 . A very sharp increase in dissolved calcium with depth occurs in Units IV and V, probably as a result of calcium supply from basement alteration reactions. The high levels of dissolved calcium at this site support carbonate precipitation, even at very low alkalinity $(<2 \mathrm{mM})$. This expectation is consistent with calculated saturation values for calcite and dolomite (Fig. F60) and the presence of carbonate throughout the cored section as vein filling, carbonate cements, and discrete layers as thick as $2.7 \mathrm{~cm}$ (see "Lithology"). Bulk powder XRD shows that analcime $\left(\mathrm{NaAlSi}_{2} \mathrm{O}_{6} \cdot \mathrm{H}_{2} \mathrm{O}\right)$, heulandite $\left(\left[\mathrm{Ca}, \mathrm{Na}_{2}\right]\left[\mathrm{Al}_{2} \mathrm{Si}_{7} \mathrm{O}_{18}\right] \cdot 6 \mathrm{H}_{2} \mathrm{O}\right)$, and/or clinoptilolite $\left([\mathrm{Na}, \mathrm{K}, \mathrm{Ca}]_{2-3} \mathrm{Al}_{3}\left[\mathrm{Al}, \mathrm{Si}_{2} \mathrm{Si}_{13} \mathrm{O}_{36} \cdot 12 \mathrm{H}_{2} \mathrm{O}\right)\right.$ are present in Unit $\mathrm{V}$. These zeolites form as the devitrification product of glass in tuffs and volcanic rocks. The decrease in $\mathrm{Na}$ in interstitial water in the lower sections sampled is consistent with the formation of these minerals, which may also be favored by high calcium concentration in the basal fluids. As shown in Figure F60, Na-clinoptilolite is the best candidate to control $\mathrm{Na}$ concentration in interstitial water, as it reaches equilibrium below $500 \mathrm{~m}$ CSF, and the lack of potassium in the fluids probably hinders formation of K-clinoptilolite.

Strontium and lithium profiles also show significant enrichment at depth relative to seawater. The increase in strontium in interstitial water as a product of reaction with volcanoclastic material is well established (e.g., Gieskes et al., 1990), and shore-based isotopic characterization of dissolved strontium will aid in constraining this Sr source. In contrast, authigenic clay formation at low to moderate temperatures incorporates $\mathrm{Li}$, with preference to the light ${ }^{6} \mathrm{Li}$ isotope, such that there is a decrease in the Li content of interstitial water, and $\mathrm{Li}$ should become isotopically heavier because of this process (e.g., Chan and Kastner, 2000). Field and laboratory observations document remobilization of lithium from aluminosilicates at temperatures ranging from $70^{\circ}$ to $100^{\circ} \mathrm{C}$ (Edmond et al., 1979; Seyfried et al., 1984), and the isotopic composition of the mobilized Li depends on the temperature-dependent isotopic fractionation. The deeper the sediment source, the lighter the dissolved Li should be; this is because at higher temperatures there is less of an isotopic fractionation. Light $\mathrm{Li}$ isotopic signature has been observed at the décollement zone of ODP Sites 808 (Nankai) and 1040 (offshore Costa Rica), which signifies migration of deeply generated fluids (You et al., 1995; Chan and Kastner, 2000). 


\section{Organic geochemistry}

The organic geochemistry program during Expedition 322 aimed to characterize the composition of sediments entering the subduction system with respect to their role as a habitat for the deep subseafloor biosphere. The main objectives were to characterize (1) potential energy sources of the deep biosphere (i.e., the amount and quality of organic matter within the sediment); (2) the availability of hydrogen $\left(\mathrm{H}_{2}\right)$, which represents an alternative energy source that results from the degradation of organic matter, mineral-water interactions, or radiolysis of water; (3) the presence of methane that could be exploited as an energy source in the process of anaerobic methane oxidation and which may lead to the formation of authigenic carbonate; and (4) sources of methane and other hydrocarbon gases that formed in the course of biogenic and thermogenic alteration of organic matter during sediment burial.

To achieve these objectives, we (1) measured the quantity and composition of hydrocarbon gases $\left(\mathrm{C}_{1}-\mathrm{C}_{4}\right)$ and hydrogen by headspace technique, (2) determined the potential of the sediments to produce and consume hydrogen in incubation experiments, (3) characterized the composition of the particulate sedimentary organic matter by elemental analysis and Rock-Eval pyrolysis, and (4) measured the concentration of total inorganic carbon in the sediments.

\section{Hydrocarbon gases}

At Site C0011, hydrocarbon gas concentrations increase with depth (Table T19). Methane $\left(C_{1}\right)$ was present in all samples of Hole C0011B. Ethane $\left(\mathrm{C}_{2}\right)$ was detected in all cores taken from depths $>425 \mathrm{~m}$ CSF, except for Core 322-C0011B-30R. Propane $\left(\mathrm{C}_{3}\right)$ was first observed at $569 \mathrm{~m} \mathrm{CSF}$ and was present in almost all deeper cores. Isobutane $\left(\mathrm{C}_{4}\right)$ occurred sporadically at depths $>675 \mathrm{~m} \mathrm{CSF}$. The occurrence of ethane below $422 \mathrm{~m}$ CSF results in low $\mathrm{C}_{1} / \mathrm{C}_{2}$ ratios $\sim 280 \pm 80$ that generally decrease with depth but show a reversal to higher $C_{1} / C_{2}$ values at the bottom of the hole (Fig. F61).

The $\mathrm{C}_{1} / \mathrm{C}_{2}$ ratio is generally used to obtain information on the origin of the hydrocarbons. When high amounts of $C_{1}$ are present $(>10,000 \mathrm{ppm})$, very high $\mathrm{C}_{1} / \mathrm{C}_{2}$ ratios indicate methane formation by biological processes. In contrast, major amounts of higher molecular weight hydrocarbons in shallow depths suggest thermogenic hydrocarbon sources and gas migration. However, minor amounts of $\mathrm{C}_{2}-\mathrm{C}_{4}$ can also be generated in situ during early, low-temperature diagenesis of organic matter, and it is becoming increasingly recognized that $\mathrm{C}_{2}-\mathrm{C}_{4}$ gases can also be produced biogenically along with $\mathrm{C}_{1}$, although not in high concentrations (Vogel et al., 1982; Wiesenburg et al., 1985; Oremland et al., 1988; Hinrichs et al., 2006). The very low $C_{1} / C_{2}$ ratios $(\sim 280 \pm 80)$ at Site C0011 are unusual for sediments with organic carbon contents of $<0.5 \mathrm{wt} \%$. These data are within the normal range in the context of safety considerations (Fulthorpe and Blum, 1992; Shipboard Scientific Party, 1995) when plotted versus an estimated temperature, assuming a geothermal gradient of $0.056^{\circ} \mathrm{C} / \mathrm{m}$ and a bottom water temperature of $3^{\circ} \mathrm{C}$ (Fig. F62). The potential sources of the higher hydrocarbon gases (i.e., in situ production and/or migration from deeper, hotter sources) remain to be explored by additional shore-based investigations.

\section{Hydrogen gas}

At Site C0011, we aimed to determine $\mathrm{H}_{2}$ concentrations directly using the extraction method. This method is based on the assumption that $\mathrm{H}_{2}$, which is initially present in a wet sediment sample, exsolves from the liquid phase when it is slurried with an $\mathrm{NaCl}$ solution and can be captured in the defined headspace of a closed vial. Using mass balance considerations, the initial concentrations of dissolved $\mathrm{H}_{2}$ were calculated from the analyzed concentrations of $\mathrm{H}_{2}$ in the headspace gas after accounting for the contribution of $\mathrm{H}_{2}$ from the reagent blank.

$\mathrm{H}_{2}$ concentrations in the headspace gas cover a large range (from 0.27 to $62.9 \mathrm{ppmv}$ ) (Table T20). The lowest concentrations are only slightly higher than the reagent blank of 0.214 ppmv, but in the majority of samples, $\mathrm{H}_{2}$ concentrations are at least three times higher. The corresponding dissolved $\mathrm{H}_{2}$ concentrations range from 0.049 to $17.4 \mu \mathrm{M}$ and average $1 \pm$ $3 \mu \mathrm{M}$. The dissolved $\mathrm{H}_{2}$ concentrations do not show a clear trend with depth (Fig. F63).

Because $\mathrm{H}_{2}$ concentrations were unexpectedly high, we investigated the potential contamination of samples with $\mathrm{H}_{2}$ that might be generated and introduced into the sample in the course of RCB drilling. Starting with Core 322-C0011B-23R, samples were taken from the free fluids that had accumulated between the cut core and the core liner whenever there was enough fluid inside the core liner. Samples were retrieved when the core was cut into sections and headspace vials were filled completely with drilling fluid and crimp capped before a headspace of pure $\mathrm{N}_{2}$ was introduced into the headspace vial. As opposed to sediment samples, the drilling fluid was not slurried with an $\mathrm{NaCl}$ solution. In a total of 13 samples, the undiluted drilling fluids yielded 1.28 to $544 \mathrm{ppmv} \mathrm{H}_{2}$ in the headspace gas (Table T21). The 
corresponding dissolved $\mathrm{H}_{2}$ concentrations range from $0.030 \mu \mathrm{M}$ to $1.86 \mu \mathrm{M}$ (Table T21) and do not show a clear trend with depth (Fig. F63).

The high levels of $\mathrm{H}_{2}$ in the drilling fluid demonstrate the high potential for contaminating sediment with $\mathrm{H}_{2}$ in the course of RCB drilling and coring. There is, however, no clear relationship between $\mathrm{H}_{2}$ concentrations in the drilling fluid and sediment samples (Fig. F63). Within the data set, $\mathrm{H}_{2}$ concentrations in the interstitial water of sediments are both higher and lower than $\mathrm{H}_{2}$ concentrations in the drilling fluid. Because cores in general were severely disturbed and intensively exposed to drilling fluid in the course of RCB drilling and coring, the extraction method does not yield reliable information on in situ interstitial water $\mathrm{H}_{2}$ concentrations at Site C0011.

In order to better constrain interstitial water $\mathrm{H}_{2}$ concentrations, we subsampled whole-round cores that had been taken for shore-based analyses (biogeochemistry and deep biosphere studies) and investigated $\mathrm{H}_{2}$ concentrations using the incubation method. This method allows the determination of dissolved $\mathrm{H}_{2}$ concentrations based on two fundamental assumptions: (a) gaseous $\mathrm{H}_{2}$ is in equilibrium with dissolved $\mathrm{H}_{2}$, and (b) the incubation of samples in the laboratory leads to the establishment of a steady state between production and consumption of $\mathrm{H}_{2}$ that is representative of in situ equilibrium. The suitability of this method for deep subseafloor sediments is questionable because microorganisms in deep marine subsurface sediments metabolize at very low rates (D'Hondt et al., 2002; Parkes et al., 2005). Therefore, it is not clear whether steady state can be reached within an acceptable time frame in the laboratory or if such a steady state would be representative of in situ conditions.

At Site C0011, nine samples were investigated using the incubation method (Table T22). For each sample, incubation experiments comprised three replicates. The variability between the replicates is large, with Section 322-C0011B-45R-4 representing an extreme case (Fig. F64), and might be related to the lithification of the sediment, which hindered homogenization of the samples before they were split into replicates. In spite of the large variability between replicates, the following trends were observed. In general, an initial increase in $\mathrm{H}_{2}$ concentrations is followed by a decrease, suggesting active consumption of $\mathrm{H}_{2}$ in the sediments. To avoid contact with atmospheric oxygen, three samples (i.e., from Sections 322-C0011B-15R-3, 25R-2, and 32R-5) were stored prior to sample processing in the $\mathrm{N}_{2}$ atmosphere of an anaerobic chamber that contained an admixture of $2 \% \mathrm{H}_{2}$. Though the headspace of the incubation vials was thoroughly flushed with pure $\mathrm{N}_{2}$ and $\mathrm{H}_{2}$ concentrations were below detection limit when the incubation experiment started, the elevated initial levels of $\mathrm{H}_{2}$ in these three samples might result from some contamination of the sample with $\mathrm{H}_{2}$ during storage. In samples that were incubated for $>200 \mathrm{~h}$, $\mathrm{H}_{2}$ concentrations approach constant levels that suggest a steady state between $\mathrm{H}_{2}$ production and consumption. In all but the deepest sample (322C0011B-58R-6, 123-135 cm; 682.61-862.73 m CSF) final concentrations of dissolved $\mathrm{H}_{2}$ ranged from 1 to $10 \mathrm{nM} . \mathrm{H}_{2}$ concentrations in replicates of the deepest sample were $>70 \mathrm{nM}$ but $<120 \mathrm{nM}$. Thus, $\mathrm{H}_{2}$ concentrations determined using the incubation method are a factor of 100 to 1000 lower than $\mathrm{H}_{2}$ concentrations that resulted from the extraction method.

The large difference between $\mathrm{H}_{2}$ concentrations obtained using the two different methods could have resulted from an underestimation of $\mathrm{H}_{2}$ concentrations by the incubation method (because of low metabolic activity in the recovered samples) and/or from an overestimation of $\mathrm{H}_{2}$ concentrations by the extraction method (because of $\mathrm{H}_{2}$ contamination in the course of drilling). Shipboard investigations did not allow clear differentiation between these two effects. Though both methods have severe limitations, they still allow us to delineate the lower and upper limits of in situ $\mathrm{H}_{2}$ concentrations in Hole C0011B to $\sim 1 \mathrm{nM}$ and $17 \mu \mathrm{M}$, respectively.

\section{Carbon, nitrogen, and sulfur contents of the solid phase}

Carbon, nitrogen, and sulfur contents are low throughout the cored interval of Site C0011 (Table T23). In general, inorganic carbon contents $(0.4 \pm$ $0.9 \mathrm{wt} \%)$ are similar to organic carbon contents $(0.3 \pm$ $0.1 \mathrm{wt} \%)$. Inorganic carbon contents show more scatter in lithologic Unit III than in other lithologic units, but organic carbon contents are more uniform in Unit III (Fig. F65). Inorganic carbon contents correspond to a mean calcium carbonate content of $2.92 \mathrm{wt} \%$, but local increases in Unit III reach up to $61.7 \mathrm{wt} \%$ (Table T23). Total sulfur and total nitrogen contents average $0.4 \pm 1 \mathrm{wt} \%$ and $0.06 \pm 0.02 \mathrm{wt} \%$, respectively. Nitrogen content decreases with depth in Unit III but shows no clear trends in the other lithologic units. Total organic carbon (TOC)/total nitrogen (TN) ratios of $\sim 6 \pm 3$ indicate a marine origin of the sedimentary organic matter (Fig. F66).

\section{Characterization of the type and maturity of organic matter by Rock-Eval pyrolysis}

At Site C0011, the type and maturity of the organic matter was characterized in a selection of 76 samples 
using shipboard Rock-Eval pyrolysis. Fourteen samples yielded poorly resolved $S_{2}$ peaks with peak maxima $\left(T_{\max }\right) \sim 605^{\circ} \mathrm{C}$ and were excluded from the data set presented in this report. Thermal cracking of nonvolatile organic matter $\left(S_{2}\right)$ generally released $<0.2 \mathrm{mg}$ hydrocarbon (HC)/g sediment, and pyrolysis of the kerogen $\left(\mathrm{S}_{3}\right)$ produced $<1.4 \mathrm{mg} \mathrm{CO}_{2} / \mathrm{g}$ sediment (Table T24). $S_{2}$ and $S_{3}$ values show little variation throughout all four cored lithologic units (Fig. F67). The hydrogen index (HI) and oxygen index (OI) average $30 \pm 20 \mathrm{mg} \mathrm{HC} / \mathrm{g}$ TOC and $300 \pm 100 \mathrm{mg}$ $\mathrm{CO}_{2} / \mathrm{g}$ TOC (Table T24; Fig. F67), respectively, thus suggesting a kerogen of Type III evolution. $T_{\max }$ values average $420^{\circ} \pm 10^{\circ} \mathrm{C}$ and indicate sedimentary organic matter at a thermally immature stage (Table T24). $T_{\max }$ did not vary with depth (Fig. F67).

\section{Microbiology}

Twelve $10 \mathrm{~cm}$ long whole-round cores were taken from Hole C0011B for molecular microbiology (phylogenetic) studies and stored at $-80^{\circ} \mathrm{C}$, including two for community archival purposes. Where dedicated microbiology whole-round sampling was not possible, twenty-six $10 \mathrm{~cm}^{3}$ "chips" were obtained from cleaned whole rounds used for interstitial water analyses.

In addition, ten $5 \mathrm{~cm}$ long whole-round cores were taken, subsampled for fluorescence in situ hybridization (FISH) and cell counting studies, and stored anaerobically at $4^{\circ} \mathrm{C}$ for shore-based cultivation studies. Eleven $2-3 \mathrm{~cm}^{3}$ samples were also taken from the $5 \mathrm{~cm}$ long whole-round cores. One of these samples came from the $10 \mathrm{~cm}$ long whole-round cores described above (prior to ultralow freezing). These samples were preserved for shore-based cell counting and FISH studies.

Three working-half split cores were sampled for roughly $10 \mathrm{~cm}^{3}$ carbonaceous mud fragments ("chunks"); these samples were obtained 2-3 h after $\mathrm{X}$-ray CT scanning.

Forty-three 1-2 mL interstitial water samples were obtained for shipboard spectrophotometric analyses of ferrous iron and acid volatile sulfide. Data from these measurements are presented in "Inorganic geochemistry."

Table T25 presents the depth and type distribution of the samples obtained from Hole C0011B.

\section{Downhole measurements}

Direct measurements of in situ pressure and temperature are critical to help define fluid, chemical and heat transport, diagenesis, and microbial activity in marine sediments. Additionally, the data are valuable for validating shipboard and shore-based estimates of pressure and stress from consolidation experiments and from porosity-depth data. The pressure and temperature fields also impact the strength behavior of sediments, so direct measurements can be used to help evaluate conditions that promote or impede fault slip.

\section{Sediment temperature-pressure tool}

The SET-P tool was deployed with the RCB BHA with the aim to measure in situ temperature and pressure within unlithified sand-dominated layers below $675 \mathrm{~m}$ LSF. Prior to drilling operations in Hole C0011B, the SET-P tool was connected to the CDS and placed into the RCB BHA to ensure that the landing mechanism was engaging correctly. During this test, the distance that the tip of the SET-P tool extended beyond the drill bit was measured. With the RCB BHA-CDS-SET-P configuration, it was determined that the SET-P tool tip extended $\sim 1.1 \mathrm{~m}$ beyond the drill bit. This extension was limited by the outer diameter of the SET-P tool spacer and the inner diameter at the drill bit. This impeded the telescoping capability of the CDS during deployments; thus, there was no means to decouple the SET-P tool from the drill string. Therefore, weight on bit (WOB) would have to be maintained during deployments into the formation. Additional measurements of the tool string showed that the distance was $16.75 \mathrm{~m}$ from where the wireline connected to the sinker bar (top of tool string) and the tip of the SET-P tool.

To evaluate deployment operations and provide a sensor test on the SET-P tool, a test deployment was completed in the drill string above the seafloor at the location of Hole C0011B. The deployment consisted of lowering the SET-P tool downhole with stops when the tool tip was at 988 and 1989 meters below sea level (mbsl) for reference measurements (Table T26). The SET-P tool was then recovered on the drill floor. Drilling fluid was circulated while lowering and recovering the tool; however, no circulation occurred during the reference measurements. During the short reference holds $(<3 \mathrm{~min})$, the measured pressure decreased to the hydrostatic pressure, assuming seawater density of $1.024 \mathrm{~g} / \mathrm{cm}^{3}$ (Fig. F68). By the end of the reference holds, the measured pressures were within $2 \%$ of the hydrostatic pressure. Longer holds likely would have resulted in smaller error, but noting the short reference holds and stretch in the wireline, these results confirmed the tool was functioning correctly. The measured temperature in the drill string decreased initially while lowering the tool but reached a value near $2.2^{\circ} \mathrm{C}$ 
below 1000 mbsl. Based on the pressure and temperature observations, the test deployment was successful. All raw data for the test deployment are available in SET-P in "Supplementary material."

A second SET-P tool deployment was scheduled to penetrate the formation at $\sim 680 \mathrm{~m}$ CSF. This deployment targeted the top of a thick sand layer interpreted from LWD gamma ray and resistivity data in Hole C0011A. The deployment strategy was to complete a hole stability check and deploy the SET-P tool with $30 \mathrm{~min}$ of pressure and temperature measurement in the formation. The hole stability check would have been preceded by 10 and 20 min holds without circulation and rotation. Overpull would have been measured after each hold to establish conditions in the borehole. A $1.3 \mathrm{SG}$ mud $\left(25 \mathrm{~m}^{3}\right)$ would have been spotted on the bottom of the hole prior to each hold and prior to the SET-P tool deployment. The WOB would have been 10-20 kN throughout the holds and the deployment into the formation.

Drilling parameters were variable while approaching the target deployment depth because of thin, hard layers interbedded with softer layers. Coring showed that the harder layers were carbonate rich. However, the thin sand layers identified in the LWD data were not recovered in cores. These hard horizons, a lack of knowledge about the depth of the sand top, and no sand recovery forced a reassessment of the target horizon for the SET-P tool deployment. This included shorter coring advancements. Even with shorter advancements, any reasonable correlation between MSCL-W and LWD data was ambiguous in this interval. For a successful SET-P tool deployment, we needed to advance the drill bit in the mudstone to $\sim 1 \mathrm{~m}$ above the top of the target sand bed so the probe tip would penetrate the top of the sand without damaging the hydrologic integrity of the mudstone. This ambiguity in correlating LWD and MSCL-W data, the presence of hard layers, and the lack of recovery to confirm unlithified sand layers led to our decision to abort the SET-P tool deployment at Site C0011.

\section{Logging and core-log-seismic integration}

\section{Hole C0011A logging data quality}

Near the end of Expedition 319, LWD and MWD data were collected in Hole C0011A. The MWD tool provided drilling parameters, and LWD data were obtained using Schlumberger's geoVISION tool (see "Operations" in Expedition 319 Scientists, 2010). Real-time data from MWD and real-time and memory data from geoVISION were collected. The geoVISION memory data were environmentally corrected. The mudline was identified at $4078 \mathrm{~m}$ LWD depth below rig floor (LRF) from LWD gamma ray and resistivity data. All LWD data were converted to LWD depth below seafloor (LSF) based on the mudline depth. Figure F69 shows the overview of the data from MWD and geoVISION. Generally, the data quality, except the resistivity images, is good and no vertical tool shocks were detected with sensors in the tools. The amount of stick-slip, caused by unstable bit rotation, increases with depth in the borehole. Between 596 and $629 \mathrm{~m} \mathrm{LSF}$, the stable ROP following a wiper trip resulted in high-quality resistivity images. Elsewhere in the borehole, variations in rotations per minute (rpm) and high angular acceleration index (AAI) indicate that the bit rotation was not stable. Sections of missing images are the result of the sudden rotation caused by stick-slip, consistent with AAI spikes (Fig. F70). The ship's heave also produced some discontinuities in the resistivity images, resulting in an overlap of images at the same depth (Fig. F70). Overall, the resistivity images are of poor quality. The close correspondence of deep- and shallow-button resistivity values indicates little or no significant drilling mud invasion into the formation (Fig. F69).

\section{Log characterization and interpretation}

Site C0011 logging units were characterized from visual inspection of gamma ray and ring resistivity log responses (Fig. F47). Five primary logging units were defined based on variations in trend lines and log character, with each logging unit further divided into subunits, defined by more subtle variations (Table T27). Statistical variations were calculated on gamma ray and resistivity values in logging units and subunits (Fig. F71). Lithologic interpretations were made based on log character and relative values, with some guidance from previous coring and logging results at Site 1173 in the Shikoku Basin (Moore, Taira, Klaus, et al., 2001; Mikada, Becker, Moore, Klaus, et al., 2002). We classified the background lithology as hemipelagic mud, with relatively constant gamma ray and ring resistivity values. A differentiation between volcanic ash and sand was based primarily on peaks in gamma ray and ring resistivity values: low gamma ray with high resistivity was interpreted to be ash, and low gamma ray with low resistivity was interpreted to be sand. Previous ODP studies (Legs 131, 190, and 196) characterized the upper Shikoku Basin sediments as rich in ash layers, whereas the lower Shikoku Basin sediments are dominated at Site 1177 by sand turbidites (Moore, Taira, Klaus, et al., 2001; Mikada, Becker, Moore, Klaus, et al., 2002; Taira, Hill, Firth, et al., 1991). 


\section{Logging Unit 1 (0-251.5 m LSF)}

Logging Unit 1 (0-251.5 m LSF) exhibits an initial increase in gamma ray and resistivity over the upper $5 \mathrm{~m}$, which is potentially caused by a transition from unconsolidated mud-rich sediments near the seafloor to more consolidated mud-rich sediments with depth. Then the gamma ray log maintains minor fluctuations around a constant trend ( 72 gAPI), while the ring resistivity log exhibits a very gradual decrease ( $\sim .70$ to $0.50 \Omega \mathrm{m})$ (Fig. F47). We interpret the response of low gamma ray and ring resistivity $\log$ values to be consistent with a lithology of sandy mud (Fig. F47); however, another factor could be the influence of high porosity. Both the gamma ray and ring resistivity logs exhibit only small variations through this interval, but we can still define three subunits. A stepped increase in the gamma ray log trend ( $\sim 77$ gAPI) corresponds to a gradual decrease in the ring resistivity trend at $100.0 \mathrm{~m} \mathrm{LSF}$ and marks the base of logging Subunit 1A (0-100.0 m LSF). Logging Subunit 1B (100.0-212.0 m LSF) exhibits a gradual decrease in ring resistivity log values and slightly increasing gamma ray log values, potentially associated with simple increased compaction with depth. Because there is only a minor variance between logging Subunits $1 \mathrm{~A}$ and $1 \mathrm{~B}$, they are both categorized as sandy mud intervals. Logging Subunit 1C (212.0$251.5 \mathrm{~m} \mathrm{LSF}$ ) exhibits a lower gamma ray trend line ( 70 gAPI) with a sharp contact; a similar sharp decrease in ring resistivity log values marks the top of the subunit boundary. Ring resistivity values are low in comparison with the other subunits $(\sim 0.50 \Omega \mathrm{m})$ and remain constant to the base of the subunit. The lower gamma ray signature suggests a coarser texture to this subunit, and therefore, it is categorized as muddy sand. Within this subunit, between 216 and $220 \mathrm{~m}$ LSF, a series of low-value gamma ray peaks correspond to high-value ring resistivity peaks, and these features are interpreted as thin ash layers. A sharp increase in both logs at $251.5 \mathrm{~m}$ LSF marks the logging Unit $1 / 2$ boundary (Fig. F47).

\section{Logging Unit 2 (251.5-478.5 m LSF)}

Below the sharp increase in gamma ray and resistivity, which may correspond to a change from coarser grained sediment to a background hemipelagic mud, logging Unit 2 (251.5-478.5 m LSF) exhibits a gradual increase in the ring resistivity log until a constant trend line is reached $(\sim 0.85-0.90 \Omega \mathrm{m})$ and dominates the logging unit. The gamma ray log has a stepped increase marking the top of the unit to a constant trend line ( $\sim 95$ gAPI); minor fluctuations around this trend line suggest a silt-sand alternation with the background hemipelagic mud. The most striking features within logging Unit 2 are a series of prominent, high-value resistivity spikes, corresponding to lowvalue gamma ray peaks. These features vary in thickness from a few decimeters to tens of meters and are interpreted to be ash and volcaniclastic sand layers (Fig. F72). The first occurrence at $\sim 337.0 \mathrm{~m} \mathrm{LSF}$ marks the upper boundary of logging Subunit 2B (337.0-478.5 m LSF). In this subunit, gamma ray log values exhibit a blocky character, with sharp contacts both at the top and bottom of each feature. At corresponding depths, ring resistivity values are high, with gradual increases from the baseline value and sharp basal transitions. The thickest layers are concentrated $\sim 345.0-410.0 \mathrm{~m}$ LSF, although minor occurrences continue to the base of the logging unit at $478.5 \mathrm{~m}$ LSF. Logging Subunit 2A (251.5-337.0 m LSF) exhibits the more constant and uniform character of the unit and is interpreted to be dominated by silt-rich hemipelagic mudstone (Fig. F47). The base of logging Unit 2 (and Subunit 2B) is placed at the base of the lowermost low-value gamma ray peak (478.5 m LSF), below which there is a sharp increase in gamma ray and ring resistivity log values.

In Hole C0011A, based on the last occurrence of ash/ volcaniclastic layers in the log-based lithology, we place a tentative boundary between the middle Shikoku Basin sediments and the lower Shikoku Basin sediments at the base of logging Unit $2(478.5 \mathrm{~m}$ LSF). We place the upper boundary of the middle Shikoku Basin at the top of logging Subunit 2B (337.0 m LSF).

\section{Logging Unit 3 (478.5-736.0 m LSF)}

Logging Unit 3 (478.5-736.0 m LSF) exhibits an increased gamma ray log trend ( 107 gAPI), with little variation. Ring resistivity log values also increase in this unit and exhibit little variation, with the exception of minor spikes. There is a small step decrease in the trend, potentially caused by a decrease in the clay content, which marks the base of logging Subunit 3A (478.5-542.5 m LSF); where this lower value section occurs is logging Subunit 3B (542.5-649.0 m LSF). An apparent change in gamma ray and resistivity baseline values at $\sim 596 \mathrm{~m} \mathrm{LSF}$ and a return to the previous baseline at $\sim 629 \mathrm{~m}$ LSF is likely due to a reamed-down interval during the drilling process rather than any change in the formation. Around $649.0 \mathrm{~m}$ LSF, a change occurs in the log character, with the introduction of low-value gamma ray peaks and corresponding low ring resistivity spikes, which are interpreted as sand or sandstone beds. Through logging Subunit 3C (649.0-736.0 m LSF), these spikes increase in concentration, thickness, and amplitude. The initial spikes are only minor deviations from the trend line in both gamma ray and resistivity logs, changing to very low gamma ray values 
( 35-25 gAPI) that define features of meter-scale thickness with increasing depth. At $\sim 700.00 \mathrm{~m} \mathrm{LSF}$, two thick sandstones are interpreted, below which the character of the spikes decreases until the top of logging Unit 4 (Fig. F73).

\section{Logging Unit 4 (736.0-867.0 m LSF)}

Logging Unit 4 (736.0-867.0 m LSF) exhibits a very different character from the units above and appears to correspond to a series of strong reflections in seismic data (Fig. F74). As Figure F74 illustrates, the variability in gamma ray and ring resistivity log values is greater than that in logging Units 1-3. Logging Unit 4 can be divided into four "packages" of sediment, which exhibit coarsening- and fining-upward trends (Fig. F74). These are interpreted to be more consolidated sandy turbidite packages. The base of logging Unit 4 (867.0 $\mathrm{m} \mathrm{LSF}$ ) is characterized by a change to more uniform gamma ray log values and a sharp increase in ring resistivity log values (Fig. F47).

\section{Logging Unit 5 (867.0-950.5 m LSF)}

Logging Unit 5 (867.0-950.5 m LSF) is characterized by a sharp increase in ring resistivity log values, which then remain constant with minor fluctuations around the trend line. In contrast, no corresponding sharp change occurs in gamma ray, but rather gamma ray values decrease slightly with depth and exhibit less variation than logging Unit 4. Logging Subunit 5A (867.0-938.5 m LSF) is characterized by minor fluctuations in gamma ray values, with corresponding fluctuations in ring resistivity log values, and encompasses most of logging Unit 5. The gamma ray log values suggest a hemipelagic mudstone, but higher ring resistivity log values indicate a more consolidated or compacted nature (Fig. F71). In the lowermost section, a sharp decrease in gamma ray $\log$ values marks the Subunit 5A/5B boundary. Ring resistivity values in Subunit 5B (938.5-950.5 m LSF) remain very similar to Subunit 5A (Fig. F71). The contrast between the change in gamma ray log and continuation of the resistivity log suggests a compositional change between the two subunits. Lower gamma ray log values imply an increase in sand/silt, leading to a category of consolidated silty/ sandy mudstone.

\section{Structural image analysis}

Resistivity images were generated from the deep-, medium-, and shallow-button resistivities, and both static and dynamic processing were applied. Largescale variations are most clearly observed in static images, while smaller-scale features are highlighted in dynamic images. Bedding, resistive and conductive fractures, faults, and breakouts were recorded.

\section{Bedding and fractures}

Bedding dip and orientation were fairly constant throughout the whole drilled interval, dipping consistently toward to the north, at a shallow $5^{\circ}-20^{\circ}$ angle (Figs. F22, F47). This dip direction is consistent with the regional dip of reflections, observed in seismic data (Fig. F1) as well as core observations (see "Structural geology"). Abundant bedding-parallel conductive and resistive fractures were also observed, although it is possible that some of the features interpreted as resistive fractures are actually ash layers (Fig. F75A), whereas some of the conductive fractures may be silty layers. However, the resolution of the logging data does not allow us to make this distinction.

Some lithologic variations can be distinguished in the resistivity images. For example, the volcaniclastic sandstones found in cores within lithologic Unit II (see "Lithology") can be identified in the dynamic resistivity images as having a more "mottled" appearance (Fig. F75B). Local high-angle faults $\left(>50^{\circ}\right)$ are observed cutting across fractures and bedding and, in some cases, offsetting borehole breakouts (Fig. F75C). These faults exhibit a general southward dip (Fig. F22) and increase in concentration through logging Unit 3. Only one fault is recorded in logging Units 4 and 5 . However, the lack of faults in the lower units may be due to the degradation of image quality over this interval. The chaotic deposit recognized in the cores from 400.86 to $411.15 \mathrm{~m} \mathrm{CSF}$ (see "Lithology") can be identified in resistivity images at 399.5-409.5 m LSF (Fig. F75D).

\section{Borehole breakouts}

Breakout analysis was performed to assess the orientation of the maximum horizontal stress direction within the borehole. Breakouts appear as two vertical conductive zones, with $180^{\circ}$ of separation between them (e.g., Fig. F75C). They typically form perpendicular to the direction of maximum horizontal stress in the borehole. Assuming that they are Coulomb shear failures because of circumferential stress of the borehole wall, the breakout width is related to the horizontal differential stress. The parameters needed to calculate the differential horizontal stress $\left(S_{\mathrm{H} \max }-S_{\mathrm{hmin}}\right)$ from breakout width were not available, however, and the calculation was not done on board.

At Site C0011, breakouts are most prevalent in the hemipelagic sediments of logging Units 3 and 4, particularly in an interval between $\sim 600$ and $650 \mathrm{~m}$ LSF (Fig. F47). Analyses indicate a mean azimuth of $115^{\circ}$ and, therefore, an azimuth of $205^{\circ}$ for the maximum horizontal compressive stress $\left(S_{\text {Hmax }}\right)$ (Fig. F76). This north-northeast-south-southwest trend is roughly perpendicular to the convergent direction of the 
Philippine Sea plate (Fig. F77) and to the dominant maximum horizontal compressive stress determined at IODP sites within the accretionary prism during NanTroSEIZE Stage 1 (Kinoshita et al., 2008) and Site 808 (Ienaga et al., 2006; McNeill et al., 2004). The shallow sediments of the Kumano Basin at IODP Site C0002 exhibit a similar perpendicular-to-convergence azimuth (Kinoshita et al., 2008).

\section{Seismic analysis}

\section{Seismic stratigraphy}

A high-resolution, three dimensional (3-D) multichannel seismic (MCS) reflection survey was carried out in the Nankai Trough off the Kii Peninsula using R/V Kairei of the Japan Agency for Marine-Earth Science and Technology in March 2006 (Park et al., 2008). A $\sim 5 \mathrm{~km}, 204$ channel streamer and $\sim 100 \mathrm{~m}$ separated dual source (two G-guns plus one GI-gun) were used for the 3-D MCS survey. Flip-flop shooting with a $30 \mathrm{~m}$ interval yields $\sim 50 \mathrm{~m}$ separated two common midpoint lines, resulting in a $3.5 \mathrm{~km} \times$ $52 \mathrm{~km}$ 3-D seismic volume. Recording length with a $1 \mathrm{~ms}$ sampling interval is $10 \mathrm{~s}$. Depths of source and streamer cable are $5 \mathrm{~m}$ and $8 \mathrm{~m}$, respectively. After applying a bandpass filter, amplitude recovery, deconvolution, multiple suppression, 3-D geometry (bin size $25 \mathrm{~m} \times 50 \mathrm{~m}$ ), flexible binning, and normal moveout velocity analysis for the 3-D data, an interval velocity volume model for 3-D prestack depth migration (PSDM) was constructed and updated. A velocity uncertainty test demonstrated that the final 3 -D PSDM velocity has an $\sim 5 \%$ maximum velocity uncertainty at $\sim 6 \mathrm{~km}$ depth.

We show a small part of In-line 93 and Cross-line 816 of the 3-D PSDM across Site C0011 and their interpretations in Figures F78 and F79, respectively. Based on reflection characteristics, we identify seven seismic reflection units, which are denoted as A-G. According to Ike et al. (2008b), seismic Units A-C and D-F correspond to upper and lower Shikoku Basin strata, respectively, whereas Unit $G$ is igneous oceanic crust of the Philippine Sea plate. Unit A shows a very flat seafloor reflection and northwest tilting with a slope of $\sim 4^{\circ}$. Several continuous and subparallel bedding planes are observed within this unit. The upper boundary of Unit B at 4325 mbsl shows relatively weak and discontinuous reflection, while its lower boundary at 4435 mbsl shows very strong reflection. We observe several normal faults cutting the upper boundary. Unit B represents chaotic reflection character. This unit shows northeast tilting with a gentle slope of $\sim 2^{\circ}$ on Cross-line 816 . On In-line 93 , the upper boundary of Unit $\mathrm{C}$ at 4435 mbsl shows very strong reflection except for several regions of faulting, while its lower boundary at 4574 mbsl shows discontinuous reflection. In contrast, the lower boundary exhibits almost continuous reflection on Cross-line 816. We did not observe the normal faults on Cross-line 816, which seem to cut through this unit as shown on In-line 93. Unit D exhibits transparent reflection character. We observe three continuous reflectors within this unit on Cross-line 816. The upper boundary of Unit E at 4835 mbsl shows continuous reflection with low frequency and is displaced by normal faults. We observe successive strong and continuous reflections within this unit. Unit $\mathrm{F}$ is characterized by transparent reflection character. The top of basement Unit G is at 5204 mbsl.

\section{Synthetic seismograms}

Synthetic seismograms calculated from an acoustic impedance model, or more simply from a velocity model based on a geological model or well logs, are simulated traces comparable to the seismic sections obtained after processing of seismic data (e.g., surface seismic reflection after common depth point stacking). They are used to identify the causes of seismic markers and to calibrate surface seismic events in time and amplitude (Boyer and Mari, 1997). Displaying the synthetic seismogram beside the seismic data in the vicinity of the borehole provides information about specific boundaries of interest and a quality check on velocity models and density logs.

Most conventional synthetic seismograms are calculated from well logs (sonic and density). In order to create a synthetic seismogram, a source wavelet is convolved with a reflection coefficient series that is generated by using the check shot curve, sonic log, and density log. Wireline logging operations, unfortunately, were not conducted at Site C0011, so a check shot curve, sonic log, and density log were not available for conventional synthetic seismogram calculation. As an alternative, we attempted to create a synthetic seismogram using $P$-wave velocity $\left(V_{\mathrm{P}}\right)$ and bulk density data obtained from measurements on discrete core samples (see "Physical properties"). We used Paradigm Ltd.'s software package Epos3 for the synthetic seismogram calculation.

Depth intervals of measured $V_{\mathrm{P}}$ and density data from Hole C0011B are 340.4-866.9 $\mathrm{m}$ CSF and 340.4-876.0 m CSF, respectively. We edited some erroneous spikes in the $V_{\mathrm{P}}$ and density data. $V_{\mathrm{P}}$ was measured on each core sample in three components $\left(x-, y\right.$-, and $z$-axis). We adopted $z$-axis $V_{\mathrm{p}}$ data, whose direction is similar to that of a seismic wave during a check shot survey. For a check shot curve, we used the $z$-axis $V_{\mathrm{p}}$ data for a range of $340-876 \mathrm{mbsf}$. The 3-D PSDM velocities of Park et al. (2008) guided the check shot curve for the depth ranges of 0-340 mbsf 
and 876-1200 mbsf. We adopted the Ricker wavelet as a source wavelet. Figure F80 shows the synthetic seismograms beside the seismic data along PSDM Cross-line 816.

We recognize a reasonably good match between the PSDM and synthetic seismogram waveforms at the upper boundary of seismic Unit C, even though there is a mismatch of depth. In contrast, we identify mismatches of both waveform and depth at the lower boundary of Unit $\mathrm{C}$ as well as the upper boundary of Unit E. Consequently, a highly correlated synthetic seismogram could not be achieved. The mismatch is probably because of (1) sparse intervals of core recovery and subsequent measurements, (2) errors in physical properties data due to widespread coring disturbance, and (3) uncertainty of PSDM velocities. Such a poor recovery of core samples may affect the waveform mismatch between the PSDM and synthetic seismogram. The depth mismatch is attributed to the uncertainty of PSDM velocities. Figure F80A shows that the PSDM velocities are overestimated for the discrete core sample velocities, particularly at depths between 4450 and 4650 mbsl.

\section{Core-Log-Seismic integration}

\section{Log units, seismic, and lithology}

Once logging units had been defined, we compared them to the available core data in an attempt to correlate features from the core with features in the logs. We used the MSCL-W data as the intermediate step between discrete measurements from core and the log data. An average consistent offset of $\sim 4 \mathrm{~m}$ was observed between the core and log data, with features in the core data regularly appearing deeper than the same features in the logs (e.g., Fig. F72). This offset may be due to uncertain seafloor identification in drilling/coring depths or local variations in lithology between Holes C0011A and C0011B.

\section{Logging Unit 1 (0-251.5 m LSF)}

Logging Unit 1 comprises the uncored upper section of Hole C0011B; therefore, no comparison with core can be made at this site. However, a lithologic interpretation can be made based on the core and log data obtained at Sites 1173 and 1177 during previous Legs 190 and 196 (Moore, Taira, Klaus, et al., 2001; Mikada, Becker, Moore, Klaus, et al., 2002). The log character of logging Unit 1 closely resembles that of $\log$ Unit 2 defined at Site 1173, which Leg 190 showed is composed of hemipelagic mud (silty clay) with interbedded volcanic ash (Shipboard Scientific Party, 2001b, 2002). Cores show that the sand content of the hemipelagic mud is consistently low. The character of resistivity images and identification of high-resistivity, bedding-parallel features that may be ash layers at Site C0011 (e.g., Fig. F75A) are also comparable to Site 1173 images, where cores were available to confirm the presence of ash. Logging Unit 1 correlates with seismic Unit A (Fig. F81).

\section{Logging Unit 2 (251.5-478.5 m LSF)}

Coring began at the upper boundary of logging Subunit 2B (337.0 m LSF), which corresponds to the top of lithologic Unit II (340 m CSF). There is a good stratigraphic correlation between LWD data from Hole C0011A and physical properties data from Hole C0011B, particularly between LWD gamma ray and MSCL-W natural gamma ray (NGR) data.

The correlation between tuffaceous and volcaniclastic sandstones found in cores (lithologic Unit II) and log character (logging Subunit 2B) is shown in Figure F72. In the logs, these sandstones of the middle Shikoku Basin facies are characterized by low gamma ray with sharp tops and bases, gradually increasing resistivity intervals with sharp bases (both characteristic of channels), and high resistivity intervals in images (Fig. F75B). In physical property data, these channel-like features are characterized by low NGR (Fig. F72), low to background electrical resistivity values, and high magnetic susceptibility. This interval of sandstones correlates with a package of strong and discontinuous seismic reflections at the upper boundary of seismic Unit C (Fig. F78).

The hemipelagic sediments observed between Unit II sandstones in the core also correspond well to the areas of high gamma ray and moderate resistivity, and the silt turbidites are characterized by low gamma ray and low resistivity, which were initially interpreted as sandstones from the logging data (Fig. F72; e.g., $388 \mathrm{~m} \mathrm{LSF}$ ).

The base of lithologic Unit II ( 479 m CSF) is below a thin cemented sandstone bed, which is characterized in the logging data by a low gamma ray peak and a very high resistivity spike (Fig. F72), allowing a good tie between the logging units and lithologic units throughout this section. The base of logging Unit 2 also corresponds to the lower boundary of seismic Unit C (Fig. F81).

\section{Logging Unit 3 (478.5-736.0 m LSF)}

Given the homogeneous nature of the lithology and log character through much of logging Unit 3, it is not possible to make a detailed correlation between the logs and the core NGR data. Correlation between logs and core data is also more limited in intervals of poor core recovery and core quality. However, the lower Shikoku Basin lithofacies of hemipelagic mudstone confirms the log-based lithologic interpre- 
tation of a background hemipelagic mud. The shift in both gamma ray and resistivity baseline values $\sim 550 \mathrm{~m}$ LSF that marks the logging Subunit 3A/3B boundary may correspond to a change in sedimentation rate observed in the core data between $\sim 550$ and $570 \mathrm{~m}$ CSF (see "Paleomagnetism" and "Lithology").

In logging Subunit 3B, we interpret the logs to represent the increasing appearance of silt and sandstone interbeds within the hemipelagic mudstone (Fig. F73); however, no sand layers were recovered in cores throughout this interval. Two significant features at the base of logging Unit 3, interpreted as thick sand layers from the logs, may actually correspond to cemented siltstones at the base of a fairly homogeneous interval of silty claystone in cores. These features have very low gamma ray values, which would be expected from such a lithology, but the high resistivity of these features is unexpected. The discrepancy between cored lithology and log interpretation may also be related to poor core recovery through some of the section. The seismic character within this unit is mainly transparent, with discontinuous, faint reflections, so it is also possible that the sandstones interpreted from logs at Hole C0011A are not laterally extensive and, therefore, are not present in Hole C0011B.

Below this point there is no longer a straightforward correlation between logging units and lithologic units. Logging Subunit 3C continues to $~ 736 \mathrm{~m} \mathrm{LSF}$, maintaining the fluctuating nature of the gamma ray and resistivity log responses; however, a lithologic change from homogeneous silty claystone to thin interbeds of clayey siltstone at $\sim 674 \mathrm{~m}$ CSF marks the base of lithologic Unit III (see "Lithology"). The logging Unit 3 boundary also corresponds to the lower boundary of seismic Unit D (Fig. F81).

\section{Logging Unit 4 (736.0-867.0 m LSF)}

Logging Unit 4 is characterized by a repeating pattern of coarsening-up and fining-up intervals in gamma ray, as well as a corresponding pattern of increasing and decreasing resistivity. In these patterns, we recognize the appearance of four packages, all with similar log character (Fig. F74). Within this logging unit, the observed mid-frequency variability in both gamma ray and resistivity is greater than that in any other logging unit.

The upper and lower parts of logging Unit 4 were cored ( 730-783 and $\sim 844-870 \mathrm{~m} \mathrm{LSF})$; the intermediate interval was washed down. NGR data from the MSCL-W provided a good means of correlating the cores and logs for both cored sections of this logging unit (Fig. F74). Lithology from cores indicates that the shallowest package is composed mainly of silty claystone (i.e., mudstone) with alternations of mixed silty claystone and siltstone. The upper portion of the second package was also recovered in cores and contains a transition from alternating silty claystone and siltstone to sandstone. The third package was not cored, but the fourth package was cored and found to be composed of a transition from siltstone and silty claystone to interbeds of silicic tuff, tuffaceous siltstone, and silty claystone, corresponding to lithologic Unit IV (see "Lithology"). Although we cannot confirm the lithology of the intermediate packages without cores, the log character suggests that the second package may be composed of mixed hemipelagic mudstone and siltstone, while the third package may be tuff and tuffaceous siltstone and silty claystone.

In seismic character, logging Unit 4 corresponds to an interval (4835-5204 mbsl) with a series of strong, continuous reflections (seismic Unit E; Figs. F78, F81), similar in seismic character to the lower Shikoku Basin-turbidites class (LSB-T) defined by Ike et al. (2008b), which correspond to the Miocene turbidites drilled at Site 1177 (Shipboard Scientific Party, 2001b).

\section{Logging Unit 5 (867.0-950.5 m LSF)}

Very little core was recovered in this logging unit, so a stratigraphic correlation between core and logs is not possible. Both cores from this unit (Cores 322C0011B-60R and 61R) had minimal core recovery because of the degradation of the drill bit as well as an increase in the hardness of the formation. This change in material properties agrees with the character of the log data, which show a distinct increase in resistivity across the boundary between logging Units 4 and 5 (Fig. F47). Gamma ray decreases in this unit, which we interpreted as a change in lithology, from a consolidated mudstone to a more coarse grained, sandy mudstone. This logging unit may correspond to seismic Unit $\mathrm{F}$, which is characterized by transparent reflections.

\section{References}

Acton, G.D., Okada, M., Clement, B.M., Lund, S.P., and Williams, T., 2002. Paleomagnetic overprints in ocean sediment cores and their relationship to shear deformation caused by piston coring. J. Geophys. Res., 107(B4):2067. doi:10.1029/2001JB000518

Boyer, S., and Mari, J.-L., 1997. Oil and Gas Exploration Techniques: Seismic Surveying and Well-Logging: Paris (Editions Technip).

Canfield, D.E., Raiswell, R., and Bottrell, S., 1992. The reactivity of sedimentary iron minerals toward sulfide. Am. J. Sci., 292:659-683.

Cas, R.A.F., and Wright, J.V., 1991. Subaqueous pyroclastic flows and ignimbrites: an assessment. Bull. Volcanol., 53(5):357-380. doi:10.1007/BF00280227 
Chan, L.-H., and Kastner, M., 2000. Lithium isotopic compositions of pore fluids and sediments in the Costa Rica subduction zone: implications for fluid processes and sediment contribution to the arc volcanoes. Earth Planet. Sci. Lett., 183(1-2):275-290. doi:10.1016/S0012821X(00)00275-2

D'Hondt, S., Rutherford, S., and Spivack., A.J., 2002. Metabolic activity of the subsurface life in deep-sea sediments. Science, 295(5562):2067-2070. doi:10.1126/ science. 1064878

Edmond, J.M., Measures, C., McDuff, R.E., Chan, L.H., Collier, R., Grant, B., Gordon, L.I., and Corliss, J.B., 1979. Ridge crest hydrothermal activity and the balances of the major and minor elements in the ocean: the Galapagos data. Earth Planet. Sci. Lett., 46(1):1-18. doi:10.1016/0012-821X(79)90061-X

Erickson, S.N., and Jarrard, R.D., 1998. Velocity-porosity relationships for water-saturated siliciclastic sediments. J. Geophys. Res., 103(B12):30385-30406. doi:10.1029/ 98JB02128

Expedition 319 Scientists, 2010. Site C0011. In Saffer, D., McNeill, L., Byrne, T., Araki, E., Toczko, S., Eguchi, N., Takahashi, K., and the Expedition 319 Scientists, Proc. IODP, 319: Tokyo (Integrated Ocean Drilling Program Management International, Inc.). doi:10.2204/ iodp.proc.319.105.2010

Fabian, K., McEnroe, S.A., Robinson, P., and Shcherbakov, V.P., 2008. Exchange bias indentifies lamellar magnetism as the origin of the natural remanent magnetization in titanohematite with ilmenite exsolution from Modum, Norway. Earth Planet. Sci. Lett., 268(3-4):339353. doi:10.1016/j.epsl.2008.01.034

Felix, M., and Peakall, J., 2006. Transformation of debris flows into turbidity currents: mechanisms inferred from laboratory experiments. Sedimentology, 53(1):107-123. doi:10.1111/j.1365-3091.2005.00757.x

Freundt, A., 2003. Entrance of hot pyroclastic flows into the sea: experimental observations. Bull. Volcanol., 65(23):144-164. doi:10.1007/s00445-002-0250-1

Freundt, A., and Schmincke, H.-U., 1998. Emplacement of ash layers related to high-grade ignimbrite P1 in the sea around Gran Canaria. In Weaver, P.P.E., Schmincke, H.U., Firth, J.V., and Duffield, W. (Eds.), Proc. ODP, Sci. Results, 157: College Station, TX (Ocean Drilling Program), 201-218. doi:10.2973/ odp.proc.sr.157.112.1998

Fulthorpe, C.S., and Blum, P. (Eds.), 1992. Ocean Drilling Program guidelines for pollution prevention and safety. JOIDES J., 18(7). http://www.odplegacy.org/PDF/ Admin/JOIDES_Journal/JJ_1992_V18_No7.pdf

Gieskes, J.M., Blanc, G., Vrolijk, P., Elderfield, H., and Barnes, R., 1990. Interstitial water chemistry-major constituents. In Moore, J.C., Mascle, A., et al., Proc. ODP, Sci. Results, 110: College Station, TX (Ocean Drilling Program), 155-178. doi:10.2973/ odp.proc.sr.110.170.1990

Hinrichs, K.-U., Hayes, J.M., Bach, W., Spivack, A.J., Hmelo, L.R., Holm, N.G., Johnson, C.G., and Sylva, S.P., 2006. Biological formation of ethane and propane in the deep marine subsurface. Proc. Nat. Acad. Sci., 103(40):14684-14689. doi:10.1073/pnas.0606535103
Hoffman, N.W., and Tobin, H.J., 2004. An empirical relationship between velocity and porosity for underthrust sediments in the Nankai Trough accretionary prism. In Mikada, H., Moore, G.F., Taira, A., Becker, K., Moore, J.C., and Klaus, A. (Eds.), Proc. ODP, Sci. Results, 190/196: College Station, TX (Ocean Drilling Program), 1-23. doi:10.2973/odp.proc.sr.190196.355.2004

Hoshi, H., Sumii, A., and Shinsei, H., 2007. Miocene igneous activity and tectonics in the Kii Peninsula. Chishitsugaku Zasshi, 113(7):281-282.

Ienaga, M., McNeill, L.C., Mikada, H., Saito, S., Goldberg, D., and Moore, J.C., 2006. Borehole image analysis of the Nankai accretionary wedge, ODP Leg 196: structural and stress studies. Tectonophysics, 426(1-2):207-220. doi:10.1016/j.tecto.2006.02.018

Ike, T., Moore, G.F., Kuramoto, S., Park, J-O., Kaneda, Y., and Taira, A., 2008a. Tectonics and sedimentation around Kashinosaki Knoll: a subducting basement high in the eastern Nankai Trough. Isl. Arc, 17(3):358-375. doi:10.1111/j.1440-1738.2008.00625.x

Ike, T., Moore, G.F., Kuramoto, S., Park, J.-O., Kaneda, Y., and Taira, A., 2008b. Variations in sediment thickness and type along the northern Philippine Sea plate at the Nankai Trough. Isl. Arc, 17(3):342-357. doi:10.1111/ j.1440-1738.2008.00624.x

Ishizuka, O., Uto, K., Makoto, Y., and Hochstaedter, A.G., 1998. K-Ar ages from seamount chains in the back-arc region of the Izu-Ogasawara arc. Isl. Arc, 7(3):408-421. doi:10.1111/j.1440-1738.1998.00199.x

Ishizuka, O., Uto, K., and Yuasa, M., 2003. Volcanic history of the back-arc region of the Izu-Bonin (Ogasawara) arc. In Larter, R.D., and Leat, P.T. (Eds.), Tectonic and Magmatic Processes. Geol. Soc. Spec. Publ., 219(1):187-205. doi:10.1144/GSL.SP.2003.219.01.09

Johnson, J.W., Oelkers, E.H., and Helgeson, H.C., 1992. SUPCRT92: a software package for calculating the standard molal thermodynamic properties of minerals, gases, aqueous species, and reactions from 1 to 5000 bar and 0 to $1000^{\circ} \mathrm{C}$. Comput. Geosci., 18(7):899-947. doi:10.1016/0098-3004(92)90029-Q

Jordanova, D., Jordanova, N., Henry, B., Hus, J., Bascou, J., Funaki, M., and Dimov, D., 2007. Changes in mean magnetic susceptibility and its anisotropy of rock samples as a result of alternating field demagnetization. Earth Planet. Sci. Lett., 255(3-4):390-401. doi:10.1016/ j.epsl.2006.12.025

Kimura, J.-I., Stern, R.J., and Yoshida, T., 2005. Reinitiation of subduction and magmatic responses in SW Japan during Neogene time. Geol. Soc. Am. Bull., 117(78):969-986. doi:10.1130/B25565.1

Kinoshita, M., Tobin, H., Moe, K.T., and the Expedition 314 Scientists, 2008. NanTroSEIZE Stage 1A: NanTroSEIZE LWD transect. IODP Prel. Rept., 314. doi:10.2204/ iodp.pr.314.2008

Kirschvink, J.L., 1980. The least-squares line and plane and the analysis of palaeomagnetic data. Geophys. J. R. Astron. Soc., 62(3):699-718. doi:10.1111/j.1365246X.1980.tb02601.x

Lallemant, S., Chamot-Rooke, N., Le Pichon, X., and Rangin, C., 1989. Zenisu Ridge: a deep intraoceanic thrust related to subduction, off southwest Japan. Tec- 
tonophysics, 160(1-4):151-153, 157-174. doi:10.1016/ 0040-1951(89)90389-2

Lawrence, J.R., and Gieskes, J.M., 1981. Constraints on water transport and alteration in the oceanic crust from the isotopic composition of pore water. J. Geophys. Res., 86(B9):7924-7934. doi:10.1029/JB086iB09p07924

Le Pichon, X., Iiyama, T., Chamley, H., Charvet, J., Faure, M., Fujimoto, H., Furuta, T., Ida, Y., Kagami, H., Lallemant, S., Leggett, J., Murata, A., Okada, H., Rangin, C., Renard, V., Taira, A., and Tokuyama, H., 1987. Nankai Trough and the fossil Shikoku Ridge: results of Box 6 Kaiko survey. Earth Planet. Sci. Lett., 83(1-4):186-198. doi:10.1016/0012-821X(87)90065-3

Lourens, L.J., Hilgen, F.J., Shackleton, N.J., Laskar, J., and Wilson, D., 2004. The Neogene period. In Gradstein, F.M., Ogg, J.G., and Smith, A.G. (Eds.), A Geological Time Scale 2004. Cambridge (Cambridge Univ. Press), 409-440.

Lowrie, W., 1990. Identification of ferromagnetic minerals in a rock by coercivity and unblocking temperature properties. Geophys. Res. Lett., 17:159-162.

Machida, S., Ishii, T., Kimura, J.-I., Awaji, S., and Kato, Y., 2008. Petrology and geochemistry of cross-chains in the Izu-Bonin back arc: three mantle components with contributions of hydrous liquids from a deeply subducted slab. Geochem., Geophys., Geosyst., 9(5):Q05002. doi:10.1029/2007GC001641

Maltman, A.J., Byrne, T., Karig, D.E., Lallemant, S., Knipe, R., and Prior, D., 1993. Deformation structures at Site 808, Nankai accretionary prism, Japan. In Hill, I.A., Taira, A., Firth, J.V., et al., Proc. ODP, Sci. Results, 131: College Station, TX (Ocean Drilling Program), 123-133. doi:10.2973/odp.proc.sr.131.110.1993

Martini, E., 1971. Standard Tertiary and Quaternary calcareous nannoplankton zonation. Proc. Int. Conf. Planktonic Microfossils, 2:739-785.

Mastbergen, D.R., and Van Den Berg, J.H., 2003. Breaching in fine sands and the generation of sustained turbidity currents in submarine canyons. Sedimentology, 50(4):625-637. doi:10.1046/j.1365-3091.2003.00554.x

McNeill, L.C., Ienaga, M., Tobin, H., Saito, S., Goldberg, D., Moore, J.C., and Mikada, H., 2004. Deformation and in situ stress in the Nankai accretionary prism from resistivity-at-bit images, ODP Leg 196. Geophys. Res. Lett., 31(2):L02602. doi:10.1029/2003GL018799

Mikada, H., Becker, K., Moore, J.C., Klaus, A., et al., 2002. Proc. ODP, Init. Repts., 196: College Station, TX (Ocean Drilling Program). doi:10.2973/odp.proc.ir.196.2002

Moore, G.F., Taira, A., Klaus, A., et al., 2001. Proc. ODP, Init. Repts., 190: College Station, TX (Ocean Drilling Program). doi:10.2973/odp.proc.ir.190.2001

Mulder, T., and Syvitski, J.P.M., 1995. Turbidity currents generated at river mouths during exceptional discharge to the world oceans. J. Geol., 103(3):285-299. doi:10.1086/629747

Nagata, T., Akimoto, S., and Uyeda, S., 1951. Reverse thermoremanent magnetism. Proc. Jpn. Acad., 27:643-645.

Naruse, H., Sequeiros, O., Garcia, M.H., Parker, G., Endo, N., Kataoka, K.S., Yokokawa, M., and Muto, T., 2008. Self-accelerating turbidity currents at laboratory scale. In Dohmen-Janssen, C.M., and Hulscher, S.J.M.H. (Eds.),
River, Coastal, and Estuarine Morphodynamics (RCEM 2007): London (Routledge Taylor and Francis Group).

Okino, K., Ohara, Y., Kasuga, S., and Kato, Y., 1999. The Philippine Sea: new survey results reveal the structure and the history of marginal basins. Geophys. Res. Lett., 26(15):2287-2290. doi:10.1029/1999GL900537

Okino, K., Shimakawa, Y., and Nagaoka, S., 1994. Evolution of the Shikoku Basin. J. Geomag. Geoelectr., 46:463479.

Oremland, R.S., Whiticar, M.J., Strohmaier, F.E., and Kiene, R.P., 1988. Bacterial ethane formation from reduced, ethylated sulfur compounds in anoxic sediments. Geochim. Cosmochim. Acta, 52(7):1895-1904. doi:10.1016/ 0016-7037(88)90013-0

Pantin, H.M., 1979. Interaction between velocity and effective density in turbidity flow: phase-plane analysis, with criteria for auto suspension. Mar. Geol., 31(1-2):5999. doi:10.1016/0025-3227(79)90057-4

Park, J.-O., Tsuru, T., No, T., Takizawa, K., Sato, S., and Kaneda, Y., 2008. High-resolution 3D seismic reflection survey and prestack depth imaging in the Nankai Trough off southeast Kii Peninsula. Butsuri Tansa, 61:231-241. (in Japanese, with abstract in English)

Parker, G., 1982. Conditions for the ignition of catastrophically erosive turbidity currents. Mar. Geol., 46(3-4):307327. doi:10.1016/0025-3227(82)90086-X

Parkes, R.J., Webster, G., Cragg, B.A., Weightman, A.J., Newberry, C.J., Ferdelman, T.G., Kallmeyer, J., Jørgensen, B.B., Aiello, I.W., and Fry, J.C., 2005. Deep sub-seafloor prokaryotes stimulated at interfaces over geological time. Nature (London, U. K.), 436(7049):390394. doi:10.1038/nature03796

Parkhurst, D.L., and Appelo, C.A.J., 1999. User's guide to PHREEQC (version 2)-a computer program for speciation, batch-reaction, one-dimensional transport and inverse geochemical calculations. USGS Water-Resour. Invest. Rep., 99-4259.

Pimmel, A., and Claypool, G., 2001. Introduction to shipboard organic geochemistry on the JOIDES Resolution. ODP Tech. Note, 30. doi:10.2973/odp.tn.30.2001

Plank, T., and Langmuir, C.H., 1998. The chemical composition of subducting sediment and its consequences for the crust and mantle. Chem. Geol., 145(3-4):325-394. doi:10.1016/S0009-2541(97)00150-2

Raffi, I., Backman, J., Fornaciari, E., Pälike, H., Rio, D., Lourens, L., and Hilgen, F., 2006. A review of calcareous nannofossil astrobiochronology encompassing the past 25 million years. Quat. Sci. Rev., 25(23-24):3113-3137. doi:10.1016/j.quascirev.2006.07.007

Rubey, W.W., and Hubbert, M.K., 1959. Role of fluid pressure in mechanics of overthrust faulting, Part 2. Overthrust belt in geosynclinal area of western Wyoming in light of fluid-pressure hypothesis. Geol. Soc. Am. Bull., 70(2):167-206. doi: 10.1130/00167606(1959)70[167:ROFPIM]2.0.CO;2

Saffer, D.M., and McKiernan, A.W., 2009. Evaluation of in situ smectite dehydration as a pore water freshening mechanism in the Nankai Trough, offshore southwest Japan. Geochem., Geophys., Geosyst., 10(2):Q02010. doi:10.1029/2008GC002226 
Saffer, D.M., Underwood, M.B., and McKiernan, A.W., 2008. Evaluation of factors controlling smectite transformation and fluid production in subduction zones: application to the Nankai Trough. Isl. Arc, 17(2):208230. doi:10.1111/j.1440-1738.2008.00614.x

Saito, S., Underwood, M.B., and Kubo, Y., 2009. NanTroSEIZE Stage 2: subduction inputs. IODP Sci. Prosp., 322. doi:10.2204/iodp.sp.322.2009

Sdrolias, M., Roest, W.R., and Müller, R.D., 2004. An expression of Philippine Sea plate rotation: the Parece Vela and Shikoku basins. Tectonophysics, 394(1-2):6986. doi:10.1016/j.tecto.2004.07.061

Seyfried, W.E., Jr., Janecky, D.R., and Mottl, M.J., 1984. Alteration of the oceanic crust: implications for geochemical cycles of lithium and boron. Geochim. Cosmochim. Acta, 48(3):557-569. doi:10.1016/00167037(84)90284-9

Shipboard Scientific Party, 1995. Site 909. In Myhre, A.M., Thiede, J., Firth, J.V., et al., Proc. ODP, Init. Repts., 151: College Station, TX (Ocean Drilling Program), 159-220. doi:10.2973/odp.proc.ir.151.107.1995

Shipboard Scientific Party, 2001a. Leg 190 summary. In Moore, G.F., Taira, A., Klaus, A., et al., Proc. ODP, Init. Repts., 190: College Station, TX (Ocean Drilling Program), 1-87. doi:10.2973/odp.proc.ir.190.101.2001

Shipboard Scientific Party, 2001b. Site 1177. In Moore, G.F., Taira, A., Klaus, A., et al., Proc. ODP, Init. Repts., 190: College Station, TX (Ocean Drilling Program), 191. doi:10.2973/odp.proc.ir.190.108.2001

Shipboard Scientific Party, 2002. Leg 196 summary: deformation and fluid flow processes in the Nankai Trough accretionary prism: logging while drilling and Advanced CORKs. In Mikada, H., Becker, K., Moore, J.C., Klaus, A., et al., Proc. ODP, Init. Repts., 196: College Station, TX (Ocean Drilling Program), 1-29. doi:10.2973/ odp.proc.ir.196.101.2002

Spinelli, G.A., Mozley, P.S., Tobin, H.J., Underwood, M.B., Hoffman, N.W., and Bellew, G.M., 2007. Diagenesis, sediment strength, and pore collapse in sediment approaching the Nankai Trough subduction zone. Geol. Soc. Am. Bull., 119(3-4):377-390. doi:10.1130/B25920.1

Steurer, J.F., and Underwood, M.B., 2003. Clay mineralogy of mudstones from the Nankai Trough reference Sites 1173 and 1177 and frontal accretionary prism Site 1174. In Mikada, H., Moore, G.F., Taira, A., Becker, K., Moore, J.C., and Klaus, A. (Eds.), Proc. ODP, Sci. Results, 190/196: College Station, TX (Ocean Drilling Program), 1-37. doi:10.2973/odp.proc.sr.190196.211.2003

Stow, D.A.V., Taira, A., Ogawa, Y., Soh, W., Taniguchi, H., and Pickering, K.T., 1998. Volcaniclastic sediments, process interaction and depositional setting of the MioPliocene Miura Group, SE Japan. Sediment. Geol., 115(14):351-381. doi:10.1016/S0037-0738(97)00100-0

Taira, A., Hill, I., Firth, J.V., et al., 1991. Proc. ODP, Init. Repts., 131: College Station, TX (Ocean Drilling Program). doi:10.2973/odp.proc.ir.131.1991
Tobin, H., Kinoshita, M., Ashi, J., Lallemant, S., Kimura, G., Screaton, E.J., Moe, K.T., Masago, H., Curewitz, D., and the Expedition 314/315/316 Scientists, 2009. NanTroSEIZE Stage 1 expeditions: introduction and synthesis of key results. In Kinoshita, M., Tobin, H., Ashi, J., Kimura, G., Lallemant, S., Screaton, E.J., Curewitz, D., Masago, H., Moe, K.T., and the Expedition 314/315/316 Scientists, Proc. IODP, 314/315/316: Washington, DC (Integrated Ocean Drilling Program Management International, Inc.). doi:10.2204/ iodp.proc.314315316.101.2009

Trofimovs, J., Amy, L., Boudon, G., Deplus, C., Doyle, E., Fournier, N., Hart, M.B., Komorowski, J.C., Le Friant, A., Lock, E.J., Pudsey, C., Ryan, G., Sparks, R.S.J., and Talling, P.J., 2006. Submarine pyroclastic deposits formed at the Soufrière Hills Volcano, Montserrat (1995-2003): what happens when pyroclastic flows enter the ocean? Geology, 34(7):549-552. doi:10.1130/G22424.1

Ujiie, K., Maltman, A.J., and Sánchez-Gómez, M., 2004. Origin of deformation bands in argillaceous sediments at the toe of the Nankai accretionary prism, southwest Japan. J. Struct. Geol., 26(2):221-231. doi:10.1016/ j.jsg.2003.06.001

Vogel, T.M., Oremland, R.S., and Kvenvolden, K.A., 1982. Low-temperature formation of hydrocarbon gases in San Francisco Bay sediment (California, U.S.A.). Chem. Geol., 37(3-4):289-298. doi:10.1016/ 0009-2541(82)90084-5

Wiesenburg, D.A., Brooks, J.M., and Bernard, B.B., 1985. Biogenic hydrocarbon gases and sulfate reduction in the Orca Basin brine. Geochim. Cosmochim. Acta, 49(10):2069-2080. doi:10.1016/ 0016-7037(85)90064-X

Yamamoto, Y., Mukoyoshi, H., and Ogawa, Y., 2005. Structural characteristics of shallowly buried accretionary prism: rapidly uplifted Neogene accreted sediments on the Miura-Boso Peninsula, central Japan. Tectonics, 24(5):TC5008. doi:10.1029/2005TC001823

You, C.-F., Chan, L.H., Spivack, A.J., and Gieskes, J.M., 1995. Lithium, boron, and their isotopes in sediments and pore waters of Ocean Drilling Program Site 808, Nankai Trough: implications for fluid expulsion in accretionary prisms. Geology, 23(1):37-40. doi:10.1130/ 0091-7613(1995)023<0037:LBATII>2.3.CO;2

Zapletal, K., 1992. Self-reversal of isothermal remanent magnetization in a pyrrhotite $\left(\mathrm{Fe}_{7} \mathrm{~S}_{8}\right)$ crystal. Phys. Earth Planet. Inter., 70(3-4):302-311. doi:10.1016/00319201(92)90196-3

Zijderveld, J.D.A., 1967. AC demagnetization of rocks: analysis of results. In Collinson, D.W., Creer, K.M., and Runcorn, S.K. (Eds.), Methods in Palaeomagnetism: New York (Elsevier), 254-286.

Publication: 10 October 2010 MS 322-103 
Common depth point

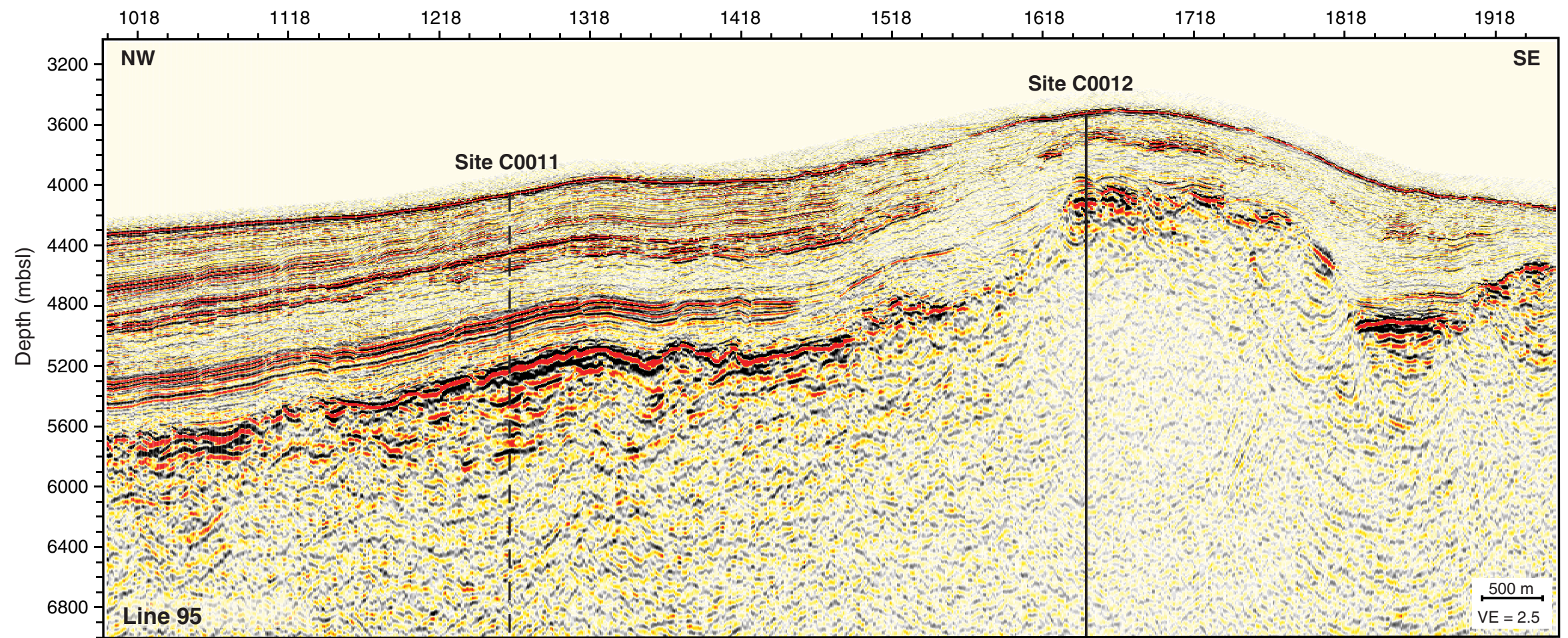


Figure F2. Summary lithology, Site C0011. LWD data only from 0 to $340 \mathrm{~m}$ LSF. Age data assigned by nannofossil biostratigraphy.

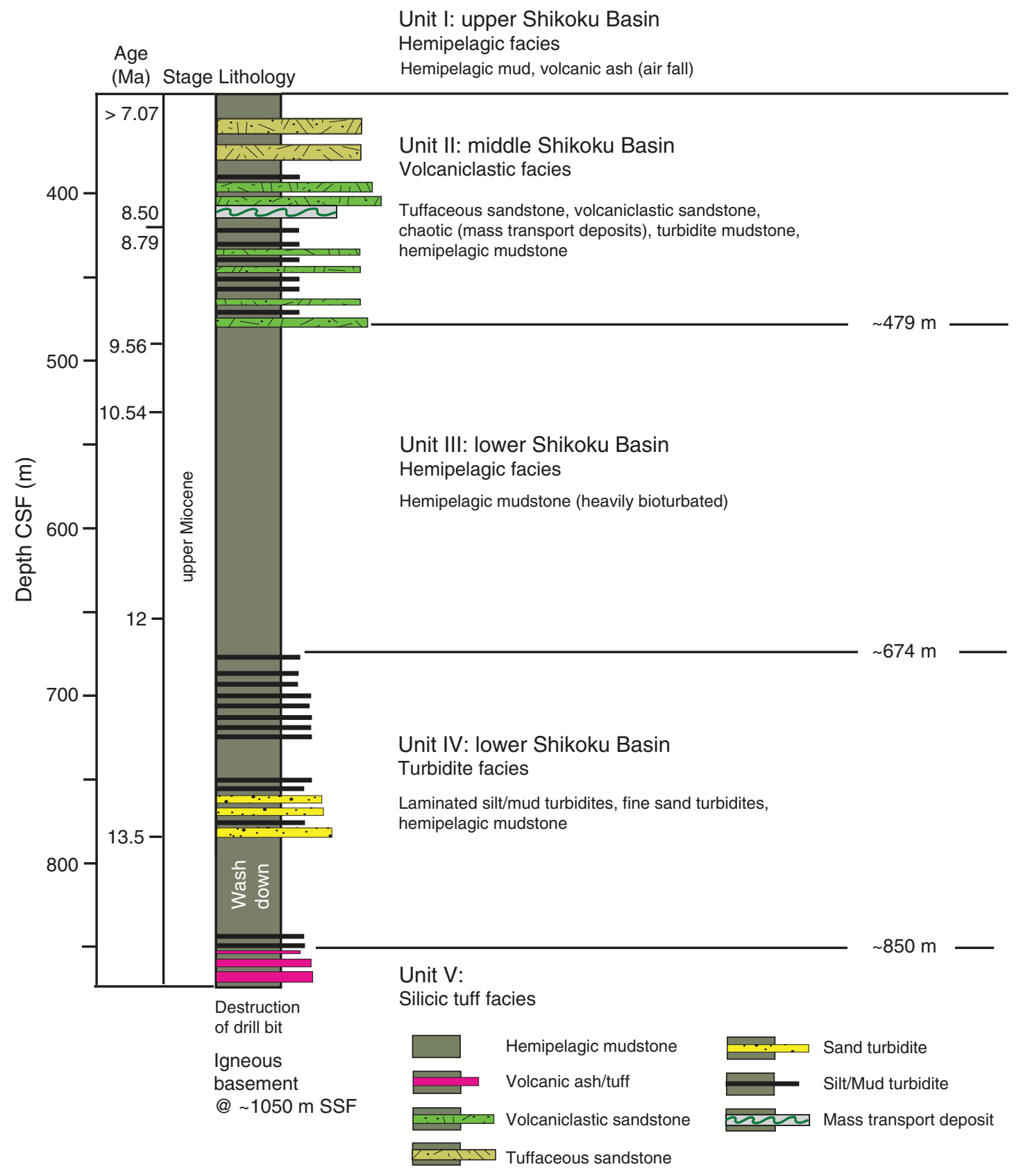


Figure F3. Core photographs of representative deposits from upper part of lithologic Unit II, Site C0011. A. Intensely bioturbated silty claystones with dark green silty claystone layers $<0.5 \mathrm{~cm}$ thick (interval 322 -C0011B11R-1, 54-69 cm). B. Tuffaceous sandstone layer (interval 322-C0011B-4R-4, 70-97 cm) with normal grading of subrounded pumice clasts at the base. Generally, there is also inverse grading of pumice clasts in the upper part.
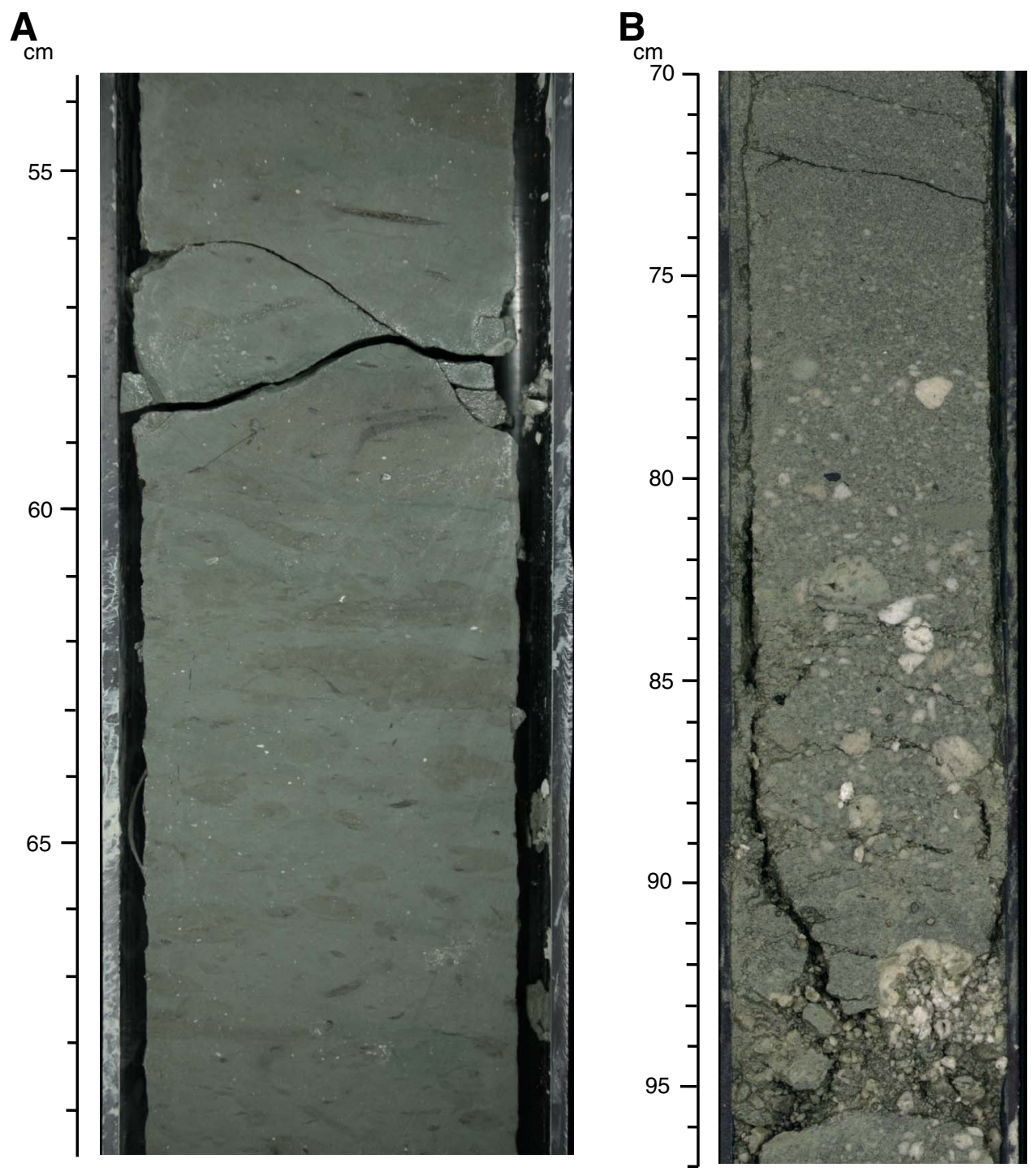
Figure F4. Thickness of turbidites (clayey siltstone, tuffaceous sandstone, volcaniclastic sandstone, and sandstone), Site C0011. Units II and IV are characterized by thick turbidites ( $>60 \mathrm{~cm}$ thick).

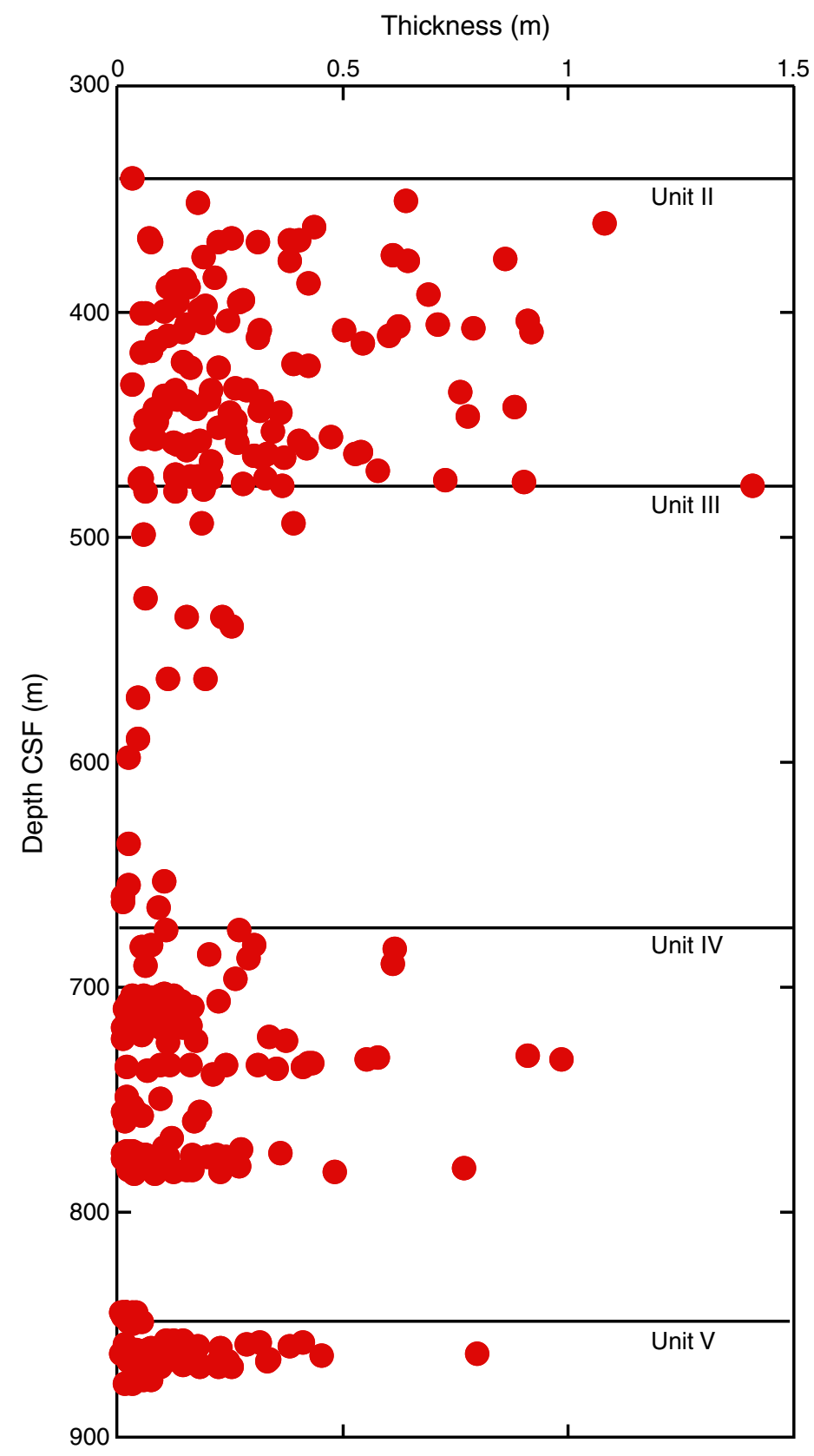


Figure F5. Core photographs of representative deposits from lower part of lithologic Unit II, Site C0011. A. Volcaniclastic sandstone (interval 322-C0011B-11R-5, 30-77 cm) with alternating normal and inverse grading, together with several ash-lens enrichment zones throughout the entire layer. Solidified ash lenses are well rounded. B. Normally graded sandstone layer (interval 322-C0011B-14R-5, 45-87 cm).

A

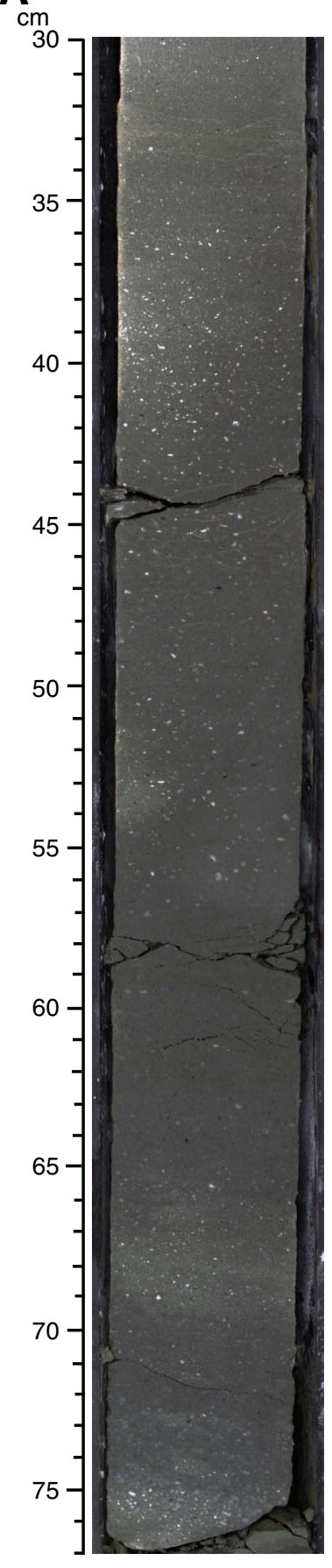

B

$\mathrm{cm}$

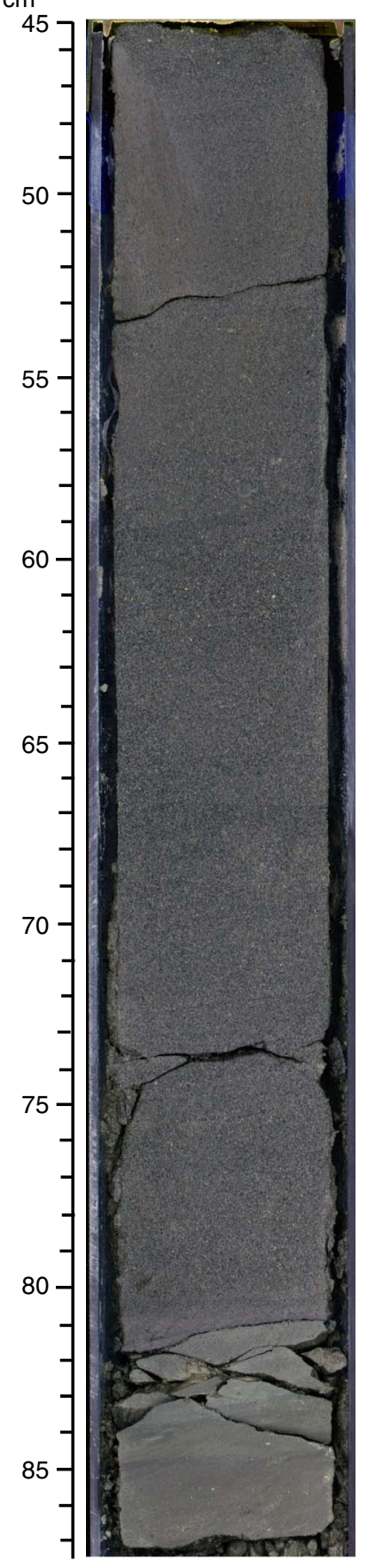


Figure F6. Core photograph examples of deformation styles within $10.29 \mathrm{~m}$ thick chaotic deposit extending from $400.86 \mathrm{~m}$ CSF (Sample 322 C0011B-7R-CC, $16.5 \mathrm{~cm}$ ) to $411.15 \mathrm{~m}$ CSF (Sample 322-C0011B-8R-7, $92 \mathrm{~cm}$ ). A. Tightly folded volcaniclastic sandstone and silty claystones (Sample 322-C0011B-8R-1, 59-74 cm). B. Folded and attenuated volcaniclastic sandstone layers within silty claystones (Sample 322-C0011B-8R-7, 24-39 cm). C. Attenuated silty claystones with high angle of dip relative to normal bedding (Sample 322-C0011B-8R-5, 15-30 cm). D. Subhorizontal small-scale faults with a normal sense of displacement from uppermost part of chaotic unit (Sample 322-C0011B-7R-CC, 24-39 cm).

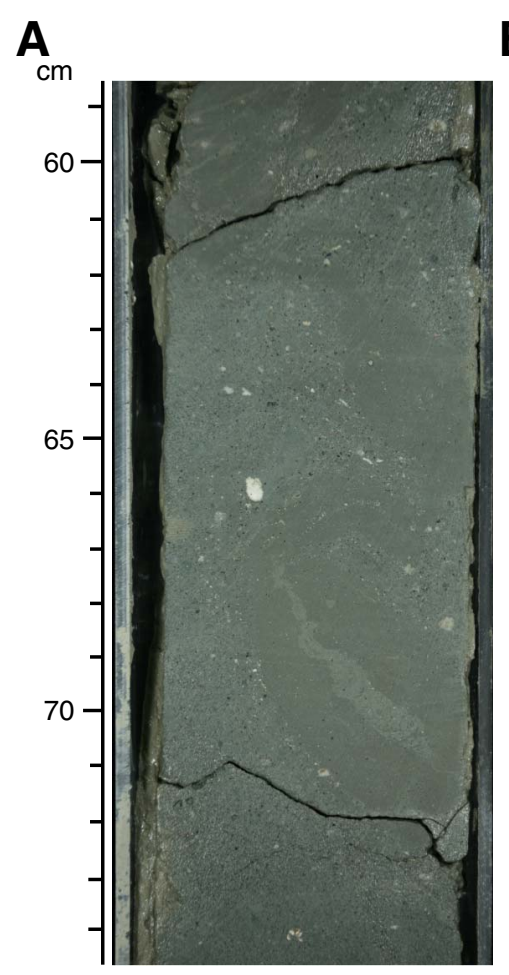

B

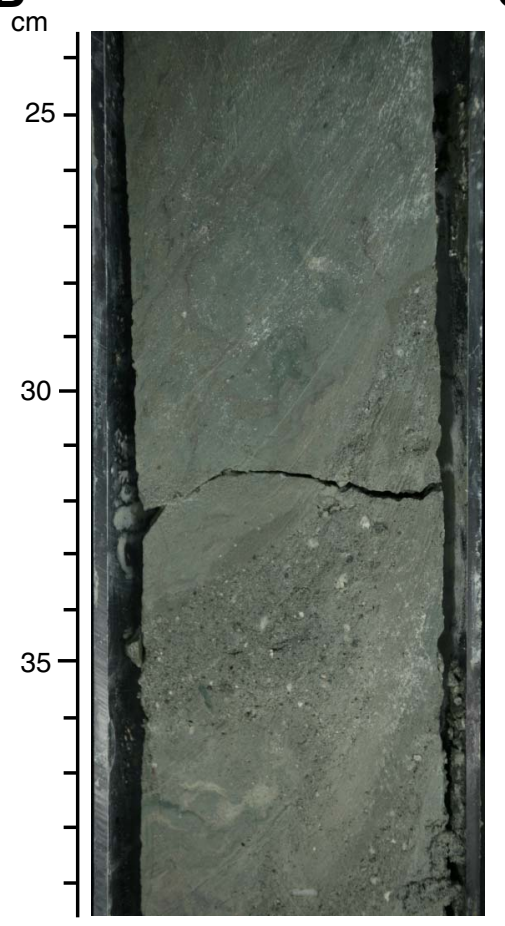

C

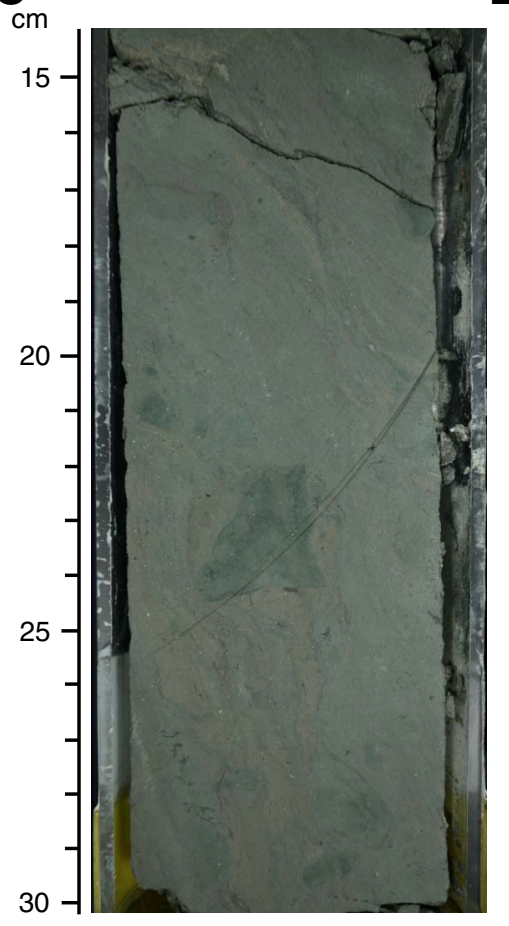

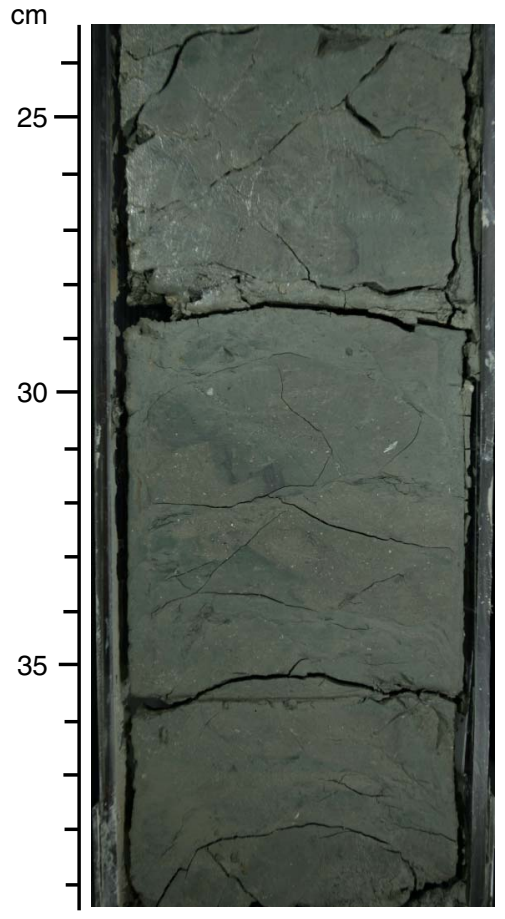


Figure F7. Total volcaniclastic components versus depth, lithologic Unit II. A. Total volcaniclastic component and total volcaniclastic component versus total lithic content. B. Pyroclasts and pyroclasts versus total lithic content. C. Volcanic lithics and volcanic lithics versus total lithic content. D. Sedimentary lithics and sedimentary lithics versus total lithic content.
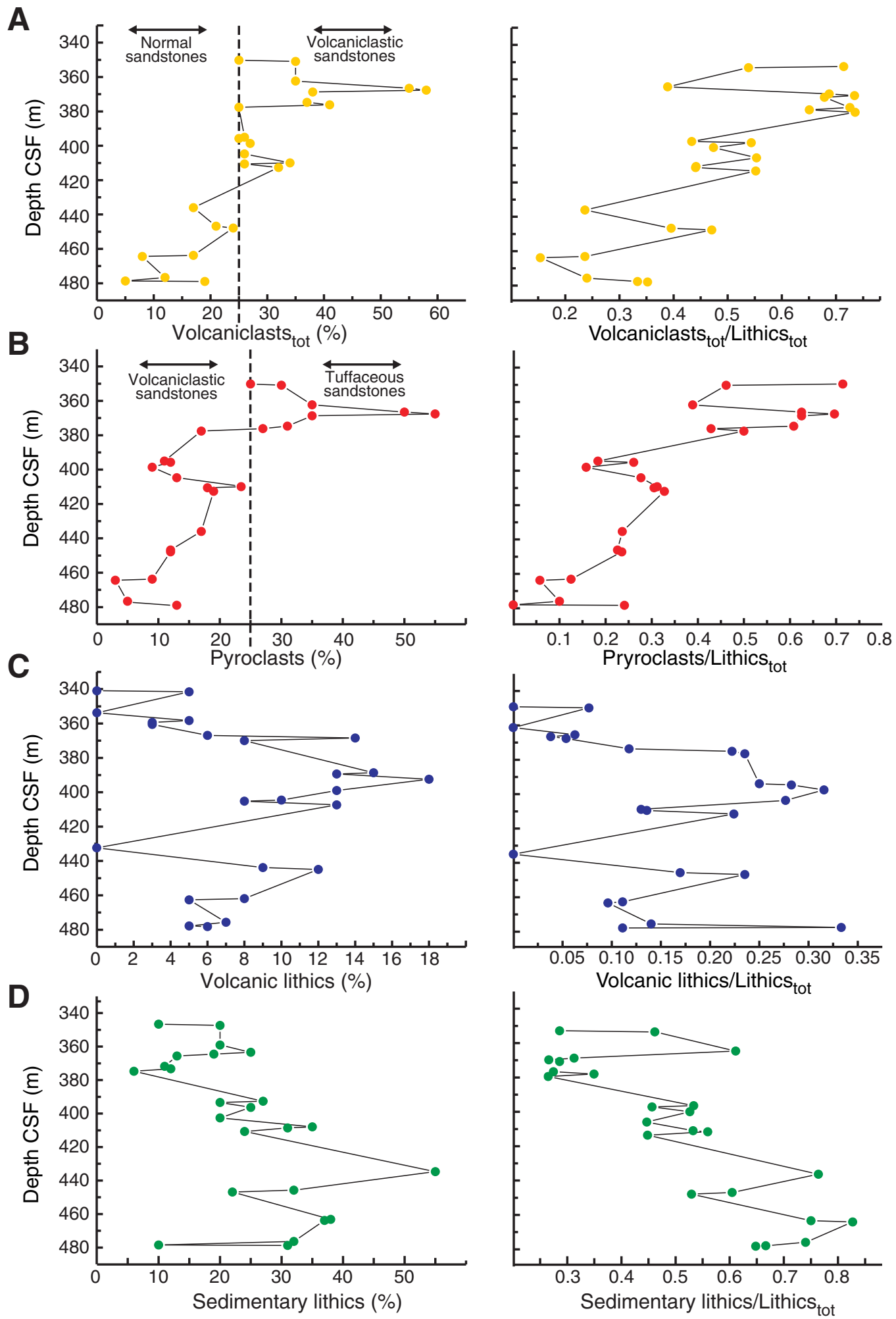
Figure F8. Representative photomicrographs from smear slides and thin section. A. Mineral assemblage within tuffaceous sandstone containing hypersthene, enstatite, amphibole, plagioclase, spinel, glass shards, and volcanic lithics (Sample 322-C0011B-5R-1, $22.5 \mathrm{~cm}$ ). B. Mineral assemblage shown in A under crossed nicols. C. Large tubular pumice clast within tuffaceous sandstone (Sample 322-C0011B-3R-3, 30-32 cm). D. Dark brown blocky mafic glass shard (Sample 322-C0011B-4R-4, $95.5 \mathrm{~cm}$ ). E. Diopside under cross-polarized light (Sample 322-C0011B-5R-4, $63 \mathrm{~cm}$ ). F. Thin section showing diagenetically replaced benthic foraminifer Cibicioides sp. (Sample 322-C0011B-15R-4, 100-102 cm).

A

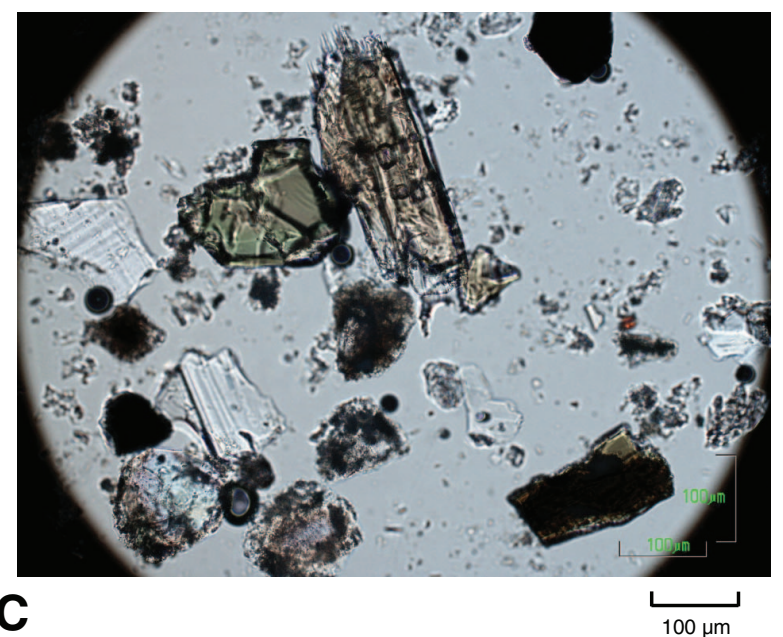

C

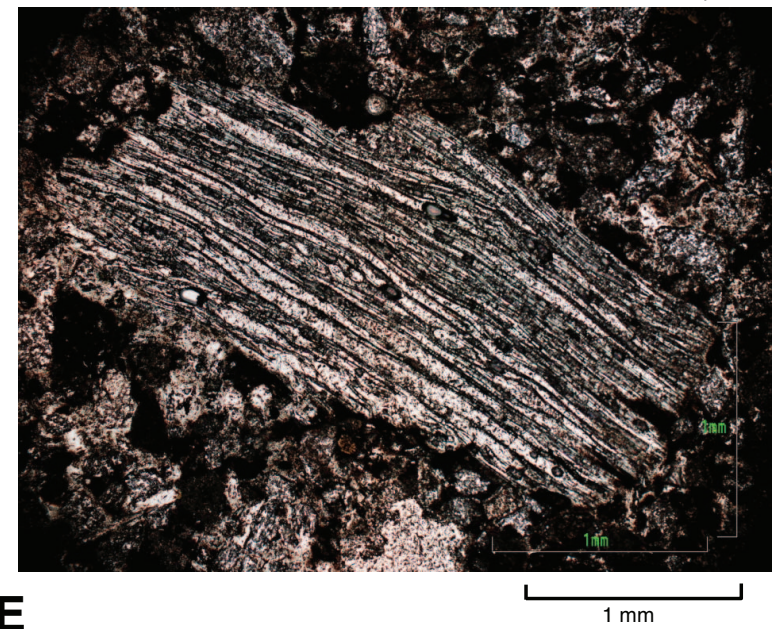

E

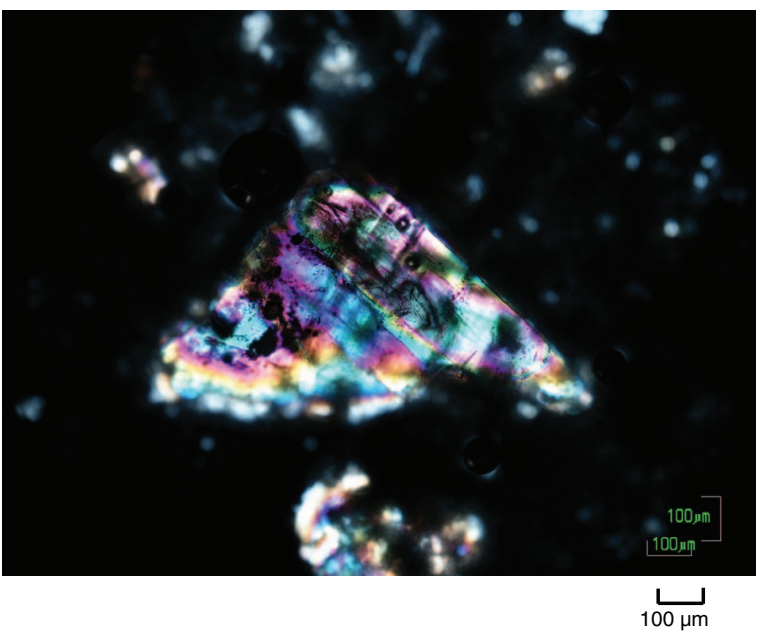

B
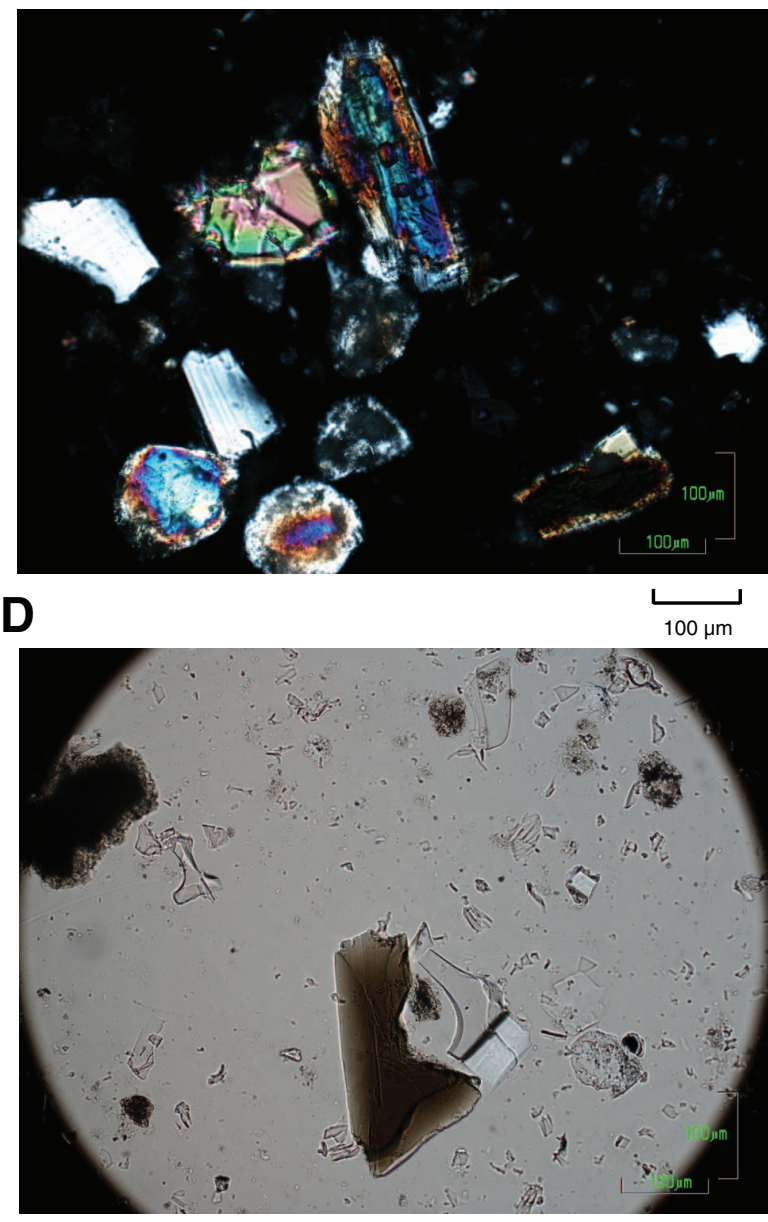

F

$100 \mu \mathrm{m}$

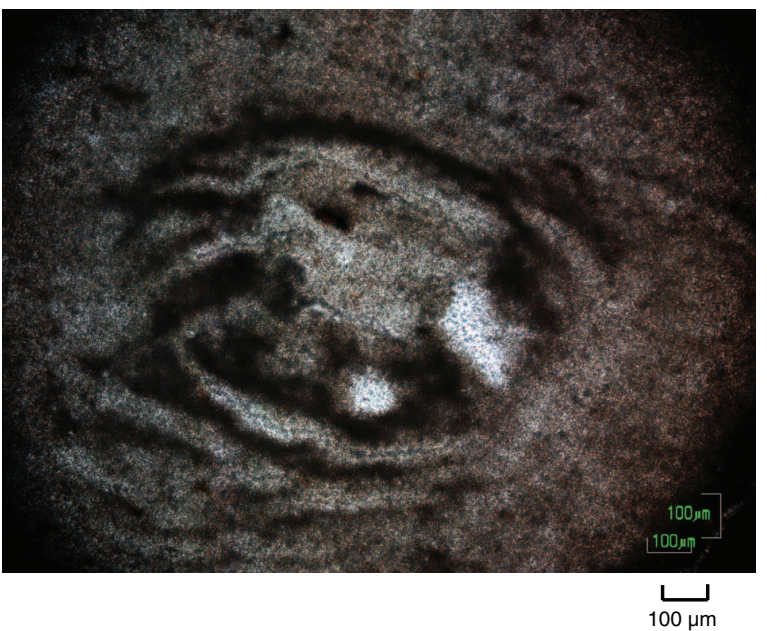


Figure F9. Core photograph of representative deposit from lithologic Unit III, Site C0011 (Sample 322-C0011B36R-3, 21-39 cm).

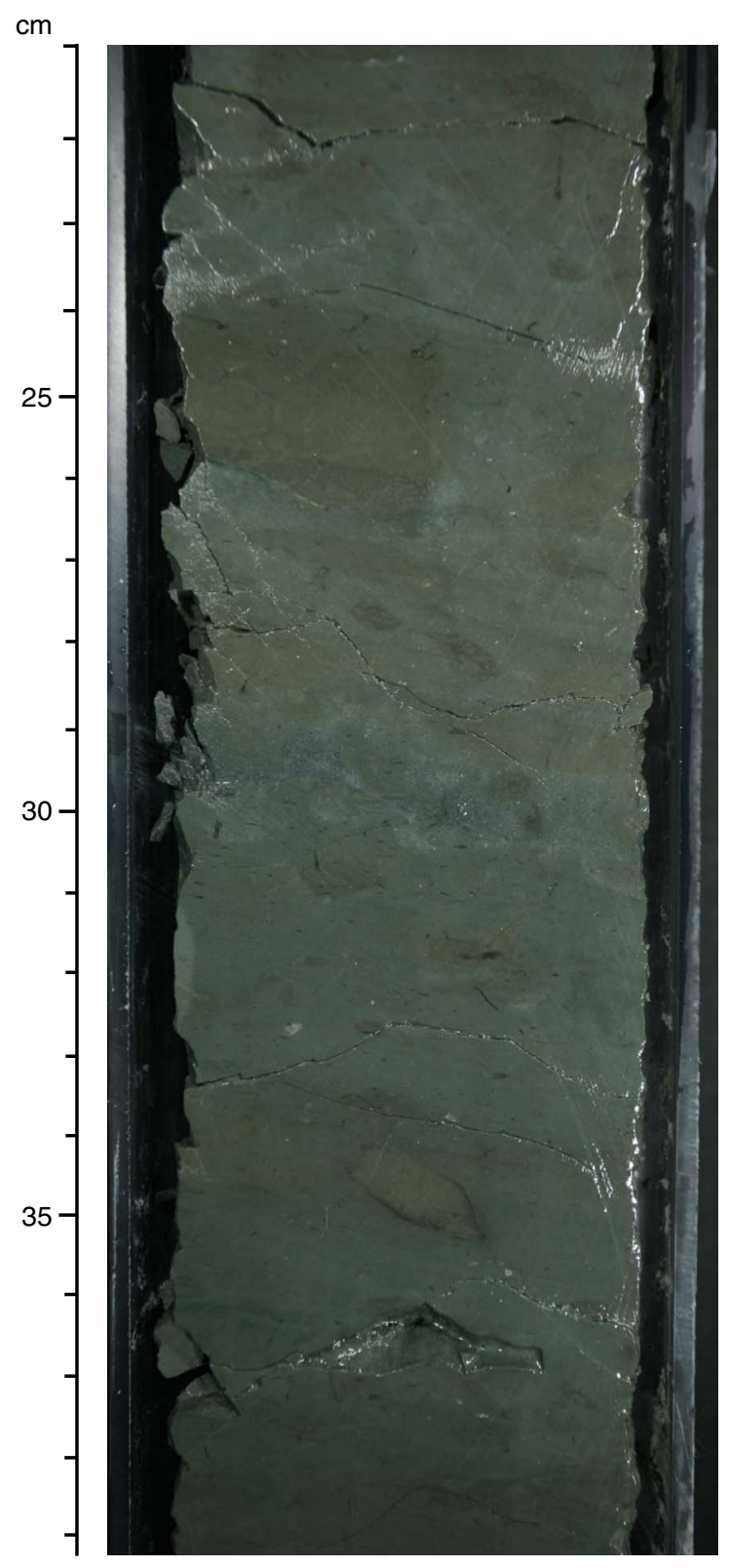


Figure F10. Smear slide data for Site C0011 versus depth. A. Ratio of feldspar to total mineral content. B. Ratio of quartz to total mineral content. C. Heavy mineral content. D. Ratio of volcanic lithics to total lithic content. E. Total mineral content. F. Sedimentary lithics. G. Total volcaniclastic component. H. Volcanic glass.
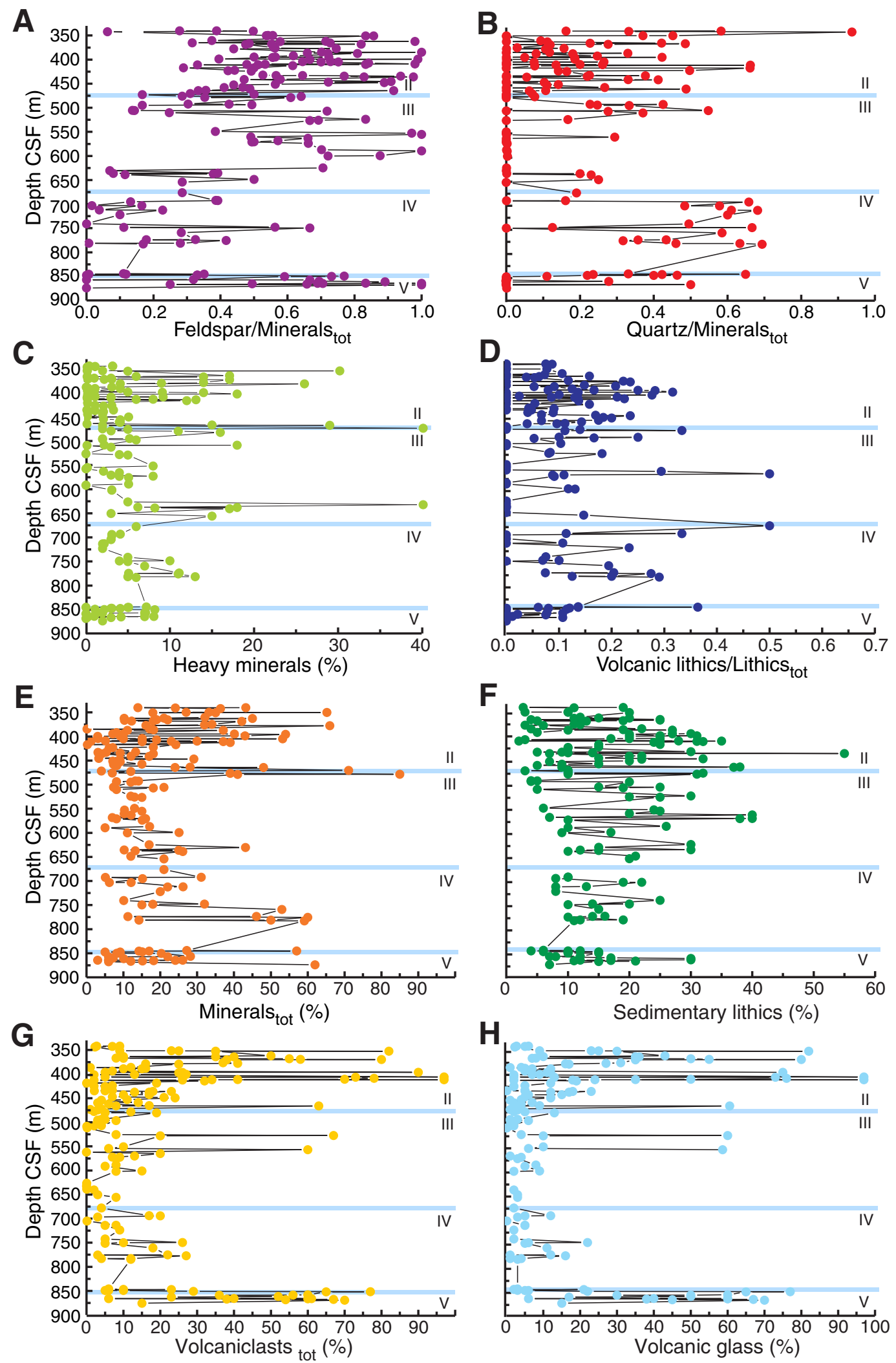
Figure F11. Core photograph of representative deposit from lithologic Unit IV, Site C0011 (Sample 322C0011B-45R-5, 80-116 cm).

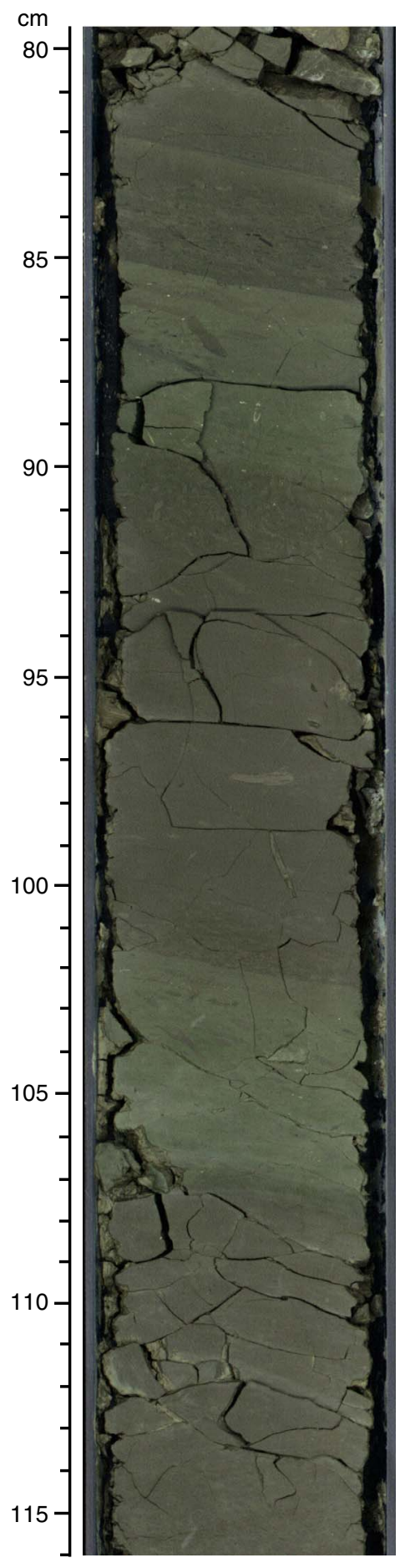


Figure F12. Core photographs of representative deposits from lithologic Unit V, Site C0011. A. Tuffaceous siltstone and light-colored tuff (Sample 322-C0011B-58R-8, 40-55 cm). B. Current-rippled and planar-laminated tuffaceous siltstone (Sample 322-C0011B-56R-1, 50-66 cm). C. Softsediment deformed tuffaceous siltstone showing load and flame structures (Sample 322-C0011B-56R-1, 10-26 cm). D. Normally graded, laminated, and loaded tuffaceous siltstone (Sample 322-C0011B-56R-3, 15-31 cm).

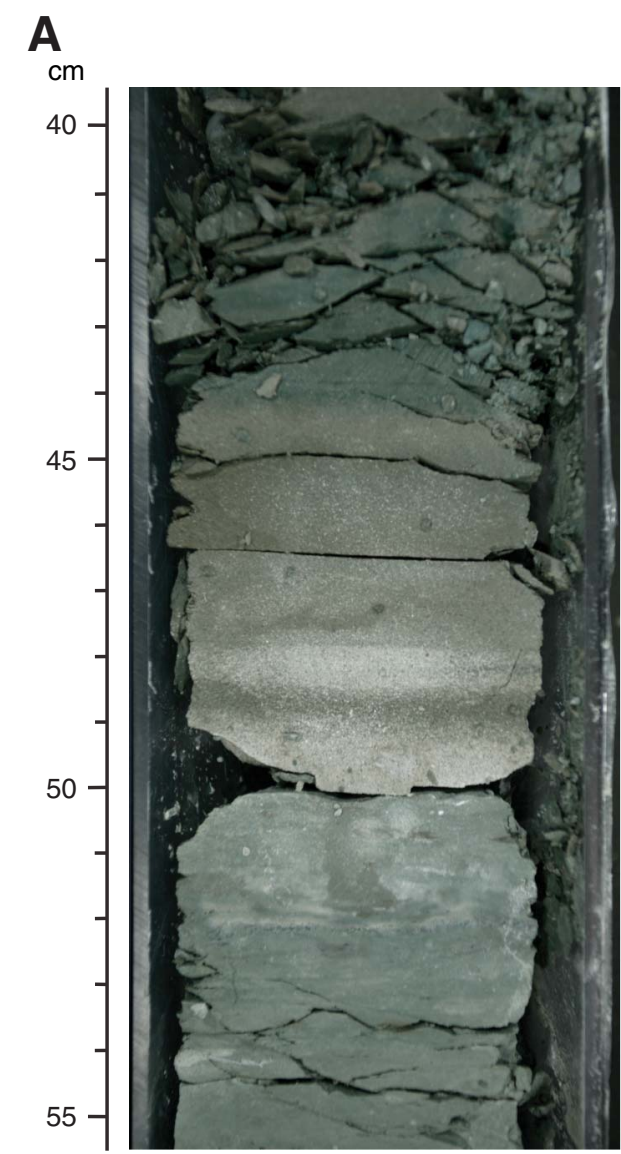

B

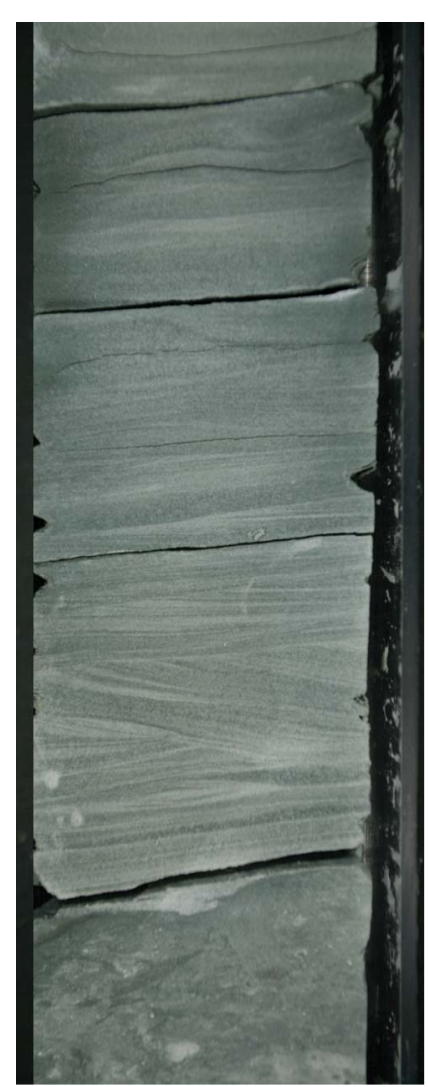

C

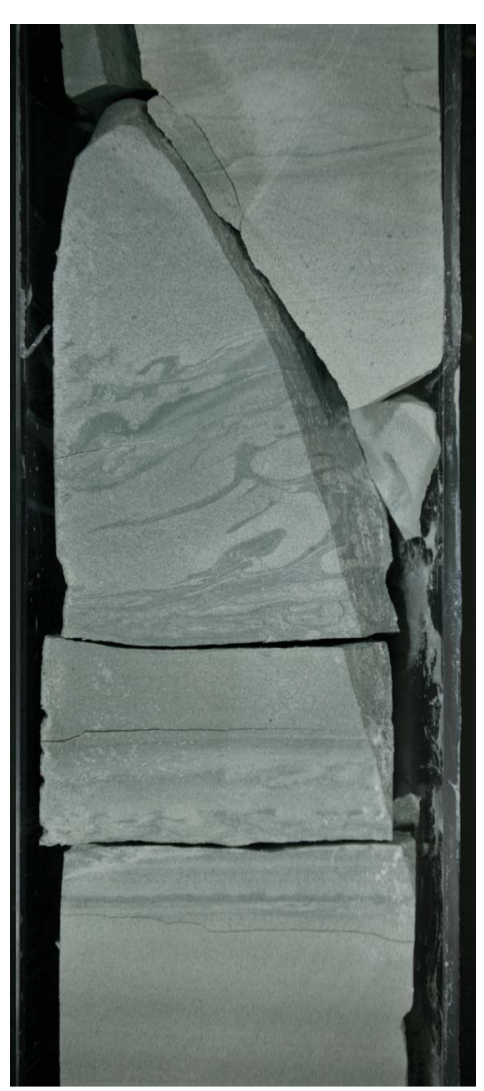

D

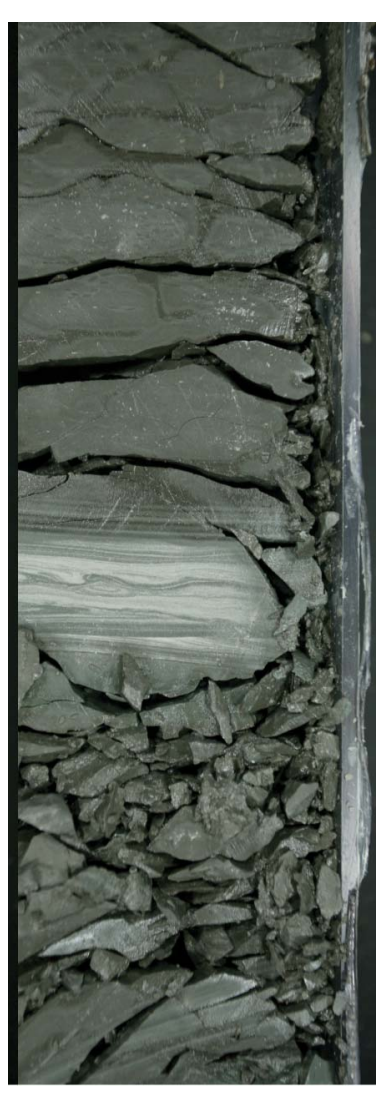


Figure F13. Summary of lithology and bulk powder XRD analyses of silty claystone samples, Site C0011, reported in relative weight percent. See text for explanation.

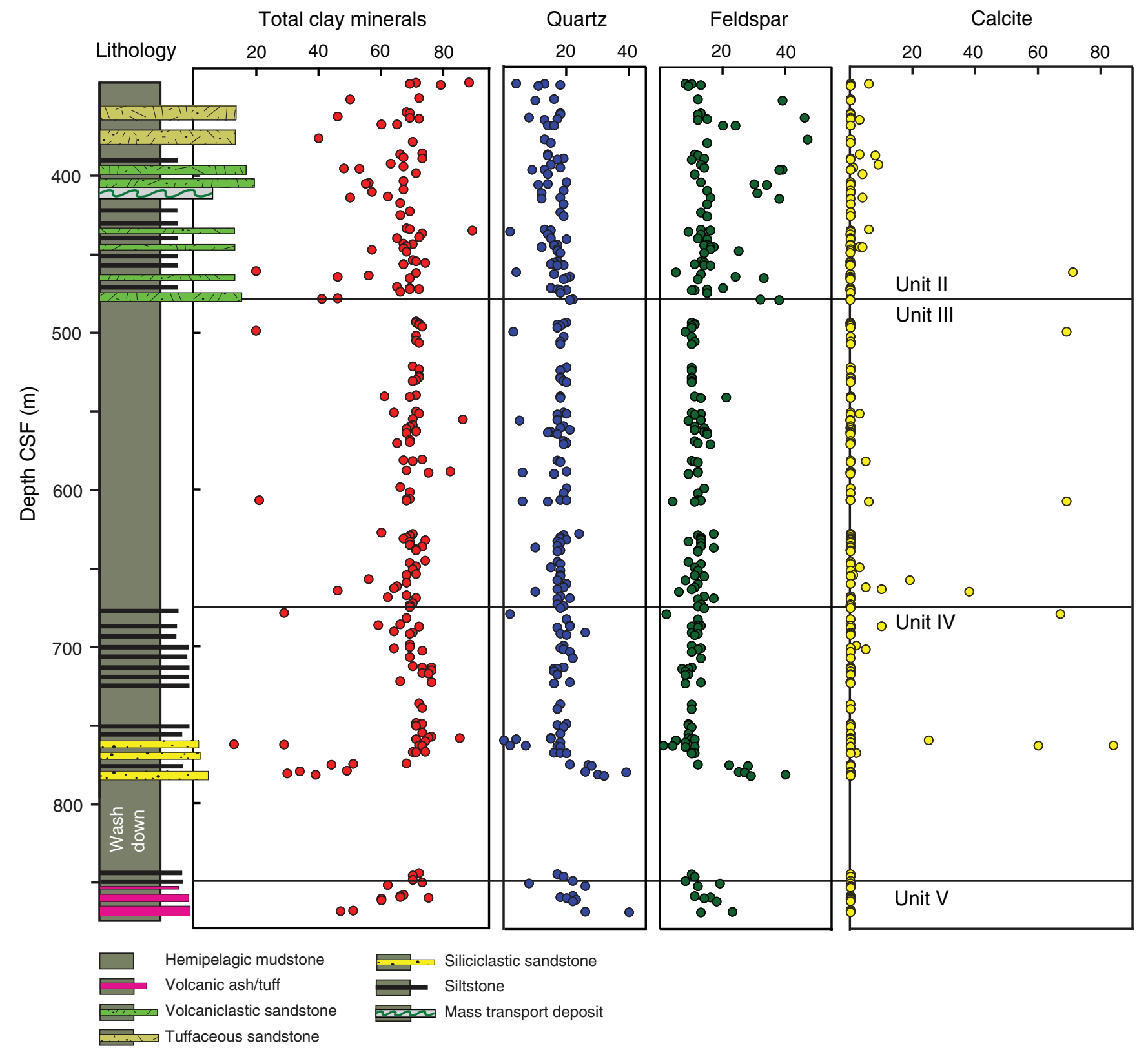


Figure F14. Zeolite diffractograms from XRD analyses. $\mathrm{C} / \mathrm{H}=$ clinoptilolite/heulandite. A. Sample 322-C0011B58R-5, 0-3 cm. B. Sample 322-C0011B-59R-3, 0-2 cm. C. Sample 322-C0011B-59R-4, 45-49 cm. D. Sample 322C0011B-57R-6, 74-76 cm.
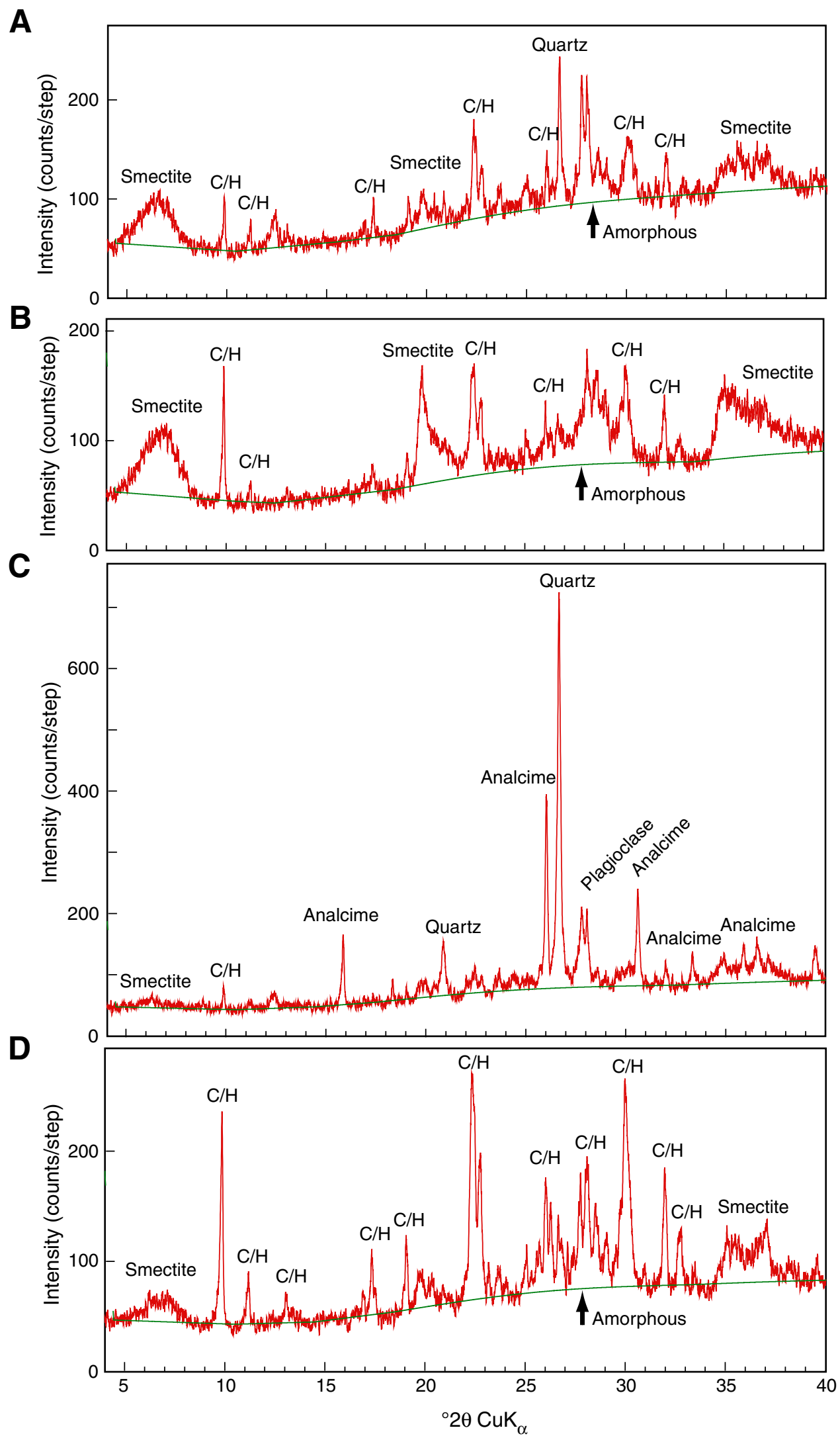
Figure F15. Major element content from XRF analysis, Site C0011. A. $\mathrm{Al}_{2} \mathrm{O}_{3}$ versus $\mathrm{SiO}_{2}$ for lithologic units. B-E. $\mathrm{Al}_{2} \mathrm{O}_{3}, \mathrm{Na}_{2} \mathrm{O}$, and $\mathrm{K}_{2} \mathrm{O}$ for different units and facies. F. MnO versus $\mathrm{P}_{2} \mathrm{O}_{5}$ for lithofacies. Vertical violet line $=$ average ODP Site 808 sediments, after Plank and Langmuir (1998).

A

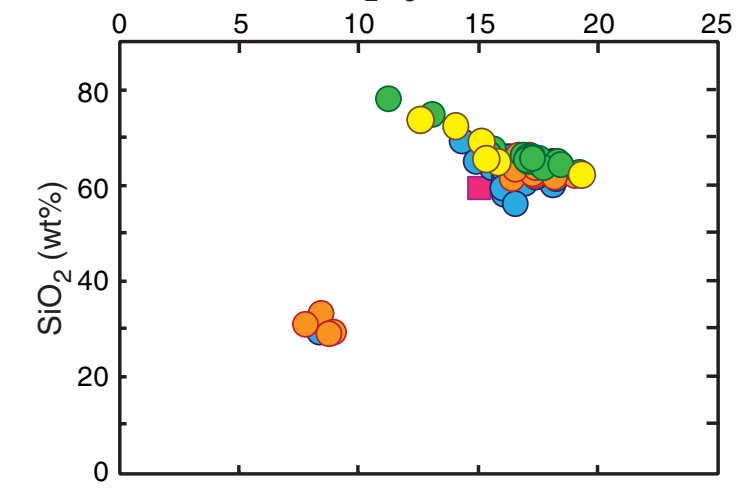

C

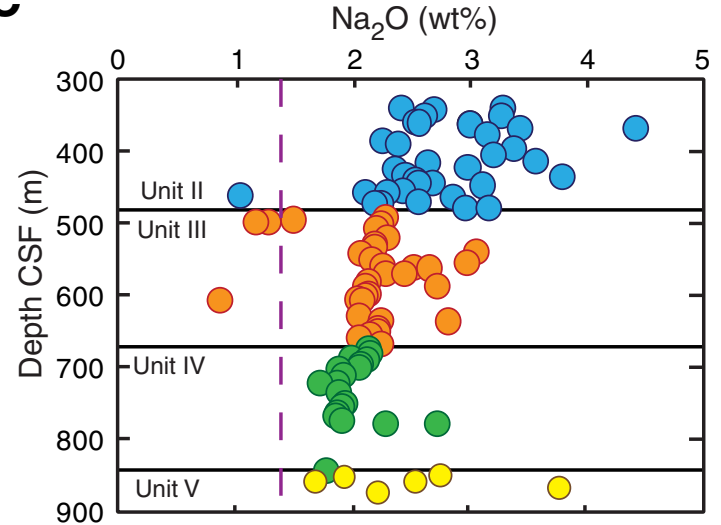

$\mathbf{E}$

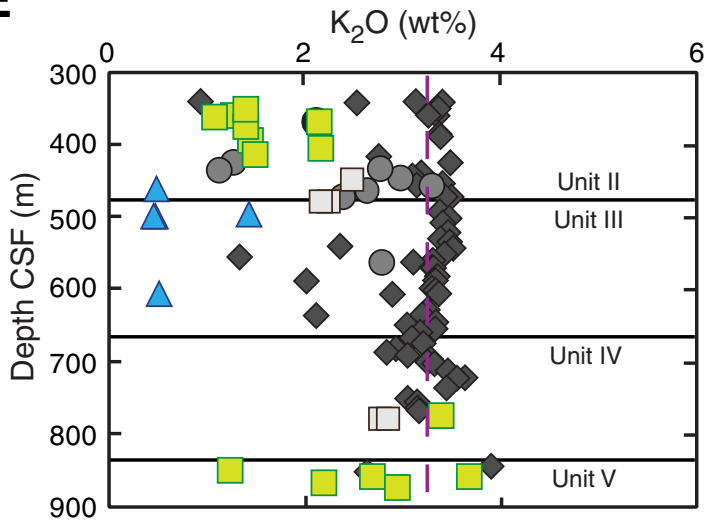

B

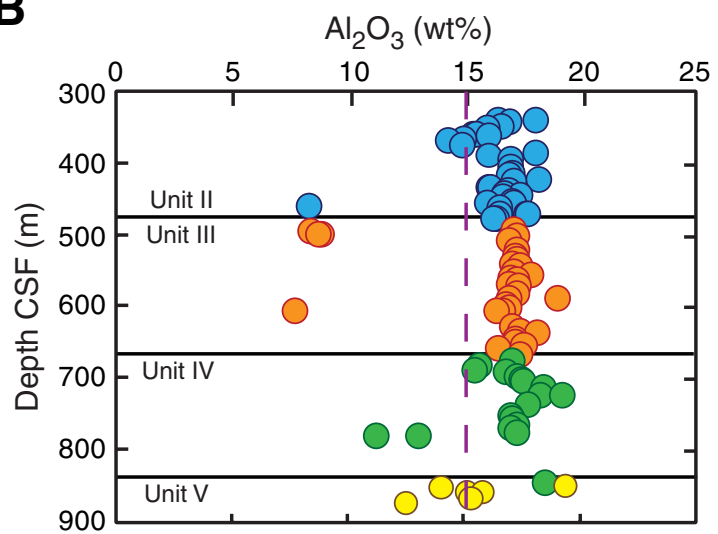

D

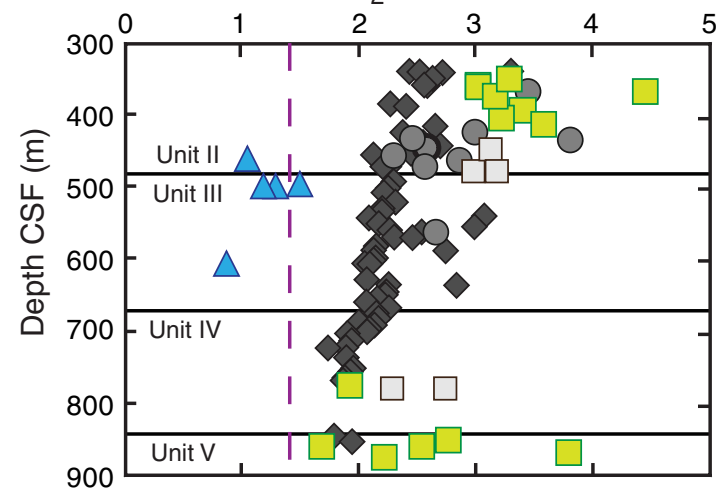

F

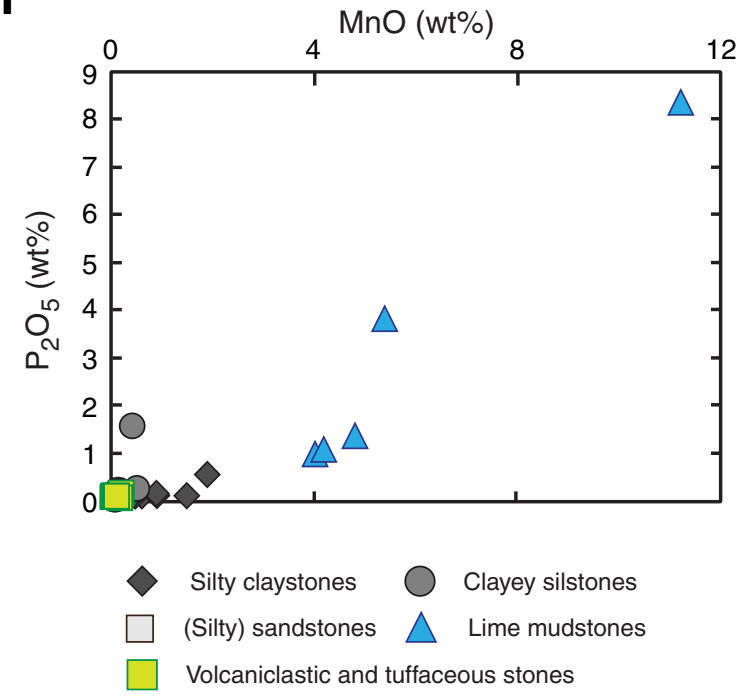


Figure F16. Range of depositional processes that could explain tuffaceous sandstones at Site C0011, upper part of lithologic Unit II. A. Primary pyroclastic flows entering marine realm and then continuing as sediment gravity flows in submarine canyons and channels until the basin plain. B. Pyroclastic flows entering marine realm, triggering submarine landslides and debris flows, and then continuing as sediment gravity flows. C. Posteruptive redeposition at some time after an eruption because of catastrophic slope-failure processes. D. Collapse of a subaerial or submarine eruption column, leading to sediment gravity flows. For B and C, it is likely that there is a considerable degree of incorporation of previously deposited (terrigenous) sediments, whereas for A and D, pyroclastics are the predominant component in any deposit (modified after Freundt, 2003; Freundt and Schmincke, 1998; and Cas and Wright, 1991).

A

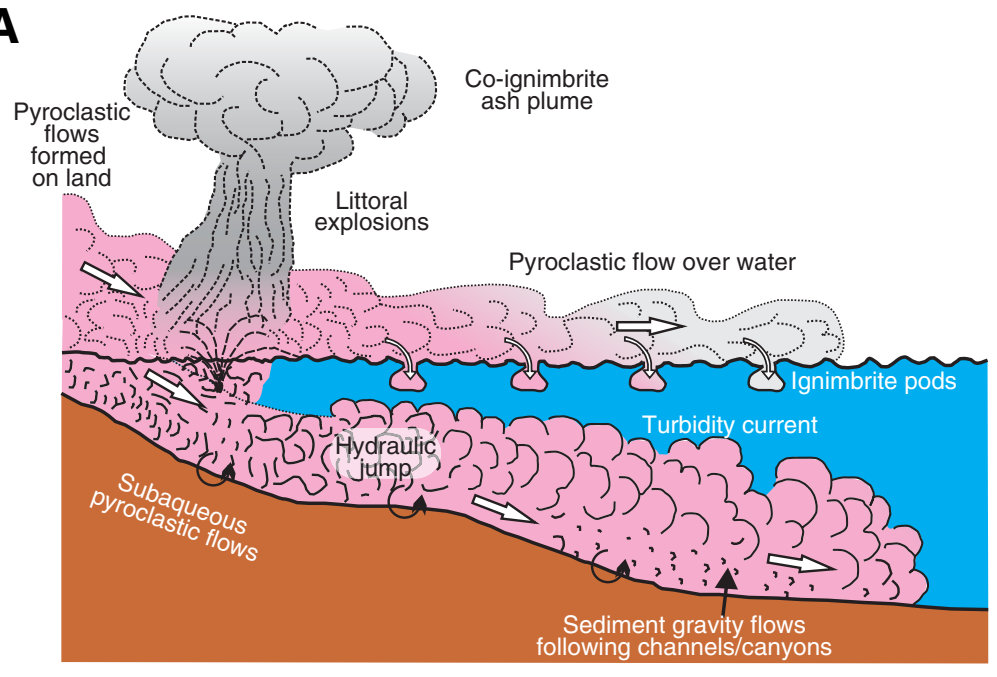

C

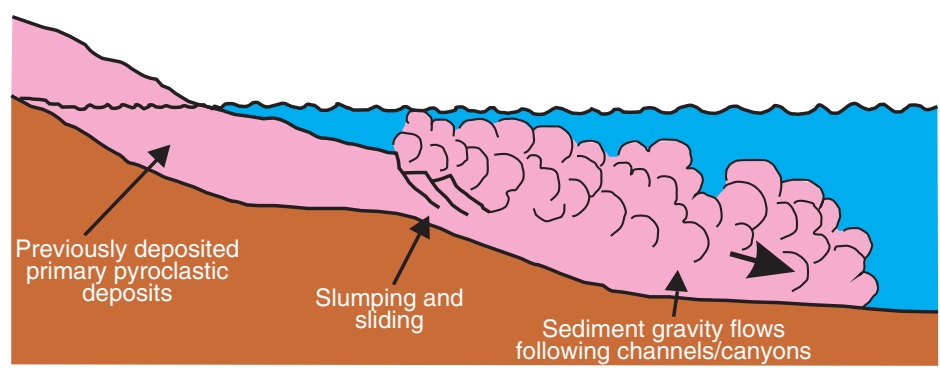

B

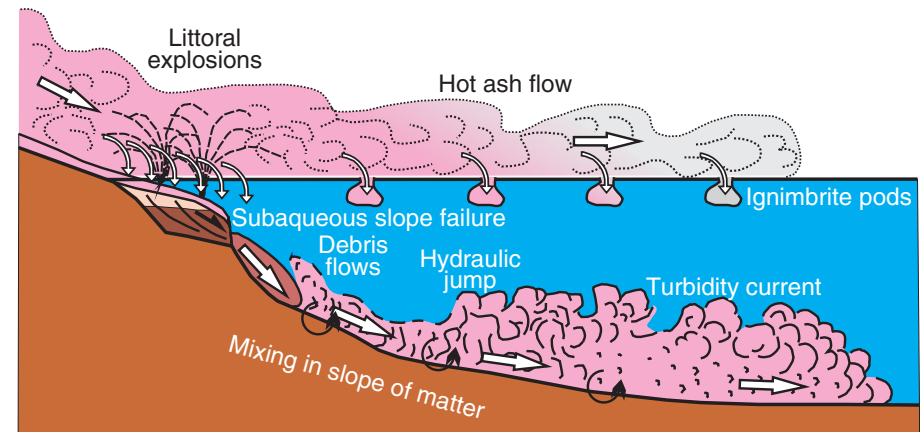

D

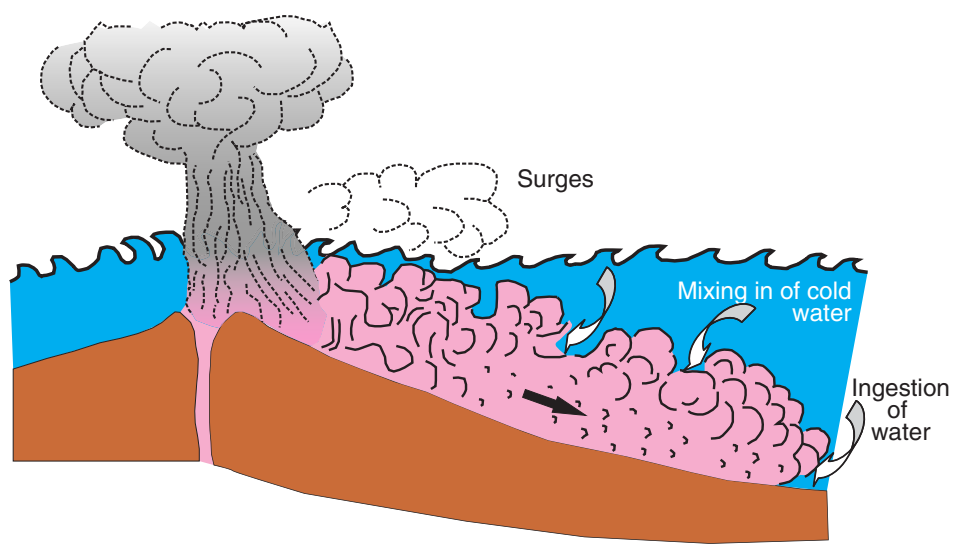


Figure F17. A. Ratio of turbidites in each core versus core number. B. Cumulative thickness of turbidites (red) and turbidite sediment accumulation rate (blue) versus cumulative thickness of hemipelagic sediments. C. Age control points plotted against cumulative thickness of hemipelagic sediments. Sediment accumulation rate for hemipelagic sediments changes at $11 \mathrm{Ma}$. See text for explanation.

A

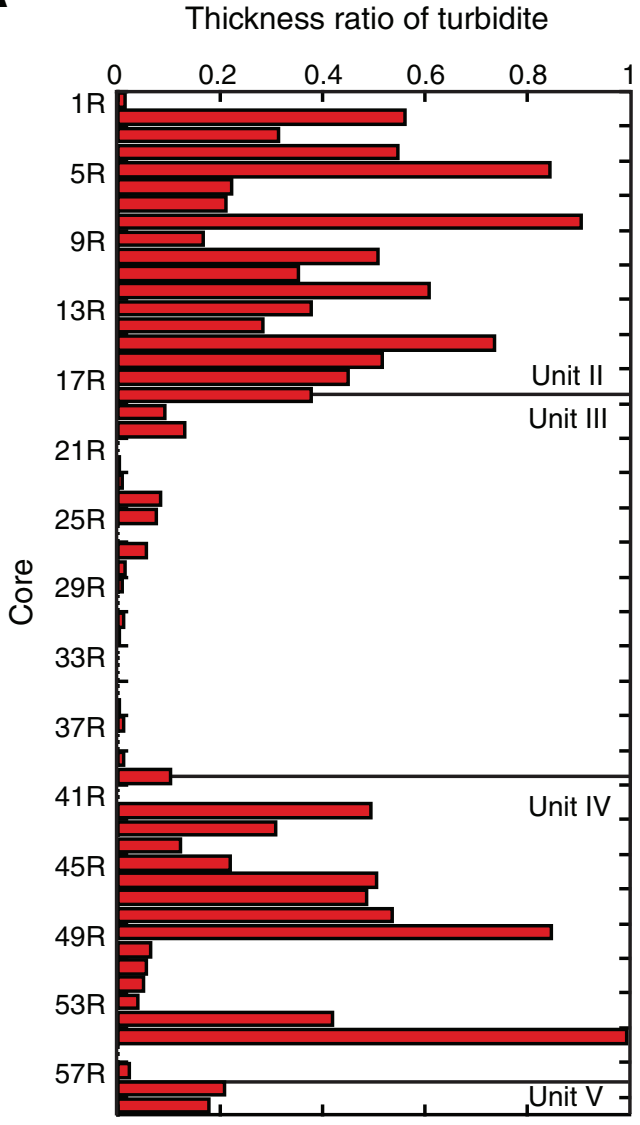

B Sediment accumulation rate

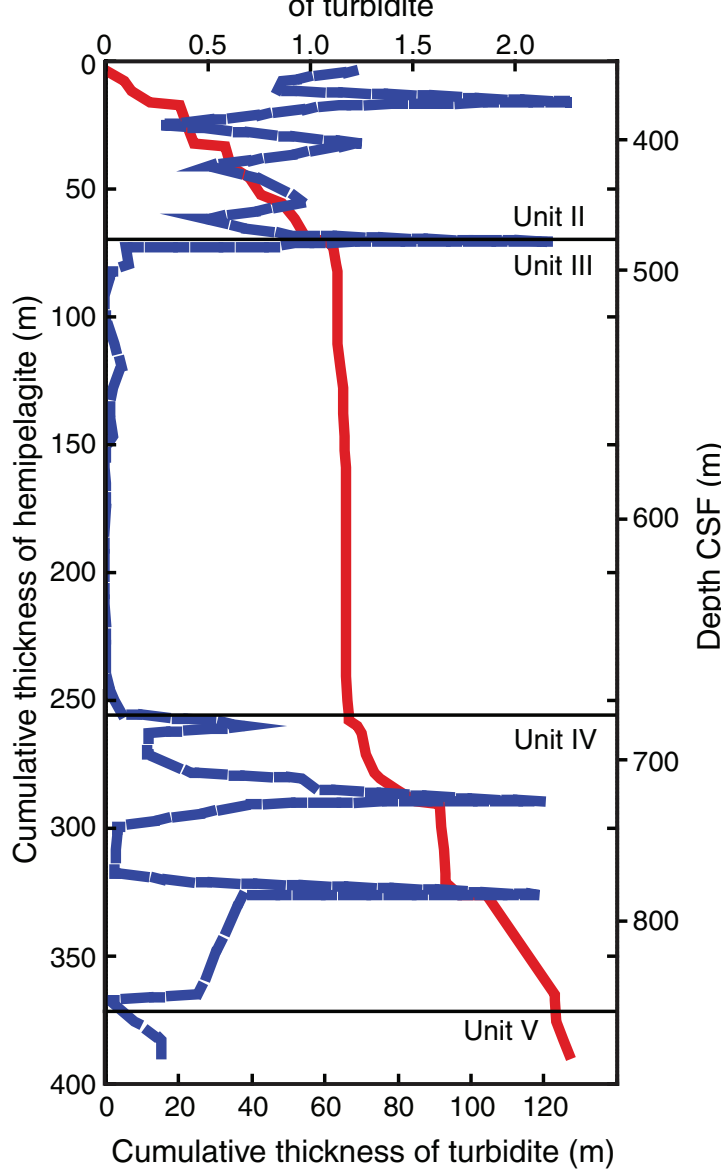

C

Age (Ma)

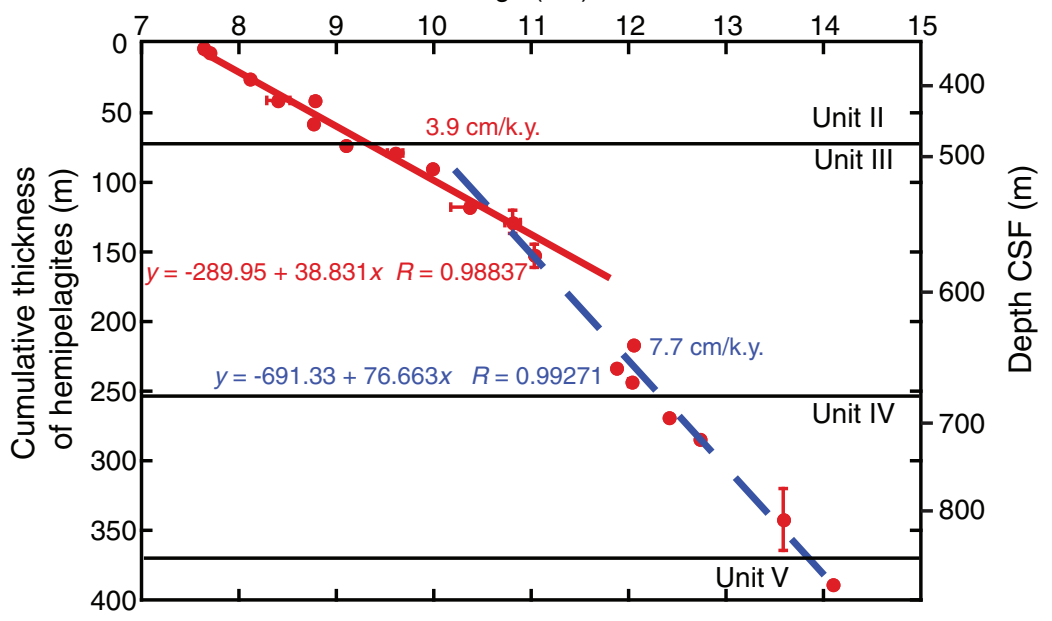


Figure F18. Calculated location of Site C0011, from $~ 12$ Ma to present day, based on estimated plate convergence rates and magnetic stripes in Shikoku Basin. See text for discussion.

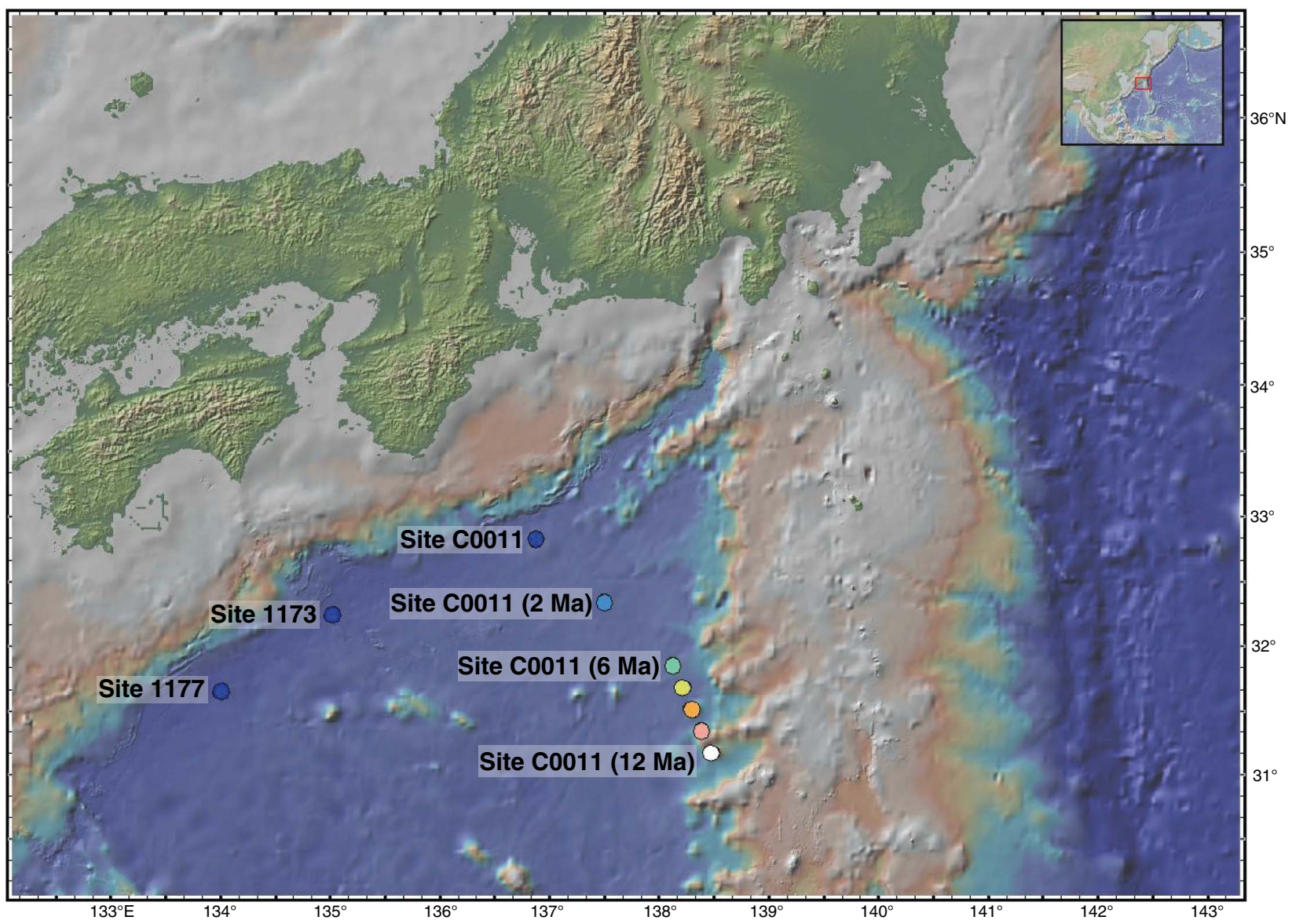


Figure F19. Summary of volcanic activity in Honshu forearc and backarc. Redrawn after Kimura et al. (2005). See text for explanation. PSP = Philippine Sea plate, LAT = low-alkali tholeiite, HMA = high-magnesium andesite, $\mathrm{MORB}=$ mid-ocean-ridge basalt.

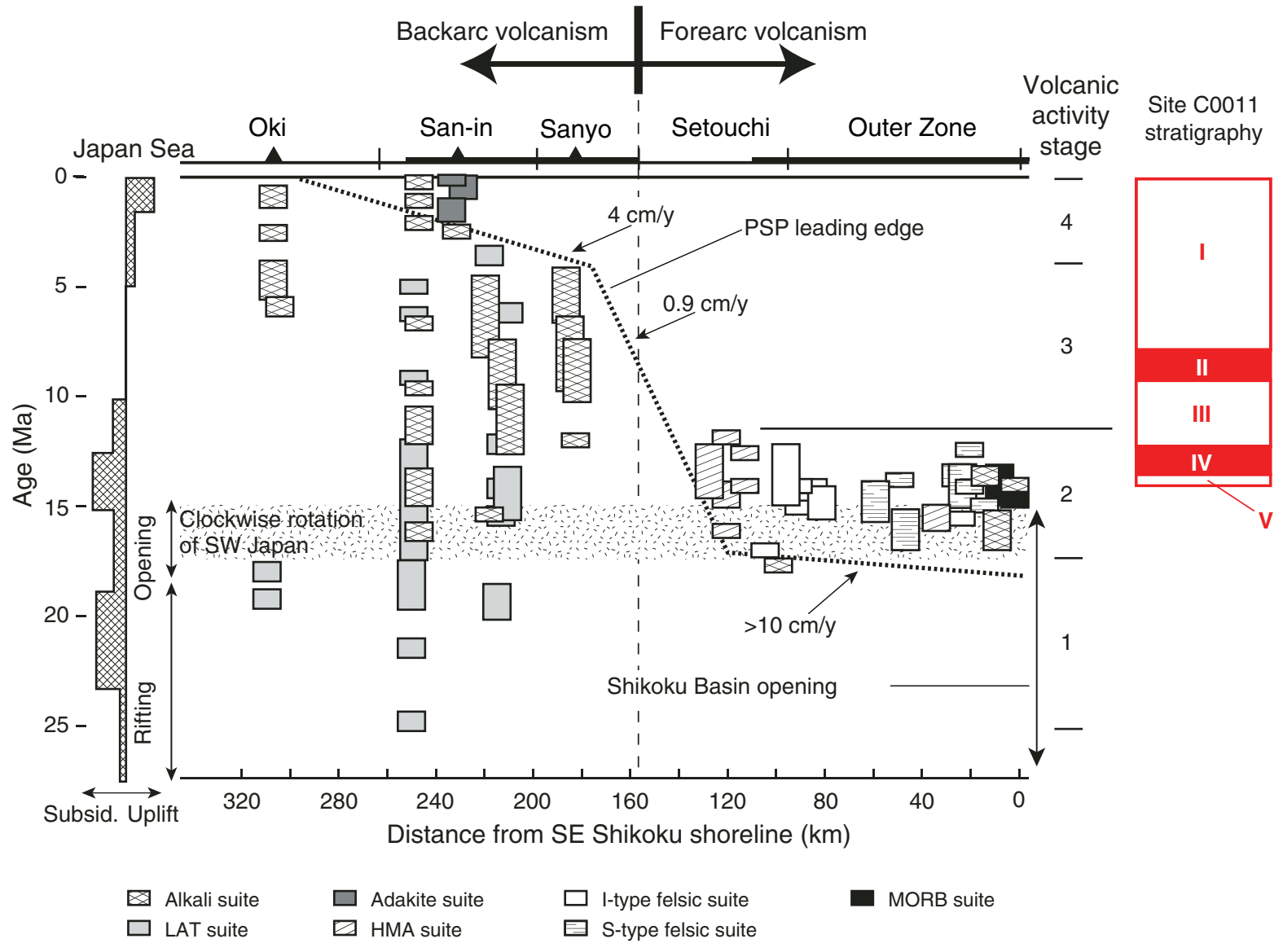


Figure F20. Dip angle variation of bedding and fault planes plotted against depth. Blue highlighted intervals correspond to chaotic deposits in core. $\mathrm{CT}=$ computed tomography.

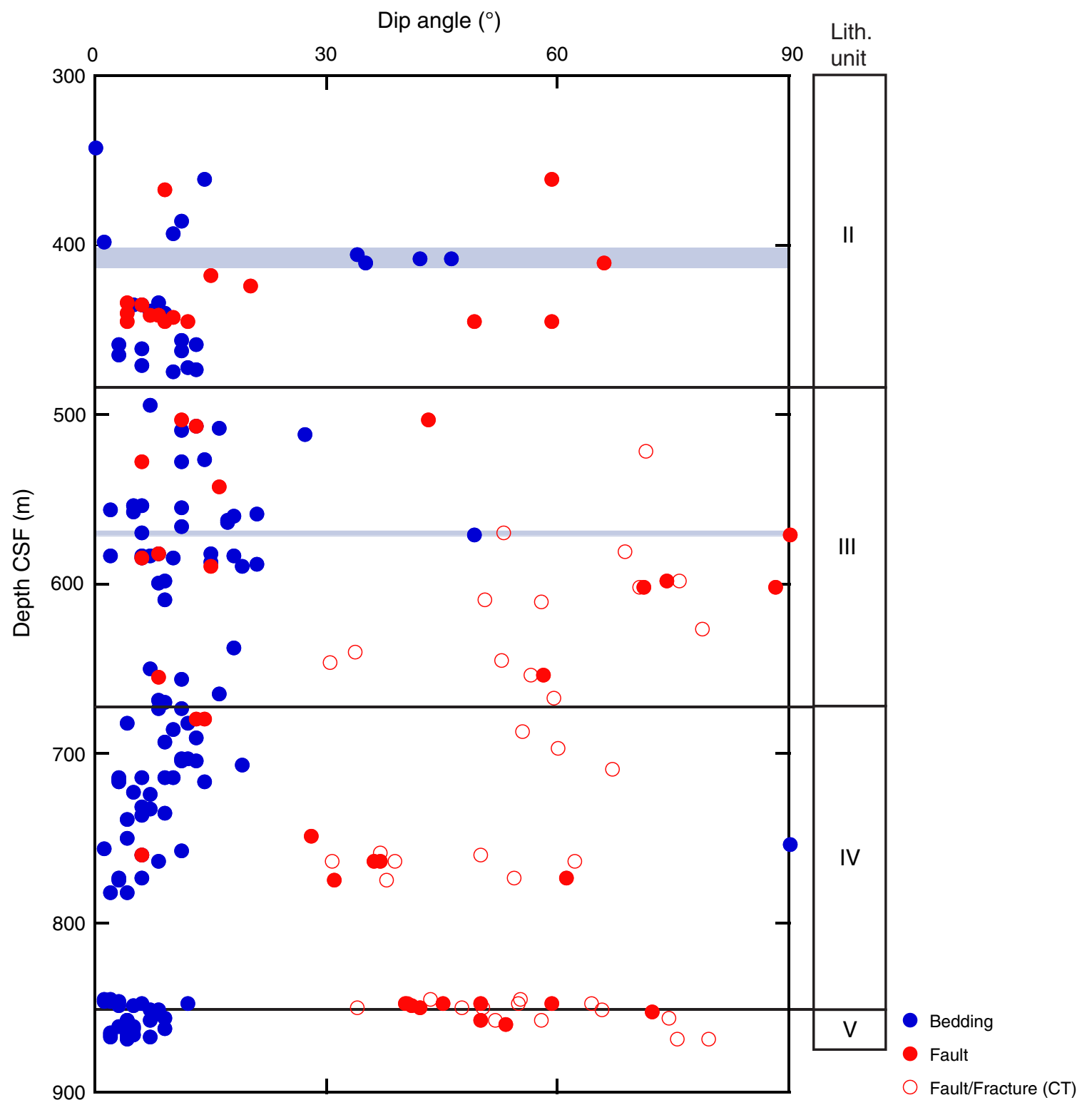


Figure F21. Stereo plots (lower hemisphere) of bedding planes and faults in Hole C0011B after paleomagnetic correction.

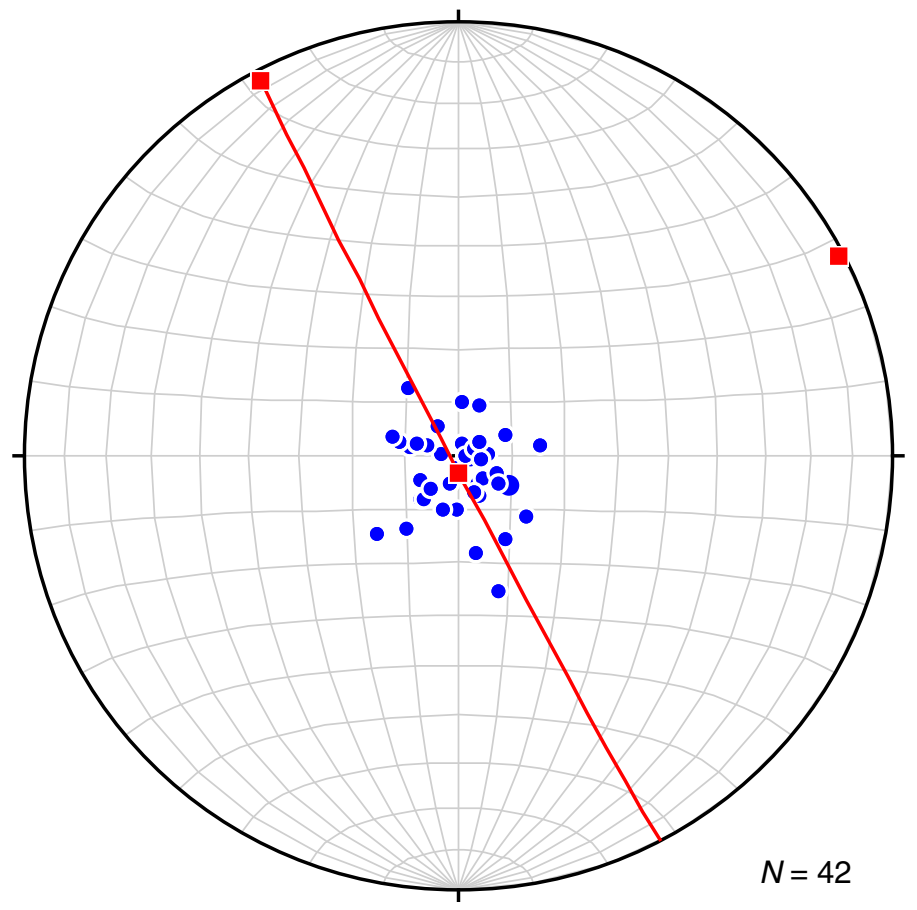

Bedding plane

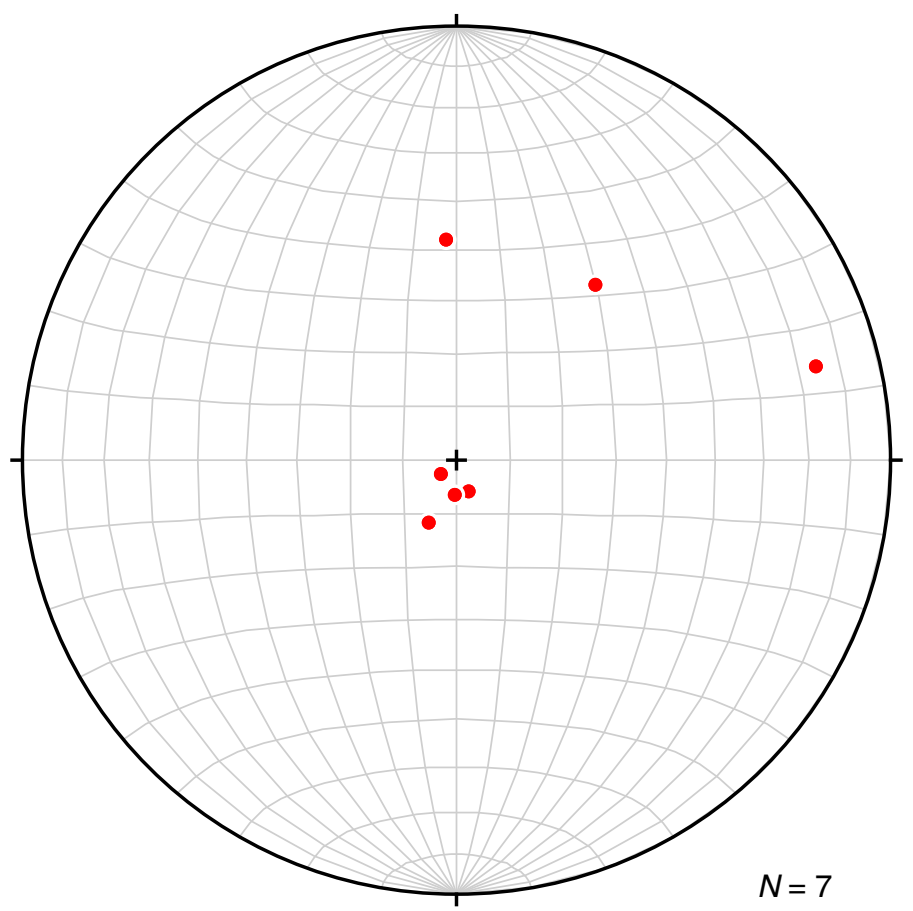

Fault 
Figure F22. Stereographs of dip and plots of distributions of dip angle and azimuth.
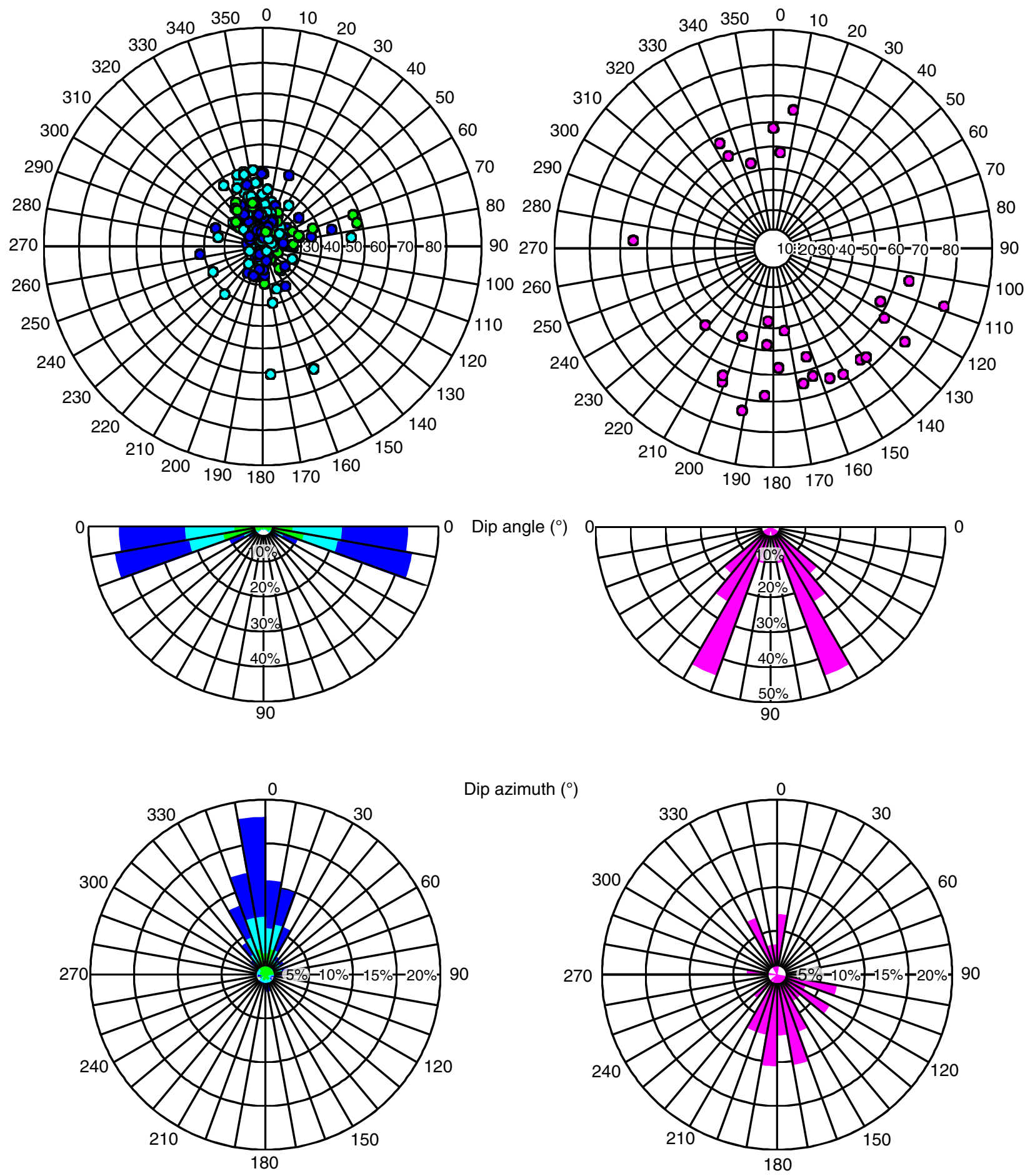

Dip azimuth $\left({ }^{\circ}\right)$

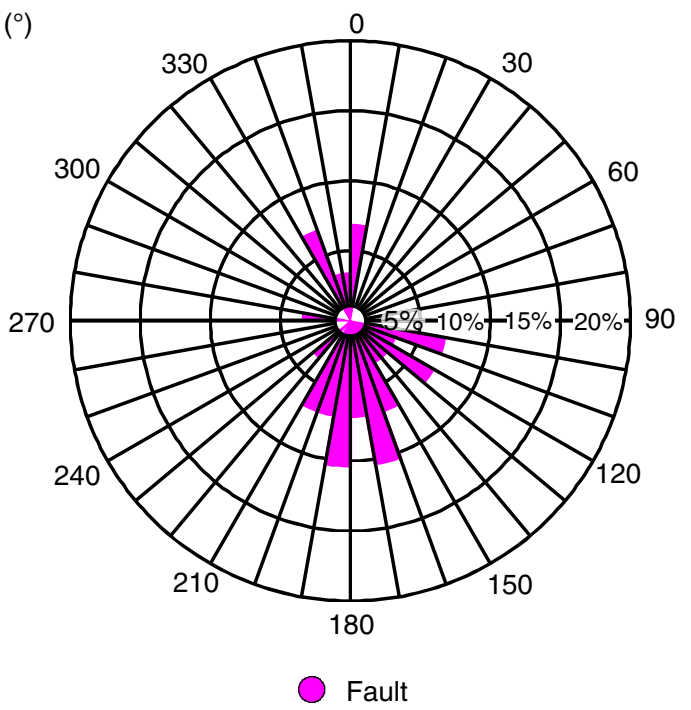

Bed boundary

Conductive fracture

Resistive fracture 
Figure F23. Typical lithologies on photo image logger (MSCL-I) and X-ray computed tomography (CT) image. A. Interval 322-C0011B-3R-3, 14-45 cm. B. Interval 322-C0011B-6R-8, 110-141 cm.

A

$\mathrm{cm}$

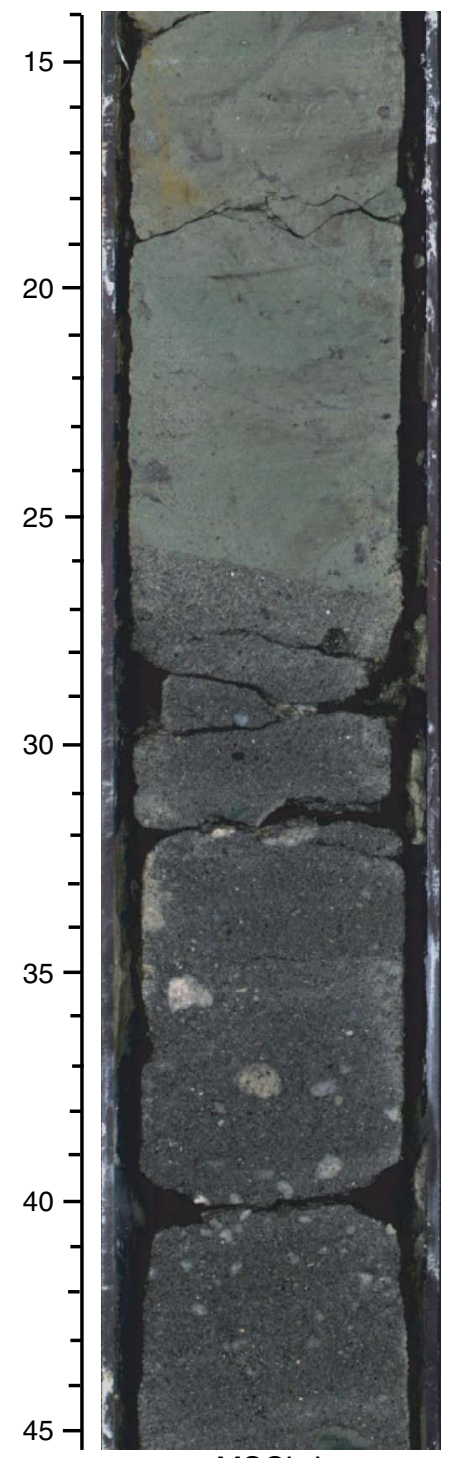

MSCL-I

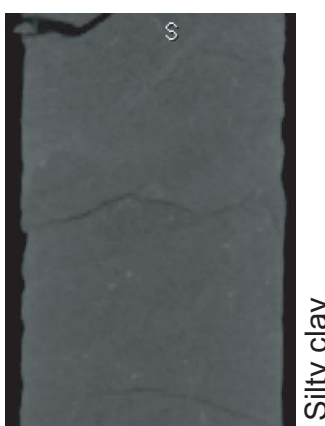

120

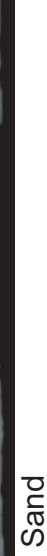

\section{象}

$130-$
-
-
-
-
-
-
-

CT
ते

B

$\mathrm{cm}$
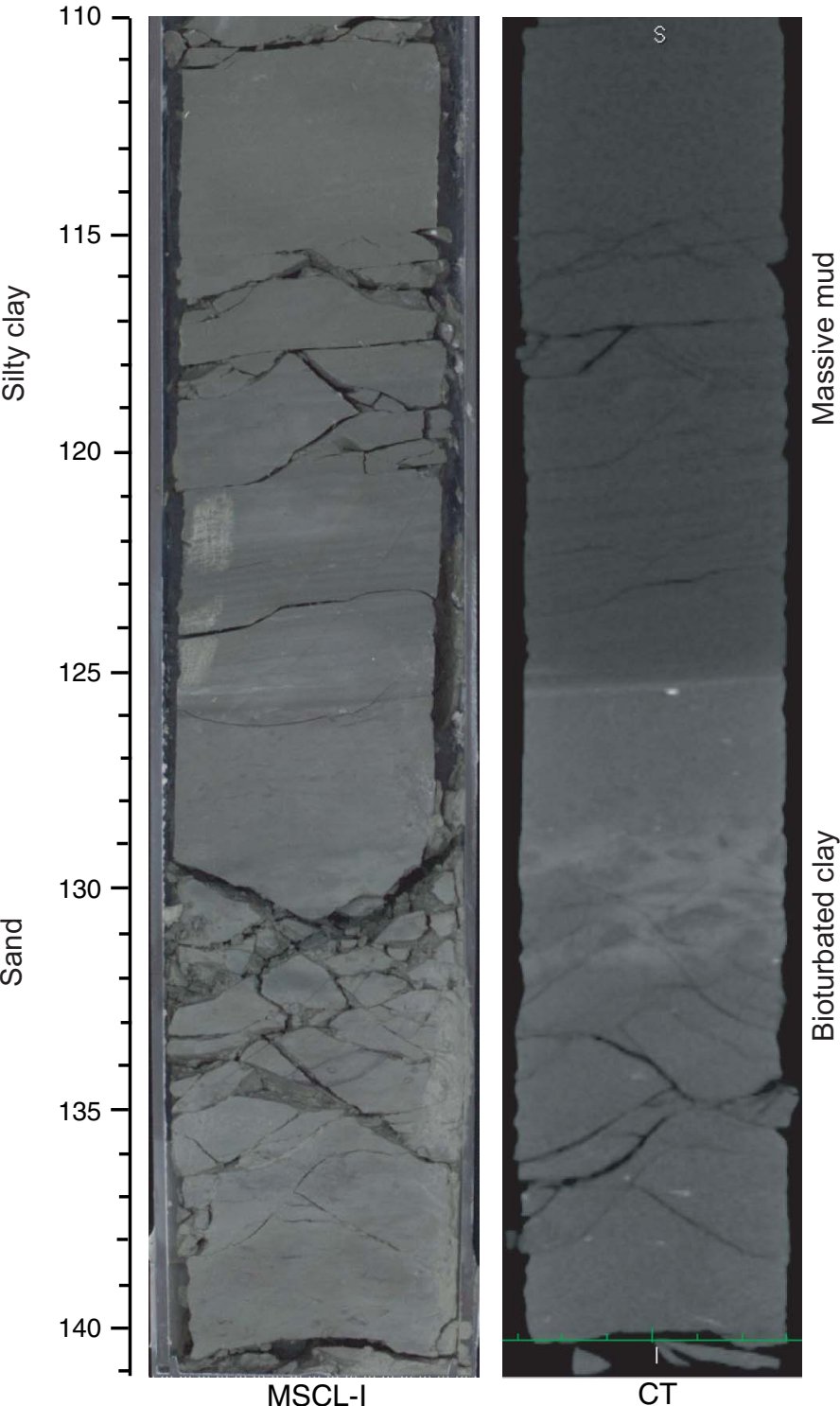

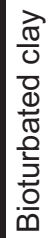


Figure F24. Example of sandstone, claystone (C), and siltstone (Silt). The different lithologies do not appear different in X-ray computed tomography (CT) image (interval 322-C0011B-54R-4, 71-89 cm). MSCL-I = photo image logger.

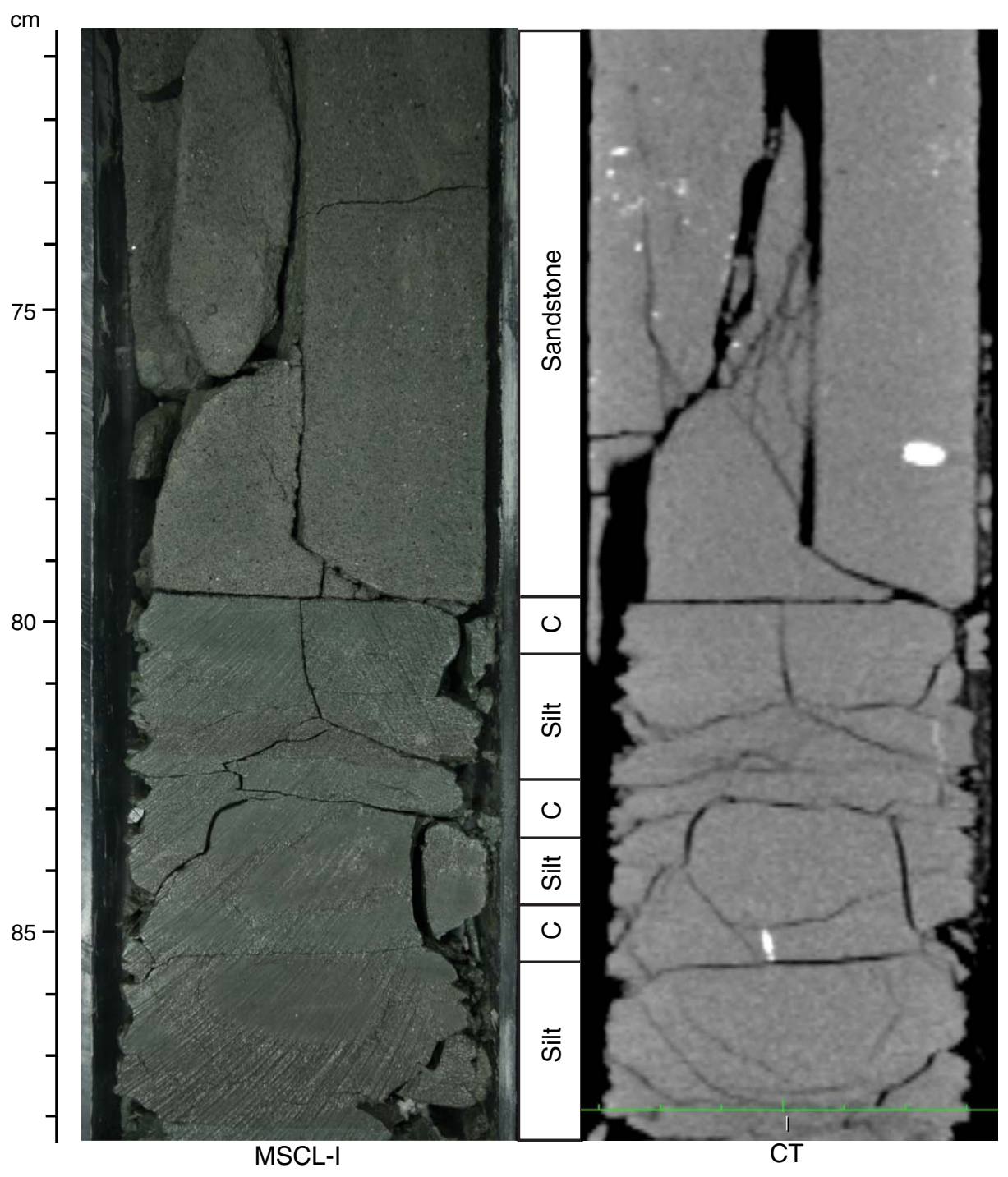


Figure F25. Example of layer-parallel fault (arrows) at $9 \mathrm{~cm}$ in interval 322-C0011B-12R-3, 1-23 cm. MSCL-I = photo image logger, CT = computed tomography.

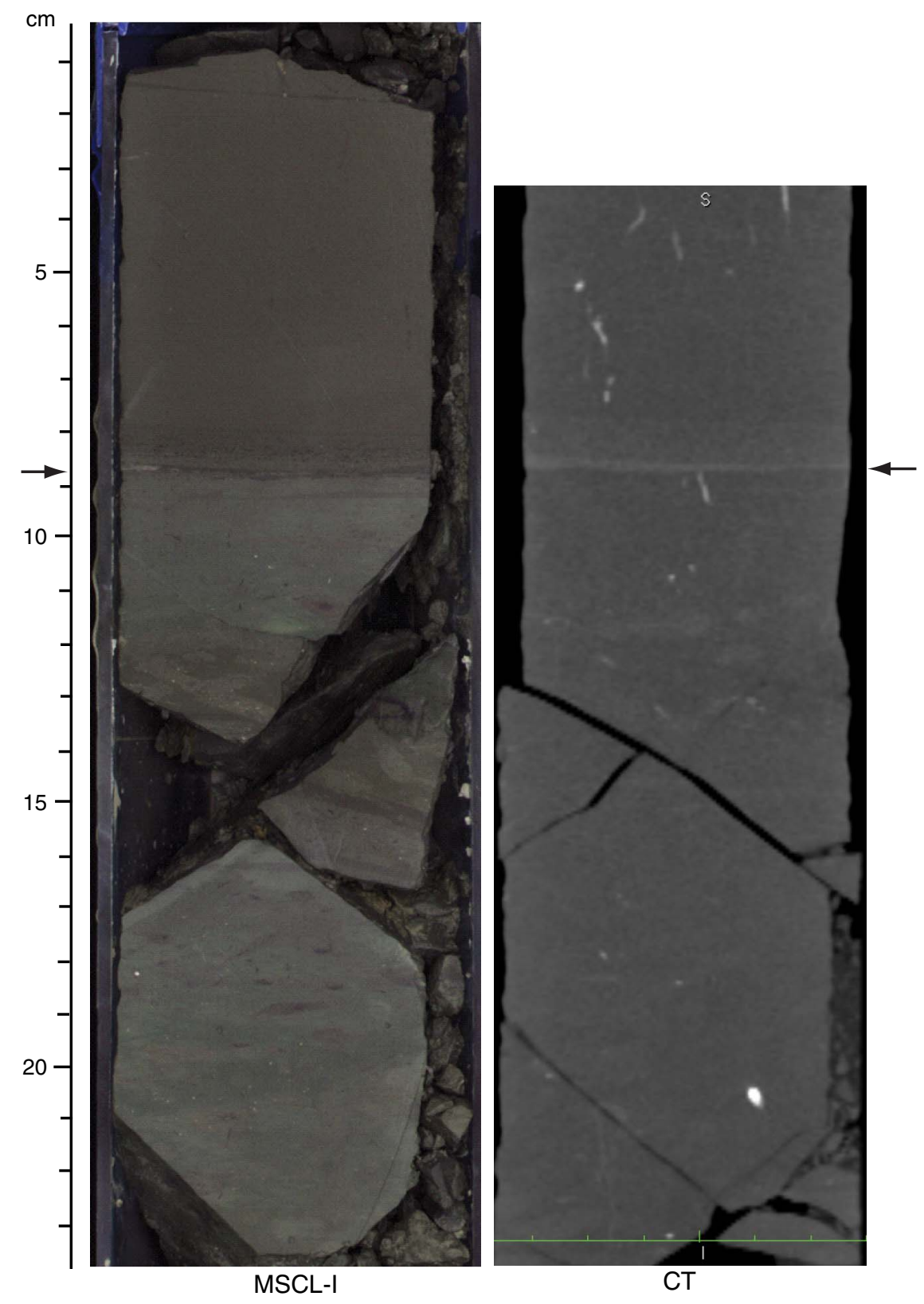


Figure F26. Composite fault system at $83-88 \mathrm{~cm}$ in interval $322-\mathrm{C} 0011 \mathrm{~B}-12 \mathrm{R}-3,77-93 \mathrm{~cm}$. MSCL-I = photo image logger, $\mathrm{CT}=$ computed tomography.
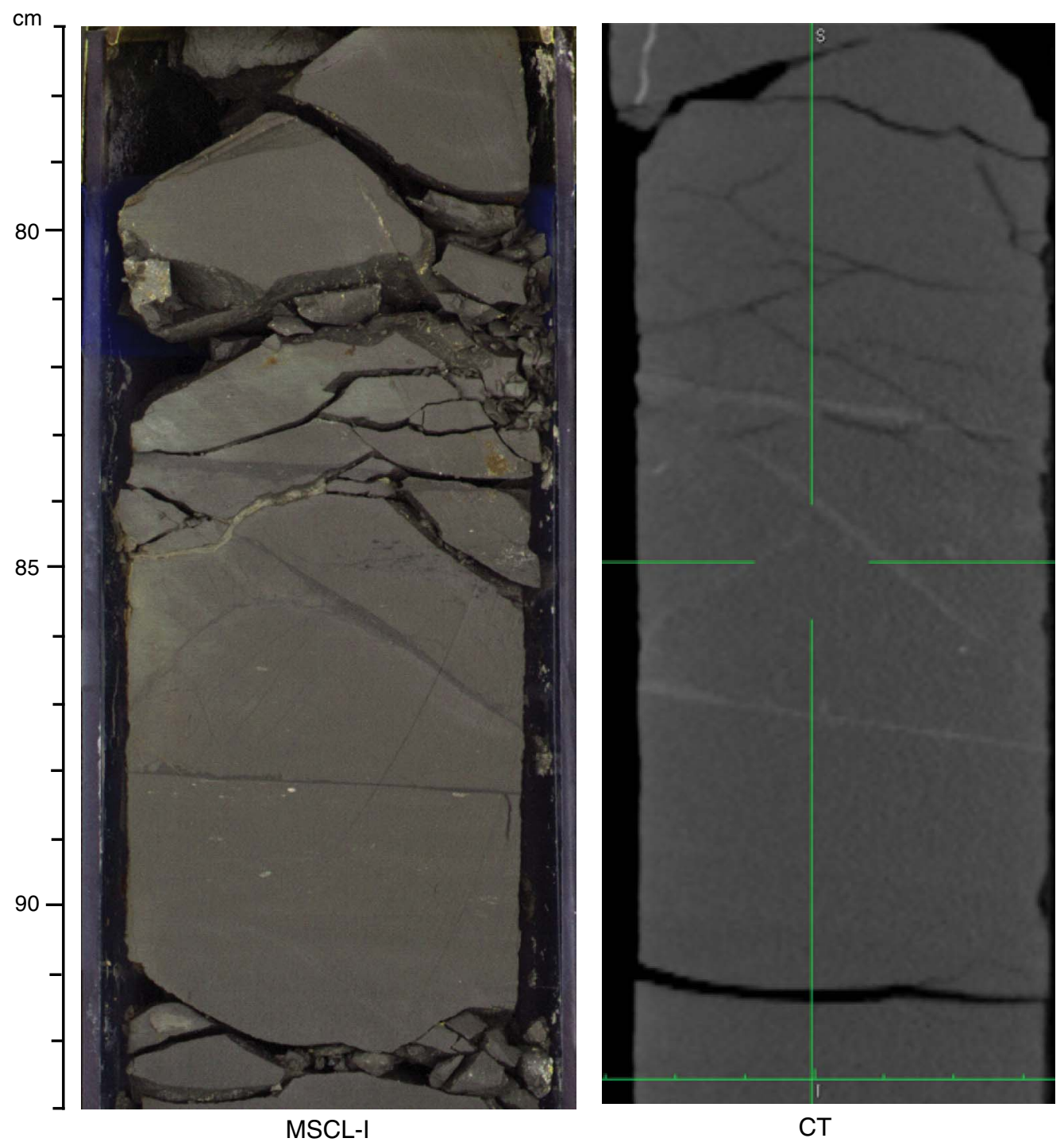
Figure F27. High-angle faults. X-ray computed tomography (CT) images show cross section parallel to the maximum inclination of the faults. A. Bright line, a possible burrow, is cut by fault (interval 322-C0011B-37R-8, $38-54 \mathrm{~cm}$ ). B. Bright layer is displaced by fault (interval 322-C0011B-32R-1, 102-126 cm). MSCL-I = photo image logger.
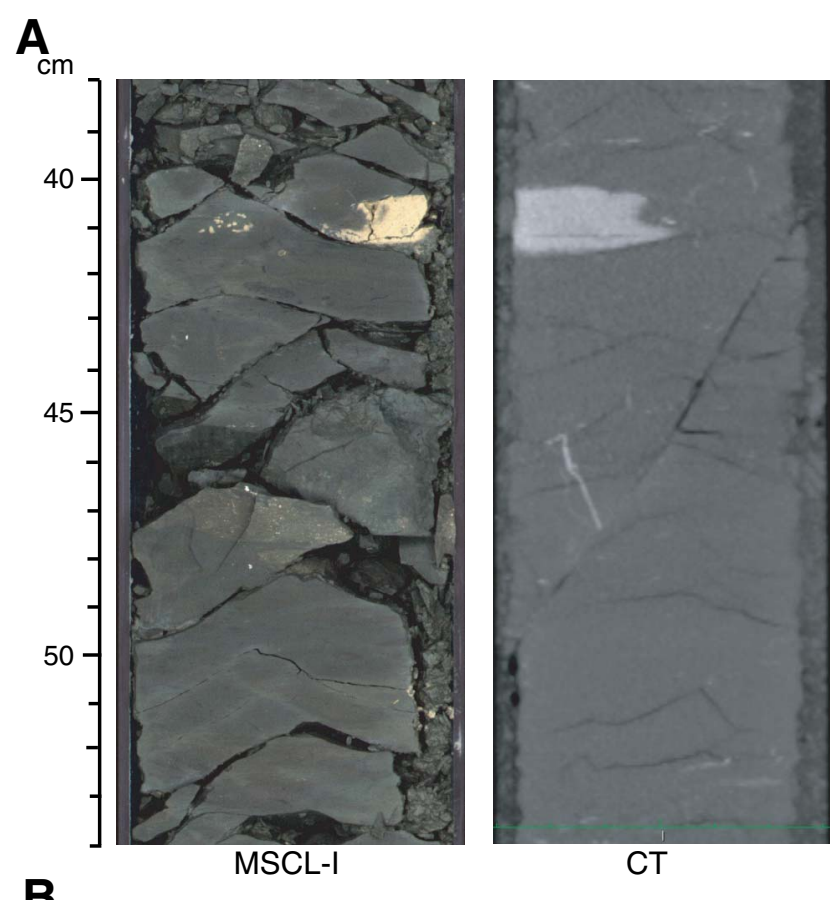

B
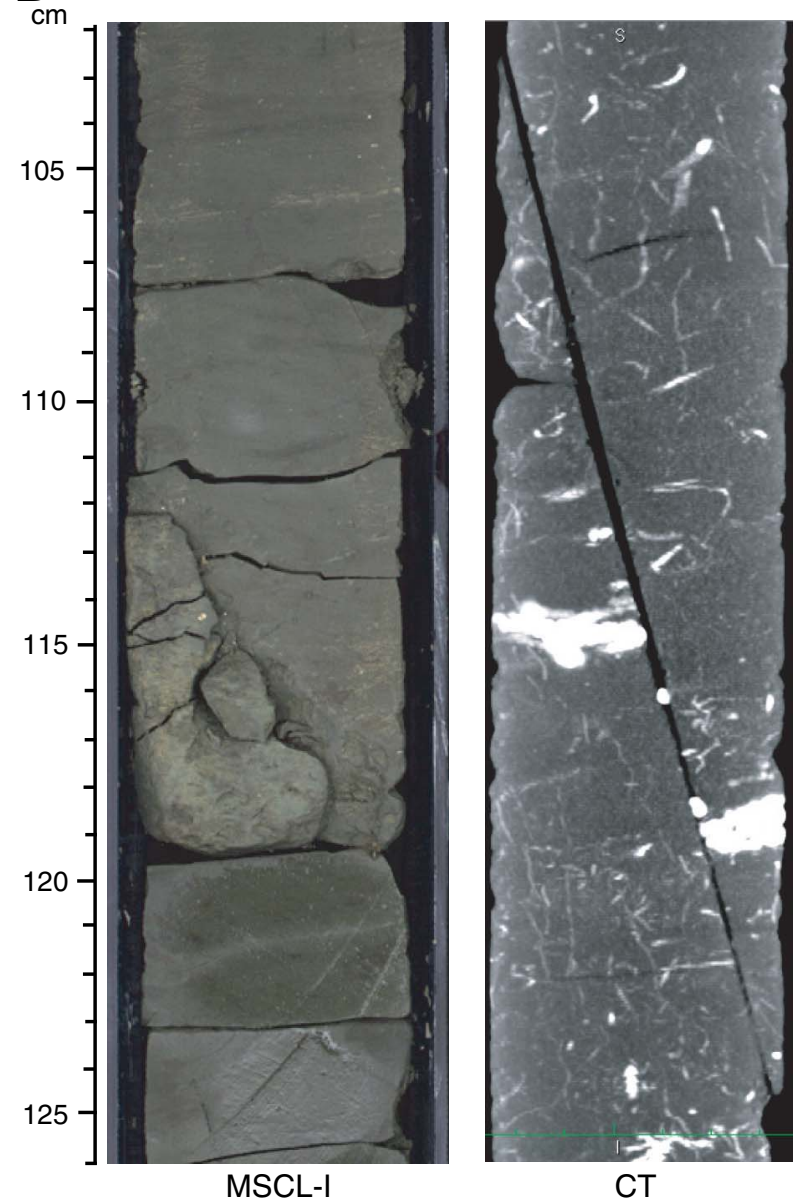

MSCL-I

CT 
Figure F28. Core photographs of bioturbated dark deformation bands (arrows). A. Interval 322-C0011B-21R-6, $45-55 \mathrm{~cm}$. B. Interval 322-C0011B-26R-5, 38-48 cm. C. Interval 322-C0011B-31R-3, 103-113 cm.

A

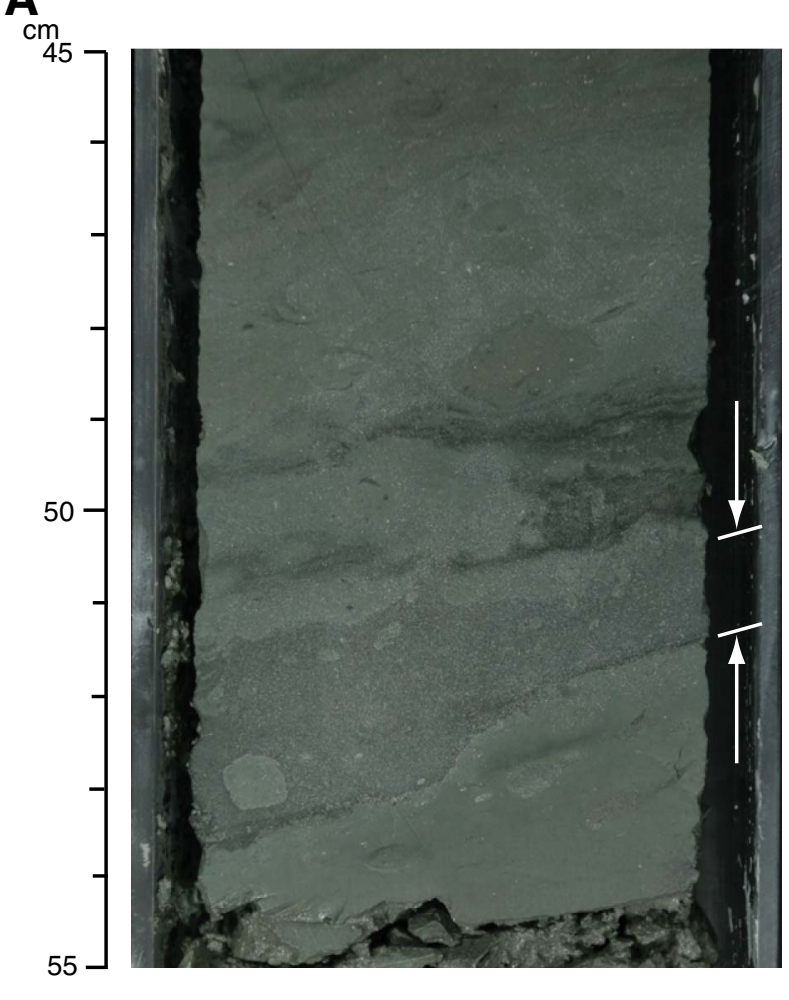

$\mathbf{C}_{\mathrm{cm}}$

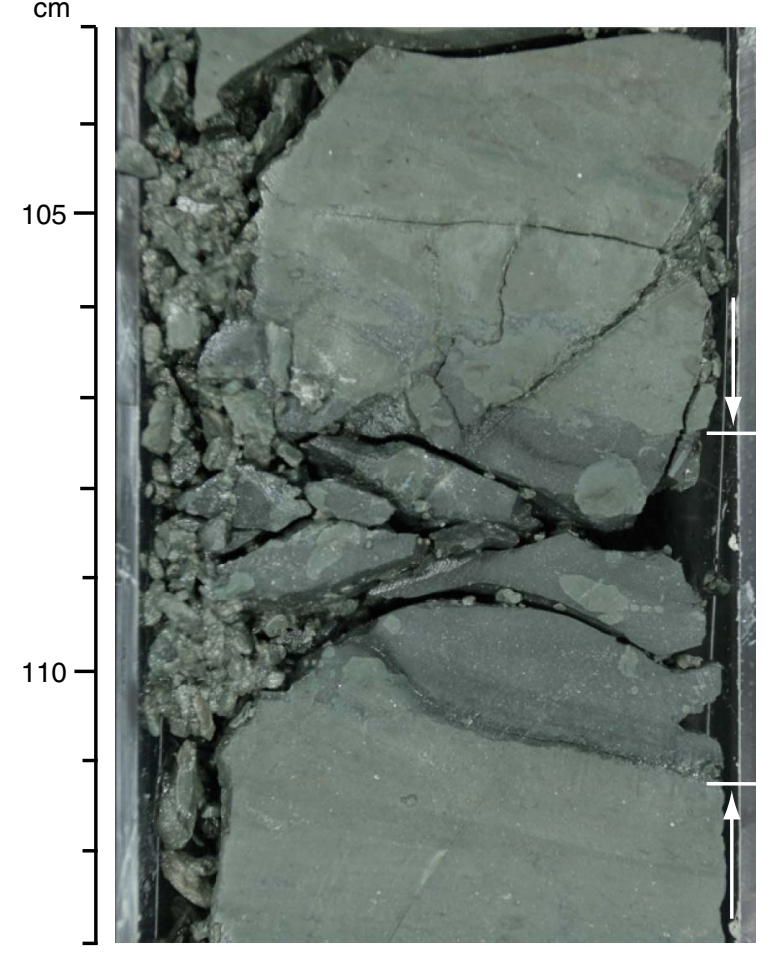

B

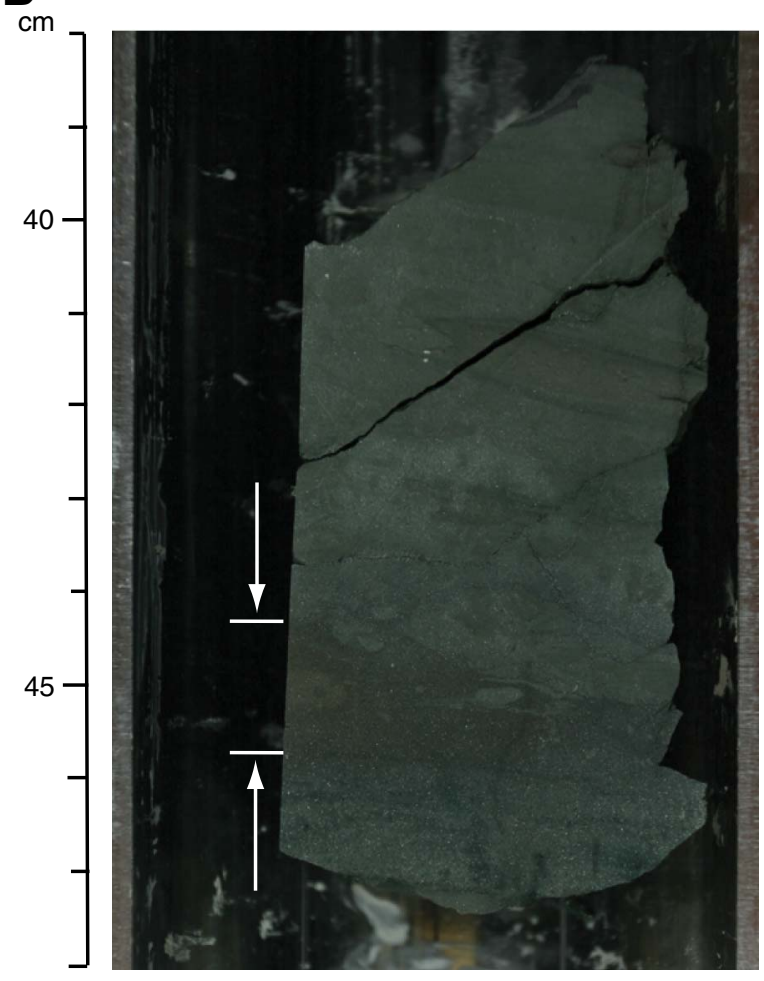


Figure F29. Fault-filling calcite vein (interval 322-C0011B-52R-5, 8-26 cm). MSCL-I = photo image logger, CT = computed tomography.
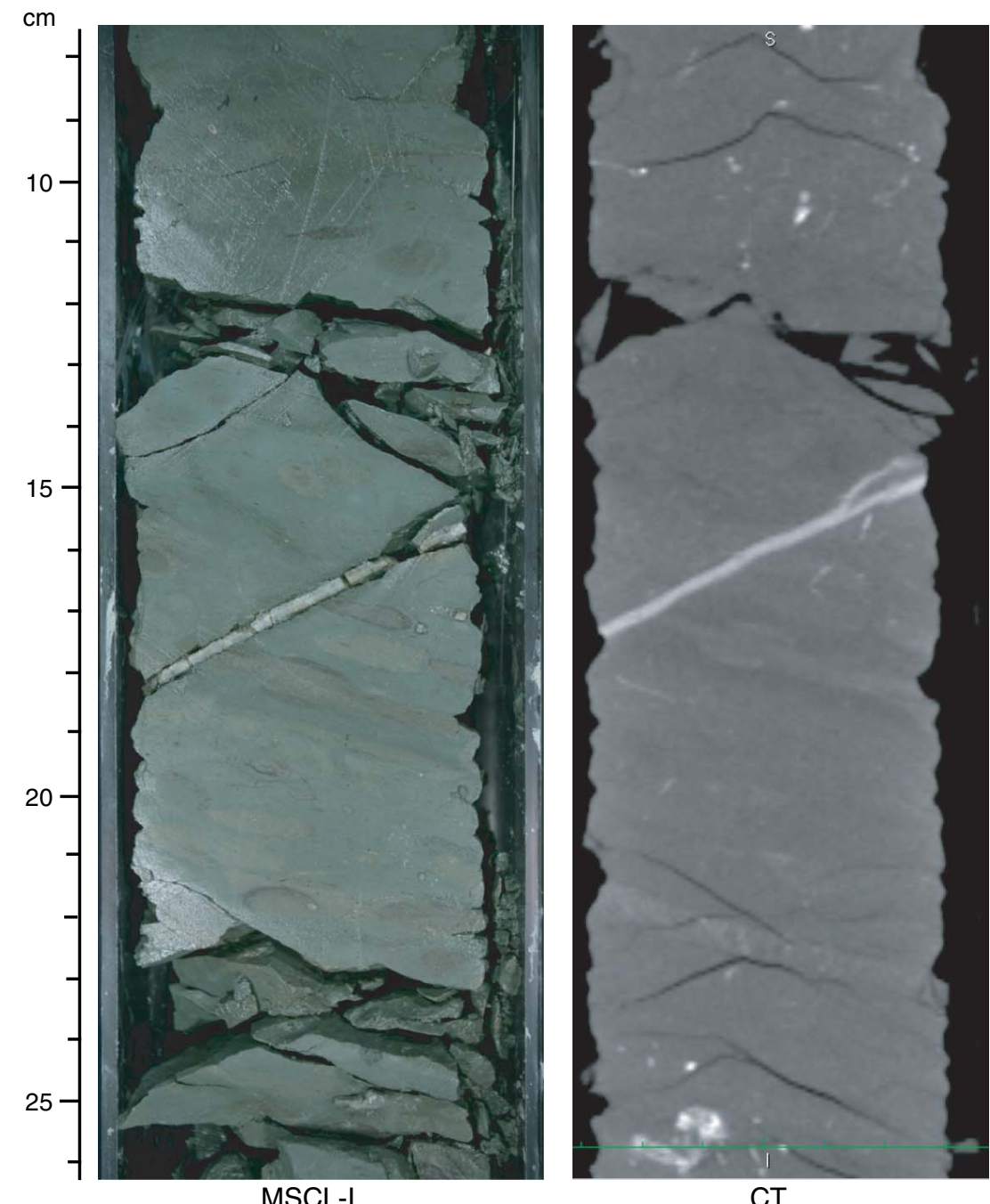
Figure F30. Example of convex-shaped drilling-induced conjugate faults (interval 322-C0011B-37R-7, 12$28 \mathrm{~cm}$ ). Fractures do not completely run through the core under X-ray computed tomography (CT) image, although they are completed after splitting. MSCL-I = photo image logger.
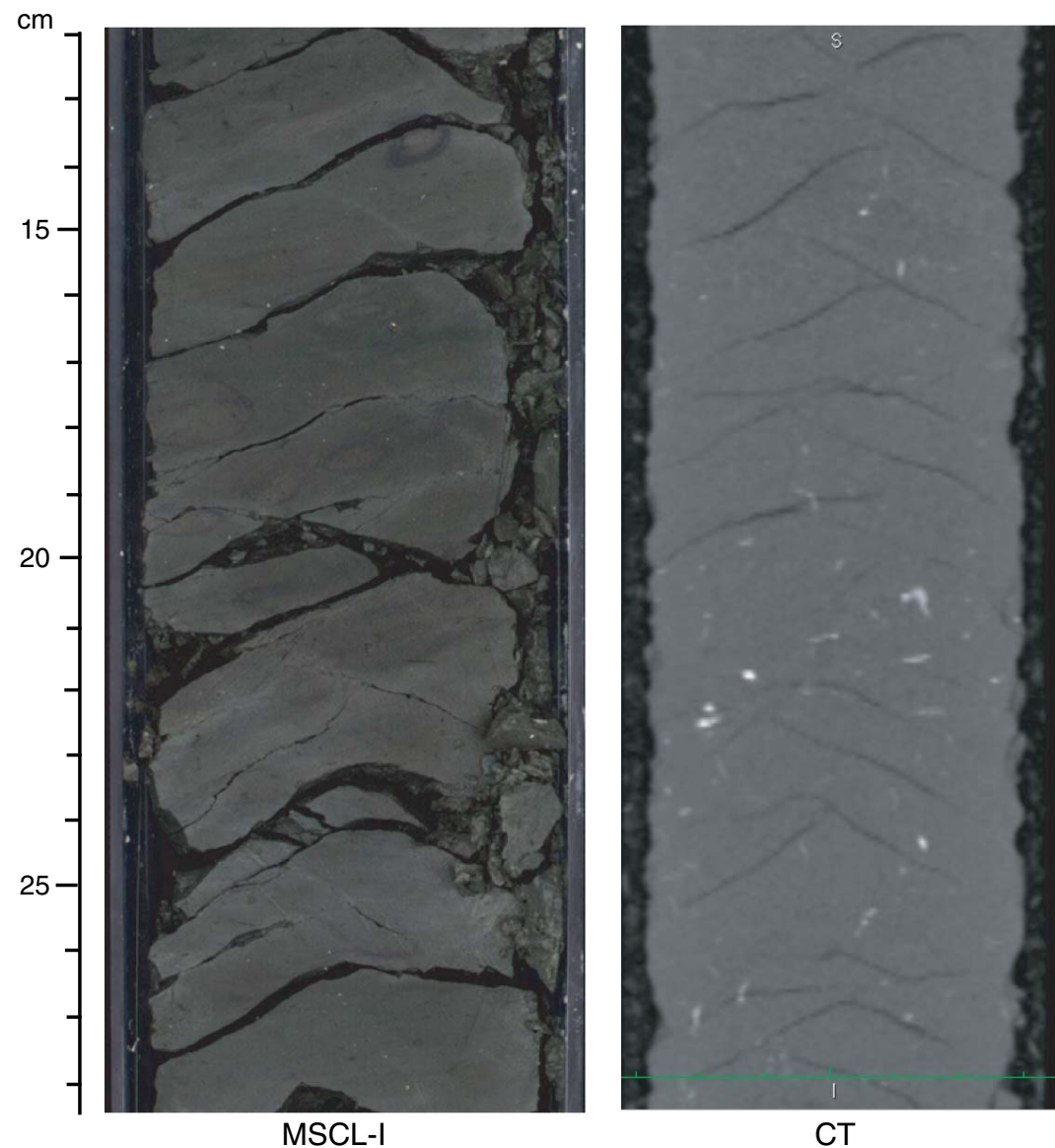

CT 
Figure F31. A-C. X-ray CT images, jigsaw puzzle (Section 322-C0011B-21R-3).
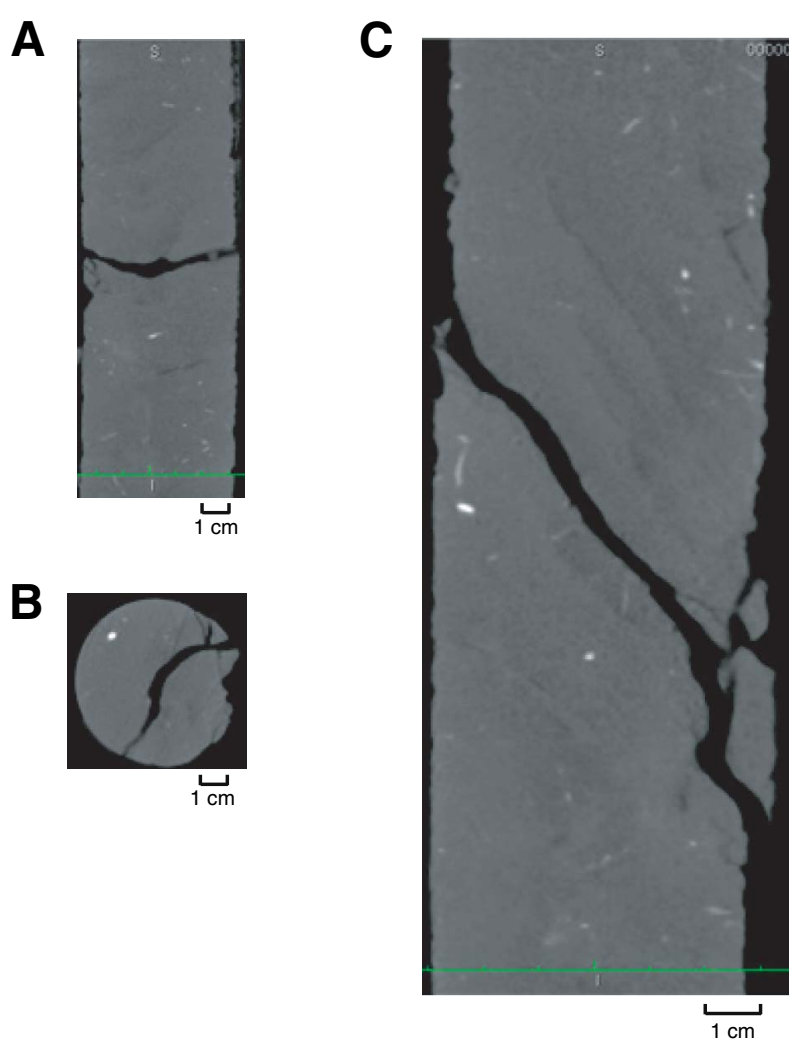
Figure F32. Well-sorted cuttings fill core liner (interval 322-C0011B-43R-7, 67-91 cm). Round vesicles are observed in the X-ray computed tomography (CT) image. MSCL-I = photo image logger.
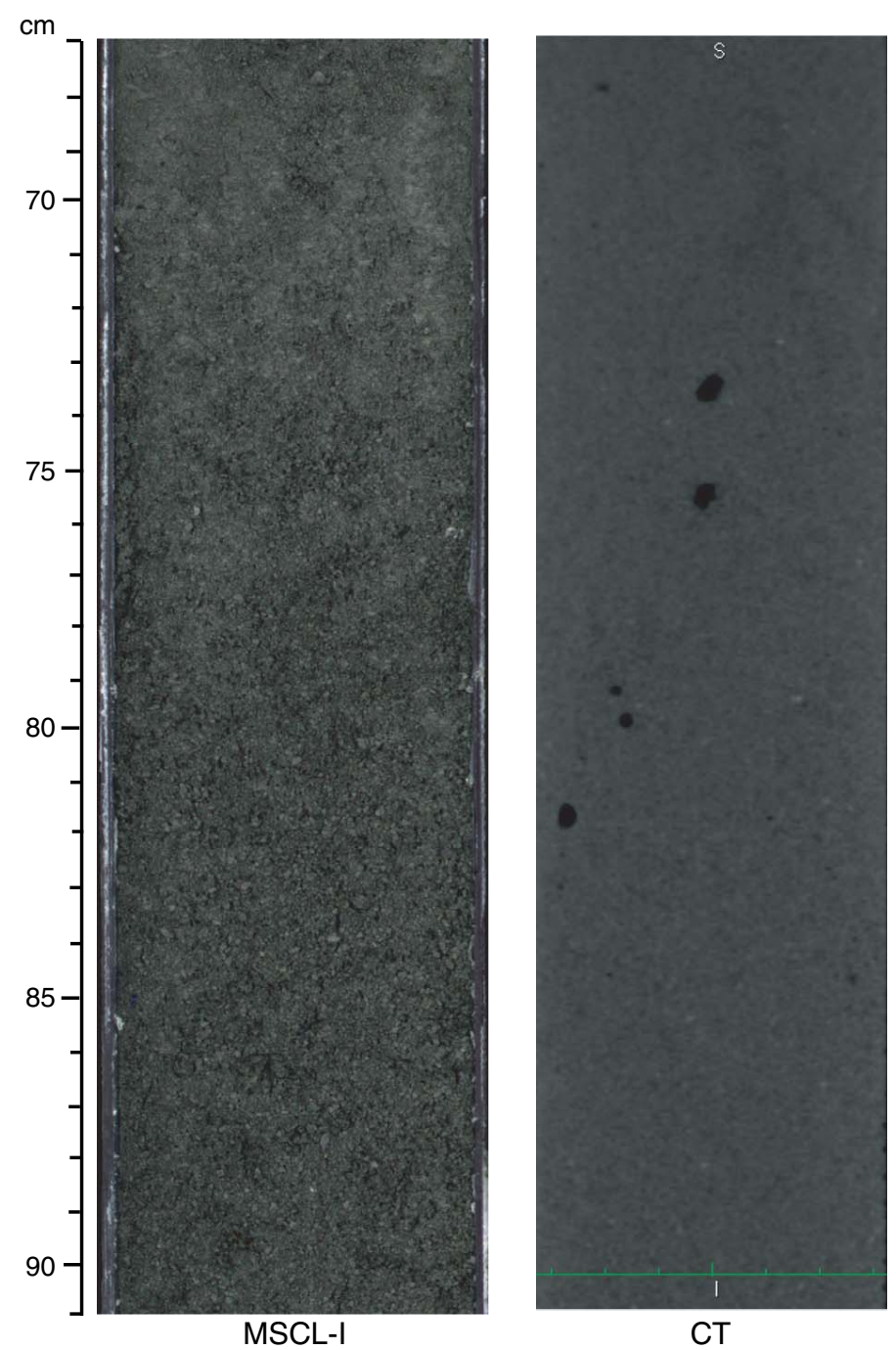
Figure F33. Cuttings from Section 322-C0011B-48R-5 with grading structure. MSCL-I = photo image logger, $\mathrm{CT}=$ computed tomography.

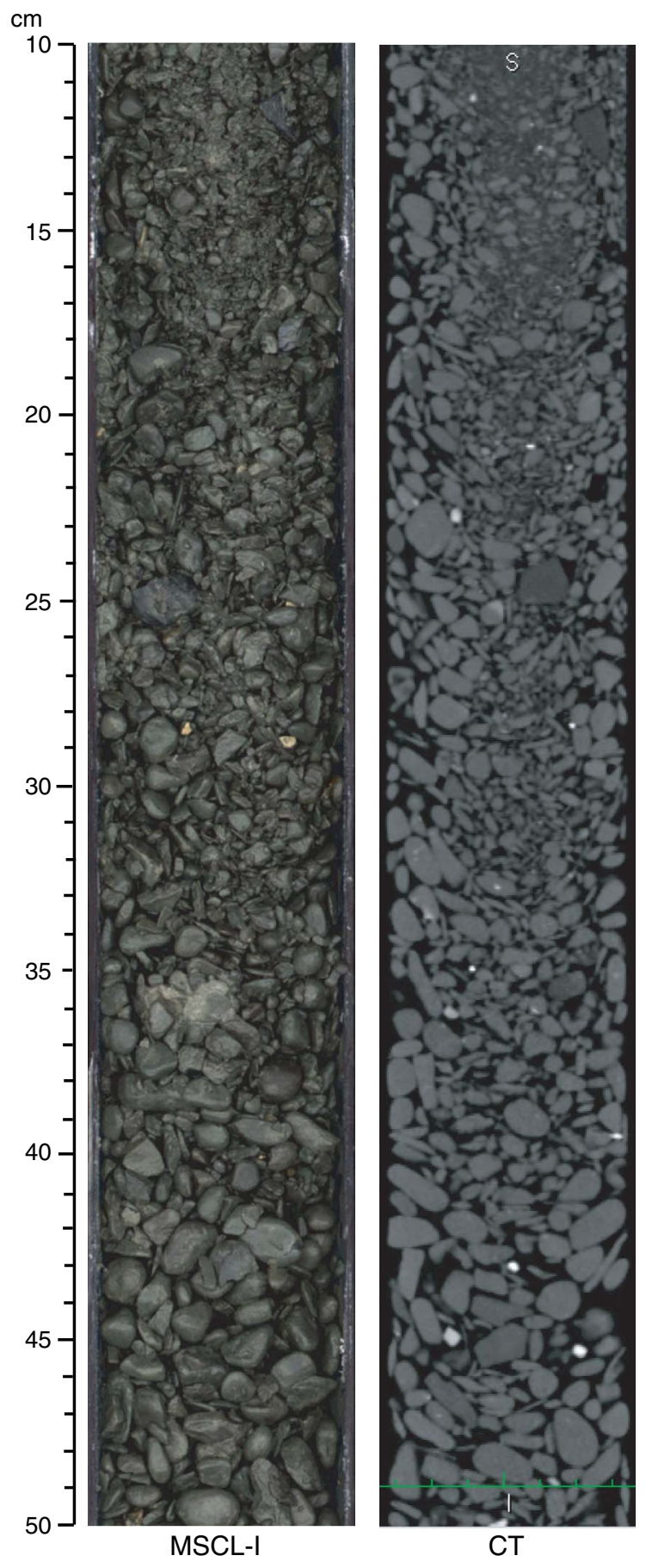


Figure F34. Chronostratigraphic correlation of Hole C0011B based on calcareous nannofossils and planktonic foraminifers. Relationship to magnetostratigraphy shown in the left panel. $\mathrm{PE}=$ paracme end, $\mathrm{FO}=$ first occurrence, $\mathrm{PB}=$ paracme beginning, $\mathrm{LO}=\mathrm{last}$ occurrence, $\mathrm{FCO}=$ first consistent occurrence.

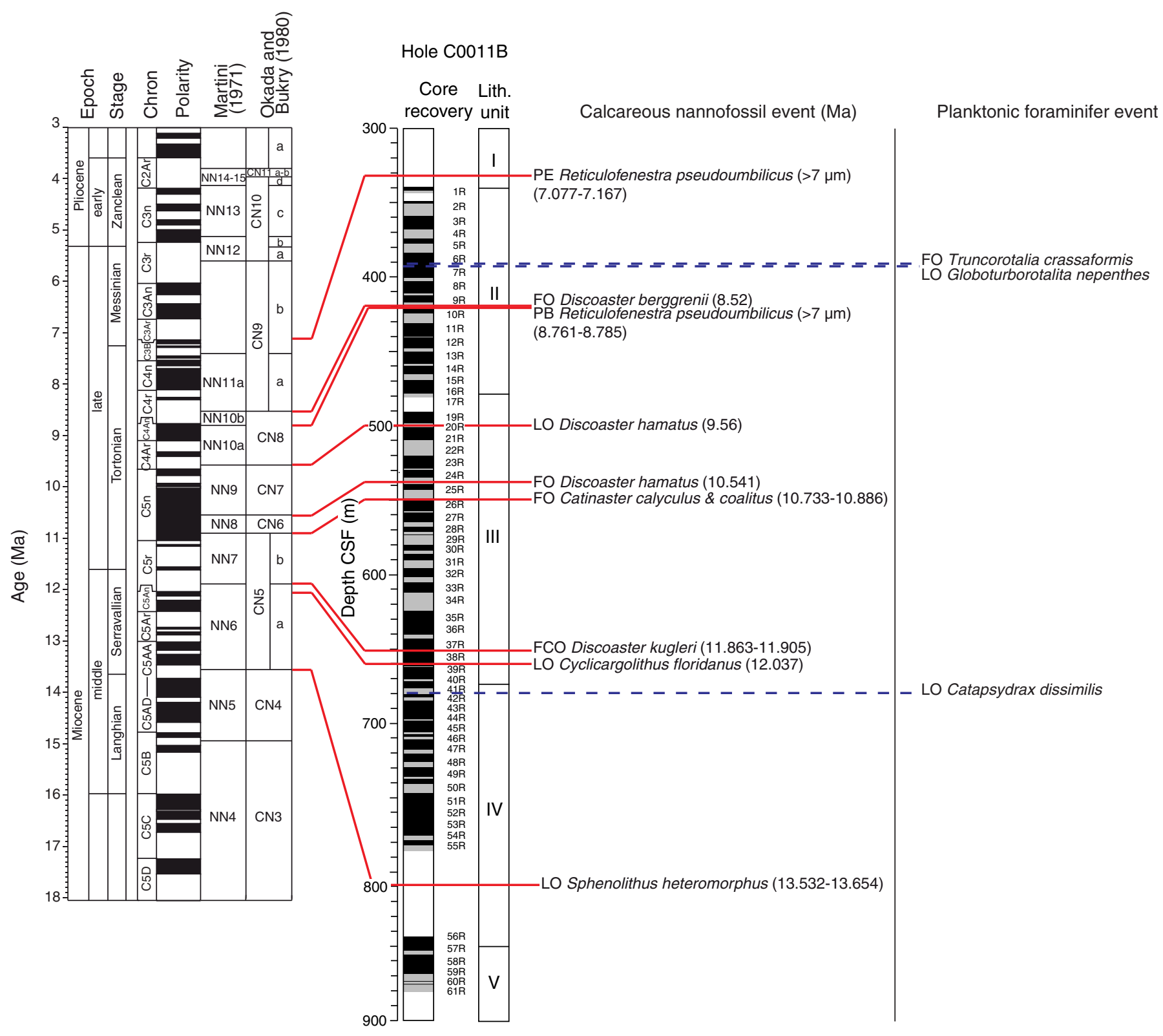


Figure F35. Age-depth plot based on calcareous nannofossils.

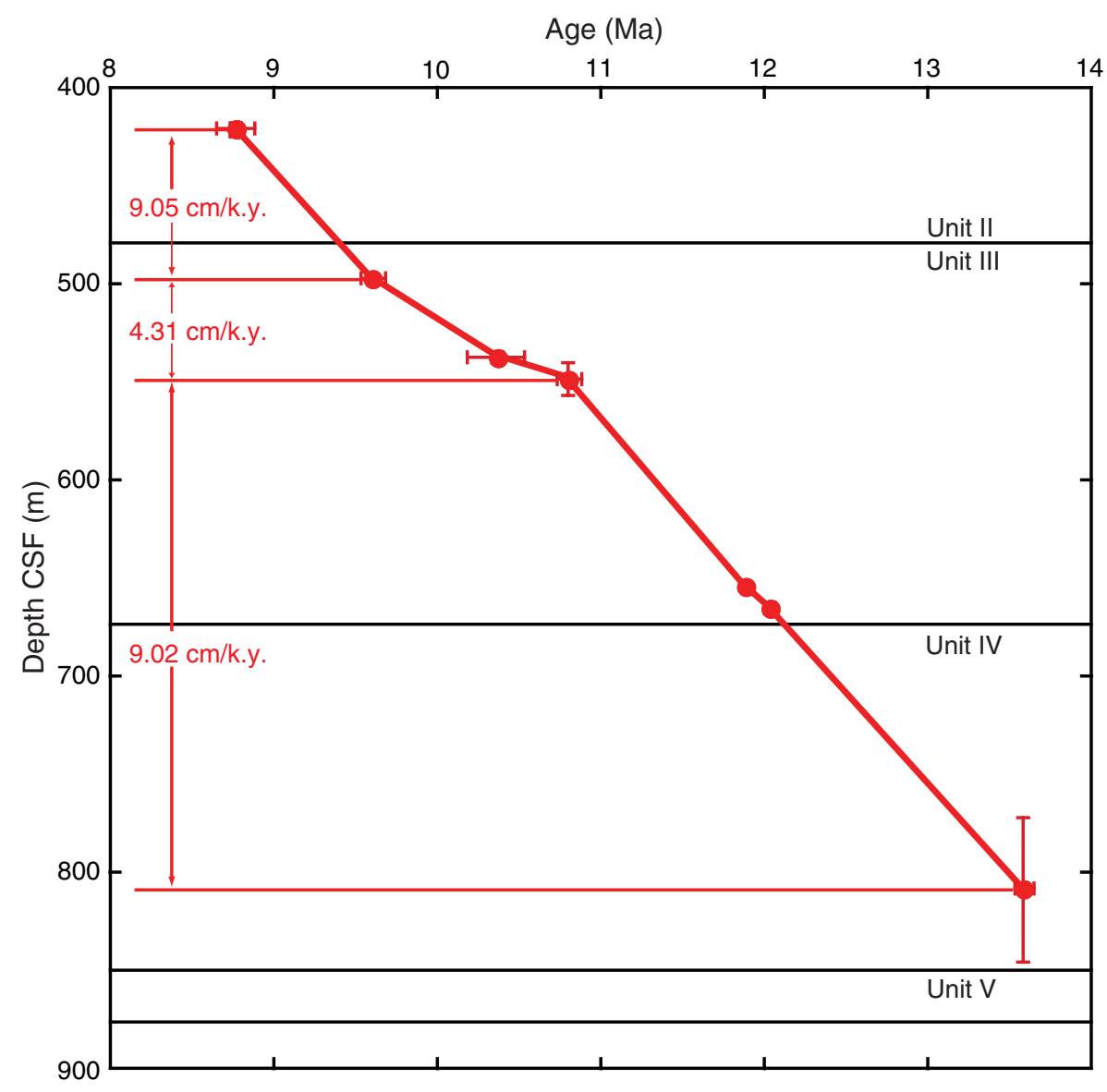


Figure F36. Results of paleomagnetic measurements on discrete samples plotted versus depth, Hole C0011B. From left to right: inclination (black = NRM before demagnetization, blue $=$ linear regression fitting), magnetozones identified $($ black $=$ normal polarity, white $=$ reversed polarity, gray $=$ undetermined, red $=$ no core recovery or no data), magnetization intensity (black $=$ NRM before demagnetization, red $=$ after AF demagnetization at $10 \mathrm{mT}$ ), magnetic susceptibility, $\mathrm{Q}$ ratio (Königsberger ratio; blue $=\mathrm{NRM}_{0 \mathrm{mT}}-\mathrm{NRM}_{10 \mathrm{mT}}$, red $=$ $\mathrm{NRM}_{10 \mathrm{~m} \text {; }}$ see text for details) are shown. Circles = claystone or siltstone, triangles = tuffaceous/volcaniclastic sandstone, rectangles $=$ silty sandstone/sandstone, inverted triangles $=$ tuff/tuffaceous siltstone.

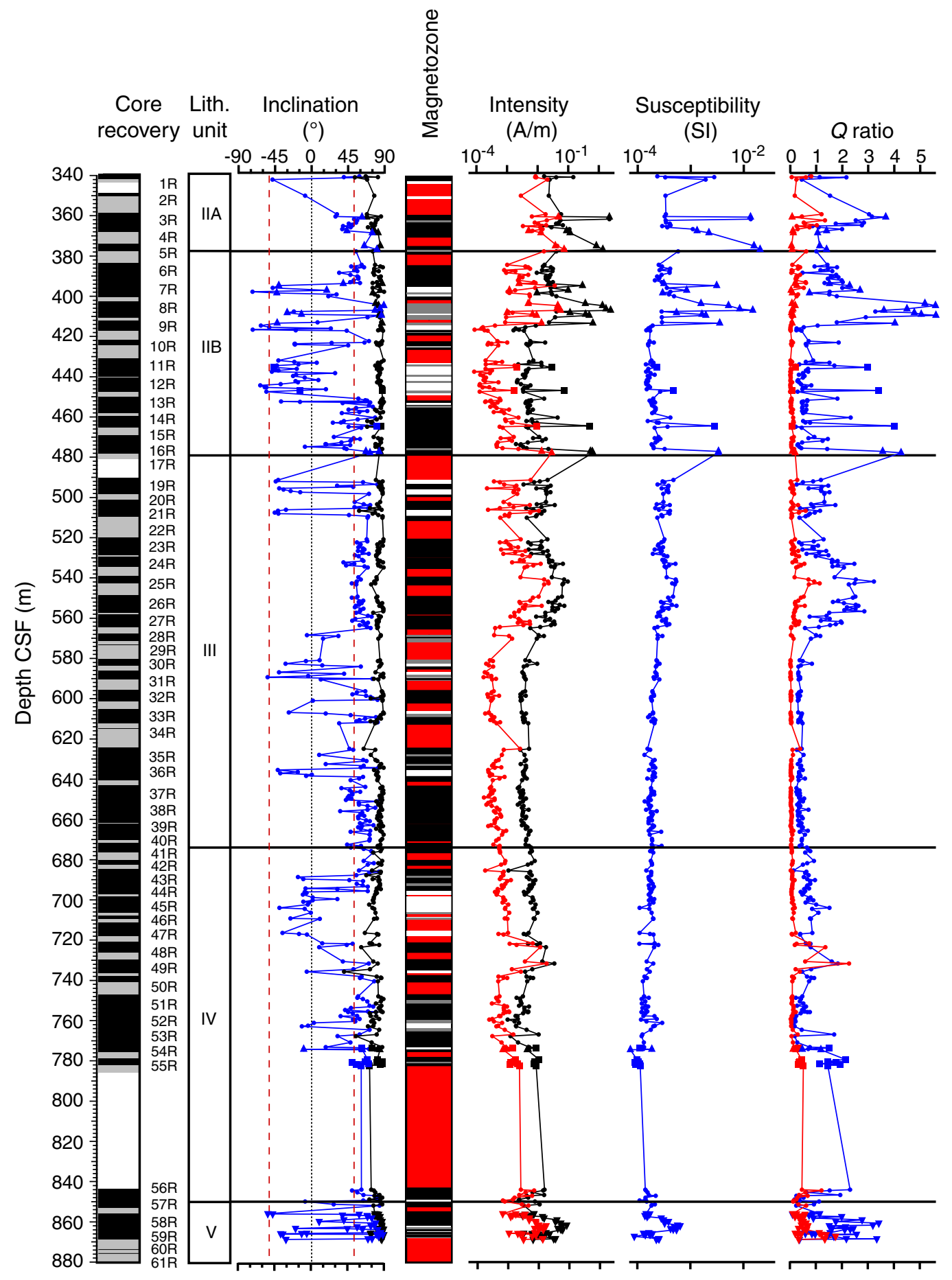


Figure F37. Representative vector endpoint diagrams of magnetization directions through stepwise AF demagnetization or thermal demagnetization. A. Sample 322-C0011B-4R-1, 72-74 cm, and (B) Sample 322-C0011B7R-1, 118-120 cm, showing isolation of stable normal and reversed ChRM component that is decaying toward the origin of the vector plot after removal of a vertical downward component of DIRM after AF demagnetization at $10 \mathrm{mT}$. C. Sample 322-C0011B-15R-4, 96-98 cm, shows demagnetization behavior through thermal demagnetization compared with AF demagnetization on (D) Sample 322-C0011B-15R-4, 99-101 cm, which was taken $3 \mathrm{~cm}$ below. E. Sample 322-C0011B-49R-7, 74-76 cm, indicating the presence of higher coercivity component, which cannot be completely demagnetized by AF at $160 \mathrm{mT}$. Open and solid circles = projection of magnetization vector endpoints onto vertical and horizontal planes, respectively. NRM = natural remanent magnetization.

A

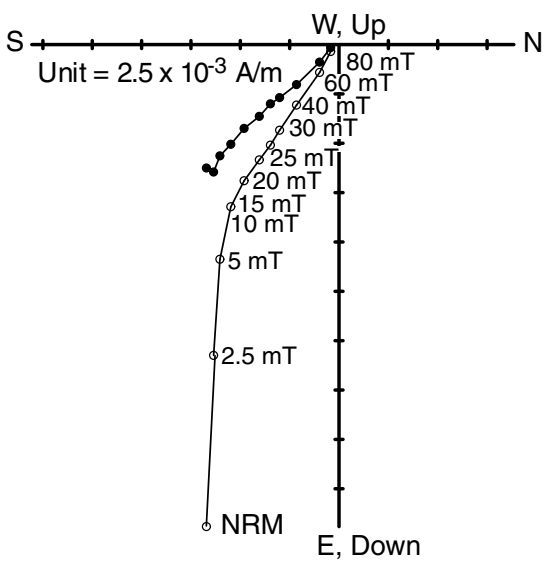

C

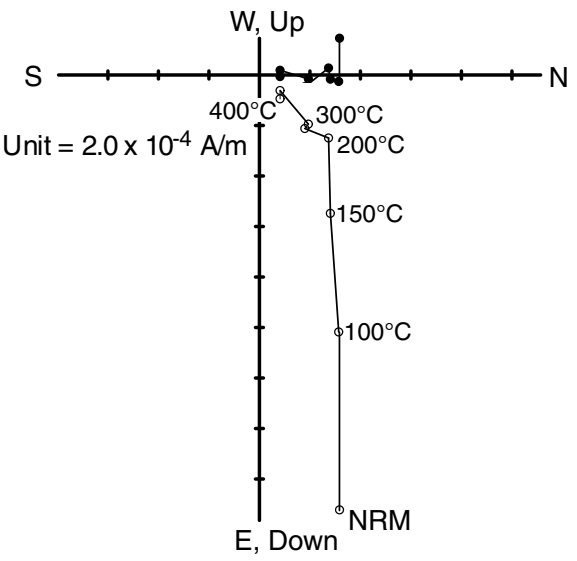

E

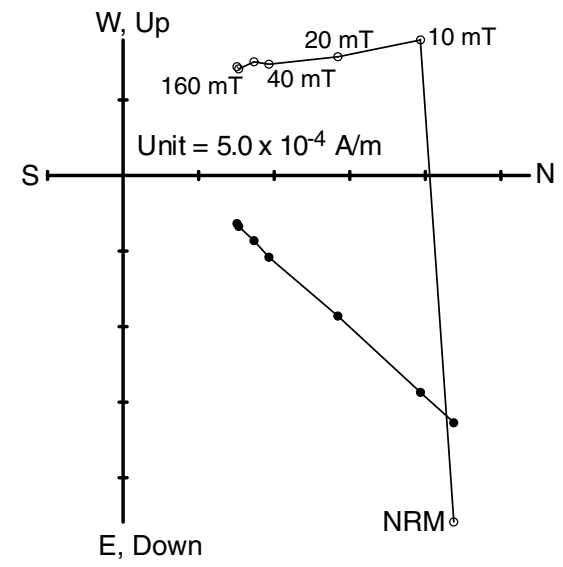

$\mathbf{B}$

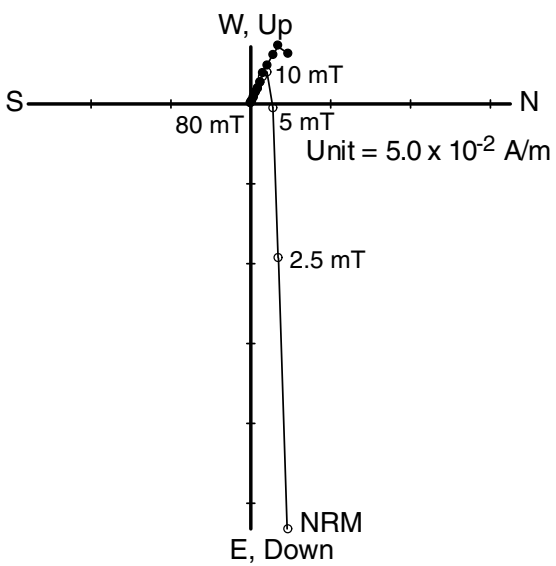

D

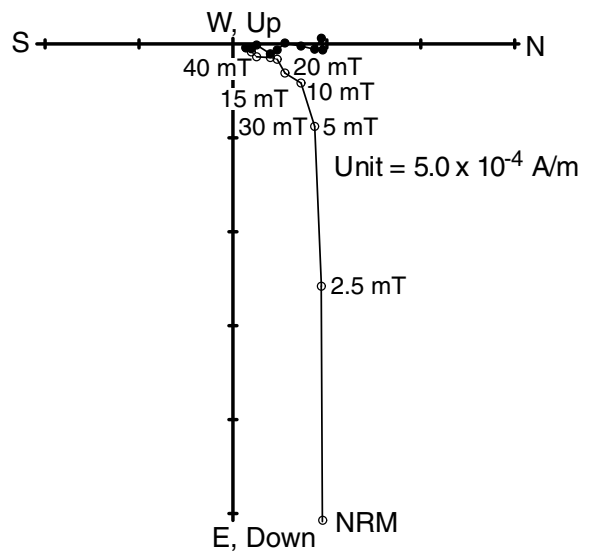


Figure F38. Directions of DIRM were estimated for samples taken from Unit II in Hole C0011B by subtracting vector components of NRM after AF demagnetization at $10 \mathrm{mT}$ from NRM before demagnetization and plotted on a stereo plot. Solid circles $=$ projected on lower hemisphere. Mean direction shows direction of very steep inclination.

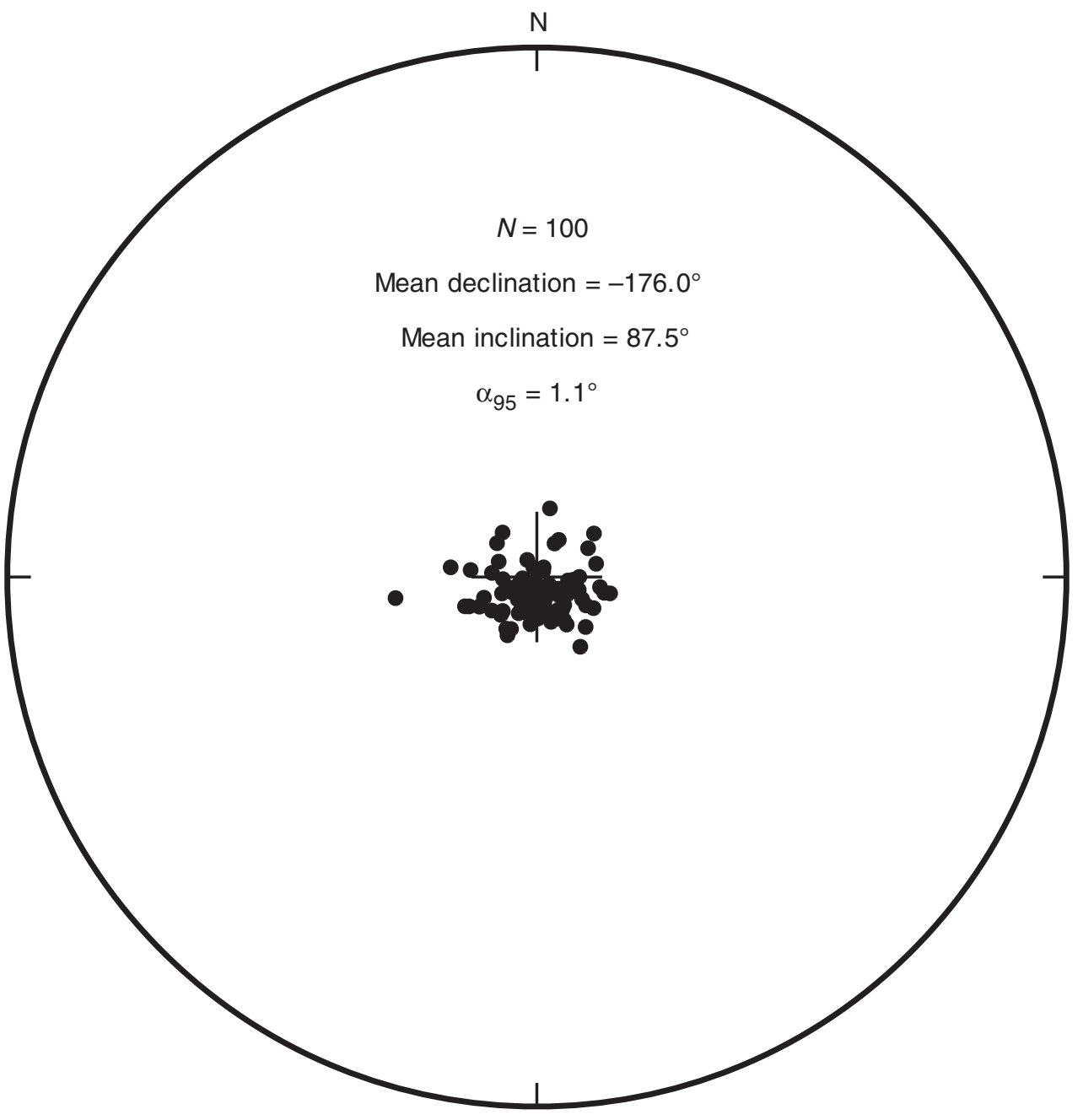


Figure F39. Demagnetization behavior, Sample 322-C0011B-7R-6, 11-13 cm (398.38 m CSF). Sample was sliced into three specimens. Vector endpoint diagrams shown for each specimen (A) top, (B) middle, and (C) bottom. Open and solid circles $=$ projection of magnetization vector endpoints onto vertical and horizontal planes, respectively. D. Inclinations after AF demagnetization at $10 \mathrm{mT}$ and inclinations of vector components after subtracting natural remanent magnetization (NRM) at $10 \mathrm{mT}$ from those before demagnetization plotted with inclination by linear regression fitting. E. Magnetization intensity after AF demagnetization at $10 \mathrm{mT}$ and intensity of the vector components after subtracting NRM at $10 \mathrm{mT}$ from those before demagnetization.

A

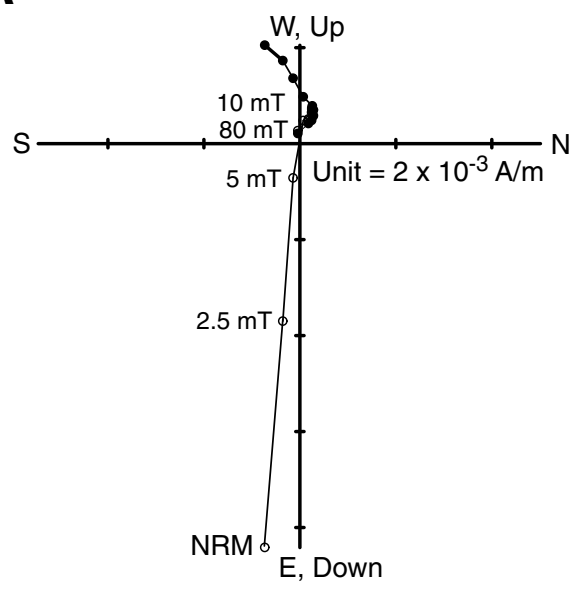

B
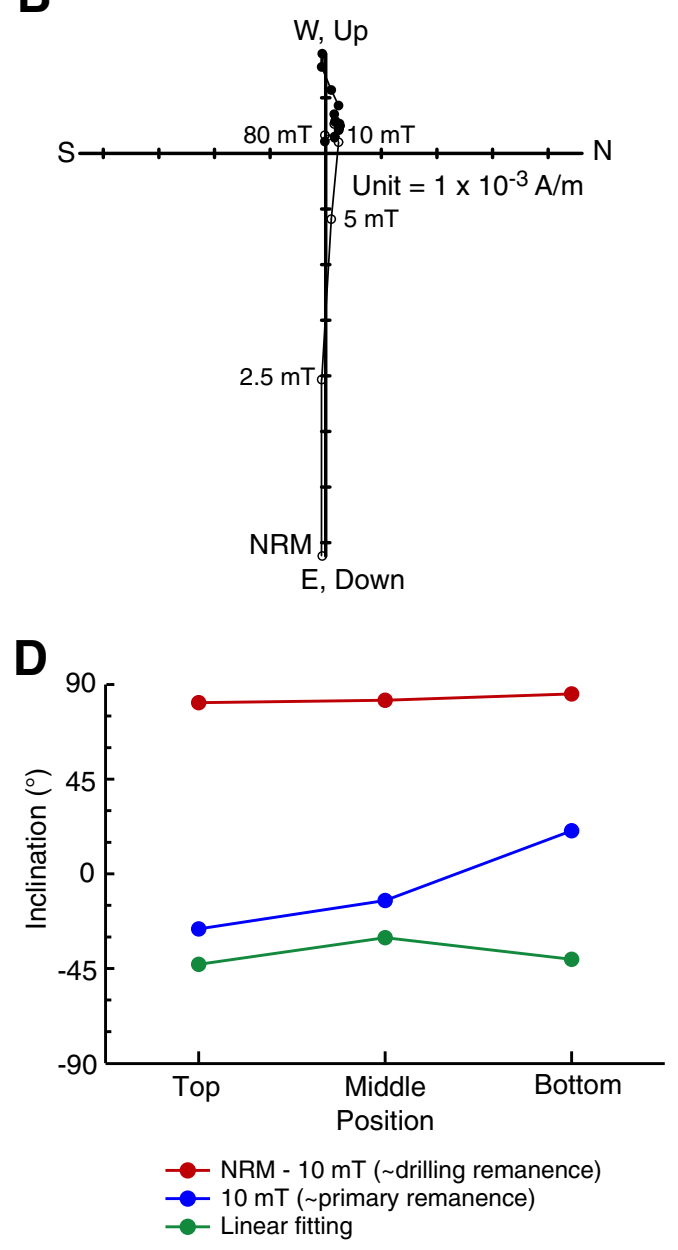

Sample 322-C0011B-7R-6, 11-13 cm

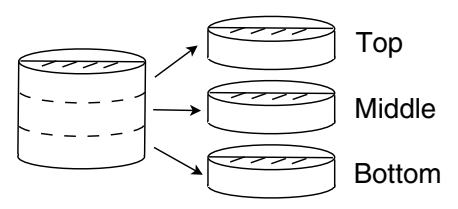

C

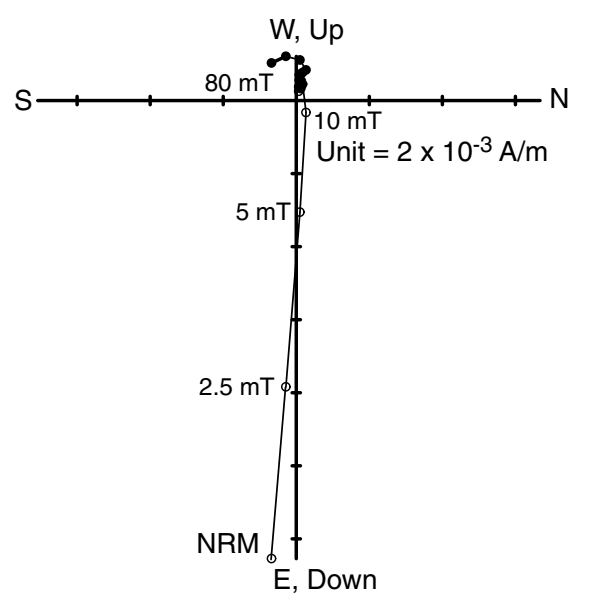

E

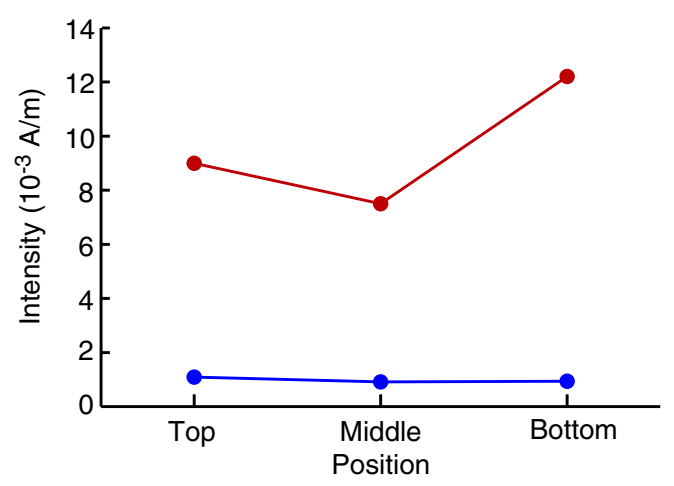


Figure F40. Vector endpoint diagrams of magnetization directions for samples showing persistent DIRM through (A) stepwise AF demagnetization (Sample 322-C0011B-16R-1, 35-37 cm) and (B) thermal demagnetization (Sample 322-C0011B-16R-1, 38-40 cm). Open and solid circles = projection of magnetization vector endpoints onto vertical and horizontal planes, respectively.

A

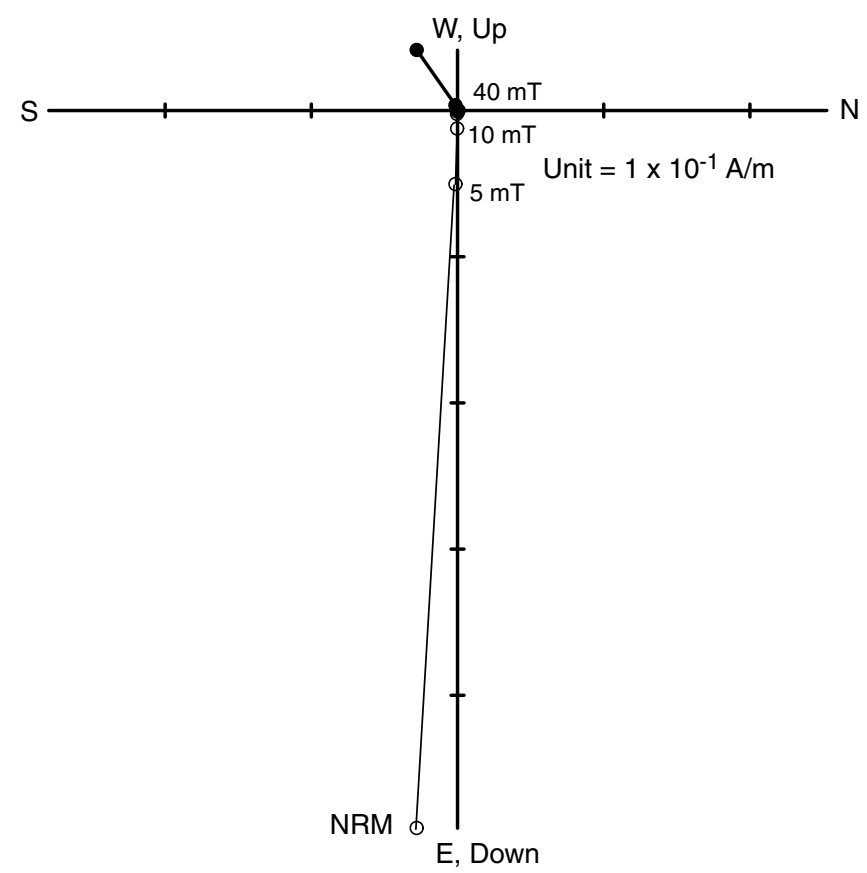

B

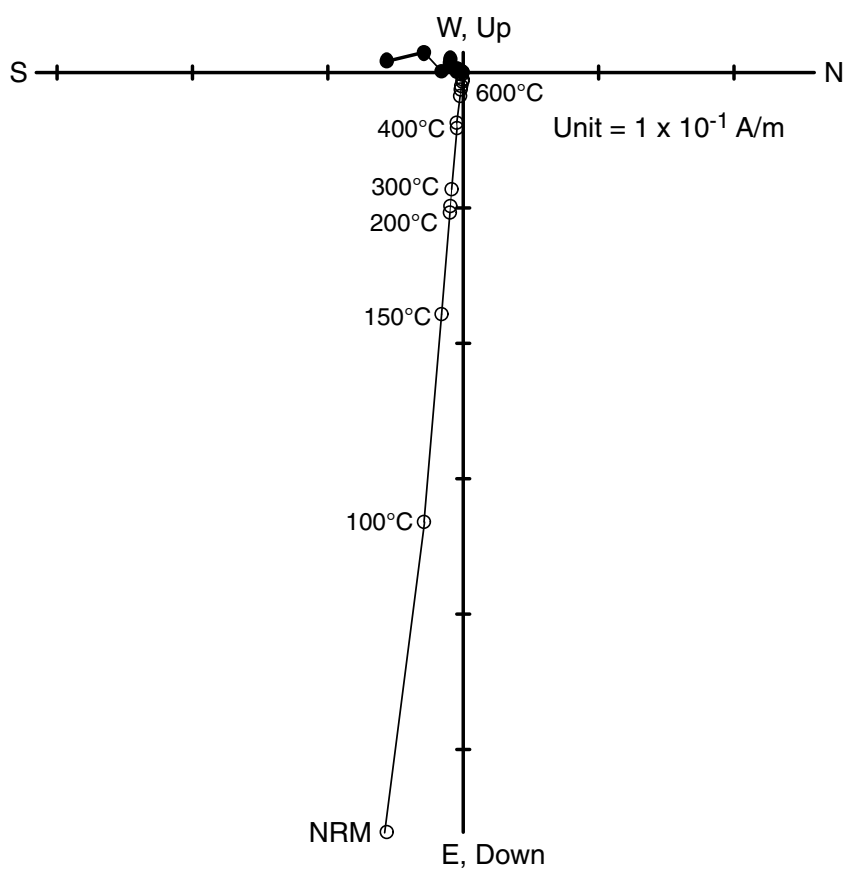


Figure F41. Depth profile showing short reversed polarity interval found at base of lithologic Unit V. From left to right: inclination, magnetization intensity (blue = NRM before demagnetization, red = NRM after AF demagnetization at $10 \mathrm{mT}$ ), and magnetic susceptibility.

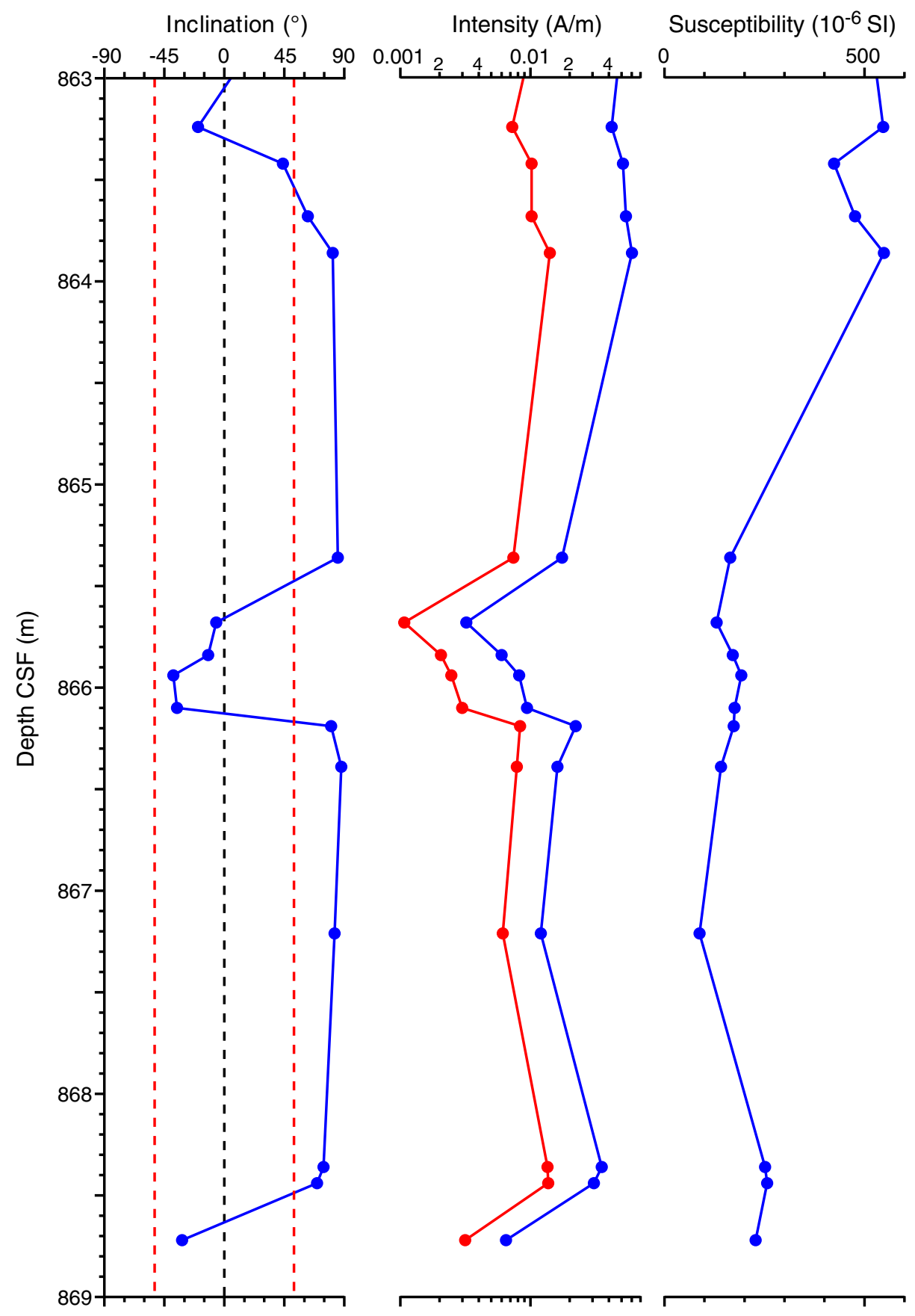


Figure F42. Age models, Hole C0011B. A. Age model for nannofossil and magnetostratigraphy produced separately. Depths of nannofossil and magnetostratigraphic datum events identified for Hole C0011B and listed in Table T11 are plotted versus expected ages. Vertical bars = uncertainty of depth, nannofossil horizontal error bars = uncertainty between oceans (Pacific/Atlantic/Mediterranean). Sedimentation rate is calculated based on least squares fitting by linear regression line using the datum events with equal weight. For magnetostratigraphy, error bars represent uncertainty of polarity boundary recognition. Errors on astronomical tuning of ATNTS2004 (Lourens et al., 2004) for age interval involved are typically $<0.2 \%$ (smaller than the radius of circles). Purple ages shown on lines representing unit boundaries are boundary ages estimated from magnetostratigraphic control points (purple curve) including errors of control points and linear fitting. (Continued on next page.)

A

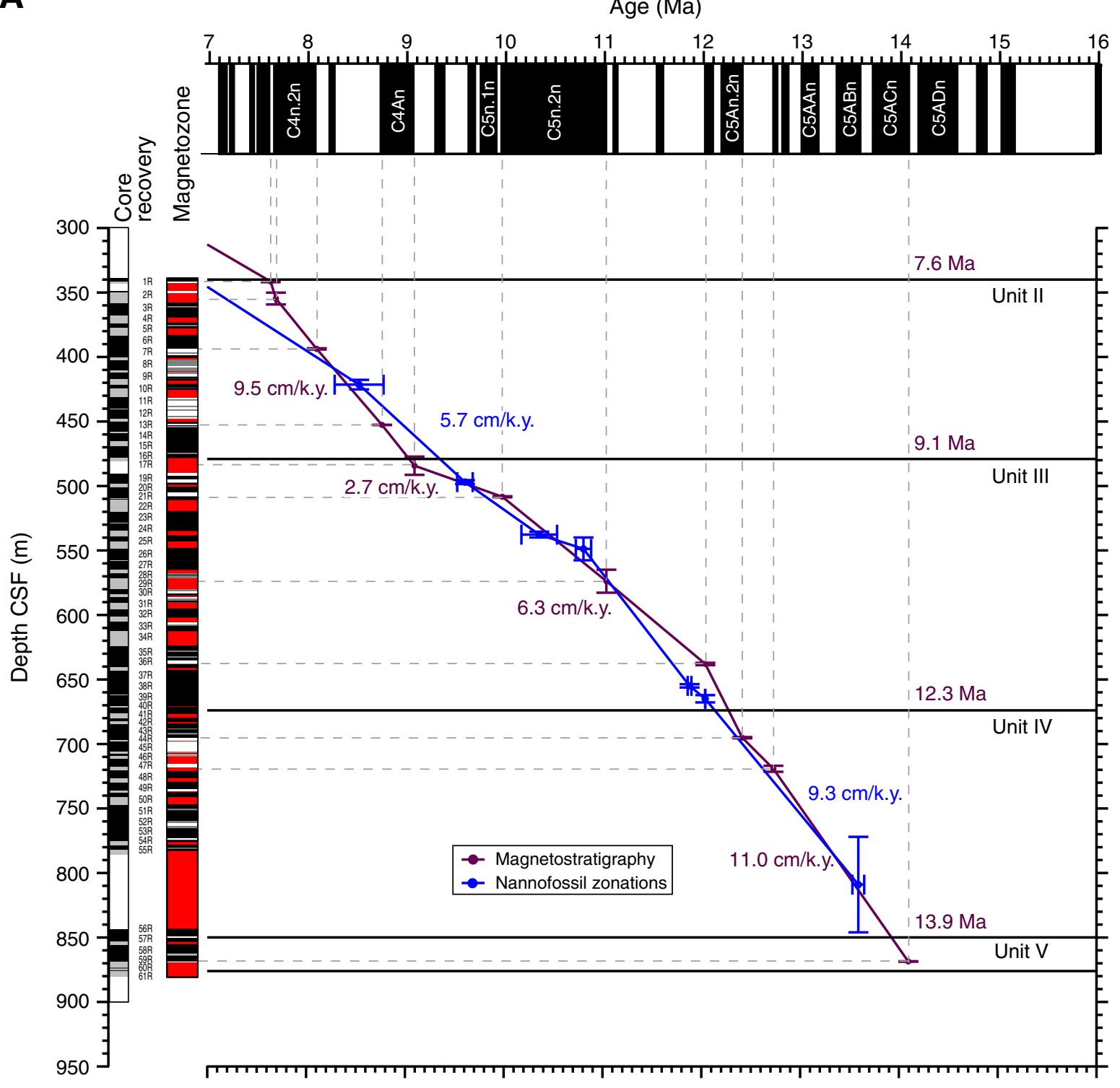


Figure F42 (continued). B. Composite age model using magnetostratigraphic and nannofossil datum events. Sedimentation rate is calculated based on linear regression of the datum events with equal weight on nannofossil and magnetostratigraphy within each depth interval. Ages shown on lines representing unit boundaries are boundary ages estimated from the composite age model including errors of control points and linear fitting.

B Age (Ma)

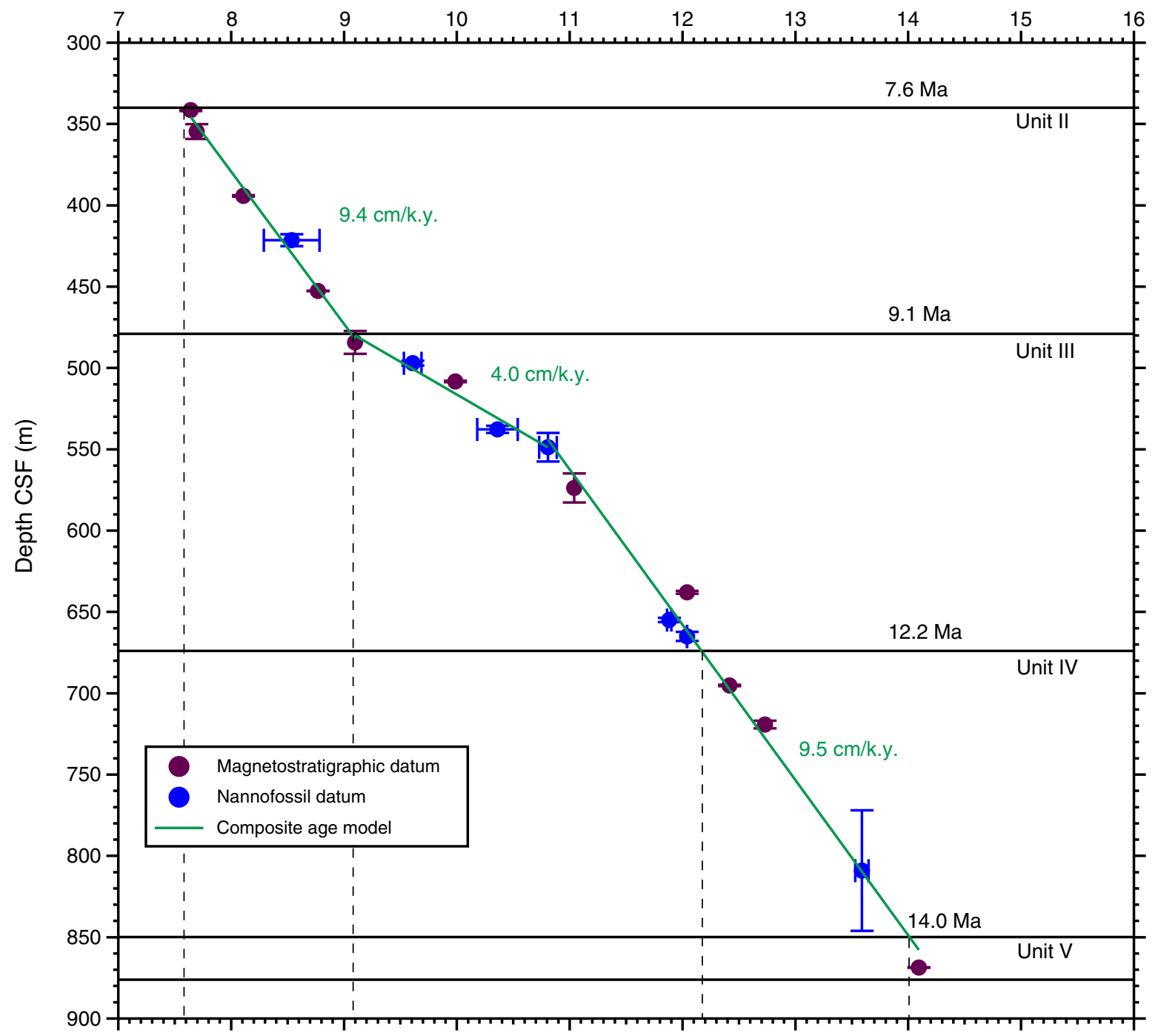


Figure F43. Results of composite IRM acquisition and thermal demagnetization experiments. A. Equal area projection of magnetization directions after imparting magnetic field with a pulse magnetizer in (1) $+Z(2.9 \mathrm{~T})$, $(2)+y(0.4 \mathrm{~T})$, and $(3)+x(0.12 \mathrm{~T})$ successively on Samples 322-C0011B-3R-4, 8-10 cm (blue; tuffaceous sandstone), and 6R-1, 34-36 cm (red; silty claystone). Open circles = projection onto lower hemisphere, closed circles $=$ projection onto upper hemisphere. Note the acquisition of magnetization for Sample 322-C0011B-3R-4, 8-10 cm (blue), in opposite directions of pulse magnetic field. B. Magnetization change through stepwise thermal demagnetization from room temperature to $600^{\circ} \mathrm{C}$ on Sample 322-C0011B-3R-4, 8-10 cm, after IRM acquisition. Polarity of $x$ magnetization component ( $0.12 \mathrm{~T}$ : low-coercivity component) changes from negative to positive at temperatures between $400^{\circ} \mathrm{C}$ and $450^{\circ} \mathrm{C}$. C. All three magnetization components for Sample 322C0011B-6R-1, 34-36 cm, show shift from positive to negative between $450^{\circ} \mathrm{C}$ and $500^{\circ} \mathrm{C}$. D. Close-up of Sample 322-C0011B-6R-1, 34-36 cm, shows unblocking temperature of $\sim 350^{\circ} \mathrm{C}$ for low- (blue; $0.12 \mathrm{~T}$ ), medium- (red; $0.4 \mathrm{~T}$ ), and high- (green; $2.9 \mathrm{~T}$ ) coercivity components.

A

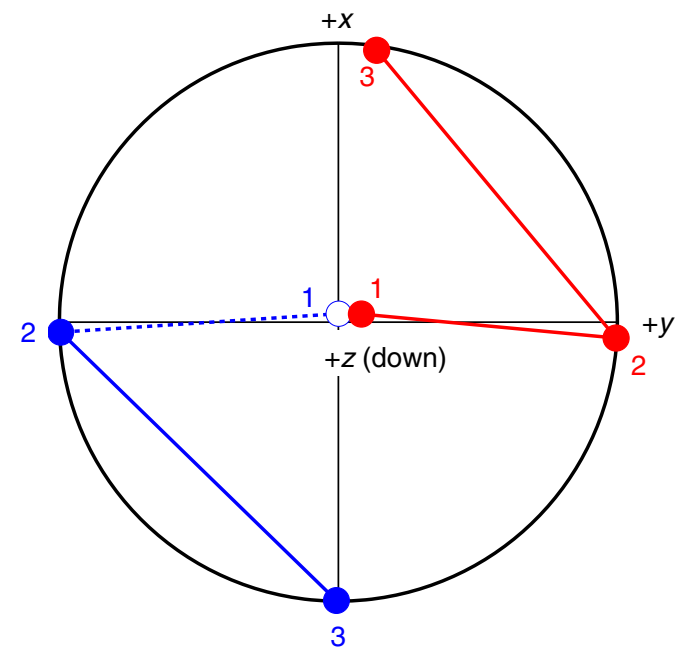

B

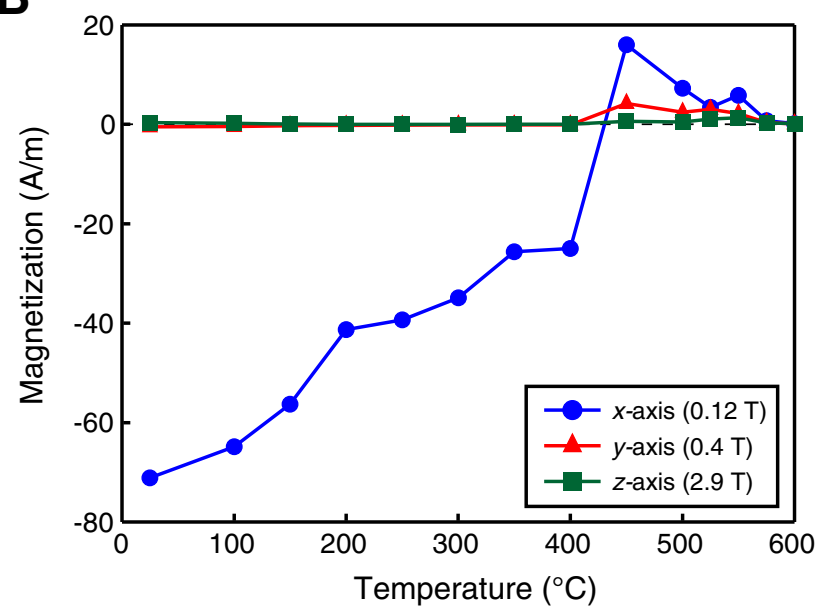

C

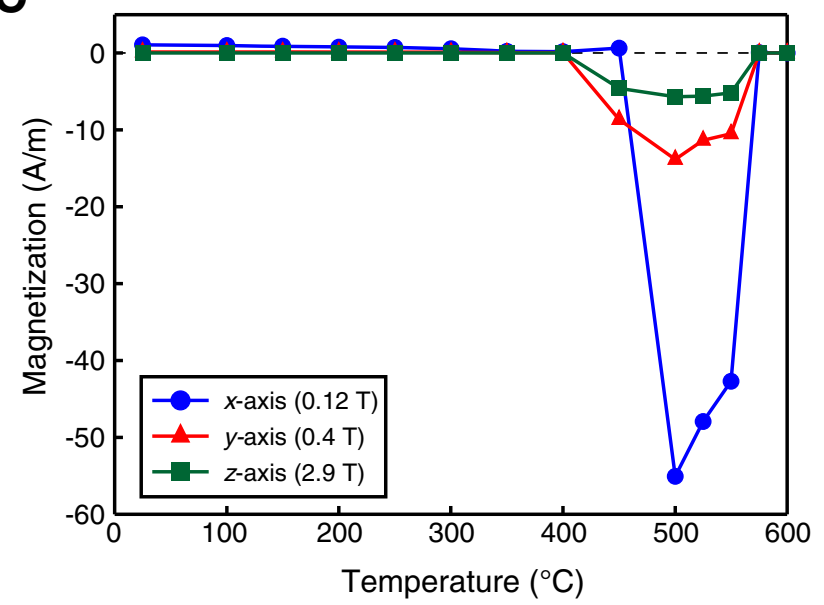

D

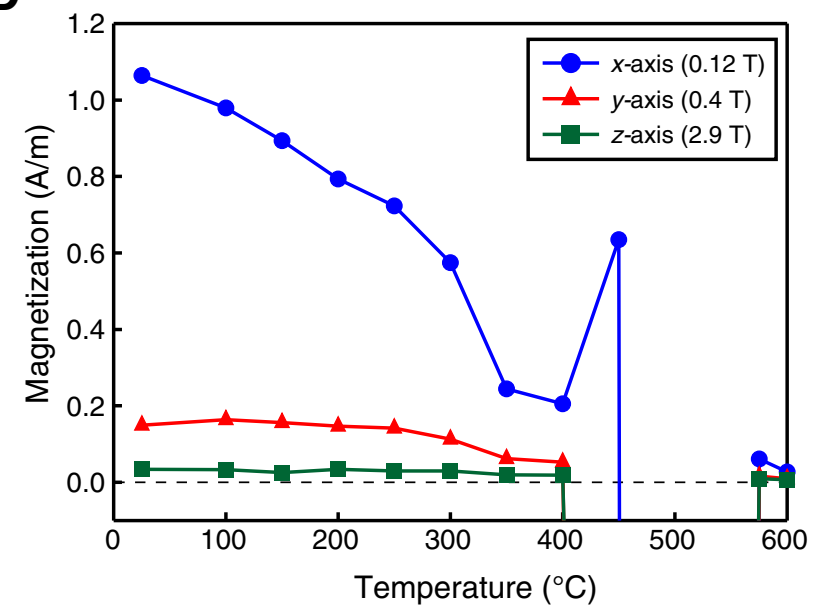


Figure F44. A. AMS principal axes projected onto lower hemisphere of equal area plot for Samples 322-C0011B$12 \mathrm{R}-5,15-17 \mathrm{~cm}$ (blue; silty sandstone), and $12 \mathrm{R}-7,9-11 \mathrm{~cm}$ (green; silty claystone). Rectangles $=K_{\max }$, triangles $=K_{\text {int }}$, circles $=K_{\min }$. Small symbols $=$ directions before demagnetization, large symbols $=$ directions after demagnetization. B. T (shape parameter) plotted versus P' (degree of anisotropy) for Samples 322-C0011B-12R-5, 15$17 \mathrm{~cm}$ (blue; silty sandstone), and 12R-7, 9-11 cm (green; silty claystone). Small symbols = directions before demagnetization, large symbols = directions after demagnetization. Note change in anisotropy parameter for silty claystone, but results are almost identical for silty sandstone. C. From left to right: downhole plot of magnetic susceptibility, $K_{\min }$ inclination, anisotropy degree $\left(\mathrm{P}^{\prime}\right)$, and shape parameter $(\mathrm{T})$ for tuffaceous/volcaniclastic sandstones and silty sandstones of Unit II.

A

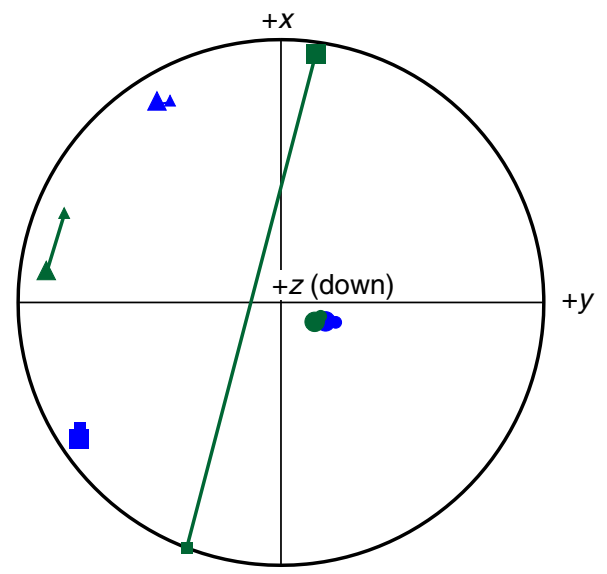

B

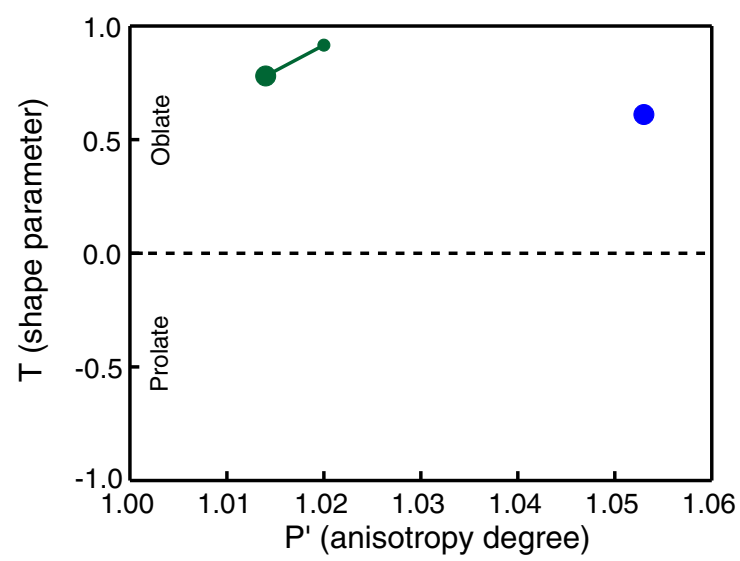

C

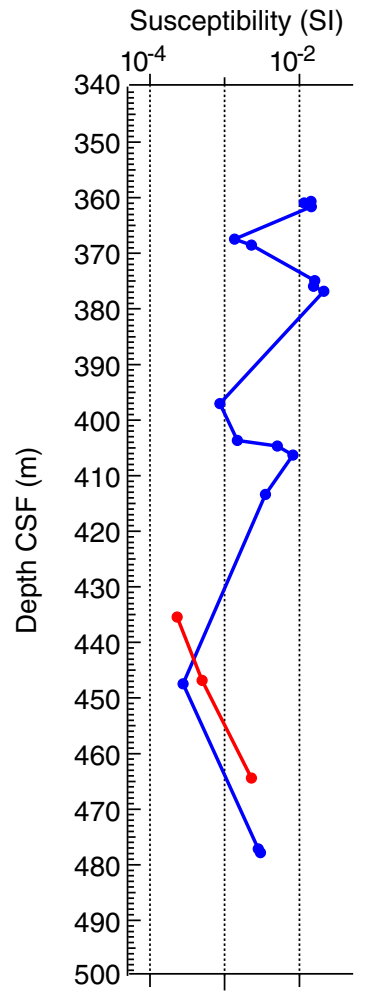

$K_{\min }$ inclination $\left({ }^{\circ}\right)$

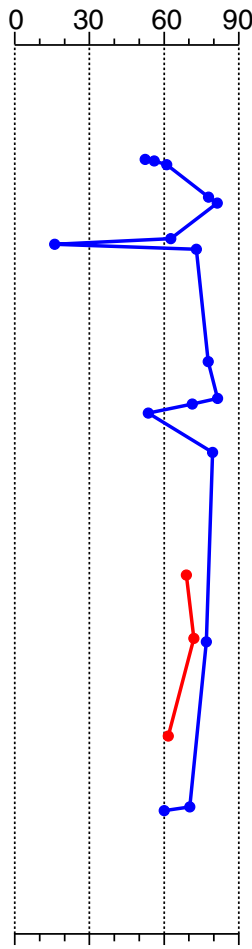

Anisotropy degree $\left(\mathrm{P}^{\prime}\right)$ Shape parameter $(\mathrm{T})$

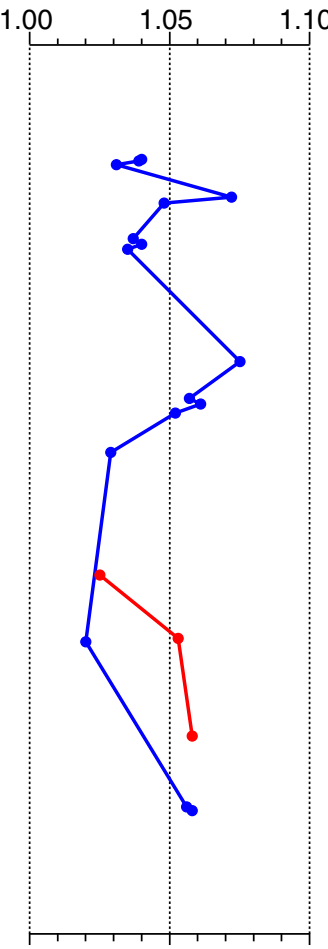

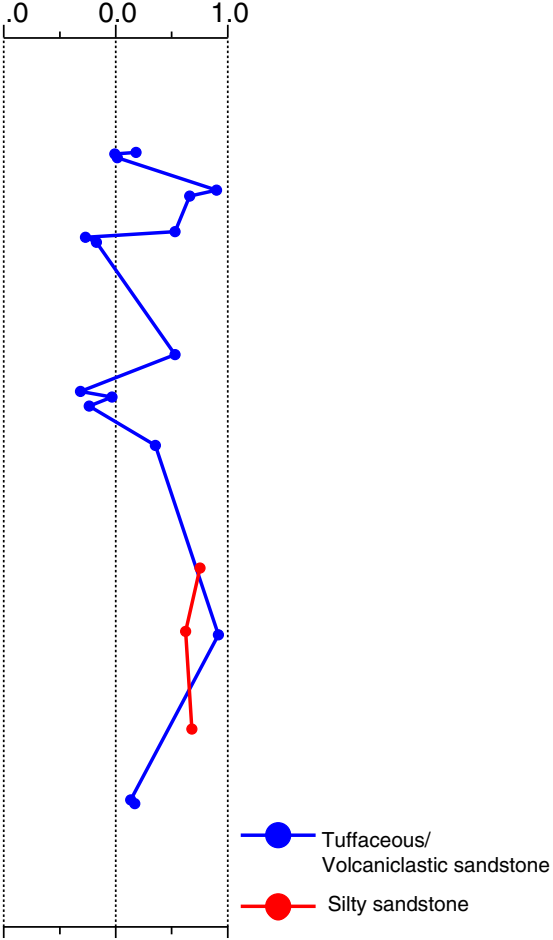


Figure F45. A. Plot of volume magnetic susceptibility versus depth measured with Kappabridge (blue circles) and multisensor core logger (MSCL) loop sensor (solid line). B. MSCL magnetic susceptibility after correction (CMS) plotted versus Kappabridge magnetic susceptibility (blue crosses) with a line of slope = 1 (broken line).

A

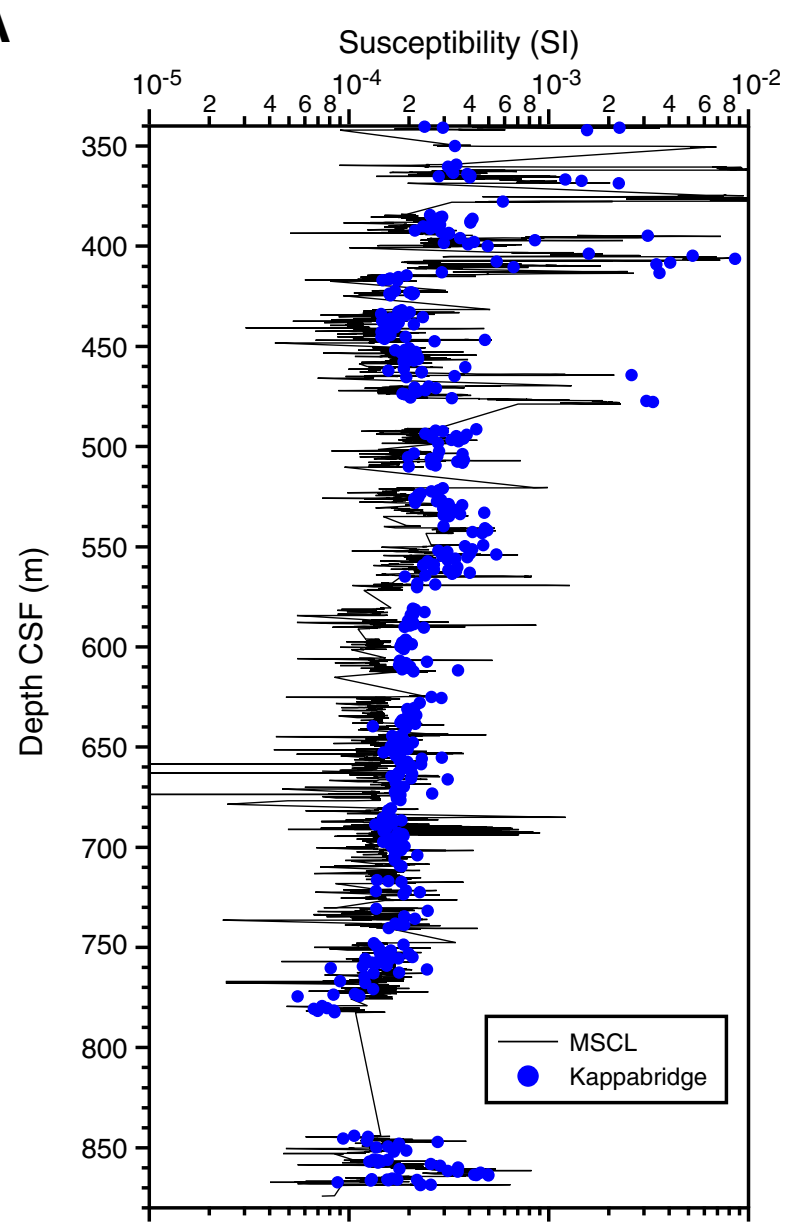

B
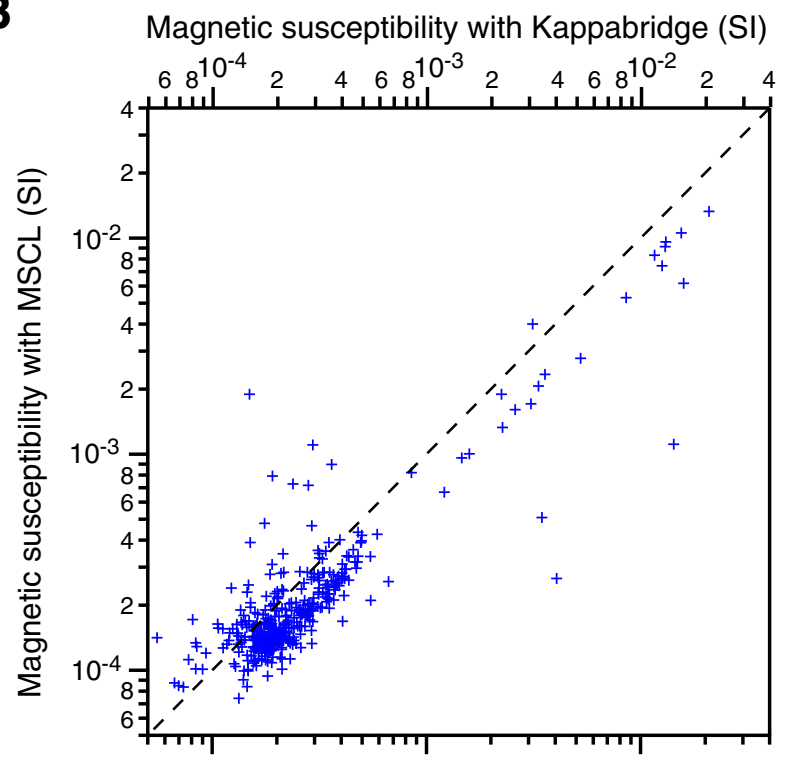
Figure F46. Gamma ray attenuation (GRA) density, magnetic susceptibility, noncontact electrical resistivity, and natural gamma radiation. Determined by MSCL-W. CMS = corrected volume magnetic susceptibility, cps = counts per second.
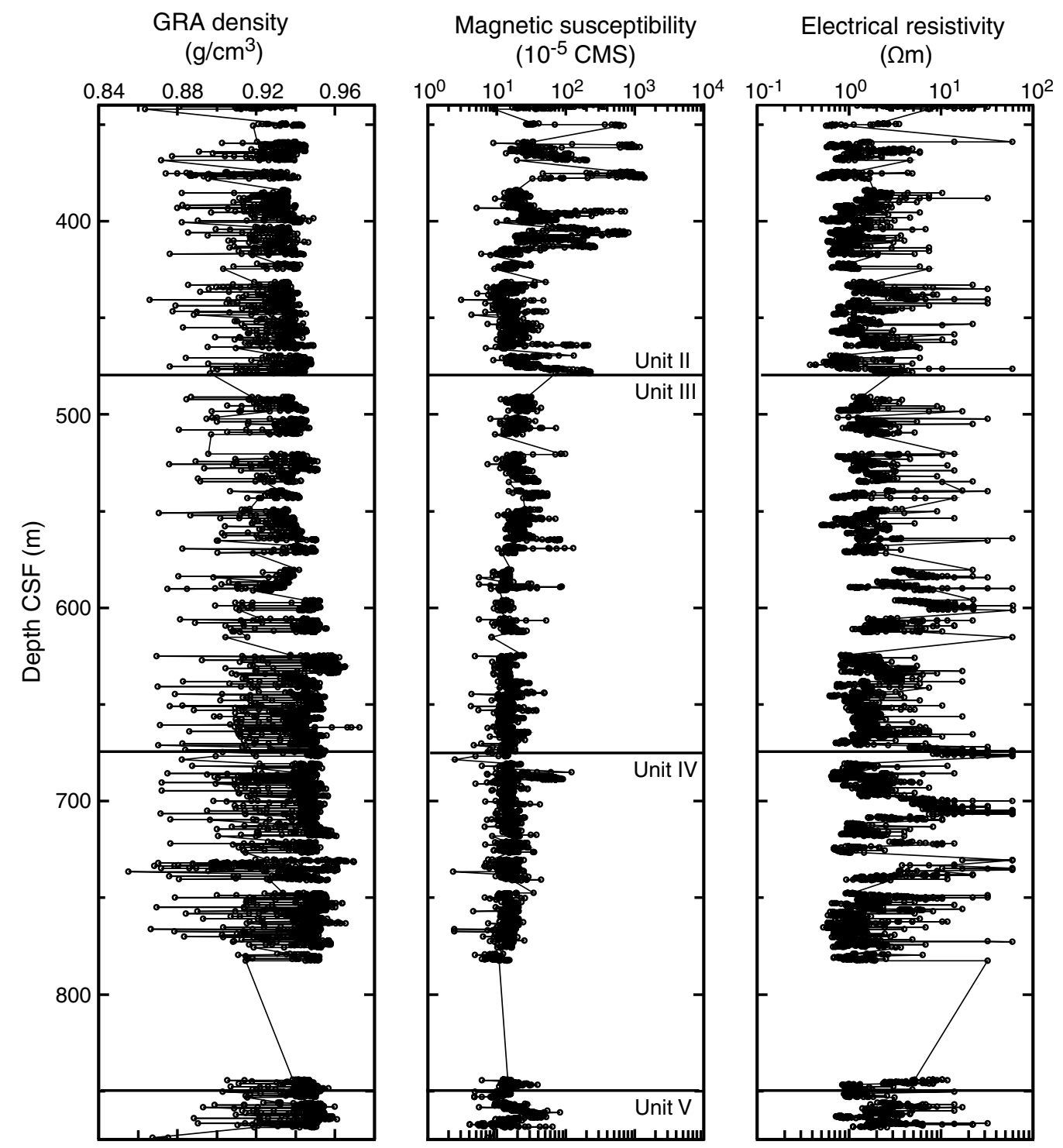
Natural gamma radiation (cps)

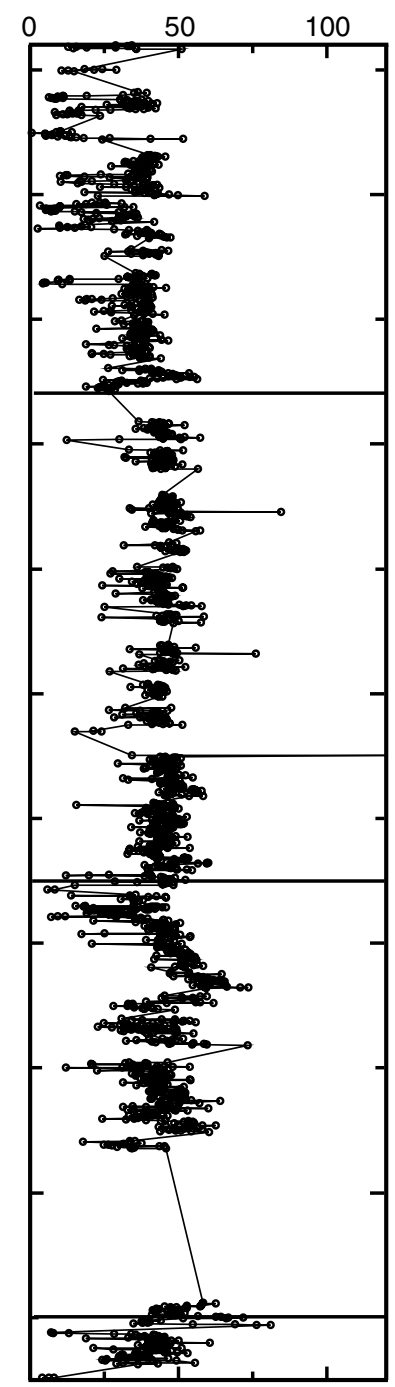


Figure F47. Depth-shifted LWD data from Hole C0011A showing resistivity image, seismic section, logging units, log-based lithologic interpretation, gamma ray, ring resistivity, and structural data and bedding dips. $\mathrm{VE}=$ vertical exaggeration .

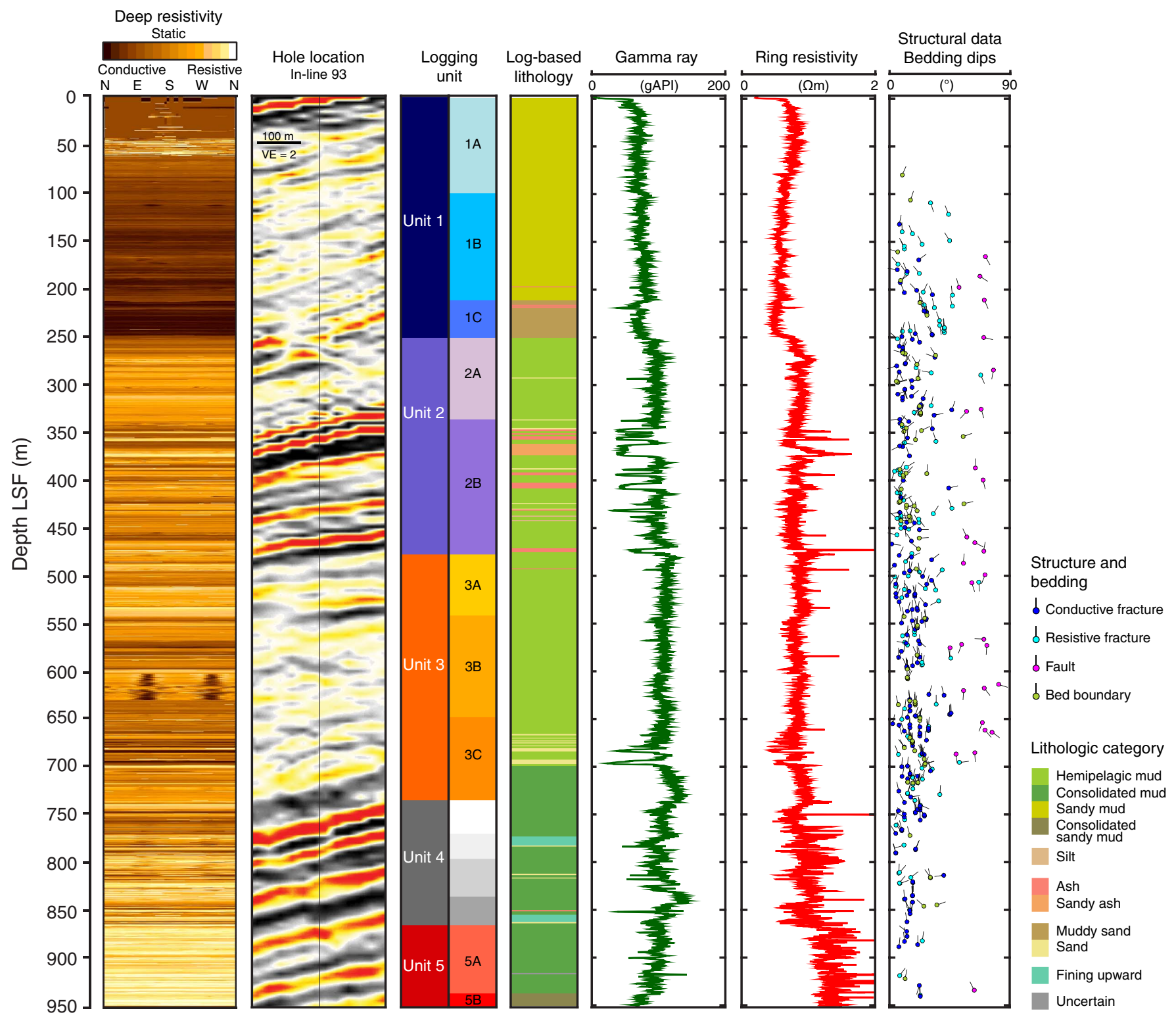


Figure F48. (A) Bulk and grain density and (B) porosity of discrete mudstone and sandstone samples determined by MAD measurements. Solid line in $\mathrm{B}=$ modeled porosity-effective stress behavior assuming hydrostatic fluid pressure. C. $P$-wave velocity measurements on cube samples in $x-, y$-, and $z$-direction of core reference frame. $\mathbf{D}$. Thermal conductivity measurements on mudstone and sandstone. Diamonds = half-space method, pluses = full-space method.

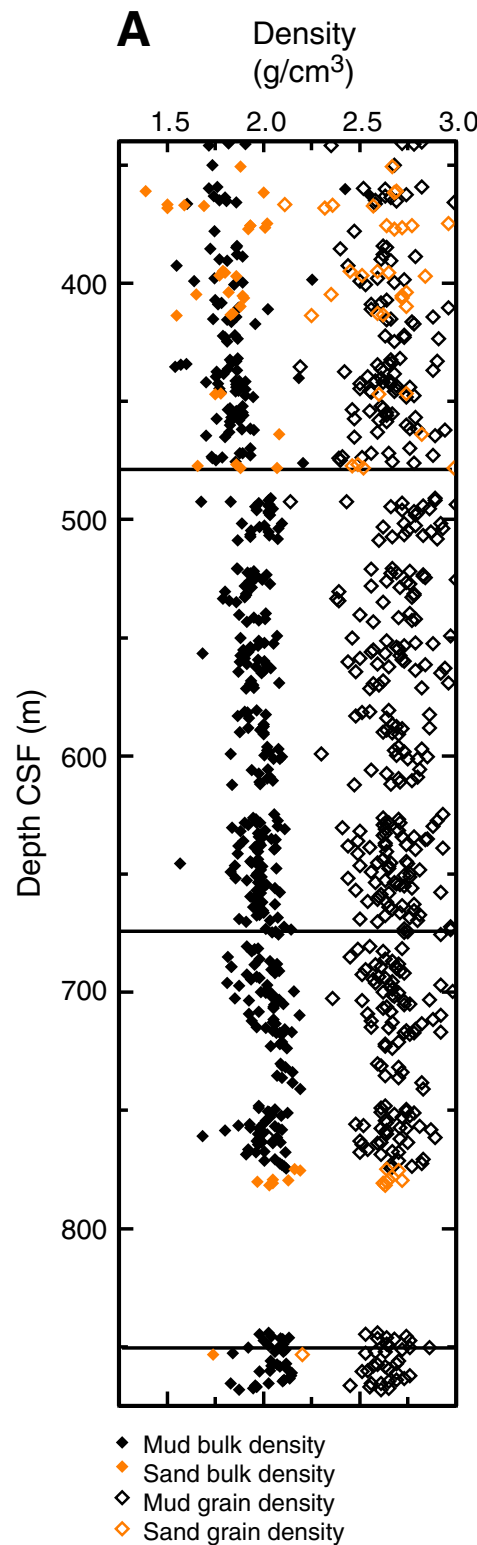

B Porosity

$(-)$

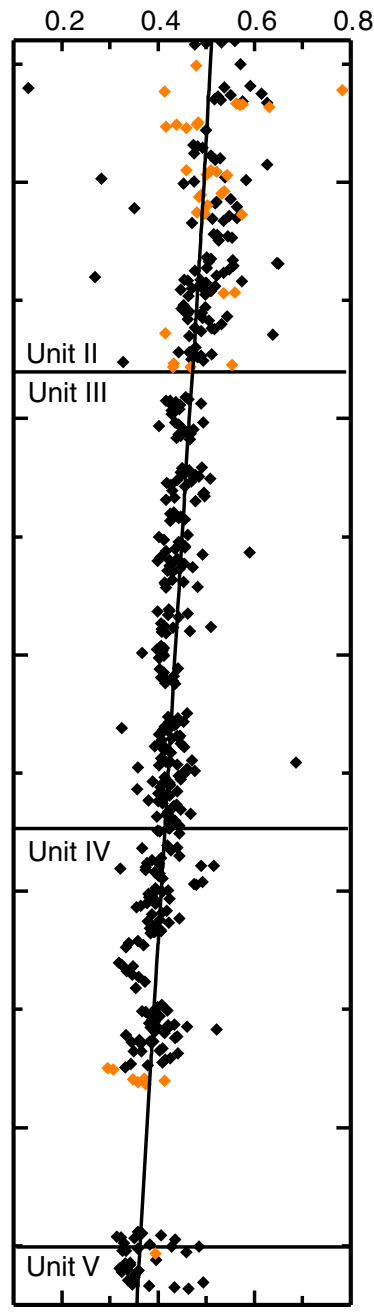

- Mud

- Sand
C $\quad v_{\mathrm{P}}$

$(\mathrm{m} / \mathrm{s})$

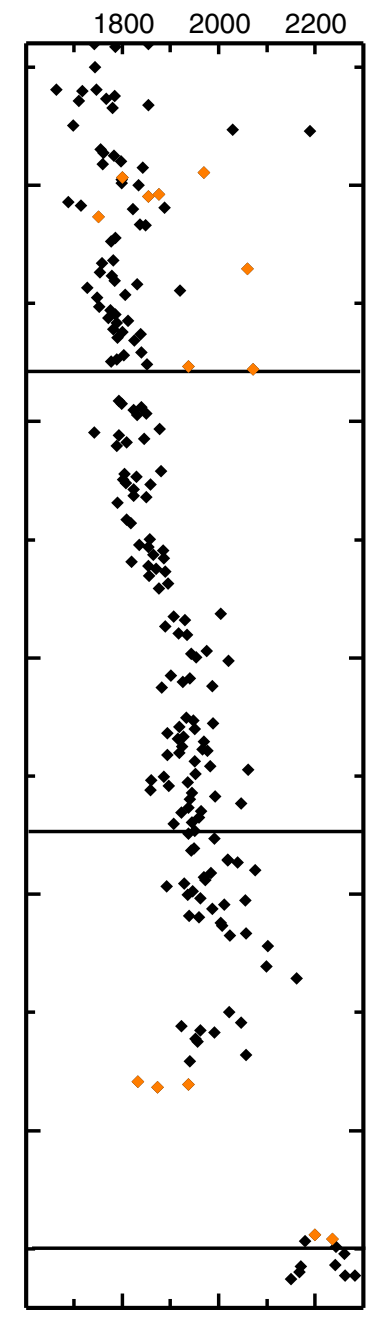

- Mud
- Sand
D Thermal conductivity $(\mathrm{W} /[\mathrm{m} \cdot \mathrm{K}])$

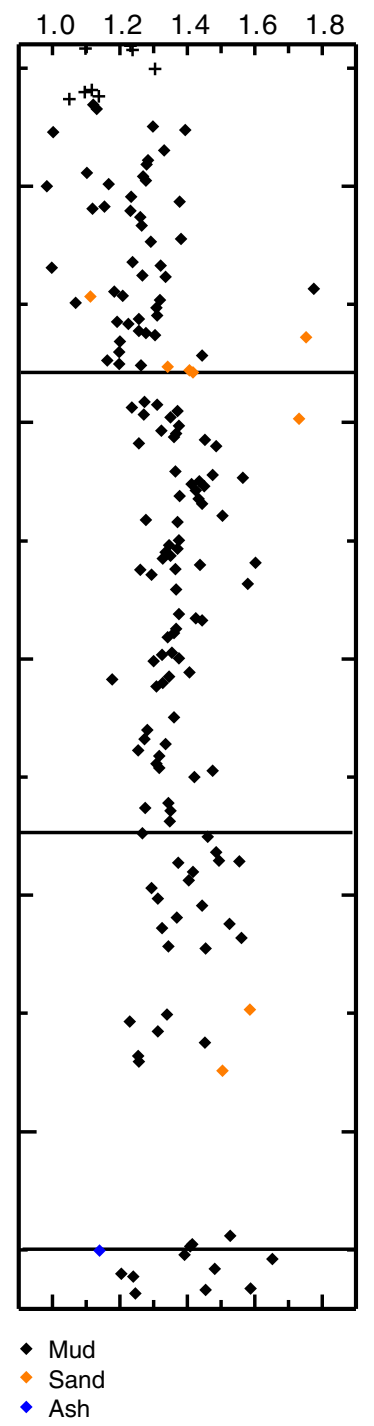


Figure F49. P-wave velocity, horizontal-plane anisotropy, and vertical-plane anisotropy on discrete cube samples, Hole C0011B. For vertical-plane anisotropy, positive values indicate horizontal $V_{\mathrm{p}}>$ vertical $V_{\mathrm{p}}$.
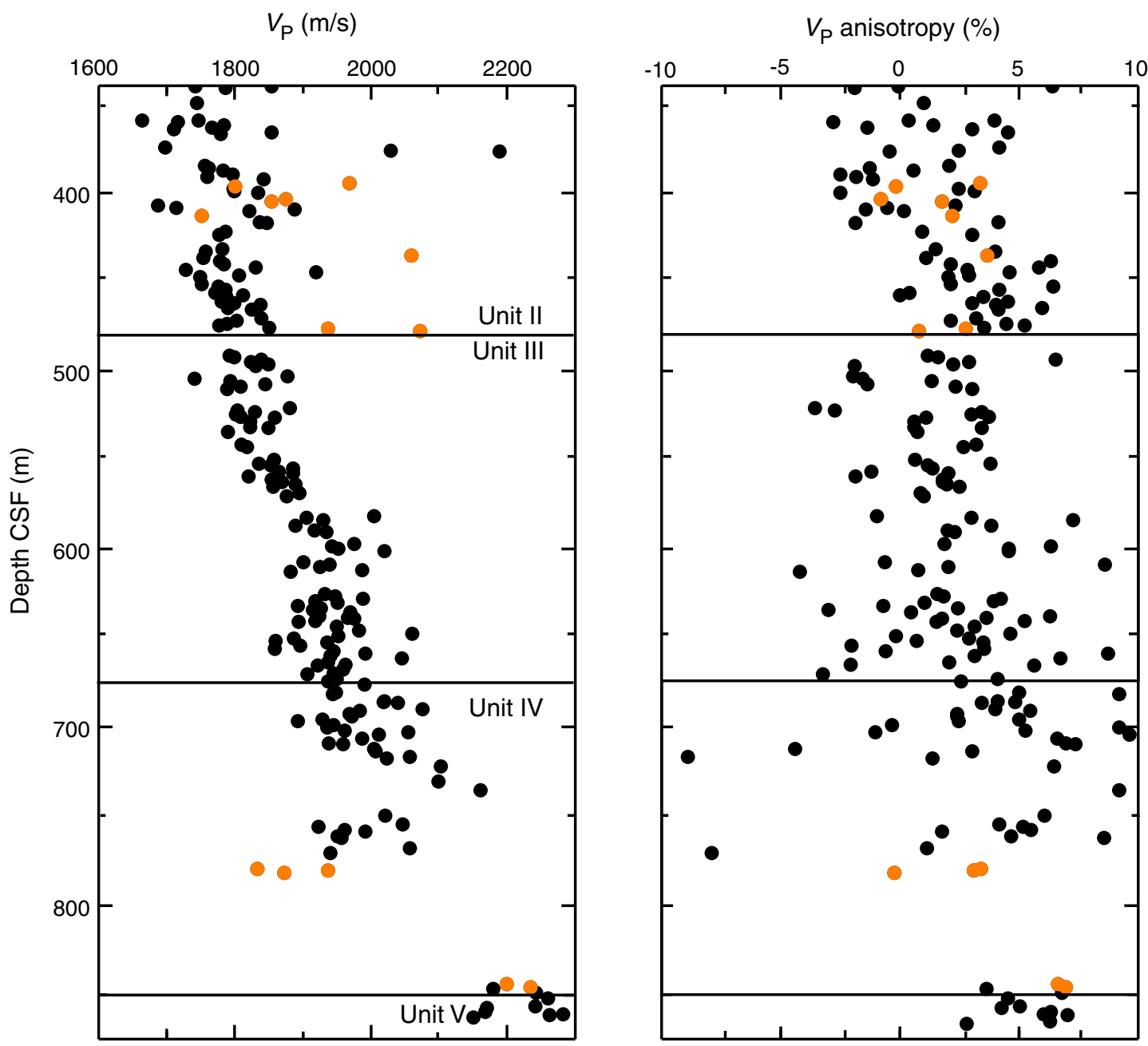

- Mud

- Sand 
Figure F50. $P$-wave velocity versus porosity for discrete samples, Hole C0011B. Solid line $=$ empirical trend for Shikoku Basin sediments defined by Hoffman and Tobin (2004), dashed lines = typical trends derived from global compilations (Erickson and Jarrard, 1998).

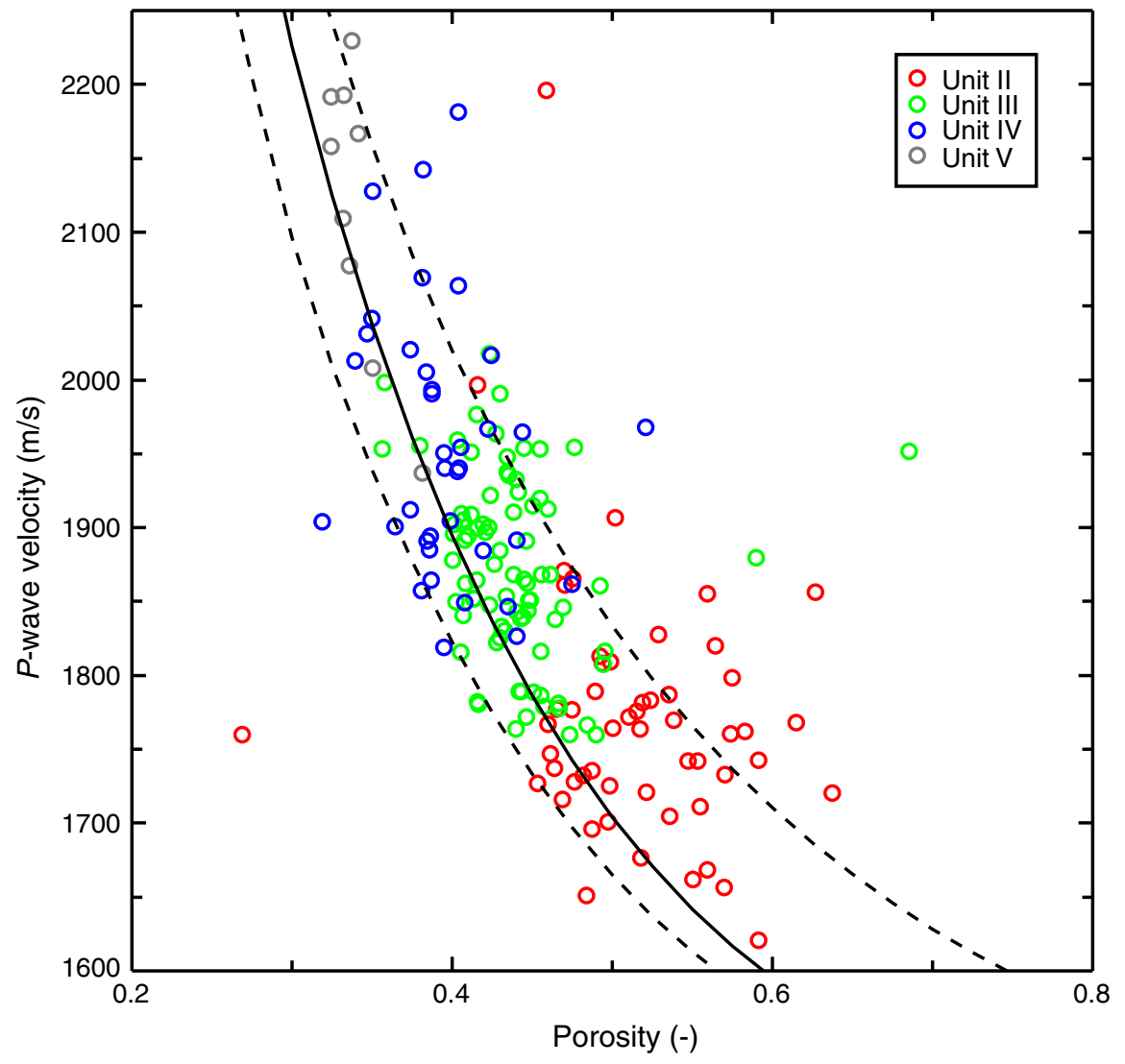


Figure F51. Electrical resistivity and vertical-plane anisotropy for discrete cube samples, Hole C0011B.
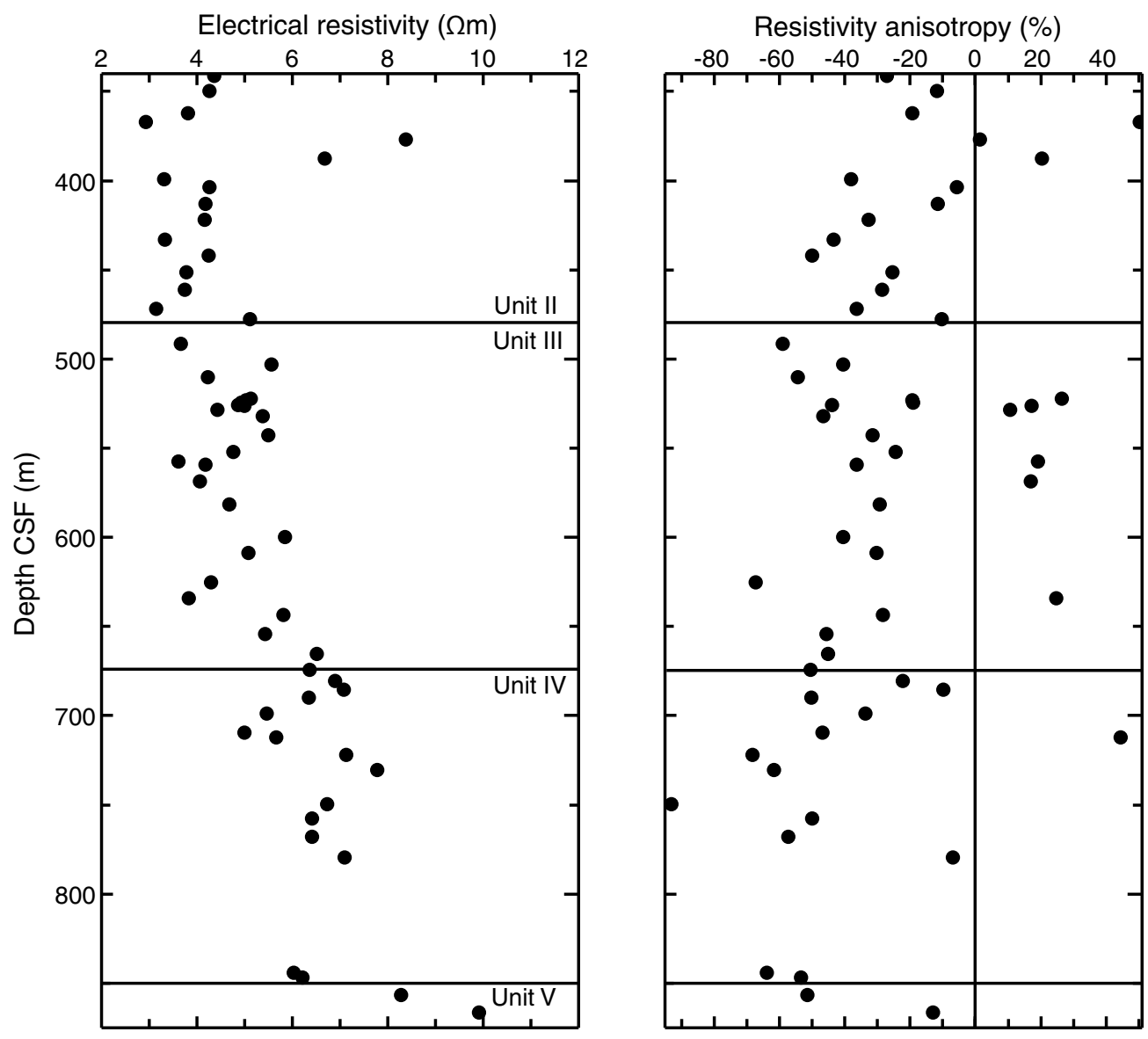
Figure F52. Porosity versus thermal conductivity of mud samples, Hole C0011B. Lines = theoretical values for different grain thermal conductivities $\left(k_{s}\right)$ based on a geometric mean mixing model.

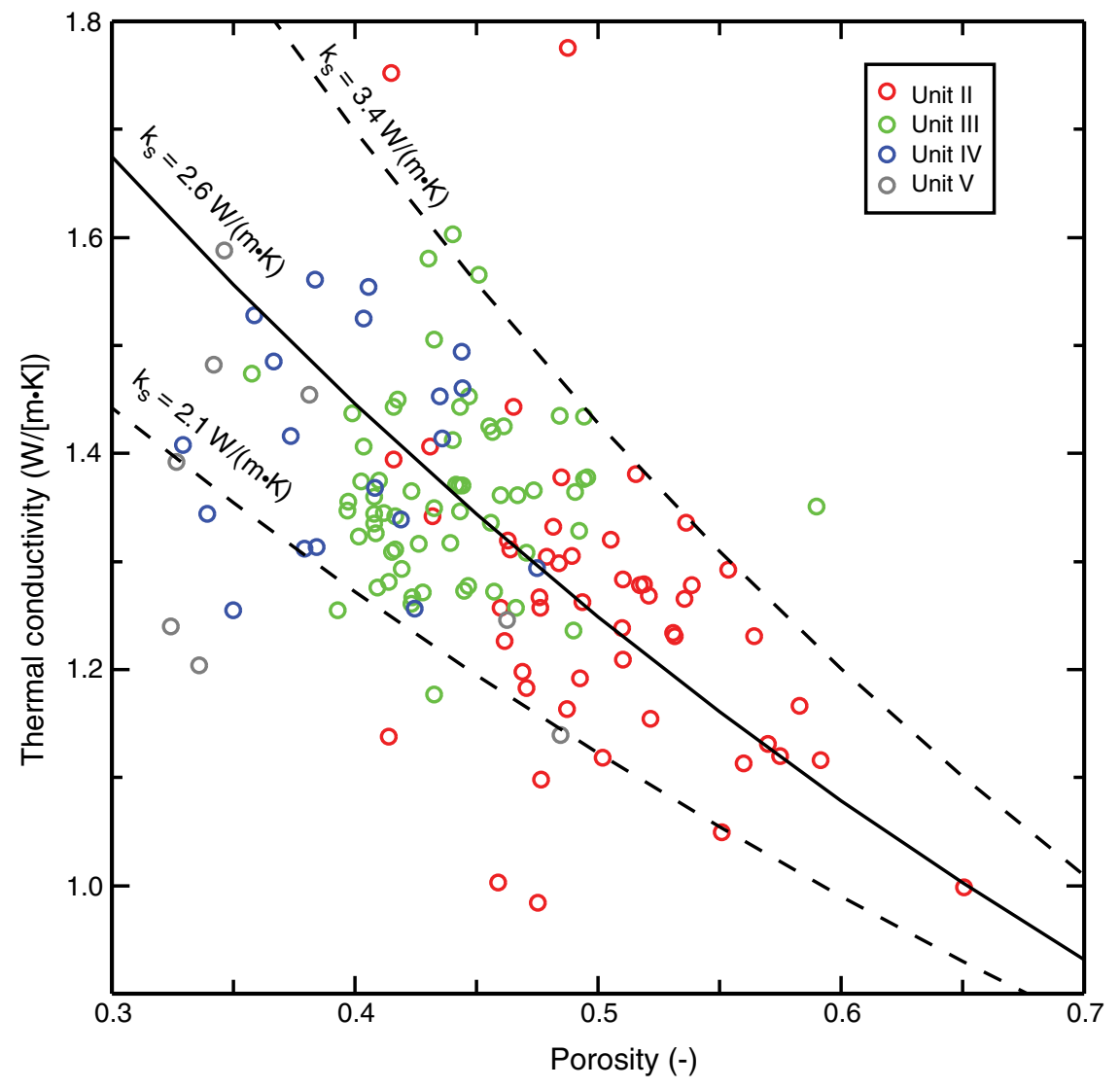


Figure F53. Porosity, $P$-wave velocity, and anisotropy of $P$-wave velocity (positive $=$ horizontal $>$ vertical), ODP Site 1177 and Site C0011.
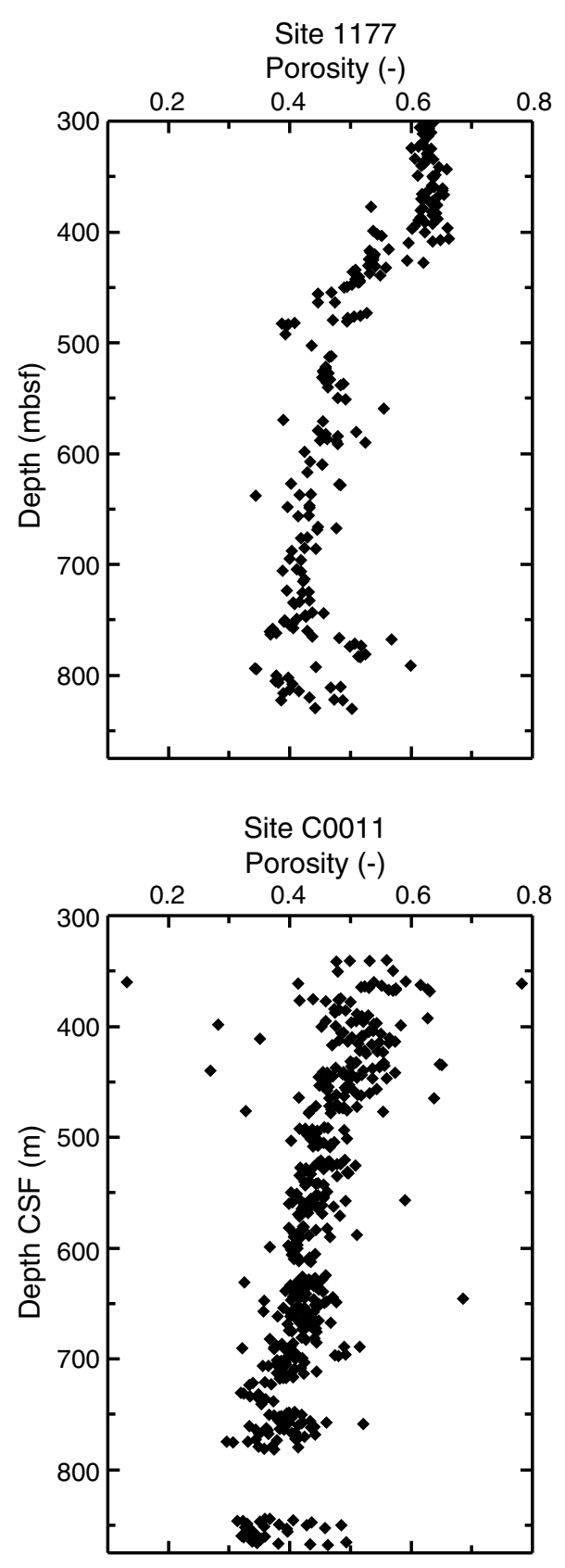

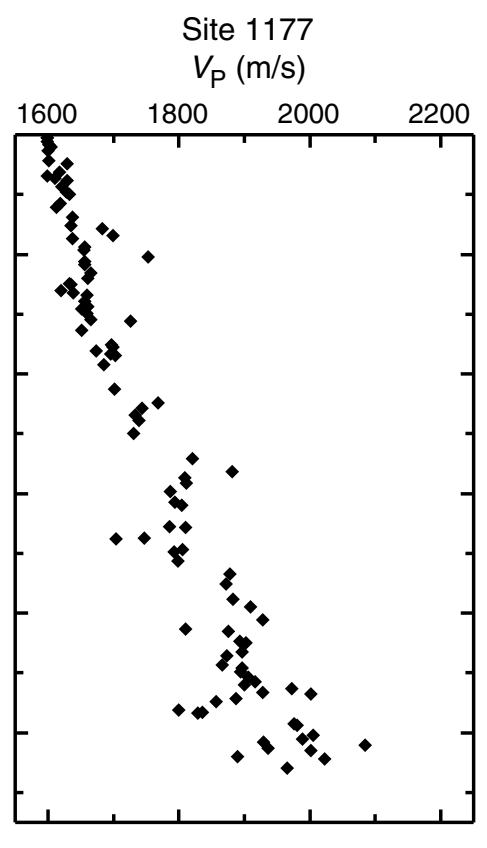

Site C0011

$V_{\mathrm{P}}(\mathrm{m} / \mathrm{s})$

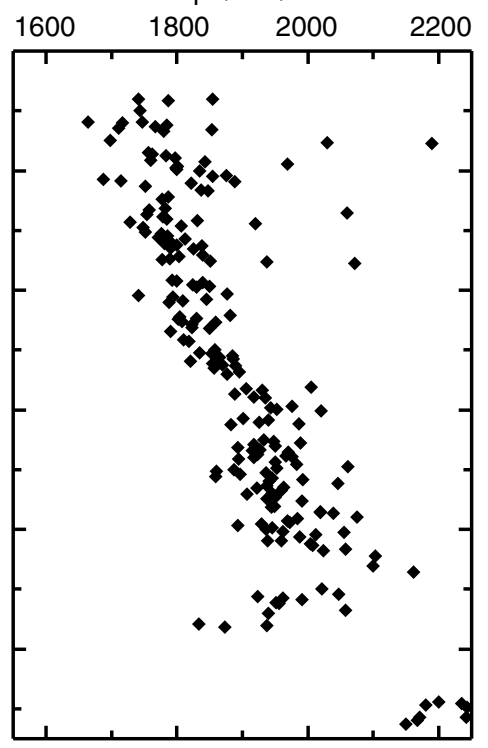

Site 1177

$V_{\mathrm{P}}$ anisotropy (\%)

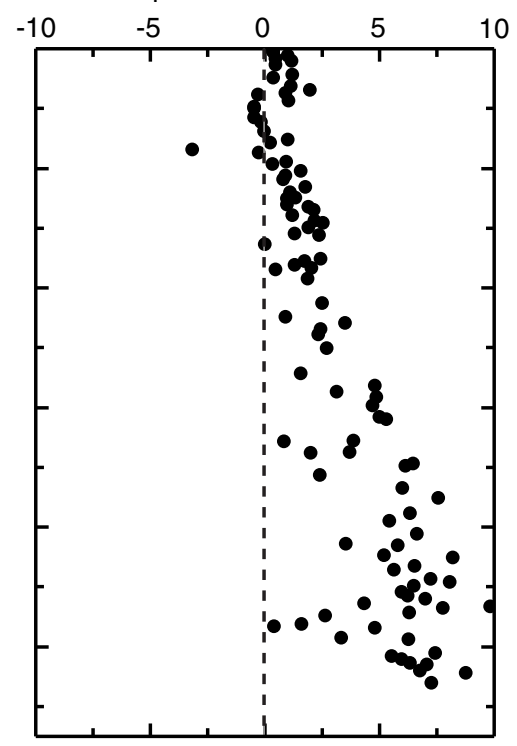

Site C0011

$V_{\mathrm{P}}$ anisotropy (\%)

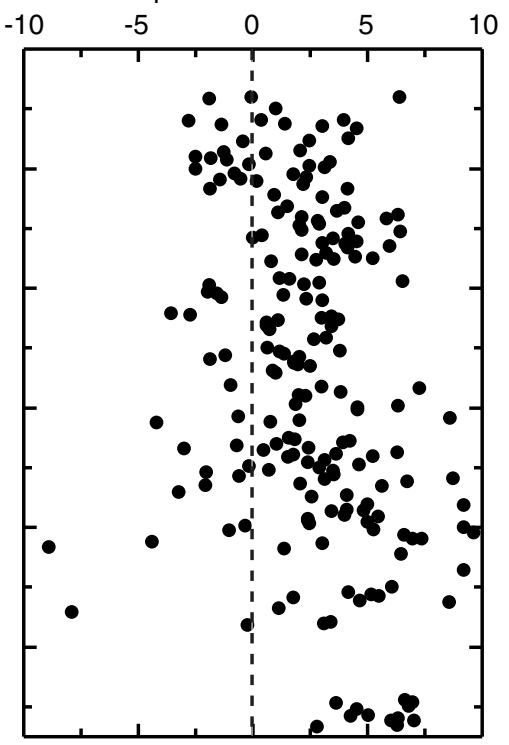


Figure F54. Photo image logger (MSCL-I) and X-ray computed tomography (CT) images showing commonly observed drilling-induced core disturbance. A. Interval 322-C0011B-7R-1, 90-103 cm (394 m CSF). B. Interval 322-C0011B-32R-4, 86-100 cm (601 m CSF).
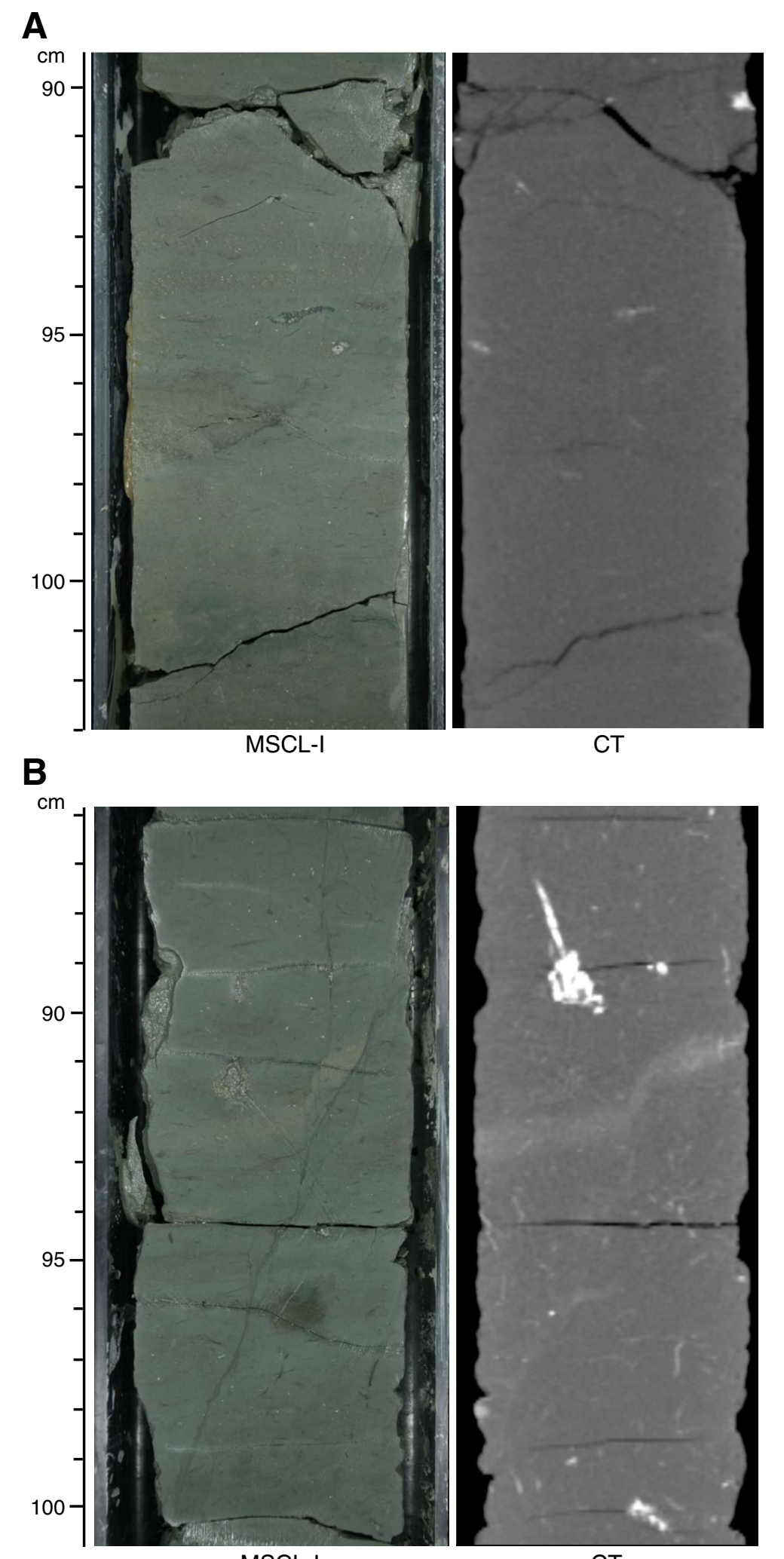

MSCL-I

CT 
Figure F55. A. Volume of interstitial water recovered as a function of depth, Hole C0011B. Blue diamonds = interstitial water extracted from silty clay, red diamonds = interstitial water extracted from sandy whole-round sections, crosses $=$ samples with $>10 \%$ contamination by drilling fluid. B. Dissolved sulfate depth profile, used to estimate (C) percent contamination values. D. Drilling fluid contamination (squares) and sulfate concentration (diamonds) as a function of volume extracted.

A

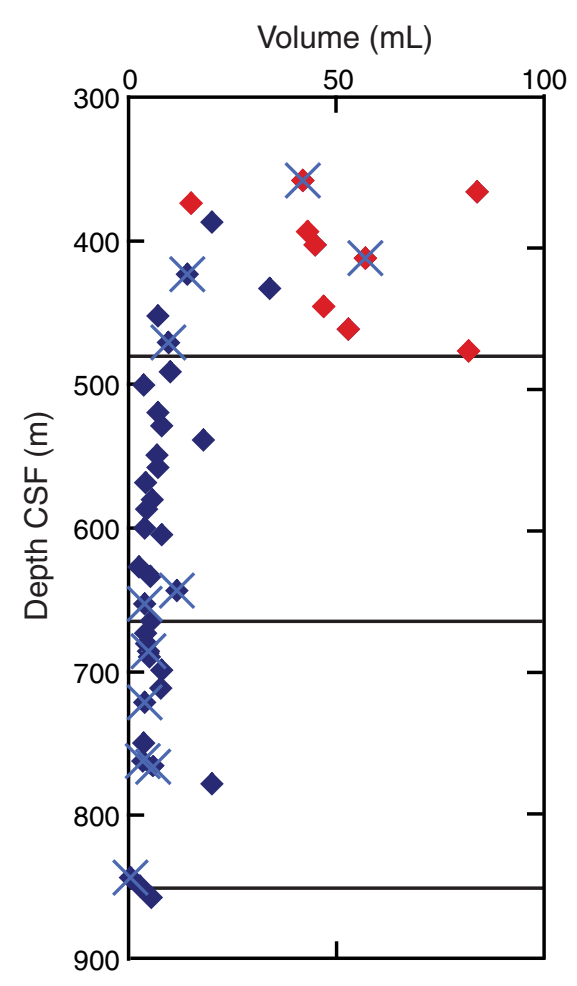

B

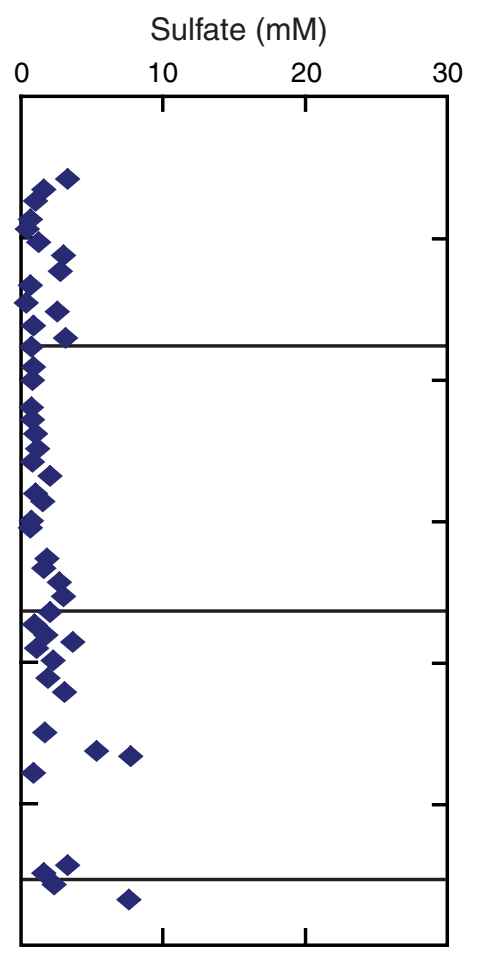

C Drilling fluid contamination (\%) Lith.

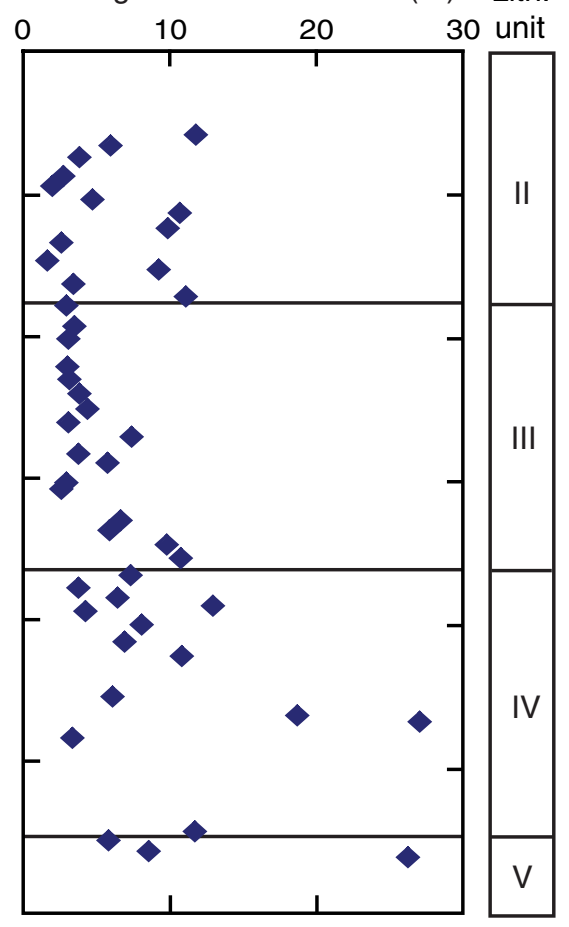

D

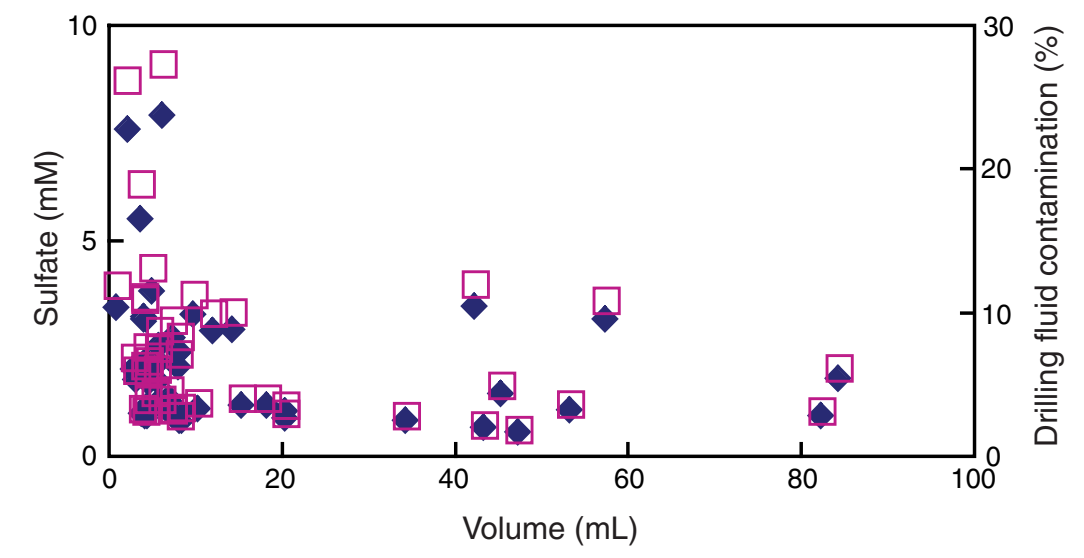


Figure F56. CT scans showing disturbance in core that led to drilling fluid contamination of the samples. A. Interval 322-C0011B-53R-2, 20-40 cm, had 27\% contamination, so the data were discarded. B. Interval 322C0011B-59R-3, 4-27 cm, was deemed too disturbed to process.

A

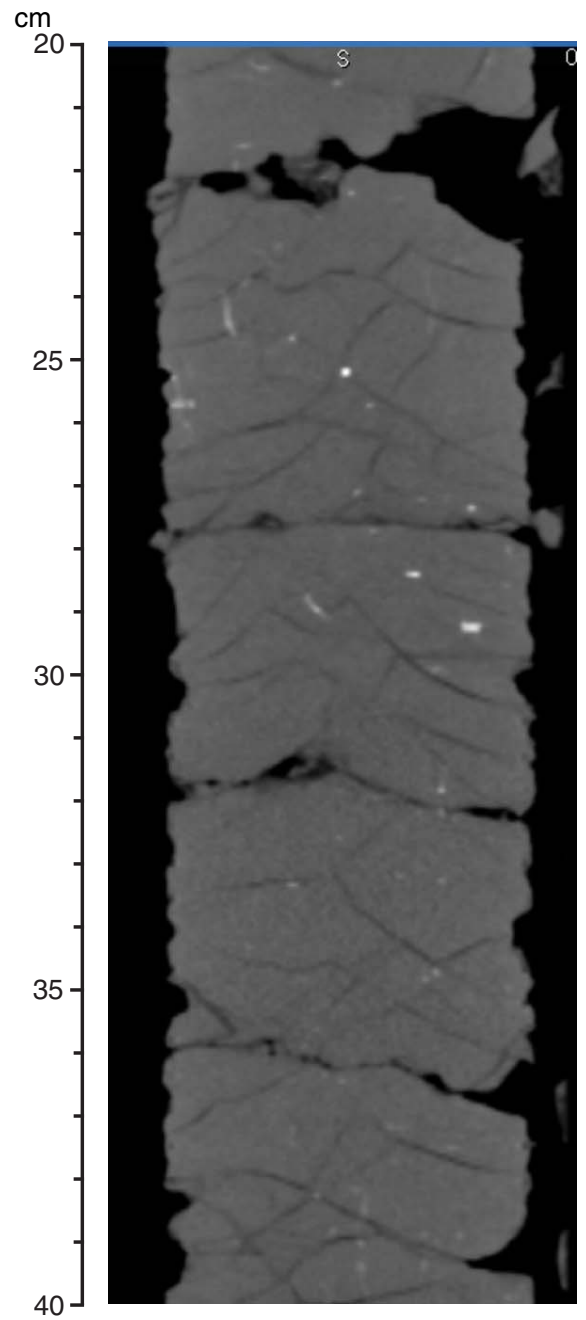

B

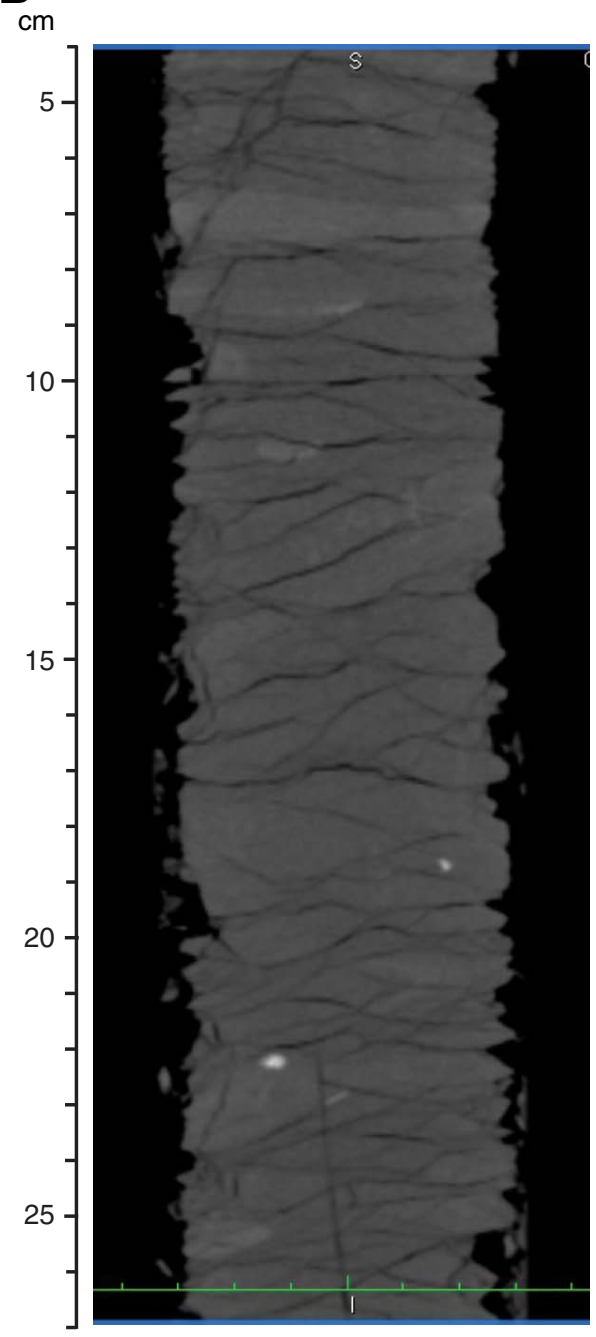


Figure F57. Depth profile of interstitial water constituents (salinity, chlorinity, bromide, pH, alkalinity, sulfate, ammonium, phosphate, hydrogen sulfide, and boron), Hole C0011B. Blue arrows = bottom seawater concentrations.

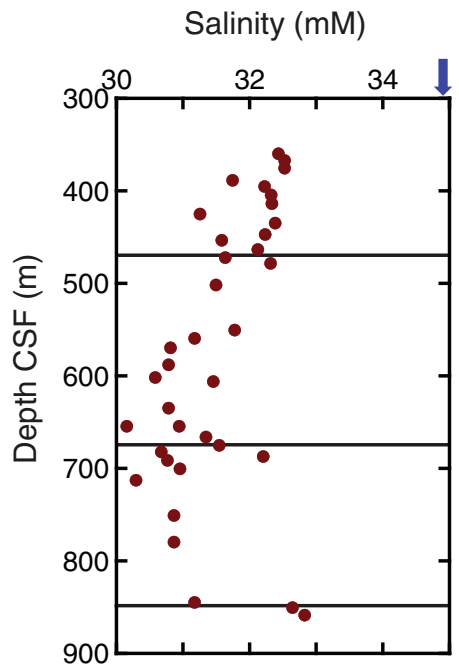

$\mathrm{Br} / \mathrm{Cl}(\mathrm{mmol} / \mathrm{mol})$

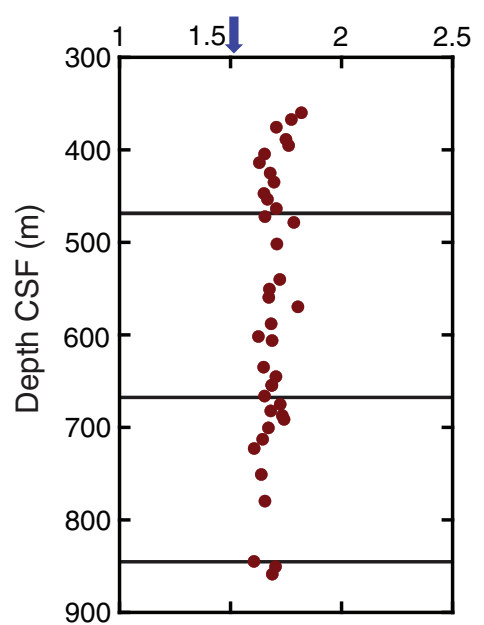

Chlorinity (mM)

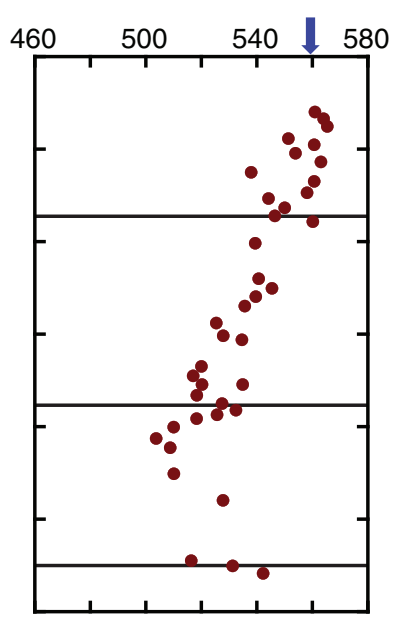

$\mathrm{NH}_{4}(\mathrm{mM})$

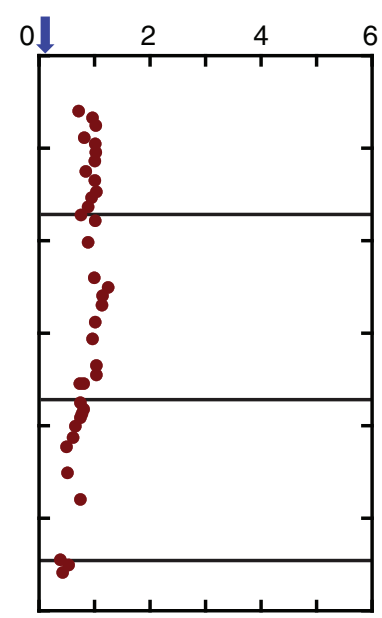

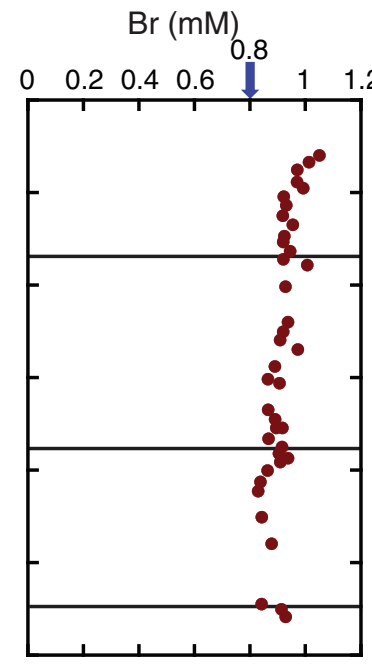

$\mathrm{PO}_{4}(\mu \mathrm{M})$

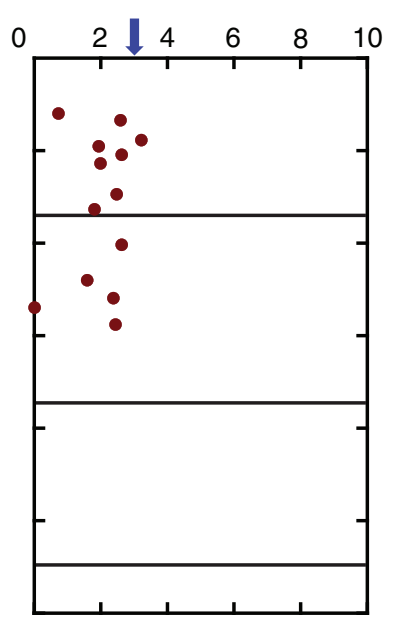

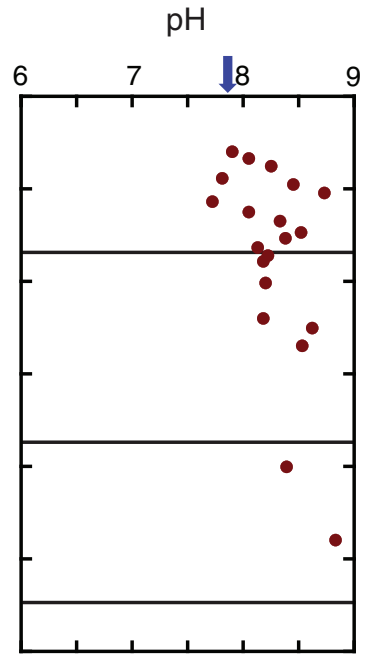

$\mathrm{HS}^{-}(\mu \mathrm{M})$

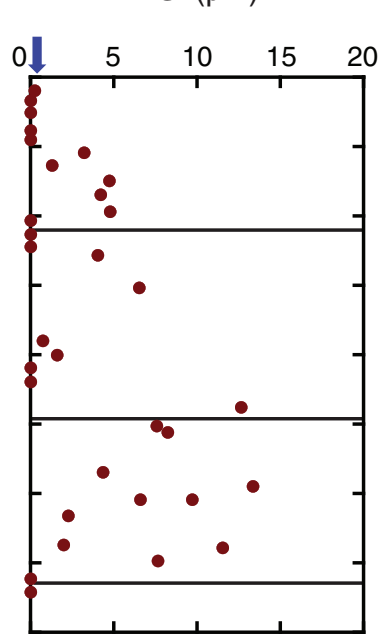

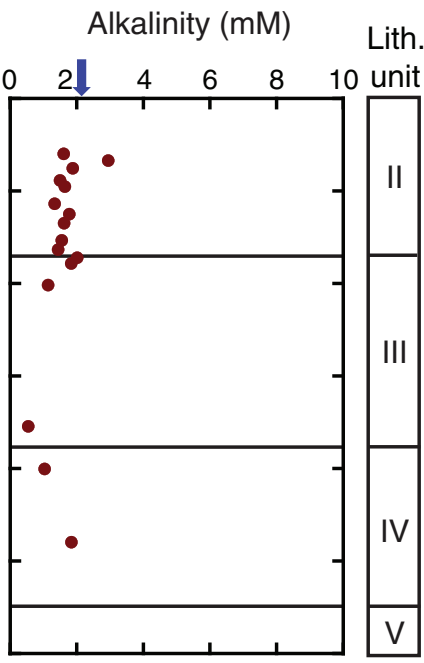

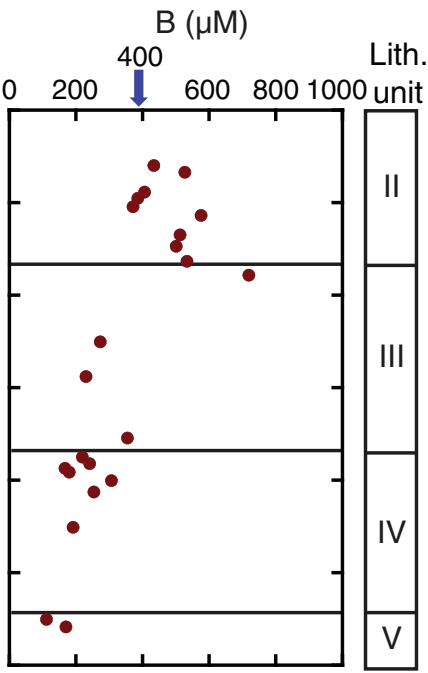


Figure F58. Depth profile of interstitial water constituents (sodium, potassium, magnesium, calcium, silica, lithium, strontium, barium, and manganese), Hole C0011B. Blue arrows = bottom seawater concentrations.

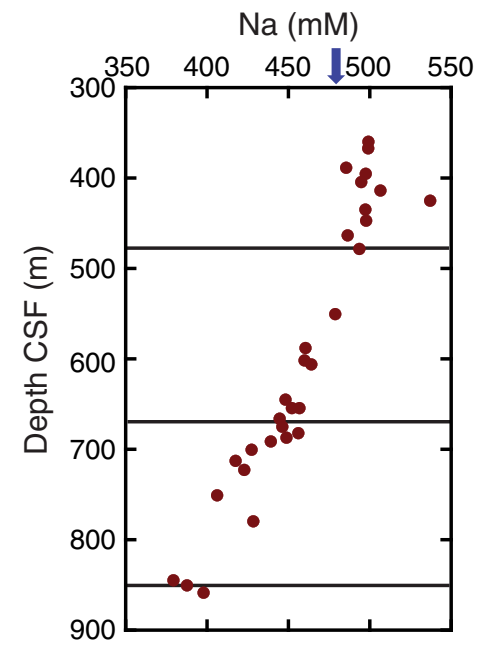

$\mathrm{Li}(\mu \mathrm{M})$

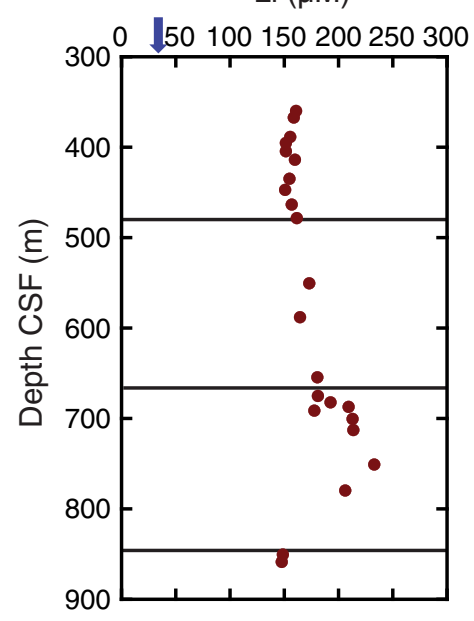

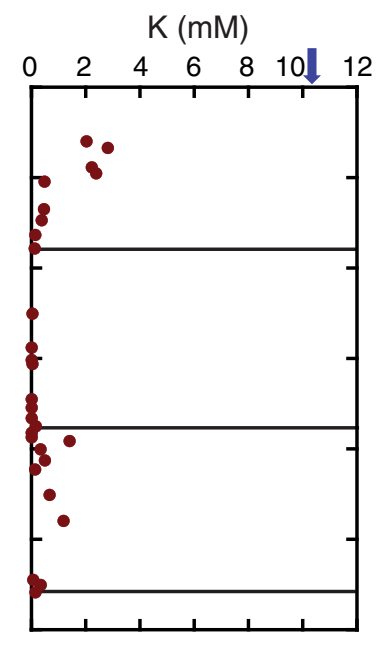

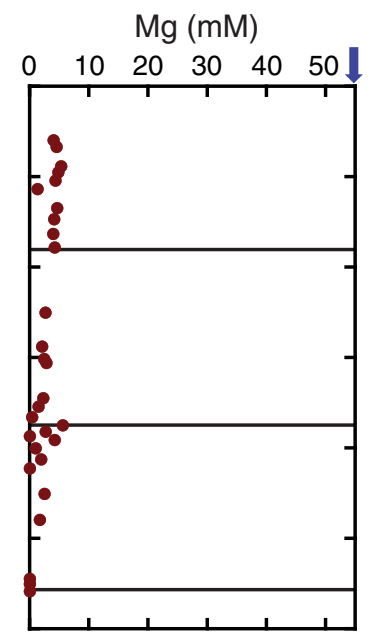

$\operatorname{Sr}(\mu \mathrm{M})$
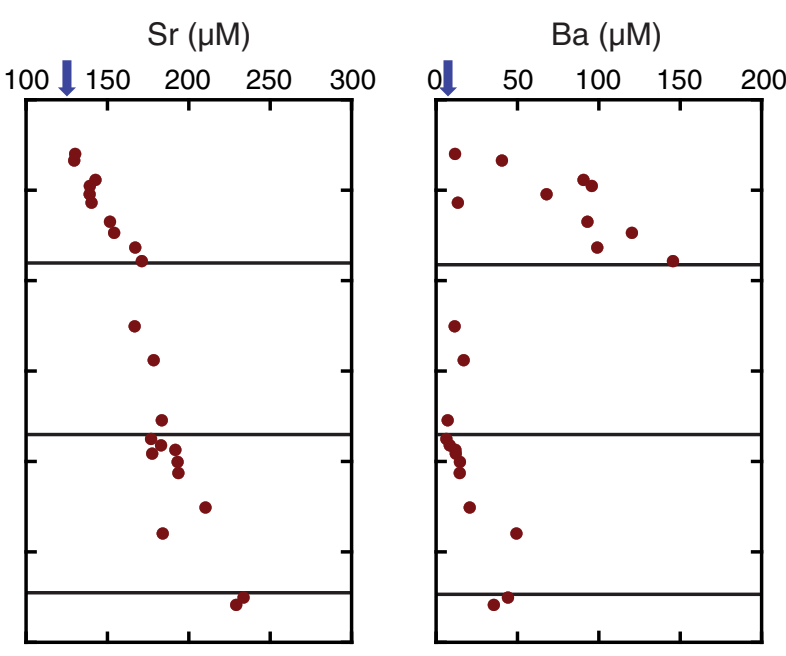
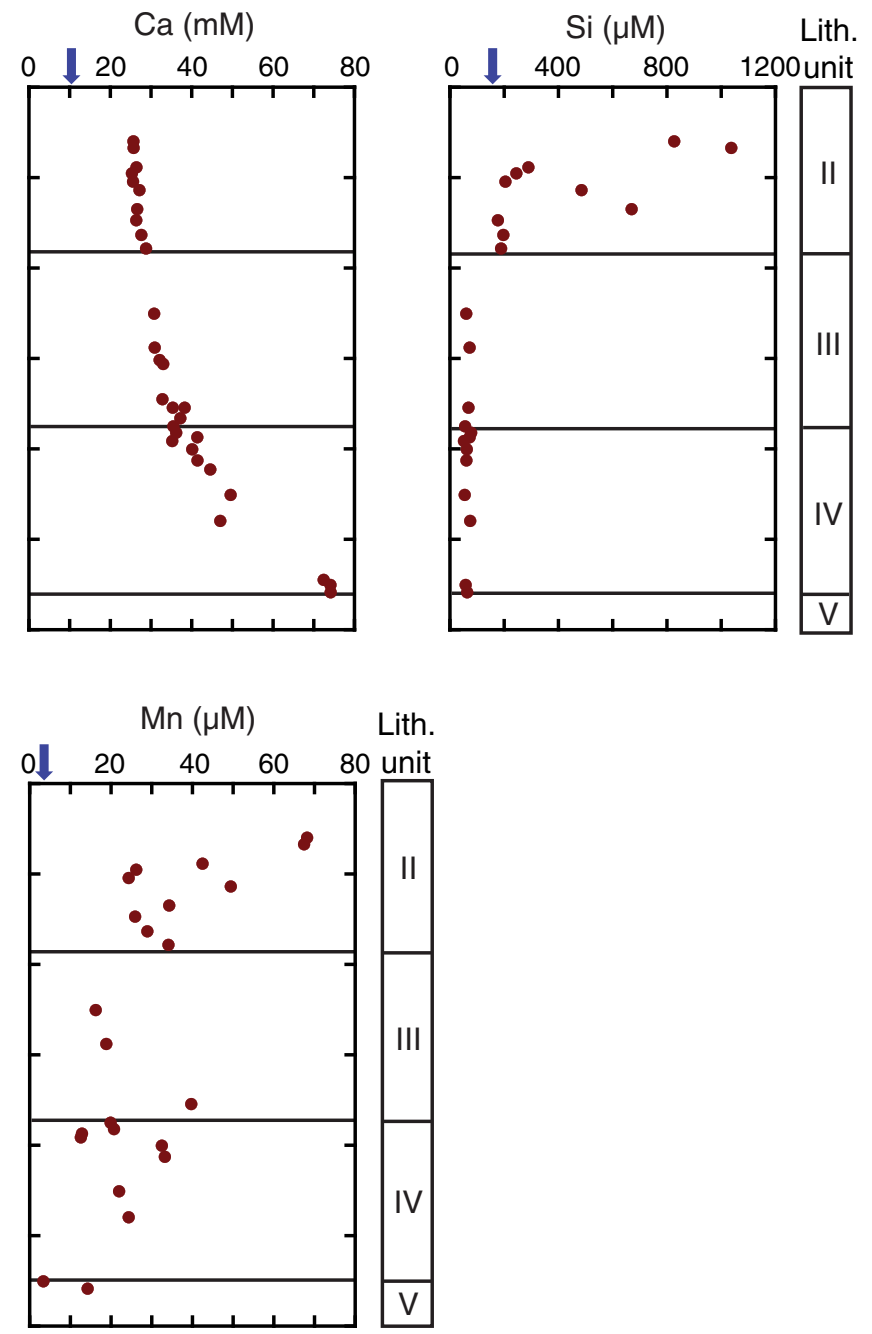
Figure F59. Site C0011 data (red) compared with ODP Site 1177 (black), drilled seaward of the deformation front during ODP Leg 190. Chloride concentration at both sites show very similar distribution; however, major cations and alkalinity data from Site C0011 are consistent with a more extensive ash alteration effect.
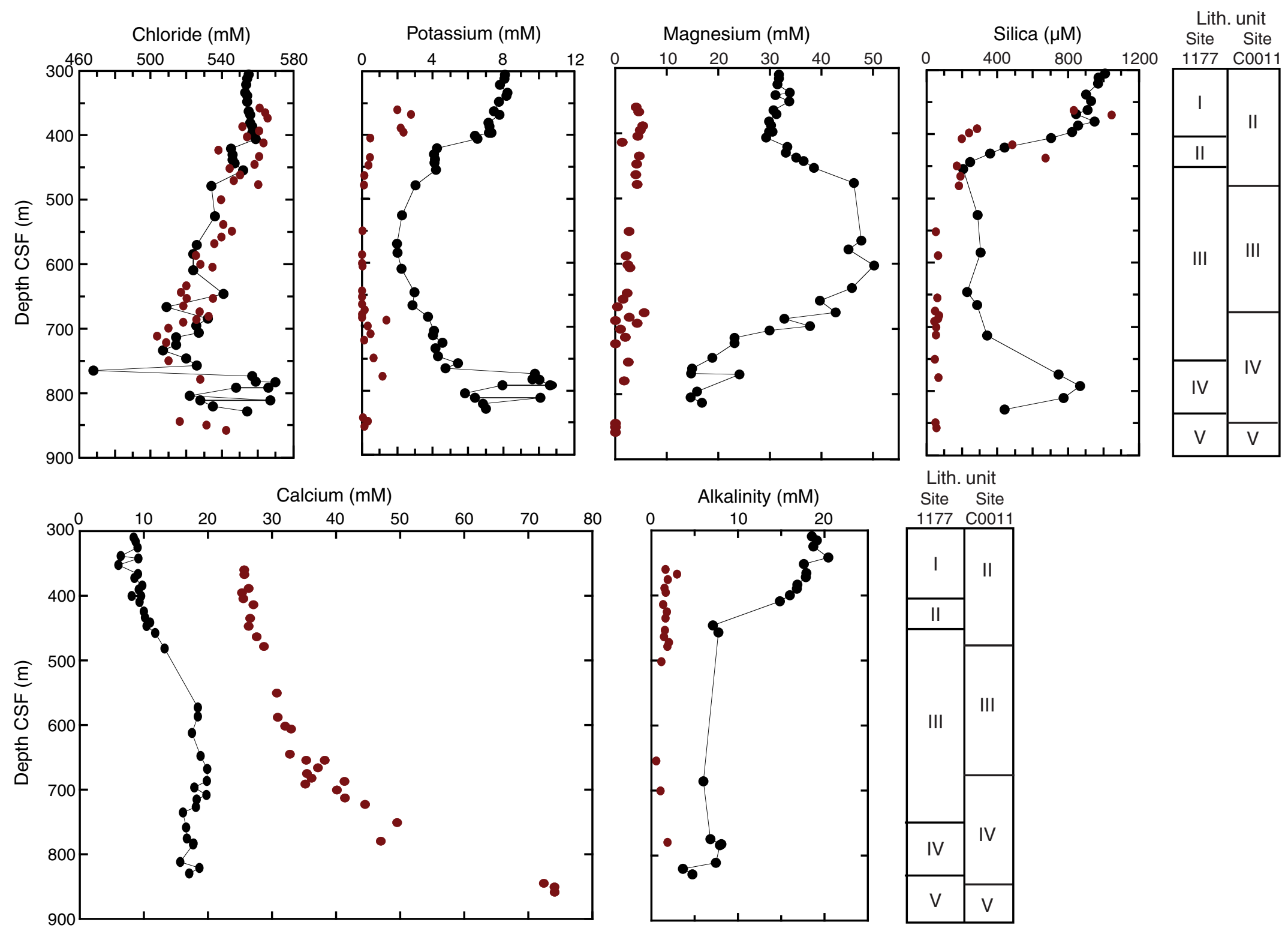
Figure F60. Depth distribution of saturation indexes calculated using interstitial water concentrations, pure end-member phases, and the PhreeqcI software package of Parkhurst and Appelo (1999). Calculations performed at $25^{\circ} \mathrm{C}$ (solid lines) and $5^{\circ} \mathrm{C}$ (dotted lines). A. Carbonates. B. Montmorillonites. C. Zeolites.

A
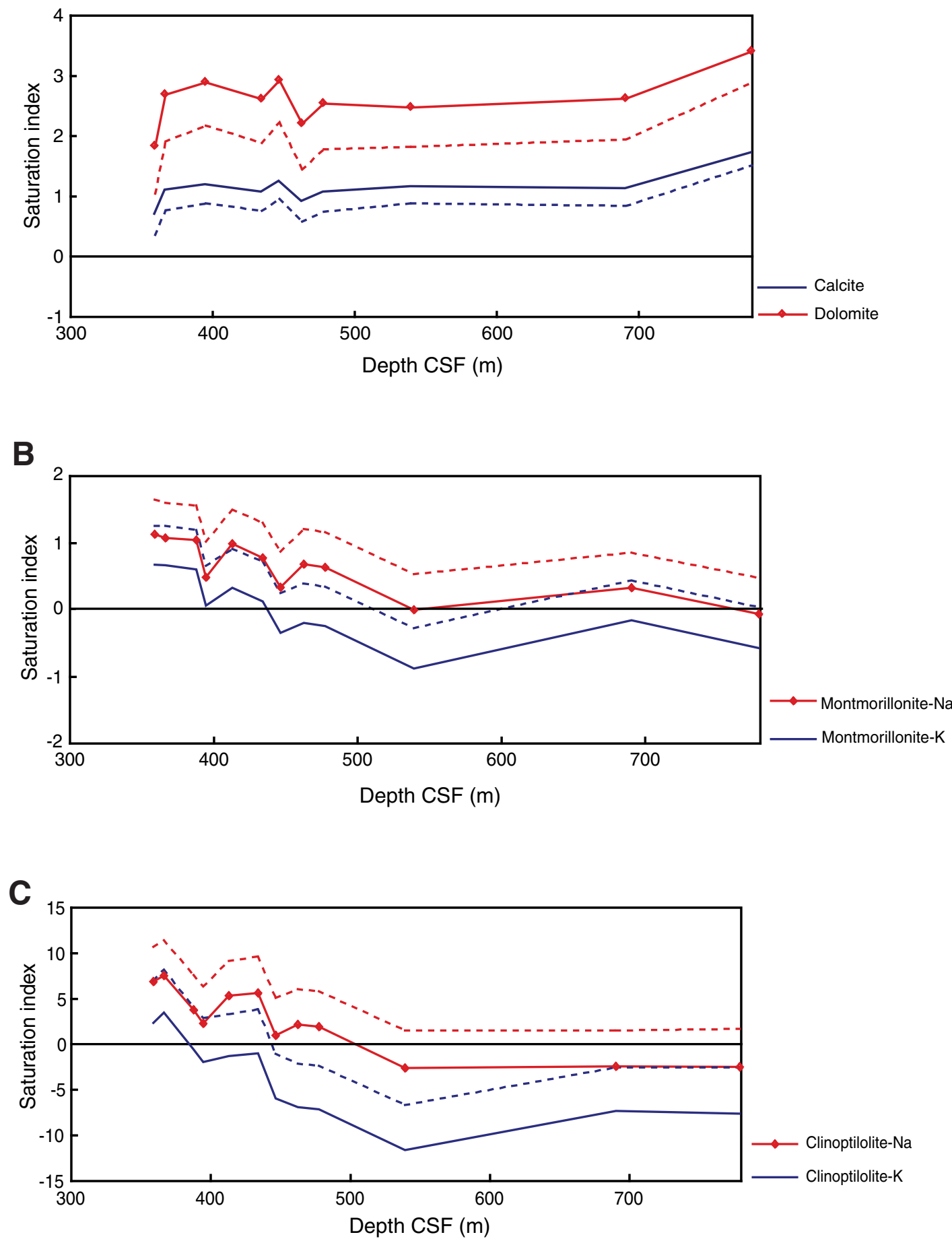
Figure F61. Profiles of methane, ethane, propane, butane, and $C_{1} / C_{2}$ molar ratios versus depth, Hole C0011B.

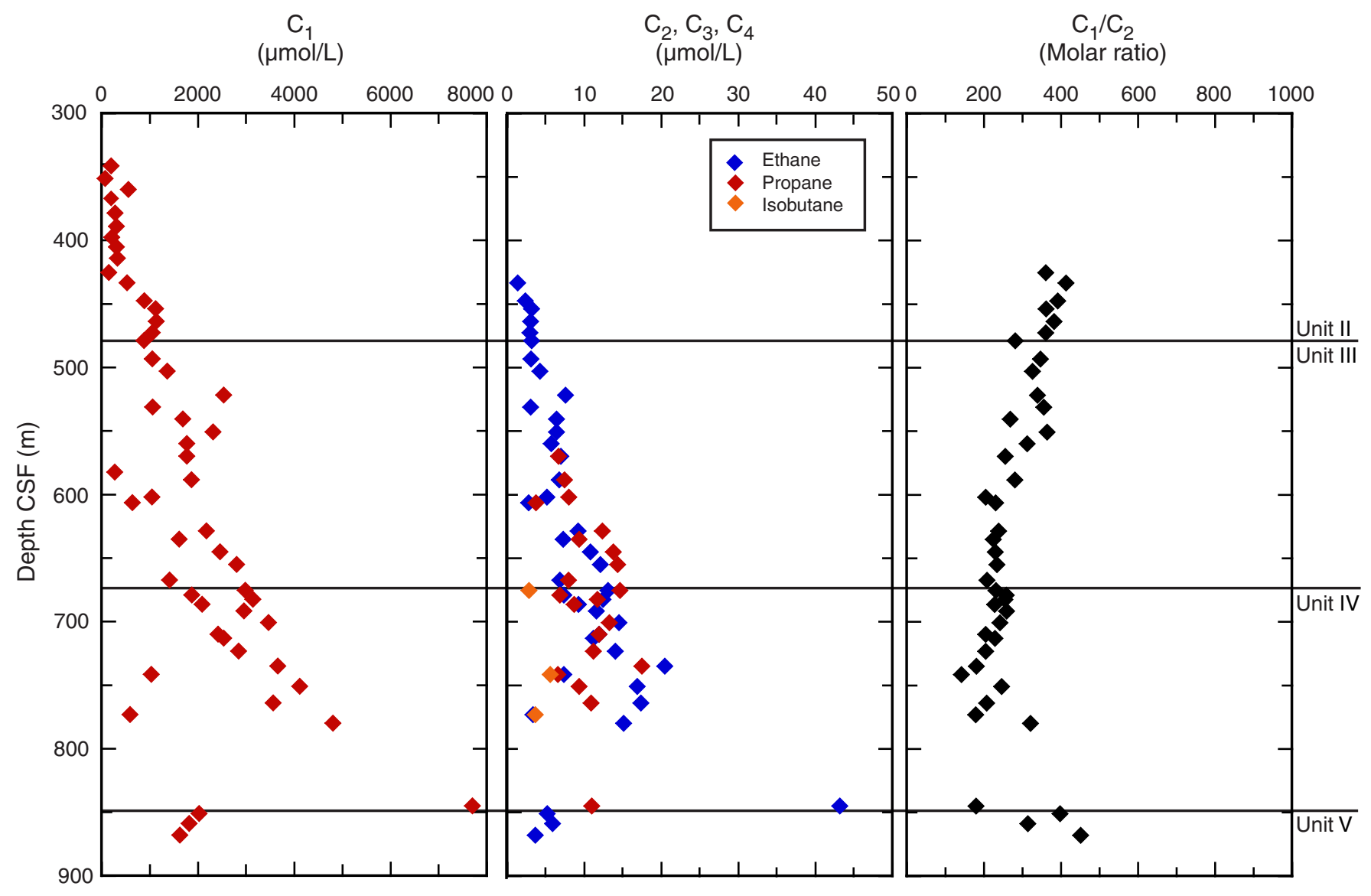


Figure F62. Plot of methane/ethane molar ratios $\left(\mathrm{C}_{1} / \mathrm{C}_{2}\right)$ versus temperature, Hole C0011B. Temperature was calculated using a geothermal gradient of $0.056^{\circ} \mathrm{C} / \mathrm{m}$ and a bottom water temperature of $3^{\circ} \mathrm{C}$. Modified from Pimmel and Claypool (2001). TOC = total organic carbon.

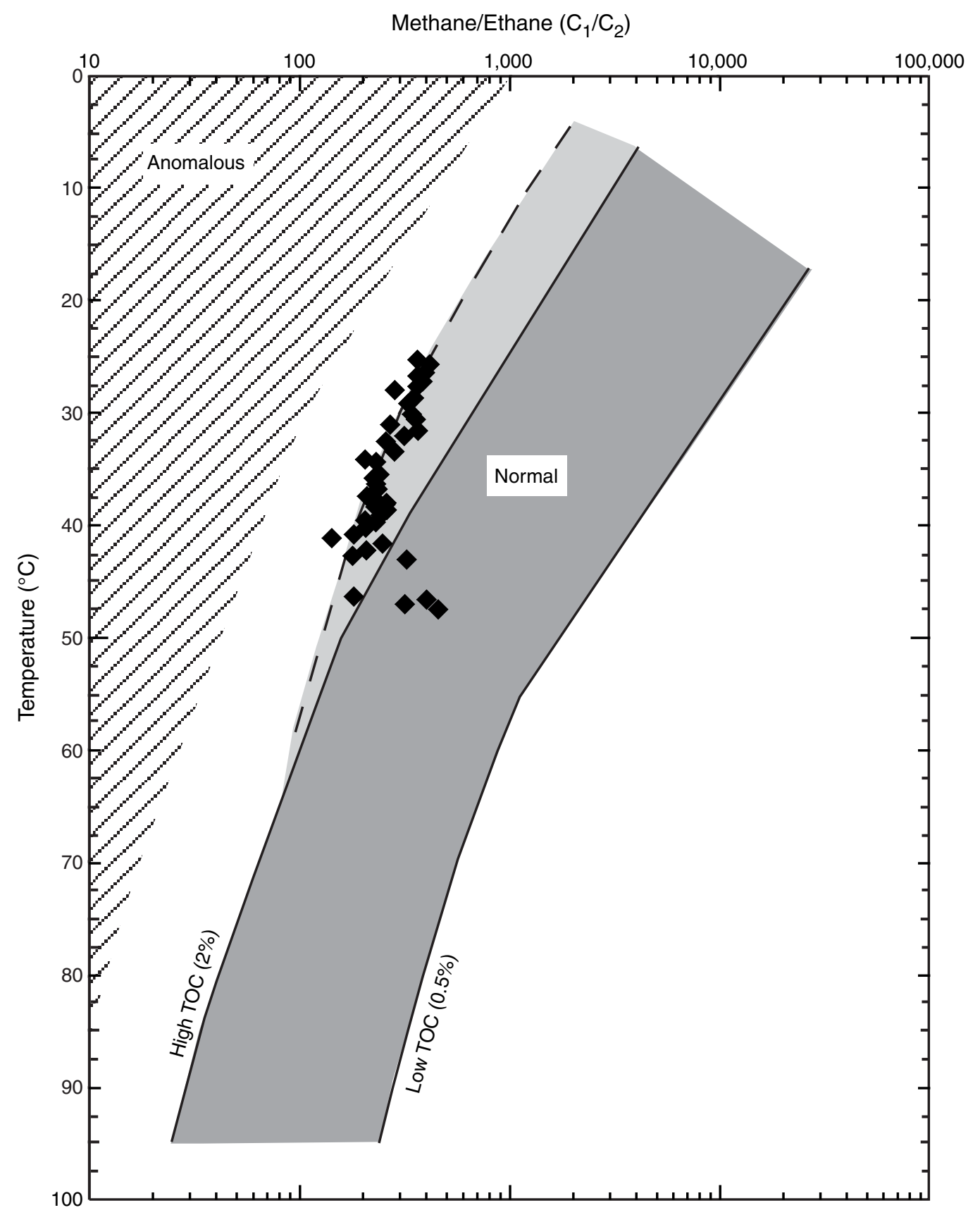


Figure F63. Depth profiles of $\mathrm{H}_{2}$ determined by extraction method from sediment and drilling fluid samples. Dashed line $=$ reagent blank (obscured by the small ticks that delimit the depth increment).

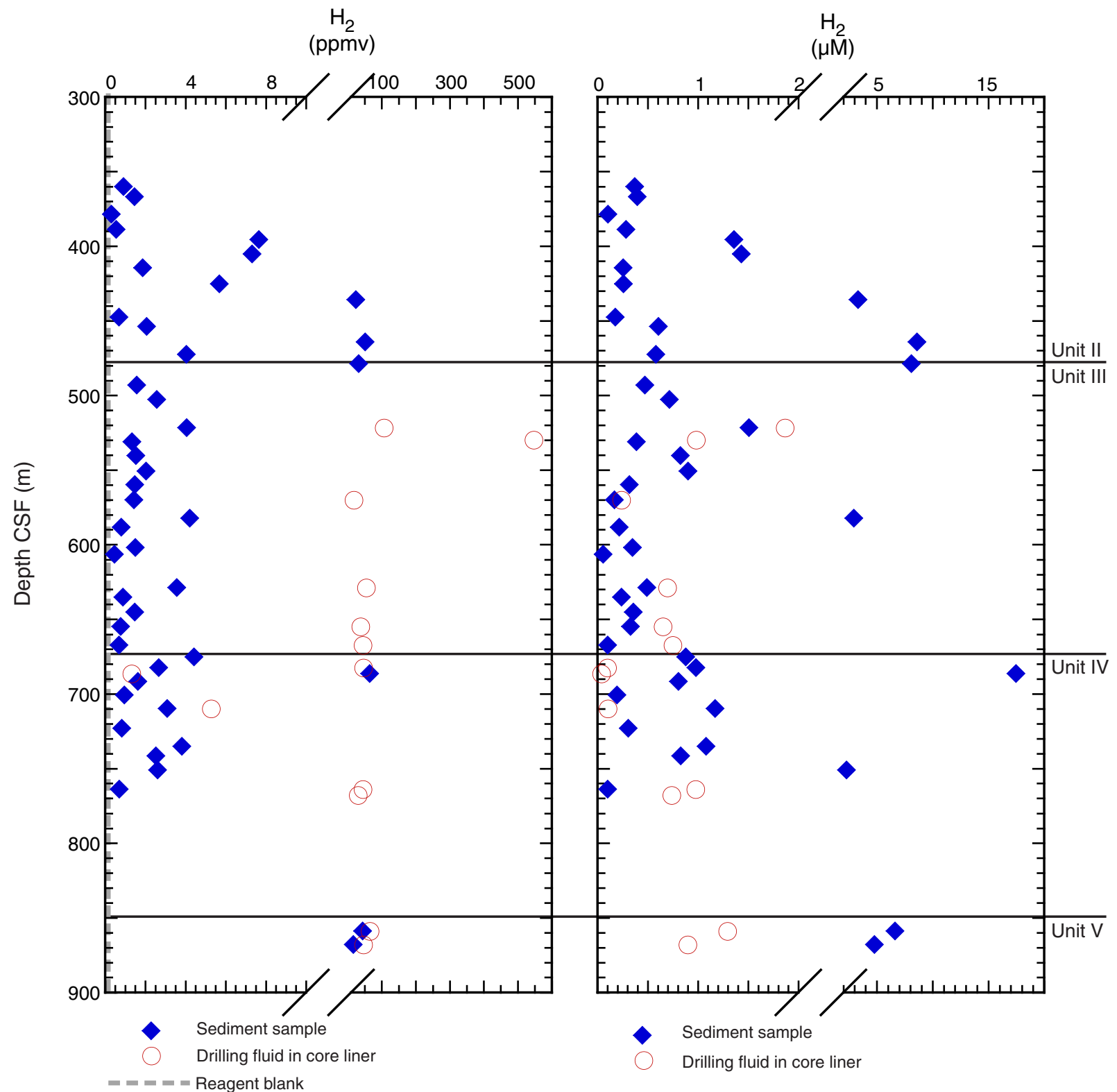


Figure F64. $\mathrm{H}_{2}$ concentrations in sediment samples, Hole C0011B, as a function of time from three replicate incubation experiments. A. Section 322-C0011B-15R-3. B. Section 322-C0011B-21R-2. C. Section 322-C0011B-25R-2. D. Section 322-C0011B-32R-5. E. Section 322-C0011B-35R-1. F. Section 322-C0011B-45R-4. G. Section 322-C0011B-48R-3. H. Section 322-C0011B-54R-3. I. Section 322-C0011B-58R-6. For information on samples and incubation temperature see Table T22.

A

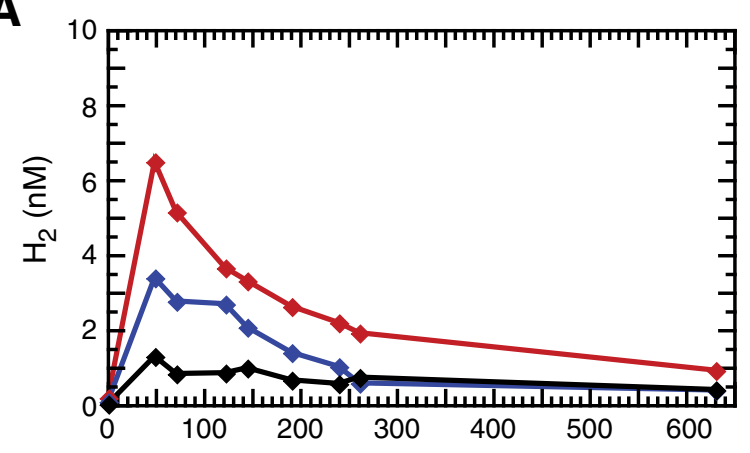

B

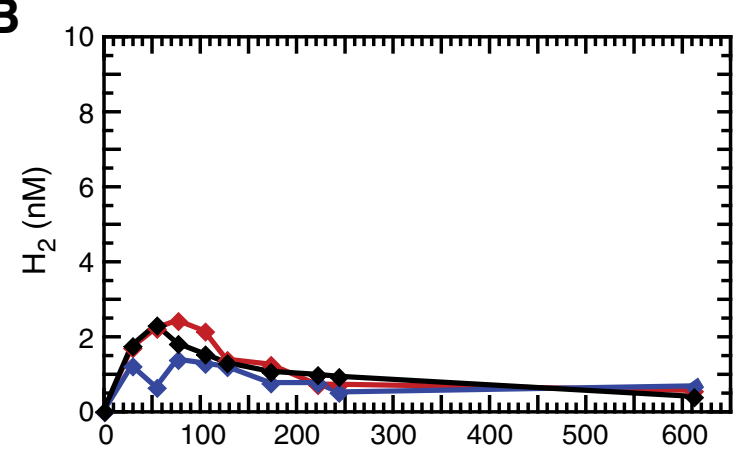

C

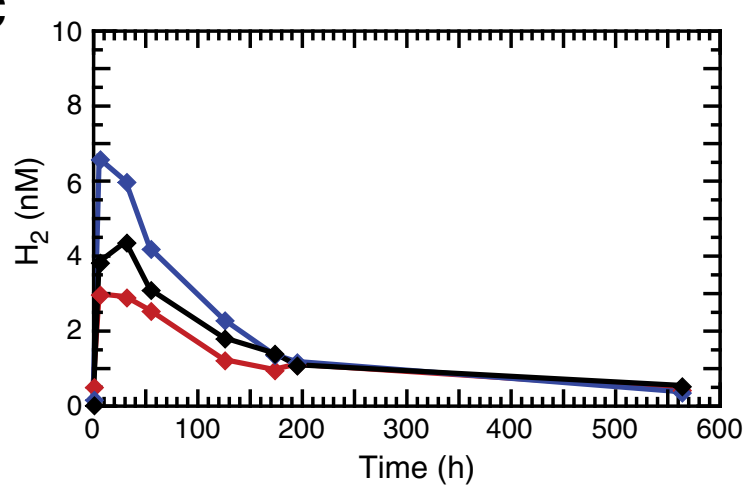

D

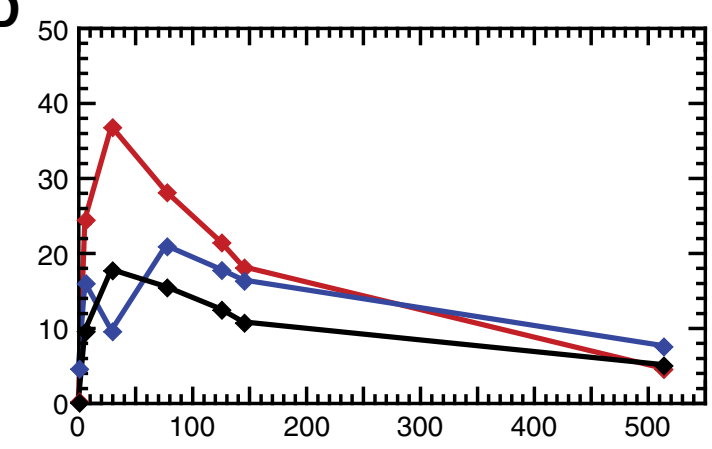

E

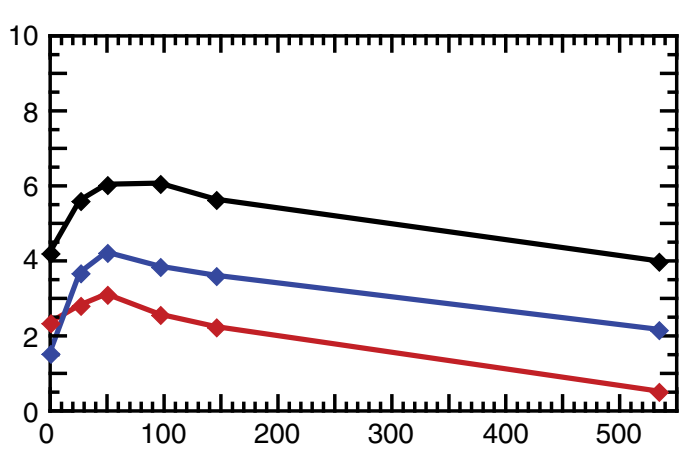

$F$
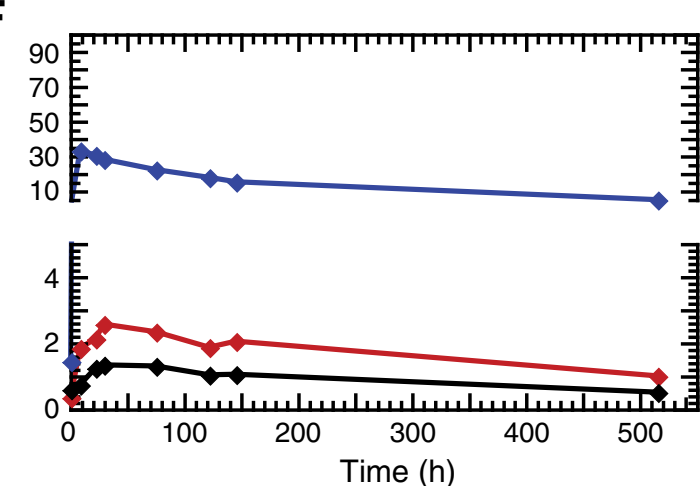

$\mathbf{G}_{1}$

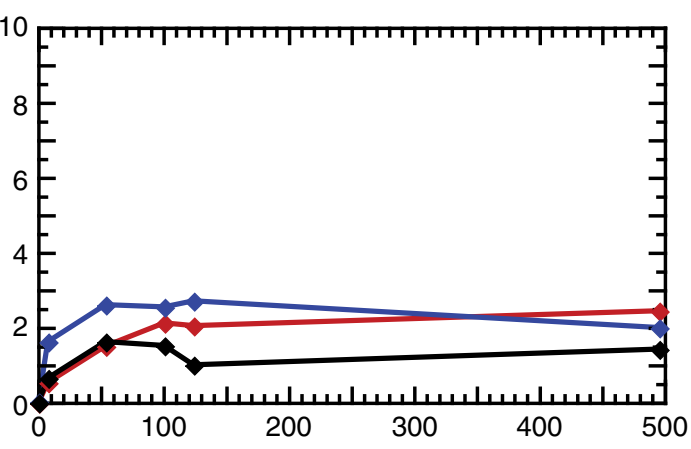

H

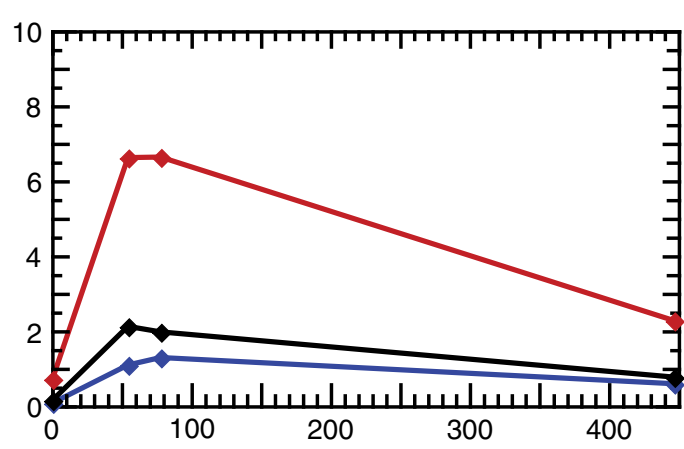

I

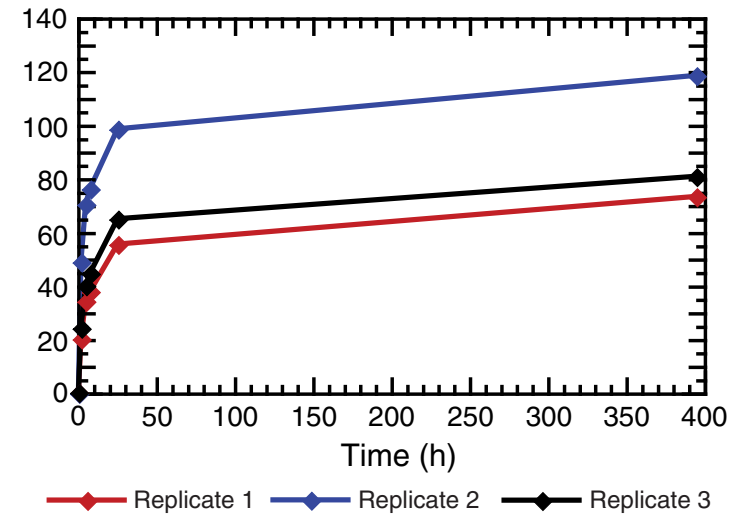


Figure F65. Depth profiles of inorganic carbon, total organic carbon, total nitrogen, and total sulfur, Hole C0011B.

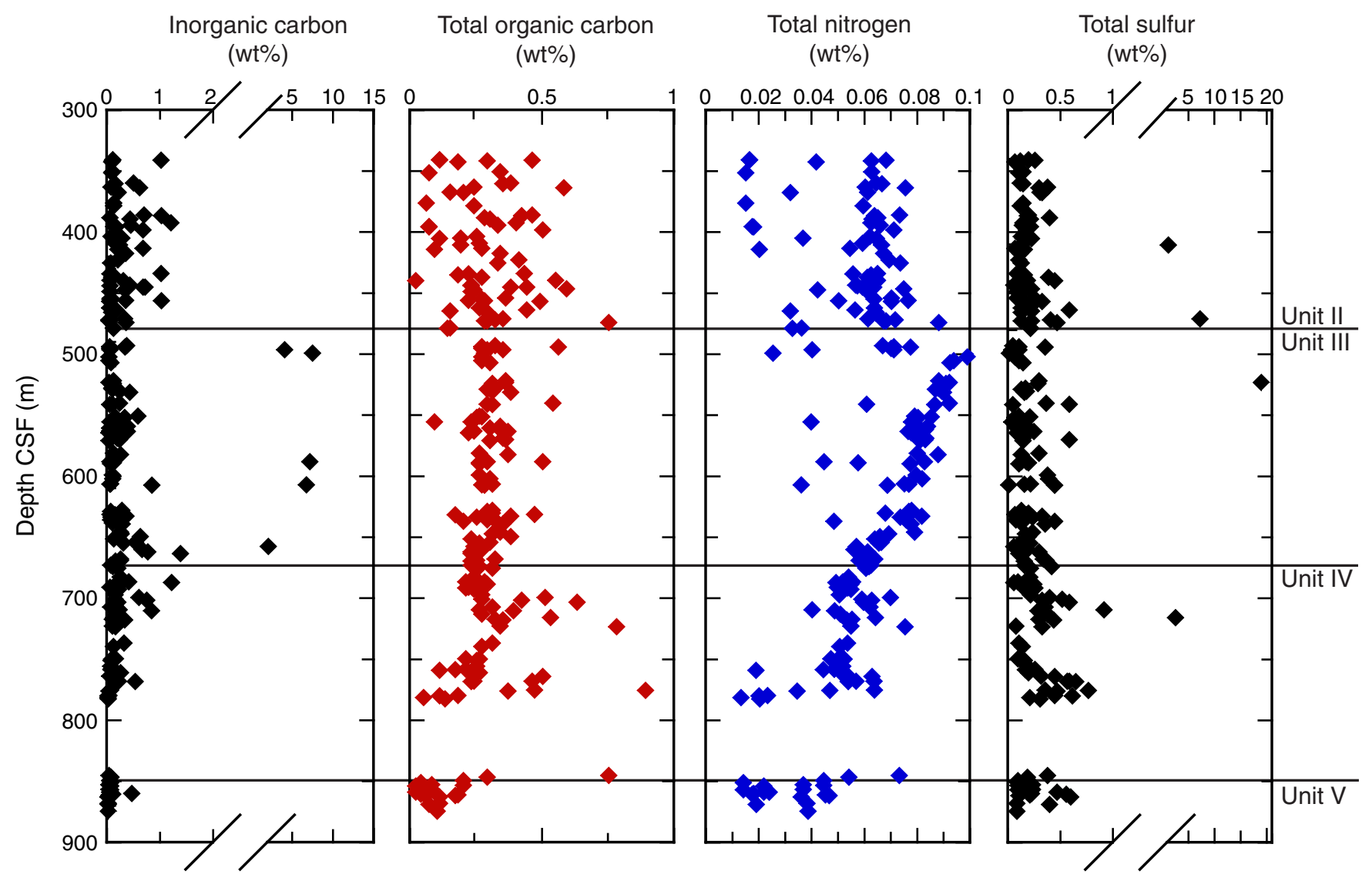


Figure F66. Depth profile of total organic carbon (TOC) to total nitrogen (TN) ratio, Hole C0011B. Vertical dashed line $=$ difference between terrigenous and marine sources for organic carbon .

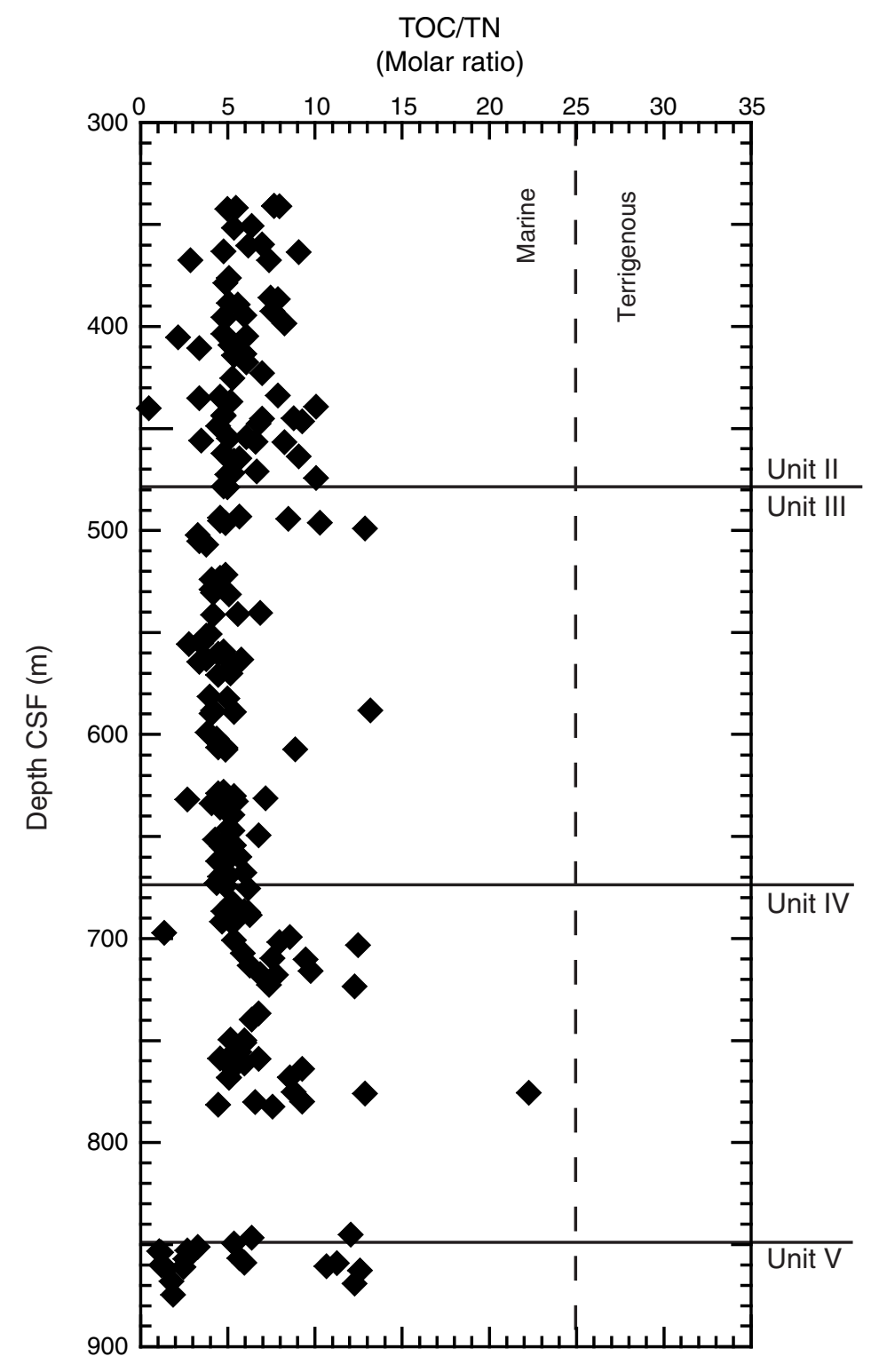


Figure F67. Depth profiles of the type and maturity of organic matter by Rock-Eval pyrolysis of sediments, Hole C0011B. $T_{\max }=$ temperature at which the maximum release of hydrocarbons from cracking of kerogen occurs during pyrolysis, $\mathrm{S}_{2}=$ amount of hydrocarbons $(\mathrm{HC})$ generated through thermal cracking of nonvolatile organic matter, $\mathrm{S}_{3}=$ amount of $\mathrm{CO}_{2}$ produced during pyrolysis of kerogen, $\mathrm{HI}=$ hydrogen index, OI $=$ oxygen index, TOC $=$ total organic carbon.

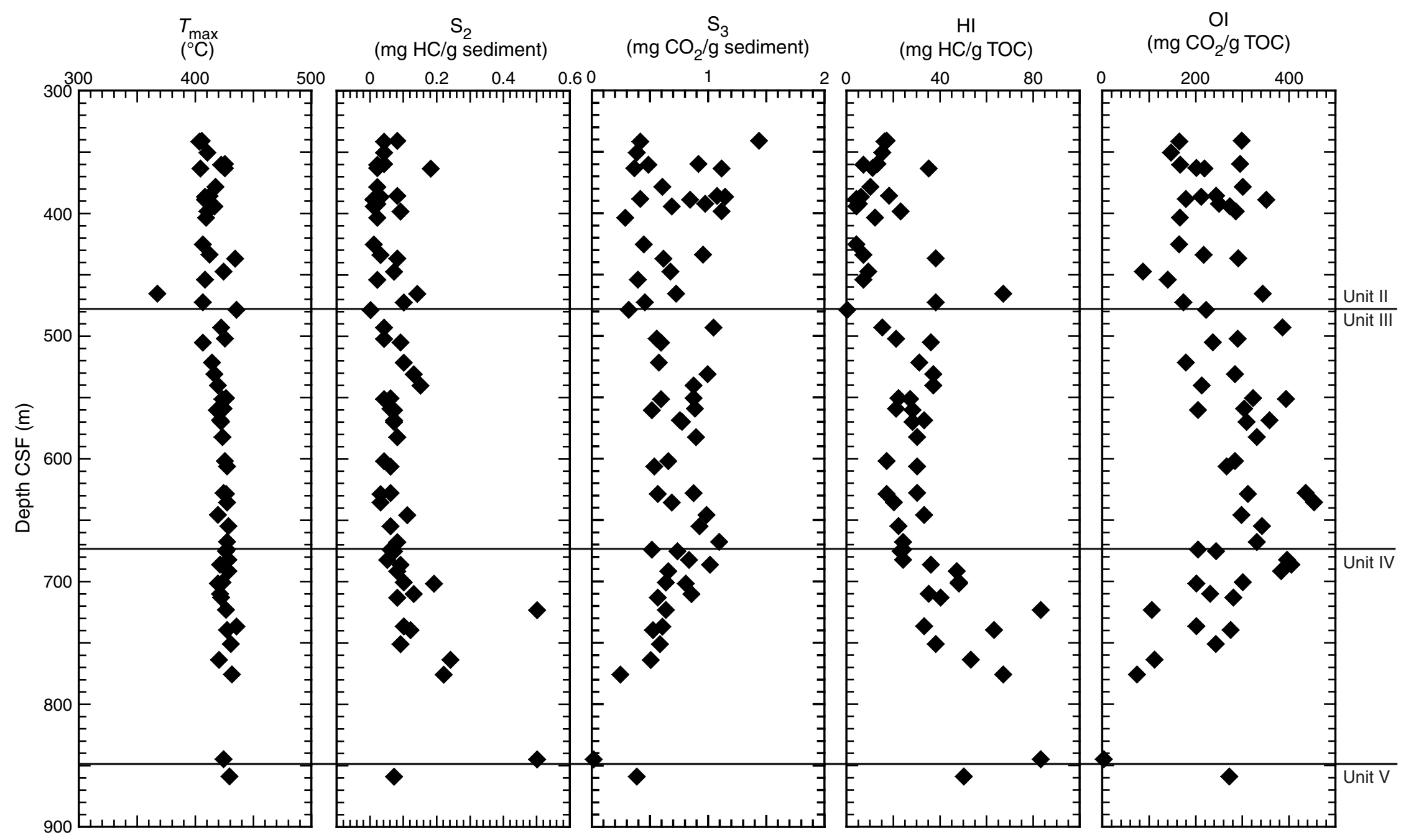


Figure F68. Measured pressure (green) and temperature (red) during SET-P tool Deployment 1, Hole C0011B. Hydrostatic references (blue) are calculated water pressure at 988 and 1989 mbsl assuming seawater density of $1.024 \mathrm{~g} / \mathrm{cm}^{3}$.

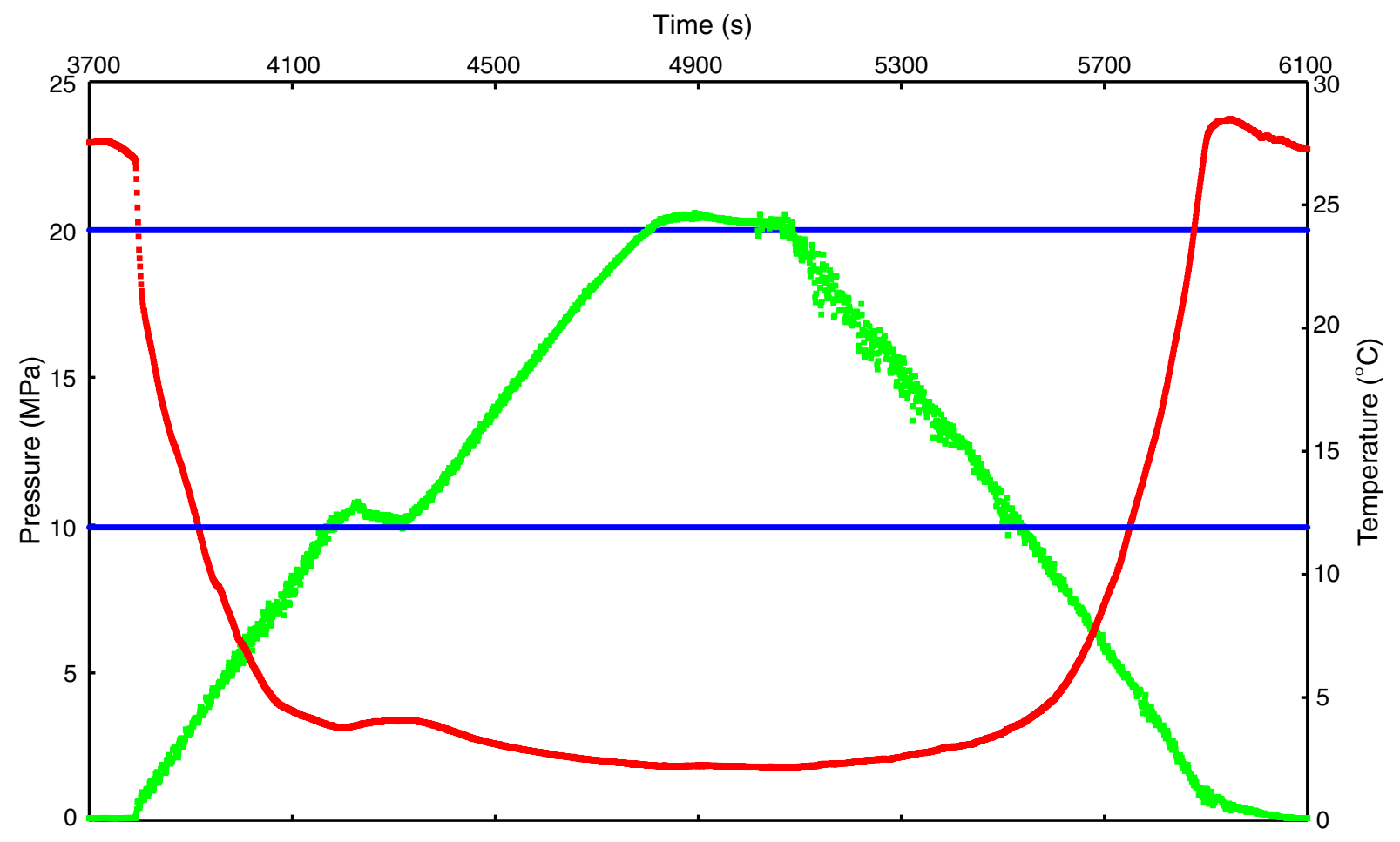


Figure F69. Overview of LWD/MWD data, Hole C0011A. Data include gamma ray, ring resistivity (RING), bit resistivity (RBIT), average shallow-button resistivity, average medium-button resistivity, average deep-button resistivity, rate of penetration (ROP), weight on bit (WOB), stick-slip, rotations per minute (RPM), and a static deep-button electrical resistivity image.

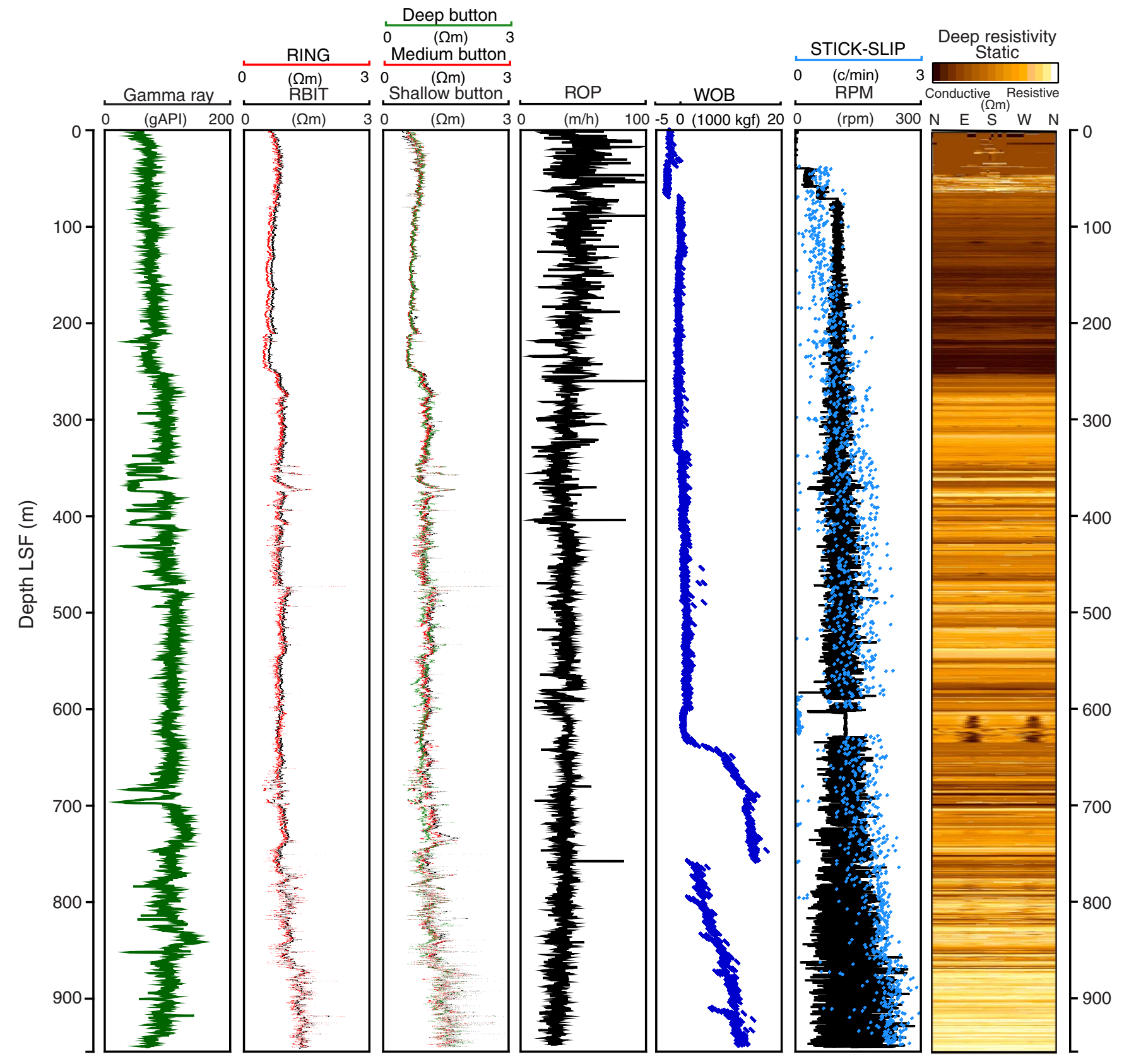


Figure F70. Missing data and discontinuities in deep-button resistivity images. Data include rotations per minute (RPM), angular acceleration index (AAI), rate of penetration (ROP), gamma ray, ring resistivity, and static and dynamic electrical resistivity images. Red arrows = stick-slip features, blue arrows $=$ features due to ship's heave.

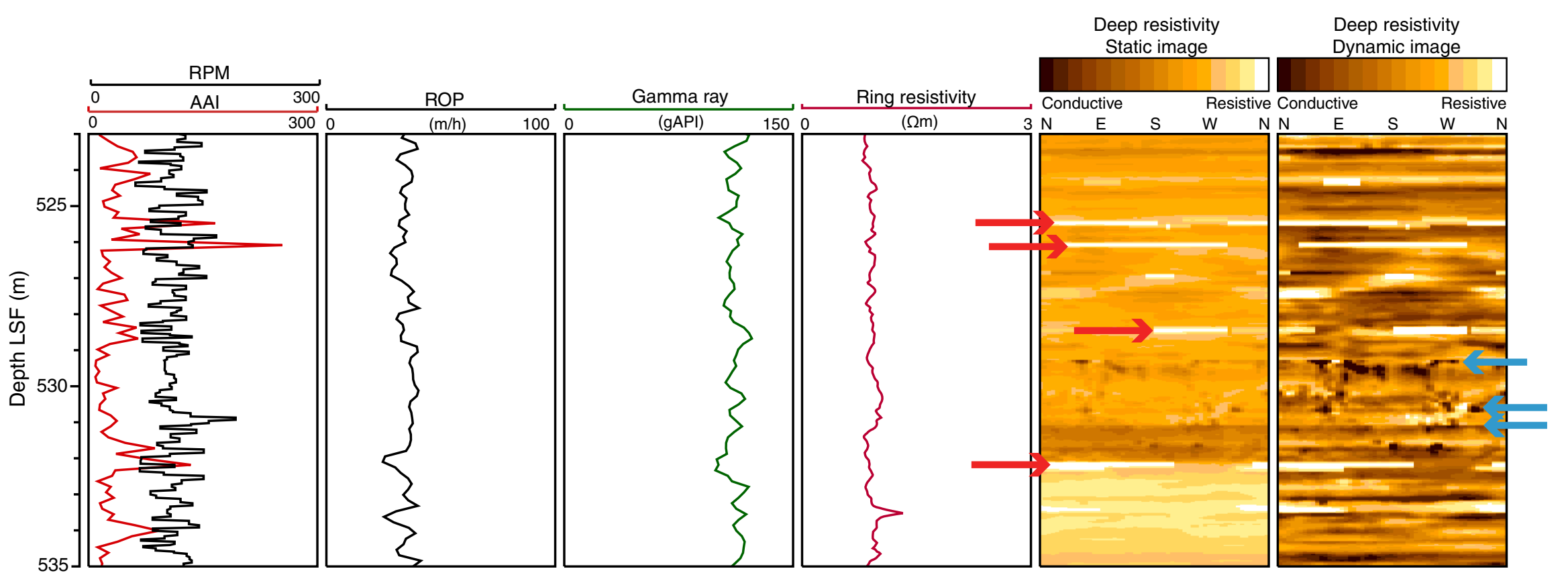


Figure F71. Statistical variations of gamma ray and resistivity values in logging units.
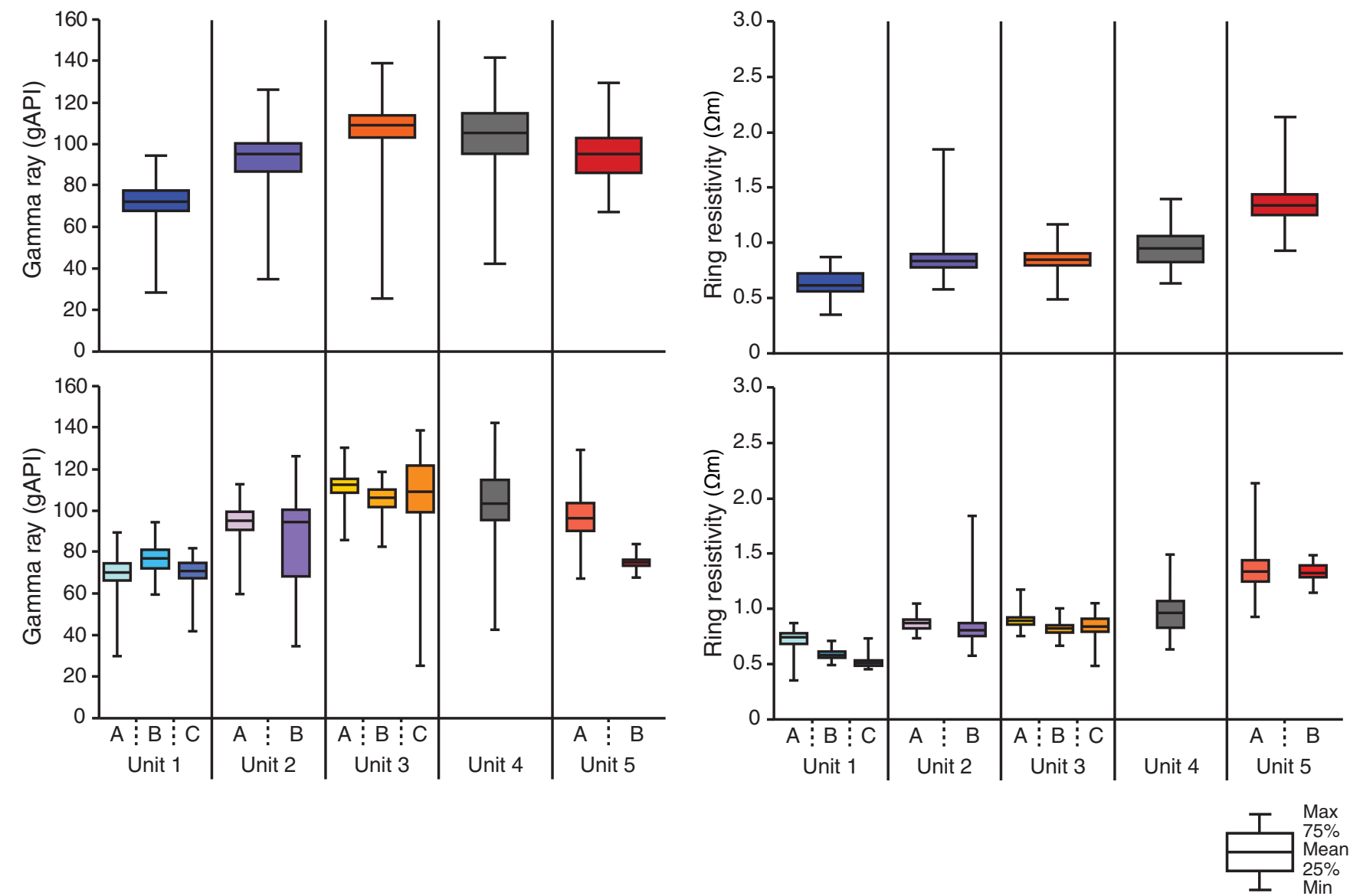
Figure F72. LWD data from an interval of logging Unit 2, showing correlations between logs and physical properties data. $\mathrm{MSCL}=$ multisensor core logger, $\mathrm{NGR}$ = natural gamma ray.

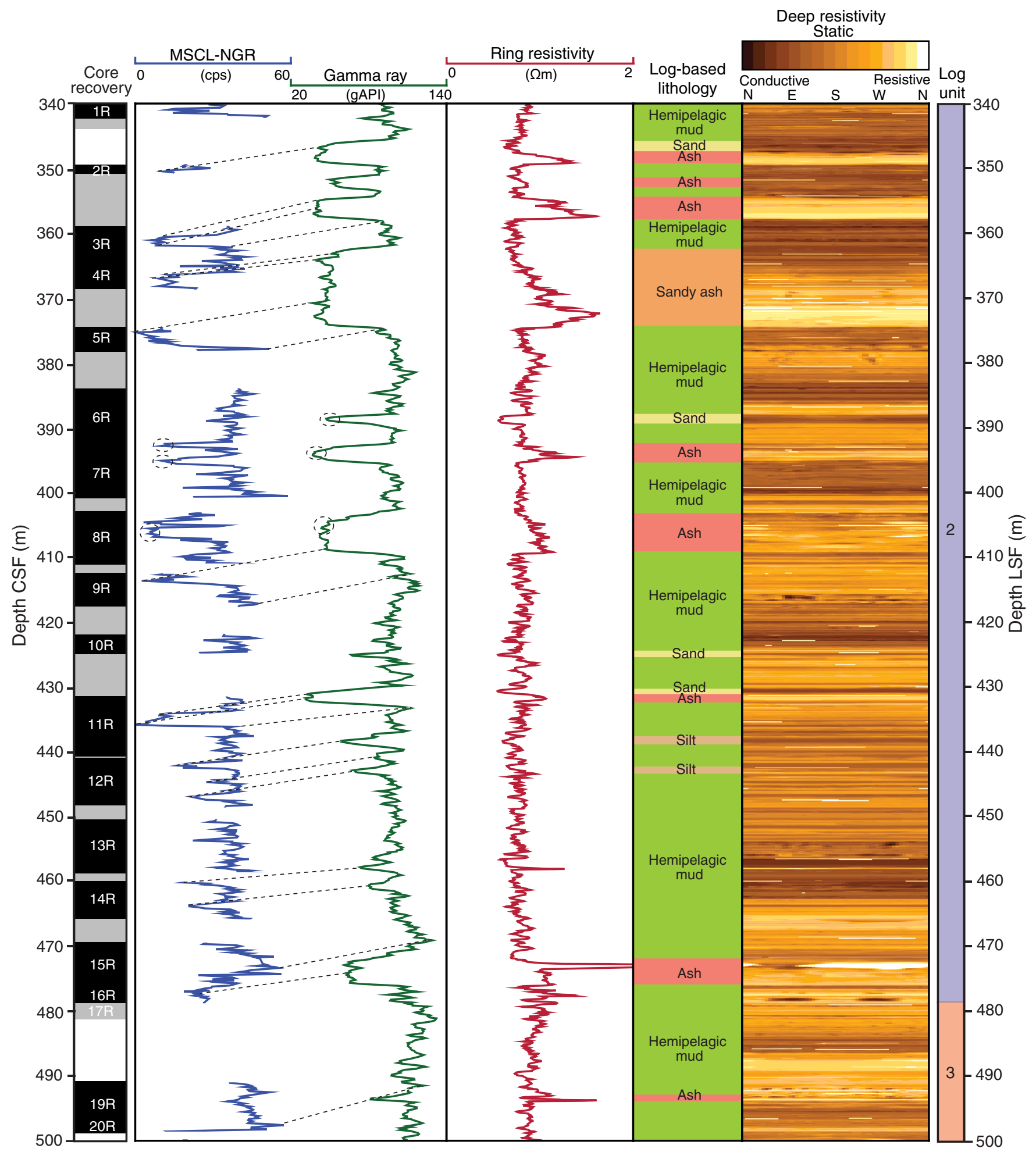


Figure F73. LWD data from an interval of logging Unit 3, highlighting low gamma ray and resistivity intervals and thickness of features interpreted as sandy layers.

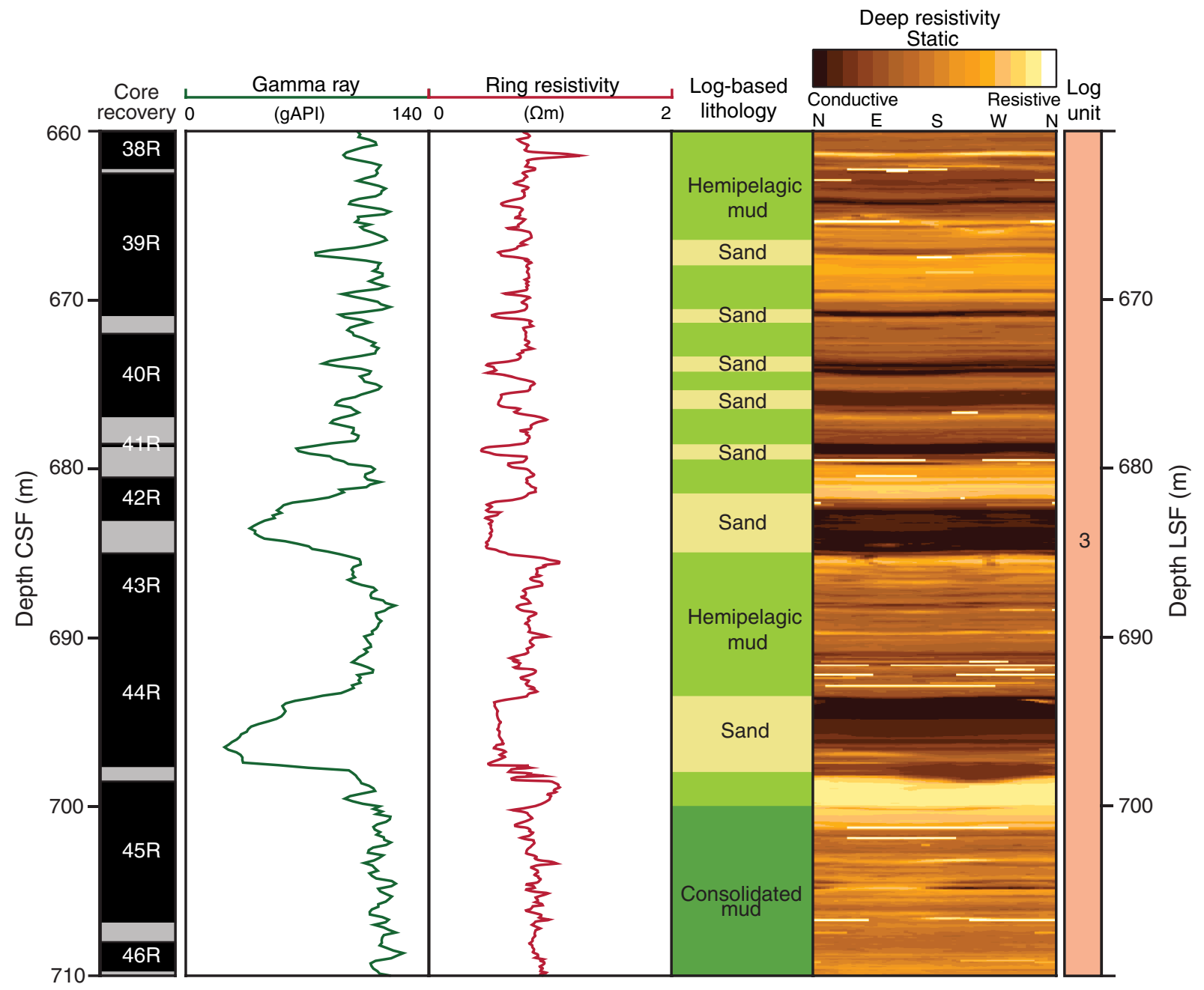


Figure F74. LWD data from logging Unit 4, showing gamma ray and resistivity logs. Left panel shows seismic data from the region. Natural gamma ray (NGR) data (blue) for correlation between logs and cores, with colored core lithology from visual core descriptions. Heavy black lines = four packages of similar log character. VE = vertical exaggeration, $\mathrm{MSCL}=$ multisensor core logger.

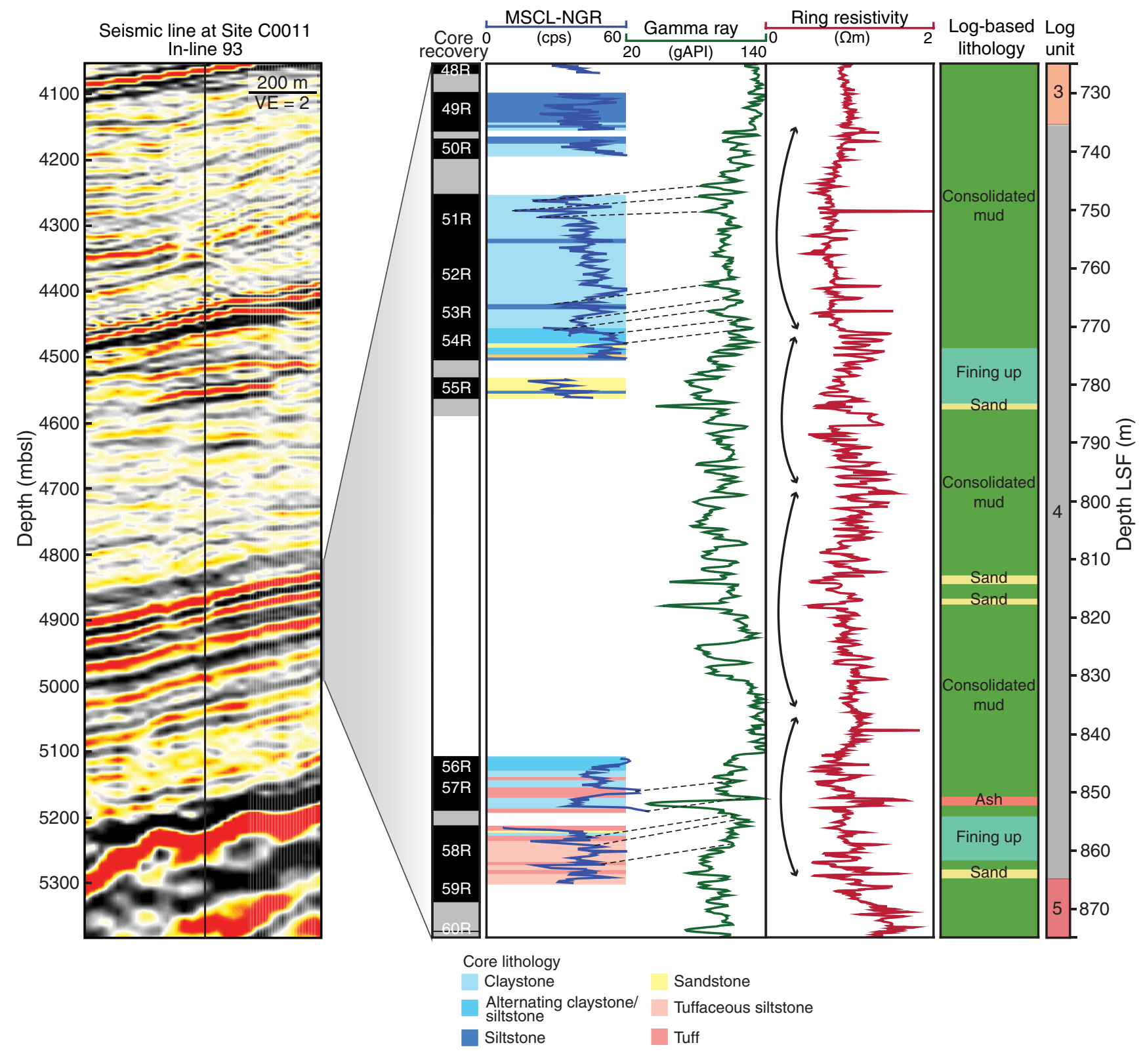


Figure F75. Selection of resistivity images, Hole C0011A. A. Bedding-parallel resistive layers that may correspond to ash layers in logging Unit 1. B. Volcaniclastic sandstone (354.5-357.8 m LSF, equivalent to 360.4$362.0 \mathrm{~m} \mathrm{CSF}$ ) in logging Unit 2. C. Borehole breakouts offset by high-angle faults. D. Low-angle faults and image of chaotic deposit in logging Unit 2, described in further detail in "Lithology."

A
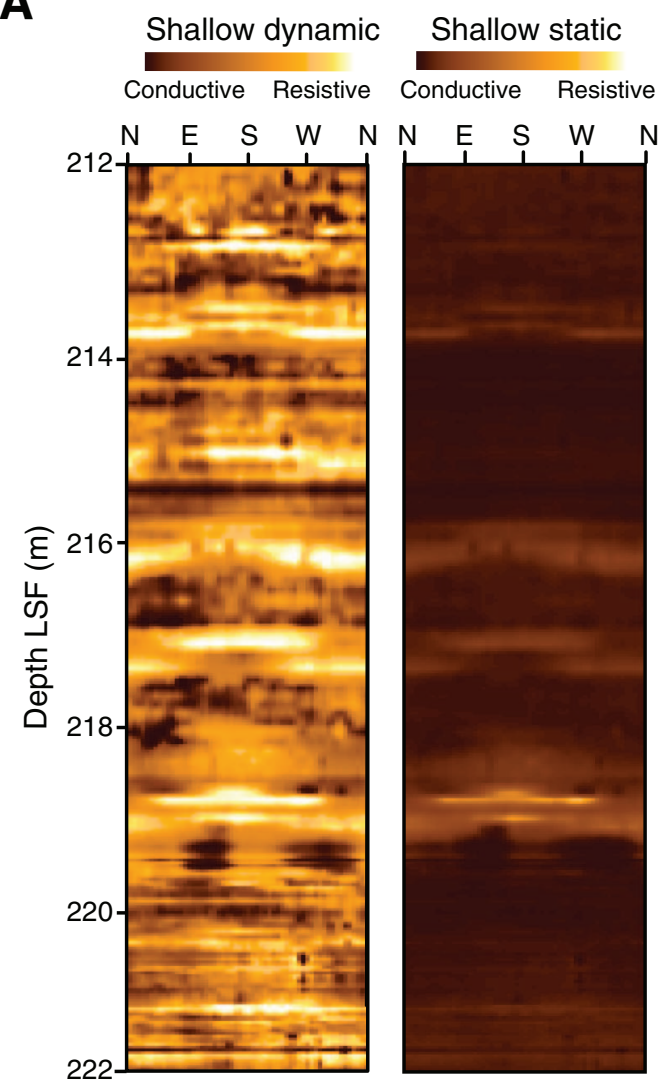

C

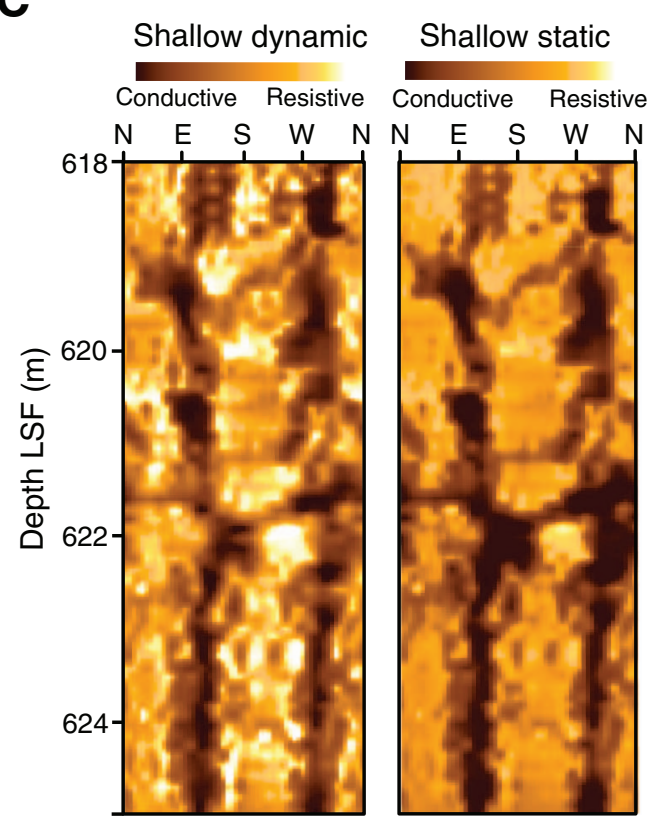

B
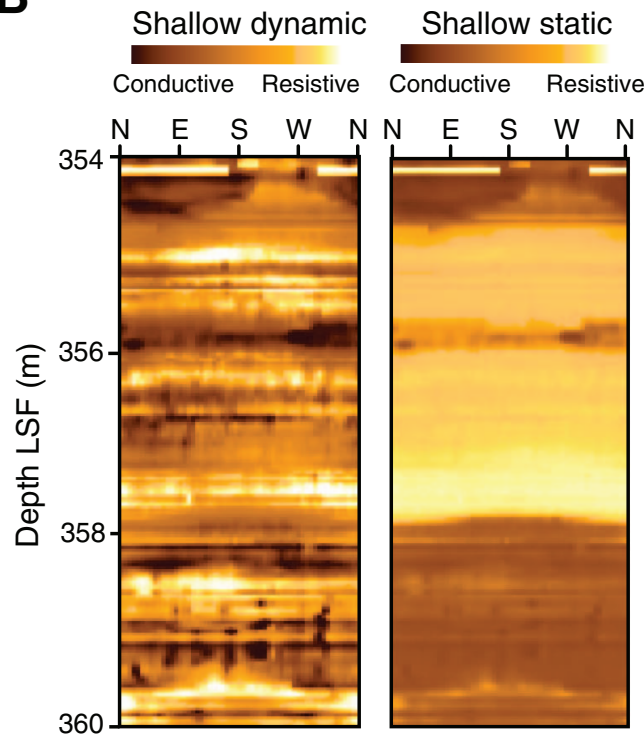

D
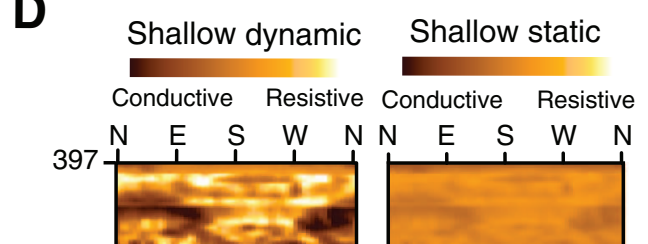$$
397
$$

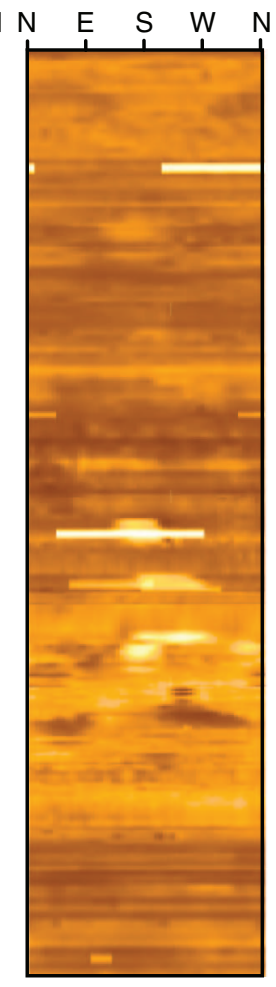


Figure F76. Azimuths of borehole breakouts in Hole C0011A. Std dev = standard deviation.

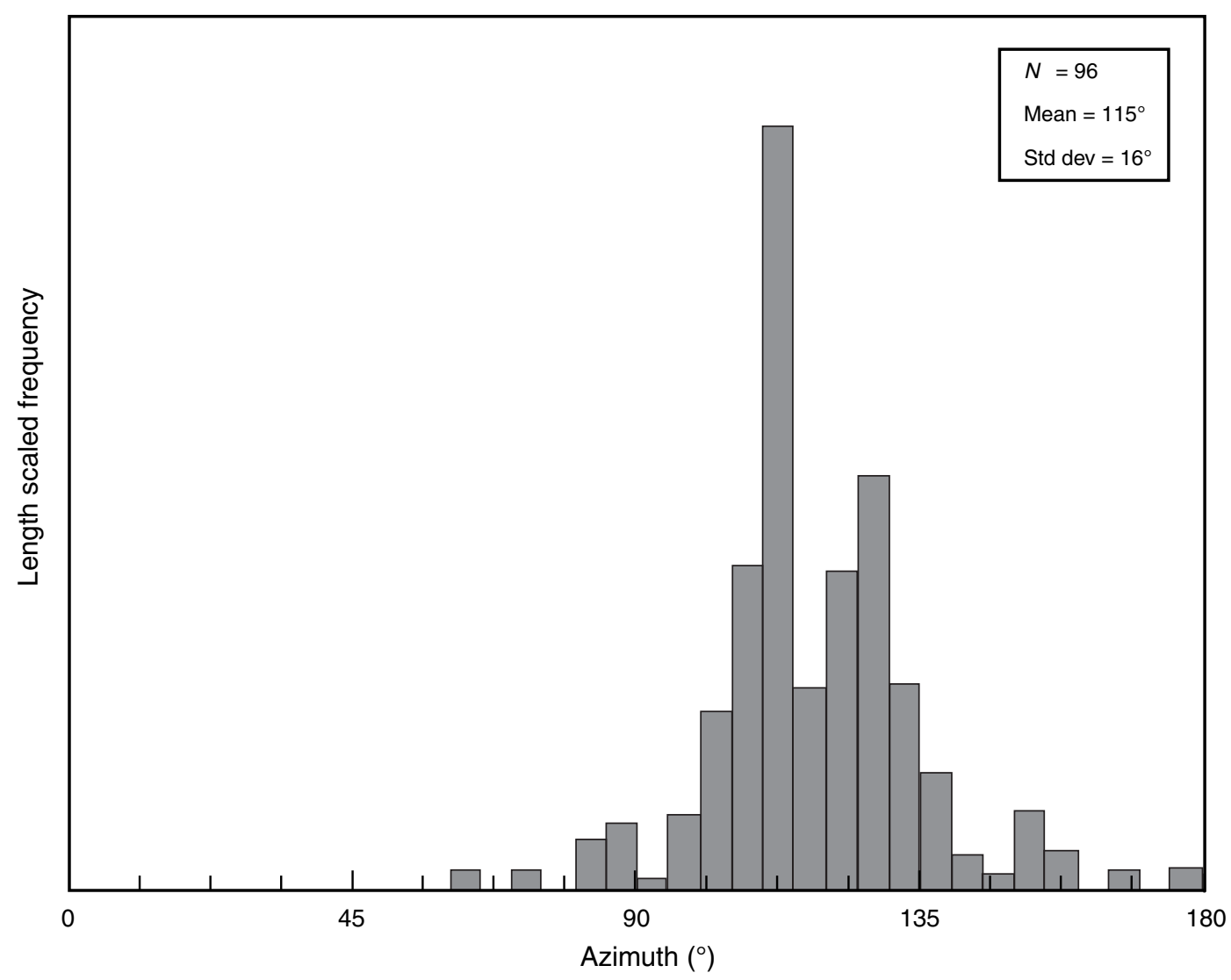


Figure F77. Bathymetric plot of the Nankai transect, with site locations from NanTroSEIZE Stage 1 and maximum horizontal compressive stress direction at each site as indicated by borehole breakouts. Site C0011 (purple arrow) has a north-northeast-south-southwest azimuth, near perpendicular to convergence direction of Philippine Sea plate (northwest-southeast) (yellow arrows) and sites within accretionary prism (red arrows). It is near-parallel to azimuth indicated in shallow sediments of Kumano Basin (blue arrow).

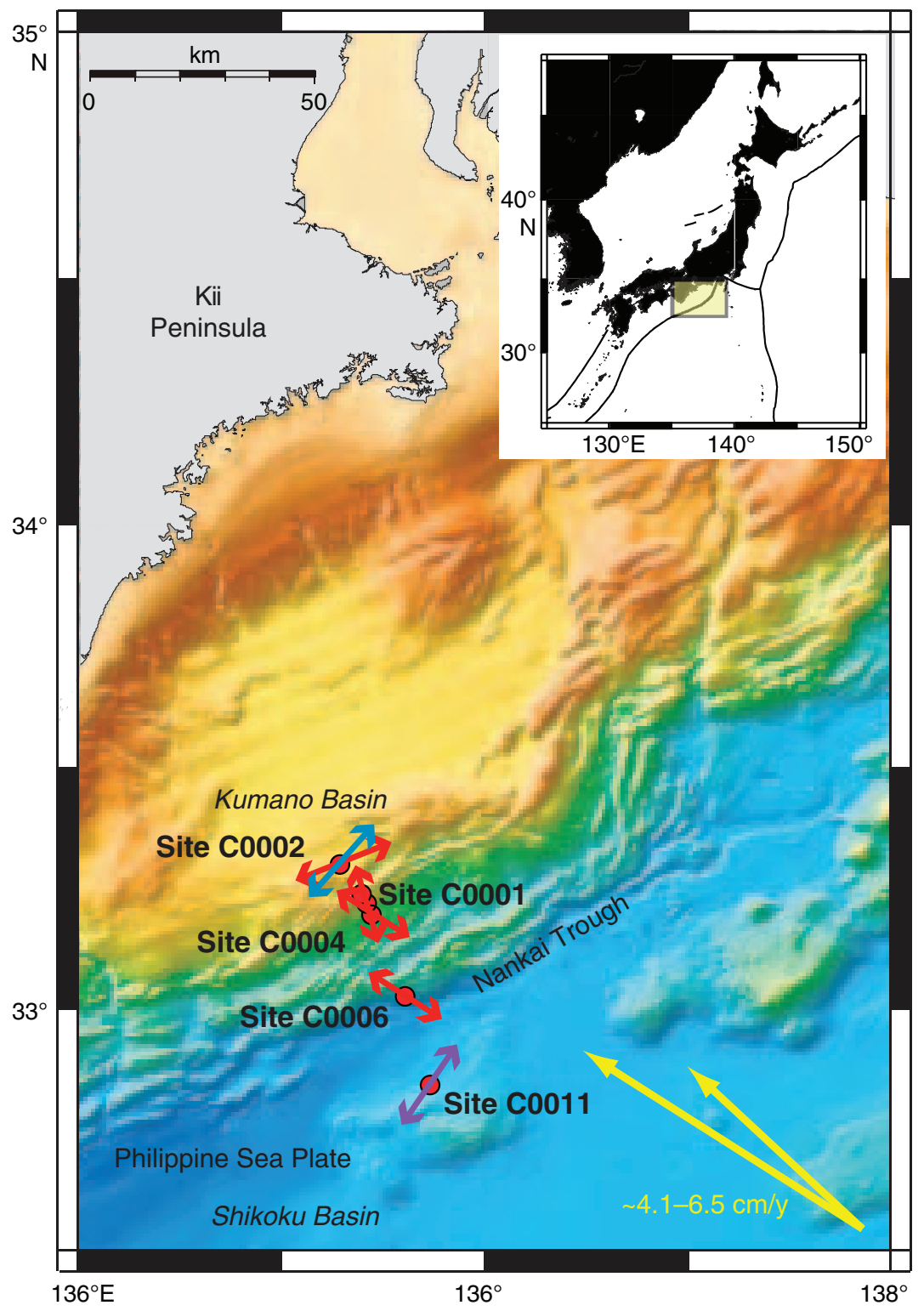


Figure F78. 3-D prestack depth-migrated seismic reflection profile along In-line 93, Site C0011. A. Uninterpreted. B. Interpreted. Blue lines $=$ normal faults. $\mathrm{VE}=$ vertical exaggeration.
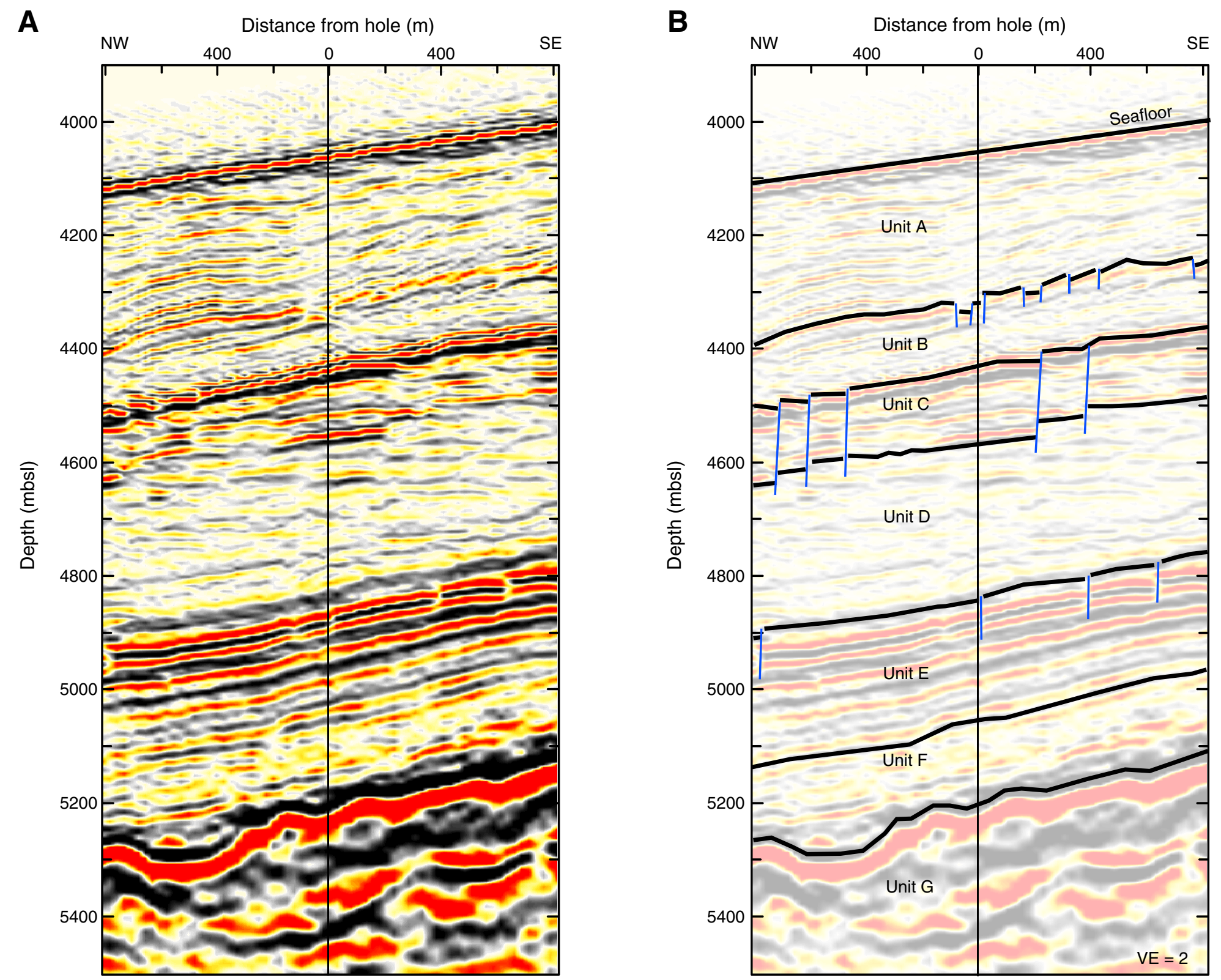
Figure F79. 3-D prestack depth-migrated seismic reflection profile along Cross-line 816, Site C0011. A. Uninterpreted. B. Interpreted. VE $=$ vertical exaggeration.
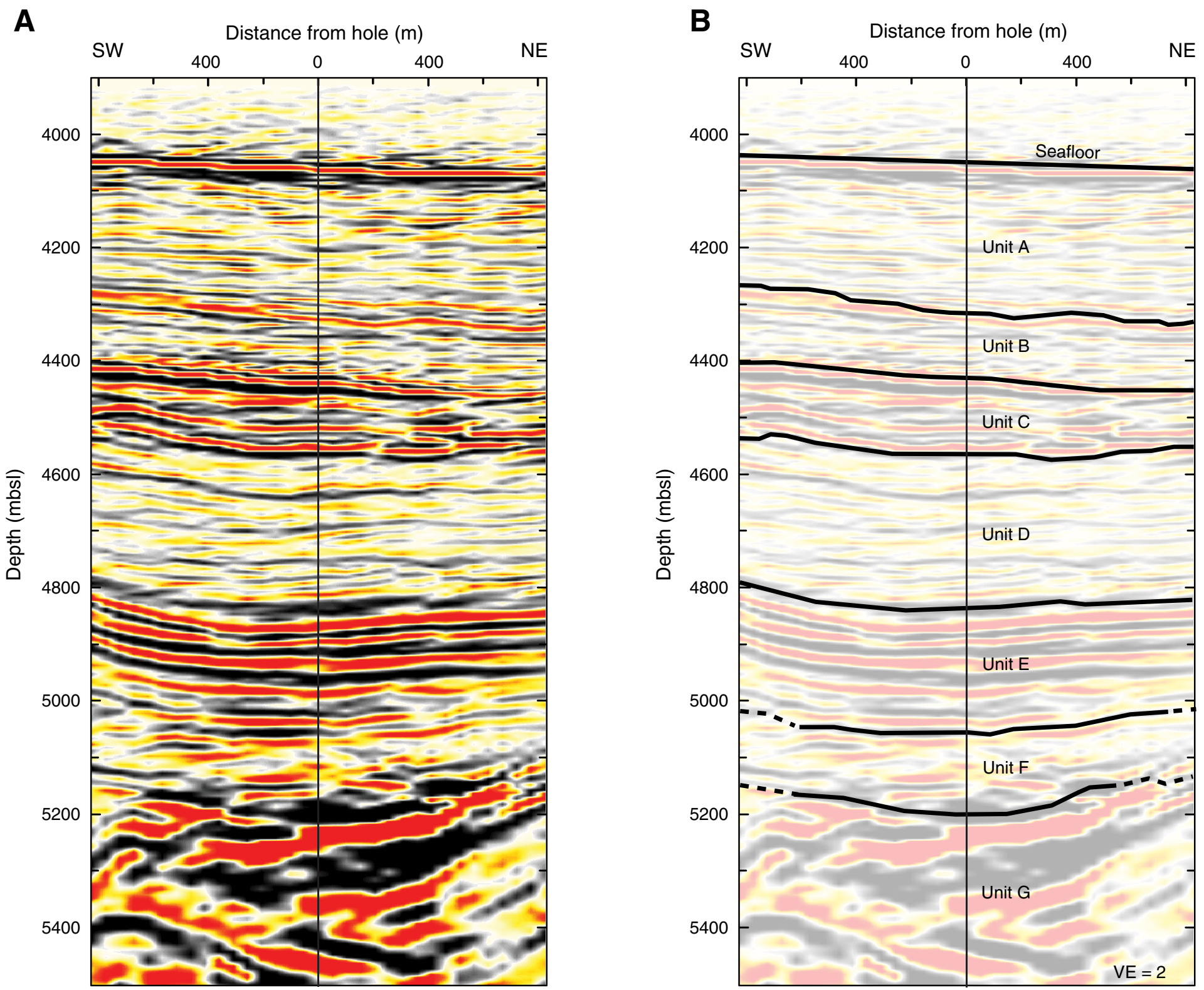
Figure F80. Synthetic seismogram, Hole C0011B. A. $P$-wave velocity measurements (blue) on discrete core samples and prestack depth migration (PSDM)-derived $P$-wave velocity (black dashed). B. Bulk density measurements on discrete core samples. C. Fifteen traces of Cross-line (XL) 816 closest to borehole. D. Calculated synthetic (Synth.) seismograms shown as five identical traces side by side. E. Fifteen traces of Cross-line 816 closest to borehole. F. LWD gamma ray log, Hole C0011A. G. LWD ring resistivity log, Hole C0011A.

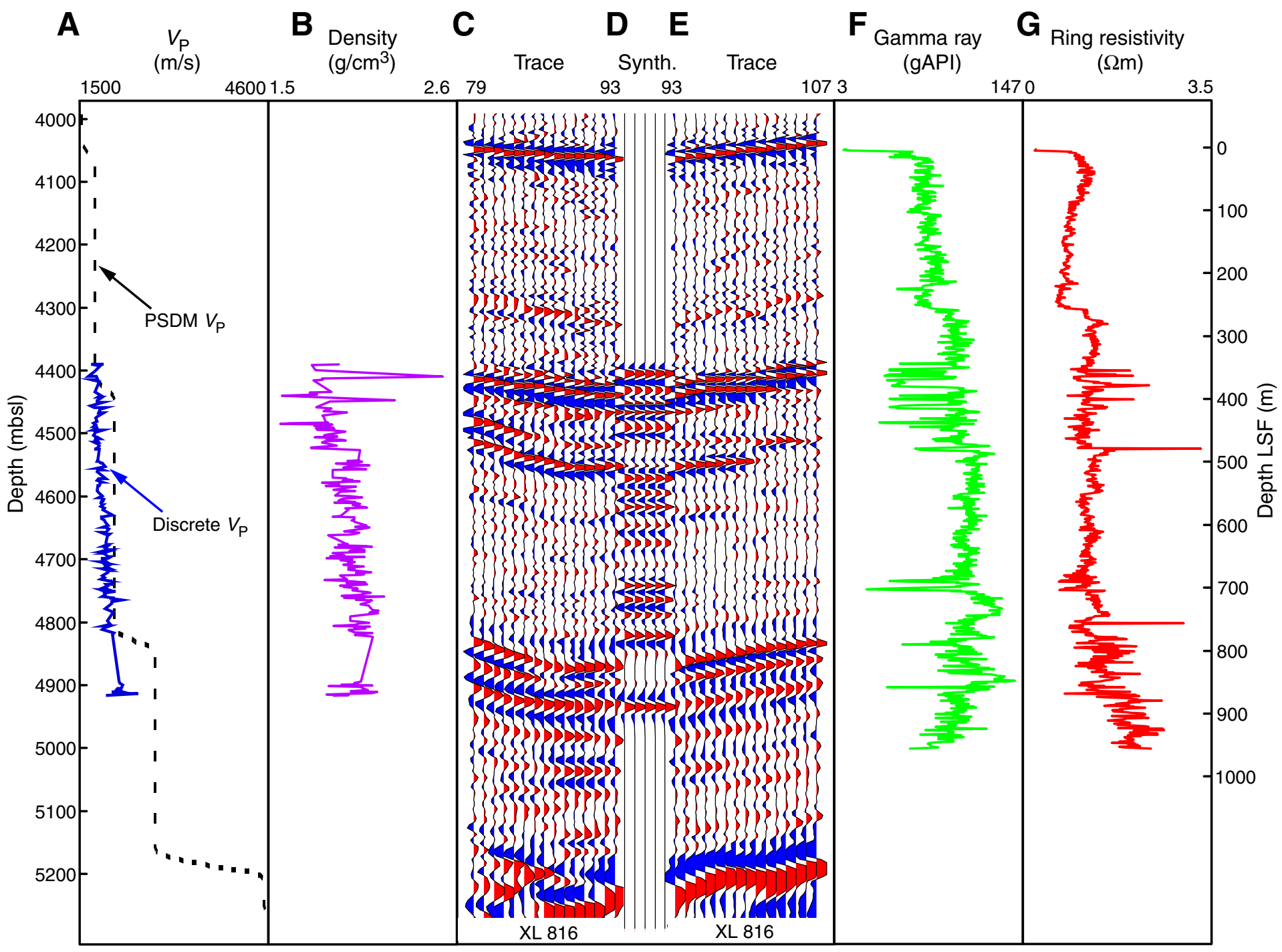


Figure F81. Logging units (1-5) and seismic units (A-G) superimposed on 3-D prestack depth-migrated seismic reflection profile (In-line 93) through Hole C0011A. VE = vertical exaggeration.

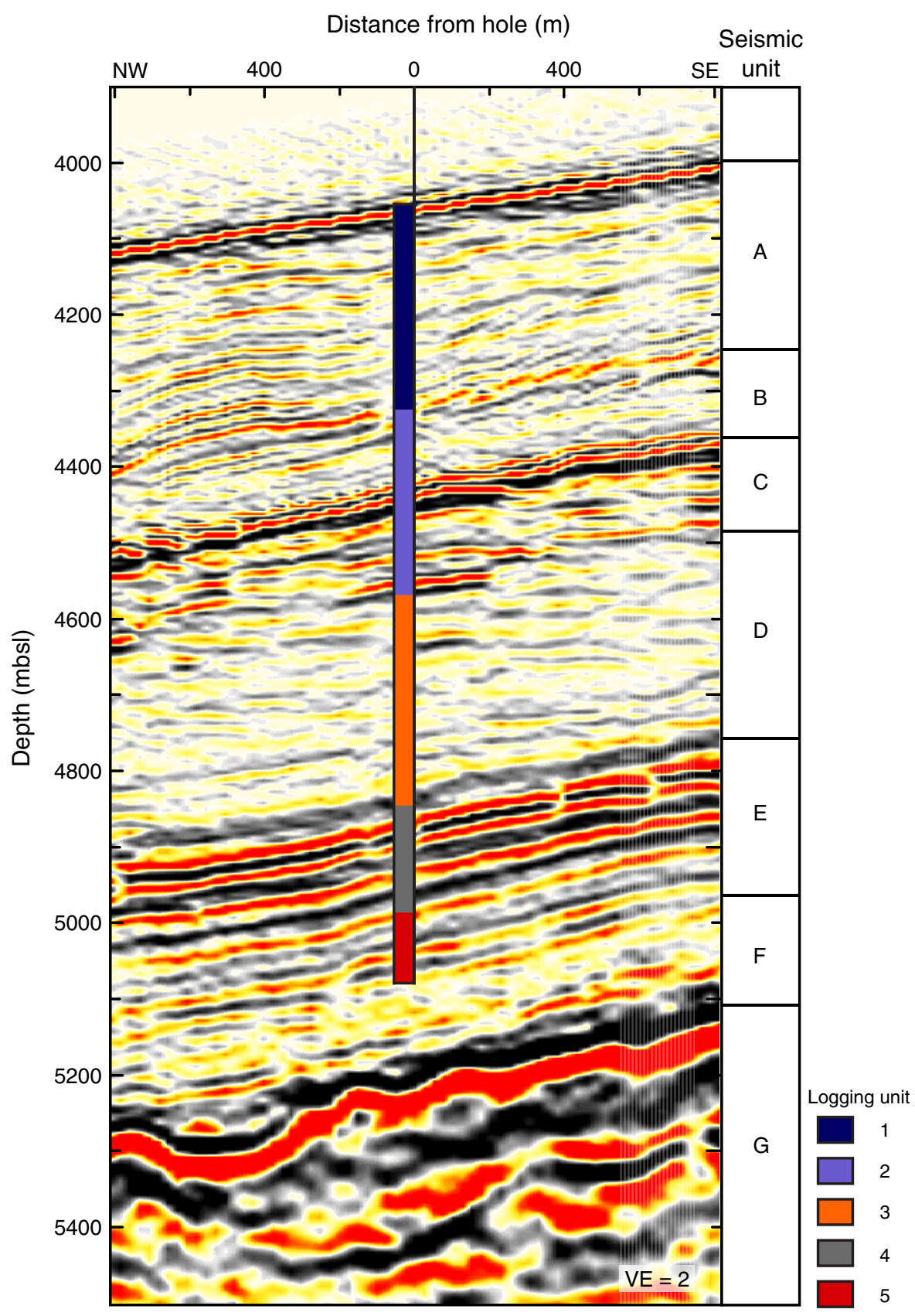


Table T1. Coring summary, Site C0011. (See table note.) (Continued on next page.)

Hole C0011B

Latitude: $32^{\circ} 49.7369^{\prime} \mathrm{N}$

Longitude: $136^{\circ} 52.9074^{\prime} \mathrm{E}$

Seafloor (DRF, m): 4077.0

Distance between rig floor and sea level $(\mathrm{m}): 28.3$

Water depth (m): 4048.7

Total depth (DRF, m): 4958.0

Total penetration (CSF, $\mathrm{m}): 881.0$

Total length of cored section $(\mathrm{m}): 483.3$

Total core recovered $(\mathrm{m}): 329.2$

Core recovery (\%): 68.1

Total number of cores: 61

\begin{tabular}{|c|c|c|c|c|c|c|c|c|c|}
\hline \multirow[b]{2}{*}{ Core } & \multirow{2}{*}{$\begin{array}{c}\text { Date } \\
\text { (September } \\
\text { 2009) }\end{array}$} & \multirow{2}{*}{$\begin{array}{l}\text { Local time } \\
\text { (h) }\end{array}$} & \multicolumn{2}{|c|}{ Depth DRF (m) } & \multicolumn{2}{|c|}{ Depth CSF (m) } & \multirow{2}{*}{$\begin{array}{l}\text { Advanced } \\
\text { (m) }\end{array}$} & \multirow{2}{*}{$\begin{array}{l}\text { Recovered } \\
\text { (m) }\end{array}$} & \multirow{2}{*}{$\begin{array}{c}\text { Recovery } \\
\text { (\%) }\end{array}$} \\
\hline & & & Top & Bottom & Top & Bottom & & & \\
\hline \multicolumn{10}{|c|}{ 322-C0011B- } \\
\hline $1 \mathrm{R}$ & 9 & 0258 & 4417.0 & 4426.5 & 340.0 & 349.5 & 9.5 & 2.22 & 23.4 \\
\hline $2 \mathrm{R}$ & 9 & 1315 & 4426.6 & 4436.0 & 349.6 & 359.0 & 9.5 & 1.30 & 13.7 \\
\hline $3 R$ & 9 & 1623 & 4436.0 & 4442.0 & 359.0 & 365.0 & 6.0 & 6.26 & 104.3 \\
\hline $4 \mathrm{R}$ & 9 & 2327 & 4442.0 & 4451.5 & 365.0 & 374.5 & 9.5 & 3.55 & 37.4 \\
\hline $5 \mathrm{R}$ & 10 & 0235 & 4451.5 & 4461.0 & 374.5 & 384.0 & 9.5 & 3.65 & 38.4 \\
\hline $6 \mathrm{R}$ & 10 & 0607 & 4461.0 & 4470.5 & 384.0 & 393.5 & 9.5 & 9.40 & 98.9 \\
\hline $7 \mathrm{R}$ & 10 & 0907 & 4470.5 & 4480.0 & 393.5 & 403.0 & 9.5 & 7.31 & 76.9 \\
\hline $8 \mathrm{R}$ & 10 & 1247 & 4480.0 & 4489.5 & 403.0 & 412.5 & 9.5 & 8.19 & 86.2 \\
\hline 9R & 10 & 1511 & 4489.5 & 4499.0 & 412.5 & 422.0 & 9.5 & 4.90 & 51.6 \\
\hline $10 \mathrm{R}$ & 10 & 1802 & 4499.0 & 4508.5 & 422.0 & 431.5 & 9.5 & 3.05 & 32.1 \\
\hline $11 \mathrm{R}$ & 10 & 2023 & 4508.5 & 4518.0 & 431.5 & 441.0 & 9.5 & 9.13 & 96.1 \\
\hline $12 \mathrm{R}$ & 10 & 2324 & 4518.0 & 4527.5 & 441.0 & 450.5 & 9.5 & 7.31 & 76.9 \\
\hline $13 \mathrm{R}$ & 11 & 0857 & 4527.5 & 4537.0 & 450.5 & 460.0 & 9.5 & 8.16 & 85.9 \\
\hline $14 \mathrm{R}$ & 11 & 1148 & 4537.0 & 4546.5 & 460.0 & 469.5 & 9.5 & 5.78 & 60.8 \\
\hline $15 R$ & 11 & 1204 & 4546.5 & 4553.8 & 469.5 & 476.8 & 7.3 & 7.36 & 100.8 \\
\hline $16 \mathrm{R}$ & 12 & 1645 & 4553.8 & 4556.0 & 476.8 & 479.0 & 2.2 & 1.98 & 90.0 \\
\hline $17 \mathrm{R}$ & 12 & 2045 & 4556.0 & 4558.4 & 479.0 & 481.4 & 2.4 & 0.05 & 2.1 \\
\hline $18 \mathrm{R}$ & 13 & 0034 & 4558.4 & 4567.9 & 481.4 & 490.9 & 9.5 & 0.00 & 0.0 \\
\hline $19 \mathrm{R}$ & 13 & 0549 & 4567.9 & 4575.4 & 490.9 & 498.4 & 7.5 & 7.30 & 97.3 \\
\hline $20 \mathrm{R}$ & 13 & 0930 & 4575.4 & 4578.5 & 498.4 & 501.5 & 3.1 & 0.58 & 18.7 \\
\hline $21 \mathrm{R}$ & 13 & 1404 & 4578.5 & 4587.9 & 501.5 & 510.9 & 9.4 & 8.81 & 93.7 \\
\hline $22 \mathrm{R}$ & 13 & 1755 & 4587.9 & 4597.4 & 510.9 & 520.4 & 9.5 & 0.23 & 2.4 \\
\hline $23 \mathrm{R}$ & 13 & 2050 & 4597.4 & 4606.9 & 520.4 & 529.9 & 9.5 & 8.91 & 93.8 \\
\hline $24 \mathrm{R}$ & 13 & 2351 & 4606.9 & 4616.4 & 529.9 & 539.4 & 9.5 & 5.21 & 54.8 \\
\hline $25 \mathrm{R}$ & 14 & 0359 & 4616.4 & 4626.0 & 539.4 & 549.0 & 9.6 & 4.03 & 42.0 \\
\hline $26 \mathrm{R}$ & 14 & 0730 & 4626.0 & 4635.5 & 549.0 & 558.5 & 9.5 & 8.51 & 89.6 \\
\hline $27 \mathrm{R}$ & 14 & 1054 & 4635.5 & 4645.0 & 558.5 & 568.0 & 9.5 & 6.81 & 71.7 \\
\hline $28 \mathrm{R}$ & 14 & 1409 & 4645.0 & 4650.6 & 568.0 & 573.6 & 5.6 & 4.02 & 71.8 \\
\hline $29 R$ & 14 & 1725 & 4650.6 & 4657.4 & 573.6 & 580.4 & 6.8 & 0.30 & 4.4 \\
\hline $30 \mathrm{R}$ & 15 & 0410 & 4657.4 & 4663.5 & 580.4 & 586.5 & 6.1 & 4.02 & 65.9 \\
\hline $31 \mathrm{R}$ & 15 & 0827 & 4663.5 & 4673.0 & 586.5 & 596.0 & 9.5 & 4.53 & 47.7 \\
\hline $32 \mathrm{R}$ & 15 & 1147 & 4673.0 & 4682.5 & 596.0 & 605.5 & 9.5 & 6.03 & 63.5 \\
\hline $33 R$ & 15 & 1456 & 4682.5 & 4692.0 & 605.5 & 615.0 & 9.5 & 7.24 & 76.2 \\
\hline $34 \mathrm{R}$ & 15 & 1746 & 4692.0 & 4701.5 & 615.0 & 624.5 & 9.5 & 0.32 & 3.4 \\
\hline $35 \mathrm{R}$ & 15 & 2127 & 4701.5 & 4711.0 & 624.5 & 634.0 & 9.5 & 9.92 & 104.4 \\
\hline $36 \mathrm{R}$ & 16 & 0021 & 4711.0 & 4720.5 & 634.0 & 643.5 & 9.5 & 7.18 & 75.6 \\
\hline $37 \mathrm{R}$ & 16 & 0330 & 4720.5 & 4730.0 & 643.5 & 653.0 & 9.5 & 10.08 & 106.1 \\
\hline $38 \mathrm{R}$ & 16 & 0637 & 4730.0 & 4739.5 & 653.0 & 662.5 & 9.5 & 9.41 & 99.1 \\
\hline $39 \mathrm{R}$ & 16 & 1044 & 4739.5 & 4749.0 & 662.5 & 672.0 & 9.5 & 8.50 & 89.5 \\
\hline $40 \mathrm{R}$ & 16 & 1434 & 4749.0 & 4755.5 & 672.0 & 678.5 & 6.5 & 4.92 & 75.7 \\
\hline $41 \mathrm{R}$ & 16 & 1735 & 4755.5 & 4757.5 & 678.5 & 680.5 & 2.0 & 0.25 & 12.5 \\
\hline $42 \mathrm{R}$ & 16 & 2108 & 4757.5 & 4762.0 & 680.5 & 685.0 & 4.5 & 3.64 & 80.9 \\
\hline $43 R$ & 17 & 0330 & 4762.0 & 4766.0 & 685.0 & 689.0 & 4.0 & 8.45 & 211.3 \\
\hline $44 \mathrm{R}$ & 17 & 0907 & 4766.0 & 4775.5 & 689.0 & 698.5 & 9.5 & 8.62 & 90.7 \\
\hline $45 \mathrm{R}$ & 17 & 1342 & 4775.5 & 4785.0 & 698.5 & 708.0 & 9.5 & 8.37 & 88.1 \\
\hline $46 \mathrm{R}$ & 17 & 2008 & 4785.0 & 4788.5 & 708.0 & 711.5 & 3.5 & 1.79 & 51.1 \\
\hline $47 R$ & 18 & 0128 & 4788.5 & 4798.0 & 711.5 & 721.0 & 9.5 & 6.58 & 69.3 \\
\hline $48 \mathrm{R}$ & 18 & 0638 & 4798.0 & 4807.1 & 721.0 & 730.1 & 9.1 & 5.90 & 64.8 \\
\hline $49 \mathrm{R}$ & 18 & 1100 & 4807.1 & 4815.0 & 730.1 & 738.0 & 7.9 & 6.68 & 84.6 \\
\hline $50 \mathrm{R}$ & 18 & 1745 & 4815.0 & 4824.5 & 738.0 & 747.5 & 9.5 & 3.75 & 39.5 \\
\hline $51 \mathrm{R}$ & 20 & 1400 & 4824.5 & 4834.0 & 747.5 & 757.0 & 9.5 & 10.15 & 106.8 \\
\hline $52 \mathrm{R}$ & 20 & 1730 & 4834.0 & 4843.5 & 757.0 & 766.5 & 9.5 & 10.15 & 106.8 \\
\hline $53 \mathrm{R}$ & 20 & 2207 & 4843.5 & 4847.2 & 766.5 & 770.2 & 3.7 & 5.71 & 154.3 \\
\hline
\end{tabular}


Table T1 (continued).

\begin{tabular}{|c|c|c|c|c|c|c|c|c|c|}
\hline \multirow[b]{2}{*}{ Core } & \multirow{2}{*}{$\begin{array}{c}\text { Date } \\
\text { (September } \\
\text { 2009) }\end{array}$} & \multirow{2}{*}{$\begin{array}{l}\text { Local time } \\
\text { (h) }\end{array}$} & \multicolumn{2}{|c|}{ Depth DRF (m) } & \multicolumn{2}{|c|}{ Depth CSF (m) } & \multirow{2}{*}{$\begin{array}{l}\text { Advanced } \\
\text { (m) }\end{array}$} & \multirow{2}{*}{$\begin{array}{l}\text { Recovered } \\
\text { (m) }\end{array}$} & \multirow{2}{*}{$\begin{array}{c}\text { Recovery } \\
\text { (\%) }\end{array}$} \\
\hline & & & Top & Bottom & Top & Bottom & & & \\
\hline $54 \mathrm{R}$ & 21 & 0455 & 4847.2 & 4856.0 & 770.2 & 779.0 & 8.8 & 5.77 & 65.6 \\
\hline $55 \mathrm{R}$ & 21 & 0908 & 4856.0 & 4863.3 & 779.0 & 786.3 & 7.3 & 3.64 & 49.9 \\
\hline $56 \mathrm{R}$ & 22 & 0404 & 4921.0 & 4923.4 & 844.0 & 846.4 & 2.4 & 2.54 & 105.8 \\
\hline $57 R$ & 22 & 0937 & 4923.4 & 4932.9 & 846.4 & 855.9 & 9.5 & 6.93 & 72.9 \\
\hline $58 \mathrm{R}$ & 22 & 1545 & 4932.9 & 4942.4 & 855.9 & 865.4 & 9.5 & 9.89 & 104.1 \\
\hline $59 R$ & 22 & 2145 & 4942.4 & 4951.0 & 865.4 & 874.0 & 8.6 & 3.73 & 43.4 \\
\hline $60 R$ & 23 & 0215 & 4951.0 & 4953.0 & 874.0 & 876.0 & 2.0 & 0.15 & 7.5 \\
\hline $61 R$ & 23 & 1249 & 4953.0 & 4958.0 & 876.0 & 881.0 & 5.0 & 0.05 & 1.0 \\
\hline
\end{tabular}

Note: $\mathrm{DRF}=$ drilling depth below rig floor, $\mathrm{CSF}=$ core depth below seafloor.

Table T2. Bottom-hole assembly, Hole C0011A. (See table note.)

\begin{tabular}{lrr}
\hline \multicolumn{1}{c}{ BHA component } & $\begin{array}{c}\text { Length } \\
(\mathrm{m})\end{array}$ & $\begin{array}{c}\text { Cumulative } \\
\text { length } \\
(\mathrm{m})\end{array}$ \\
\hline 12-1/4 inch bit & 0.28 & 0.28 \\
RAB-8 (solid float/12-1/8 inch sleeve) & 3.78 & 4.06 \\
Telescope 825 HF & 8.50 & 12.56 \\
12-1/4 inch stabilizer & 2.34 & 14.90 \\
8 inch nonmagnetic drill collar & 9.13 & 24.03 \\
8-1/2 inch drilling collar & 9.30 & 33.33 \\
8-1/2 inch drilling collar & 9.30 & 42.63 \\
8-1/2 inch drilling collar & 9.30 & 51.93 \\
8-1/2 inch drilling collar & 9.30 & 61.23 \\
8-1/2 inch drilling collar & 9.30 & 70.53 \\
8-1/2 inch drilling collar & 9.30 & 79.83 \\
Mechanical jar & 10.70 & 90.53 \\
8-1/2 inch drilling collar & 9.30 & 99.83 \\
8-1/2 inch drilling collar & 9.30 & 109.13 \\
8-1/2 inch drilling collar & 9.30 & 118.43 \\
8-1/2 inch drilling collar & 9.30 & 127.73 \\
8-1/2 inch drilling collar & 9.30 & 137.03 \\
Crossover sub & 1.00 & 138.03 \\
5-7/8 inch 26.40 drill pipe (steel) & 10.00 & 148.03 \\
\hline
\end{tabular}

Note: $\mathrm{BHA}=$ bottom-hole assembly.

Table T3. Summary of lithologic units, Site C0011. (See table note.)

\begin{tabular}{|c|c|c|c|c|c|c|c|c|}
\hline \multirow[b]{2}{*}{ Unit } & \multirow[b]{2}{*}{ Unit name } & \multicolumn{2}{|c|}{ Core, section, interval $(\mathrm{cm})$} & \multicolumn{2}{|c|}{ Depth CSF (m) } & \multirow{2}{*}{$\begin{array}{l}\text { Thickness } \\
\text { (m) }\end{array}$} & \multirow{2}{*}{$\begin{array}{l}\text { Dominant } \\
\text { lithology }\end{array}$} & \multirow{2}{*}{$\begin{array}{l}\text { Minor } \\
\text { lithology }\end{array}$} \\
\hline & & Top & Bottom & Top & Bottom & & & \\
\hline 1 & Upper Shikoku Basin & $\begin{array}{l}\text { 322-C0011B- } \\
* * * \text { Drilled wi }\end{array}$ & $\begin{array}{l}\text { 322-C0011B- } \\
\text { hout coring }\end{array}$ & 0.00 & 340.00 & 340.00 & - & - \\
\hline II & $\begin{array}{l}\text { Middle Shikoku Basin } \\
\text { tuffaceous sandstones, } \\
\text { volcaniclastic sandstones }\end{array}$ & $1 \mathrm{R}-1,0$ & $17 \mathrm{R}-\mathrm{CC}, 6$ & 340.00 & 479.06 & 139.06 & Silty claystone & $\begin{array}{l}\text { Tuffaceous sandstone } \\
\text { Volcaniclastic sandstone } \\
\text { Clayey siltstone }\end{array}$ \\
\hline III & $\begin{array}{l}\text { Lower Shikoku Basin } \\
\text { hemipelagites }\end{array}$ & $17 \mathrm{R}-\mathrm{CC}, 6$ & $40 \mathrm{R}-2,58$ & 479.06 & 673.98 & 194.92 & Silty claystone & $\begin{array}{l}\text { Calcareous claystone } \\
\text { Lime mudstone }\end{array}$ \\
\hline IV & $\begin{array}{l}\text { Lower Shikoku Basin } \\
\text { turbidites }\end{array}$ & $40 R-2,58$ & $57 R-3,73$ & 673.98 & 849.95 & 175.97 & Tuffaceous silty claystone & Silty sandstone \\
\hline $\mathrm{V}$ & Volcaniclastic-rich deposits & $57 \mathrm{R}-3,73$ & $61 \mathrm{R}-\mathrm{CC}, 5$ & 849.95 & 876.05 & 26.10 & Tuffaceous sandy siltstone & $\begin{array}{l}\text { Silty claystone } \\
\text { Tuff layer }\end{array}$ \\
\hline
\end{tabular}

Note: $-=$ not available. 
Table T4. Results of bulk powder X-ray diffraction analysis, Hole C0011B. (See table note.) (Continued on next three pages.)

\begin{tabular}{|c|c|c|c|c|c|c|c|c|c|c|c|c|c|c|c|c|c|c|}
\hline \multirow[b]{3}{*}{$\begin{array}{l}\text { Core, section, } \\
\text { interval }(\mathrm{cm})\end{array}$} & \multirow[b]{3}{*}{$\begin{array}{l}\text { Depth } \\
\text { CSF }(m)\end{array}$} & \multicolumn{8}{|c|}{ Measured values of X-ray diffraction peaks } & \multicolumn{9}{|c|}{ Abundance calculated from SVD normalization factors } \\
\hline & & \multicolumn{4}{|c|}{ Peak intensity (counts/step) } & \multicolumn{4}{|c|}{ Integrated peak area (total counts) } & \multicolumn{5}{|c|}{ Absolute (wt\%) } & \multicolumn{4}{|c|}{ Relative (wt\%) } \\
\hline & & 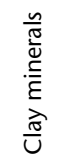 & $\begin{array}{l}\frac{y}{2} \\
\frac{\pi}{\partial} \\
0\end{array}$ & $\begin{array}{l}\frac{\bar{\pi}}{0} \\
\frac{0}{0} \\
\frac{0}{v}\end{array}$ & $\frac{\stackrel{\mathscr{U}}{U}}{\frac{U}{U}}$ & 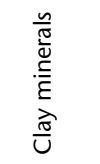 & $\begin{array}{l}\frac{Y}{2} \\
\frac{\pi}{2} \\
O^{\prime}\end{array}$ & $\begin{array}{l}\frac{\bar{\pi}}{0} \\
\frac{0}{0} \\
\frac{0}{0}\end{array}$ & $\frac{\stackrel{ \pm}{U}}{\frac{U}{U}}$ & $\begin{array}{l}\frac{n}{\sigma} \\
\frac{\sigma}{d} \\
\frac{\mathscr{E}}{E} \\
\frac{\vec{\sigma}}{U}\end{array}$ & $\frac{\frac{N}{2}}{\frac{\pi}{2}}$ & $\begin{array}{l}\frac{\bar{\pi}}{0} \\
\frac{0}{0} \\
\frac{0}{v}\end{array}$ & $\frac{\stackrel{\mathscr{U}}{U}}{\frac{U}{U}}$ & $\begin{array}{l}\bar{\pi} \\
\stackrel{0}{0}\end{array}$ & $\begin{array}{l}\frac{n}{\mathbb{U}} \\
\frac{\mathscr{U}}{\bar{E}} \\
\frac{\vec{U}}{U}\end{array}$ & $\begin{array}{l}\frac{N}{2} \\
\frac{\pi}{\partial} \\
O\end{array}$ & $\begin{array}{l}\frac{\bar{\pi}}{0} \\
\frac{0}{0} \\
\frac{0}{0}\end{array}$ & $\frac{\stackrel{U}{U}}{\frac{U}{U}}$ \\
\hline $\begin{array}{l}\text { 322-C0011B- } \\
\text { Unit II }\end{array}$ & & & & & & & & & & & & & & & & & & \\
\hline 1R-1, 22 & 340.22 & 99 & 318 & 163 & 42 & 11,265 & 12,520 & 10,439 & 3,491 & 118.6 & 5.1 & 10.5 & 0.1 & 134.3 & 88 & 4 & 8 & $\operatorname{Tr}$ \\
\hline $1 R-1,38$ & 340.38 & 66 & 634 & 107 & 209 & 6,239 & 23,370 & 8,895 & 8,619 & 67.5 & 12.4 & 9.2 & 5.6 & 94.7 & 71 & 13 & 10 & 6 \\
\hline $1 \mathrm{R}-2,26$ & 341.14 & 67 & 871 & 147 & 30 & 6,114 & 32,750 & 11,631 & 1,894 & 67.5 & 17.8 & 12.6 & 0.1 & 98.0 & 69 & 18 & 13 & $\operatorname{Tr}$ \\
\hline $1 \mathrm{R}-2,90$ & 341.77 & 75 & 473 & 99 & 28 & 7,638 & 22,159 & 9,461 & 2,167 & 81.5 & 11.4 & 9.7 & 0.1 & 102.7 & 79 & 11 & 9 & $\mathrm{Tr}$ \\
\hline $2 \mathrm{R}-1,59$ & 350.09 & 73 & 819 & 139 & 32 & 6,995 & 31,728 & 11,754 & 1,866 & 76.4 & 17.0 & 12.6 & 0.1 & 106.1 & 72 & 16 & 12 & $\mathrm{Tr}$ \\
\hline 2R-CC, 19 & 350.97 & 27 & 601 & 522 & 51 & 2,905 & 20,106 & 29,752 & 2,537 & 49.6 & 10.1 & 39.0 & 0.1 & 98.8 & 50 & 10 & 39 & $\mathrm{Tr}$ \\
\hline $3 \mathrm{R}-1,22$ & 359.22 & 62 & 865 & 153 & 103 & 5,801 & 31,465 & 11,321 & 4,624 & 64.4 & 17.1 & 12.3 & 0.4 & 94.2 & 68 & 18 & 13 & $\mathrm{Tr}$ \\
\hline $3 R-2,25$ & 359.86 & 63 & 818 & 124 & 30 & 5,655 & 30,351 & 10,323 & 1,861 & 62.1 & 16.5 & 11.1 & 0.1 & 89.8 & 69 & 18 & 12 & $\mathrm{Tr}$ \\
\hline $3 R-4,37$ & 361.92 & 39 & 622 & 806 & 39 & 2,723 & 21,471 & 45,187 & 2,024 & 58.9 & 10.3 & 60.2 & 0.1 & 129.4 & 46 & 8 & 46 & $\mathrm{Tr}$ \\
\hline $3 R-4,118.5$ & 362.74 & 61 & 713 & 160 & 19 & 5,856 & 29,454 & 12,548 & 1,243 & 65.7 & 15.8 & 14.1 & 0.1 & 95.8 & 69 & 17 & 15 & $\operatorname{Tr}$ \\
\hline $3 R-5,19$ & 363.15 & 62 & 602 & 114 & 132 & 5,854 & 22,663 & 9,682 & 6,084 & 64.2 & 12.0 & 10.5 & 2.6 & 89.2 & 72 & 13 & 12 & 3 \\
\hline $4 \mathrm{R}-2,45$ & 366.86 & 45 & 641 & 166 & 46 & 4,989 & 24,368 & 15,519 & 2,605 & 59.6 & 12.9 & 18.7 & 0.1 & 91.3 & 65 & 14 & 20 & $\operatorname{Tr}$ \\
\hline $4 \mathrm{R}-3,0$ & 366.94 & 42 & 790 & 236 & 53 & 4,472 & 28,649 & 18,435 & 2,532 & 56.4 & 15.3 & 22.6 & 0.1 & 94.5 & 60 & 16 & 24 & $\mathrm{Tr}$ \\
\hline $5 \mathrm{R}-2,25$ & 375.62 & 19 & 868 & 801 & 43 & 1,774 & 29,305 & 39,820 & 2,182 & 45.2 & 15.2 & 52.7 & 0.1 & 113.3 & 40 & 13 & 47 & $\operatorname{Tr}$ \\
\hline $5 R-4,105$ & 378.01 & 60 & 762 & 146 & 29 & 6,442 & 29,054 & 13,406 & 1,599 & 72.2 & 15.5 & 15.1 & 0.1 & 102.9 & 70 & 15 & 15 & $\operatorname{Tr}$ \\
\hline $6 \mathrm{R}-1,128$ & 385.28 & 74 & 644 & 101 & 166 & 6,351 & 24,403 & 9,455 & 6,552 & 68.9 & 13.0 & 9.9 & 2.8 & 94.5 & 73 & 14 & 11 & 3 \\
\hline $6 \mathrm{R}-2,70$ & 386.11 & 60 & 628 & 117 & 218 & 5,521 & 24,251 & 10,131 & 9,634 & 61.3 & 13.0 & 11.1 & 7.4 & 92.7 & 66 & 14 & 12 & 8 \\
\hline $6 \mathrm{R}-3,105$ & 387.87 & 62 & 937 & 149 & 25 & 6,190 & 35,773 & 12,989 & 1,499 & 69.1 & 19.5 & 14.3 & 0.1 & 103.0 & 67 & 19 & 14 & $\operatorname{Tr}$ \\
\hline $6 \mathrm{R}-5,25$ & 388.68 & 64 & 758 & 110 & 31 & 6,199 & 28,411 & 8,994 & 1,947 & 66.6 & 15.3 & 9.2 & 0.1 & 91.3 & 73 & 17 & 10 & $\operatorname{Tr}$ \\
\hline $6 \mathrm{R}-8,15$ & 391.92 & 57 & 712 & 131 & 254 & 5,546 & 27,642 & 11,619 & 11,049 & 62.5 & 14.9 & 13.0 & 9.1 & 99.4 & 63 & 15 & 13 & 9 \\
\hline $7 \mathrm{R}-1,38$ & 393.88 & 73 & 820 & 149 & 102 & 5,604 & 31,447 & 12,146 & 4,889 & 63.0 & 17.1 & 13.5 & 0.8 & 94.5 & 67 & 18 & 14 & 1 \\
\hline $7 R-2,8$ & 394.99 & 39 & 893 & 563 & 35 & 3,684 & 33,059 & 39,874 & 2,344 & 64.0 & 17.1 & 52.1 & 0.1 & 133.3 & 48 & 13 & 39 & $\operatorname{Tr}$ \\
\hline $7 R-3,0$ & 395.14 & 46 & 701 & 622 & 56 & 4,531 & 25,915 & 40,764 & 3,088 & 73.4 & 12.8 & 53.4 & 0.1 & 139.7 & 53 & 9 & 38 & $\operatorname{Tr}$ \\
\hline 7R-5, 101.5 & 397.85 & 60 & 578 & 93 & 157 & 5,987 & 23,524 & 9,448 & 7,073 & 65.3 & 12.5 & 10.1 & 3.8 & 91.6 & 71 & 14 & 11 & 4 \\
\hline $8 \mathrm{R}-1,4$ & 403.04 & 58 & 832 & 160 & 24 & 6,182 & 36,731 & 12,248 & 1,745 & 68.4 & 20.1 & 13.3 & 0.1 & 101.9 & 67 & 20 & 13 & $\operatorname{Tr}$ \\
\hline $8 R-2,0$ & 404.27 & 46 & 735 & 320 & 73 & 3,960 & 25,915 & 23,665 & 3,863 & 55.4 & 13.6 & 30.1 & 0.5 & 99.5 & 56 & 14 & 30 & $\mathrm{Tr}$ \\
\hline $8 \mathrm{R}-3,19$ & 404.78 & 44 & 557 & 365 & 59 & 4,275 & 24,217 & 29,683 & 2,892 & 62.9 & 12.3 & 38.3 & 0.1 & 113.6 & 55 & 11 & 34 & $\operatorname{Tr}$ \\
\hline $8 R-5,104$ & 408.45 & 64 & 867 & 135 & 33 & 5,544 & 32,109 & 12,365 & 2,315 & 62.4 & 17.5 & 13.8 & 0.1 & 93.8 & 67 & 19 & 15 & $\operatorname{Tr}$ \\
\hline $8 R-6,107$ & 409.89 & 45 & 638 & 334 & 58 & 3,916 & 22,755 & 23,246 & 2,909 & 54.7 & 11.8 & 29.7 & 0.1 & 96.3 & 57 & 12 & 31 & $\operatorname{Tr}$ \\
\hline $9 \mathrm{R}-1,33$ & 412.83 & 48 & 685 & 125 & 110 & 4,286 & 27,243 & 11,494 & 5,663 & 49.7 & 14.9 & 13.2 & 3.0 & 80.8 & 62 & 18 & 16 & 4 \\
\hline $9 \mathrm{R}-2,0$ & 413.63 & 38 & 749 & 490 & 53 & 3,281 & 25,492 & 32,238 & 3,384 & 54.9 & 13.1 & 42.0 & 0.1 & 110.1 & 50 & 12 & 38 & $\operatorname{Tr}$ \\
\hline $9 R-5,14$ & 417.00 & 59 & 783 & 149 & 67 & 5,517 & 33,235 & 12,713 & 3,648 & 62.4 & 18.1 & 14.2 & 0.1 & 94.9 & 66 & 19 & 15 & $\mathrm{Tr}$ \\
\hline $10 \mathrm{R}-1,32$ & 422.32 & 66 & 704 & 133 & 42 & 6,038 & 31,418 & 11,630 & 2,624 & 66.8 & 17.0 & 12.7 & 0.1 & 96.7 & 69 & 18 & 13 & $\mathrm{Tr}$ \\
\hline $10 \mathrm{R}-3,0$ & 424.75 & 68 & 950 & 160 & 23 & 5,800 & 34,441 & 12,824 & 1,400 & 65.2 & 18.8 & 14.3 & 0.1 & 98.3 & 66 & 19 & 15 & $\operatorname{Tr}$ \\
\hline $11 \mathrm{R}-2,31$ & 433.21 & 56 & 440 & 104 & 149 & 5,013 & 20,415 & 9,658 & 7,669 & 56.0 & 10.8 & 10.8 & 5.3 & 82.9 & 68 & 13 & 13 & 6 \\
\hline $11 \mathrm{R}-2,85$ & 433.75 & 62 & 707 & 130 & 28 & 5,653 & 26,584 & 12,883 & 1,131 & 64.1 & 14.2 & 14.8 & 0.1 & 93.2 & 69 & 15 & 16 & $\operatorname{Tr}$ \\
\hline $11 \mathrm{R}-4,0$ & 434.64 & 71 & 154 & 85 & 36 & 8,290 & 6,917 & 8,490 & 3,150 & 88.0 & 2.4 & 8.9 & 0.1 & 99.4 & 89 & 2 & 9 & $\operatorname{Tr}$ \\
\hline 11R-5, 107 & 436.31 & 77 & 791 & 114 & 0 & 6,867 & 28,113 & 12,120 & 0 & 75.4 & 14.9 & 13.3 & 0.0 & 103.7 & 73 & 14 & 13 & 0 \\
\hline 11R-7, 71 & 438.77 & 68 & 795 & 131 & 0 & 6,801 & 29,638 & 11,725 & 3,166 & 74.6 & 15.8 & 12.7 & 0.1 & 103.2 & 72 & 15 & 12 & $\operatorname{Tr}$ \\
\hline 11R-7, 132 & 439.38 & 70 & 822 & 128 & 67 & 4,995 & 31,842 & 12,109 & 3,166 & 56.9 & 17.4 & 13.6 & 0.1 & 88.0 & 65 & 20 & 15 & $\mathrm{Tr}$ \\
\hline $12 \mathrm{R}-2,50$ & 442.91 & 59 & 807 & 146 & 99 & 5,762 & 30,800 & 13,014 & 4,350 & 65.2 & 16.6 & 14.7 & 0.1 & 96.7 & 67 & 17 & 15 & $\operatorname{Tr}$ \\
\hline $12 \mathrm{R}-2,82$ & 443.23 & 69 & 800 & 130 & 0 & 6,414 & 30,960 & 12,836 & 0 & 71.4 & 16.6 & 14.3 & 0.0 & 102.3 & 70 & 16 & 14 & 0 \\
\hline $12 \mathrm{R}-3,50$ & 444.33 & 63 & 657 & 129 & 143 & 6,058 & 24,120 & 14,662 & 6,991 & 69.8 & 12.6 & 17.2 & 3.4 & 103.0 & 68 & 12 & 17 & 3 \\
\hline $12 \mathrm{R}-3,75$ & 444.58 & 59 & 589 & 142 & 138 & 5,758 & 23,058 & 13,306 & 6,809 & 65.9 & 12.1 & 15.5 & 3.5 & 96.9 & 68 & 12 & 16 & 4 \\
\hline $12 \mathrm{R}-4,62$ & 445.87 & 54 & 663 & 117 & 77 & 5,139 & 26,909 & 12,462 & 3,765 & 58.8 & 14.5 & 14.3 & 0.1 & 87.7 & 67 & 17 & 16 & $\operatorname{Tr}$ \\
\hline $12 \mathrm{R}-6,0$ & 446.96 & 45 & 830 & 188 & 70 & 4,095 & 29,713 & 18,472 & 3,746 & 52.7 & 16.0 & 22.7 & 0.3 & 91.8 & 57 & 17 & 25 & $\operatorname{Tr}$ \\
\hline $12 \mathrm{R}-7,83$ & 448.16 & 56 & 951 & 143 & 0 & 6,369 & 35,127 & 13,700 & 0 & 71.3 & 19.0 & 15.3 & 0.0 & 105.7 & 68 & 18 & 14 & 0 \\
\hline $13 R-3,30$ & 453.62 & 75 & 784 & 144 & 0 & 7,200 & 35,561 & 13,007 & 0 & 79.0 & 19.2 & 14.1 & 0.0 & 112.3 & 70 & 17 & 13 & 0 \\
\hline $13 R-4,51$ & 454.19 & 74 & 881 & 142 & 0 & 7,172 & 32,561 & 13,706 & 0 & 79.4 & 17.4 & 15.2 & 0.0 & 112.0 & 71 & 16 & 14 & 0 \\
\hline 13R-5, 26 & 455.35 & 65 & 744 & 93 & 85 & 6,653 & 27,097 & 9,938 & 3,738 & 71.9 & 14.5 & 10.4 & 0.1 & 96.9 & 74 & 15 & 11 & $\operatorname{Tr}$ \\
\hline $13 R-5,78$ & 455.87 & 56 & 716 & 105 & 0 & 4,831 & 27,980 & 10,203 & 0 & 53.9 & 15.2 & 11.3 & 0.0 & 80.4 & 67 & 19 & 14 & 0 \\
\hline 13R-5, 104 & 456.13 & 69 & 806 & 128 & 0 & 6,081 & 32,738 & 14,226 & 0 & 69.0 & 17.7 & 16.2 & 0.0 & 102.8 & 67 & 17 & 16 & 0 \\
\hline 14R-1, 49 & 460.49 & 19 & 150 & 60 & 394 & 1,093 & 5,161 & 3,612 & 42,802 & 15.0 & 2.8 & 4.2 & 54.9 & 76.9 & 20 & 4 & 5 & 71 \\
\hline $14 \mathrm{R}-2,18$ & 461.59 & 75 & 882 & 124 & 0 & 6,892 & 32,586 & 12,846 & 0 & 76.0 & 17.5 & 14.1 & 0.0 & 107.6 & 71 & 16 & 13 & 0 \\
\hline $14 \mathrm{R}-4,0$ & 463.16 & 49 & 1,005 & 214 & 33 & 4,169 & 35,512 & 18,391 & 0 & 53.0 & 19.4 & 22.3 & 0.0 & 94.7 & 56 & 21 & 24 & 0 \\
\hline $14 \mathrm{R}-5,45$ & 464.07 & 40 & 1,283 & 391 & 0 & 3,428 & 43,095 & 30,646 & 0 & 54.2 & 23.5 & 39.0 & 0.0 & 116.7 & 46 & 20 & 33 & 0 \\
\hline $14 \mathrm{R}-6,4$ & 465.08 & 81 & 746 & 106 & 0 & 6,405 & 35,526 & 11,297 & 0 & 69.9 & 19.4 & 12.0 & 0.0 & 101.3 & 69 & 19 & 12 & 0 \\
\hline 15R-1, 103 & 470.53 & 42 & 508 & 130 & 33 & 3,436 & 17,672 & 10,232 & 0 & 40.6 & 9.4 & 12.2 & 0.0 & 62.2 & 65 & 15 & 20 & 0 \\
\hline $15 \mathrm{R}-2,45$ & 471.35 & 61 & 830 & 152 & 0 & 6,260 & 32,021 & 13,266 & 0 & 70.1 & 17.3 & 14.9 & 0.0 & 102.2 & 69 & 17 & 15 & 0 \\
\hline 15R-2, 111 & 472.01 & 67 & 886 & 132 & 25 & 5,933 & 34,421 & 10,285 & 0 & 64.6 & 18.9 & 10.8 & 0.0 & 94.2 & 69 & 20 & 11 & 0 \\
\hline
\end{tabular}


Table T4 (continued). (Continued on next page.)

\begin{tabular}{|c|c|c|c|c|c|c|c|c|c|c|c|c|c|c|c|c|c|c|}
\hline \multirow[b]{3}{*}{$\begin{array}{l}\text { Core, section, } \\
\text { interval }(\mathrm{cm})\end{array}$} & \multirow[b]{3}{*}{$\begin{array}{l}\text { Depth } \\
\text { CSF }(m)\end{array}$} & \multicolumn{8}{|c|}{ Measured values of $\mathrm{X}$-ray diffraction peaks } & \multicolumn{9}{|c|}{ Abundance calculated from SVD normalization factors } \\
\hline & & \multicolumn{4}{|c|}{ Peak intensity (counts/step) } & \multicolumn{4}{|c|}{ Integrated peak area (total counts) } & \multicolumn{5}{|c|}{ Absolute (wt\%) } & & elative & (wto & \\
\hline & & $\begin{array}{l}\frac{n}{\bar{\sigma}} \\
\frac{\tilde{\sigma}}{\bar{\varepsilon}} \\
\frac{\pi}{U}\end{array}$ & 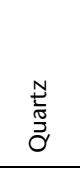 & $\begin{array}{l}\frac{\overline{0}}{0} \\
\frac{\overline{0}}{\overline{0}} \\
\frac{0}{\nu}\end{array}$ & 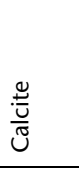 & 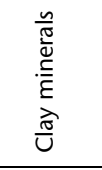 & 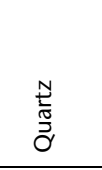 & $\begin{array}{l}\frac{\bar{\sigma}}{0} \\
\frac{\overline{0}}{0} \\
\frac{0}{0}\end{array}$ & 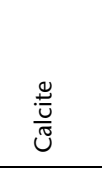 & 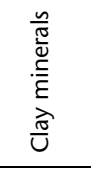 & $\begin{array}{l}\frac{v}{0} \\
\frac{0}{0} \\
\text { Oे }\end{array}$ & $\begin{array}{l}\frac{\hbar \pi}{0} \\
\frac{0}{0} \\
\frac{0}{0} \\
\end{array}$ & 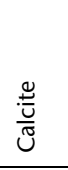 & $\begin{array}{l}\bar{\Xi} \\
\stackrel{0}{0}\end{array}$ & 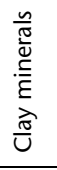 & $\begin{array}{l}\frac{1}{7} \\
\frac{0}{2} \\
0\end{array}$ & $\begin{array}{l}\frac{\pi}{0} \\
\frac{0}{0} \\
\frac{0}{0} \\
\end{array}$ & $\frac{\stackrel{ \pm}{U}}{\frac{\pi}{\sigma}}$ \\
\hline $15 \mathrm{R}-3,0$ & 472.03 & 74 & 903 & 126 & 27 & 6,832 & 33,471 & 10,303 & 0 & 73.5 & 18.1 & 10.6 & 0.0 & 102.2 & 72 & 18 & 10 & 0 \\
\hline $15 R-4,117$ & 473.72 & 60 & 746 & 113 & 85 & 5,277 & 30,488 & 12,093 & 4,024 & 59.8 & 16.6 & 13.6 & 0.1 & 90.0 & 66 & 18 & 15 & $\operatorname{Tr}$ \\
\hline 16R-1, 103 & 477.83 & 20 & 1,120 & 264 & 0 & 2,861 & 38,726 & 24,551 & 0 & 44.4 & 21.3 & 31.0 & 0.0 & 96.6 & 46 & 22 & 32 & 0 \\
\hline $16 \mathrm{R}-2,0$ & 478.21 & 26 & 1,159 & 404 & 0 & 2,216 & 40,791 & 30,858 & 0 & 42.5 & 22.3 & 39.7 & 0.0 & 104.5 & 41 & 21 & 38 & 0 \\
\hline & & & & & & & & & & & & & & Average: & 64 & 15 & 18 & 4 \\
\hline Unit III & & & & & & & & & & & & & & & & & & \\
\hline 19R-3, 0 & 492.65 & 65 & 928 & 131 & 50 & 6,122 & 33,334 & 9,083 & 0 & 65.6 & 18.2 & 9.1 & 0.0 & 93.0 & 71 & 20 & 10 & 0 \\
\hline 19R-4, 20 & 493.22 & 74 & 979 & 144 & 27 & 6,521 & 34,345 & 10,269 & 0 & 70.4 & 18.7 & 10.6 & 0.0 & 99.7 & 71 & 19 & 11 & 0 \\
\hline $19 R-4,74$ & 493.76 & 60 & 734 & 114 & 70 & 5,930 & 27,980 & 9,274 & 3,561 & 64.3 & 15.1 & 9.7 & 0.1 & 89.1 & 72 & 17 & 11 & $\mathrm{Tr}$ \\
\hline $19 \mathrm{R}-5,32$ & 494.72 & 75 & 967 & 123 & 22 & 6,937 & 35,209 & 10,226 & 0 & 74.4 & 19.2 & 10.3 & 0.0 & 103.9 & 72 & 18 & 10 & 0 \\
\hline 19R-6, 19 & 495.95 & 75 & 888 & 145 & 22 & 7,172 & 33,194 & 10,517 & 1,126 & 77.1 & 17.9 & 10.8 & 0.1 & 105.9 & 73 & 17 & 10 & $\operatorname{Tr}$ \\
\hline $20 \mathrm{R}-1,15$ & 498.55 & 17 & 143 & 86 & 575 & 1,189 & 5,011 & 5,715 & 47,602 & 17.7 & 2.7 & 7.1 & 61.0 & 88.4 & 20 & 3 & 8 & 69 \\
\hline $21 \mathrm{R}-2,0$ & 501.6 & 67 & 923 & 117 & 31 & 6,574 & 34,041 & 10,168 & 1,401 & 70.9 & 18.5 & 10.4 & 0.1 & 100 & 71 & 19 & 10 & $\mathrm{Tr}$ \\
\hline $21 \mathrm{R}-4,106$ & 504.73 & 71 & 884 & 122 & 25 & 6,507 & 32,698 & 10,199 & 1,862 & 70.3 & 17.8 & 10.5 & 0.1 & 98 & 71 & 18 & 11 & $\mathrm{Tr}$ \\
\hline $21 \mathrm{R}-5,130$ & 506.38 & 69 & 888 & 132 & 21 & 6,553 & 32,441 & 9,264 & 1,360 & 70.1 & 17.6 & 9.3 & 0.1 & 97.1 & 72 & 18 & 10 & $\mathrm{Tr}$ \\
\hline $23 \mathrm{R}-2,0$ & 521.15 & 65 & 947 & 120 & 42 & 6,288 & 34,305 & 9,421 & 2,265 & 67.6 & 18.8 & 9.5 & 0.1 & 95.9 & 70 & 20 & 10 & $\operatorname{Tr}$ \\
\hline $23 R-4,30$ & 523.2 & 74 & 865 & 120 & 25 & 6,707 & 32,475 & 9,665 & 68 & 71.9 & 17.6 & 9.8 & 0.1 & 99.4 & 72 & 18 & 10 & $\mathrm{Tr}$ \\
\hline 23R-7, 106 & 527. & 73 & 946 & 136 & 30 & 7,012 & 35,230 & 9,955 & & 75.1 & 19.2 & 9 & 0.1 & 104.3 & 72 & 18 & 10 & $\operatorname{Tr}$ \\
\hline $23 \mathrm{R}-8,53$ & 528.2 & 71 & 912 & 115 & 20 & 6,602 & 32,100 & 9,8 & 1,2 & 71.1 & 17.4 & 10.1 & 0.1 & 98.6 & 72 & 18 & 10 & $\mathrm{Tr}$ \\
\hline $24 \mathrm{R}-1,0$ & 529.90 & 62 & 879 & 117 & 53 & 6,225 & 33,078 & 9,292 & 2,891 & 66.9 & 18.1 & 9.4 & 0.1 & 94.4 & 71 & 19 & 10 & $\mathrm{Tr}$ \\
\hline $24 \mathrm{R}-2,17$ & 530.64 & 73 & 895 & 125 & 96 & 5,950 & 33,556 & 8,855 & 4,578 & 63.9 & 18.4 & 8.8 & 0.1 & 91.3 & 70 & 20 & 10 & $\mathrm{Tr}$ \\
\hline $25 \mathrm{R}-1,30$ & 539.70 & 64 & 881 & 121 & 58 & & 32,641 & 10,0 & & 68.8 & 17.8 & 10.3 & 0.1 & & 71 & 18 & 11 & $\operatorname{Tr}$ \\
\hline $25 \mathrm{R}-2,50$ & 540.36 & 52 & 1,046 & 224 & 28 & 5,431 & 36,626 & 18,829 & 1,616 & 65.8 & 19.9 & 22 & 0.1 & 108 & 61 & 18 & 21 & $\mathrm{Tr}$ \\
\hline $25 \mathrm{R}-3,22$ & 540.71 & 69 & 963 & 129 & 0 & 6,567 & 34,965 & 12,101 & 0 & 72.1 & 19.0 & 13.0 & 0.0 & 104.2 & 69 & 18 & 13 & $\mathrm{Tr}$ \\
\hline 26R-1, 112 & 550.12 & 64 & 893 & 87 & 137 & 6,183 & 33,093 & 9,166 & 4,822 & 66.5 & 18.1 & 9.2 & 0.1 & 93.9 & 71 & 19 & 10 & $\mathrm{Tr}$ \\
\hline $26 \mathrm{R}-2,67$ & 550.89 & 61 & 966 & 134 & 0 & 5,720 & 36,438 & 12,322 & 6,407 & 64.1 & 20.0 & 13.5 & 2.6 & 100.2 & 64 & 20 & 13 & 3 \\
\hline $26 \mathrm{R}-3,25$ & 551.2 & 78 & 903 & 111 & 51 & 6,838 & 33, & 10,9 & 253 & 74.1 & 18.0 & 11.4 & 0.1 & 10 & 72 & 17 & 11 & $\mathrm{Tr}$ \\
\hline $26 \mathrm{R}-5,104$ & 554.7 & 69 & & 127 & 0 & & & & & 75.8 & 18.4 & & 0.0 & 10 & 70 & 17 & 13 & 0 \\
\hline $26 \mathrm{R}-6,5$ & 555.1 & 68 & 299 & 111 & 0 & 10,185 & 13,210 & 11,165 & 0 & 108.3 & 5.7 & 11.7 & 0.0 & 125.7 & 86 & 5 & 9 & 0 \\
\hline $27 \mathrm{R}-1,22$ & 558.72 & 70 & 947 & 136 & 103 & 6,432 & 34,592 & 10,670 & 3,820 & 69.9 & 18.9 & 11.1 & 0.1 & 100.0 & 70 & 19 & 11 & $\mathrm{Tr}$ \\
\hline $27 \mathrm{R}-2,48$ & 559.8 & 70 & 922 & 126 & 0 & & 34,324 & 12,867 & 0 & 71.9 & 18.6 & 14 & 0.0 & 10 & 69 & 18 & 14 & 0 \\
\hline $27 \mathrm{R}-$ & & 60 & 900 & 88 & 59 & 648 & & & 927 & 61.6 & 19.0 & 10 & 0.1 & & 68 & 21 & 11 & $\operatorname{Tr}$ \\
\hline $27 R-4,108$ & & 69 & 795 & 138 & 0 & & 31,305 & 13,786 & 0 & 77.4 & 16.7 & 15 & 0.0 & 109.5 & 71 & 15 & 14 & 0 \\
\hline $27 R-4,138$ & 562.68 & 49 & 653 & 129 & 73 & 6,078 & 24,898 & 13,076 & 4,345 & 68.7 & 13.1 & 15.0 & 0.1 & 96.9 & 71 & 14 & 15 & $\mathrm{Tr}$ \\
\hline $27 \mathrm{R}-5,110$ & 563.81 & 68 & 892 & 152 & 0 & 6,440 & 33,783 & 13,945 & 0 & 72.3 & 18.2 & 15.7 & 0.0 & 106.2 & 68 & 17 & 15 & 0 \\
\hline 28R-1, 17 & 568.1 & 75 & 933 & 145 & 46 & 397 & 35,258 & 10,815 & & 69.6 & 19.3 & & 0.1 & 100 & 69 & 19 & 11 & $\operatorname{Tr}$ \\
\hline $28 \mathrm{R}-2,0$ & 569.4 & 69 & 885 & 133 & 56 & 5,681 & 32,181 & 9,912 & 3,174 & 62.0 & 17.6 & 10. & 0.1 & 90.2 & 69 & 20 & 12 & $\operatorname{Tr}$ \\
\hline $28 \mathrm{R}-3,18$ & 570.17 & 63 & 864 & 145 & 0 & 5,580 & 33,644 & 13,352 & 0 & 63.3 & 18.3 & 15.1 & 0.0 & 96.8 & 65 & 19 & 16 & 0 \\
\hline $30 \mathrm{R}-1,30$ & 580.70 & 73 & 880 & 73 & 30 & 7,047 & 32,053 & 10,394 & 1,550 & 75.9 & 17.3 & 10.7 & 0.1 & 103.9 & 73 & 17 & 10 & $\mathrm{Tr}$ \\
\hline $30 \mathrm{R}-1,76$ & 581.16 & 67 & 786 & 127 & 165 & 5,726 & 30,314 & 9,568 & 7,517 & 62.5 & 16.5 & 10.0 & 4.3 & 93.3 & 67 & 18 & 11 & 5 \\
\hline & & 64 & & 107 & 40 & & & & & 9.4 & 17.7 & & 0.1 & & 70 & 8 & 12 & $\operatorname{Tr}$ \\
\hline $31 \mathrm{R}-1,10$ & 5 & 73 & 873 & 147 & 30 & & 34,6 & 10,730 & 584 & 66.0 & 19.0 & 11 & 0.1 & 96. & 68 & 20 & 12 & $\mathrm{Tr}$ \\
\hline $31 \mathrm{R}-2,50$ & 588.36 & 84 & 345 & 173 & 0 & & 15,884 & 13,486 & 0 & 101.1 & 7.3 & 15.1 & 0.0 & 123.5 & 82 & 6 & 12 & 0 \\
\hline $31 \mathrm{R}-3,77$ & 589.17 & 84 & 872 & 119 & 0 & 7,816 & 32,046 & 9,976 & 0 & 83.1 & 17.2 & 9.9 & 0.0 & 110.2 & 75 & 16 & 9 & 0 \\
\hline $32 \mathrm{R}-2,95$ & 598.38 & 64 & 914 & 131 & 23 & 5,724 & 35,339 & 12,705 & 1,8 & 64.3 & 19.3 & 14.1 & 0.1 & 97.8 & 66 & 20 & 14 & $\mathrm{Tr}$ \\
\hline $2-5,0$ & & 75 & & 125 & 36 & & & 11,414 & 1,748 & 69.7 & 19 & 12 & 0.1 & 101 & 69 & 19 & 12 & $\operatorname{Tr}$ \\
\hline $33 \mathrm{R}-1,22$ & 60 & 74 & 1,011 & 126 & 0 & & 36,229 & 12,524 & 0 & 75.3 & 19.7 & 13. & 0.0 & 108 & 99 & 18 & 12 & 0 \\
\hline $33 R-2,0$ & 605.94 & 66 & 1,025 & 151 & 28 & 6,549 & 38,652 & 12,521 & 1,955 & 72.2 & 21.2 & 13.4 & 0.1 & 106.9 & 68 & 20 & 13 & $\operatorname{Tr}$ \\
\hline $33 \mathrm{R}-3,17$ & 606.65 & 20 & 255 & 34 & 570 & 1,316 & 8,656 & 3,045 & 42,916 & 16.6 & 4.9 & 3.2 & 54.7 & 79.5 & 21 & 6 & 4 & 69 \\
\hline $33 \mathrm{R}-3,32$ & 606.80 & 56 & 704 & 91 & 136 & & 26,750 & 10,336 & 9,229 & 68.6 & 14.3 & 11.1 & 6.2 & 100.2 & 68 & 14 & 11 & 6 \\
\hline $35 \mathrm{R}-3,23$ & 627.39 & 31 & & 77 & 33 & & 26,036 & 9,056 & 1, & 36.5 & 14.4 & 10 & 0.1 & 61.3 & 60 & 24 & 17 & $\operatorname{Tr}$ \\
\hline $35 R-4,0$ & 628.1 & 69 & 853 & 133 & 27 & 6,446 & 34,445 & 11,080 & & 70.3 & 18.8 & 11.7 & 0.1 & 100.9 & 70 & 19 & 12 & $\operatorname{Tr}$ \\
\hline $35 \mathrm{R}-5,87$ & 629.4 & 68 & 840 & 136 & 49 & 6,063 & 32,346 & 11,282 & & 66.8 & 17.6 & 12.2 & 0.1 & 96.7 & 69 & 18 & 13 & $\operatorname{Tr}$ \\
\hline $35 \mathrm{R}-6,60$ & 630.54 & 64 & 829 & 149 & 28 & 6,454 & 34,763 & 12,772 & 1,809 & 71.6 & 18.9 & 14.0 & 0.1 & 104.6 & 68 & 18 & 13 & $\operatorname{Tr}$ \\
\hline $35 \mathrm{R}-6,115$ & 631.06 & 63 & 834 & 139 & 39 & & 35,025 & 11,648 & 2,392 & 65.9 & 19.2 & 12.6 & 0.1 & 97.7 & 67 & 20 & 13 & $\operatorname{Tr}$ \\
\hline 35R-7, 94 & 632.21 & 69 & & 113 & 60 & 6,957 & 31,366 & 9,507 & 2,650 & 74.4 & 16.9 & 9.5 & 0.1 & 101.0 & 74 & 17 & 9 & $\operatorname{Tr}$ \\
\hline $35 \mathrm{R}-8,44$ & 633.08 & 68 & & 146 & 29 & & & 12,412 & 2,293 & 70.1 & 18.5 & 13.6 & 0.1 & 102.2 & 69 & 18 & 13 & $\operatorname{Tr}$ \\
\hline $36 \mathrm{R}-2,50$ & 635.17 & 63 & 589 & 107 & 26 & 5,949 & 30,705 & 11,470 & 1,464 & 65.8 & 16.6 & 12.5 & 0.1 & 95.1 & 69 & 17 & 13 & $\operatorname{Tr}$ \\
\hline $36 \mathrm{R}-3,96$ & 636.17 & 64 & 476 & 199 & 33 & 6,787 & 20,165 & 15,165 & 2,281 & 77.3 & 10.1 & 17.9 & 0.1 & 105.5 & 73 & 10 & 17 & $\operatorname{Tr}$ \\
\hline $36 \mathrm{R}-4,127$ & 637.89 & 71 & 902 & 116 & 0 & 7,021 & 35,280 & 12,164 & 0 & 76.7 & 19.1 & 13.0 & 0.0 & 108.7 & 71 & 18 & 12 & 0 \\
\hline $36 \mathrm{R}-5,69$ & & 72 & 898 & 104 & 73 & 7,080 & 33,548 & 12,136 & & 77.5 & 18.1 & 13.0 & 0.1 & 108.6 & 71 & 17 & 12 & $\operatorname{Tr}$ \\
\hline $37 R-2,50$ & 645.18 & 72 & 817 & 111 & 57 & 6,901 & 30,965 & 9,334 & & 73.8 & 16.7 & 9.3 & 0.1 & 99.9 & 74 & 17 & 9 & $\operatorname{Tr}$ \\
\hline $37 R-4,9$ & 646.61 & 72 & 937 & 164 & 68 & 6,634 & 35,414 & 12,872 & 2,990 & 73.5 & 19.2 & 14.0 & 0.1 & 106.8 & 69 & 18 & 13 & $\operatorname{Tr}$ \\
\hline
\end{tabular}


Table T4 (continued). (Continued on next page.)

\begin{tabular}{|c|c|c|c|c|c|c|c|c|c|c|c|c|c|c|c|c|c|c|}
\hline \multirow[b]{3}{*}{$\begin{array}{l}\text { Core, section, } \\
\text { interval }(\mathrm{cm})\end{array}$} & \multirow[b]{3}{*}{$\begin{array}{c}\text { Depth } \\
\operatorname{CSF}(\mathrm{m})\end{array}$} & \multicolumn{8}{|c|}{ Measured values of X-ray diffraction peaks } & \multicolumn{9}{|c|}{ Abundance calculated from SVD normalization factors } \\
\hline & & \multicolumn{4}{|c|}{ Peak intensity (counts/step) } & \multicolumn{4}{|c|}{ Integrated peak area (total counts) } & \multicolumn{5}{|c|}{ Absolute (wt\%) } & & lative & (wt\% & \\
\hline & & $\begin{array}{l}\frac{n}{\sigma} \\
\frac{\sigma}{\omega} \\
\cdot \frac{.}{\xi} \\
\frac{\pi}{U}\end{array}$ & $\begin{array}{l}\frac{v}{0} \\
\frac{0}{2} \\
\text { Ơ }\end{array}$ & $\begin{array}{l}\frac{1}{\overline{0}} \\
\frac{\bar{n}}{0} \\
\frac{0}{L}\end{array}$ & 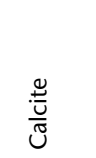 & 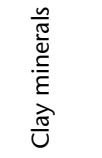 & $\begin{array}{l}\frac{1}{0} \\
\frac{0}{2} \\
\frac{0}{2}\end{array}$ & $\begin{array}{l}\frac{1}{\overline{0}} \\
\frac{\bar{n}}{0} \\
\frac{0}{L}\end{array}$ & $\frac{\stackrel{0}{U}}{\frac{\pi}{\pi}}$ & $\begin{array}{l}\frac{u}{\pi} \\
\frac{\pi}{\tilde{E}} \\
\frac{c}{\varepsilon} \\
\frac{\pi}{U}\end{array}$ & $\begin{array}{l}\frac{1}{2} \\
\frac{1}{2} \\
\sigma^{\prime}\end{array}$ & $\begin{array}{l}\frac{i}{\bar{\sigma}} \\
\frac{0}{0} \\
\frac{0}{v}\end{array}$ & $\frac{\stackrel{\mathscr{J}}{\frac{U}{N}}}{\mathrm{U}}$ & $\begin{array}{l}\overline{\widetilde{\pi}} \\
\stackrel{0}{\circ}\end{array}$ & $\begin{array}{l}\frac{n}{\frac{n}{\pi}} \\
\frac{\tilde{U}}{\bar{\varepsilon}} \\
\frac{\pi}{U} \\
\frac{\pi}{U}\end{array}$ & $\begin{array}{l}\frac{1}{2} \\
\frac{\pi}{2} \\
0\end{array}$ & $\begin{array}{l}\frac{1}{0} \\
\frac{0}{\frac{0}{0}} \\
\frac{0}{L}\end{array}$ & 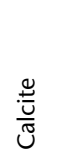 \\
\hline $37 \mathrm{R}-5,110$ & 648.88 & 66 & 731 & 95 & 152 & 6,329 & 27,478 & 9,873 & 6,729 & 68.8 & 14.7 & 10.4 & 2.9 & 96.8 & 71 & 15 & 11 & 3 \\
\hline 37R-7, 33 & 650.81 & 66 & 846 & 125 & 27 & 6,235 & 32,261 & 10,854 & 1,943 & 68.2 & 17.5 & 11.5 & 0.1 & 97.3 & 70 & 18 & 12 & $\operatorname{Tr}$ \\
\hline $38 \mathrm{R}-1,72$ & 653.72 & 64 & 857 & 78 & 117 & 5,996 & 30,343 & 9,608 & 4,801 & 65.1 & 16.5 & 10.0 & 0.6 & 92.1 & 71 & 18 & 11 & 1 \\
\hline $38 \mathrm{R}-2,0$ & 654.39 & 61 & 746 & 130 & 34 & 5,601 & 31,030 & 11,442 & 2,149 & 62.4 & 16.9 & 12.6 & 0.1 & 91.9 & 68 & 18 & 14 & $\mathrm{Tr}$ \\
\hline $38 \mathrm{R}-4,64$ & 656.98 & 55 & 672 & 97 & 245 & 4,516 & 27,089 & 6,866 & 16,488 & 49.1 & 15.0 & 6.8 & 17.1 & 87.9 & 56 & 17 & 8 & 19 \\
\hline $38 \mathrm{R}-6,18$ & 659.35 & 55 & 805 & 136 & 60 & 5,529 & 31,771 & 9,949 & 3,275 & 60.6 & 17.4 & 10.5 & 0.1 & 88.6 & 68 & 20 & 12 & $\mathrm{Tr}$ \\
\hline 38R-7, 92 & 661.49 & 64 & 791 & 128 & 167 & 5,492 & 32,213 & 9,566 & 7,385 & 60.1 & 17.7 & 10.0 & 4.3 & 92.0 & 65 & 19 & 11 & 5 \\
\hline $39 \mathrm{R}-1,24$ & 662.74 & 58 & 701 & 103 & 187 & 5,260 & 27,105 & 8,350 & 10,387 & 57.3 & 14.8 & 8.6 & 8.5 & 89.2 & 64 & 17 & 10 & 10 \\
\hline $39 \mathrm{R}-2,38$ & 664.29 & 30 & 308 & 49 & 347 & 2,817 & 12,119 & 4,043 & 21,854 & 31.2 & 6.6 & 4.1 & 26.0 & 67.8 & 46 & 10 & 6 & 38 \\
\hline $39 \mathrm{R}-4,50$ & 667.24 & 64 & 540 & 109 & 49 & 5,209 & 27,718 & 10,582 & 3,133 & 58.1 & 15.0 & 11.7 & 0.1 & 84.9 & 68 & 18 & 14 & $\mathrm{Tr}$ \\
\hline 39R-5, 108 & 668.41 & 57 & 939 & 183 & 48 & 5,522 & 39,444 & 15,664 & 2,854 & 64.3 & 21.6 & 18.0 & 0.1 & 104.0 & 62 & 21 & 17 & $\operatorname{Tr}$ \\
\hline $39 \mathrm{R}-6,25$ & 669.00 & 58 & 791 & 119 & 48 & 6,482 & 30,929 & 10,971 & 2,717 & 70.8 & 16.7 & 11.7 & 0.1 & 99.3 & 71 & 17 & 12 & $\mathrm{Tr}$ \\
\hline $40 \mathrm{R}-1,30$ & 672 & 62 & 805 & 130 & 26 & 6,517 & 32,706 & 12,152 & 2,261 & 71.9 & 17.7 & 13.2 & 0.1 & 102.9 & 70 & 17 & 13 & $\mathrm{Tr}$ \\
\hline $40 \mathrm{R}-2,17$ & 673.57 & 69 & 881 & 118 & 0 & 6,179 & 34,702 & 11,395 & 0 & 67.8 & 18.9 & 12.2 & 0.0 & 98.9 & 69 & 19 & 12 & 0 \\
\hline & & & & & & & & & & & & & & verage: & 68 & 17 & 12 & 9 \\
\hline Unit IV & & & & & & & & & & & & & & & & & & \\
\hline $40 \mathrm{R}-3,0$ & 674.82 & 63 & 914 & 121 & 53 & 6,505 & 34,538 & 13,044 & 1,946 & 72.3 & 18.7 & 14.4 & 0.1 & 105.5 & 69 & 18 & 14 & $\mathrm{Tr}$ \\
\hline$c, 14$ & 678. & 20 & 84 & 23 & 644 & 2,007 & 3,037 & 1,580 & 41,3 & 22.6 & 1.5 & 1.3 & 52.5 & & 29 & 2 & 2 & 67 \\
\hline $42 \mathrm{R}-2,0$ & 681.8 & 74 & 905 & 122 & 66 & 6,746 & 39,992 & 12,014 & 3,8 & 73.8 & 21.9 & 12.6 & 0.1 & & 68 & 20 & 12 & $\mathrm{Tr}$ \\
\hline $43 \mathrm{R}-2,40$ & 685.8 & 69 & 995 & 170 & 70 & 6,879 & 43,347 & 13,646 & 3,9 & 76.1 & 23.8 & 14.6 & 0.1 & & 66 & 21 & 13 & $\mathrm{Tr}$ \\
\hline $43 \mathrm{R}-3,0$ & 685.87 & 61 & 858 & 117 & 110 & 6,006 & 38,581 & 11,203 & 4,925 & 66.0 & 21.3 & 11.8 & 0.4 & 99.4 & 66 & 21 & 12 & $\mathrm{Tr}$ \\
\hline$-4,56$ & 686 & 55 & 852 & 116 & 195 & 5,388 & 38,0 & 10,0 & 11,8 & 59.4 & 21.1 & 10.4 & 10.0 & & 59 & 21 & 10 & 10 \\
\hline 43R-5, 117 & 687.2 & 67 & 765 & 136 & 41 & 6,611 & 31,184 & 10,929 & & 72.0 & 16.8 & 11.6 & 0.1 & & 72 & 17 & 12 & $\mathrm{Tr}$ \\
\hline & 690.4 & 69 & 1,180 & 148 & 27 & & 51,772 & & & 71.7 & & 11 & 0.1 & & 64 & 26 & 10 & $\mathrm{Tr}$ \\
\hline $44 \mathrm{R}-3,0$ & 691.0 & 69 & 779 & 136 & 22 & 6,538 & 34,006 & 11,565 & 1,5 & 71.6 & 18.5 & 12.3 & 0.1 & 10 & 70 & 18 & 12 & $\mathrm{Tr}$ \\
\hline $44 \mathrm{R}-4,21$ & 691.9 & 65 & 906 & 134 & 49 & 6,385 & 37,287 & 10,844 & 3,022 & 69.4 & 20.4 & 11.2 & 0.1 & 101.2 & 69 & 20 & 11 & $\mathrm{Tr}$ \\
\hline $45 \mathrm{R}-1,24$ & 698.7 & 61 & 809 & 118 & 146 & 5,939 & 32,472 & 9,0 & 5,7 & 64.1 & 17 & 9 & 1.9 & & 69 & 19 & 10 & 2 \\
\hline $45 \mathrm{R}-3,0$ & 700.2 & 77 & 810 & 145 & 40 & & 33,790 & 11,921 & 2,2 & 69.8 & 18 & 12. & 0.1 & & 69 & 8 & 13 & $\mathrm{Tr}$ \\
\hline $45 R-4,37$ & & 60 & 827 & 161 & 163 & 5,399 & 32,796 & & 7,475 & 59.9 & 18.0 & 11.3 & 4.4 & 93.6 & 64 & 19 & 12 & 5 \\
\hline $45 \mathrm{R}-5,44$ & 702.68 & 67 & 819 & 102 & 29 & 6,062 & 33,811 & 9,119 & 2,209 & 65.1 & 18.5 & 9.1 & -3.0 & 89.8 & 73 & 21 & 10 & $\mathrm{Tr}$ \\
\hline $45 \mathrm{R}-8,12$ & 706.66 & 68 & 924 & 150 & 26 & 5,835 & 36,695 & 11,706 & 1,629 & 64.6 & 20.1 & 12.6 & -3.7 & 93.6 & 69 & 22 & 13 & $\mathrm{Tr}$ \\
\hline 2,0 & & 47 & 571 & 99 & 25 & & & & & 7.8 & & & 0 & & 70 & 9 & 10 & $\mathrm{Tr}$ \\
\hline 471 & & 72 & 724 & 78 & 56 & & 27,255 & & & 69. & 14. & & 0.1 & & 76 & 6 & 7 & $\operatorname{Tr}$ \\
\hline & & 82 & 920 & 112 & 30 & & 33,167 & & & 77.0 & 17.9 & 9.9 & 0.1 & & 73 & 17 & 9 & $\mathrm{Tr}$ \\
\hline $47 R-4,60$ & 715.20 & 67 & 741 & 81 & 29 & 6,062 & 25,372 & 7,096 & 1,458 & 64.0 & 13.7 & 6.8 & 0.1 & 84.5 & 76 & 16 & 8 & $\mathrm{Tr}$ \\
\hline $47 R-5,83$ & 716.85 & 77 & 862 & 119 & 32 & 6,862 & 31,708 & 9,343 & & 73.3 & 17.2 & 9.3 & 0.1 & & 73 & 17 & 9 & $\mathrm{Tr}$ \\
\hline 47 & & 68 & 824 & 95 & 58 & 6,6 & 29,783 & & 3,068 & 71.1 & 16.1 & 8. & 0 & & 75 & 7 & 8 & $\mathrm{Tr}$ \\
\hline $48 \mathrm{R}-2,9$ & 722.0 & 70 & 1,008 & 145 & 18 & & 36,348 & 11,5 & 0 & 64.2 & 19.9 & 12.4 & 0.0 & 96 & 66 & 21 & 13 & 0 \\
\hline $48 \mathrm{R}-3,25$ & 722.79 & 80 & 763 & 91 & 26 & 7,131 & 28,827 & & 1,622 & 75.3 & 15.5 & 7.9 & 0.1 & 98.7 & 76 & 16 & 8 & $\mathrm{Tr}$ \\
\hline $49 \mathrm{R}-7,122$ & 736.14 & 67 & 874 & 107 & 24 & 6,457 & 31,850 & 9,107 & 1,331 & 69.1 & 17.3 & 9.1 & 0.1 & 95.6 & 72 & 18 & 10 & $\mathrm{Tr}$ \\
\hline 50R-2, 31 & 739.11 & 69 & 846 & 124 & 32 & 6,718 & 31,428 & 9,991 & & 72.3 & 17.0 & 10.3 & 0.1 & & 73 & 17 & 10 & $\mathrm{Tr}$ \\
\hline $51 R$ & 748.7 & & 876 & 103 & 50 & 6,620 & 35,951 & & & 70. & 19.7 & 8 & .1 & 98 & 71 & & 9 & $\operatorname{Tr}$ \\
\hline $51 \mathrm{R}-2,56$ & 749.3 & 81 & 854 & 115 & 28 & 6,916 & 32,491 & & & 73.8 & 17.6 & 9.3 & 0.1 & 100.8 & 73 & 17 & 9 & $\mathrm{Tr}$ \\
\hline $51 R-4,0$ & 750.51 & 65 & 527 & 98 & 27 & 6,032 & 31,604 & 8,842 & 1,257 & 64.7 & 17.2 & 8.9 & 0.1 & 90.9 & 71 & 19 & 10 & $\operatorname{Tr}$ \\
\hline 51R-7, 135 & 754.94 & 70 & 800 & 95 & 19 & 6,775 & 32,970 & 8,816 & & 72.0 & 17.9 & 8.6 & 0.1 & 98.6 & 73 & 18 & 9 & $\mathrm{Tr}$ \\
\hline $52 \mathrm{R}-1,6$ & & 81 & 769 & 97 & 23 & & 29,833 & & & 78.6 & 16.0 & 8 & .1 & & 76 & 5 & 9 & $\mathrm{Tr}$ \\
\hline $52 \mathrm{R}-1,1$ & 758.0 & 76 & 758 & 116 & 30 & 1 & 29,408 & 10,3 & 1,7 & 80 & 15.7 & 10. & 0.1 & 107. & 75 & 15 & 10 & $\operatorname{Tr}$ \\
\hline $52 \mathrm{R}-2,11$ & 758.40 & 95 & 310 & 113 & 37 & 10,514 & 12,077 & 13,071 & 2,502 & 113.1 & 4.9 & 14.3 & 0.1 & 132.4 & 85 & 4 & 11 & $\mathrm{Tr}$ \\
\hline $52 \mathrm{R}-2,76$ & 759.0 & 75 & 43 & 66 & 589 & 8,979 & 2,057 & 6,657 & 30,672 & 94.9 & 0.1 & 6.3 & 33.2 & 134.5 & 71 & 0 & 5 & 25 \\
\hline $52 \mathrm{R}-3,95$ & 760.4 & 70 & 820 & 121 & 48 & 7,015 & 33,081 & 8,887 & 3,350 & 74.5 & 18.0 & 8.6 & 0.1 & 101.1 & 74 & 18 & 8 & $\mathrm{Tr}$ \\
\hline $52 \mathrm{R}-5,15$ & & 18 & & 23 & 1,514 & & & 1,384 & 75,729 & 15.0 & 2. & 1.1 & 98.0 & 116 & 13 & & 1 & 84 \\
\hline $52 \mathrm{R}-5,34$ & 762.5 & 21 & 22 & 30 & 553 & 1,498 & 8,076 & 2,345 & 28,6 & 17.4 & 4.5 & 2.3 & 36.0 & 60.1 & 29 & 7 & 4 & 60 \\
\hline $52 \mathrm{R}-5,82$ & 763.00 & 66 & 806 & 117 & 28 & 6,766 & 32,232 & 10,499 & & 73.1 & 17.4 & 10.9 & 0.1 & 101.6 & 72 & 17 & 11 & $\mathrm{Tr}$ \\
\hline $52 \mathrm{R}-6,0$ & 763.34 & 79 & 877 & 83 & 19 & 6,907 & 33,700 & 8,391 & 1,518 & 72.9 & 18.4 & 7.9 & 0.1 & 99.3 & 73 & 18 & 8 & $\mathrm{Tr}$ \\
\hline $53 \mathrm{R}-1,82$ & 767.0 & 67 & 677 & 105 & 45 & 6,708 & 28,525 & 9,228 & 2,66 & 71.9 & 15.3 & 9.3 & 0.1 & 96.6 & 74 & 16 & 10 & $\mathrm{Tr}$ \\
\hline 53R-1, 112 & 767.2 & 72 & 743 & 120 & 113 & & 31,014 & 9,599 & 5,6 & 65.7 & 16.9 & 9.9 & 1.6 & 94. & 70 & 18 & 11 & 2 \\
\hline & 767.3 & 67 & & 111 & 59 & & & 9,439 & & 69.0 & 19.0 & 9.4 & 0.1 & 97. & 71 & 20 & 10 & $\mathrm{Tr}$ \\
\hline $54 \mathrm{R}-5,44$ & 774.68 & 64 & 904 & 115 & 21 & & 36,080 & 10,564 & 1,22 & 64.4 & 19.8 & 11.1 & 0.1 & 95.4 & 68 & 21 & 12 & $\mathrm{Tr}$ \\
\hline $54 \mathrm{R}-5,70$ & 774.94 & 48 & 1,417 & 285 & 20 & 4,122 & 49,843 & 19,543 & 899 & 52.7 & 27.8 & 23.2 & 0.1 & 103.8 & 51 & 27 & 22 & $\mathrm{Tr}$ \\
\hline 54R-5, 110 & 775.34 & 37 & 1,779 & 335 & 15 & 3,627 & 59,658 & 27,569 & 82 & 53.2 & 33.3 & 33.9 & 0.1 & 120.5 & 44 & 28 & 28 & $\operatorname{Tr}$ \\
\hline 55R-1, 27 & 779.27 & 50 & 1,497 & 285 & 18 & 4,127 & 52,575 & 23,053 & 81 & 55.2 & 29.3 & 27.9 & 0.1 & 112.5 & 49 & 26 & 25 & $\operatorname{Tr}$ \\
\hline & 779.50 & 28 & 2,627 & 352 & 9 & & 83,020 & & 603 & 41.4 & 47.2 & 32.3 & 0.1 & & 34 & 39 & 27 & $\operatorname{Tr}$ \\
\hline $55 \mathrm{R}-3,77$ & 780.87 & 31 & 2,358 & 544 & 16 & 1,516 & 77,318 & 45,035 & 1,057 & 44.2 & 43.3 & 57.6 & 0.1 & 145.2 & 30 & 30 & 40 & $\operatorname{Tr}$ \\
\hline
\end{tabular}


Table T4 (continued).

\begin{tabular}{|c|c|c|c|c|c|c|c|c|c|c|c|c|c|c|c|c|c|c|}
\hline \multirow[b]{3}{*}{$\begin{array}{l}\text { Core, section, } \\
\text { interval }(\mathrm{cm})\end{array}$} & \multirow[b]{3}{*}{$\begin{array}{l}\text { Depth } \\
\text { CSF (m) }\end{array}$} & \multicolumn{8}{|c|}{ Measured values of X-ray diffraction peaks } & \multicolumn{9}{|c|}{ Abundance calculated from SVD normalization factors } \\
\hline & & \multicolumn{4}{|c|}{ Peak intensity (counts/step) } & \multicolumn{4}{|c|}{ Integrated peak area (total counts) } & \multicolumn{5}{|c|}{ Absolute (wt\%) } & \multicolumn{4}{|c|}{ Relative (wt\%) } \\
\hline & & 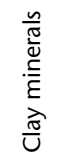 & $\frac{\frac{y}{2}}{\frac{\pi}{2}}$ & $\begin{array}{l}\frac{\bar{\pi}}{0} \\
\frac{0}{0} \\
\frac{0}{v}\end{array}$ & $\frac{\stackrel{\theta}{U}}{\frac{U}{U}}$ & 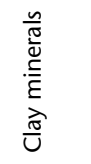 & $\frac{\frac{N}{2}}{\frac{\pi}{2}}$ & $\begin{array}{l}\frac{i}{\pi} \\
\frac{0}{n} \\
\frac{0}{0} \\
\frac{1}{4}\end{array}$ & 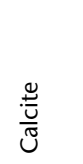 & 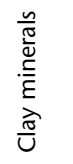 & $\frac{\stackrel{y}{d}}{\frac{\pi}{2}}$ & $\begin{array}{l}\frac{\grave{\pi}}{0} \\
\frac{0}{0} \\
\frac{0}{v}\end{array}$ & $\frac{\stackrel{\oplus}{U}}{U}$ & 矛 & 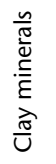 & $\begin{array}{l}\frac{Y}{2} \\
\frac{\pi}{2} \\
O\end{array}$ & $\begin{array}{l}\frac{\bar{\pi}}{0} \\
\frac{0}{0} \\
\frac{0}{v}\end{array}$ & $\frac{\stackrel{\mathscr{U}}{U}}{\stackrel{U}{U}}$ \\
\hline $55 R-5,23$ & 781.85 & 33 & 1,879 & 267 & 20 & 2,694 & 62,400 & 26,175 & 872 & 42.8 & 35.1 & 32.1 & 0.1 & 110.2 & 39 & 32 & 29 & $\operatorname{Tr}$ \\
\hline $56 \mathrm{R}-2,0$ & 844.53 & 73 & 789 & 89 & 20 & 6,433 & 30,574 & 9,556 & 1,440 & 69.2 & 16.5 & 9.8 & 0.1 & 95.7 & 72 & 17 & 10 & $\mathrm{Tr}$ \\
\hline $56 \mathrm{R}-3,100$ & 846.03 & 63 & 861 & 103 & 26 & 6,443 & 33,747 & 10,412 & 1,497 & 69.8 & 18.4 & 10.8 & 0.1 & 99.1 & 70 & 19 & 11 & $\mathrm{Tr}$ \\
\hline \multirow[t]{2}{*}{ 57R-2, 96} & 848.77 & 78 & 1,043 & 108 & 28 & 7,680 & 45,129 & 9,699 & 1,601 & 81.0 & 24.9 & 8.9 & 0.1 & 114.9 & 70 & 22 & 8 & $\mathrm{Tr}$ \\
\hline & & & & & & & & & & & & & \multicolumn{2}{|c|}{ Average: } & 65 & 18 & 12 & 28 \\
\hline \multicolumn{19}{|l|}{ Unit V } \\
\hline $57 R-4,0$ & 850.44 & 88 & 284 & 115 & 30 & 4,416 & 12,090 & 11,107 & 2,136 & 51.3 & 5.9 & 13.4 & 0.1 & 70.7 & 73 & 8 & 19 & $\mathrm{Tr}$ \\
\hline $57 R-5,120$ & 852.25 & 64 & 1,108 & 130 & 26 & 5,960 & 49,220 & 11,816 & 1,475 & 65.3 & 27.5 & 12.1 & 0.1 & 105.0 & 62 & 26 & 12 & $\mathrm{Tr}$ \\
\hline 58R-2, 119 & 858.296 & 53 & 704 & 92 & 24 & 5,278 & 43,036 & 10,053 & 1,396 & 57.6 & 24.0 & 10.2 & 0.1 & 91.9 & 63 & 26 & 11 & $\mathrm{Tr}$ \\
\hline $58 \mathrm{R}-3,0$ & 858.34 & 62 & 984 & 109 & 20 & 6,451 & 42,293 & 11,382 & 1,396 & 70.2 & 23.4 & 11.7 & 0.1 & 105.4 & 67 & 22 & 11 & $\mathrm{Tr}$ \\
\hline $58 \mathrm{R}-4,40$ & 859.27 & 39 & 451 & 75 & 16 & 3,549 & 20,935 & 8,645 & 862 & 40.5 & 11.4 & 9.8 & 0.1 & 61.8 & 66 & 18 & 16 & $\mathrm{Tr}$ \\
\hline $58 \mathrm{R}-4,100$ & 859.84 & 61 & 836 & 133 & 31 & 5,780 & 36,372 & 12,239 & 1,561 & 64.5 & 19.9 & 13.4 & 0.1 & 97.9 & 66 & 20 & 14 & $\mathrm{Tr}$ \\
\hline 58R-5, 72 & 860.91 & 52 & 833 & 134 & 18 & 4,799 & 38,573 & 13,257 & 894 & 55.4 & 21.3 & 15.0 & 0.1 & 91.8 & 60 & 23 & 16 & $\mathrm{Tr}$ \\
\hline $58 \mathrm{R}-6,45$ & 861.87 & 62 & 882 & 194 & 25 & 4,952 & 38,941 & 15,195 & 1,920 & 58.3 & 21.5 & 17.5 & 0.1 & 97.4 & 60 & 22 & 18 & $\mathrm{Tr}$ \\
\hline $59 \mathrm{R}-4,45$ & 868.44 & 29 & 646 & 131 & 27 & 2,491 & 29,446 & 11,908 & 1,130 & 32.0 & 16.4 & 14.2 & 0.1 & 62.7 & 51 & 26 & 23 & $\mathrm{Tr}$ \\
\hline \multirow[t]{2}{*}{$60 \mathrm{R}-\mathrm{CC}, 0$} & 868.80 & 42 & 1,170 & 97 & 14 & 3,117 & 53,468 & 9,873 & 491 & 35.5 & 30.5 & 10.1 & 0.1 & 76.2 & 47 & 40 & 13 & $\mathrm{Tr}$ \\
\hline & & & & & & & & & & & & & \multicolumn{2}{|c|}{ Average: } & 61 & 23 & 15 & $\mathrm{Tr}$ \\
\hline
\end{tabular}

Note: SVD = singular value decomposition, $\operatorname{Tr}=$ trace. 
Table T5. Results of XRF analysis, Hole C0011B. (See table note.) (Continued on next page.)

\begin{tabular}{|c|c|c|c|c|c|c|c|c|c|c|c|c|c|c|}
\hline \multirow{2}{*}{$\begin{array}{l}\text { Core, section, } \\
\text { interval }(\mathrm{cm})\end{array}$} & \multirow{2}{*}{$\begin{array}{l}\text { Depth } \\
\text { CSF }(m)\end{array}$} & \multirow{2}{*}{$\begin{array}{l}\text { Lithologic } \\
\text { unit }\end{array}$} & \multicolumn{12}{|c|}{ Oxide abundance (wt\%) } \\
\hline & & & $\mathrm{SiO}_{2}$ & $\mathrm{Al}_{2} \mathrm{O}_{3}$ & $\mathrm{Fe}_{2} \mathrm{O}_{3}$ & $\mathrm{MnO}$ & $\mathrm{MgO}$ & $\mathrm{CaO}$ & $\mathrm{Na}_{2} \mathrm{O}$ & $\mathrm{K}_{2} \mathrm{O}$ & $\mathrm{TiO}_{2}$ & $\mathrm{P}_{2} \mathrm{O}_{5}$ & LOI & Total \\
\hline \multicolumn{15}{|l|}{ 322-C0011B- } \\
\hline $1 \mathrm{R}-1,22-24$ & 340.20 & $\| A$ & 65.4 & 18.1 & 6.15 & 0.07 & 2.62 & 1.64 & 3.29 & 0.93 & 0.40 & 0.06 & 6.1 & 98.6 \\
\hline 1R-1, 38-40 & 340.40 & IIA & 60.8 & 16.5 & 6.80 & 0.22 & 2.53 & 5.77 & 2.42 & 3.12 & 0.66 & 0.09 & 9.5 & 98.9 \\
\hline $1 \mathrm{R}-2,26-26.5$ & 341.10 & $\| A$ & 65.1 & 17.0 & 6.19 & 0.19 & 2.48 & 0.97 & 2.51 & 3.40 & 0.71 & 0.08 & 5.9 & 98.6 \\
\hline 1R-2, 89.5-90.5 & 342.00 & IIA & 64.6 & 17.0 & 6.81 & 0.17 & 2.75 & 0.93 & 2.71 & 2.52 & 0.66 & 0.07 & 6.0 & 98.2 \\
\hline 2R-1, 59-61 & 350.00 & IIA & 64.9 & 16.6 & 6.21 & 0.14 & 2.48 & 1.03 & 2.62 & 3.35 & 0.68 & 0.08 & 5.1 & 98.1 \\
\hline 2R-CC, 19-21 & 351.00 & IIA & 64.2 & 16.0 & 5.76 & 0.12 & 2.32 & 5.13 & 3.27 & 1.40 & 0.58 & 0.10 & 3.1 & 98.9 \\
\hline $3 R-1,22-24$ & 359.20 & IIA & 65.7 & 15.4 & 5.41 & 0.35 & 2.18 & 2.81 & 2.55 & 3.25 & 0.63 & 0.12 & 6.8 & 98.3 \\
\hline $3 R-2,25-27$ & 359.90 & $\| A$ & 66.8 & 15.5 & 5.79 & 0.19 & 2.30 & 1.25 & 2.58 & 3.34 & 0.62 & 0.16 & 5.4 & 98.5 \\
\hline $3 R-3,33-35$ & 360.50 & $\| A$ & 64.1 & 15.5 & 6.34 & 0.12 & 2.73 & 5.13 & 3.01 & 1.26 & 0.57 & 0.09 & 2.3 & 98.8 \\
\hline $3 R-4,37-39$ & 361.90 & $\| A$ & 62.2 & 16.1 & 7.05 & 0.10 & 2.42 & 5.50 & 3.01 & 1.07 & 0.66 & 0.09 & 2.1 & 98.2 \\
\hline $4 \mathrm{R}-3,0-2$ & 366.90 & IIA & 67.6 & 15.0 & 5.14 & 0.09 & 1.92 & 2.87 & 3.44 & 2.11 & 0.49 & 0.10 & 5.3 & 98.7 \\
\hline $4 R-4,86-88$ & 368.10 & $\| A$ & 69.5 & 14.3 & 4.00 & 0.10 & 1.35 & 2.87 & 4.43 & 2.14 & 0.43 & 0.09 & 6.4 & 99.2 \\
\hline $5 R-2,25-27$ & 375.60 & $\| A$ & 65.4 & 14.9 & 5.98 & 0.12 & 2.07 & 4.90 & 3.16 & 1.40 & 0.62 & 0.10 & 2.6 & 98.7 \\
\hline $6 \mathrm{R}-1,128-130$ & 385.30 & IIB & 60.4 & 18.1 & 6.35 & 0.23 & 2.60 & 4.02 & 2.26 & 3.36 & 0.75 & 0.10 & 7.9 & 98.1 \\
\hline $6 \mathrm{R}-5,25-27$ & 388.70 & IIB & 63.3 & 16.1 & 7.05 & 1.49 & 2.51 & 1.31 & 2.40 & 3.38 & 0.66 & 0.09 & 6.1 & 98.3 \\
\hline $7 R-3,0-2$ & 395.10 & IIB & 64.6 & 17.0 & 5.37 & 0.05 & 1.85 & 4.14 & 3.39 & 1.44 & 0.68 & 0.10 & 3.6 & 98.6 \\
\hline $8 \mathrm{R}-2,0-2$ & 404.30 & IIB & 63.6 & 17.0 & 5.60 & 0.08 & 2.05 & 3.80 & 3.21 & 2.16 & 0.72 & 0.10 & 5.1 & 98.4 \\
\hline $9 \mathrm{R}-2,0-2$ & 413.60 & IIB & 63.3 & 17.1 & 5.36 & 0.07 & 1.73 & 4.60 & 3.56 & 1.48 & 0.72 & 0.10 & 4.6 & 98.0 \\
\hline $9 \mathrm{R}-4,71-73$ & 416.20 & IIB & 60.5 & 16.9 & 6.60 & 0.17 & 2.26 & 5.49 & 2.64 & 2.75 & 0.71 & 0.14 & 7.7 & 98.2 \\
\hline 10R-1, 87.5-89.5 & 422.90 & IIB & 61.5 & 18.2 & 9.37 & 0.06 & 2.64 & 1.85 & 2.99 & 1.26 & 0.55 & 0.06 & 7.0 & 98.5 \\
\hline 10R-3, 0-2 & 424.80 & IIB & 65.2 & 17.2 & 5.88 & 0.07 & 2.32 & 0.73 & 2.37 & 3.48 & 0.70 & 0.08 & 4.9 & 98.0 \\
\hline $11 \mathrm{R}-2,31-33$ & 433.21 & IIB & 58.2 & 16.1 & 6.08 & 0.40 & 2.30 & 8.17 & 2.46 & 2.77 & 0.69 & 1.58 & 8.7 & 98.7 \\
\hline $11 R-4,0-2$ & 434.64 & IIB & 66.0 & 16.1 & 6.25 & 0.07 & 2.45 & 2.00 & 3.80 & 1.12 & 0.39 & 0.05 & 7.4 & 98.2 \\
\hline $11 \mathrm{R}-7,71-73$ & 438.77 & IIB & 64.9 & 16.9 & 6.53 & 0.07 & 2.40 & 0.87 & 2.54 & 3.18 & 0.68 & 0.07 & 4.9 & 98.2 \\
\hline $12 \mathrm{R}-2,82-84$ & 443.23 & IIB & 66.1 & 16.7 & 6.06 & 0.06 & 2.28 & 0.92 & 2.69 & 3.09 & 0.70 & 0.07 & 4.9 & 98.7 \\
\hline $12 \mathrm{R}-3,50-52$ & 444.33 & IIB & 61.8 & 17.4 & 6.04 & 0.17 & 2.40 & 4.50 & 2.57 & 2.98 & 0.70 & 0.15 & 7.2 & 98.7 \\
\hline $12 \mathrm{R}-6,0-2$ & 446.96 & IIB & 64.6 & 16.7 & 5.13 & 0.13 & 2.01 & 3.19 & 3.11 & 2.47 & 0.63 & 0.09 & 5.8 & 98.1 \\
\hline $13 R-3,30-35$ & 453.62 & IIB & 65.6 & 17.1 & 5.91 & 0.11 & 2.35 & 0.63 & 2.44 & 3.40 & 0.72 & 0.09 & 5.0 & 98.3 \\
\hline $13 R-5,78-80$ & 455.87 & IIB & 59.7 & 16.0 & 9.15 & 1.90 & 2.82 & 2.22 & 2.12 & 3.13 & 0.67 & 0.53 & 8.1 & 98.3 \\
\hline $13 R-5,104-106$ & 456.13 & IIB & 65.0 & 17.2 & 6.53 & 0.07 & 2.48 & 0.67 & 2.30 & 3.29 & 0.69 & 0.08 & 5.2 & 98.3 \\
\hline 14R-1, 49-50 & 460.49 & IIB & 29.7 & 8.3 & 7.23 & 4.81 & 2.76 & 45.50 & 1.05 & 0.48 & 0.37 & 1.35 & 29.5 & 101.6 \\
\hline $14 R-4,0-2$ & 463.16 & IIB & 65.1 & 16.6 & 6.22 & 0.07 & 2.22 & 1.86 & 2.86 & 2.63 & 0.70 & 0.08 & 5.5 & 98.2 \\
\hline 15R-1, 103-105 & 470.53 & IIB & 56.5 & 16.5 & 14.47 & 0.51 & 1.97 & 2.68 & 2.57 & 2.39 & 0.72 & 0.24 & 9.8 & 98.5 \\
\hline 15R-2, 111-113 & 472.03 & IIB & 65.0 & 17.7 & 6.20 & 0.06 & 2.36 & 0.54 & 2.25 & 3.49 & 0.73 & 0.08 & 4.7 & 98.3 \\
\hline $15 R-3,0-2$ & 472.03 & IIB & 64.9 & 17.8 & 6.14 & 0.05 & 2.32 & 0.57 & 2.20 & 3.42 & 0.73 & 0.08 & 6.1 & 98.2 \\
\hline 16R-1, 103-105 & 477.83 & IIB & 65.7 & 16.4 & 5.77 & 0.06 & 1.79 & 2.79 & 2.97 & 2.23 & 0.62 & 0.07 & 3.8 & 98.4 \\
\hline $16 \mathrm{R}-2,0-2$ & 478.21 & IIB & 66.1 & 16.3 & 5.44 & 0.06 & 1.73 & 2.96 & 3.17 & 2.15 & 0.63 & 0.08 & 3.2 & 98.6 \\
\hline 19R-3, 0-2 & 492.65 & IIII & 64.1 & 17.1 & 6.57 & 0.31 & 2.30 & 1.63 & 2.29 & 3.37 & 0.72 & 0.08 & 4.7 & 98.5 \\
\hline $19 R-5,133-135$ & 495.73 & III & 33.3 & 8.4 & 13.37 & 11.24 & 2.68 & 17.82 & 1.49 & 1.43 & 0.36 & 8.38 & 17.6 & 98.4 \\
\hline 20R-1, 15-17 & 498.55 & III & 29.6 & 8.9 & 7.27 & 4.02 & 2.08 & 45.87 & 1.29 & 0.47 & 0.36 & 0.96 & 28.9 & 100.9 \\
\hline 20R-1, 15-17 & 498.55 & III & 29.2 & 8.7 & 7.25 & 4.19 & 2.10 & 46.51 & 1.18 & 0.45 & 0.33 & 1.06 & 28.9 & 101.0 \\
\hline $21 \mathrm{R}-2,0-2$ & 501.65 & III & 65.5 & 17.3 & 6.43 & 0.07 & 2.28 & 0.49 & 2.24 & 3.46 & 0.72 & 0.08 & 4.6 & 98.5 \\
\hline $21 \mathrm{R}-7,7-9$ & 507.97 & III & 65.1 & 16.9 & 6.50 & 0.60 & 2.39 & 0.81 & 2.20 & 3.40 & 0.70 & 0.10 & 5.3 & 98.8 \\
\hline $23 R-2,0-2$ & 521.15 & III & 65.0 & 17.3 & 6.56 & 0.12 & 2.46 & 0.88 & 2.30 & 3.45 & 0.68 & 0.09 & 5.6 & 98.8 \\
\hline $24 \mathrm{R}-1,0-2$ & 529.90 & IIII & 64.5 & 17.2 & 6.44 & 0.15 & 2.39 & 1.44 & 2.19 & 3.38 & 0.70 & 0.08 & 5.8 & 98.5 \\
\hline $24 \mathrm{R}-4,90.5-92.5$ & 534.20 & III & 65.2 & 17.3 & 6.31 & 0.13 & 2.46 & 0.75 & 2.19 & 3.47 & 0.71 & 0.10 & 5.4 & 98.6 \\
\hline $25 \mathrm{R}-2,50-52$ & 540.36 & III & 66.4 & 17.1 & 5.34 & 0.09 & 1.84 & 1.73 & 3.06 & 2.35 & 0.70 & 0.09 & 4.6 & 98.7 \\
\hline $25 \mathrm{R}-4,111-113$ & 543.00 & III & 65.6 & 17.4 & 6.45 & 0.08 & 2.36 & 0.48 & 2.08 & 3.51 & 0.71 & 0.08 & 4.8 & 98.7 \\
\hline 26R-2, 67-69 & 550.89 & III & 65.0 & 17.1 & 6.43 & 0.30 & 2.39 & 0.78 & 2.16 & 3.42 & 0.71 & 0.10 & 4.9 & 98.4 \\
\hline $26 \mathrm{R}-6,5-7$ & 555.14 & III & 62.4 & 17.9 & 8.93 & 0.08 & 2.92 & 1.44 & 2.98 & 1.33 & 0.61 & 0.05 & 5.8 & 98.6 \\
\hline $27 \mathrm{R}-2,48-56$ & 559.84 & III & 65.9 & 17.0 & 6.51 & 0.07 & 2.40 & 0.66 & 2.25 & 3.30 & 0.70 & 0.09 & 4.9 & 98.8 \\
\hline 27R-4, 108-110 & 562.38 & III & 64.7 & 17.3 & 6.48 & 0.07 & 2.45 & 1.02 & 2.53 & 3.10 & 0.73 & 0.08 & 4.6 & 98.5 \\
\hline $27 R-4,138-140$ & 562.68 & III & 62.3 & 17.3 & 6.75 & 0.14 & 2.44 & 3.07 & 2.66 & 2.79 & 0.74 & 0.18 & 6.3 & 98.3 \\
\hline 28R-2, 0-2 & 569.46 & III & 64.2 & 16.9 & 6.72 & 0.13 & 2.54 & 1.60 & 2.29 & 3.29 & 0.70 & 0.09 & 5.7 & 98.5 \\
\hline $28 \mathrm{R}-3,18-20$ & 570.17 & III & 64.8 & 17.3 & 6.12 & 0.07 & 2.39 & 0.80 & 2.45 & 3.30 & 0.73 & 0.08 & 4.8 & 98.1 \\
\hline 30R-2, 0-2 & 581.78 & III & 64.1 & 17.3 & 6.45 & 0.60 & 2.43 & 1.20 & 2.14 & 3.34 & 0.73 & 0.09 & 6.8 & 98.4 \\
\hline $31 \mathrm{R}-1,120-122$ & 587.70 & III & 65.6 & 16.9 & 6.22 & 0.08 & 2.29 & 0.91 & 2.12 & 3.32 & 0.69 & 0.09 & 26.5 & 98.3 \\
\hline $31 \mathrm{R}-2,50-52$ & 588.36 & III & 62.2 & 19.0 & 7.25 & 0.13 & 2.61 & 1.60 & 2.73 & 2.01 & 0.70 & 0.08 & 5.7 & 98.4 \\
\hline $32 \mathrm{R}-2,95-98$ & 598.38 & III & 65.4 & 16.8 & 6.35 & 0.20 & 2.32 & 0.79 & 2.13 & 3.29 & 0.70 & 0.09 & 4.9 & 98.0 \\
\hline $32 \mathrm{R}-5,0-2$ & 601.39 & III & 65.6 & 16.9 & 6.22 & 0.08 & 2.29 & 0.91 & 2.12 & 3.32 & 0.69 & 0.09 & 4.9 & 98.3 \\
\hline $33 \mathrm{R}-2,0-3$ & 605.94 & III & 66.3 & 16.7 & 6.02 & 0.09 & 2.40 & 0.69 & 2.04 & 3.36 & 0.72 & 0.09 & 4.7 & 98.4 \\
\hline $33 R-3,17-19$ & 606.65 & III & 31.1 & 7.7 & 4.15 & 5.39 & 1.96 & 44.66 & 0.87 & 0.51 & 0.34 & 3.82 & 26.9 & 100.5 \\
\hline $33 \mathrm{R}-3,32-34$ & 606.80 & III & 61.5 & 16.4 & 7.11 & 0.38 & 2.30 & 4.74 & 2.08 & 2.88 & 0.70 & 0.10 & 7.5 & 98.2 \\
\hline $35 R-4,0-3$ & 628.37 & III & 65.5 & 17.1 & 6.32 & 0.14 & 2.29 & 0.79 & 2.06 & 3.24 & 0.69 & 0.08 & 4.7 & 98.2 \\
\hline $36 \mathrm{R}-2,50-52$ & 635.17 & III & 65.4 & 17.4 & 6.21 & 0.08 & 2.36 & 0.86 & 2.25 & 3.19 & 0.75 & 0.08 & 4.8 & 98.5 \\
\hline 36R-3, 96-98 & 636.17 & III & 61.8 & 18.1 & 7.34 & 0.14 & 2.29 & 2.33 & 2.83 & 2.11 & 1.00 & 0.09 & 5.5 & 98.1 \\
\hline $37 \mathrm{R}-2,50-53$ & 645.29 & III & 64.6 & 17.2 & 6.31 & 0.13 & 2.39 & 1.67 & 2.23 & 3.33 & 0.72 & 0.08 & 5.9 & 98.6 \\
\hline
\end{tabular}


Table T5 (continued).

\begin{tabular}{|c|c|c|c|c|c|c|c|c|c|c|c|c|c|c|}
\hline \multirow{2}{*}{$\begin{array}{l}\text { Core, section, } \\
\text { interval }(\mathrm{cm})\end{array}$} & \multirow{2}{*}{$\begin{array}{l}\text { Depth } \\
\operatorname{CSF}(m)\end{array}$} & \multirow{2}{*}{$\begin{array}{c}\text { Lithologic } \\
\text { unit }\end{array}$} & \multicolumn{12}{|c|}{ Oxide abundance (wt\%) } \\
\hline & & & $\mathrm{SiO}_{2}$ & $\mathrm{Al}_{2} \mathrm{O}_{3}$ & $\mathrm{Fe}_{2} \mathrm{O}_{3}$ & $\mathrm{MnO}$ & $\mathrm{MgO}$ & $\mathrm{CaO}$ & $\mathrm{Na}_{2} \mathrm{O}$ & $\mathrm{K}_{2} \mathrm{O}$ & $\mathrm{TiO}_{2}$ & $\mathrm{P}_{2} \mathrm{O}_{5}$ & LOI & Total \\
\hline $37 R-5,110-112$ & 649.25 & III & 62.5 & 17.2 & 6.55 & 0.10 & 2.44 & 3.78 & 2.22 & 3.03 & 0.73 & 0.08 & 7.1 & 98.6 \\
\hline $38 \mathrm{R}-2,0-2$ & 654.39 & III & 65.4 & 17.6 & 6.66 & 0.48 & 2.42 & 1.39 & 2.15 & 3.32 & 0.76 & 0.09 & 5.5 & 100.3 \\
\hline $38 \mathrm{R}-6,18-20$ & 659.35 & III & 63.4 & 16.5 & 7.06 & 0.90 & 2.33 & 2.07 & 2.06 & 3.17 & 0.70 & 0.09 & 6.6 & 98.2 \\
\hline $39 R-4,50-52$ & 667.24 & III & 63.8 & 17.4 & 6.43 & 0.11 & 2.41 & 1.82 & 2.25 & 3.08 & 0.74 & 0.08 & 5.7 & 98.1 \\
\hline $40 \mathrm{R}-3,0-2$ & 674.82 & IV & 65.3 & 17.0 & 6.17 & 0.08 & 2.32 & 1.54 & 2.14 & 3.20 & 0.72 & 0.08 & 5.1 & 98.5 \\
\hline $42 \mathrm{R}-2,0-2$ & 681.88 & IV & 67.9 & 15.6 & 5.37 & 0.09 & 2.12 & 1.81 & 2.16 & 2.92 & 0.66 & 0.08 & 5.2 & 98.7 \\
\hline $43 R-3,0-2$ & 686.95 & IV & 66.7 & 15.4 & 5.44 & 0.10 & 2.13 & 2.71 & 1.99 & 2.83 & 0.68 & 0.07 & 5.7 & 98.1 \\
\hline $44 \mathrm{R}-3,0-2$ & 691.09 & IV & 66.4 & 16.8 & 6.18 & 0.23 & 2.32 & 0.86 & 2.12 & 3.04 & 0.72 & 0.08 & 4.7 & 98.8 \\
\hline $44 \mathrm{R}-7,65-67$ & 696.19 & IV & 65.7 & 17.3 & 6.11 & 0.38 & 2.38 & 0.94 & 2.08 & 3.27 & 0.73 & 0.09 & 5.0 & 99.0 \\
\hline $45 \mathrm{R}-3,0-2$ & 700.28 & IV & 64.9 & 17.5 & 6.23 & 0.07 & 2.24 & 1.14 & 2.06 & 3.24 & 0.72 & 0.09 & 5.1 & 98.1 \\
\hline $45 R-5,44-46$ & 702.68 & IV & 65.7 & 17.5 & 6.34 & 0.10 & 2.09 & 0.97 & 1.89 & 3.31 & 0.78 & 0.07 & 5.7 & 98.8 \\
\hline $47 \mathrm{R}-2,0-2$ & 712.61 & IV & 64.4 & 18.4 & 6.17 & 0.43 & 2.18 & 0.99 & 1.93 & 3.45 & 0.78 & 0.10 & 5.4 & 98.9 \\
\hline 48R-2, 9-11 & 722.09 & IV & 65.2 & 18.3 & 5.95 & 0.06 & 2.06 & 0.73 & 1.88 & 3.63 & 0.80 & 0.10 & 5.0 & 98.7 \\
\hline $48 \mathrm{R}-3,25-27$ & 722.79 & IV & 62.9 & 19.2 & 6.87 & 0.10 & 2.26 & 0.78 & 1.73 & 3.54 & 0.83 & 0.09 & 6.3 & 98.3 \\
\hline $49 \mathrm{R}-7,122-124$ & 736.14 & IV & 63.8 & 17.7 & 6.72 & 0.89 & 2.20 & 0.95 & 1.88 & 3.44 & 0.76 & 0.14 & 5.6 & 98.5 \\
\hline $51 \mathrm{R}-4,0-2$ & 750.75 & IV & 66.2 & 17.0 & 6.39 & 0.04 & 2.28 & 0.93 & 1.94 & 3.04 & 0.77 & 0.08 & 4.7 & 98.7 \\
\hline 51R-7, 135-137 & 755.53 & IV & 65.4 & 17.1 & 6.28 & 0.05 & 2.32 & 0.81 & 1.92 & 3.14 & 0.73 & 0.09 & 4.7 & 97.8 \\
\hline $52 \mathrm{R}-6,0-2$ & 763.84 & IV & 66.3 & 17.2 & 6.55 & 0.06 & 2.35 & 0.75 & 1.87 & 3.14 & 0.76 & 0.08 & 5.2 & 99.1 \\
\hline $53 \mathrm{R}-2,0-2$ & 767.71 & IV & 65.5 & 17.0 & 6.70 & 0.05 & 2.28 & 1.58 & 1.86 & 3.16 & 0.73 & 0.08 & 5.7 & 98.9 \\
\hline $54 \mathrm{R}-5,44-46$ & 774.68 & IV & 66.0 & 17.2 & 5.97 & 0.04 & 2.30 & 0.74 & 1.92 & 3.40 & 0.76 & 0.09 & 4.8 & 98.4 \\
\hline $55 \mathrm{R}-1,27-29$ & 779.27 & IV & 75.0 & 13.0 & 3.21 & 0.02 & 1.05 & 0.96 & 2.73 & 2.76 & 0.42 & 0.06 & 2.4 & 99.3 \\
\hline $55 \mathrm{R}-2,0-2$ & 779.50 & IV & 78.3 & 11.2 & 2.66 & 0.02 & 0.70 & 0.83 & 2.28 & 2.84 & 0.40 & 0.07 & 1.7 & 99.3 \\
\hline $56 \mathrm{R}-2,0-2$ & 844.53 & IV & 64.5 & 18.5 & 6.51 & 0.05 & 2.11 & 0.90 & 1.78 & 3.89 & 0.77 & 0.09 & 5.3 & 99.0 \\
\hline $57 \mathrm{R}-4,0-2$ & 850.45 & V & 62.5 & 19.3 & 6.69 & 0.07 & 2.48 & 2.67 & 2.76 & 1.23 & 0.47 & 0.11 & 5.8 & 98.3 \\
\hline 57R-5, 120-123 & 852.25 & $\mathrm{~V}$ & 72.5 & 14.0 & 4.49 & 0.05 & 1.66 & 1.40 & 1.93 & 2.63 & 0.57 & 0.09 & 4.1 & 99.4 \\
\hline $58 \mathrm{R}-3,0-2$ & 858.34 & V & 69.3 & 15.1 & 5.25 & 0.09 & 2.05 & 1.26 & 1.68 & 3.68 & 0.66 & 0.11 & 3.9 & 99.2 \\
\hline $58 \mathrm{R}-4,40-42$ & 859.29 & V & 65.2 & 15.8 & 7.63 & 0.18 & 1.97 & 1.63 & 2.54 & 2.68 & 0.47 & 0.06 & 6.7 & 98.2 \\
\hline $59 \mathrm{R}-3,0-2$ & 867.48 & $\mathrm{~V}$ & 65.8 & 15.3 & 6.26 & 0.21 & 1.79 & 2.15 & 3.78 & 2.20 & 0.75 & 0.17 & 5.3 & 98.4 \\
\hline 60R-CC, $0-6$ & 874.06 & V & 73.9 & 12.5 & 4.00 & 0.11 & 1.44 & 1.47 & 2.22 & 2.95 & 0.45 & 0.11 & 3.3 & 99.1 \\
\hline
\end{tabular}

Note: LOI = loss on ignition. 
Table T6. Summary of stratigraphic relations at Site C0011 and correlation with equivalent units at ODP sites and IODP Site C0012. (See table note.)

\begin{tabular}{|c|c|c|c|c|c|c|c|c|c|c|c|c|c|c|}
\hline \multirow{2}{*}{ Unit } & \multirow{2}{*}{ Unit name } & \multirow{2}{*}{\multicolumn{2}{|c|}{$\begin{array}{l}\text { Core, section, } \\
\text { interval }(\mathrm{cm})\end{array}$}} & \multirow{2}{*}{\multicolumn{2}{|c|}{ Depth CSF $(m)$}} & \multirow{2}{*}{$\begin{array}{l}\text { Thickness } \\
(\mathrm{m})\end{array}$} & \multirow{2}{*}{$\begin{array}{l}\text { Stratigraphic } \\
\text { age }\end{array}$} & \multirow{2}{*}{$\begin{array}{l}\text { Lithologic } \\
\text { description }\end{array}$} & \multirow{2}{*}{$\begin{array}{l}\text { Processes } \\
\text { of formation }\end{array}$} & \multicolumn{5}{|c|}{ Stratigraphic correlation } \\
\hline & & & & & & & & & & $\begin{array}{l}\text { Site } \\
808\end{array}$ & $\begin{array}{l}\text { Site } \\
1173\end{array}$ & $\begin{array}{c}\text { Site } \\
1174\end{array}$ & $\begin{array}{l}\text { Site } \\
1177\end{array}$ & $\begin{array}{l}\text { Site } \\
\text { C0012 }\end{array}$ \\
\hline 1 & Upper Shikoku Basin & $\begin{array}{l}322-C 0011 \mathrm{~B}- \\
* * * \text { Drilled wi }\end{array}$ & $\begin{array}{l}\text { 322-C0011B- } \\
\text { out coring }\end{array}$ & 0.00 & 340.00 & 340.00 & Pliocene? & - & - & $\begin{array}{l}\text { Subunit } \\
\text { IVA }\end{array}$ & Unit II & Unit III & Unit I & Unit I \\
\hline II & $\begin{array}{l}\text { Middle Shikoku Basin } \\
\text { tuffaceous } \\
\text { sandstones, } \\
\text { volcaniclastic } \\
\text { sandstones }\end{array}$ & $1 \mathrm{R}-1,0$ & $17 \mathrm{R}-\mathrm{CC}, 6$ & 340.00 & 479.06 & 139.06 & $\begin{array}{l}\text { late Miocene } \\
\quad(7.6-9.1 \mathrm{Ma})\end{array}$ & $\begin{array}{l}\text { Silty claystone, } \\
\text { tuffaceous } \\
\text { sandstone, } \\
\text { volcaniclastic } \\
\text { sandstone }\end{array}$ & $\begin{array}{l}\text { Hemipelagic settling and } \\
\text { volcaniclastic turbidity } \\
\text { currents in submarine } \\
\text { fan system }\end{array}$ & NA & NA & NA & NA & Unit II \\
\hline III & $\begin{array}{l}\text { Lower Shikoku Basin } \\
\text { hemipelagites }\end{array}$ & $17 \mathrm{R}-\mathrm{CC}, 6$ & $40 \mathrm{R}-2,58$ & 479.06 & 673.98 & 194.92 & $\begin{array}{l}\text { late-middle } \\
\text { Miocene } \\
(9.1-12.3 \mathrm{Ma})\end{array}$ & $\begin{array}{l}\text { Silty claystone and } \\
\text { lime mudstone }\end{array}$ & Hemipelagic settling & $\begin{array}{l}\text { Subunit } \\
\text { IVB }\end{array}$ & Unit III & Unit IV & Unit II & Unit III \\
\hline IV & $\begin{array}{l}\text { Lower Shikoku Basin } \\
\text { turbidites }\end{array}$ & $40 \mathrm{R}-2,58$ & $57 R-3,73$ & 673.98 & 849.95 & 175.97 & $\begin{array}{c}\text { middle Miocene } \\
(12.3-13.9 \mathrm{Ma})\end{array}$ & $\begin{array}{l}\text { Silty claystone, } \\
\text { clayey siltstone, } \\
\text { and silty sandstone }\end{array}$ & $\begin{array}{l}\text { Hemipelagic settling and } \\
\text { terrigenous turbidity } \\
\text { currents in submarine } \\
\text { fan system }\end{array}$ & NA & NA & NA & Unit III & Unit IV \\
\hline v & $\begin{array}{l}\text { Volcaniclastic-rich } \\
\text { deposits }\end{array}$ & $57 R-3,74$ & $61 \mathrm{R}-\mathrm{CC}, 5$ & 849.95 & 876.05 & 26.10 & $\begin{array}{l}\text { middle Miocene } \\
\quad(>13.9 \mathrm{Ma})\end{array}$ & $\begin{array}{l}\text { Silty claystone, } \\
\text { tuffaceous } \\
\text { claystone, and tuff }\end{array}$ & $\begin{array}{l}\text { Hemipelagic settling, } \\
\text { volcaniclastic turbidity } \\
\text { currents, and air fall } \\
\text { pyroclastic deposition }\end{array}$ & Unit V & Unit IV & Unit V & Unit IV & Unit V \\
\hline
\end{tabular}

Note: NA = not available. 
Table T7. Paleomagnetic directions used for reorientation of coherent blocks, Site C0011. (See table note.)

\begin{tabular}{|c|c|c|c|c|c|c|}
\hline \multirow[b]{2}{*}{$\begin{array}{l}\text { Core, section, } \\
\text { interval }(\mathrm{cm})\end{array}$} & \multirow[b]{2}{*}{$\begin{array}{l}\text { Depth } \\
\text { CSF }(m)\end{array}$} & \multirow[b]{2}{*}{$\begin{array}{c}\text { Lithologic } \\
\text { unit }\end{array}$} & \multirow[b]{2}{*}{ Lithology } & \multicolumn{3}{|c|}{ Characteristic remanent magnetization } \\
\hline & & & & $\begin{array}{l}\text { Declination } \\
\left({ }^{\circ}\right)\end{array}$ & $\begin{array}{c}\text { Inclination } \\
\left({ }^{\circ}\right)\end{array}$ & $\begin{array}{l}\text { Maximum angular } \\
\text { deviation }\left(^{\circ}\right)\end{array}$ \\
\hline \multicolumn{7}{|l|}{ 322-C0011B- } \\
\hline 6R-1, 119.5-122 & 385.21 & II & Clay & 116.5 & 48.8 & 3.1 \\
\hline $6 \mathrm{R}-8,127-129$ & 393.05 & & Clay & 77.2 & 47.4 & 1.5 \\
\hline $11 \mathrm{R}-3,15-17$ & 434.47 & & Clay & 176.9 & -42.7 & 5.1 \\
\hline $11 \mathrm{R}-8,12-14$ & 439.60 & & Clay & -47.0 & -44.8 & 13.4 \\
\hline $13 \mathrm{R}-6,105-107$ & 457.56 & & Clay & -26.8 & 58.8 & 7.8 \\
\hline $14 R-5,124-126$ & 464.87 & & Clay & 122.9 & 45.6 & 8.2 \\
\hline $15 R-1,46-48$ & 469.97 & & Clay & 90.6 & 27.5 & 3.2 \\
\hline 15R-4, 99-101 & 473.55 & & Clay & -2.8 & 31.4 & 11.7 \\
\hline 19R-4, 108-110 & 494.11 & III & Clay & -107.7 & 71.1 & 3.0 \\
\hline $21 \mathrm{R}-3,4-6$ & 502.31 & & Clay & 166.3 & 53.0 & 11.7 \\
\hline $21 \mathrm{R}-5,106-108$ & 506.15 & & Clay & 48.2 & -31.8 & 9.1 \\
\hline $21 \mathrm{R}-8,4-6$ & 509.36 & & Clay & -27.1 & 69.6 & 4.0 \\
\hline 23R-7, 30-32 & 526.61 & & Clay & -49.4 & 64.3 & 3.2 \\
\hline 23R-7, 98-100 & 527.29 & & Clay & -58.0 & 63.5 & 1.1 \\
\hline 26R-4, 105-107 & 553.34 & & Clay & 16.6 & 58.2 & 7.9 \\
\hline 26R-5, 20-22 & 553.89 & & Clay & 14.1 & 55.0 & 1.8 \\
\hline $26 \mathrm{R}-6,17-19$ & 555.27 & & Clay & -30.9 & 63.8 & 0.2 \\
\hline 26R-7, 9-11 & 556.62 & & Clay & -38.5 & 62.9 & 1.8 \\
\hline $27 \mathrm{R}-1,72-74$ & 559.23 & & Clay & -27.3 & 70.2 & 2.4 \\
\hline $27 R-4,31-33$ & 561.62 & & Clay & -85.7 & 63.2 & 1.1 \\
\hline $27 \mathrm{R}-5,21-23$ & 562.93 & & Clay & -111.3 & 66.0 & 1.4 \\
\hline $28 \mathrm{R}-1,86-88$ & 568.87 & & Clay & 156.4 & 33.0 & 7.3 \\
\hline $30 R-4,35-37$ & 584.08 & & Clay & -55.1 & 69.0 & 8.2 \\
\hline $31 \mathrm{R}-1,36-38$ & 586.87 & & Clay & 112.4 & -40.3 & 9.3 \\
\hline $31 \mathrm{R}-3,30-32$ & 588.71 & & Clay & 41.6 & 55.2 & 14.8 \\
\hline $32 \mathrm{R}-1,86-88$ & 596.87 & & Clay & -51.0 & 55.9 & 3.8 \\
\hline $32 \mathrm{R}-2,113-115$ & 598.57 & & Clay & 26.6 & 67.0 & 6.5 \\
\hline $39 R-2,2-4$ & 663.94 & & Clay & 18.7 & 57.4 & 5.2 \\
\hline 40R-1, 112-114 & 673.13 & & Clay & 176.9 & 60.9 & 8.0 \\
\hline 44R-1, 115-117 & 690.16 & IV & Clay & -67.0 & 62.8 & 8.3 \\
\hline $44 R-4,32-34$ & 692.02 & & Clay & 5.5 & 64.5 & 8.0 \\
\hline $48 \mathrm{R}-1,53-55$ & 721.54 & & Clay & -16.9 & 71.2 & 3.9 \\
\hline $49 \mathrm{R}-5,85-87$ & 734.42 & & Clay & -112.2 & 58.9 & 6.5 \\
\hline $51 \mathrm{R}-6,97-99$ & 753.74 & & Clay & -39.4 & 48.4 & 3.9 \\
\hline 51R-7, 126-128 & 755.45 & & Clay & -43.7 & 70.9 & 8.6 \\
\hline $54 \mathrm{R}-4,121-123$ & 774.05 & & Clay & -72.9 & 69.5 & 8.2 \\
\hline $56 \mathrm{R}-1,4-6$ & 844.05 & & Clay & 47.9 & 60.2 & 3.2 \\
\hline $56 \mathrm{R}-1,44-46$ & 844.45 & & Clay & 46.1 & 49.7 & 1.1 \\
\hline $56 \mathrm{R}-3,20-22$ & 845.38 & & Clay & 133.2 & 56.2 & 5.4 \\
\hline 57R-3, 15-17 & 849.38 & & Silty clay & -60.7 & 60.4 & 7.7 \\
\hline 58R-1, 16-18 & 856.07 & $\mathrm{~V}$ & Fine-grained tuff & 30.9 & -47.9 & 6.8 \\
\hline $58 \mathrm{R}-1,41-43$ & 856.32 & & Fine-grained tuff & -173.4 & 63.5 & 3.1 \\
\hline 58R-1, 98-100 & 856.89 & & Fine-grained tuff & -118.1 & 70.4 & 2.1 \\
\hline
\end{tabular}

Note: Maximum angular deviation calculated from Kirschvink (1980). 
Table T8. Distribution of calcareous nannofossils, Hole C0011B. This table is available in an oversized format. 


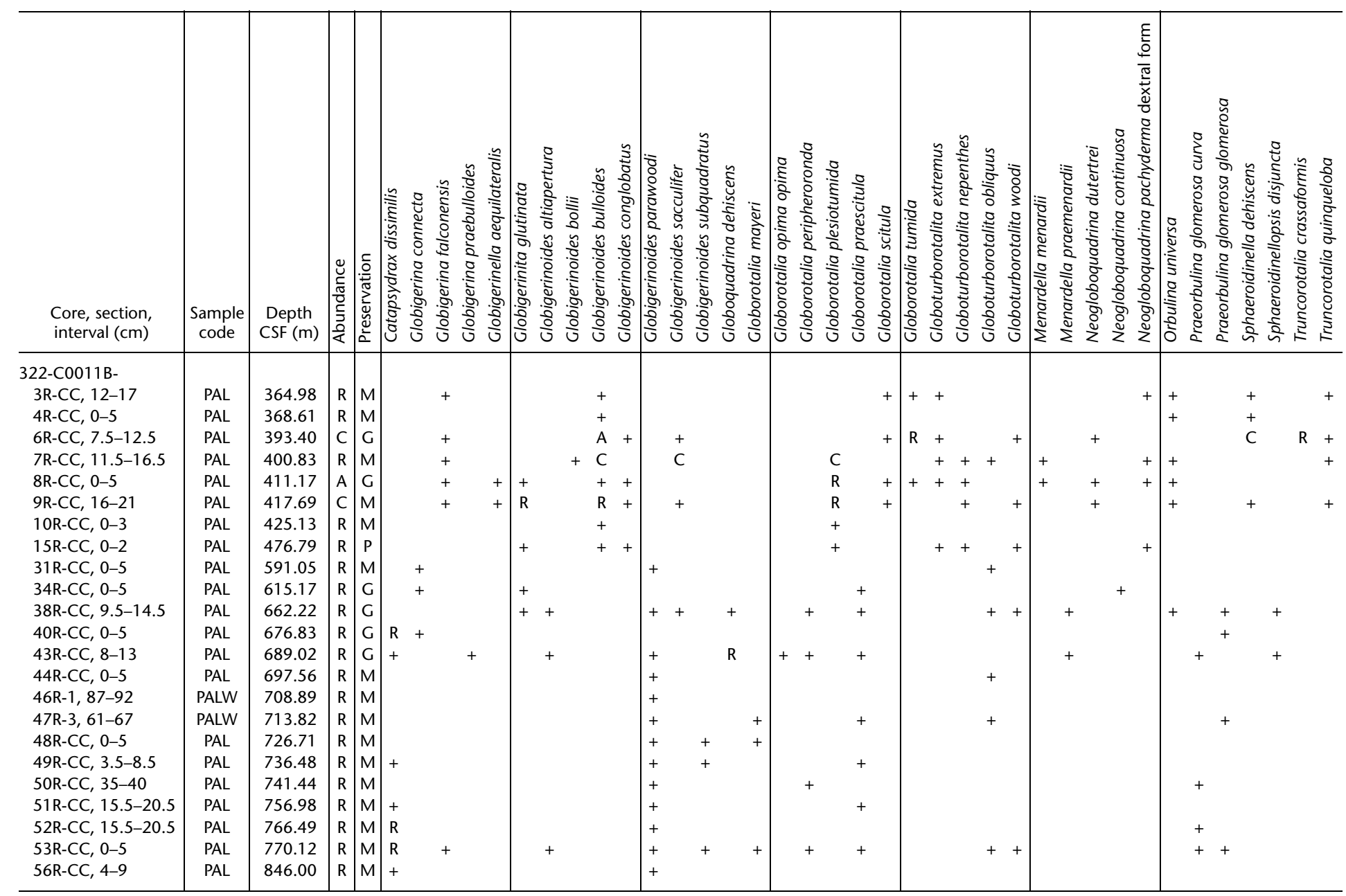

Notes: $\mathrm{PAL}=$ paleontologic sample, $\mathrm{PALW}=$ additional paleontologic sample. Abundance: $\mathrm{A}=$ abundant, $\mathrm{C}=$ common, $\mathrm{R}=$ rare,$+=$ present, $\mathrm{B}=$ barren. Preservation: $\mathrm{G}=\mathrm{good}, \mathrm{M}=$ medium, $\mathrm{P}=$ poor. Barren samples: 322-C0011B-1R-CC, $35.5-40.5 \mathrm{~cm} ; 2 \mathrm{R}-\mathrm{CC}, 0-5 \mathrm{~cm} ; 5 \mathrm{R}-\mathrm{CC}, 11-16 \mathrm{~cm} ; 11 \mathrm{R}-\mathrm{CC}, 0-3 \mathrm{~cm} ; 12 \mathrm{R}-\mathrm{CC}, 0-5 \mathrm{~cm} ; 13 \mathrm{R}-\mathrm{CC}, 0-5 \mathrm{~cm} ; 14 \mathrm{R}-\mathrm{CC}, 0-5 \mathrm{~cm} ; 16 \mathrm{R}-\mathrm{CC}, 0-5 \mathrm{~cm} ;$ $17 \mathrm{R}-\mathrm{CC}, 0-5 \mathrm{~cm}$; 19R-CC, 7.5-12.5 cm; 19R-5, 127-131 cm; 20R-CC, 22-27 cm; 21R-CC, 11-16 cm; 22R-CC, 15-20 cm; 23R-CC, 0-5 cm; 23R-1, 49-53 cm; 24R-CC, 23-28 cm; 26R-CC, 7-12 cm; 27R-CC, 0-5 cm; 28R-CC-bottom $5 \mathrm{~cm}$; 30R-CC, 0-5 cm; 33R-CC, 0-7 cm; 35R-CC, 0-5 cm; 37R-CC, 10.5-15.5 cm; 39R-CC, 0-1 cm; 41R-CC, 15.5-20.5 cm; 42R-CC, 0-5 cm; 45R-7, 136-141 cm; 54R-CC, 35.5-40.5 cm; 55R-CC, 12.5-17.5 cm; 57R-CC, 16-21 cm; 58R-CC, 0-5 cm; 59R-CC, 25-30 cm; 60R-CC, 11-12 cm; 61R-CC, 0-5 cm. No samples: 18R-CC; 25R-CC; 32R-CC. 
Table T10. Calcareous nannofossil events and absolute age, Hole C0011B. (See table notes.)

\begin{tabular}{|c|c|c|c|c|c|c|c|c|c|c|c|}
\hline \multirow[b]{2}{*}{ Zone } & \multirow[b]{2}{*}{ Calcareous nannofossil event } & \multicolumn{4}{|c|}{ Age $(\mathrm{Ma})$} & \multicolumn{2}{|c|}{ Core, section, interval $(\mathrm{cm})$} & \multicolumn{3}{|c|}{ Depth CSF (m) } & \multirow{2}{*}{$\begin{array}{c}\text { Depth } \\
\text { error }(m)\end{array}$} \\
\hline & & Upper & Lower & Middle & Error & Top & Bottom & Top & Bottom & Middle & \\
\hline & & & & & & 322-C0011B- & 322-C0011B- & & & & \\
\hline NN11a/NN10b & FO Discoaster berggrenii & 8.29 & 8.52 & 8.405 & 0.115 & 9R-CC, 16-21 & 10R-CC, 0-3.3 & 417.69 & 425.13 & 421.41 & 3.71 \\
\hline NN10a/NN10b & PB Reticulofenestra pseudoumbilicus (>7 $\mu \mathrm{m})$ & 8.761 & 8.785 & 8.773 & 0.012 & 9R-CC, 16-21 & 10R-CC, 0-3.3 & 417.69 & 425.13 & 421.41 & 3.71 \\
\hline NN10a/NN9 & LO Discoaster hamatus & 9.53 & 9.687 & 9.6085 & 0.0785 & 19R-5, 109 & 21R-CC, 11-16 & 495.38 & 510.39 & 502.89 & 7.50 \\
\hline NN9/NN8 & FO Discoaster hamatus & 10.18 & 10.54 & 10.36 & 0.18 & 24R-CC, 23-28 & $25 R-5,8-10$ & 535.20 & 543.39 & 539.29 & 4.09 \\
\hline NN8/NN7 & FO Catinaster coalitus & 10.73 & 10.886 & 10.808 & 0.078 & $25 R-5,8-10$ & 26R-7, 103 & 543.39 & 557.54 & 550.46 & 7.07 \\
\hline NN7/NN6 & FO Discoaster kugleri & 11.863 & 11.9 & 11.8815 & 0.0185 & 37R-CC, 10.5-15.5 & $38 \mathrm{R}-3,127$ & 652.98 & 655.05 & 654.02 & 1.03 \\
\hline LO C. floridanus & LO Cyclicargolithus floridanus & 12.037 & 12.037 & 12.037 & 0 & 38R-CC, 9.5-14.5 & $39 R-5,43-43.5$ & 662.22 & 667.75 & 664.98 & 2.76 \\
\hline NN6/NN5 & LO Sphenolithus heteromorphus & 13.53 & 13.65 & 13.59 & 0.06 & $53 \mathrm{R}-\mathrm{CC}, 0-5$ & 56R-CC, 4-9 & 770.12 & 846.00 & 808.06 & 37.93 \\
\hline
\end{tabular}

Notes: Age based on Raffi et al. (2006). LO = last occurrence, FO = first occurrence, PB = paracme beginning. Depth is center of interval. 
Table T11. Paleomagnetic and biostratigraphic datums, Site C0011. (See table notes.) (Continued on next page.)

\begin{tabular}{|c|c|c|c|c|c|c|c|c|c|c|c|c|}
\hline \multirow{2}{*}{$\begin{array}{l}\text { Magnetic datum } \\
\text { (chron or } \\
\text { subchron) }\end{array}$} & \multirow[b]{2}{*}{ Polarity } & \multirow{2}{*}{$\begin{array}{l}\text { Boundary } \\
\text { age (Ma) }\end{array}$} & \multicolumn{4}{|c|}{ Depth CSF (m) } & \multirow{2}{*}{$\begin{array}{c}\text { Biostratigraphic } \\
\text { datum } \\
\text { (Nannofossil) }\end{array}$} & \multirow{2}{*}{$\begin{array}{l}\text { Age } \\
\text { (Ma) }\end{array}$} & \multicolumn{4}{|c|}{ Depth CSF (m) } \\
\hline & & & Upper & Lower & Middle & Uncertainty & & & Upper & Lower & Middle & Uncertainty \\
\hline \multicolumn{13}{|l|}{ C4n.1n } \\
\hline & & 7.642 & 340.87 & 342.00 & 341.44 & 0.56 & & & & & & \\
\hline C4n.1r & & 7695 & 35005 & 35928 & 35467 & 467 & & & & & & \\
\hline C $4 n \cdot 2 n$ & & & & & & & & & & & & \\
\hline C4r.1r & & 8.108 & 393.69 & 394.69 & 394.19 & 0.50 & & & & & & \\
\hline & & 8.254 & & & & & & & & & & \\
\hline C4r.1n & & 8.300 & & & & & & & & & & \\
\hline C $4 r .2 r$ & & 8.769 & 452.54 & 452.79 & 452.67 & 0.13 & NN11a/NN10 & $8.54 \pm 0.24$ & 417.67 & 425.12 & 421.39 & 3.72 \\
\hline C4An & & 9.098 & 477.19 & 491,34 & 484.27 & 7.07 & & & & & & \\
\hline C4Ar.1r & & 9.321 & & & & & & & & & & \\
\hline C4Ar.1n & & 9.409 & & & & & & & & & & \\
\hline C4rAr.2r & & 9.656 & & & & & NN10a/NN9 & $9.61 \pm 0.08$ & 495.49 & 498.51 & 497.00 & 1.51 \\
\hline C4Ar.2n & & 9.717 & & & & & & & & & & \\
\hline C4Ar.3r & & 9.779 & & & & & & & & & & \\
\hline C5n.1n & & 9.934 & & & & & & & & & & \\
\hline C5n.1r & & 9.987 & 508.01 & 508.72 & 508.37 & 0.36 & & & & & & \\
\hline C $5 n .2 n$ & & & & & & & NN9/NN8 & $10.36 \pm 0.18$ & 535.46 & 539.94 & 537.70 & 2.24 \\
\hline & & 11.040 & 564.88 & 582.65 & 573.77 & 8.88 & NN8/NN7 & $10.81 \pm 0.08$ & 539.94 & 557.55 & 548.74 & 8.80 \\
\hline C5r.1r & & 11.118 & & & & & & & & & & \\
\hline C5r.1n & & 11.154 & & & & & & & & & & \\
\hline$C 5 r .2 r$ & & 11.554 & & & & & & & & & & \\
\hline C5r.2n & & 11.614 & & & & & & & & & & \\
\hline & & & & & & & NN7/NN6 & $11.88 \pm 0.02$ & 653.60 & 656.20 & 654.90 & 1.30 \\
\hline C5r.3r & & & & & & & & & & & & \\
\hline & & 12.041 & 637.02 & 638.84 & 637.93 & 0.91 & LO C. floridanus & 12.04 & 662.20 & 667.76 & 664.98 & 2.78 \\
\hline C5An.1n & & 12.116 & & & & & & & & & & \\
\hline C5An.1r & & 12.207 & & & & & & & & & & \\
\hline C5An.2n & & 12.415 & 694.67 & 69562 & 695,15 & 0.48 & & & & & & \\
\hline C5Ar.1r & & 12.730 & 716.91 & 721.54 & 719.23 & 2.31 & & & & & & \\
\hline C5Ar.1n & & 12.765 & & & & & & & & & & \\
\hline C5Ar.2r & & 12.820 & & & & & & & & & & \\
\hline C5Ar.2n & & 12.878 & & & & & & & & & & \\
\hline C5Ar.3r & & 13.015 & & & & & & & & & & \\
\hline C5AAn & & 13.183 & & & & & & & & & & \\
\hline C5AAr & & 13.369 & & & & & & & & & & \\
\hline C5ABn & & 13.605 & & & & & NN6/NN5 & $13.59 \pm 0.06$ & 771.92 & 846.00 & 808.96 & 37.04 \\
\hline
\end{tabular}


Table T11 (continued).

\begin{tabular}{|c|c|c|c|c|c|c|c|c|c|c|c|c|}
\hline \multirow{2}{*}{$\begin{array}{l}\text { Magnetic datum } \\
\text { (chron or } \\
\text { subchron) }\end{array}$} & \multirow[b]{2}{*}{ Polarity } & \multirow{2}{*}{$\begin{array}{l}\text { Boundary } \\
\text { age (Ma) }\end{array}$} & \multicolumn{4}{|c|}{ Depth CSF (m) } & \multirow{2}{*}{$\begin{array}{c}\text { Biostratigraphic } \\
\text { datum } \\
\text { (Nannofossil) }\end{array}$} & \multirow{2}{*}{$\begin{array}{l}\text { Age } \\
(\mathrm{Ma})\end{array}$} & \multicolumn{4}{|c|}{ Depth CSF (m) } \\
\hline & & & Upper & Lower & Middle & Uncertainty & & & Upper & Lower & Middle & Uncertainty \\
\hline & & 13.734 & & & & & & & & & & \\
\hline \multicolumn{13}{|l|}{ C5ACn } \\
\hline $\mathrm{C} 5 \mathrm{ACr}$ & & 14.095 & 868.44 & 868.72 & 868.58 & 0.14 & & & & & & \\
\hline
\end{tabular}

Notes: Black = normal polarity, white $=$ reversed polarity. $\mathrm{LO}=$ last occurrence. 
Table T12. Mudstone MAD data, Hole C0011B. (Continued on next six pages.)

\begin{tabular}{|c|c|c|c|c|c|c|c|c|}
\hline \multirow{2}{*}{$\begin{array}{l}\text { Core, section, } \\
\text { interval }(\mathrm{cm})\end{array}$} & \multirow{2}{*}{$\begin{array}{l}\text { Depth } \\
\text { CSF }(m)\end{array}$} & \multicolumn{2}{|c|}{$W_{\mathrm{c}}$} & \multirow[b]{2}{*}{ Porosity } & \multirow{2}{*}{$\begin{array}{l}\text { Void } \\
\text { ratio }\end{array}$} & \multicolumn{3}{|c|}{ Density $\left(\mathrm{g} / \mathrm{cm}^{3}\right)$} \\
\hline & & Wet & Dry & & & Bulk & Dry & Grain \\
\hline \multicolumn{9}{|l|}{ 322-C0011B- } \\
\hline $1 \mathrm{R}-1,40-41$ & 340.41 & 0.32 & 0.46 & 0.56 & 1.27 & 1.81 & 1.24 & 2.82 \\
\hline $1 R-1,84-85$ & 340.85 & 0.30 & 0.43 & 0.53 & 1.14 & 1.82 & 1.27 & 2.72 \\
\hline $1 \mathrm{R}-2,25-26$ & 341.13 & 0.27 & 0.37 & 0.50 & 1.00 & 1.91 & 1.39 & 2.78 \\
\hline 1R-2, 100-101 & 341.88 & 0.28 & 0.40 & 0.48 & 0.91 & 1.72 & 1.23 & 2.35 \\
\hline $2 R-1,51-53.5$ & 350.02 & 0.34 & 0.51 & 0.57 & 1.33 & 1.74 & 1.15 & 2.68 \\
\hline $3 R-1,31.5-32.5$ & 359.32 & 0.34 & 0.53 & 0.59 & 1.45 & 1.76 & 1.15 & 2.82 \\
\hline $3 R-2,25-27$ & 359.87 & 0.32 & 0.47 & 0.54 & 1.16 & 1.72 & 1.16 & 2.52 \\
\hline $3 R-3,16.5-18$ & 360.34 & 0.06 & 0.06 & 0.13 & 0.15 & 2.42 & 2.29 & 2.63 \\
\hline $3 R-4,118.5-120.5$ & 362.75 & 0.37 & 0.60 & 0.62 & 1.60 & 2.55 & 1.05 & 2.74 \\
\hline 3R-5, 18.5-20.5 & 363.16 & 0.32 & 0.48 & 0.55 & 1.23 & 1.74 & 1.18 & 2.63 \\
\hline $3 R-5,80-81.5$ & 363.77 & 0.30 & 0.42 & 0.52 & 1.10 & 1.80 & 1.26 & 2.66 \\
\hline $3 R-6,56-57.5$ & 364.93 & 0.30 & 0.43 & 0.52 & 1.07 & 1.77 & 1.24 & 2.58 \\
\hline $4 R-1,29-30$ & 365.30 & 0.30 & 0.43 & 0.53 & 1.13 & 1.81 & 1.26 & 2.69 \\
\hline $4 R-1,98-99.5$ & 365.99 & 0.32 & 0.46 & 0.57 & 1.35 & 1.86 & 1.27 & 2.99 \\
\hline 4R-2, 2-3.5 & 366.43 & 0.40 & 0.67 & 0.63 & 1.68 & 1.61 & 0.96 & 2.58 \\
\hline 5R-4, 105-108 & 378.03 & 0.29 & 0.41 & 0.50 & 1.00 & 1.75 & 1.24 & 2.47 \\
\hline $6 \mathrm{R}-1,24.5-25.5$ & 384.25 & 0.26 & 0.35 & 0.47 & 0.90 & 1.86 & 1.38 & 2.62 \\
\hline 6R-1, 99.5-100.5 & 385.00 & 0.27 & 0.36 & 0.48 & 0.93 & 1.86 & 1.37 & 2.64 \\
\hline 6R-2, 10-11.5 & 385.52 & 0.29 & 0.41 & 0.49 & 0.97 & 1.72 & 1.22 & 2.40 \\
\hline 6R-3, 105-107 & 387.88 & 0.26 & 0.35 & 0.47 & 0.90 & 1.86 & 1.38 & 2.62 \\
\hline $6 R-5,25-27$ & 388.69 & 0.28 & 0.38 & 0.51 & 1.04 & 1.89 & 1.37 & 2.79 \\
\hline 6R-6, 108-109 & 390.03 & 0.31 & 0.44 & 0.53 & 1.12 & 1.77 & 1.23 & 2.61 \\
\hline 6R-7, 32-33 & 390.68 & 0.29 & 0.42 & 0.52 & 1.08 & 1.81 & 1.28 & 2.66 \\
\hline 6R-8, 99.5-100.5 & 392.77 & 0.41 & 0.71 & 0.63 & 1.68 & 1.55 & 0.91 & 2.44 \\
\hline 7R-5, 101.5-103.5 & 397.86 & 0.32 & 0.46 & 0.54 & 1.17 & 1.75 & 1.19 & 2.59 \\
\hline 7R-6, 23-24 & 398.49 & 0.13 & 0.15 & 0.28 & 0.39 & 2.25 & 1.96 & 2.73 \\
\hline 7R-6, 97-98 & 399.23 & 0.36 & 0.57 & 0.58 & 1.40 & 1.64 & 1.04 & 2.50 \\
\hline 7R-7, 16-17 & 399.83 & 0.26 & 0.35 & 0.48 & 0.91 & 1.89 & 1.40 & 2.68 \\
\hline 7R-7, 100-101 & 400.67 & 0.25 & 0.33 & 0.45 & 0.83 & 1.85 & 1.38 & 2.53 \\
\hline 8R-4, 107-108 & 407.07 & 0.32 & 0.48 & 0.55 & 1.23 & 1.75 & 1.19 & 2.64 \\
\hline 8R-5, 104-106 & 408.46 & 0.30 & 0.43 & 0.52 & 1.09 & 1.78 & 1.25 & 2.61 \\
\hline $8 R-6,18.5-20$ & 409.01 & 0.30 & 0.43 & 0.52 & 1.98 & 1.77 & 1.23 & 2.56 \\
\hline $8 R-7,16-18$ & 410.40 & 0.31 & 0.45 & 0.56 & 1.30 & 1.87 & 1.29 & 2.96 \\
\hline $8 R-7,72-73.5$ & 410.95 & 0.18 & 0.22 & 0.35 & 0.54 & 2.02 & 1.66 & 2.56 \\
\hline 9R-3, 27-29 & 414.32 & 0.30 & 0.43 & 0.55 & 1.21 & 1.86 & 1.30 & 2.88 \\
\hline 9R-3, 105-107 & 415.10 & 0.33 & 0.50 & 0.56 & 1.29 & 1.74 & 1.16 & 2.66 \\
\hline $9 R-4,21.5-23$ & 415.67 & 0.29 & 0.41 & 0.51 & 1.05 & 1.81 & 1.29 & 2.64 \\
\hline $9 R-4,101-102.5$ & 416.47 & 0.30 & 0.43 & 0.54 & 1.15 & 1.83 & 1.28 & 2.77 \\
\hline $9 R-5,32-33.5$ & 417.19 & 0.25 & 0.33 & 0.47 & 0.89 & 1.96 & 1.47 & 2.78 \\
\hline 10R-1, 18-19 & 422.19 & 0.29 & 0.40 & 0.52 & 1.06 & 1.85 & 1.32 & 2.73 \\
\hline 10R-1, 32-34 & 422.33 & 0.30 & 0.43 & 0.52 & 1.10 & 1.79 & 1.25 & 2.63 \\
\hline 10R-1, 99-100.5 & 423.00 & 0.31 & 0.45 & 0.54 & 1.19 & 1.80 & 1.25 & 2.73 \\
\hline 10R-2, 20-22 & 423.62 & 0.30 & 0.44 & 0.55 & 1.24 & 1.86 & 1.30 & 2.91 \\
\hline 10R-3, 0-2 & 424.76 & 0.30 & 0.42 & 0.53 & 1.11 & 1.81 & 1.27 & 2.68 \\
\hline $11 \mathrm{R}-1,25-26.5$ & 431.76 & 0.27 & 0.38 & 0.50 & 1.00 & 1.87 & 1.35 & 2.71 \\
\hline 11R-1, 93-94 & 432.44 & 0.29 & 0.40 & 0.51 & 1.04 & 1.82 & 1.30 & 2.66 \\
\hline $11 \mathrm{R}-2,18.5-20$ & 433.09 & 0.31 & 0.44 & 0.55 & 1.25 & 1.86 & 1.29 & 2.90 \\
\hline 11R-2, 85-87 & 433.76 & 0.28 & 0.39 & 0.51 & 1.02 & 1.84 & 1.32 & 2.67 \\
\hline $11 R-3,9.5-11$ & 434.41 & 0.41 & 0.71 & 0.65 & 1.83 & 1.60 & 0.94 & 2.65 \\
\hline $11 \mathrm{R}-4,0-2$ & 434.65 & 0.42 & 0.74 & 0.65 & 1.86 & 1.57 & 0.91 & 2.59 \\
\hline $11 \mathrm{R}-5,23-25$ & 435.48 & 0.37 & 0.59 & 0.56 & 1.25 & 1.54 & 0.97 & 2.19 \\
\hline 11R-5, 107-109 & 436.32 & 0.28 & 0.39 & 0.50 & 1.01 & 1.82 & 1.30 & 2.61 \\
\hline 11R-6, 29-31 & 436.95 & 0.30 & 0.43 & 0.55 & 1.21 & 1.86 & 1.30 & 2.88 \\
\hline 11R-6, 99-101 & 437.65 & 0.28 & 0.38 & 0.48 & 0.91 & 1.76 & 1.27 & 2.42 \\
\hline 11R-7, 25-26.5 & 438.31 & 0.31 & 0.44 & 0.54 & 1.16 & 1.79 & 1.24 & 2.68 \\
\hline 11R-8, 26-27 & 439.73 & 0.30 & 0.44 & 0.52 & 1.09 & 1.75 & 1.22 & 2.54 \\
\hline 11R-8, 76-77 & 440.23 & 0.13 & 0.14 & 0.27 & 0.37 & 2.18 & 1.91 & 2.61 \\
\hline $12 \mathrm{R}-1,24-26$ & 441.25 & 0.27 & 0.37 & 0.49 & 0.95 & 1.85 & 1.35 & 2.65 \\
\hline $12 \mathrm{R}-1,25-26$ & 441.26 & 0.25 & 0.33 & 0.46 & 0.83 & 1.87 & 1.41 & 2.58 \\
\hline $12 \mathrm{R}-1,72-74$ & 441.73 & 0.25 & 0.33 & 0.46 & 0.86 & 1.91 & 1.43 & 2.66 \\
\hline 12R-1, 97-98 & 441.98 & 0.35 & 0.53 & 0.57 & 1.35 & 1.70 & 1.12 & 2.62 \\
\hline $12 \mathrm{R}-2,24-25$ & 442.66 & 0.29 & 0.41 & 0.50 & 1.00 & 1.76 & 1.25 & 2.50 \\
\hline $12 \mathrm{R}-2,50-52$ & 442.92 & 0.27 & 0.37 & 0.49 & 0.96 & 1.86 & 1.36 & 2.66 \\
\hline $12 \mathrm{R}-2,99-100$ & 443.41 & 0.27 & 0.36 & 0.49 & 0.95 & 1.88 & 1.38 & 2.69 \\
\hline $12 \mathrm{R}-3,25-26$ & 444.09 & 0.29 & 0.40 & 0.52 & 1.08 & 1.86 & 1.33 & 2.76 \\
\hline $12 \mathrm{R}-3,75-77$ & 444.59 & 0.29 & 0.40 & 0.49 & 0.98 & 1.77 & 1.26 & 2.50 \\
\hline 12R-3, 100-101 & 444.84 & 0.25 & 0.34 & 0.47 & 0.89 & 1.91 & 1.43 & 2.69 \\
\hline
\end{tabular}


Table T12 (continued). (Continued on next page.)

\begin{tabular}{|c|c|c|c|c|c|c|c|c|}
\hline \multirow{2}{*}{$\begin{array}{l}\text { Core, section, } \\
\text { interval }(\mathrm{cm})\end{array}$} & \multirow{2}{*}{$\begin{array}{l}\text { Depth } \\
\text { CSF (m) }\end{array}$} & \multicolumn{2}{|c|}{$W_{c}$} & \multirow[b]{2}{*}{ Porosity } & \multirow{2}{*}{$\begin{array}{l}\text { Void } \\
\text { ratio }\end{array}$} & \multicolumn{3}{|c|}{ Density $\left(\mathrm{g} / \mathrm{cm}^{3}\right)$} \\
\hline & & Wet & Dry & & & Bulk & Dry & Grain \\
\hline $12 \mathrm{R}-4,25-26$ & 445.51 & 0.25 & 0.33 & 0.45 & 0.81 & 1.87 & 1.41 & 2.55 \\
\hline $12 R-4,62-64$ & 445.88 & 0.27 & 0.38 & 0.50 & 0.98 & 1.86 & 1.35 & 2.68 \\
\hline $12 R-4,100-101$ & 446.26 & 0.29 & 0.42 & 0.51 & 1.04 & 1.78 & 1.26 & 2.56 \\
\hline $12 \mathrm{R}-7,25-26$ & 447.58 & 0.27 & 0.37 & 0.50 & 0.99 & 1.91 & 1.40 & 2.78 \\
\hline $12 R-7,83-85$ & 448.17 & 0.24 & 0.32 & 0.46 & 0.86 & 1.95 & 1.47 & 2.74 \\
\hline $13 \mathrm{R}-2,20-22$ & 452.12 & 0.25 & 0.33 & 0.45 & 0.83 & 1.89 & 1.43 & 2.61 \\
\hline $13 R-2,96-98$ & 452.88 & 0.28 & 0.39 & 0.50 & 0.99 & 1.83 & 1.32 & 2.62 \\
\hline $13 R-3,30-35$ & 453.65 & 0.25 & 0.34 & 0.45 & 0.81 & 1.81 & 1.35 & 2.46 \\
\hline $13 R-4,51-53$ & 454.20 & 0.25 & 0.34 & 0.46 & 0.84 & 1.86 & 1.39 & 2.55 \\
\hline 13R-4, 111-113 & 454.80 & 0.25 & 0.34 & 0.46 & 0.87 & 1.89 & 1.42 & 2.64 \\
\hline $13 R-5,26-28$ & 455.36 & 0.27 & 0.37 & 0.49 & 0.97 & 1.86 & 1.36 & 2.67 \\
\hline 13R-5, 100-101 & 456.10 & 0.25 & 0.33 & 0.46 & 0.85 & 1.89 & 1.42 & 2.64 \\
\hline $13 R-6,25-26$ & 456.76 & 0.30 & 0.44 & 0.54 & 1.19 & 1.83 & 1.28 & 2.79 \\
\hline 13R-6, 90-91 & 457.41 & 0.29 & 0.40 & 0.49 & 0.97 & 1.76 & 1.25 & 2.47 \\
\hline $13 R-7,25-26$ & 458.17 & 0.25 & 0.34 & 0.46 & 0.86 & 1.87 & 1.40 & 2.60 \\
\hline 13R-7, 80-81 & 458.72 & 0.28 & 0.40 & 0.51 & 1.02 & 1.82 & 1.31 & 2.64 \\
\hline $14 \mathrm{R}-1,24-25$ & 460.25 & 0.30 & 0.42 & 0.53 & 1.13 & 1.83 & 1.28 & 2.74 \\
\hline 14R-2, 17.5-19.5 & 461.60 & 0.25 & 0.34 & 0.48 & 0.91 & 1.93 & 1.44 & 2.76 \\
\hline 14R-2, 47-49 & 461.89 & 0.28 & 0.38 & 0.51 & 1.05 & 1.89 & 1.36 & 2.80 \\
\hline $14 \mathrm{R}-2,87-89$ & 462.29 & 0.27 & 0.37 & 0.52 & 1.07 & 1.95 & 1.42 & 2.94 \\
\hline $14 \mathrm{R}-4,0-2$ & 463.17 & 0.27 & 0.38 & 0.49 & 0.96 & 1.82 & 1.32 & 2.59 \\
\hline 14R-5, 100-101 & 464.63 & 0.38 & 0.62 & 0.64 & 1.76 & 1.70 & 1.05 & 2.89 \\
\hline $14 R-6,4-6$ & 465.09 & 0.26 & 0.36 & 0.46 & 0.87 & 1.80 & 1.32 & 2.47 \\
\hline 15R-1, 39-41 & 469.90 & 0.25 & 0.34 & 0.48 & 0.91 & 1.93 & 1.44 & 2.76 \\
\hline $15 \mathrm{R}-3,0-2$ & 472.04 & 0.25 & 0.34 & 0.47 & 0.87 & 1.89 & 1.42 & 2.65 \\
\hline $15 R-2,124-126$ & 472.15 & 0.24 & 0.32 & 0.44 & 0.79 & 1.88 & 1.42 & 2.56 \\
\hline $15 R-4,21.5-22.5$ & 472.77 & 0.27 & 0.37 & 0.51 & 1.05 & 1.93 & 1.41 & 2.88 \\
\hline $15 R-4,87.5-88.5$ & & 0.29 & 0.41 & & & & 1.23 & 2.41 \\
\hline 15R-4, 117-119 & 473.73 & 0.28 & 0.39 & 0.49 & 0.95 & 1.79 & 1.29 & 2.51 \\
\hline $15 R-5,12-14.5$ & 474.09 & 0.28 & 0.40 & & 0.93 & 1.73 & 1.24 & 2.39 \\
\hline 15R-5, 111-112.5 & 475.08 & 0.27 & 0.38 & 0.47 & 0.88 & 1.75 & 1.27 & 2.40 \\
\hline $15 R-6,26-28$ & 475.65 & 0.27 & 0.37 & 0.49 & 0.98 & 1.86 & 1.35 & 2.67 \\
\hline $15 R-6,85-87$ & 476.24 & 0.15 & 0.18 & 0.33 & 0.49 & 2.20 & 1.87 & 2.78 \\
\hline $19 R-1,25-26$ & 491.16 & 0.23 & 0.30 & 0.46 & 0.84 & 2.04 & 1.57 & 2.89 \\
\hline 19R-1, 100-101 & 491.91 & 0.23 & 0.31 & 0.46 & 0.86 & 2.03 & 1.55 & 2.89 \\
\hline 19R-2, 25.5-27.5 & 492.57 & 0.25 & 0.34 & 0.42 & 0.71 & 1.68 & 1.25 & 2.14 \\
\hline $19 R-3,0-2$ & 492.66 & 0.24 & 0.31 & 0.43 & 0.74 & 1.83 & 1.39 & 2.43 \\
\hline $19 R-4,20-22$ & 493.23 & 0.23 & 0.29 & 0.44 & 0.78 & 1.98 & 1.53 & 2.72 \\
\hline $19 R-4,125-127$ & 494.28 & 0.22 & 0.29 & 0.45 & 0.80 & 2.03 & 1.57 & 2.83 \\
\hline $19 R-5,32-34$ & 494.73 & 0.22 & 0.29 & 0.43 & 0.75 & 1.96 & 1.52 & 2.66 \\
\hline 19R-5, 110.5-112 & & & & & & & 1.60 & \\
\hline 19R-6, 19-21 & 495.96 & 0.23 & 0.30 & 0.44 & 0.80 & 1.96 & 1.51 & 2.72 \\
\hline 19R-6, 103-104 & & 0.22 & 0.28 & & 0.75 & 2.03 & 1.59 & 2.78 \\
\hline 19R-7, 21-24 & 497.42 & 0.22 & 0.28 & 0.43 & 0.77 & 2.03 & 1.58 & 2.80 \\
\hline 19R-7, 99-101 & 498.19 & 0.22 & 0.28 & 0.43 & 0.75 & 2.03 & 1.59 & 2.79 \\
\hline 21R-1, 10-11 & 501.61 & 0.27 & 0.37 & 0.49 & 0.98 & 1.89 & 1.38 & 2.73 \\
\hline $21 \mathrm{R}-2,0-2$ & 501.66 & 0.21 & 0.27 & 0.43 & 0.77 & 2.09 & 1.65 & 2.92 \\
\hline $21 \mathrm{R}-3,25-26$ & 502.52 & 0.23 & 0.29 & 0.44 & 0.80 & 2.01 & 1.55 & 2.79 \\
\hline 21R-3, 100-101 & 503.27 & 0.21 & 0.26 & 0.40 & 0.67 & 1.98 & 1.57 & 2.62 \\
\hline $21 R-4,7.5-9.5$ & 503.76 & 0.22 & 0.28 & 0.45 & 0.81 & 2.08 & 1.62 & 2.93 \\
\hline 21R-4, 106-108 & 504.74 & 0.25 & 0.33 & 0.47 & 0.90 & 1.93 & 1.45 & 2.75 \\
\hline 21R-5, 19-21 & 505.28 & 0.23 & 0.30 & 0.46 & 0.84 & 2.03 & 1.56 & 2.87 \\
\hline 21R-5, 130-132 & 506.39 & 0.25 & 0.33 & 0.47 & 0.88 & 1.93 & 1.45 & 2.73 \\
\hline $21 \mathrm{R}-6,25-26$ & & 0.22 & 0.29 & & 0.80 & 2.03 & 1.58 & 2.83 \\
\hline 21R-6, 98-99 & 507.48 & 0.24 & 0.31 & 0.45 & 0.81 & 1.93 & 1.48 & 2.67 \\
\hline 21R-7, 25-26 & 508.16 & 0.22 & 0.28 & 0.44 & 0.78 & 2.07 & 1.62 & 2.90 \\
\hline 21R-7, 100-101 & 508.91 & 0.26 & 0.34 & 0.47 & 0.87 & 1.87 & 1.39 & 2.60 \\
\hline $23 R-1,26-27$ & 520.67 & 0.27 & 0.37 & 0.49 & 0.96 & 1.86 & 1.36 & 2.67 \\
\hline $23 \mathrm{R}-2,0-2$ & 521.16 & 0.25 & 0.33 & 0.45 & 0.82 & 1.87 & 1.41 & 2.56 \\
\hline $23 R-3,25-26$ & 521.82 & 0.24 & 0.32 & 0.46 & 0.87 & 1.95 & 1.48 & 2.76 \\
\hline $23 R-3,95-96$ & 522.52 & 0.25 & 0.33 & 0.46 & 0.86 & 1.92 & 1.44 & 2.69 \\
\hline $23 R-3,117.5-119.5$ & 522.75 & 0.24 & 0.31 & 0.45 & 0.81 & 1.93 & 1.47 & 2.66 \\
\hline $23 R-4,30-32$ & 523.28 & 0.23 & 0.30 & 0.45 & 0.82 & 2.02 & 1.56 & 2.83 \\
\hline 23R-4, 115-116 & 524.13 & 0.25 & 0.33 & 0.48 & 0.92 & 1.97 & 1.48 & 2.83 \\
\hline $23 R-5,21-22$ & 524.61 & 0.25 & 0.34 & 0.48 & 0.94 & 1.96 & 1.46 & 2.84 \\
\hline $23 R-6,37-38$ & 526.21 & 0.23 & 0.31 & 0.44 & 0.79 & 1.93 & 1.48 & 2.64 \\
\hline $23 R-7,25-26$ & 526.56 & 0.25 & 0.33 & 0.47 & 0.89 & 1.94 & 1.46 & 2.74 \\
\hline 23R-7, 106-108 & 527.37 & 0.21 & 0.27 & 0.42 & 0.72 & 2.03 & 1.61 & 2.76 \\
\hline $23 R-8,53-55$ & 528.25 & 0.23 & 0.30 & 0.43 & 0.75 & 1.90 & 1.47 & 2.56 \\
\hline
\end{tabular}


Table T12 (continued). (Continued on next page.)

\begin{tabular}{|c|c|c|c|c|c|c|c|c|}
\hline \multirow{2}{*}{$\begin{array}{l}\text { Core, section, } \\
\text { interval }(\mathrm{cm})\end{array}$} & \multirow{2}{*}{$\begin{array}{l}\text { Depth } \\
\text { CSF (m) }\end{array}$} & \multicolumn{2}{|c|}{$W_{\mathrm{c}}$} & \multirow[b]{2}{*}{ Porosity } & \multirow{2}{*}{$\begin{array}{l}\text { Void } \\
\text { ratio }\end{array}$} & \multicolumn{3}{|c|}{ Density $\left(\mathrm{g} / \mathrm{cm}^{3}\right)$} \\
\hline & & Wet & Dry & & & Bulk & Dry & Grain \\
\hline 23R-8, 99-100 & 528.70 & 0.24 & 0.32 & 0.46 & 0.84 & 1.94 & 1.47 & 2.71 \\
\hline $24 \mathrm{R}-2,17-22$ & 530.67 & 0.24 & 0.32 & 0.43 & 0.75 & 1.80 & 1.36 & 2.39 \\
\hline $24 \mathrm{R}-2,100.5-101.5$ & 531.48 & 0.27 & 0.36 & 0.50 & 0.98 & 1.91 & 1.40 & 2.78 \\
\hline $24 \mathrm{R}-3,25-26$ & 532.14 & 0.27 & 0.36 & 0.49 & 0.98 & 1.91 & 1.40 & 2.78 \\
\hline $24 \mathrm{R}-3,100-101$ & 532.89 & 0.27 & 0.36 & 0.50 & 0.99 & 1.90 & 1.39 & 2.77 \\
\hline $24 \mathrm{R}-4,25-26$ & 533.55 & 0.25 & 0.33 & 0.43 & 0.77 & 1.79 & 1.34 & 2.38 \\
\hline $24 R-4,104-105$ & 534.34 & 0.23 & 0.30 & 0.42 & 0.71 & 1.82 & 1.40 & 2.39 \\
\hline $24 R-5,19-20$ & 534.90 & 0.26 & 0.36 & 0.48 & 0.92 & 1.86 & 1.37 & 2.62 \\
\hline $25 \mathrm{R}-1,30-32$ & 539.71 & 0.22 & 0.28 & 0.43 & 0.76 & 2.01 & 1.57 & 2.76 \\
\hline $25 R-2,50-52$ & 540.37 & 0.23 & 0.30 & 0.42 & 0.74 & 1.87 & 1.44 & 2.50 \\
\hline $25 R-3,99-100$ & 541.49 & 0.23 & 0.31 & 0.45 & 0.81 & 1.95 & 1.49 & 2.70 \\
\hline $25 \mathrm{R}-4,25-26$ & 542.15 & 0.23 & 0.29 & 0.44 & 0.80 & 2.01 & 1.55 & 2.79 \\
\hline $25 R-4,99-100$ & 542.89 & 0.24 & 0.31 & 0.46 & 0.84 & 1.97 & 1.51 & 2.77 \\
\hline $25 \mathrm{R}-5,10-11$ & 543.41 & 0.23 & 0.29 & 0.43 & 0.74 & 1.91 & 1.48 & 2.57 \\
\hline $26 \mathrm{R}-1,25-26$ & 549.26 & 0.23 & 0.30 & 0.46 & 0.86 & 2.07 & 1.60 & 2.97 \\
\hline $26 \mathrm{R}-1,112-114$ & 550.13 & 0.22 & 0.28 & 0.40 & 0.67 & 1.88 & 1.47 & 2.46 \\
\hline $26 \mathrm{R}-3,25-27$ & 551.28 & 0.21 & 0.27 & 0.41 & 0.70 & 1.98 & 1.56 & 2.64 \\
\hline 26R-3, 119-120 & 552.22 & 0.23 & 0.29 & 0.44 & 0.80 & 2.01 & 1.55 & 2.79 \\
\hline $26 \mathrm{R}-4,29-30$ & 552.57 & 0.22 & 0.29 & 0.45 & 0.81 & 2.05 & 1.59 & 2.88 \\
\hline $26 \mathrm{R}-4,124-125$ & 553.52 & 0.23 & 0.30 & 0.44 & 0.80 & 1.97 & 1.52 & 2.73 \\
\hline $26 \mathrm{R}-5,25-26$ & 553.93 & 0.24 & 0.32 & 0.46 & 0.84 & 1.93 & 1.46 & 2.69 \\
\hline 26R-5, 104-106 & 554.73 & 0.24 & 0.32 & 0.46 & 0.84 & 1.94 & 1.47 & 2.70 \\
\hline $26 \mathrm{R}-6,25-26$ & 555.34 & 0.23 & 0.31 & 0.43 & 0.77 & 1.90 & 1.45 & 2.57 \\
\hline 26R-6, 100-101 & 556.09 & 0.22 & 0.29 & 0.42 & 0.71 & 1.92 & 1.49 & 2.56 \\
\hline $26 \mathrm{R}-7,25-26$ & 556.77 & 0.36 & 0.56 & 0.59 & 1.44 & 1.68 & 1.08 & 2.63 \\
\hline 26R-7, 97-98 & 557.49 & 0.27 & 0.37 & 0.49 & 0.97 & 1.88 & 1.38 & 2.71 \\
\hline $27 R-1,22-24$ & 558.73 & 0.22 & 0.28 & 0.40 & 0.68 & 1.90 & 1.49 & 2.50 \\
\hline $27 R-1,83-84$ & 559.34 & 0.23 & 0.30 & 0.44 & 0.79 & 1.97 & 1.52 & 2.72 \\
\hline $27 R-2,48-56$ & 559.88 & 0.22 & 0.28 & 0.42 & 0.74 & 2.01 & 1.57 & 2.73 \\
\hline $27 \mathrm{R}-3,25-26$ & 560.18 & 0.22 & 0.28 & 0.40 & 0.66 & 1.88 & 1.47 & 2.44 \\
\hline 27R-3, 115-117 & 561.08 & 0.23 & 0.30 & 0.43 & 0.76 & 1.92 & 1.47 & 2.59 \\
\hline $27 R-4,25-26$ & 561.55 & 0.23 & 0.30 & 0.45 & 0.83 & 2.02 & 1.55 & 2.84 \\
\hline 27R-4, 100-101 & 562.30 & 0.22 & 0.28 & 0.42 & 0.73 & 1.96 & 1.53 & 2.65 \\
\hline $27 R-5,25-26$ & 562.96 & 0.24 & & & 0.89 & 2.04 & 1.55 & 2.94 \\
\hline 27R-5, 110-112 & 563.82 & 0.23 & 0.29 & 0.44 & 0.80 & 2.00 & 1.55 & 2.79 \\
\hline 27R-6, 19-20 & 564.32 & 0.23 & 0.30 & 0.42 & 0.72 & 1.87 & 1.44 & 2.48 \\
\hline 27R-6, 102-104 & 565.16 & 0.22 & 0.28 & 0.43 & 0.74 & 1.99 & 1.55 & 2.92 \\
\hline 28R-1, 17-19 & 568.18 & 0.23 & 0.30 & 0.43 & 0.76 & 1.93 & 1.49 & 2.62 \\
\hline $28 \mathrm{R}-1,132-134$ & 569.33 & 0.22 & 0.29 & 0.45 & 0.83 & 2.08 & 1.62 & 2.96 \\
\hline $28 \mathrm{R}-2,0-2$ & 569.47 & 0.22 & 0.28 & 0.41 & 0.71 & 1.93 & 1.51 & 2.57 \\
\hline $28 \mathrm{R}-3,20-22$ & 570.20 & 0.22 & 0.28 & 0.42 & 0.71 & 1.95 & 1.52 & 2.60 \\
\hline 28R-3, 114-115 & 571.14 & 0.25 & 0.34 & 0.48 & 0.93 & 1.95 & 1.46 & 2.82 \\
\hline 28R-4, 18-19 & 571.59 & 0.22 & 0.29 & 0.42 & 0.71 & 1.91 & 1.49 & 2.55 \\
\hline $30 \mathrm{R}-1,30-32$ & 580.71 & 0.22 & 0.28 & 0.42 & 0.73 & 1.97 & 1.53 & 2.65 \\
\hline 30R-1, 107-108 & 581.48 & 0.23 & 0.30 & 0.42 & 0.73 & 1.90 & 1.47 & 2.55 \\
\hline $30 \mathrm{R}-2,0-2$ & 581.79 & 0.21 & 0.27 & 0.40 & 0.66 & 1.92 & 1.51 & 2.51 \\
\hline $30 \mathrm{R}-3,23-24$ & 582.55 & 0.23 & 0.31 & & 0.86 & 2.01 & 1.54 & 2.86 \\
\hline 30R-3, 100-101 & 583.32 & 0.23 & 0.30 & 0.42 & 0.73 & 1.87 & 1.44 & 2.48 \\
\hline $30 R-4,22-23$ & 583.94 & 0.24 & 0.31 & 0.44 & 0.80 & 1.93 & 1.47 & 2.64 \\
\hline 31R-1, 29-30 & 586.80 & 0.21 & 0.26 & 0.41 & 0.69 & 2.00 & 1.59 & 2.67 \\
\hline $31 \mathrm{R}-1,108-110$ & 587.59 & 0.21 & 0.27 & 0.41 & 0.70 & 2.00 & 1.58 & 2.69 \\
\hline $31 \mathrm{R}-2,50-52$ & 588.37 & 0.27 & 0.37 & 0.51 & 1.04 & 1.92 & 1.40 & 2.86 \\
\hline $31 \mathrm{R}-3,19-22$ & 588.61 & 0.22 & 0.28 & 0.43 & 0.76 & 1.99 & 1.55 & 2.72 \\
\hline $31 \mathrm{R}-3,77-80$ & 589.19 & 0.21 & 0.27 & 0.41 & 0.69 & 1.98 & 1.57 & 2.64 \\
\hline $31 R-4,16-18$ & 590.00 & 0.25 & 0.34 & 0.47 & 0.87 & 1.88 & 1.40 & 2.62 \\
\hline 31R-5, 17-19 & 590.35 & 0.21 & 0.26 & 0.41 & 0.69 & 2.00 & 1.58 & 2.67 \\
\hline $31 R-5,72-73$ & 590.90 & 0.21 & 0.27 & 0.42 & 0.71 & 2.00 & 1.58 & 2.70 \\
\hline $32 \mathrm{R}-1,22-24$ & 596.23 & 0.21 & 0.26 & 0.41 & 0.69 & 2.02 & 1.60 & 2.70 \\
\hline $32 \mathrm{R}-1,106-108$ & 597.07 & 0.20 & 0.25 & 0.41 & 0.70 & 2.08 & 1.66 & 2.82 \\
\hline $32 \mathrm{R}-2,25-26$ & 597.69 & 0.20 & 0.25 & 0.40 & 0.66 & 2.02 & 1.61 & 2.68 \\
\hline $32 \mathrm{R}-2,100-101$ & 598.44 & 0.21 & 0.26 & 0.41 & 0.69 & 2.03 & 1.61 & 2.73 \\
\hline $32 \mathrm{R}-3,25-26$ & 599.10 & 0.21 & 0.26 & 0.37 & 0.58 & 1.83 & 1.45 & 2.30 \\
\hline $32 R-3,103-104$ & 599.88 & 0.21 & 0.26 & 0.41 & 0.69 & 2.01 & 1.59 & 2.69 \\
\hline $32 \mathrm{R}-4,25-26$ & 600.50 & 0.20 & 0.25 & 0.41 & 0.70 & 2.10 & 1.67 & 2.85 \\
\hline $32 \mathrm{R}-4,108-109$ & 601.33 & 0.20 & 0.25 & 0.40 & 0.68 & 2.09 & 1.67 & 2.80 \\
\hline $32 \mathrm{R}-5,0-2$ & 601.40 & 0.20 & 0.25 & 0.40 & 0.67 & 2.05 & 1.64 & 2.75 \\
\hline $33 \mathrm{R}-1,22-24$ & 605.73 & 0.22 & 0.29 & 0.44 & 0.79 & 2.02 & 1.57 & 2.81 \\
\hline $33 R-2,0-3$ & 605.96 & 0.21 & 0.27 & 0.40 & 0.68 & 1.94 & 1.53 & 2.56 \\
\hline $33 R-3,93-95$ & 607.42 & 0.21 & 0.27 & 0.41 & 0.70 & 1.98 & 1.55 & 2.64 \\
\hline
\end{tabular}


Table T12 (continued). (Continued on next page.)

\begin{tabular}{|c|c|c|c|c|c|c|c|c|}
\hline \multirow{2}{*}{$\begin{array}{l}\text { Core, section, } \\
\text { interval }(\mathrm{cm})\end{array}$} & \multirow{2}{*}{$\begin{array}{l}\text { Depth } \\
\text { CSF (m) }\end{array}$} & \multicolumn{2}{|c|}{$W_{c}$} & \multirow[b]{2}{*}{ Porosity } & \multirow{2}{*}{$\begin{array}{l}\text { Void } \\
\text { ratio }\end{array}$} & \multicolumn{3}{|c|}{ Density $\left(\mathrm{g} / \mathrm{cm}^{3}\right)$} \\
\hline & & Wet & Dry & & & Bulk & Dry & Grain \\
\hline 33R-4, 100-101 & 608.89 & 0.22 & 0.28 & 0.43 & 0.76 & 2.03 & 1.59 & 2.80 \\
\hline $33 R-5,38-39$ & 609.69 & 0.21 & 0.26 & 0.41 & 0.69 & 2.02 & 1.60 & 2.70 \\
\hline $33 R-5,133-134$ & 610.64 & 0.21 & 0.26 & 0.42 & 0.71 & 2.05 & 1.62 & 2.77 \\
\hline $33 R-6,33-35$ & 611.05 & 0.22 & 0.29 & 0.43 & 0.76 & 1.98 & 1.54 & 2.71 \\
\hline $33 R-6,124-125$ & 611.96 & 0.21 & 0.27 & 0.42 & 0.71 & 1.98 & 1.56 & 2.66 \\
\hline $33 R-7,25-26$ & 612.40 & 0.24 & 0.32 & 0.44 & 0.77 & 1.84 & 1.39 & 2.47 \\
\hline $35 \mathrm{R}-1,25-26$ & 624.76 & 0.23 & 0.30 & 0.46 & 0.85 & 2.06 & 1.58 & 2.93 \\
\hline $35 R-2,25-26$ & 626.17 & 0.22 & 0.28 & 0.42 & 0.73 & 1.95 & 1.52 & 2.62 \\
\hline 35R-2, 100-101 & 626.92 & 0.23 & 0.30 & 0.44 & 0.79 & 1.96 & 1.51 & 2.70 \\
\hline $35 R-3,23-25$ & 627.58 & 0.22 & 0.28 & 0.44 & 0.79 & 2.07 & 1.62 & 2.90 \\
\hline $35 R-3,96-97$ & 628.30 & 0.24 & 0.32 & 0.45 & 0.83 & 1.90 & 1.44 & 2.63 \\
\hline $35 \mathrm{R}-4,0-3$ & 628.38 & 0.22 & 0.28 & 0.42 & 0.73 & 1.96 & 1.53 & 2.65 \\
\hline $35 R-4,0-3$ & 628.38 & 0.22 & 0.29 & 0.43 & 0.76 & 1.98 & 1.54 & 2.71 \\
\hline $35 \mathrm{R}-5,25-26$ & 629.16 & 0.23 & 0.31 & 0.44 & 0.78 & 1.92 & 1.47 & 2.62 \\
\hline $35 R-5,87-89$ & 629.79 & 0.21 & 0.27 & 0.43 & 0.77 & 2.07 & 1.63 & 2.88 \\
\hline $35 R-6,16.5-17.5$ & 630.48 & 0.23 & 0.30 & 0.41 & 0.71 & 1.84 & 1.41 & 2.41 \\
\hline $35 R-6,60-62$ & 630.92 & 0.16 & 0.19 & 0.32 & 0.48 & 2.11 & 1.78 & 2.63 \\
\hline $35 R-6,115-117$ & 631.47 & 0.21 & 0.27 & 0.41 & 0.70 & 2.01 & 1.59 & 2.70 \\
\hline $35 R-7,25-26$ & 632.00 & 0.23 & 0.30 & 0.42 & 0.72 & 1.88 & 1.45 & 2.50 \\
\hline 35R-7, 94-96 & 632.69 & 0.21 & 0.27 & 0.41 & 0.69 & 1.97 & 1.55 & 2.63 \\
\hline $35 R-8,44-46$ & 633.61 & 0.21 & 0.26 & 0.40 & 0.67 & 1.98 & 1.57 & 2.62 \\
\hline 35R-8, 99-100 & 634.16 & 0.23 & 0.30 & 0.45 & 0.80 & 2.00 & 1.54 & 2.78 \\
\hline $36 \mathrm{R}-1,25-26$ & 634.26 & 0.23 & 0.30 & 0.44 & 0.78 & 1.97 & 1.52 & 2.72 \\
\hline $36 \mathrm{R}-2,50-52$ & 635.18 & 0.22 & 0.29 & 0.44 & 0.80 & 2.04 & 1.59 & 2.85 \\
\hline $36 \mathrm{R}-3,25-26$ & 635.46 & 0.21 & 0.27 & 0.43 & 0.75 & 2.06 & 1.63 & 2.84 \\
\hline 36R-3, 100-101 & 636.21 & 0.22 & 0.28 & 0.41 & 0.69 & 1.89 & 1.48 & 2.49 \\
\hline $36 \mathrm{R}-4,25-26$ & 636.87 & 0.21 & 0.26 & 0.40 & 0.68 & 1.98 & 1.56 & 2.63 \\
\hline 36R-4, 100-101 & 637.62 & 0.23 & 0.30 & 0.45 & 0.81 & 1.97 & 1.51 & 2.74 \\
\hline $36 \mathrm{R}-4,127-129$ & 637.90 & 0.21 & 0.26 & 0.40 & 0.67 & 1.99 & 1.57 & 2.63 \\
\hline $36 \mathrm{R}-5,25-26$ & 638.28 & & & 0.41 & 0.68 & & & 2.44 \\
\hline 36R-5, 69-71 & 638.73 & 0.21 & 0.26 & 0.39 & 0.65 & 1.95 & 1.55 & 2.55 \\
\hline 36R-5, 100-101 & & 0.23 & 0.29 & & 0.84 & 2.06 & 1.60 & 2.93 \\
\hline $36 R-6,34-35$ & 639.78 & 0.21 & 0.26 & 0.42 & 0.71 & 2.05 & 1.63 & 2.79 \\
\hline 36R-6, 118-119 & 640.62 & 0.22 & 0.27 & 0.41 & 0.71 & 1.97 & 1.55 & 2.64 \\
\hline $36 \mathrm{R}-7,42-43$ & 641.28 & 0.23 & 0.31 & 0.43 & 0.74 & 1.87 & 1.43 & 2.49 \\
\hline $37 \mathrm{R}-1,19-20$ & 643.70 & 0.21 & 0.27 & 0.41 & 0.68 & 1.97 & 1.56 & 2.62 \\
\hline 37R-1, 109-110 & 644.60 & 0.25 & 0.33 & 0.47 & 0.89 & 1.93 & 1.45 & 2.74 \\
\hline $37 R-2,50-53$ & 645.31 & 0.22 & 0.28 & 0.42 & 0.71 & 1.94 & 1.51 & 2.59 \\
\hline $37 \mathrm{R}-2,50-53$ & 645.31 & 0.22 & 0.28 & 0.42 & 0.74 & 1.96 & 1.53 & 2.66 \\
\hline $37 R-3,25-26$ & 645.58 & 0.45 & 0.81 & 0.69 & 2.18 & 1.57 & 0.86 & 2.75 \\
\hline 37R-3, 102-103 & 646.35 & 0.24 & 0.32 & 0.44 & 0.78 & 1.85 & 1.40 & 2.50 \\
\hline 37R-4, 9-11 & 646.83 & 0.21 & 0.26 & 0.40 & 0.67 & 2.00 & 1.58 & 2.65 \\
\hline 37R-4, 99-100 & & & & & 0.56 & & 1.70 & 2.65 \\
\hline 37R-5, 25-26 & 648.40 & 0.24 & 0.31 & 0.46 & 0.85 & 1.99 & 1.52 & 2.81 \\
\hline 37R-5, 98-99 & & & & & & 1.83 & 1.34 & 2.56 \\
\hline $37 R-6,25-26$ & 649.81 & 0.24 & 0.31 & 0.46 & 0.84 & 1.97 & 1.50 & 2.76 \\
\hline $37 R-6,100-101$ & 650.56 & 0.23 & 0.31 & 0.45 & 0.82 & 1.96 & 1.50 & 2.73 \\
\hline $37 R-7,33-35$ & 651.31 & 0.23 & 0.29 & 0.44 & 0.79 & 1.99 & 1.54 & 2.76 \\
\hline 37R-7, 100-101 & 651.98 & 0.23 & 0.30 & 0.41 & 0.71 & 1.85 & 1.43 & 2.44 \\
\hline $37 \mathrm{R}-8,20-22$ & 652.59 & 0.24 & 0.31 & 0.45 & 0.81 & 1.92 & 1.46 & 2.63 \\
\hline 37R-8, 109-110 & 653.48 & 0.21 & 0.27 & 0.41 & 0.71 & 1.99 & 1.57 & 2.68 \\
\hline $38 \mathrm{R}-1,72-74$ & 653.73 & 0.20 & 0.25 & 0.39 & 0.64 & 1.97 & 1.57 & 2.58 \\
\hline 38R-1, 130-131 & 654.31 & 0.22 & 0.28 & 0.42 & 0.74 & 1.99 & 1.55 & 2.69 \\
\hline $38 \mathrm{R}-2,0-2$ & 654.40 & 0.21 & 0.26 & 0.41 & 0.70 & 2.02 & 1.60 & 2.71 \\
\hline $38 \mathrm{R}-3,25-26$ & 655.19 & 0.22 & 0.28 & 0.43 & 0.74 & 2.00 & 1.57 & 2.73 \\
\hline 38R-3, 104-105 & & 0.20 & 0.25 & 0.41 & 0.68 & 2.06 & 1.65 & 2.77 \\
\hline $38 R-4,64-66$ & 656.99 & 0.19 & 0.23 & 0.36 & 0.55 & 1.96 & 1.60 & 2.48 \\
\hline 38R-4, 136-137 & 657.71 & 0.22 & 0.28 & 0.44 & 0.78 & 2.09 & 1.64 & 2.92 \\
\hline $38 \mathrm{R}-5,24-26$ & 658.01 & 0.21 & 0.27 & 0.41 & 0.69 & 1.98 & 1.57 & 2.65 \\
\hline 38R-5, 101-102 & 658.78 & 0.21 & 0.26 & 0.40 & 0.67 & 1.97 & 1.56 & 2.61 \\
\hline $38 R-6,25-26$ & 659.42 & 0.22 & 0.29 & 0.42 & 0.73 & 1.93 & 1.50 & 2.60 \\
\hline 38R-7, 25-26 & 660.82 & 0.21 & 0.27 & 0.41 & 0.69 & 1.95 & 1.54 & 2.59 \\
\hline 38R-7, 92-94 & 661.50 & 0.20 & 0.25 & 0.38 & 0.61 & 1.97 & 1.58 & 2.54 \\
\hline $38 \mathrm{R}-8,24-25$ & 661.83 & 0.21 & 0.26 & 0.40 & 0.67 & 1.99 & 1.58 & 2.64 \\
\hline $39 \mathrm{R}-1,23.5-25.5$ & 662.75 & 0.20 & 0.26 & 0.41 & 0.69 & 2.06 & 1.64 & 2.78 \\
\hline 39R-1, 99-100 & 663.50 & 0.23 & 0.29 & 0.44 & 0.78 & 1.98 & 1.53 & 2.72 \\
\hline 39R-2, 25-26 & 664.16 & 0.23 & 0.29 & 0.43 & 0.76 & 1.95 & 1.50 & 2.65 \\
\hline 39R-2, 97-98 & 664.88 & 0.22 & 0.29 & 0.43 & 0.76 & 1.96 & 1.52 & 2.67 \\
\hline $39 \mathrm{R}-3,25-26$ & 665.57 & 0.23 & 0.30 & 0.45 & 0.81 & 2.00 & 1.54 & 2.78 \\
\hline
\end{tabular}


Table T12 (continued). (Continued on next page.)

\begin{tabular}{|c|c|c|c|c|c|c|c|c|}
\hline \multirow{2}{*}{$\begin{array}{l}\text { Core, section, } \\
\text { interval }(\mathrm{cm})\end{array}$} & \multirow{2}{*}{$\begin{array}{l}\text { Depth } \\
\text { CSF (m) }\end{array}$} & \multicolumn{2}{|c|}{$W_{\mathrm{c}}$} & \multirow[b]{2}{*}{ Porosity } & \multirow{2}{*}{$\begin{array}{l}\text { Void } \\
\text { ratio }\end{array}$} & \multicolumn{3}{|c|}{ Density $\left(\mathrm{g} / \mathrm{cm}^{3}\right)$} \\
\hline & & Wet & Dry & & & Bulk & Dry & Grain \\
\hline $39 R-3,99-100$ & 666.31 & 0.22 & 0.27 & 0.42 & 0.73 & 2.00 & 1.57 & 2.71 \\
\hline $39 R-4,50-52$ & 667.25 & 0.24 & 0.32 & 0.47 & 0.88 & 1.98 & 1.50 & 2.81 \\
\hline $39 R-5,25-26$ & 667.58 & 0.22 & 0.28 & 0.42 & 0.71 & 1.96 & 1.54 & 2.63 \\
\hline $39 R-5,108-110$ & 668.42 & 0.20 & 0.24 & 0.40 & 0.66 & 2.07 & 1.67 & 2.76 \\
\hline $39 R-6,25-27$ & 669.01 & 0.23 & 0.30 & 0.42 & 0.74 & 1.87 & 1.44 & 2.50 \\
\hline 39R-6, 100-101 & 669.75 & 0.22 & 0.28 & 0.43 & 0.76 & 2.04 & 1.59 & 2.80 \\
\hline 39R-7, 23-24 & 670.39 & 0.23 & 0.30 & 0.43 & 0.77 & 1.91 & 1.47 & 2.59 \\
\hline $40 \mathrm{R}-1,30-32$ & 672.31 & 0.22 & 0.27 & 0.44 & 0.80 & 2.11 & 1.65 & 2.97 \\
\hline 40R-1, 116-117 & 673.17 & 0.21 & 0.27 & 0.42 & 0.73 & 2.01 & 1.58 & 2.73 \\
\hline 40R-2, 17-19 & 673.58 & 0.20 & 0.25 & 0.42 & 0.74 & 2.14 & 1.71 & 2.97 \\
\hline 40R-2, 101-102 & 674.42 & 0.20 & 0.25 & 0.40 & 0.66 & 2.06 & 1.65 & 2.75 \\
\hline $40 \mathrm{R}-3,0-2$ & 674.83 & 0.20 & 0.25 & 0.40 & 0.68 & 2.04 & 1.63 & 2.73 \\
\hline $40 R-4,25-26$ & 675.60 & 0.22 & 0.28 & 0.44 & 0.80 & 2.08 & 1.62 & 2.92 \\
\hline $42 \mathrm{R}-1,25-26$ & 680.76 & 0.22 & 0.29 & 0.42 & 0.72 & 1.91 & 1.48 & 2.55 \\
\hline $42 \mathrm{R}-1,103-104$ & 681.54 & 0.23 & 0.30 & 0.44 & 0.79 & 1.97 & 1.52 & 2.72 \\
\hline $42 \mathrm{R}-2,0-2$ & 681.89 & 0.19 & 0.24 & 0.37 & 0.58 & 1.95 & 1.58 & 2.49 \\
\hline $42 \mathrm{R}-3,24-25$ & 682.66 & 0.23 & 0.29 & 0.43 & 0.75 & 1.94 & 1.50 & 2.62 \\
\hline $43 R-1,25-26$ & 685.26 & 0.25 & 0.33 & 0.44 & 0.80 & 1.82 & 1.36 & 2.45 \\
\hline $43 R-1,99-100$ & 686.00 & 0.21 & 0.27 & 0.41 & 0.68 & 1.98 & 1.56 & 2.63 \\
\hline $43 R-2,40-42$ & 686.82 & 0.19 & 0.24 & 0.39 & 0.63 & 2.03 & 1.64 & 2.67 \\
\hline $43 R-4,56-58$ & 688.05 & 0.19 & 0.23 & 0.38 & 0.61 & 2.07 & 1.68 & 2.70 \\
\hline $43 R-4,98-99$ & 688.46 & 0.21 & 0.27 & 0.40 & 0.67 & 1.95 & 1.54 & 2.58 \\
\hline $44 \mathrm{R}-1,25-26$ & 689.26 & 0.29 & 0.41 & 0.52 & 1.07 & 1.83 & 1.30 & 2.69 \\
\hline $43 R-5,47-48$ & 689.36 & 0.27 & 0.38 & 0.49 & 0.96 & 1.83 & 1.33 & 2.61 \\
\hline $44 \mathrm{R}-1,100-101$ & 690.01 & 0.19 & 0.23 & 0.37 & 0.60 & 2.07 & 1.68 & 2.69 \\
\hline $44 \mathrm{R}-2,0-3$ & 690.43 & 0.16 & 0.19 & 0.32 & 0.47 & 2.04 & 1.71 & 2.53 \\
\hline $44 R-3,0-2$ & 691.10 & 0.18 & 0.23 & 0.37 & 0.60 & 2.08 & 1.70 & 2.71 \\
\hline $44 \mathrm{R}-4,21-23$ & 691.91 & 0.20 & 0.24 & 0.39 & 0.65 & 2.06 & 1.66 & 2.73 \\
\hline $44 \mathrm{R}-4,100-101$ & 692.70 & 0.22 & 0.28 & 0.40 & 0.68 & 1.91 & 1.50 & 2.51 \\
\hline $44 \mathrm{R}-5,24-25$ & 693.35 & 0.21 & 0.26 & 0.40 & 0.67 & 1.97 & 1.56 & 2.60 \\
\hline $44 R-5,99-100$ & 694.10 & 0.21 & 0.26 & 0.40 & 0.68 & 1.98 & 1.57 & 2.63 \\
\hline $44 R-6,24-25$ & 694.77 & 0.22 & 0.28 & 0.41 & 0.69 & 1.93 & 1.52 & 2.57 \\
\hline $44 \mathrm{R}-7,25-26$ & 696.20 & 0.28 & 0.39 & 0.49 & 0.97 & 1.81 & 1.31 & 2.58 \\
\hline 44R-7, 101-102 & 696.96 & 0.24 & 0.32 & & 0.90 & 2.02 & 1.53 & 2.92 \\
\hline $44 \mathrm{R}-8,25-26$ & 697.23 & 0.26 & 0.36 & 0.48 & 0.92 & 1.87 & 1.38 & 2.66 \\
\hline $45 R-1,24-26$ & & 0.20 & 0.25 & & 0.65 & 2.02 & 1.62 & 2.67 \\
\hline 45R-1, 108-109 & 699.59 & 0.20 & 0.25 & 0.42 & 0.72 & 2.16 & 1.73 & 2.98 \\
\hline 45R-2, 18-19 & 700.12 & 0.20 & 0.26 & 0.40 & 0.65 & 1.99 & 1.58 & 2.62 \\
\hline $45 R-3,0-2$ & 700.29 & 0.21 & 0.26 & 0.41 & 0.69 & 2.01 & 1.59 & 2.70 \\
\hline $45 R-4,36.5-38.5$ & 701.19 & 0.19 & 0.23 & 0.38 & 0.61 & 2.05 & 1.66 & 2.67 \\
\hline $45 R-4,99-100$ & 701.81 & 0.19 & 0.24 & 0.39 & 0.63 & 2.04 & 1.65 & 2.68 \\
\hline $45 R-5,27.5-29$ & 702.52 & 0.21 & 0.27 & 0.38 & 0.62 & 1.85 & 1.46 & 2.36 \\
\hline $45 R-5,104$ & 703.28 & 0.21 & 0.26 & 0.42 & 0.74 & 2.08 & 1.75 & 2.86 \\
\hline $45 R-5,124.5-126.5$ & 703.50 & 0.21 & 0.26 & 0.39 & 0.65 & 1.92 & 1.52 & 2.51 \\
\hline $45 \mathrm{R}-6,21-22$ & 703.87 & 0.19 & 0.24 & 0.39 & 0.63 & 2.07 & 1.68 & 2.73 \\
\hline $45 R-6,127-128$ & 704.93 & 0.18 & 0.22 & 0.38 & 0.61 & 2.10 & 1.72 & 2.76 \\
\hline 45R-7, 10-11 & 705.19 & 0.20 & 0.24 & & 0.65 & 2.06 & 1.65 & 2.73 \\
\hline 45R-7, 113-114 & 706.22 & 0.18 & 0.22 & 0.36 & 0.57 & 2.05 & 1.68 & 2.64 \\
\hline $45 R-8,12-15$ & 706.67 & 0.18 & 0.22 & & 0.55 & 2.05 & 1.69 & 2.62 \\
\hline 46R-1, 27-28 & 708.28 & 0.22 & 0.28 & 0.42 & 0.72 & 1.98 & 1.55 & 2.66 \\
\hline $46 \mathrm{R}-1,105-107$ & 709.06 & 0.22 & 0.28 & 0.41 & 0.69 & 1.92 & 1.51 & 2.54 \\
\hline $46 \mathrm{R}-2,25-27$ & 709.66 & 0.18 & 0.22 & 0.39 & 0.63 & 2.19 & 1.79 & 2.92 \\
\hline $47 R-1,20-21$ & 711.71 & 0.22 & 0.28 & 0.44 & 0.80 & 2.05 & 1.60 & 2.88 \\
\hline $47 \mathrm{R}-1,72-73$ & 712.23 & 0.21 & 0.27 & 0.40 & 0.68 & 1.94 & 1.53 & 2.56 \\
\hline $47 R-2,0-2$ & 712.62 & 0.19 & 0.23 & 0.38 & 0.61 & 2.05 & 1.66 & 2.67 \\
\hline $47 R-3,25-26$ & 713.44 & 0.21 & 0.27 & 0.42 & 0.73 & 2.06 & 1.63 & 2.82 \\
\hline $47 R-4,14-15$ & 714.75 & 0.20 & 0.25 & 0.39 & 0.64 & 1.96 & 1.57 & 2.56 \\
\hline $47 R-4,60-62$ & 715.21 & 0.20 & 0.25 & 0.39 & 0.65 & 2.01 & 1.61 & 2.65 \\
\hline $47 R-4,100-101$ & 715.61 & 0.19 & 0.23 & 0.38 & 0.62 & 2.11 & 1.72 & 2.79 \\
\hline 47R-5, 24-25 & 716.27 & 0.20 & 0.25 & 0.40 & 0.68 & 2.05 & 1.63 & 2.74 \\
\hline $47 R-5,83-85$ & 716.86 & 0.19 & 0.24 & 0.41 & 0.68 & 2.15 & 1.73 & 2.92 \\
\hline 47R-5, 113-115 & 717.16 & 0.17 & 0.20 & 0.39 & 0.65 & 2.09 & 1.68 & 2.78 \\
\hline 47R-5, 113-115 & 717.16 & 0.19 & 0.24 & 0.39 & 0.64 & 2.07 & 1.67 & 2.73 \\
\hline 47R-6, 23-24 & 717.67 & 0.19 & 0.23 & 0.38 & 0.62 & 2.10 & 1.70 & 2.76 \\
\hline $48 \mathrm{R}-1,21-23$ & 721.22 & 0.18 & 0.21 & 0.36 & 0.56 & 2.10 & 1.73 & 2.70 \\
\hline $48 R-1,96-98$ & 721.97 & 0.17 & 0.20 & 0.34 & 0.51 & 2.09 & 1.74 & 2.63 \\
\hline $48 \mathrm{R}-3,25-27$ & 722.80 & 0.19 & 0.23 & 0.37 & 0.59 & 2.04 & 1.66 & 2.63 \\
\hline $48 R-4,37-38$ & 723.76 & 0.16 & 0.19 & 0.33 & 0.50 & 2.12 & 1.78 & 2.67 \\
\hline $49 R-1,29-30$ & 730.40 & 0.16 & 0.19 & 0.32 & 0.47 & 2.09 & 1.76 & 2.59 \\
\hline
\end{tabular}


Table T12 (continued). (Continued on next page.)

\begin{tabular}{|c|c|c|c|c|c|c|c|c|}
\hline \multirow{2}{*}{$\begin{array}{l}\text { Core, section, } \\
\text { interval }(\mathrm{cm})\end{array}$} & \multirow{2}{*}{$\begin{array}{l}\text { Depth } \\
\text { CSF (m) }\end{array}$} & \multicolumn{2}{|c|}{$W_{\mathrm{c}}$} & \multirow[b]{2}{*}{ Porosity } & \multirow{2}{*}{$\begin{array}{l}\text { Void } \\
\text { ratio }\end{array}$} & \multicolumn{3}{|c|}{ Density $\left(\mathrm{g} / \mathrm{cm}^{3}\right)$} \\
\hline & & Wet & Dry & & & Bulk & Dry & Grain \\
\hline 49R-1, 99-100 & 731.10 & 0.16 & 0.19 & 0.32 & 0.48 & 2.10 & 1.76 & 2.61 \\
\hline 49R-2, 16-17 & 731.77 & 0.17 & 0.20 & 0.35 & 0.53 & 2.11 & 1.76 & 2.70 \\
\hline $49 R-5,39-40$ & 733.96 & 0.16 & 0.19 & 0.33 & 0.50 & 2.15 & 1.81 & 2.72 \\
\hline $49 \mathrm{R}-7,31-32$ & 735.24 & 0.17 & 0.21 & 0.35 & 0.53 & 2.07 & 1.72 & 2.63 \\
\hline 49R-7, 125-126 & 736.18 & 0.18 & 0.21 & 0.36 & 0.56 & 2.10 & 1.73 & 2.70 \\
\hline $50 R-1,45-46$ & 738.46 & 0.18 & 0.22 & 0.37 & 0.60 & 2.15 & 1.77 & 2.82 \\
\hline $50 R-3,60-62$ & 740.89 & 0.17 & 0.20 & 0.35 & 0.55 & 2.19 & 1.83 & 2.83 \\
\hline $51 R-1,56-58$ & 748.07 & 0.21 & 0.27 & 0.41 & 0.69 & 1.98 & 1.56 & 2.63 \\
\hline 51R-1, 136-139 & 748.88 & 0.21 & 0.26 & 0.40 & 0.66 & 1.98 & 1.57 & 2.61 \\
\hline $51 R-2,58-60$ & 749.49 & 0.20 & 0.24 & 0.40 & 0.65 & 2.06 & 1.66 & 2.74 \\
\hline $51 R-3,45-46$ & 750.41 & 0.21 & 0.27 & 0.42 & 0.72 & 2.02 & 1.59 & 2.74 \\
\hline $51 R-4,0-2$ & 750.76 & 0.18 & 0.23 & 0.37 & 0.58 & 2.03 & 1.66 & 2.61 \\
\hline $51 R-4,2-53$ & 751.03 & 0.18 & 0.22 & 0.37 & 0.60 & 2.13 & 1.74 & 2.78 \\
\hline $51 R-5,23-24$ & 751.57 & 0.19 & 0.24 & 0.39 & 0.63 & 2.04 & 1.65 & 2.68 \\
\hline $51 \mathrm{R}-5,98-100$ & 752.32 & 0.19 & 0.23 & 0.38 & 0.62 & 2.09 & 1.70 & 2.76 \\
\hline $51 \mathrm{R}-6,24-25$ & 753.00 & 0.20 & 0.26 & 0.40 & 0.68 & 2.03 & 1.62 & 2.72 \\
\hline 51R-7, 22-24 & 754.41 & 0.20 & 0.25 & 0.39 & 0.63 & 2.01 & 1.61 & 2.63 \\
\hline 51R-7, 101-102 & 755.20 & 0.20 & 0.25 & 0.39 & 0.65 & 2.01 & 1.60 & 2.64 \\
\hline 51R-8, 21-22 & 755.81 & 0.20 & 0.25 & 0.38 & 0.62 & 1.93 & 1.54 & 2.48 \\
\hline 51R-8, 97-98 & 756.57 & 0.24 & 0.31 & 0.43 & 0.77 & 1.87 & 1.43 & 2.52 \\
\hline 51R-9, 19-20 & 756.80 & 0.21 & 0.26 & 0.42 & 0.73 & 2.06 & 1.63 & 2.81 \\
\hline $51 R-9,84-85$ & 757.45 & 0.24 & 0.32 & 0.46 & 0.85 & 1.93 & 1.46 & 2.71 \\
\hline $52 \mathrm{R}-1,60-62$ & 757.61 & 0.19 & 0.23 & 0.38 & 0.62 & 2.08 & 1.69 & 2.74 \\
\hline $52 \mathrm{R}-1,60-62$ & 757.61 & 0.21 & 0.26 & 0.40 & 0.66 & 1.98 & 1.57 & 2.61 \\
\hline $52 \mathrm{R}-1,112-114$ & 758.13 & 0.21 & 0.26 & 0.42 & 0.72 & 2.10 & 1.67 & 2.87 \\
\hline $52 \mathrm{R}-2,11-13$ & 758.52 & 0.30 & 0.42 & 0.52 & 1.09 & 1.80 & 1.27 & 2.64 \\
\hline $52 \mathrm{R}-2,94-95$ & 759.34 & 0.20 & 0.25 & 0.39 & 0.65 & 2.00 & 1.60 & 2.63 \\
\hline $52 \mathrm{R}-3,25-26$ & 760.07 & 0.21 & 0.27 & 0.41 & 0.71 & 1.97 & 1.55 & 2.64 \\
\hline 52R-3, 95.5-98 & 760.78 & 0.20 & 0.25 & 0.33 & 0.50 & 1.69 & 1.34 & 2.02 \\
\hline $52 \mathrm{R}-4,25-26$ & 761.49 & 0.22 & 0.28 & 0.44 & 0.79 & 2.07 & 1.62 & 2.89 \\
\hline 52R-4, 100-101 & 762.24 & 0.23 & 0.29 & 0.44 & 0.77 & 1.97 & 1.53 & 2.71 \\
\hline $52 \mathrm{R}-5,22-23$ & 762.87 & 0.19 & 0.23 & 0.36 & 0.57 & 1.96 & 1.60 & 2.50 \\
\hline $52 R-5,82-84$ & 763.48 & 0.19 & 0.23 & 0.38 & 0.62 & 2.09 & 1.70 & 2.75 \\
\hline 52R-5, 97-98 & 763.62 & 0.20 & 0.25 & 0.39 & 0.64 & 1.99 & 1.59 & 2.61 \\
\hline $52 \mathrm{R}-6,0-2$ & 763.85 & 0.17 & 0.21 & 0.34 & 0.53 & 2.05 & 1.70 & 2.59 \\
\hline $52 R-7,5-6$ & 764.50 & 0.19 & 0.23 & 0.36 & 0.57 & 1.97 & 1.60 & 2.51 \\
\hline $53 R-1,15-16$ & 766.66 & 0.22 & 0.28 & 0.41 & 0.69 & 1.92 & 1.50 & 2.54 \\
\hline $53 \mathrm{R}-1,82-84$ & 767.33 & 0.21 & 0.26 & 0.40 & 0.68 & 2.00 & 1.59 & 2.67 \\
\hline 53R-1, 112-114 & 767.63 & 0.19 & 0.24 & 0.37 & 0.58 & 1.96 & 1.59 & 2.50 \\
\hline $53 R-2,0-2$ & 767.72 & 0.17 & 0.20 & 0.35 & 0.54 & 2.11 & 1.76 & 2.70 \\
\hline $53 R-3,25-26$ & 768.57 & 0.24 & 0.31 & 0.44 & 0.79 & 1.91 & 1.46 & 2.61 \\
\hline $54 R-1,38-39$ & 770.59 & 0.21 & 0.27 & 0.42 & 0.74 & 2.06 & 1.63 & 2.83 \\
\hline 54R-1, 99-100 & 771.20 & 0.21 & 0.27 & 0.41 & 0.71 & 2.00 & 1.58 & 2.70 \\
\hline 54R-2, 74-75 & 772.36 & 0.20 & 0.25 & 0.41 & 0.69 & 2.09 & 1.67 & 2.82 \\
\hline $54 R-4,13-15$ & 772.97 & 0.17 & 0.20 & 0.34 & 0.52 & 2.10 & 1.75 & 2.66 \\
\hline 54R-4, 97-98 & 773.81 & 0.18 & 0.23 & 0.38 & 0.61 & 2.11 & 1.72 & 2.77 \\
\hline $54 R-5,44-46$ & 774.69 & 0.16 & 0.19 & 0.33 & 0.50 & 2.12 & 1.78 & 2.66 \\
\hline 56R-1, 20-21 & 844.21 & 0.18 & 0.22 & 0.36 & 0.56 & 2.03 & 1.66 & 2.59 \\
\hline $56 \mathrm{R}-2,0-2$ & 844.58 & 0.19 & 0.23 & 0.37 & 0.58 & 1.98 & 1.60 & 2.53 \\
\hline $56 \mathrm{R}-3,30-31$ & 845.48 & 0.20 & 0.26 & 0.41 & 0.68 & 2.04 & 1.63 & 2.74 \\
\hline 56R-3, 100-101 & 846.18 & 0.15 & 0.18 & 0.31 & 0.46 & 2.13 & 1.81 & 2.64 \\
\hline 57R-1, 25-26 & 846.66 & 0.16 & 0.19 & 0.32 & 0.48 & 2.09 & 1.76 & 2.59 \\
\hline 57R-1, 29-30 & 846.70 & 0.17 & 0.21 & 0.35 & 0.54 & 2.10 & 1.74 & 2.68 \\
\hline 57R-1, 100-101 & 847.41 & 0.22 & 0.29 & 0.44 & 0.77 & 2.00 & 1.55 & 2.76 \\
\hline 57R-2, 96-98 & 848.78 & 0.16 & 0.19 & 0.33 & 0.49 & 2.10 & 1.77 & 2.64 \\
\hline 57R-3, 17-19 & 849.40 & 0.19 & 0.24 & 0.38 & 0.62 & 2.03 & 1.64 & 2.65 \\
\hline 57R-3, 116-118 & 850.39 & 0.26 & 0.35 & 0.48 & 0.94 & 1.92 & 1.42 & 2.76 \\
\hline $57 R-4,0-2$ & 850.46 & 0.21 & 0.27 & 0.43 & 0.75 & 2.08 & 1.64 & 2.86 \\
\hline 57R-5, 25-26 & 851.30 & 0.17 & 0.21 & 0.36 & 0.56 & 2.11 & 1.75 & 2.72 \\
\hline 57R-5, 100-101 & 852.05 & 0.17 & 0.20 & 0.33 & 0.50 & 2.06 & 1.72 & 2.58 \\
\hline $57 R-5,120-123$ & 852.26 & 0.16 & 0.19 & 0.33 & 0.49 & 2.10 & 1.77 & 2.63 \\
\hline 57R-6, 23-25 & 852.70 & 0.26 & 0.34 & 0.46 & 0.85 & 1.84 & 1.37 & 2.53 \\
\hline 58R-1, 22-23 & 856.13 & 0.20 & 0.25 & 0.40 & 0.66 & 2.04 & 1.63 & 2.70 \\
\hline 58R-1, 119-120 & 857.10 & 0.17 & 0.20 & 0.34 & 0.52 & 2.12 & 1.77 & 2.69 \\
\hline $58 \mathrm{R}-2,32-34$ & 857.56 & 0.16 & 0.20 & 0.33 & 0.50 & 2.07 & 1.73 & 2.59 \\
\hline 58R-2, 99-100 & 858.23 & 0.17 & 0.21 & 0.34 & 0.52 & 2.04 & 1.69 & 2.57 \\
\hline $58 \mathrm{R}-3,0-2$ & 858.48 & 0.17 & 0.20 & 0.34 & 0.51 & 2.08 & 1.74 & 2.63 \\
\hline $58 R-4,40-42$ & 859.45 & 0.15 & 0.18 & 0.32 & 0.47 & 2.13 & 1.80 & 2.65 \\
\hline 58R-4, 100-102 & 860.05 & 0.17 & 0.20 & 0.34 & 0.51 & 2.03 & 1.69 & 2.54 \\
\hline
\end{tabular}


Table T12 (continued).

\begin{tabular}{|c|c|c|c|c|c|c|c|c|}
\hline \multirow{2}{*}{$\begin{array}{l}\text { Core, section, } \\
\text { interval }(\mathrm{cm})\end{array}$} & \multirow{2}{*}{$\begin{array}{l}\text { Depth } \\
\text { CSF }(m)\end{array}$} & \multicolumn{2}{|c|}{$W_{c}$} & \multirow[b]{2}{*}{ Porosity } & \multirow{2}{*}{$\begin{array}{l}\text { Void } \\
\text { ratio }\end{array}$} & \multicolumn{3}{|c|}{ Density $\left(\mathrm{g} / \mathrm{cm}^{3}\right)$} \\
\hline & & Wet & Dry & & & Bulk & Dry & Grain \\
\hline 58R-5, 0-3 & 860.47 & 0.19 & 0.23 & 0.36 & 0.56 & 1.98 & 1.61 & 2.51 \\
\hline 58R-5, 72-74 & 861.18 & 0.15 & 0.18 & 0.32 & 0.48 & 2.15 & 1.82 & 2.69 \\
\hline $58 \mathrm{R}-6,44.5-46.5$ & 862.19 & 0.17 & 0.20 & 0.35 & 0.54 & 2.14 & 1.78 & 2.76 \\
\hline $58 R-7,32-33$ & 863.41 & 0.17 & 0.20 & 0.35 & 0.54 & 2.13 & 1.78 & 2.73 \\
\hline 58R-7, 100-101 & 864.09 & 0.17 & 0.20 & 0.35 & 0.53 & 2.11 & 1.75 & 2.69 \\
\hline $58 \mathrm{R}-8,25-26$ & 864.75 & 0.16 & 0.20 & 0.34 & 0.51 & 2.10 & 1.75 & 2.65 \\
\hline 58R-8, 98-99 & 865.48 & 0.17 & 0.21 & 0.34 & 0.53 & 2.03 & 1.67 & 2.56 \\
\hline $59 \mathrm{R}-1,23-24$ & 865.64 & 0.28 & 0.38 & 0.49 & 0.97 & 1.83 & 1.32 & 2.61 \\
\hline 59R-1, 103-104 & 866.44 & 0.18 & 0.22 & 0.35 & 0.53 & 1.96 & 1.60 & 2.45 \\
\hline $59 \mathrm{R}-2,24-25$ & 866.99 & 0.20 & 0.25 & 0.38 & 0.62 & 1.97 & 1.57 & 2.55 \\
\hline 59R-3, 0-2 & 867.49 & 0.23 & 0.30 & 0.43 & 0.77 & 1.94 & 1.50 & 2.65 \\
\hline $59 R-4,20-21$ & 868.19 & 0.25 & 0.34 & 0.46 & 0.86 & 1.87 & 1.40 & 2.61 \\
\hline 61R-CC, 0-1 & 876.01 & 0.20 & 0.25 & 0.38 & 0.62 & 1.99 & 1.60 & 2.59 \\
\hline
\end{tabular}

Table T13. Sandstone MAD data, Hole C0011B.

\begin{tabular}{|c|c|c|c|c|c|c|c|c|}
\hline \multirow{2}{*}{$\begin{array}{l}\text { Core, section, } \\
\text { interval }(\mathrm{cm})\end{array}$} & \multirow{2}{*}{$\begin{array}{l}\text { Depth } \\
\text { CSF (m) }\end{array}$} & \multicolumn{2}{|c|}{$W_{c}$} & \multirow[b]{2}{*}{ Porosity } & \multirow{2}{*}{$\begin{array}{l}\text { Void } \\
\text { ratio }\end{array}$} & \multicolumn{3}{|c|}{ Density $\left(\mathrm{g} / \mathrm{cm}^{3}\right)$} \\
\hline & & Wet & Dry & & & Bulk & Dry & Grain \\
\hline \multicolumn{9}{|l|}{ 322-C0011B- } \\
\hline 2R-1, 113-115 & 350.64 & 0.26 & 0.35 & 0.48 & 0.92 & 1.88 & 1.39 & 2.67 \\
\hline $3 R-3,98-99.5$ & 361.16 & 0.58 & 1.36 & 0.78 & 3.58 & 1.39 & 0.59 & 2.69 \\
\hline $3 R-4,17-18.5$ & 361.73 & 0.21 & 0.27 & 0.41 & 0.71 & 2.00 & 1.57 & 2.68 \\
\hline $4 \mathrm{R}-2,45-47$ & 366.87 & 0.38 & 0.63 & 0.56 & 1.29 & 1.50 & 0.92 & 2.11 \\
\hline $4 \mathrm{R}-3,0-2$ & 366.95 & 0.37 & 0.59 & 0.58 & 1.35 & 1.59 & 1.00 & 2.36 \\
\hline $4 R-4,26-28$ & 367.51 & 0.35 & 0.54 & 0.57 & 1.32 & 1.69 & 1.10 & 2.57 \\
\hline 4R-4, 104-106 & 368.29 & 0.43 & 0.75 & 0.63 & 1.71 & 1.50 & 0.86 & 2.32 \\
\hline 5R-1, 18-19.5 & 374.69 & 0.25 & 0.32 & 0.48 & 0.94 & 2.02 & 1.53 & 2.96 \\
\hline $5 R-2,25-27$ & 375.63 & 0.23 & 0.30 & 0.44 & 0.78 & 1.93 & 1.48 & 2.64 \\
\hline $5 R-3,17-18$ & 375.81 & 0.25 & 0.34 & 0.48 & 0.92 & 1.93 & 1.44 & 2.77 \\
\hline 5R-3, 100-101 & 376.64 & 0.21 & 0.27 & 0.42 & 0.71 & 2.01 & 1.59 & 2.72 \\
\hline $5 R-4,18.5-20$ & 377.15 & 0.25 & 0.32 & 0.46 & 0.85 & 1.92 & 1.45 & 2.68 \\
\hline $7 \mathrm{R}-2,7.5-9.5$ & 395.00 & 0.26 & 0.36 & 0.46 & 0.85 & 1.79 & 1.32 & 2.45 \\
\hline 7R-3, 0-2 & 395.15 & 0.29 & 0.41 & 0.51 & 1.04 & 1.79 & 1.27 & 2.59 \\
\hline 7R-4, 10-12 & 395.61 & 0.30 & 0.42 & 0.52 & 1.09 & 1.80 & 1.27 & 2.65 \\
\hline $7 R-4,123-125$ & 396.74 & 0.29 & 0.41 & 0.50 & 1.00 & 1.77 & 1.25 & 2.51 \\
\hline $7 R-5,25-26$ & 397.09 & 0.30 & 0.43 & 0.54 & 1.19 & 1.86 & 1.30 & 2.84 \\
\hline $8 R-1,90-92$ & 403.91 & 0.30 & 0.43 & 0.54 & 1.16 & 1.82 & 1.27 & 2.74 \\
\hline $8 R-3,19-21$ & 404.79 & 0.33 & 0.49 & 0.53 & 1.13 & 1.65 & 1.10 & 2.35 \\
\hline $8 R-3,87-88$ & 405.46 & 0.26 & 0.36 & 0.49 & 0.96 & 1.89 & 1.39 & 2.72 \\
\hline $8 R-4,23-24$ & 406.23 & 0.26 & 0.35 & 0.48 & 0.94 & 1.90 & 1.40 & 2.72 \\
\hline 8R-6, 107-109 & 409.90 & 0.27 & 0.38 & 0.50 & 2.00 & 1.88 & 1.36 & 2.74 \\
\hline $9 R-1,32.5-34.5$ & 412.84 & 0.27 & 0.37 & 0.48 & 0.93 & 1.84 & 1.35 & 2.59 \\
\hline 9R-1, 108-110 & 413.59 & 0.28 & 0.39 & 0.50 & 0.98 & 1.83 & 1.32 & 2.62 \\
\hline $9 \mathrm{R}-2,0-2$ & 413.64 & 0.38 & 0.61 & 0.57 & 1.35 & 1.55 & 0.96 & 2.25 \\
\hline $12 \mathrm{R}-5,19-20$ & 446.86 & 0.32 & 0.48 & 0.56 & 1.27 & 1.78 & 1.21 & 2.74 \\
\hline $12 \mathrm{R}-6,0-2$ & 446.97 & 0.31 & 0.46 & 0.54 & 1.16 & 1.75 & 1.21 & 2.60 \\
\hline $14 R-5,45-47$ & 464.08 & 0.21 & 0.26 & 0.42 & 0.71 & 2.08 & 1.65 & 2.82 \\
\hline $15 R-7,25-27$ & 476.84 & 0.24 & 0.31 & 0.43 & 0.76 & 1.86 & 1.41 & 2.49 \\
\hline 16R-1, 48-50 & 477.29 & 0.34 & 0.52 & 0.55 & 1.24 & 1.66 & 1.10 & 2.46 \\
\hline 16R-1, 131-132 & 478.12 & 0.24 & 0.31 & 0.43 & 0.76 & 1.88 & 1.43 & 2.52 \\
\hline $16 \mathrm{R}-2,0-2$ & 478.22 & 0.23 & 0.30 & 0.47 & 0.88 & 2.07 & 1.60 & 2.99 \\
\hline 54R-5, 70-72 & 774.95 & 0.14 & 0.16 & 0.30 & 0.42 & 2.16 & 1.86 & 2.64 \\
\hline 54R-5, 110-112 & 775.35 & 0.14 & 0.17 & 0.31 & 0.44 & 2.19 & 1.87 & 2.70 \\
\hline $55 R-1,27-29$ & 779.28 & 0.19 & 0.23 & 0.37 & 0.59 & 2.05 & 1.67 & 2.65 \\
\hline $55 \mathrm{R}-2,0-2$ & 779.51 & 0.17 & 0.20 & 0.35 & 0.53 & 2.13 & 1.77 & 2.72 \\
\hline $55 \mathrm{R}-3,8-9$ & 780.19 & 0.21 & 0.27 & 0.41 & 0.71 & 1.97 & 1.55 & 2.64 \\
\hline 55R-3, 77-79.5 & 780.88 & 0.18 & 0.22 & 0.36 & 0.56 & 2.05 & 1.68 & 2.62 \\
\hline $55 R-5,23-25$ & 781.86 & 0.19 & 0.23 & 0.37 & 0.60 & 2.03 & 1.64 & 2.63 \\
\hline $57 R-6,74-76.5$ & 853.21 & 0.23 & 0.30 & 0.40 & 0.65 & 1.74 & 1.33 & 2.20 \\
\hline
\end{tabular}


Table T14. $P$-wave velocity, Hole C0011B. (Continued on next two pages.)

\begin{tabular}{|c|c|c|c|c|c|c|}
\hline \multirow{2}{*}{$\begin{array}{l}\text { Core, section, } \\
\text { interval }(\mathrm{cm})\end{array}$} & \multirow{2}{*}{$\begin{array}{c}\text { Depth } \\
\text { CSF (m) }\end{array}$} & \multicolumn{3}{|c|}{$V_{\mathrm{p}}(\mathrm{m} / \mathrm{s})$} & \multicolumn{2}{|c|}{ Anisotropy (\%) } \\
\hline & & $x$ & $y$ & $z$ & Horizontal & Vertical \\
\hline \multicolumn{7}{|l|}{ 322-C0011B- } \\
\hline 1R-1, 44.5 & 340.45 & 1845 & 1863 & 1855 & -0.97 & -0.05 \\
\hline 1R-1, 44.5 & 340.45 & 1684 & 1873 & 1668 & -10.61 & 6.40 \\
\hline $1 \mathrm{R}-2,55.5$ & 341.43 & 1720 & 1830 & 1809 & -6.22 & -1.89 \\
\hline $2 \mathrm{R}-1,52.2$ & 350.02 & 1699 & 1801 & 1733 & -5.87 & 1.00 \\
\hline $3 R-1,53.5$ & 359.51 & 1664 & 1707 & 1620 & -2.55 & 3.96 \\
\hline $3 R-1,53.5$ & 359.51 & 1730 & 1768 & 1743 & -2.17 & 0.36 \\
\hline $3 R-3,19.5$ & 360.31 & 1750 & 1652 & 1749 & 5.76 & -2.80 \\
\hline $3 R-4,95$ & 362.36 & 1822 & 1764 & 1768 & 3.25 & 1.41 \\
\hline $3 R-5,74.5$ & 363.51 & 1701 & 1818 & 1783 & -6.63 & -1.35 \\
\hline $3 R-6,25.8$ & 364.39 & 1681 & 1776 & 1676 & -5.50 & 3.04 \\
\hline $4 \mathrm{R}-1,119$ & 366.19 & 1896 & 1868 & 1798 & 1.49 & 4.55 \\
\hline $4 R-4,15.8$ & 367.40 & 1878 & 1806 & 1656 & 3.87 & 10.61 \\
\hline $5 \mathrm{R}-1,22.5$ & 374.73 & 1741 & 1702 & 1651 & 2.27 & 4.18 \\
\hline $5 R-3,84.3$ & 376.48 & 2020 & 2072 & 1996 & -2.51 & 2.46 \\
\hline $5 R-4,23.3$ & 377.19 & 2169 & 2204 & 2196 & -1.62 & -0.44 \\
\hline $6 \mathrm{R}-1,103.3$ & 385.01 & 1803 & 1733 & 1732 & 3.92 & 2.06 \\
\hline $6 \mathrm{R}-2,105$ & 386.40 & 1760 & 1749 & 1777 & 0.61 & -1.26 \\
\hline 6R-3, 89.5 & 387.63 & 1784 & 1789 & 1777 & -0.30 & 0.56 \\
\hline $6 \mathrm{R}-6,105.5$ & 389.85 & 1803 & 1761 & 1827 & 2.32 & -2.51 \\
\hline 6R-7, 107.5 & 391.25 & 1734 & 1764 & 1781 & -1.70 & -1.84 \\
\hline $6 \mathrm{R}-8,107.5$ & 392.64 & 1827 & 1845 & 1856 & -0.98 & -1.12 \\
\hline 7R-1, 114 & 394.64 & 2011 & 1971 & 1925 & 1.99 & 3.36 \\
\hline $7 \mathrm{R}-4,129$ & 396.79 & 1834 & 1765 & 1802 & 3.87 & -0.16 \\
\hline $7 R-5,97$ & 397.81 & 1780 & 1847 & 1769 & -3.68 & 2.46 \\
\hline $7 R-6,96$ & 399.22 & 1837 & 1800 & 1762 & 2.02 & 3.15 \\
\hline 7R-7, 47 & 400.14 & 1785 & 1853 & 1865 & -3.70 & -2.52 \\
\hline $8 R-1,96$ & 403.96 & 1792 & 1949 & 1886 & -8.39 & -0.81 \\
\hline $8 R-3,36$ & 404.95 & 1886 & 1845 & 1832 & 2.20 & 1.78 \\
\hline $8 R-4,112$ & 407.12 & 1689 & 1713 & 1662 & -1.43 & 2.33 \\
\hline $8 R-5,131$ & 408.72 & 1715 & 1709 & 1721 & 0.35 & -0.52 \\
\hline $8 R-6,73$ & 409.55 & 1825 & 1933 & 1907 & -5.75 & -1.44 \\
\hline 8R-7, 11 & 410.34 & 1833 & 1813 & 1820 & 1.13 & 0.16 \\
\hline $9 \mathrm{R}-1,83$ & 413.33 & 1757 & 1772 & 1726 & -0.81 & 2.21 \\
\hline $9 \mathrm{R}-4,116$ & 416.61 & 1862 & 1862 & 1787 & -0.02 & 4.12 \\
\hline $9 \mathrm{R}-5,24.5$ & 417.11 & 1843 & 1830 & 1871 & 0.69 & -1.87 \\
\hline 10R-1, 24 & 422.24 & 1787 & 1797 & 1775 & -0.60 & 0.93 \\
\hline 10R-2, 59 & 424.00 & 1799 & 1792 & 1742 & 0.39 & 3.04 \\
\hline $11 \mathrm{R}-1,29.5$ & 431.80 & 1795 & 1787 & 1764 & 0.41 & 1.50 \\
\hline $11 \mathrm{R}-2,25$ & 433.15 & 1774 & 1788 & 1711 & -0.75 & 4.01 \\
\hline $11 \mathrm{R}-5,24.5$ & 435.49 & 2060 & 2109 & 2010 & -2.35 & 3.66 \\
\hline $11 \mathrm{R}-6,16$ & 436.81 & 1769 & 1753 & 1742 & 0.95 & 1.10 \\
\hline $11 \mathrm{R}-7,36$ & 438.42 & 1819 & 1812 & 1704 & 0.39 & 6.33 \\
\hline $11 \mathrm{R}-8,92.5$ & 440.39 & 1786 & 1808 & 1760 & -1.22 & 2.12 \\
\hline $12 \mathrm{R}-1,100.5$ & 442.01 & 1875 & 1857 & 1760 & 0.96 & 5.83 \\
\hline $12 \mathrm{R}-2,110.5$ & 443.52 & 1738 & 1751 & 1696 & -0.76 & 2.85 \\
\hline $12 \mathrm{R}-3,93.5$ & 444.77 & 1940 & 1957 & 1861 & -0.89 & 4.60 \\
\hline $12 \mathrm{R}-4,114.5$ & 446.40 & 1828 & 1819 & 1772 & 0.49 & 2.88 \\
\hline $12 \mathrm{R}-7,27.5$ & 447.60 & 1762 & 1759 & 1725 & 0.19 & 2.05 \\
\hline $13 \mathrm{R}-1,97.5$ & 451.48 & 1753 & 1775 & 1727 & -1.27 & 2.13 \\
\hline $13 \mathrm{R}-2,99.5$ & 452.91 & 1798 & 1830 & 1701 & -1.75 & 6.44 \\
\hline $13 \mathrm{R}-4,96.5$ & 454.65 & 1828 & 1793 & 1737 & 1.91 & 4.15 \\
\hline $13 R-5,106.5$ & 456.16 & 1793 & 1755 & 1767 & 2.14 & 0.41 \\
\hline $13 \mathrm{R}-6,100.5$ & 457.51 & 1861 & 1764 & 1813 & 5.39 & -0.01 \\
\hline $13 \mathrm{R}-7,46.5$ & 458.38 & 1835 & 1783 & 1747 & 2.86 & 3.52 \\
\hline $14 \mathrm{R}-1,111.5$ & 461.12 & 1812 & 1804 & 1728 & 0.41 & 4.52 \\
\hline $14 \mathrm{R}-2,86.5$ & 462.28 & 1822 & 1814 & 1764 & 0.44 & 3.03 \\
\hline $14 \mathrm{R}-3,23.5$ & 463.06 & 1879 & 1846 & 1789 & 1.77 & 4.03 \\
\hline $14 \mathrm{R}-5,102.5$ & 464.65 & 1821 & 1830 & 1720 & -0.51 & 5.96 \\
\hline $14 \mathrm{R}-6,82.5$ & 465.86 & 1824 & 1877 & 1776 & -2.86 & 4.13 \\
\hline $15 \mathrm{R}-1,137.5$ & 470.84 & 1885 & 1833 & 1801 & 2.78 & 3.20 \\
\hline $15 \mathrm{R}-2,109.5$ & 471.94 & 1821 & 1811 & 1777 & 0.55 & 2.13 \\
\hline $15 \mathrm{R}-4,139.5$ & 473.84 & 1815 & 1815 & 1736 & 0.02 & 4.48 \\
\hline $15 \mathrm{R}-5,90.5$ & 474.74 & 1809 & 1808 & 1716 & 0.06 & 5.25 \\
\hline $15 \mathrm{R}-6,57.5$ & 475.81 & 1874 & 1872 & 1808 & 0.11 & 3.53 \\
\hline $15 \mathrm{R}-7,21.5$ & 476.63 & 1963 & 1947 & 1902 & 0.80 & 2.76 \\
\hline $16 \mathrm{R}-1,101.5$ & 477.82 & 2063 & 2092 & 2061 & -1.40 & 0.80 \\
\hline $19 \mathrm{R}-1,57$ & 491.45 & 1801 & 1798 & 1779 & 0.19 & 1.17 \\
\hline $19 \mathrm{R}-2,28.5$ & 492.54 & 1802 & 1817 & 1780 & -0.85 & 1.62 \\
\hline
\end{tabular}


Table T14 (continued). (Continued on next page.)

\begin{tabular}{|c|c|c|c|c|c|c|}
\hline \multirow{2}{*}{$\begin{array}{l}\text { Core, section, } \\
\text { interval }(\mathrm{cm})\end{array}$} & \multirow{2}{*}{$\begin{array}{l}\text { Depth } \\
\text { CSF (m) }\end{array}$} & \multicolumn{3}{|c|}{$V_{\mathrm{P}}(\mathrm{m} / \mathrm{s})$} & \multicolumn{2}{|c|}{ Anisotropy (\%) } \\
\hline & & $x$ & $y$ & $z$ & Horizontal & Vertical \\
\hline $19 R-4,98.5$ & 493.91 & 1870 & 1889 & 1760 & -1.01 & 6.55 \\
\hline $19 R-5,105.8$ & 495.32 & 1849 & 1834 & 1789 & 0.81 & 2.89 \\
\hline $19 R-6,101.5$ & 496.60 & 1853 & 1874 & 1822 & -1.11 & 2.24 \\
\hline 19R-7, 25.5 & 497.25 & 1821 & 1817 & 1854 & 0.22 & -1.89 \\
\hline $21 \mathrm{R}-3,107.5$ & 503.34 & 1861 & 1868 & 1902 & -0.36 & -1.98 \\
\hline $21 \mathrm{R}-4,93.5$ & 504.61 & 1730 & 1735 & 1760 & -0.29 & -1.57 \\
\hline $21 \mathrm{R}-5,76.5$ & 505.85 & 1812 & 1791 & 1778 & 1.18 & 1.34 \\
\hline $21 \mathrm{R}-6,95.5$ & 507.45 & 1833 & 1841 & 1862 & -0.47 & -1.35 \\
\hline $21 R-7,103.5$ & 508.94 & 1831 & 1815 & 1781 & 0.84 & 2.33 \\
\hline $21 \mathrm{R}-8,91.5$ & 510.22 & & 1816 & 1761 & & 3.04 \\
\hline $23 R-1,54$ & 520.94 & 1847 & & 1915 & & -3.58 \\
\hline $23 \mathrm{R}-3,58$ & 522.15 & 1816 & 1759 & 1838 & 3.19 & -2.75 \\
\hline $23 R-4,41.5$ & 523.39 & 1823 & 1879 & 1788 & -3.04 & 3.43 \\
\hline $23 \mathrm{R}-5,25$ & 524.65 & 1820 & 1820 & 1766 & -0.04 & 2.99 \\
\hline $23 R-6,28$ & 526.12 & 1836 & 1825 & 1764 & 0.62 & 3.73 \\
\hline 23R-7, 28 & 526.58 & 1860 & 1872 & 1846 & -0.66 & 1.10 \\
\hline 23R-8, 101 & 528.72 & 1806 & 1848 & 1816 & -2.26 & 0.60 \\
\hline $24 \mathrm{R}-2,104$ & 531.51 & 1806 & 1848 & 1816 & -2.26 & 0.60 \\
\hline 24R-3, 29 & 532.17 & 1848 & 1892 & 1807 & -2.35 & 3.43 \\
\hline $24 \mathrm{R}-4,102$ & 534.32 & 1789 & 1801 & 1782 & -0.67 & 0.73 \\
\hline 25R-3, 107 & 541.56 & 1823 & 1835 & 1772 & -0.62 & 3.18 \\
\hline $25 \mathrm{R}-4,101$ & 542.90 & 1850 & 1819 & 1786 & 1.67 & 2.67 \\
\hline $26 \mathrm{R}-1,95.5$ & 549.96 & 1860 & 1863 & 1850 & -0.14 & 0.63 \\
\hline $26 \mathrm{R}-3,114.5$ & 552.17 & 1847 & 1869 & 1789 & -1.20 & 3.79 \\
\hline $26 \mathrm{R}-4,100.5$ & 553.28 & 1872 & 1850 & 1839 & 1.20 & 1.16 \\
\hline $26 \mathrm{R}-5,102.5$ & 554.70 & 1912 & 1876 & 1868 & 1.92 & 1.36 \\
\hline $26 \mathrm{R}-6,141.5$ & 556.50 & 1861 & 1854 & 1879 & 0.38 & -1.19 \\
\hline 26R-7, 126.5 & 557.78 & 1904 & 1893 & 1860 & 0.54 & 2.03 \\
\hline 27R-1, 82 & 559.32 & 1843 & 1774 & 1843 & 3.81 & -1.85 \\
\hline $27 \mathrm{R}-3,123$ & 561.15 & 1846 & 1885 & 1833 & -2.09 & 1.79 \\
\hline $27 R-4,108.5$ & 562.38 & 1869 & 1893 & 1848 & -1.29 & 1.80 \\
\hline $27 R-5,88.5$ & 563.59 & 1924 & 1881 & 1865 & 2.26 & 1.97 \\
\hline $27 R-6,108.5$ & 565.21 & 1852 & 1891 & 1825 & -2.08 & 2.52 \\
\hline $28 \mathrm{R}-1,70$ & 568.70 & 1889 & 1912 & 1884 & -1.25 & 0.85 \\
\hline $28 \mathrm{R}-3,58$ & 570.57 & 1866 & 1899 & 1864 & -1.75 & 0.99 \\
\hline $30 \mathrm{R}-1,103$ & 581.43 & 1970 & 2027 & 2018 & -2.85 & -0.97 \\
\hline $30 \mathrm{R}-3,26$ & 582.57 & 1917 & 1933 & 1868 & -0.81 & 3.00 \\
\hline $30 \mathrm{R}-4,25$ & 583.97 & 1977 & 1976 & 1838 & 0.05 & 7.26 \\
\hline $31 \mathrm{R}-1,31.5$ & 586.82 & 1903 & 1923 & 1841 & -1.03 & 3.85 \\
\hline $31 \mathrm{R}-3,118$ & 589.58 & 1895 & 1965 & 1891 & -3.64 & 2.02 \\
\hline $31 R-5,20.5$ & 590.38 & 1954 & 1944 & 1905 & 0.53 & 2.29 \\
\hline $32 \mathrm{R}-1,104.5$ & 597.05 & 1978 & 1997 & 1951 & -0.96 & 1.87 \\
\hline $32 \mathrm{R}-2,95.5$ & 598.39 & 1963 & 2005 & 1862 & -2.08 & 6.33 \\
\hline $32 \mathrm{R}-3,94$ & 599.78 & 1979 & 1985 & 1894 & -0.30 & 4.56 \\
\hline $32 \mathrm{R}-4,102$ & 601.27 & 2079 & 2022 & 1959 & 2.78 & 4.58 \\
\hline $33 R-3,97$ & 607.45 & 1884 & 1910 & 1909 & -1.37 & -0.63 \\
\hline $33 R-4,86$ & 608.75 & 2046 & 1943 & 1830 & 5.16 & 8.58 \\
\hline $33 R-5,102.3$ & 610.32 & 1927 & 1951 & 1900 & -1.24 & 2.05 \\
\hline $33 R-6,118$ & 611.89 & 1979 & 2005 & 1977 & -1.31 & 0.77 \\
\hline $33 R-7,54$ & 612.69 & 1803 & 1908 & 1935 & -5.68 & -4.20 \\
\hline $35 \mathrm{R}-1,80$ & 625.25 & 1965 & 1921 & 1913 & 2.30 & 1.57 \\
\hline $35 R-2,87.5$ & 626.66 & 1947 & 1972 & 1924 & -1.29 & 1.84 \\
\hline $35 \mathrm{R}-3,74$ & 627.87 & 2017 & 2016 & 1933 & 0.05 & 4.23 \\
\hline $35 R-5,55$ & 629.17 & 1930 & 1956 & 1868 & -1.34 & 3.94 \\
\hline 35R-6, 11 & 630.08 & 1988 & 1927 & 1937 & 3.13 & 1.03 \\
\hline $35 \mathrm{R}-7,61$ & 631.90 & 1857 & 1920 & 1902 & -3.35 & -0.70 \\
\hline $35 R-8,69$ & 633.31 & 1952 & 1934 & 1896 & 0.91 & 2.44 \\
\hline $36 \mathrm{R}-1,19$ & 634.19 & 1896 & 1896 & 1954 & -0.02 & -3.00 \\
\hline $36 \mathrm{R}-3,42$ & 635.63 & 1931 & 2015 & 1963 & -4.24 & 0.48 \\
\hline $36 \mathrm{R}-4,103$ & 637.65 & 1983 & 1945 & 1844 & 1.92 & 6.31 \\
\hline $36 \mathrm{R}-5,87$ & 638.90 & 1996 & 1985 & 1919 & 0.52 & 3.64 \\
\hline $36 \mathrm{R}-5,129$ & 639.32 & 1993 & 1982 & 1953 & 0.57 & 1.76 \\
\hline $36 R-6,86$ & 640.30 & 1943 & 1960 & 1852 & -0.87 & 5.23 \\
\hline 36R-7, 24 & 641.10 & 1860 & 1948 & 1875 & -4.62 & 1.53 \\
\hline $37 \mathrm{R}-1,17.5$ & 643.66 & 1970 & 1971 & 1909 & -0.05 & 3.14 \\
\hline $37 R-3,73.3$ & 645.89 & 1998 & 2000 & 1951 & -0.08 & 2.40 \\
\hline $37 R-4,97$ & 647.44 & 2114 & 2071 & 1998 & 2.04 & 4.63 \\
\hline $37 R-5,138.5$ & 649.15 & 1962 & 1940 & 1954 & 1.13 & -0.15 \\
\hline $37 R-6,115$ & 650.25 & 1899 & 1912 & 1851 & -0.68 & 2.88 \\
\hline
\end{tabular}


Table T14 (continued).

\begin{tabular}{|c|c|c|c|c|c|c|}
\hline \multirow{2}{*}{$\begin{array}{l}\text { Core, section, } \\
\text { interval }(\mathrm{cm})\end{array}$} & \multirow{2}{*}{$\begin{array}{l}\text { Depth } \\
\text { CSF }(m)\end{array}$} & \multicolumn{3}{|c|}{$V_{\mathrm{P}}(\mathrm{m} / \mathrm{s})$} & \multicolumn{2}{|c|}{ Anisotropy (\%) } \\
\hline & & $x$ & $y$ & $z$ & Horizontal & Vertical \\
\hline 37R-7, 135 & 651.76 & 1816 & 1914 & 1852 & -5.24 & 0.69 \\
\hline 37R-8, 97 & 652.73 & 1935 & 1981 & 1891 & -2.33 & 3.49 \\
\hline $38 \mathrm{R}-1,114$ & 654.14 & 1873 & 1893 & 1922 & -1.08 & -2.04 \\
\hline $38 \mathrm{R}-3,99$ & 655.92 & 1886 & 1875 & 1815 & 0.62 & 3.53 \\
\hline $38 \mathrm{R}-4,97$ & 657.31 & 1930 & 1953 & 1953 & -1.17 & -0.60 \\
\hline $38 \mathrm{R}-5,100$ & 658.76 & 2062 & 2037 & 1878 & 1.20 & 8.74 \\
\hline $38 R-6,77$ & 659.94 & 1985 & 1937 & 1900 & 2.45 & 3.14 \\
\hline $38 \mathrm{R}-7,95.5$ & 661.52 & 2102 & 2081 & 1955 & 1.00 & 6.73 \\
\hline 39R-1, 101 & 663.51 & 1967 & 1933 & 1910 & 1.71 & 2.06 \\
\hline $39 R-2,98$ & 664.89 & 1953 & 1946 & 1990 & 0.32 & -2.07 \\
\hline $39 R-3,24$ & 665.56 & 1928 & 1988 & 1851 & -3.05 & 5.63 \\
\hline $39 R-5,27$ & 667.60 & & 1959 & & & \\
\hline 39R-6, 99 & 669.74 & & 1945 & & & \\
\hline 39R-7, 18 & 670.33 & 1858 & 1914 & 1948 & -2.97 & -3.23 \\
\hline 40R-1, 121 & 673.21 & 1998 & 1954 & 1897 & 2.21 & 4.09 \\
\hline 40R-2, 99 & 674.39 & 1956 & 1952 & 1905 & 0.17 & 2.56 \\
\hline $40 \mathrm{R}-4,102$ & 676.37 & 2026 & 2093 & 1854 & -3.25 & 10.50 \\
\hline $42 \mathrm{R}-1,28$ & 680.78 & 1972 & 1989 & 1884 & -0.88 & 4.98 \\
\hline $42 \mathrm{R}-1,102$ & 681.52 & 2004 & 2001 & 1826 & 0.17 & 9.21 \\
\hline 43R-1, 103 & 685.46 & 2049 & 2044 & 1965 & 0.24 & 4.10 \\
\hline $43 \mathrm{R}-2,28$ & 685.76 & 2037 & 2065 & 1954 & -1.35 & 4.82 \\
\hline $43 R-4,102$ & 686.57 & 2051 & 2074 & 1993 & -1.12 & 3.43 \\
\hline 44R-1, 97 & 689.97 & 2104 & 2102 & 2020 & 0.13 & 4.01 \\
\hline $44 \mathrm{R}-2,65$ & 691.06 & 2006 & 2033 & 1912 & -1.34 & 5.47 \\
\hline $44 \mathrm{R}-4,115$ & 692.84 & 1976 & 1994 & 1938 & -0.92 & 2.39 \\
\hline 44R-5, 103 & 694.13 & 1986 & 1990 & 1940 & -0.20 & 2.41 \\
\hline $44 \mathrm{R}-6,105$ & 695.57 & 1976 & 1945 & 1865 & 1.56 & 5.00 \\
\hline $44 \mathrm{R}-7,64$ & 696.58 & 1919 & 1897 & 1862 & 1.19 & 2.46 \\
\hline $45 R-1,35$ & 698.85 & 1939 & 1949 & 1950 & -0.51 & -0.34 \\
\hline $45 \mathrm{R}-2,27$ & 700.20 & 2035 & 1953 & 1819 & 4.13 & 9.19 \\
\hline $45 R-4,110$ & 701.91 & 2005 & 1987 & 1894 & 0.90 & 5.26 \\
\hline $45 R-5,46$ & 702.70 & 2101 & 1995 & 2069 & 5.19 & -1.03 \\
\hline $45 R-6,74$ & 704.40 & 2085 & 2066 & 1885 & 0.92 & 9.62 \\
\hline $45 \mathrm{R}-7,127$ & 706.36 & 2012 & 2049 & 1901 & -1.81 & 6.61 \\
\hline $46 \mathrm{R}-1,130$ & 709.30 & 1982 & 1984 & 1849 & -0.07 & 6.98 \\
\hline $46 \mathrm{R}-2,36$ & 709.76 & 2045 & 1968 & 1864 & 3.85 & 7.35 \\
\hline $47 \mathrm{R}-1,75$ & 712.25 & 2025 & 1924 & 2064 & 5.10 & -4.41 \\
\hline $47 R-3,28$ & 713.47 & 2017 & 2037 & 1967 & -1.02 & 3.02 \\
\hline $47 R-5,53$ & 716.55 & 2001 & 1989 & 2181 & 0.63 & -8.91 \\
\hline $47 R-6,22$ & 717.65 & 2050 & 2015 & 2005 & 1.71 & 1.35 \\
\hline $48 \mathrm{R}-2,9$ & 722.09 & 2139 & 2156 & 2013 & -0.79 & 6.47 \\
\hline 49R-1, 39 & 730.49 & 2199 & 2195 & 1904 & 0.15 & 14.29 \\
\hline $49 R-7,59$ & 735.51 & 2229 & 2225 & 2031 & 0.20 & 9.19 \\
\hline $51 \mathrm{R}-3,6$ & 749.83 & 2058 & 2065 & 1940 & -0.32 & 6.06 \\
\hline 51R-7, 79 & 754.42 & 2061 & 2090 & 1990 & -1.38 & 4.18 \\
\hline $51 \mathrm{R}-9,7$ & 756.00 & 1986 & 1926 & 1857 & 3.07 & 5.16 \\
\hline $52 \mathrm{R}-1,67$ & 757.62 & 2028 & 1968 & 1891 & 2.99 & 5.51 \\
\hline $52 \mathrm{R}-2,33$ & 758.60 & 1987 & 2019 & 1968 & -1.58 & 1.77 \\
\hline $52 \mathrm{R}-4,23$ & 761.14 & 2016 & 1947 & 1891 & 3.52 & 4.66 \\
\hline $52 \mathrm{R}-5,9$ & 762.32 & 1949 & 2075 & 1846 & -6.26 & 8.57 \\
\hline $53 R-3,32$ & 767.92 & 2061 & 2069 & 2041 & -0.40 & 1.14 \\
\hline $54 \mathrm{R}-1,42$ & 770.62 & & 1864 & 2017 & & -7.89 \\
\hline $55 R-1,43$ & 779.43 & 1850 & 1858 & 1792 & -0.41 & 3.39 \\
\hline $55 R-3,57$ & 780.67 & 1889 & 2025 & 1897 & -6.98 & 3.11 \\
\hline $55 R-5,22$ & 781.84 & 1897 & 1847 & 1876 & 2.67 & -0.23 \\
\hline 56R-1, 25 & 844.23 & 2258 & 2238 & 2104 & 0.89 & 6.62 \\
\hline 56R-3, 98 & 846.01 & 2308 & 2265 & 2133 & 1.88 & 6.96 \\
\hline 57R-1, 49 & 846.89 & 2176 & 2236 & 2127 & -2.72 & 3.63 \\
\hline 57R-2, 134 & 849.15 & 2229 & 2358 & 2142 & -5.62 & 6.82 \\
\hline 57R-5, 110 & 852.15 & 2282 & 2308 & 2193 & -1.13 & 4.55 \\
\hline 58R-1, 108 & 856.93 & 2256 & 2302 & 2167 & -2.00 & 5.05 \\
\hline $58 \mathrm{R}-2,35$ & 857.50 & 2125 & 2278 & 2109 & -6.92 & 4.28 \\
\hline $58 \mathrm{R}-4,111.5$ & 859.95 & 2233 & 2193 & 2077 & 1.79 & 6.32 \\
\hline $58 \mathrm{R}-5,120$ & 861.37 & 2331 & 2325 & 2192 & 0.24 & 6.03 \\
\hline $58 \mathrm{R}-6,6$ & 861.50 & 2348 & 2282 & 2158 & 2.82 & 7.02 \\
\hline 58R-7, 28 & 862.99 & 2188 & 2255 & 2008 & -2.99 & 10.11 \\
\hline $58 \mathrm{R}-8,109$ & 865.11 & 2338 & 2411 & 2230 & -3.05 & 6.29 \\
\hline 59R-1, 101 & 866.41 & 2473 & 2550 & 2442 & -3.07 & 2.81 \\
\hline
\end{tabular}


Table T15. Electrical resistivity, Hole C0011B.

\begin{tabular}{|c|c|c|c|c|c|}
\hline \multirow{2}{*}{$\begin{array}{l}\text { Core, section, } \\
\text { interval }(\mathrm{cm})\end{array}$} & \multirow{2}{*}{$\begin{array}{l}\text { Depth } \\
\text { CSF (m) }\end{array}$} & \multicolumn{3}{|c|}{ Resistivity $(\Omega \mathrm{m})$} & \multirow{2}{*}{$\begin{array}{c}\text { Vertical } \\
\text { anisotropy } \\
(\%)\end{array}$} \\
\hline & & $x$ & y & $z$ & \\
\hline \multicolumn{6}{|l|}{ 322-C0011B- } \\
\hline 1R-2, 55.5 & 341.43 & 4.28 & 3.61 & 5.19 & -27.10 \\
\hline $2 \mathrm{R}-1,52.2$ & 350.02 & 3.49 & 4.72 & 4.62 & -11.90 \\
\hline $3 R-4,95$ & 362.36 & 2.31 & 4.79 & 4.31 & -19.34 \\
\hline $4 R-4,15.8$ & 367.40 & 3.38 & 3.38 & 2.02 & 50.31 \\
\hline $5 R-4,23.3$ & 377.19 & 8.18 & 8.67 & 8.31 & 1.38 \\
\hline $6 R-3,89.5$ & 387.63 & 6.98 & 7.28 & 5.81 & 20.38 \\
\hline 7R-6, 96 & 399.22 & 2.82 & 2.89 & 4.20 & -38.14 \\
\hline $8 R-1,96$ & 403.96 & 4.11 & 4.25 & 4.42 & -5.60 \\
\hline $9 \mathrm{R}-1,83$ & 413.33 & 4.07 & 3.97 & 4.51 & -11.42 \\
\hline $10 \mathrm{R}-1,24$ & 422.24 & 3.69 & 3.67 & 5.12 & -32.75 \\
\hline $11 \mathrm{R}-2,25$ & 433.15 & 2.63 & 3.00 & 4.38 & -43.39 \\
\hline $12 \mathrm{R}-1,100.5$ & 442.01 & 3.56 & 3.40 & 5.79 & -49.90 \\
\hline $13 R-1,97.5$ & 451.48 & 3.51 & 3.38 & 4.45 & -25.47 \\
\hline $14 \mathrm{R}-1,111.5$ & 461.12 & 3.55 & 3.21 & 4.50 & -28.50 \\
\hline $15 R-2,109.5$ & 471.94 & 2.90 & 2.60 & 3.97 & -36.43 \\
\hline 16R-1, 101.5 & 477.82 & 4.51 & 5.36 & 5.47 & -10.26 \\
\hline $19 \mathrm{R}-1,57$ & 491.45 & 2.58 & 3.16 & 5.26 & -58.96 \\
\hline $21 \mathrm{R}-3,107.5$ & 503.34 & 4.63 & 4.88 & 7.17 & -40.47 \\
\hline 21R-8, 91.5 & 510.22 & 3.54 & 3.24 & 5.92 & -54.36 \\
\hline $23 R-3,58$ & 522.15 & 4.75 & 6.38 & 4.26 & 26.44 \\
\hline $23 R-4,41.5$ & 523.39 & 4.67 & 4.72 & 5.70 & -19.32 \\
\hline $23 R-5,25$ & 524.65 & 4.33 & 4.89 & 5.58 & -19.02 \\
\hline $23 \mathrm{R}-6,28$ & 526.12 & 4.11 & 4.10 & 6.42 & -43.94 \\
\hline 23R-7, 28 & 526.58 & 6.27 & 4.29 & 4.44 & 17.17 \\
\hline 23R-8, 101 & 528.72 & 5.47 & 3.70 & 4.13 & 10.52 \\
\hline 24R-3, 29 & 532.17 & 4.52 & 4.44 & 7.20 & -46.59 \\
\hline $25 R-4,101$ & 542.90 & 5.24 & 4.54 & 6.72 & -31.54 \\
\hline $26 \mathrm{R}-3,114.5$ & 552.17 & 5.40 & 3.33 & 5.58 & -24.44 \\
\hline $26 \mathrm{R}-7,126.5$ & 557.78 & 3.77 & 3.89 & 3.16 & 19.12 \\
\hline 27R-1, 82 & 559.32 & 4.04 & 3.25 & 5.26 & -36.26 \\
\hline $28 \mathrm{R}-1,70$ & 568.70 & 3.78 & 4.78 & 3.61 & 17.02 \\
\hline 30R-1, 103 & 581.43 & 3.97 & 4.44 & 5.66 & -29.39 \\
\hline $32 \mathrm{R}-3,94$ & 599.78 & 5.23 & 4.79 & 7.54 & -40.37 \\
\hline $33 R-4,86$ & 608.75 & 4.74 & 4.34 & 6.16 & -30.30 \\
\hline $35 \mathrm{R}-1,80$ & 625.25 & 2.79 & 3.65 & 6.47 & -67.20 \\
\hline 36R-1, 19 & 634.19 & 3.18 & 5.11 & 3.23 & 24.75 \\
\hline $37 \mathrm{R}-1,17.5$ & 643.66 & 5.35 & 5.14 & 6.98 & -28.27 \\
\hline $38 \mathrm{R}-1,114$ & 654.14 & 4.57 & 4.51 & 7.22 & -45.67 \\
\hline 39R-3, 24 & 665.56 & 6.26 & 4.66 & 8.64 & -45.14 \\
\hline $40 \mathrm{R}-2,99$ & 674.39 & 4.27 & 6.13 & 8.71 & -50.43 \\
\hline $42 \mathrm{R}-1,28$ & 680.78 & 7.09 & 5.65 & 7.96 & -22.18 \\
\hline $43 \mathrm{R}-1,103$ & 685.46 & 6.21 & 7.47 & 7.55 & -9.83 \\
\hline 44R-1, 97 & 689.97 & 5.17 & 5.22 & 8.67 & -50.19 \\
\hline $45 \mathrm{R}-1,35$ & 698.85 & 4.88 & 4.76 & 6.78 & -33.80 \\
\hline $46 \mathrm{R}-2,36$ & 709.76 & 4.18 & 4.12 & 6.69 & -46.84 \\
\hline $47 \mathrm{R}-1,75$ & 712.25 & 4.63 & 8.29 & 4.11 & 44.46 \\
\hline $48 \mathrm{R}-2,9$ & 722.09 & 4.14 & 6.45 & 10.78 & -68.20 \\
\hline $49 \mathrm{R}-1,39$ & 730.49 & 5.75 & 6.24 & 11.34 & -61.71 \\
\hline 51R-3, 6 & 749.83 & 4.06 & 4.48 & 11.69 & -92.96 \\
\hline $52 \mathrm{R}-1,67$ & 757.62 & 5.10 & 5.40 & 8.75 & -50.09 \\
\hline $53 \mathrm{R}-3,32$ & 767.92 & 4.59 & 5.51 & 9.12 & -57.33 \\
\hline $55 \mathrm{R}-1,43$ & 779.43 & 6.89 & 6.97 & 7.43 & -6.92 \\
\hline $56 \mathrm{R}-1,25$ & 844.23 & 4.07 & 5.12 & 8.91 & -63.89 \\
\hline 57R-1, 49 & 846.89 & 4.93 & 5.06 & 8.64 & -53.44 \\
\hline $58 \mathrm{R}-1,108$ & 856.93 & 6.39 & 7.06 & 11.39 & -51.56 \\
\hline 59R-1, 101 & 866.41 & 8.20 & 10.76 & 10.79 & -12.90 \\
\hline
\end{tabular}


Table T16. Thermal conductivity, Hole C0011B.

\begin{tabular}{|c|c|c|c|c|c|}
\hline & \\
\hline $\begin{array}{l}\text { Core, section, } \\
\text { interval }(\mathrm{cm})\end{array}$ & $\begin{array}{l}\text { Depth } \\
\operatorname{CSF}(\mathrm{m})\end{array}$ & $\begin{array}{l}\text { Thermal } \\
\text { conductivity } \\
(\mathrm{W} /[\mathrm{m} \cdot \mathrm{K}])\end{array}$ & $\begin{array}{l}\text { Core, section, } \\
\text { interval }(\mathrm{cm})\end{array}$ & $\begin{array}{l}\text { Depth } \\
\text { CSF }(m)\end{array}$ & $\begin{array}{l}\text { Thermal } \\
\text { conductivity } \\
(\mathrm{W} /[\mathrm{m} \cdot \mathrm{K}])\end{array}$ \\
\hline 322-C0011B- & & & 16R-3, 10 & 478.72 & 1.42 \\
\hline 1R-1, 70 & 340.70 & 1.23 & $19 R-1,50$ & 491.39 & 1.27 \\
\hline $1 \mathrm{R}-2,85$ & 341.73 & 1.10 & 19R-2, 31 & 492.56 & 1.31 \\
\hline 1R-CC, 24 & 342.25 & 1.24 & $19 R-4,92$ & 493.85 & 1.24 \\
\hline 2R-1, 97 & 350.47 & 1.30 & 19R-5, 100 & 495.27 & 1.37 \\
\hline $3 R-1,37$ & 359.36 & 1.12 & 19R-6, 101 & 496.60 & 1.27 \\
\hline $3 R-3,18$ & 360.29 & 1.10 & 19R-7, 88 & 497.86 & 1.35 \\
\hline $3 R-4,60$ & 362.02 & 1.14 & $20 \mathrm{R}-1,16$ & 498.56 & 1.73 \\
\hline $3 R-5,40$ & 363.18 & 1.05 & $21 \mathrm{R}-1,3$ & 501.53 & 1.38 \\
\hline $4 \mathrm{R}-1,69$ & 365.69 & 1.12 & $21 \mathrm{R}-3,120$ & 503.46 & 1.32 \\
\hline $4 \mathrm{R}-3,11$ & 367.05 & 1.13 & $21 \mathrm{R}-4,115$ & 504.82 & 1.37 \\
\hline $5 \mathrm{R}-1,41$ & 374.91 & 1.30 & $21 \mathrm{R}-5,107$ & 506.15 & 1.36 \\
\hline $5 R-3,73$ & 376.37 & 1.39 & $21 \mathrm{R}-6,101$ & 507.50 & 1.45 \\
\hline $5 R-4,10$ & 377.06 & 1.00 & 21R-7, 89 & 508.79 & 1.26 \\
\hline $6 \mathrm{R}-1,103$ & 385.01 & 1.33 & $21 \mathrm{R}-8,80$ & 510.11 & 1.49 \\
\hline $6 \mathrm{R}-6,14$ & 388.96 & 1.28 & $23 \mathrm{R}-1,36$ & 520.76 & 1.36 \\
\hline 6R-7, 57 & 390.76 & 1.28 & $23 R-3,62$ & 522.22 & 1.48 \\
\hline 7R-1, 104 & 394.54 & 1.10 & $23 R-4,49$ & 523.49 & 1.57 \\
\hline $7 \mathrm{R}-4,35$ & 395.85 & 1.27 & $23 \mathrm{R}-5,49$ & 524.92 & 1.44 \\
\hline 7R-5, 93 & 397.77 & 1.28 & 23R-6, 18 & 526.05 & 1.41 \\
\hline $7 R-6,90$ & 399.16 & 1.17 & 23R-7, 80 & 527.13 & 1.45 \\
\hline 7R-7, 40 & 400.07 & 0.98 & $23 \mathrm{R}-8,115$ & 528.89 & 1.43 \\
\hline $8 R-3,6$ & 404.65 & 1.23 & $24 \mathrm{R}-2,78$ & 531.25 & 1.38 \\
\hline $8 R-4,50$ & 406.50 & 1.38 & $24 \mathrm{R}-3,50$ & 532.38 & 1.43 \\
\hline $8 \mathrm{R}-5,124$ & 408.65 & 1.15 & 24R-4, 111 & 534.41 & 1.44 \\
\hline $8 \mathrm{R}-6,81$ & 409.63 & 1.12 & $25 \mathrm{R}-1,16$ & 539.56 & 1.51 \\
\hline $8 R-7,32$ & 410.55 & 1.23 & $25 \mathrm{R}-3,81$ & 541.30 & 1.28 \\
\hline $9 \mathrm{R}-1,73$ & 413.23 & 1.26 & $25 \mathrm{R}-4,37$ & 542.26 & 1.37 \\
\hline $9 \mathrm{R}-4,115$ & 416.60 & 1.27 & $26 \mathrm{R}-1,94$ & 549.94 & 1.37 \\
\hline 10R-1, 24 & 422.24 & 1.38 & 26R-3, 94 & 551.96 & 1.35 \\
\hline $10 \mathrm{R}-2,22$ & 423.63 & 1.29 & 26R-4, 106 & 553.34 & 1.37 \\
\hline $11 \mathrm{R}-1,61$ & 432.11 & 1.24 & $26 \mathrm{R}-5,133$ & 555.01 & 1.34 \\
\hline $11 \mathrm{R}-2,62$ & 433.52 & 1.32 & $26 \mathrm{R}-6,140$ & 556.49 & 1.35 \\
\hline 11R-3, 24 & 434.55 & 1.00 & $26 \mathrm{R}-7,102$ & 557.54 & 1.33 \\
\hline $11 \mathrm{R}-6,124$ & 437.93 & 1.27 & $27 \mathrm{R}-1,80$ & 559.30 & 1.60 \\
\hline 11R-7, 49 & 438.59 & 1.34 & 27R-3, 38 & 560.30 & 1.44 \\
\hline $12 \mathrm{R}-2,110$ & 443.51 & 1.78 & 27R-4, 91 & 562.21 & 1.37 \\
\hline $12 \mathrm{R}-3,94$ & 444.77 & 1.18 & 27R-4, 109 & 562.39 & 1.26 \\
\hline $12 \mathrm{R}-4,119$ & 446.44 & 1.21 & $27 \mathrm{R}-6,46$ & 564.59 & 1.29 \\
\hline $12 \mathrm{R}-5,16$ & 446.83 & 1.11 & $28 \mathrm{R}-1,32$ & 568.32 & 1.58 \\
\hline $12 \mathrm{R}-7,100$ & 448.33 & 1.32 & $28 \mathrm{R}-3,60$ & 570.59 & 1.37 \\
\hline $13 R-1,100$ & 451.50 & 1.31 & $30 \mathrm{R}-1,69$ & 581.09 & 1.37 \\
\hline $13 R-4,100$ & 454.68 & 1.31 & $30 \mathrm{R}-3,52$ & 582.83 & 1.43 \\
\hline 13R-5, 105 & 456.14 & 1.26 & $30 \mathrm{R}-4,4$ & 583.76 & 1.44 \\
\hline $13 \mathrm{R}-6,100$ & 457.50 & 1.19 & $31 \mathrm{R}-1,72$ & 587.22 & 1.37 \\
\hline $13 R-7,47$ & 458.38 & 1.23 & $31 \mathrm{R}-3,85$ & 589.22 & 1.36 \\
\hline $14 \mathrm{R}-1,133$ & 461.33 & 1.26 & $31 \mathrm{R}-5,66$ & 590.80 & 1.34 \\
\hline $14 \mathrm{R}-2,80$ & 462.21 & 1.28 & $32 \mathrm{R}-1,140$ & 597.40 & 1.36 \\
\hline $14 \mathrm{R}-3,20$ & 463.03 & 1.31 & 32R-2, 91 & 598.34 & 1.33 \\
\hline $14 \mathrm{R}-5,50$ & 464.12 & 1.75 & $32 \mathrm{R}-3,100$ & 599.84 & 1.38 \\
\hline 14R-6, 82 & 465.86 & 1.20 & $32 R-4,73$ & 600.98 & 1.30 \\
\hline 15R-1, 78 & 470.26 & 1.20 & $33 \mathrm{R}-1,39$ & 605.89 & 1.41 \\
\hline 15R-2, 92 & 471.77 & 1.44 & $33 \mathrm{R}-3,97$ & 607.45 & 1.35 \\
\hline $15 R-4,130$ & 473.75 & 1.16 & $33 R-4,86$ & 608.75 & 1.18 \\
\hline $15 R-5,135$ & 475.18 & 1.20 & $33 \mathrm{R}-5,97$ & 610.27 & 1.33 \\
\hline $15 R-6,53$ & 475.76 & 1.26 & $33 R-6,97$ & 611.68 & 1.31 \\
\hline 15R-7, 20 & 476.61 & 1.34 & $35 \mathrm{R}-1,22$ & 624.71 & 1.36 \\
\hline 16R-1, 125 & 478.05 & 1.41 & $35 \mathrm{R}-6,26$ & 630.22 & 1.28 \\
\hline
\end{tabular}

\begin{tabular}{|c|c|c|}
\hline $\begin{array}{l}\text { Core, section, } \\
\text { interval }(\mathrm{cm})\end{array}$ & $\begin{array}{l}\text { Depth } \\
\text { CSF (m) }\end{array}$ & $\begin{array}{c}\text { Thermal } \\
\text { conductivity } \\
(\mathrm{W} /[\mathrm{m} \cdot \mathrm{K}])\end{array}$ \\
\hline $36 \mathrm{R}-1,8$ & 634.08 & 1.27 \\
\hline $36 \mathrm{R}-3,97$ & 636.18 & 1.34 \\
\hline 36R-5, 81 & 638.84 & 1.26 \\
\hline $36 \mathrm{R}-7,35$ & 641.21 & 1.32 \\
\hline $37 \mathrm{R}-1,98$ & 644.42 & 1.31 \\
\hline 37R-3, 97 & 646.11 & 1.32 \\
\hline $37 R-4,97$ & 647.44 & 1.47 \\
\hline $37 \mathrm{R}-6,79$ & 649.91 & 1.42 \\
\hline 37R-8, 66 & 652.44 & 1.21 \\
\hline $38 \mathrm{R}-1,127$ & 654.27 & 1.27 \\
\hline $38 \mathrm{R}-3,135$ & 656.28 & 1.33 \\
\hline $38 \mathrm{R}-4,61$ & 656.95 & 1.33 \\
\hline 38R-5, 112 & 658.88 & 1.34 \\
\hline $38 \mathrm{R}-6,89$ & 660.06 & 1.32 \\
\hline $38 \mathrm{R}-7,43$ & 661.00 & 1.34 \\
\hline $39 \mathrm{R}-1,57$ & 663.07 & 1.28 \\
\hline $39 \mathrm{R}-2,29$ & 664.20 & 1.35 \\
\hline 39R-5, 136 & 668.69 & 1.35 \\
\hline $39 \mathrm{R}-7,5$ & 670.20 & 1.27 \\
\hline 40R-2, 28 & 673.68 & 1.27 \\
\hline $40 \mathrm{R}-4,5$ & 675.40 & 1.46 \\
\hline $42 \mathrm{R}-1,128$ & 681.78 & 1.49 \\
\hline $43 \mathrm{R}-1,98$ & 685.44 & 1.49 \\
\hline $43 \mathrm{R}-2,46$ & 685.84 & 1.55 \\
\hline $43 R-4,73$ & 686.44 & 1.37 \\
\hline $44 \mathrm{R}-1,106$ & 690.06 & 1.42 \\
\hline 44R-5, 58 & 693.68 & 1.40 \\
\hline $44 \mathrm{R}-7,95$ & 696.89 & 1.29 \\
\hline $45 R-4,82$ & 701.63 & 1.44 \\
\hline 46R-1, 135 & 709.35 & 1.37 \\
\hline $47 \mathrm{R}-1,75$ & 712.25 & 1.53 \\
\hline $47 \mathrm{R}-3,88$ & 714.07 & 1.33 \\
\hline $47 R-6,56$ & 717.99 & 1.56 \\
\hline $48 \mathrm{R}-1,65$ & 721.65 & 1.34 \\
\hline $48 \mathrm{R}-2,42$ & 722.42 & 1.45 \\
\hline $51 \mathrm{R}-1,109$ & 748.51 & 1.59 \\
\hline $51 \mathrm{R}-3,63$ & 750.36 & 1.34 \\
\hline $51 \mathrm{R}-6,121$ & 753.49 & 1.23 \\
\hline $52 \mathrm{R}-1,72$ & 757.67 & 1.31 \\
\hline 52R-5, 19 & 762.41 & 1.45 \\
\hline 53R-1, 27 & 766.68 & 1.26 \\
\hline $53 \mathrm{R}-3,33$ & 767.93 & 1.26 \\
\hline $54 \mathrm{R}-1,14$ & 770.34 & 1.26 \\
\hline $54 \mathrm{R}-4,133$ & 774.16 & 1.50 \\
\hline $56 \mathrm{R}-1,25$ & 844.23 & 1.53 \\
\hline $57 \mathrm{R}-1,123$ & 847.63 & 1.41 \\
\hline $57 \mathrm{R}-2,70$ & 848.51 & 1.41 \\
\hline 57R-3, 108 & 850.30 & 1.14 \\
\hline 57R-5, 115 & 852.20 & 1.39 \\
\hline 57R-7, 75 & 853.97 & 1.65 \\
\hline $58 \mathrm{R}-2,84$ & 857.96 & 1.48 \\
\hline $58 \mathrm{R}-4,128$ & 860.10 & 1.20 \\
\hline 58R-5, 116 & 861.33 & 1.24 \\
\hline 59R-1, 93 & 866.33 & 1.59 \\
\hline 59R-2, 18 & 866.93 & 1.45 \\
\hline $59 R-4,47$ & 868.46 & 1.25 \\
\hline
\end{tabular}


Table T17. Interstitial water geochemistry (raw data), Hole C0011B. (See table note.)

\begin{tabular}{|c|c|c|c|c|c|c|c|c|c|c|c|c|c|c|c|c|c|c|c|c|c|}
\hline $\begin{array}{l}\text { Core, } \\
\text { section }\end{array}$ & $\begin{array}{c}\text { Depth } \\
\text { CSF (m) }\end{array}$ & $\mathrm{pH}$ & $\begin{array}{c}\text { Alkalinity } \\
(\mathrm{mM})\end{array}$ & Salinity & $\underset{(\mathrm{mM})}{\mathrm{Cl}}$ & $\begin{array}{c}\mathrm{Na} \\
(\mathrm{mM})\end{array}$ & $\begin{array}{l}\mathrm{NH}_{4} \\
(\mathrm{mM})\end{array}$ & $\begin{array}{c}\mathrm{H}_{4} \mathrm{SiO}_{4} \\
(\mu \mathrm{M})\end{array}$ & $\begin{array}{c}\mathrm{Ca} \\
(\mathrm{mM})\end{array}$ & $\begin{array}{c}\mathrm{Mg} \\
(\mathrm{mM})\end{array}$ & $\begin{array}{c}\mathrm{Sr} \\
(\mu \mathrm{M})\end{array}$ & $\begin{array}{c}\mathrm{Li} \\
(\mu \mathrm{M})\end{array}$ & $\underset{(\mathrm{mM})}{\mathrm{K}}$ & $\begin{array}{l}\mathrm{PO}_{4} \\
(\mu \mathrm{M})\end{array}$ & $\begin{array}{c}\mathrm{SO}_{4} \\
(\mathrm{mM})\end{array}$ & $\begin{array}{c}\mathrm{Mn} \\
(\mu \mathrm{M})\end{array}$ & $\begin{array}{c}\mathrm{Br} \\
(\mathrm{mM})\end{array}$ & $\begin{array}{c}\mathrm{Ba} \\
(\mu \mathrm{M})\end{array}$ & $\begin{array}{c}B \\
(\mu \mathrm{M})\end{array}$ & $\begin{array}{c}\mathrm{HS} \\
(\mu \mathrm{M})\end{array}$ & $\begin{array}{l}\mathrm{Fe} \mathrm{II} \\
(\mu \mathrm{M})\end{array}$ \\
\hline \multicolumn{22}{|c|}{ 322-C0011B- } \\
\hline $3 R-2$ & 359.61 & 7.90 & 1.68 & 32.7 & 561 & 480 & 0.71 & 747 & 23.8 & 10.0 & 125 & 145 & 3.0 & 0.99 & 3.44 & 60 & 1.02 & 10 & 431 & 0.3 & ND \\
\hline $4 \mathrm{R}-3$ & 366.94 & 8.05 & 2.90 & 32.7 & 564 & 505 & 0.96 & 983 & 24.7 & 7.5 & 127 & 151 & 3.3 & 2.61 & 1.75 & 63 & 1.00 & 38 & 520 & ND & ND \\
\hline $5 R-2$ & 375.36 & 8.25 & 1.89 & 32.6 & 565 & - & 1.02 & - & - & - & - & - & - & ND & 1.14 & - & 0.96 & - & - & ND & ND \\
\hline $6 \mathrm{R}-5$ & 388.43 & 7.81 & 1.51 & 31.8 & 552 & 482 & 0.81 & 285 & 25.9 & 6.7 & 141 & 152 & 2.5 & 3.20 & 0.84 & 41 & 0.96 & 88 & 405 & ND & ND \\
\hline $7 R-3$ & 395.13 & 8.45 & 1.65 & 32.3 & 561 & 496 & 1.01 & 242 & 25.0 & 5.9 & 138 & 149 & 2.6 & 1.95 & 0.62 & 26 & 0.99 & 94 & 385 & ND & ND \\
\hline $8 \mathrm{R}-2$ & 404.27 & 8.73 & - & 32.4 & 554 & 494 & 1.02 & 202 & 24.8 & 6.8 & 137 & 145 & 1.0 & 2.64 & 1.41 & 23 & 0.92 & 64 & 373 & 3.2 & ND \\
\hline $9 \mathrm{R}-2$ & 413.63 & 7.72 & 1.43 & 32.6 & 563 & 496 & 1.00 & 449 & 25.3 & 7.1 & 135 & 145 & 0.6 & 2.09 & 3.12 & 44 & 0.92 & 12 & 558 & 1.3 & ND \\
\hline 10R-3 & 424.74 & 8.05 & 1.82 & 31.6 & 540 & - & 0.84 & - & - & - & - & - & - & ND & 2.89 & - & 0.91 & - & - & 4.7 & ND \\
\hline $11 \mathrm{R}-4$ & 434.64 & 8.33 & 1.63 & 32.4 & 561 & 511 & 1.00 & 655 & 26.1 & 6.0 & 150 & 151 & 0.7 & ND & 0.79 & 33 & 0.95 & 90 & 509 & 4.2 & ND \\
\hline $12 \mathrm{R}-6$ & 446.96 & 8.52 & - & 32.3 & 558 & 498 & 1.03 & 176 & 26.0 & 5.0 & 153 & 148 & 0.6 & 2.48 & 0.52 & 25 & 0.92 & 118 & 498 & 4.8 & ND \\
\hline $13 \mathrm{R}-3$ & 453.32 & 8.38 & 1.62 & 31.9 & 545 & - & 0.94 & - & - & - & - & - & - & ND & 2.71 & - & 0.91 & - & - & ND & ND \\
\hline 14R-4 & 463.15 & 8.13 & 1.47 & 32.2 & 550 & 498 & 0.88 & 195 & 27.0 & 5.8 & 164 & 152 & 0.5 & 1.84 & 1.04 & 28 & 0.94 & 95 & 529 & ND & ND \\
\hline $15 \mathrm{R}-3$ & 472.03 & 8.22 & 2.04 & 32.0 & 548 & - & 0.75 & - & - & - & - & - & - & ND & 3.24 & - & 0.91 & - & - & ND & ND \\
\hline 16R-2 & 478.21 & 8.18 & 1.84 & 32.4 & 560 & 508 & 1.01 & 187 & 28.1 & 5.7 & 169 & 157 & 0.4 & ND & 0.89 & 33 & 1.00 & 141 & 709 & 4.0 & ND \\
\hline 19R-3 & 492.65 & 8.20 & 1.17 & 31.6 & 540 & - & 0.88 & - & - & - & - & - & - & 2.63 & 1.04 & - & 0.92 & - & - & 6.5 & ND \\
\hline $21 \mathrm{R}-2$ & 501.65 & - & - & 31.5 & 546 & - & 0.77 & - & - & - & - & - & - & 2.28 & 0.93 & - & 0.94 & - & - & 6.5 & ND \\
\hline $23 \mathrm{R}-2$ & 521.15 & - & - & 31.6 & 540 & - & 0.77 & - & - & - & - & - & - & 1.31 & 0.91 & - & 0.89 & - & - & 4.5 & ND \\
\hline 24R-1 & 529.90 & 8.18 & 1.17 & - & 541 & - & 0.99 & - & - & - & - & - & - & 1.63 & 0.96 & - & 0.93 & - & - & 0.7 & ND \\
\hline $25 \mathrm{R}-2$ & 539.86 & 8.62 & 0.99 & 31.9 & 546 & 498 & 1.24 & 64 & 29.9 & 4.7 & 164 & 167 & 0.4 & ND & 1.14 & 16 & 0.91 & 11 & 278 & 1.6 & ND \\
\hline 26R-2 & 550.22 & - & - & 31.3 & 540 & - & 1.14 & - & - & - & - & - & - & 2.40 & 1.30 & - & 0.90 & - & - & ND & ND \\
\hline $27 \mathrm{R}-2$ & 559.36 & 8.53 & 1.04 & 30.9 & 536 & - & 1.13 & - & - & - & - & - & - & - & 0.93 & - & 0.97 & - & - & ND & ND \\
\hline $28 \mathrm{R}-2$ & 569.46 & - & - & 32.2 & 548 & - & 1.21 & - & - & - & - & - & - & ND & 2.17 & - & 0.90 & - & - & 5.4 & ND \\
\hline 30R-2 & 581.78 & - & - & 30.9 & 527 & 460 & 1.01 & 75 & 30.1 & 4.1 & 175 & 160 & 0.4 & 2.45 & 1.13 & 18 & 0.89 & 16 & 237 & 12.6 & ND \\
\hline $31 \mathrm{R}-5$ & 587.86 & - & - & 30.8 & 530 & 476 & - & - & 30.8 & 5.5 & - & - & 0.5 & - & 1.69 & - & 0.86 & - & - & 7.6 & ND \\
\hline $32 \mathrm{R}-5$ & 601.39 & - & - & 31.6 & 535 & 472 & 0.96 & - & 32.2 & 4.4 & - & - & 0.4 & - & 0.90 & - & 0.90 & - & - & 8.2 & ND \\
\hline $33 R-2$ & 605.94 & - & - & 30.6 & 530 & 473 & 0.98 & 68 & 31.1 & 4.3 & 174 & 159 & 0.4 & - & 0.79 & 16 & 0.91 & 11 & 230 & ND & ND \\
\hline $35 R-4$ & 628.15 & - & - & 31.1 & 523 & - & 1.03 & - & - & - & - & - & - & - & 1.96 & - & 0.86 & - & - & 4.4 & ND \\
\hline 36R-2 & 634.67 & - & - & - & 519 & 458 & 1.03 & - & 31.4 & 5.4 & - & - & 0.5 & ND & 1.73 & - & 0.89 & - & - & 13.3 & ND \\
\hline $37 \mathrm{R}-2$ & 644.71 & - & 0.71 & 31.3 & 537 & 493 & 0.80 & 77 & 35.5 & 6.7 & 174 & 165 & 0.4 & ND & 2.87 & 36 & 0.90 & 6 & 360 & 9.7 & ND \\
\hline $38 \mathrm{R}-2$ & 654.39 & - & - & 30.7 & 524 & 450 & 0.73 & - & 32.6 & 5.5 & - & - & 0.4 & ND & 3.14 & - & 0.88 & - & - & 6.6 & 3.0 \\
\hline $39 \mathrm{R}-4$ & 666.74 & - & - & 31.6 & 521 & 457 & - & - & 35.2 & 4.4 & - & - & 0.4 & - & 2.16 & - & 0.86 & - & - & 2.3 & ND \\
\hline 40R-3 & 674.82 & - & - & 31.7 & 529 & 471 & 0.74 & 59 & 34.5 & 7.5 & 173 & 175 & 0.6 & ND & 1.12 & 19 & 0.91 & 6 & 226 & 2.0 & ND \\
\hline $42 \mathrm{R}-2$ & 681.88 & - & - & 30.9 & 534 & 457 & 0.80 & 83 & 34.4 & 6.1 & 177 & 182 & 0.5 & ND & 1.91 & 19 & 0.90 & 8 & 252 & 11.5 & ND \\
\hline $43 \mathrm{R}-3$ & 685.87 & - & - & 32.6 & 530 & 487 & 0.77 & 83 & 37.3 & 5.5 & 178 & 185 & 0.5 & - & 3.78 & 11 & 0.92 & 10 & 199 & 7.6 & ND \\
\hline $44 \mathrm{R}-3$ & 691.09 & - & - & 30.9 & 520 & 449 & 0.74 & 56 & 34.1 & 6.4 & 174 & 171 & 1.8 & - & 1.26 & 12 & 0.90 & 11 & 189 & ND & ND \\
\hline $45 \mathrm{R}-3$ & 700.28 & 8.39 & 1.13 & 31.3 & 514 & 445 & 0.65 & 70 & 37.6 & 5.4 & 185 & 197 & 1.2 & - & 2.38 & 30 & 0.86 & 13 & 315 & ND & ND \\
\hline $47 \mathrm{R}-2$ & 712.61 & - & - & 30.6 & 507 & 439 & 0.61 & 67 & 39.2 & 5.6 & 186 & 200 & 1.2 & - & 2.03 & 31 & 0.83 & 13 & 265 & ND & ND \\
\hline $48 \mathrm{R}-3$ & 722.54 & - & - & - & 514 & 430 & 0.49 & - & 40.8 & 4.9 & - & - & 1.3 & - & 3.18 & - & 0.83 & - & - & ND & ND \\
\hline 51R-4 & 750.75 & - & - & 31.1 & 513 & 458 & 0.51 & 60 & 47.1 & 5.7 & 203 & 220 & 1.3 & - & 1.79 & 21 & 0.84 & 19 & 205 & ND & ND \\
\hline $52 \mathrm{R}-6$ & 763.84 & - & - & 31.5 & 516 & 431 & 0.46 & 57 & 47.8 & 7.7 & 194 & 190 & 1.4 & - & 5.45 & 21 & 0.87 & 13 & 162 & ND & ND \\
\hline 53R-2 & 767.71 & - & - & 31.8 & 513 & 430 & 0.54 & 62 & 42.6 & 14.6 & 173 & 162 & 1.9 & - & 7.86 & 32 & 0.84 & 10 & 205 & ND & 2.3 \\
\hline $55 \mathrm{R}-2$ & 779.50 & 8.83 & 1.85 & 31.0 & 529 & 443 & 0.74 & 77 & 45.7 & 3.5 & 181 & 200 & 1.5 & ND & 1.01 & 23 & 0.87 & 47 & - & ND & ND \\
\hline $56 \mathrm{R}-2$ & 844.53 & - & - & 31.6 & 521 & 405 & 0.38 & - & 65.1 & 3.4 & - & - & 1.3 & - & 3.42 & - & 0.84 & - & - & ND & ND \\
\hline 57R-4 & 850.44 & - & - & 32.8 & 533 & 416 & 0.53 & 63 & 70.3 & 1.4 & 225 & 141 & 0.9 & - & 1.72 & 3 & 0.91 & 41 & 129 & ND & 2.5 \\
\hline $58 \mathrm{R}-3$ & 858.34 & - & - & 33.0 & 544 & 423 & 0.42 & 72 & 68.6 & 3.3 & 217 & 137 & 1.0 & - & 2.51 & 13 & 0.92 & 32 & 191 & ND & ND \\
\hline $59 \mathrm{R}-3$ & 867.47 & 8.12 & 0.84 & 35.4 & 563 & 422 & 0.52 & 114 & 82.7 & 5.0 & 239 & 143 & 0.8 & ND & 7.60 & 58 & 0.94 & 13 & 285 & ND & 20.6 \\
\hline
\end{tabular}

Note: $-=$ not determined, ND $=$ not detected. 
Table T18. Interstitial water geochemistry corrected for drill fluid contamination using an assumed seawater composition listed on the table, Hole C0011B. (See table notes.)

\begin{tabular}{|c|c|c|c|c|c|c|c|c|c|c|c|c|c|c|c|c|c|c|c|c|}
\hline $\begin{array}{l}\text { Core, } \\
\text { section }\end{array}$ & $\begin{array}{c}\text { Depth } \\
\text { CSF }(m)\end{array}$ & $\mathrm{pH}$ & $\begin{array}{l}\text { Alkalinity } \\
(\mathrm{mM})\end{array}$ & Salinity & $\begin{array}{c}\mathrm{Cl} \\
(\mathrm{mM})\end{array}$ & $\begin{array}{c}\mathrm{Na} \\
(\mathrm{mM})\end{array}$ & $\begin{array}{c}\mathrm{NH}_{4} \\
(\mathrm{mM})\end{array}$ & $\begin{array}{c}\mathrm{H}_{4} \mathrm{SiO}_{4} \\
(\mu \mathrm{M})\end{array}$ & $\begin{array}{c}\mathrm{Ca} \\
(\mathrm{mM})\end{array}$ & $\begin{array}{c}\mathrm{Mg} \\
(\mathrm{mM})\end{array}$ & $\begin{array}{c}\mathrm{Sr} \\
(\mu \mathrm{M})\end{array}$ & $\begin{array}{c}\mathrm{Li} \\
(\mu \mathrm{M})\end{array}$ & $\underset{(\mathrm{mM})}{\mathrm{K}}$ & $\begin{array}{l}\mathrm{PO}_{4} \\
(\mu \mathrm{M})\end{array}$ & $\begin{array}{c}\mathrm{SO}_{4} \\
(\mathrm{mM})\end{array}$ & $\begin{array}{c}\mathrm{Mn} \\
(\mu \mathrm{M})\end{array}$ & $\begin{array}{c}\mathrm{Br} \\
(\mathrm{mM})\end{array}$ & $\begin{array}{c}\mathrm{Ba} \\
(\mu \mathrm{M})\end{array}$ & $\begin{array}{c}\text { B } \\
(\mu \mathrm{M})\end{array}$ & $\begin{array}{c}\mathrm{HS} \\
(\mu \mathrm{M})\end{array}$ \\
\hline \multicolumn{2}{|c|}{ Seawater values: } & & 2.30 & 34.9 & 558 & 479 & 0 & 160 & 10.5 & 54.3 & 91 & 26 & 10.4 & 3.00 & 28.9 & 0 & 0.80 & 0.15 & 416 & 0.0 \\
\hline \multicolumn{21}{|c|}{ 322-C0011B- } \\
\hline $3 \mathrm{R}-2$ & 359.61 & 7.90 & 1.60 & 32.4 & 560 & 499 & 0.71 & 826 & 25.6 & 4.0 & 130 & 161 & 2.0 & 0.72 & - & 68 & 1.05 & 11 & 433 & 0.3 \\
\hline $4 \mathrm{R}-3$ & 366.94 & 8.05 & 2.94 & 32.5 & 564 & 499 & 0.96 & 1036 & 25.7 & 4.5 & 129 & 159 & 2.8 & 2.58 & - & 67 & 1.01 & 40 & 527 & ND \\
\hline $5 R-2$ & 375.36 & 8.25 & 1.87 & 32.5 & 565 & - & 1.02 & - & - & - & - & - & - & - & - & - & 0.97 & - & - & ND \\
\hline $6 \mathrm{R}-5$ & 388.43 & 7.81 & 1.49 & 31.7 & 551 & 485 & 0.81 & 289 & 26.3 & 5.3 & 143 & 155 & 2.2 & 3.21 & - & 42 & 0.97 & 90 & 405 & ND \\
\hline $7 R-3$ & 395.13 & 8.45 & 1.64 & 32.2 & 561 & 497 & 1.01 & 244 & 25.3 & 4.8 & 139 & 151 & 2.4 & 1.93 & - & 26 & 0.99 & 96 & 385 & ND \\
\hline $8 \mathrm{R}-2$ & 404.27 & 8.73 & & 32.3 & 554 & 495 & 1.02 & 204 & 25.5 & 4.3 & 139 & 151 & 0.5 & 2.62 & - & 24 & 0.92 & 68 & 370 & 3.2 \\
\hline $9 \mathrm{R}-2$ & 413.63 & 7.72 & 1.33 & 32.3 & 563 & 506 & 1.00 & 484 & 27.1 & 1.3 & 140 & 160 & - & 1.98 & - & 49 & 0.93 & 13 & 575 & 1.3 \\
\hline $10 R-3$ & 424.74 & 8.05 & 1.77 & 31.3 & 538 & - & 0.84 & - & - & - & - & - & - & - & - & - & 0.92 & - & - & 4.7 \\
\hline $11 \mathrm{R}-4$ & 434.64 & 8.33 & 1.61 & 32.4 & 561 & 497 & 1.00 & 669 & 26.6 & 4.6 & 151 & 155 & 0.5 & - & - & 34 & 0.95 & 93 & 512 & 4.2 \\
\hline $12 \mathrm{R}-6$ & 446.96 & 8.52 & & 32.2 & 558 & 498 & 1.03 & 176 & 26.3 & 4.1 & 154 & 151 & 0.4 & 2.47 & - & 26 & 0.92 & 120 & 500 & 4.8 \\
\hline $13 R-3$ & 453.32 & 8.38 & 1.54 & 31.6 & 544 & - & 0.94 & - & - & - & - & - & - & - & - & - & 0.92 & - & - & ND \\
\hline 14R-4 & 463.15 & 8.13 & 1.44 & 32.1 & 550 & 486 & 0.88 & 196 & 27.6 & 3.9 & 167 & 157 & 0.1 & 1.80 & - & 29 & 0.94 & 99 & 533 & ND \\
\hline $15 \mathrm{R}-3$ & 472.03 & 8.22 & 2.00 & 31.6 & 546 & - & 0.75 & - & - & - & - & - & - & - & - & - & 0.92 & - & - & ND \\
\hline 16R-2 & 478.21 & 8.18 & 1.82 & 32.3 & 560 & 493 & 1.01 & 187 & 28.7 & 4.2 & 171 & 161 & 0.1 & - & - & 34 & 1.01 & 145 & 718 & 4.0 \\
\hline 19R-3 & 492.65 & 8.20 & 1.13 & 31.5 & 539 & - & 0.88 & - & - & - & - & - & - & 2.62 & - & - & 0.93 & - & - & 6.5 \\
\hline $21 \mathrm{R}-2$ & 501.65 & - & - & 31.4 & 545 & - & 0.77 & - & - & - & - & - & - & 2.26 & - & - & 0.95 & - & - & 4.5 \\
\hline $23 R-2$ & 521.15 & - & - & 31.4 & 540 & - & 0.77 & - & - & - & - & - & - & 1.26 & - & - & 0.89 & - & - & 4.5 \\
\hline 24R-1 & 529.90 & 8.18 & 1.13 & - & 541 & - & 0.99 & - & - & - & - & - & - & 1.58 & - & - & 0.94 & - & - & 0.7 \\
\hline $25 \mathrm{R}-2$ & 539.86 & 8.62 & 0.94 & 31.8 & 545 & 479 & 1.24 & 60 & 30.7 & 2.6 & 167 & 173 & 0.0 & - & - & 16 & 0.92 & 11 & 272 & 1.6 \\
\hline 26R-2 & 550.22 & - & - & 31.2 & 540 & - & 1.14 & - & - & - & - & - & - & 2.37 & - & - & 0.91 & - & - & ND \\
\hline $27 \mathrm{R}-2$ & 559.36 & 8.53 & 1.00 & 30.8 & 536 & - & 1.13 & - & - & - & - & - & - & - & - & - & 0.97 & - & - & ND \\
\hline $28 \mathrm{R}-2$ & 569.46 & - & - & 31.9 & 547 & - & 1.21 & - & - & - & - & - & - & - & - & - & 0.91 & - & - & 5.4 \\
\hline 30R-2 & 581.78 & - & - & 30.8 & 525 & 460 & 1.01 & 72 & 39.9 & 2.1 & 178 & 164 & 0.0 & 2.43 & - & 19 & 0.89 & 17 & 230 & 12.6 \\
\hline $31 \mathrm{R}-5$ & 587.86 & - & - & 30.6 & 528 & 460 & - & - & 32.0 & 2.4 & - & - & - & - & - & - & 0.86 & - & - & 7.6 \\
\hline $32 \mathrm{R}-5$ & 601.39 & - & - & 31.5 & 535 & 464 & 0.96 & - & 33.0 & 2.8 & - & - & 0.0 & - & - & - & 0.91 & - & - & 8.2 \\
\hline $33 \mathrm{R}-2$ & 605.94 & - & - & 30.5 & 529 & 461 & 0.98 & 65 & 31.7 & 2.9 & 177 & 163 & 0.1 & - & - & 16 & 0.91 & 11 & 225 & ND \\
\hline $35 R-4$ & 628.15 & - & - & 30.8 & 520 & - & 1.03 & - & - & - & - & - & - & - & - & - & 0.87 & - & - & 4.4 \\
\hline 36R-2 & 634.67 & - & - & - & 517 & 448 & 1.03 & - & 32.8 & 2.3 & - & - & - & ND & - & - & 0.89 & - & - & 13.3 \\
\hline $37 \mathrm{R}-2$ & 644.71 & - & 0.54 & 30.9 & 535 & 457 & 0.80 & 68 & 38.2 & 1.5 & 183 & 180 & - & ND & - & 40 & 0.92 & 7 & 354 & 9.7 \\
\hline $38 \mathrm{R}-2$ & 654.39 & - & - & 30.2 & 520 & 452 & 0.73 & - & 35.3 & - & - & - & - & ND & - & - & 0.89 & - & - & 6.6 \\
\hline $39 \mathrm{R}-4$ & 666.74 & - & - & 31.3 & 518 & 445 & - & - & 37.2 & 0.4 & - & - & - & - & - & - & 0.87 & - & - & 2.3 \\
\hline 4OR-3 & 674.82 & - & - & 31.5 & 527 & 446 & 0.74 & 55 & 35.4 & 5.6 & 177 & 181 & 0.2 & ND & - & 20 & 0.92 & 6 & 219 & 2.0 \\
\hline $42 \mathrm{R}-2$ & 681.88 & - & - & 30.7 & 532 & 456 & 0.80 & 77 & 36.1 & 2.7 & 183 & 193 & - & ND & - & 21 & 0.90 & 8 & 241 & 11.5 \\
\hline $43 R-3$ & 685.87 & - & - & 32.2 & 526 & 449 & 0.77 & 72 & 41.3 & - & 192 & 209 & - & - & - & 13 & 0.94 & 12 & 166 & 7.6 \\
\hline $44 \mathrm{R}-3$ & 691.09 & - & - & 30.8 & 518 & 439 & 0.74 & 51 & 35.2 & 4.2 & 177 & 177 & 1.4 & - & - & 13 & 0.91 & 12 & 179 & ND \\
\hline $45 \mathrm{R}-3$ & 700.28 & 8.39 & 1.02 & 31.0 & 510 & 427 & 0.65 & 61 & 40.1 & 1.0 & 193 & 213 & 0.3 & - & - & 32 & 0.86 & 14 & 306 & ND \\
\hline 47R-2 & 712.61 & - & - & 30.3 & 504 & 417 & 0.61 & 60 & 41.4 & 1.9 & 193 & 214 & 0.5 & - & - & 33 & 0.84 & 14 & 253 & ND \\
\hline $48 \mathrm{R}-3$ & 722.54 & - & - & - & 509 & 423 & 0.49 & - & 44.5 & - & - & - & 0.1 & - & - & - & 0.83 & - & - & ND \\
\hline 51R-4 & 750.75 & - & - & 30.9 & 510 & 406 & 0.51 & 54 & 49.5 & 2.5 & 210 & 233 & 0.7 & - & - & 22 & 0.84 & 20 & 191 & ND \\
\hline $55 \mathrm{R}-2$ & 779.50 & 8.83 & 1.83 & 30.9 & 528 & 428 & 0.74 & 74 & 47.0 & 1.7 & 184 & 206 & 1.2 & ND & - & 24 & 0.88 & 49 & - & ND \\
\hline $56 \mathrm{R}-2$ & 844.53 & - & - & 31.2 & 516 & 379 & 0.38 & - & 72.4 & - & - & - & 0.1 & - & - & - & 0.84 & - & - & ND \\
\hline 57R-4 & 850.44 & - & - & 32.6 & 531 & 388 & 0.53 & 57 & 74.1 & - & 234 & 149 & 0.3 & - & - & 3 & 0.91 & 44 & 111 & ND \\
\hline $58 \mathrm{R}-3$ & 858.34 & - & - & 32.8 & 542 & 398 & 0.42 & 63 & 74.1 & - & 229 & 148 & 0.1 & - & - & 14 & 0.93 & 35 & 169 & ND \\
\hline
\end{tabular}


Table T19. Hydrocarbon gas composition in headspace samples of sediments, Hole C0011B. (See table note.)

\begin{tabular}{|c|c|c|c|c|c|c|c|c|c|c|}
\hline \multirow{2}{*}{$\begin{array}{l}\text { Core, section, } \\
\text { interval }(\mathrm{cm})\end{array}$} & \multirow{2}{*}{$\begin{array}{l}\text { Depth } \\
\operatorname{CSF}(\mathrm{m})\end{array}$} & \multicolumn{4}{|c|}{ Concentration in headspace (ppmv) } & \multirow[b]{2}{*}{$\mathrm{C}_{1} / \mathrm{C}_{2}$} & \multicolumn{4}{|c|}{ Concentration in interstitial water $(\mu \mathrm{M})$} \\
\hline & & Methane & Ethane & Propane & Isobutane & & Methane & Ethane & Propane & Isobutane \\
\hline \multicolumn{11}{|l|}{ 322-C0011B- } \\
\hline 1R-1, 83.5-87.5 & 340.86 & 105 & BD & BD & BD & - & 182 & BD & BD & BD \\
\hline $2 \mathrm{R}-1,124-128$ & 350.76 & 166 & BD & BD & BD & - & 59 & BD & BD & BD \\
\hline $3 R-1,57-61$ & 359.57 & 545 & BD & $\mathrm{BD}$ & BD & - & 538 & BD & BD & BD \\
\hline $4 R-1,136.5-140.5$ & 366.39 & 341 & BD & $\mathrm{BD}$ & $\mathrm{BD}$ & - & 182 & BD & BD & BD \\
\hline 5R-4, 104-108 & 378.02 & 346 & BD & $\mathrm{BD}$ & BD & - & 262 & BD & BD & $\mathrm{BD}$ \\
\hline $6 R-4,16-20$ & 388.31 & 477 & BD & BD & BD & - & 289 & BD & BD & BD \\
\hline 7R-2, 16-20 & 397.14 & 345 & BD & BD & BD & - & 195 & BD & BD & BD \\
\hline $8 \mathrm{R}-3,0-4$ & 404.61 & 781 & BD & $\mathrm{BD}$ & BD & - & 294 & BD & BD & $B D$ \\
\hline 9R-1, 109-113 & 413.61 & 634 & BD & $\mathrm{BD}$ & BD & - & 310 & BD & $B D$ & $\mathrm{BD}$ \\
\hline 10R-2, 130-134 & 424.73 & 697 & 1.9 & BD & BD & 359 & 132 & 0.37 & BD & $\mathrm{BD}$ \\
\hline $11 \mathrm{R}-1,136-140$ & 432.88 & 1200 & 2.9 & $\mathrm{BD}$ & BD & 411 & 514 & 1.25 & BD & $B D$ \\
\hline $12 \mathrm{R}-5,25-29$ & 446.94 & 1170 & 3.0 & $\mathrm{BD}$ & BD & 390 & 876 & 2.24 & BD & BD \\
\hline 13R-2, 137-141 & 453.30 & 1020 & 2.8 & $\mathrm{BD}$ & BD & 360 & 1110 & 3.08 & $\mathrm{BD}$ & BD \\
\hline $14 \mathrm{R}-3,29-33$ & 463.14 & 2680 & 7.0 & $\mathrm{BD}$ & BD & 381 & 1120 & 2.95 & BD & BD \\
\hline 15R-2, 109-113 & 471.95 & 1780 & 4.9 & BD & BD & 359 & 1040 & 2.89 & BD & BD \\
\hline 16R-1, 137-141 & 478.19 & 1950 & 7.0 & $\mathrm{BD}$ & BD & 280 & 863 & 3.08 & BD & BD \\
\hline 19R-2, 31-35 & 492.58 & 742 & 2.1 & $\mathrm{BD}$ & BD & 345 & 1030 & 2.99 & $\mathrm{BD}$ & $B D$ \\
\hline $21 \mathrm{R}-3,0-4$ & 502.28 & 3290 & 10.1 & $\mathrm{BD}$ & $\mathrm{BD}$ & 325 & 1350 & 4.15 & $\mathrm{BD}$ & $B D$ \\
\hline 23R-1, 69.5-74.5 & 521.12 & 2850 & 8.4 & $B D$ & BD & 337 & 2520 & 7.46 & BD & BD \\
\hline 24R-2, 0-4 & 530.49 & 1260 & 3.6 & $\mathrm{BD}$ & BD & 354 & 1050 & 2.96 & $B D$ & BD \\
\hline 25R-1, 42-46 & 539.84 & 1400 & 5.3 & $\mathrm{BD}$ & BD & 266 & 1670 & 6.28 & BD & BD \\
\hline 26R-1, 118-122 & 550.20 & 1480 & 4.1 & BD & BD & 362 & 2300 & 6.34 & BD & $\mathrm{BD}$ \\
\hline $27 \mathrm{R}-1,82-86$ & 559.34 & 1570 & 5.1 & $\mathrm{BD}$ & BD & 311 & 1750 & 5.64 & BD & $\mathrm{BD}$ \\
\hline 28R-1, 142-146 & 569.44 & 3460 & 13.6 & 13.0 & BD & 254 & 1750 & 6.89 & 6.57 & BD \\
\hline 30R-1, 134-138 & 581.76 & 285 & $\mathrm{BD}$ & BD & BD & - & 257 & BD & BD & BD \\
\hline 31R-1, 129-133 & 587.81 & 2370 & 8.5 & 9.4 & BD & 279 & 1850 & 6.64 & 7.33 & BD \\
\hline $32 \mathrm{R}-4,110.5-114.5$ & 601.37 & 1430 & 7.0 & 11.0 & BD & 203 & 1030 & 5.07 & 7.93 & BD \\
\hline $33 \mathrm{R}-1,40-44$ & 605.92 & 1490 & 6.5 & 8.7 & BD & 228 & 619 & 2.71 & 3.63 & BD \\
\hline 35R-3, 99-103 & 628.12 & 3810 & 16.1 & 21.6 & BD & 237 & 2160 & 9.13 & 12.25 & BD \\
\hline $36 \mathrm{R}-1,62.5-66.5$ & 634.65 & 1070 & 4.8 & 6.2 & BD & 222 & 1600 & 7.19 & 9.22 & $\mathrm{BD}$ \\
\hline 37R-1, 125-129 & 644.69 & 1570 & 6.9 & 8.8 & BD & 228 & 2450 & 10.72 & 13.66 & BD \\
\hline 38R-1, 135-139 & 654.37 & 1410 & 6.1 & 7.2 & BD & 232 & 2790 & 12.01 & 14.25 & $\mathrm{BD}$ \\
\hline 39R-3, 138-142 & 666.72 & 1240 & 6.0 & 7.0 & BD & 207 & 1390 & 6.75 & 7.87 & $\mathrm{BD}$ \\
\hline 40R-2, 137.5-141.5 & 674.80 & 3870 & 16.9 & 18.9 & 3.6 & 229 & 2970 & 12.98 & 14.52 & 2.74 \\
\hline $41 \mathrm{R}-1,1-5$ & 678.53 & 2270 & 8.9 & 8.2 & BD & 256 & 1860 & 7.24 & 6.73 & BD \\
\hline 42R-1, 134-138 & 681.86 & 3690 & 14.6 & 13.7 & BD & 253 & 3120 & 12.35 & 11.62 & BD \\
\hline $43 \mathrm{R}-2,49.5-53.5$ & 685.87 & 1150 & 5.1 & 4.8 & $\mathrm{BD}$ & 226 & 2070 & 9.15 & 8.60 & BD \\
\hline 44R-2, 64-68 & 691.07 & 866 & 3.4 & $\mathrm{BD}$ & BD & 257 & 2940 & 11.46 & BD & BD \\
\hline $45 \mathrm{R}-2,31-35$ & 700.26 & 4140 & 17.2 & 15.8 & $\mathrm{BD}$ & 240 & 3450 & 14.38 & 13.17 & $B D$ \\
\hline 46R-1, 135.5-139.5 & 709.38 & 2120 & 10.5 & 10.5 & BD & 203 & 2410 & 11.84 & 11.86 & BD \\
\hline 47R-1, 107-111 & 712.59 & 826 & 3.6 & BD & BD & 227 & 2520 & 11.08 & BD & BD \\
\hline $48 \mathrm{R}-2,49.5-53.5$ & 722.52 & 1180 & 5.8 & 4.6 & BD & 203 & 2830 & 13.93 & 11.09 & $\mathrm{BD}$ \\
\hline 49R-5, 101-105 & 734.59 & 2920 & 16.3 & 13.9 & BD & 179 & 3650 & 20.37 & 17.40 & BD \\
\hline 50R-CC, 0-4 & 741.05 & 806 & 5.7 & 5.1 & 4.3 & 141 & 1020 & 7.26 & 6.45 & 5.50 \\
\hline $51 \mathrm{R}-3,75.5-79.5$ & 750.49 & 1740 & 7.1 & 3.9 & BD & 244 & 4100 & 16.78 & 9.25 & BD \\
\hline 52R-5, 115-119 & 763.32 & 4670 & 22.8 & 14.3 & BD & 205 & 3540 & 17.27 & 10.83 & BD \\
\hline 54R-2, 91.5-95.5 & 772.55 & 937 & 5.3 & BD & 5.8 & 177 & 576 & 3.26 & BD & 3.54 \\
\hline $55 \mathrm{R}-1,46-50$ & 779.48 & 1430 & 4.5 & BD & BD & 319 & 4790 & 15.02 & BD & BD \\
\hline $56 \mathrm{R}-1,53-57$ & 844.51 & 3640 & 20.4 & 5.1 & BD & 179 & 7690 & 43.07 & 10.87 & BD \\
\hline 57R-3, 118.5-122.5 & 850.43 & 1370 & 3.5 & BD & BD & 396 & 2010 & 5.07 & BD & BD \\
\hline $58 \mathrm{R}-2,120-124$ & 858.33 & 4230 & 13.5 & $\mathrm{BD}$ & BD & 313 & 1800 & 5.76 & BD & BD \\
\hline $59 \mathrm{R}-2,69-73$ & 867.46 & 1990 & 4.4 & $\mathrm{BD}$ & BD & 450 & 1610 & 3.58 & BD & $\mathrm{BD}$ \\
\hline
\end{tabular}

Note: $\mathrm{BD}=$ below detection, $-=$ not applicable. 
Table T20. $\mathrm{H}_{2}$ concentration in sediment samples, determined by extraction method, Hole C0011B.

\begin{tabular}{|c|c|c|c|c|c|}
\hline $\begin{array}{l}\text { Core, section, } \\
\text { interval }(\mathrm{cm})\end{array}$ & $\begin{array}{l}\text { Depth } \\
\text { CSF (m) }\end{array}$ & $\begin{array}{l}\text { Headspace } \\
\text { volume } \\
(\mathrm{mL})\end{array}$ & $\begin{array}{l}\text { Interstitial } \\
\text { water } \\
\text { volume } \\
(\mathrm{mL})\end{array}$ & $\begin{array}{c}\mathrm{H}_{2} \\
\text { concentration } \\
\text { in headspace } \\
\text { gas (ppmv) }\end{array}$ & $\begin{array}{c}\mathrm{H}_{2} \\
\text { concentration in } \\
\text { interstitial water } \\
(\mu \mathrm{M})\end{array}$ \\
\hline \multicolumn{6}{|l|}{ 322-C0011B- } \\
\hline $3 R-1,57-61$ & 359.57 & 5.0 & 0.35 & 0.87 & 0.36 \\
\hline $4 \mathrm{R}-1,136.5-140.5$ & 366.39 & 10.0 & 1.47 & 1.42 & 0.39 \\
\hline 5R-4, 104-108 & 378.02 & 10.0 & 0.90 & 0.27 & 0.095 \\
\hline $6 \mathrm{R}-4,16-20$ & 388.31 & 11.0 & 0.76 & 0.51 & 0.30 \\
\hline $7 R-2,18.5-22.5$ & 395.12 & 5.0 & 1.17 & 7.62 & 1.35 \\
\hline $8 \mathrm{R}-3,0-4$ & 404.61 & 5.0 & 1.06 & 7.29 & 1.43 \\
\hline $9 \mathrm{R}-3,0-4$ & 414.06 & 5.0 & 1.37 & 1.83 & 0.25 \\
\hline $10 \mathrm{R}-2,130-134$ & 424.73 & 5.0 & 4.71 & 5.66 & 0.25 \\
\hline $11 \mathrm{R}-5,0-4$ & 435.30 & 5.0 & 1.46 & 22.3 & 3.24 \\
\hline $12 \mathrm{R}-5,25-29$ & 446.94 & 6.5 & 0.78 & 0.66 & 0.17 \\
\hline 13R-2, 137-141 & 453.30 & 6.0 & 0.78 & 2.02 & 0.60 \\
\hline $14 \mathrm{R}-5,0-4$ & 463.64 & 5.0 & 1.24 & 49.6 & 8.52 \\
\hline $15 R-2,109-113$ & 471.95 & 5.5 & 1.56 & 4.01 & 0.57 \\
\hline 16R-1, 137-141 & 478.19 & 5.5 & 0.87 & 30.0 & 8.01 \\
\hline $19 \mathrm{R}-2,31-35$ & 492.58 & 5.0 & 0.58 & 1.53 & 0.46 \\
\hline $21 R-3,0-4$ & 502.28 & 8.0 & 1.15 & 2.53 & 0.71 \\
\hline $23 \mathrm{R}-1,69.5-74.5$ & 521.12 & 6.0 & 0.65 & 4.03 & 1.50 \\
\hline $24 \mathrm{R}-2,0-4$ & 530.49 & 4.5 & 0.50 & 1.30 & 0.38 \\
\hline $25 \mathrm{R}-1,42-46$ & 539.84 & 4.5 & 0.28 & 1.50 & 0.82 \\
\hline $26 \mathrm{R}-1,118-122$ & 550.20 & 5.0 & 0.41 & 2.00 & 0.90 \\
\hline $27 \mathrm{R}-1,82-86$ & 559.34 & 4.5 & 0.71 & 1.45 & 0.31 \\
\hline 28R-1, 142-146 & 569.44 & 4.5 & 1.35 & 1.40 & 0.16 \\
\hline 30R-1, 134-138 & 581.76 & 6.5 & 0.38 & 4.18 & 2.88 \\
\hline 31R-1, 129-133 & 587.81 & 4.5 & 0.41 & 0.76 & 0.21 \\
\hline $32 \mathrm{R}-4,110.5-114.5$ & 601.37 & 4.5 & 0.66 & 1.47 & 0.34 \\
\hline $33 \mathrm{R}-1,40-44$ & 605.92 & 5.5 & 0.90 & 0.42 & 0.05 \\
\hline $35 R-3,99-103$ & 628.12 & 5.0 & 1.46 & 3.53 & 0.48 \\
\hline $36 \mathrm{R}-1,62.5-66.5$ & 634.65 & 5.0 & 0.52 & 0.85 & 0.23 \\
\hline 37R-1, 125-129 & 644.69 & 4.5 & 0.63 & 1.45 & 0.35 \\
\hline $38 \mathrm{R}-1,135-139$ & 654.37 & 5.0 & 0.30 & 0.74 & 0.32 \\
\hline 39R-3, 138-142 & 666.72 & 4.5 & 0.68 & 0.64 & 0.09 \\
\hline 40R-2, 137.5-141.5 & 674.80 & 5.0 & 1.02 & 4.39 & 0.87 \\
\hline 42R-1, 134-138 & 681.86 & 5.0 & 0.52 & 2.64 & 0.97 \\
\hline $43 R-2,49.5-53.5$ & 685.87 & 4.5 & 0.70 & 62.9 & 17.4 \\
\hline $44 \mathrm{R}-2,64-68$ & 691.07 & 5.5 & 0.40 & 1.59 & 0.80 \\
\hline $45 \mathrm{R}-2,31-35$ & 700.26 & 5.5 & 0.88 & 0.92 & 0.19 \\
\hline $46 \mathrm{R}-1,135.5-139.5$ & 709.38 & 6.5 & 0.68 & 3.06 & 1.16 \\
\hline $48 \mathrm{R}-2,49.5-53.5$ & 722.52 & 6.0 & 0.50 & 0.79 & 0.30 \\
\hline 49R-5, 101-105 & 734.59 & 6.0 & 0.85 & 3.79 & 1.08 \\
\hline 50R-CC, 0-4 & 741.05 & 6.4 & 0.77 & 2.49 & 0.82 \\
\hline $51 \mathrm{R}-3,75.5-79.5$ & 750.49 & 5.5 & 0.25 & 2.57 & 2.21 \\
\hline 52R-5, 115-119 & 763.32 & 5.5 & 1.17 & 0.66 & 0.09 \\
\hline $58 \mathrm{R}-2,120-124$ & 858.33 & 4.5 & 1.23 & 41.9 & 6.57 \\
\hline $59 \mathrm{R}-2,69-73$ & 867.46 & 5.5 & 0.69 & 14.1 & 4.72 \\
\hline
\end{tabular}


Table T21. $\mathrm{H}_{2}$ concentration in free drilling fluids inside the core liner, determined by extraction method, Hole C0011B.

\begin{tabular}{|c|c|c|c|c|c|}
\hline $\begin{array}{l}\text { Core, } \\
\text { section }\end{array}$ & $\begin{array}{l}\text { Depth } \\
\operatorname{CSF}(\mathrm{m})\end{array}$ & $\begin{array}{c}\text { Headspace } \\
\text { volume } \\
(\mathrm{mL})\end{array}$ & $\begin{array}{l}\text { Drilling fluid } \\
\text { volume } \\
\quad(\mathrm{mL})\end{array}$ & $\begin{array}{c}\mathrm{H}_{2} \\
\text { concentration } \\
\text { in headspace } \\
\text { gas (ppmv) }\end{array}$ & $\begin{array}{l}\mathrm{H}_{2} \\
\text { concentration } \\
\text { in drilling fluid } \\
(\mu \mathrm{M})\end{array}$ \\
\hline \multicolumn{6}{|c|}{ 322-C0011B- } \\
\hline 23R-1 & 521.12 & 5.00 & 12.00 & 104 & 1.86 \\
\hline $23 \mathrm{R}-9$ & 529.12 & 5.00 & 12.00 & 544 & 0.98 \\
\hline 28R-1 & 569.44 & 4.50 & 12.50 & 14.7 & 0.23 \\
\hline $35 \mathrm{R}-3$ & 628.12 & 4.00 & 13.00 & 51.3 & 0.69 \\
\hline 38R-1 & 654.37 & 5.00 & 12.00 & 35.8 & 0.64 \\
\hline $39 \mathrm{R}-3$ & 666.72 & 5.00 & 12.00 & 41.4 & 0.74 \\
\hline $42 \mathrm{R}-1$ & 681.86 & 5.50 & 11.50 & 43.8 & 0.09 \\
\hline $43 \mathrm{R}-2$ & 685.87 & 6.00 & 11.00 & 1.28 & 0.03 \\
\hline 46R-1 & 709.38 & 5.00 & 12.00 & 5.23 & 0.09 \\
\hline $52 \mathrm{R}-5$ & 763.32 & 6.00 & 11.00 & 41.6 & 0.97 \\
\hline 53R-1 & 767.29 & 6.50 & 10.50 & 27.7 & 0.73 \\
\hline $58 \mathrm{R}-2$ & 858.33 & 5.50 & 11.50 & 62.8 & 1.29 \\
\hline $59 \mathrm{R}-2$ & 867.46 & 5.50 & 11.50 & 43.4 & 0.90 \\
\hline
\end{tabular}


Table T22. $\mathrm{H}_{2}$ concentration in sediment samples, determined by incubation method, Hole C0011B. (See table note.) (Continued on next page.)

\begin{tabular}{|c|c|c|c|c|c|c|c|c|c|c|}
\hline \multirow[b]{2}{*}{$\begin{array}{l}\text { Core, section, } \\
\text { interval }(\mathrm{cm})\end{array}$} & \multirow[b]{2}{*}{$\begin{array}{l}\text { Depth } \\
\text { CSF (m) }\end{array}$} & \multirow[b]{2}{*}{$\begin{array}{c}T \\
\left({ }^{\circ} \mathrm{C}\right)\end{array}$} & \multirow[b]{2}{*}{$1 / \beta$} & \multirow[b]{2}{*}{$\begin{array}{c}t \\
(\mathrm{~h})\end{array}$} & \multicolumn{2}{|c|}{ Replicate 1} & \multicolumn{2}{|c|}{ Replicate 2} & \multicolumn{2}{|c|}{ Replicate 3} \\
\hline & & & & & $\begin{array}{c}\mathrm{H}_{2} \text { in } \\
\text { headspace } \\
\text { gas (ppmv) }\end{array}$ & $\begin{array}{c}\mathrm{H}_{2} \text { in } \\
\text { interstitial } \\
\text { water (nM) }\end{array}$ & $\begin{array}{c}\mathrm{H}_{2} \text { in } \\
\text { headspace } \\
\text { gas (ppmv) }\end{array}$ & $\begin{array}{c}\mathrm{H}_{2} \text { in } \\
\text { interstitial } \\
\text { water }(\mathrm{nM})\end{array}$ & $\begin{array}{c}\mathrm{H}_{2} \text { in } \\
\text { headspace } \\
\text { gas (ppmv) }\end{array}$ & $\begin{array}{c}\mathrm{H}_{2} \text { in } \\
\text { interstitial } \\
\text { water (nM) }\end{array}$ \\
\hline \multicolumn{11}{|l|}{ 322-C0011B- } \\
\hline \multirow[t]{9}{*}{$15 R-3,42-52$} & 472.50 & 40 & 69.94 & 0.0 & 0.20 & 0.11 & 0.06 & 0.04 & 0.38 & 0.21 \\
\hline & & & & 48.4 & 6.13 & 3.41 & 2.35 & 1.31 & 11.7 & 6.50 \\
\hline & & & & 70.8 & 5.01 & 2.79 & 1.52 & 0.85 & 9.28 & 5.16 \\
\hline & & & & 121.7 & 4.87 & 2.71 & 1.56 & 0.87 & 6.60 & 3.67 \\
\hline & & & & 144.3 & 3.76 & 2.09 & 1.80 & 1.00 & 5.97 & 3.32 \\
\hline & & & & 190.3 & 2.54 & 1.41 & 1.22 & 0.68 & 4.75 & 2.64 \\
\hline & & & & 239.4 & 1.87 & 1.04 & 1.05 & 0.58 & 3.97 & 2.21 \\
\hline & & & & 260.8 & 1.07 & 0.60 & 1.36 & 0.76 & 3.48 & 1.94 \\
\hline & & & & 630.5 & 0.74 & 0.41 & 0.75 & 0.42 & 1.69 & 0.94 \\
\hline \multirow[t]{10}{*}{$21 \mathrm{R}-2,36-46$} & 502.06 & 40 & 69.94 & 0.0 & 0.01 & 0.00 & 0.04 & 0.02 & 0.01 & 0.00 \\
\hline & & & & 29.3 & 2.20 & 1.22 & 3.17 & 1.76 & 3.08 & 1.71 \\
\hline & & & & 54.3 & 1.17 & 0.65 & 4.16 & 2.31 & 3.99 & 2.22 \\
\hline & & & & 76.5 & 2.50 & 1.39 & 3.27 & 1.82 & 4.37 & 2.43 \\
\hline & & & & 104.5 & 2.32 & 1.29 & 2.76 & 1.54 & 3.86 & 2.15 \\
\hline & & & & 127.3 & 2.17 & 1.20 & 2.33 & 1.30 & 2.49 & 1.39 \\
\hline & & & & 172.7 & 1.38 & 0.77 & 1.93 & 1.07 & 2.27 & 1.26 \\
\hline & & & & 221.3 & 1.38 & 0.77 & 1.78 & 0.99 & 1.29 & 0.72 \\
\hline & & & & 243.1 & 0.93 & 0.52 & 1.69 & 0.94 & 1.29 & 0.72 \\
\hline & & & & 611.8 & 1.23 & 0.68 & 0.72 & 0.40 & 1.01 & 0.56 \\
\hline \multirow[t]{8}{*}{$25 R-2,52-62$} & 540.43 & 40 & 69.94 & 0.0 & 0.32 & 0.18 & 0.06 & 0.03 & 0.93 & 0.52 \\
\hline & & & & 6.1 & 11.8 & 6.59 & 6.88 & 3.83 & 5.35 & 2.98 \\
\hline & & & & 31.2 & 10.8 & 5.99 & 7.86 & 4.37 & 5.23 & 2.91 \\
\hline & & & & 54.5 & 7.56 & 4.20 & 5.57 & 3.10 & 4.58 & 2.55 \\
\hline & & & & 125.1 & 4.14 & 2.30 & 3.25 & 1.81 & 2.21 & 1.23 \\
\hline & & & & 173.1 & 2.45 & 1.37 & 2.53 & 1.41 & 1.74 & 0.97 \\
\hline & & & & 194.4 & 2.12 & 1.18 & 1.95 & 1.09 & 1.99 & 1.11 \\
\hline & & & & 563.2 & 0.66 & 0.37 & 0.98 & 0.54 & 0.78 & 0.44 \\
\hline $32 R-5,57-67$ & 602.01 & 40 & 69.94 & 0.0 & 8.42 & 4.68 & 0.26 & 0.15 & 0.55 & 0.31 \\
\hline & & & & 5.9 & 28.9 & 16.1 & 17.4 & 9.69 & 44.1 & 24.5 \\
\hline & & & & 29.2 & 17.4 & 9.70 & 32.0 & 17.8 & 66.3 & 36.9 \\
\hline & & & & 77.0 & 37.8 & 21.0 & 27.9 & 15.5 & 50.7 & 28.2 \\
\hline & & & & 125.1 & 32.1 & 17.8 & 22.5 & 12.5 & 38.7 & 21.5 \\
\hline & & & & 145.0 & 29.5 & 16.4 & 19.4 & 10.8 & 32.6 & 18.2 \\
\hline & & & & 513.1 & 13.8 & 7.65 & 9.22 & 5.13 & 8.31 & 4.62 \\
\hline $35 R-1,46-56$ & 624.98 & 40 & 69.94 & 0.0 & 2.75 & 1.53 & 7.57 & 4.21 & 4.23 & 2.35 \\
\hline & & & & 26.4 & 6.61 & 3.68 & 10.1 & 5.61 & 5.04 & 2.81 \\
\hline & & & & 49.8 & 7.59 & 4.22 & 10.8 & 6.03 & 5.58 & 3.11 \\
\hline & & & & 96.4 & 6.93 & 3.85 & 10.9 & 6.06 & 4.63 & 2.57 \\
\hline & & & & 145.6 & 6.49 & 3.61 & 10.1 & 5.64 & 4.02 & 2.24 \\
\hline & & & & 534.0 & 3.89 & 2.17 & 7.16 & 3.99 & 0.94 & 0.52 \\
\hline $45 R-4,0-10$ & 700.86 & 50 & 70.66 & 0.0 & 2.74 & 1.46 & 1.15 & 0.61 & 0.69 & 0.37 \\
\hline & & & & 8.4 & 62.7 & 33.5 & 1.41 & 0.75 & 3.49 & 1.86 \\
\hline & & & & 22.0 & 57.8 & 30.9 & 2.36 & 1.26 & 4.02 & 2.14 \\
\hline & & & & 29.2 & 53.4 & 28.5 & 2.53 & 1.35 & 4.84 & 2.58 \\
\hline & & & & 74.8 & 41.9 & 22.4 & 2.48 & 1.32 & 4.41 & 2.35 \\
\hline & & & & 121.7 & 33.8 & 18.0 & 1.97 & 1.05 & 3.55 & 1.89 \\
\hline & & & & 145.2 & 29.0 & 15.5 & 2.00 & 1.07 & 3.88 & 2.07 \\
\hline & & & & 515.2 & 9.73 & 5.19 & 0.99 & 0.53 & 1.91 & 1.02 \\
\hline $48 \mathrm{R}-3,15-25$ & 722.69 & 50 & 70.66 & 0.0 & 0.06 & 0.03 & 0.02 & 0.01 & 0.00 & 0.00 \\
\hline & & & & 7.6 & 3.05 & 1.63 & 1.26 & 0.67 & 1.03 & 0.55 \\
\hline & & & & 53.6 & 4.91 & 2.62 & 3.08 & 1.64 & 2.85 & 1.52 \\
\hline & & & & 100.4 & 4.79 & 2.56 & 2.87 & 1.53 & 4.00 & 2.14 \\
\hline & & & & 123.7 & 5.10 & 2.72 & 1.91 & 1.02 & 3.86 & 2.06 \\
\hline & & & & 495.1 & 3.76 & 2.01 & 2.70 & 1.44 & 4.60 & 2.46 \\
\hline $54 \mathrm{R}-3,10-20$ & 772.67 & 50 & 70.66 & 0.0 & 0.16 & 0.09 & 0.33 & 0.17 & 1.38 & 0.73 \\
\hline & & & & 54.4 & 2.06 & 1.10 & 4.01 & 2.14 & 12.4 & 6.63 \\
\hline & & & & 77.7 & 2.44 & 1.30 & 3.74 & 1.99 & 12.5 & 6.65 \\
\hline & & & & 446.6 & 1.12 & 0.60 & 1.45 & 0.78 & 4.29 & 2.29 \\
\hline 58R-6, 123-135 & 862.66 & 50 & 70.66 & 0.0 & 0.44 & 0.23 & 1.06 & 0.57 & 0.90 & 0.48 \\
\hline & & & & 1.6 & 92.3 & 49.3 & 46.1 & 24.6 & 38.4 & 20.5 \\
\hline & & & & 4.7 & 133 & 70.8 & 75.7 & 40.4 & 64.9 & 34.7 \\
\hline
\end{tabular}


Table T22 (continued).

\begin{tabular}{|c|c|c|c|c|c|c|c|c|c|c|}
\hline \multirow[b]{2}{*}{$\begin{array}{l}\text { Core, section, } \\
\text { interval }(\mathrm{cm})\end{array}$} & \multirow[b]{2}{*}{$\begin{array}{l}\text { Depth } \\
\text { CSF (m) }\end{array}$} & \multirow[b]{2}{*}{$\begin{array}{c}T \\
\left({ }^{\circ} \mathrm{C}\right)\end{array}$} & \multirow[b]{2}{*}{$1 / \beta$} & \multirow[b]{2}{*}{$\begin{array}{c}t \\
(\mathrm{~h})\end{array}$} & \multicolumn{2}{|c|}{ Replicate 1} & \multicolumn{2}{|c|}{ Replicate 2} & \multicolumn{2}{|c|}{ Replicate 3} \\
\hline & & & & & $\begin{array}{c}\mathrm{H}_{2} \text { in } \\
\text { headspace } \\
\text { gas (ppmv) }\end{array}$ & $\begin{array}{c}\mathrm{H}_{2} \text { in } \\
\text { interstitial } \\
\text { water }(\mathrm{nM})\end{array}$ & $\begin{array}{c}\mathrm{H}_{2} \text { in } \\
\text { headspace } \\
\text { gas (ppmv) }\end{array}$ & $\begin{array}{c}\mathrm{H}_{2} \text { in } \\
\text { interstitial } \\
\text { water }(\mathrm{nM})\end{array}$ & $\begin{array}{c}\mathrm{H}_{2} \text { in } \\
\text { headspace } \\
\text { gas (ppmv) }\end{array}$ & $\begin{array}{c}\mathrm{H}_{2} \text { in } \\
\text { interstitial } \\
\text { water }(\mathrm{nM})\end{array}$ \\
\hline & & & & 7.6 & 143 & 76.6 & 84.4 & 45.0 & 71.7 & 38.2 \\
\hline & & & & 25.1 & 185 & 98.8 & 122 & 65.3 & 105 & 55.9 \\
\hline & & & & 394.4 & 223 & 119 & 152 & 81.1 & 138 & 73.6 \\
\hline
\end{tabular}

Note: $T$ = incubation temperature, $\beta=$ experimentally determined solubility constant corrected for temperature and salinity (Crozier and Yamamoto, 1974), $t=$ duration of incubation. 
Table T23. Total carbon, inorganic carbon, total organic carbon, total nitrogen, and total sulfur contents in the solid phase of sediments, Hole C0011B. (See table note.) (Continued on next two pages.)

\begin{tabular}{|c|c|c|c|c|c|c|c|c|}
\hline $\begin{array}{l}\text { Core, section, } \\
\text { interval }(\mathrm{cm})\end{array}$ & $\begin{array}{l}\text { Depth } \\
\operatorname{CSF}(m)\end{array}$ & $\begin{array}{c}\text { IC } \\
(w t \%)\end{array}$ & $\begin{array}{l}\mathrm{CaCO}_{3} \\
\text { (wt\%) }\end{array}$ & $\begin{array}{c}\mathrm{TN} \\
(w t \%)\end{array}$ & $\begin{array}{c}\text { TC } \\
\text { (wt\%) }\end{array}$ & $\begin{array}{c}\text { TS } \\
\text { (wt\%) }\end{array}$ & $\begin{array}{l}\text { TOC } \\
\text { (wt\%) }\end{array}$ & $\mathrm{TOC} / \mathrm{TN}$ \\
\hline \multicolumn{9}{|l|}{ 322-C0011B- } \\
\hline 1R-1, 22-24 & 340.23 & 0.10 & 0.81 & 0.0162 & 0.20 & 0.19 & 0.11 & 7.6 \\
\hline $1 \mathrm{R}-1,38-40$ & 340.39 & 1.01 & 8.39 & 0.0680 & 1.46 & 0.25 & 0.46 & 7.9 \\
\hline $1 \mathrm{R}-2,26-26.5$ & 341.14 & 0.09 & 0.77 & 0.0624 & 0.38 & 0.11 & 0.29 & 5.4 \\
\hline 1R-2, 89.5-90.5 & 341.78 & 0.08 & 0.71 & 0.0415 & 0.26 & 0.06 & 0.18 & 4.9 \\
\hline $2 R-1,59-61$ & 350.10 & 0.09 & 0.72 & 0.0625 & 0.42 & 0.14 & 0.34 & 6.3 \\
\hline 2R-CC, 19-21 & 350.98 & 0.08 & 0.69 & 0.0149 & 0.15 & 0.10 & 0.07 & 5.3 \\
\hline $3 R-1,22-24$ & 359.23 & 0.49 & 4.06 & 0.0642 & 0.87 & 0.11 & 0.38 & 6.9 \\
\hline $3 R-2,25-27$ & 359.85 & 0.14 & 1.18 & 0.0664 & 0.49 & 0.14 & 0.35 & 6.1 \\
\hline $3 R-4,118.5-120.5$ & 362.64 & 0.07 & 0.58 & 0.0600 & 0.31 & 0.37 & 0.24 & 4.7 \\
\hline $3 R-5,18.5-20.5$ & 362.99 & 0.60 & 4.97 & 0.0753 & 1.18 & 0.29 & 0.58 & 9.0 \\
\hline $4 \mathrm{R}-2,45-47$ & 366.87 & 0.19 & 1.54 & 0.0610 & 0.33 & 0.30 & 0.15 & 2.8 \\
\hline $4 \mathrm{R}-3,0-2$ & 366.95 & 0.20 & 1.64 & 0.0317 & 0.40 & 0.32 & 0.20 & 7.3 \\
\hline $5 R-2,25-27$ & 375.63 & 0.12 & 1.00 & 0.0149 & 0.18 & 0.14 & 0.06 & 5.0 \\
\hline $5 R-4,105-108$ & 378.03 & 0.12 & 0.97 & 0.0593 & 0.36 & 0.11 & 0.24 & 4.8 \\
\hline $6 \mathrm{R}-1,128-130$ & 385.29 & 0.69 & 5.79 & 0.0731 & 1.16 & 0.19 & 0.46 & 7.4 \\
\hline $6 \mathrm{R}-2,70-72$ & 386.09 & 1.02 & 8.51 & 0.0636 & 1.44 & 0.18 & 0.42 & 7.8 \\
\hline $6 \mathrm{R}-3,105-107$ & 387.81 & 0.05 & 0.41 & 0.0649 & 0.32 & 0.39 & 0.28 & 5.0 \\
\hline $6 R-5,25-27$ & 388.59 & 0.43 & 3.54 & 0.0626 & 0.72 & 0.21 & 0.30 & 5.5 \\
\hline $6 \mathrm{R}-8,15-17$ & 391.75 & 1.19 & 9.94 & 0.0623 & 1.59 & 0.14 & 0.40 & 7.5 \\
\hline $7 R-1,38-40.5$ & 393.89 & 0.44 & 3.64 & 0.0658 & 0.77 & 0.13 & 0.33 & 5.9 \\
\hline $7 R-2,7.5-9.5$ & 395.00 & 0.12 & 0.99 & 0.0173 & 0.19 & 0.21 & 0.07 & 4.7 \\
\hline $7 R-3,0-2$ & 395.15 & 0.16 & 1.35 & 0.0179 & 0.24 & 0.18 & 0.07 & 4.8 \\
\hline 7R-5, 101.5-103.5 & 397.86 & 0.67 & 5.62 & 0.0710 & 1.17 & 0.17 & 0.50 & 8.2 \\
\hline $8 R-1,4-5$ & 403.05 & 0.07 & 0.60 & 0.0619 & 0.32 & 0.12 & 0.25 & 4.7 \\
\hline $8 R-2,0-2$ & 404.28 & 0.27 & 2.28 & 0.0365 & 0.46 & 0.14 & 0.19 & 6.0 \\
\hline $8 R-3,19-21$ & 404.79 & 0.19 & 1.62 & 0.0644 & 0.31 & 0.22 & 0.11 & 2.1 \\
\hline $8 R-5,104-106$ & 408.46 & 0.14 & 1.15 & 0.0590 & 0.39 & 0.14 & 0.26 & 5.1 \\
\hline 8R-6, 107-109 & 409.90 & 0.23 & 1.93 & 0.0663 & 0.42 & 1.1 & 0.19 & 3.3 \\
\hline $9 R-1,32.5-34.5$ & 412.84 & 0.67 & 5.56 & 0.0543 & 0.94 & 0.06 & 0.27 & 5.9 \\
\hline $9 \mathrm{R}-2,0-2$ & 413.64 & 0.19 & 1.55 & 0.0200 & 0.27 & 0.15 & 0.09 & 5.3 \\
\hline $9 R-5,14-15$ & 417.01 & 0.34 & 2.84 & 0.0671 & 0.68 & 0.11 & 0.34 & 6.0 \\
\hline $10 \mathrm{R}-1,32-34$ & 422.33 & 0.19 & 1.59 & 0.0691 & 0.60 & 0.10 & 0.41 & 6.9 \\
\hline $10 \mathrm{R}-3,0-2$ & 424.76 & 0.06 & 0.47 & 0.0733 & 0.38 & 0.12 & 0.33 & 5.2 \\
\hline $11 \mathrm{R}-2,31-33$ & 433.22 & 1.01 & 8.45 & 0.0648 & 1.45 & 0.08 & 0.43 & 7.8 \\
\hline $11 \mathrm{R}-2,85-87$ & 433.76 & 0.05 & 0.42 & 0.0554 & 0.27 & 0.12 & 0.22 & 4.5 \\
\hline $11 R-4,0-2$ & 434.65 & 0.10 & 0.81 & 0.0623 & 0.27 & 0.15 & 0.18 & 3.3 \\
\hline 11R-5, 107-109 & 436.32 & 0.08 & 0.64 & 0.0609 & 0.34 & 0.38 & 0.27 & 5.1 \\
\hline 11R-7, 71-73 & 438.78 & 0.05 & 0.38 & 0.0648 & 0.60 & 0.18 & 0.55 & 10 \\
\hline $11 R-7,132-134$ & 439.39 & 0.30 & 2.47 & 0.0642 & 0.32 & 0.44 & 0.02 & 0.4 \\
\hline $12 R-2,50-52$ & 442.92 & 0.42 & 3.52 & 0.0565 & 0.65 & 0.05 & 0.23 & 4.7 \\
\hline $12 R-2,82-84$ & 443.24 & 0.05 & 0.46 & 0.0572 & 0.29 & 0.11 & 0.23 & 4.7 \\
\hline $12 R-3,50-52$ & 444.34 & 0.67 & 5.56 & 0.0590 & 1.11 & 0.15 & 0.44 & 8.7 \\
\hline $12 R-3,75-77$ & 444.59 & 0.71 & 5.90 & 0.0634 & 1.08 & 0.12 & 0.38 & 6.9 \\
\hline $12 R-4,62-64$ & 445.88 & 0.36 & 2.98 & 0.0747 & 0.95 & 0.22 & 0.59 & 9.2 \\
\hline $12 R-6,0-2$ & 446.97 & 0.33 & 2.74 & 0.0420 & 0.57 & 0.15 & 0.24 & 6.7 \\
\hline $12 R-7,83-85$ & 448.17 & 0.05 & 0.45 & 0.0610 & 0.28 & 0.08 & 0.23 & 4.4 \\
\hline $13 R-3,30-35$ & 453.65 & 0.06 & 0.49 & 0.0700 & 0.42 & 0.08 & 0.36 & 6.0 \\
\hline $13 R-4,51-53$ & 454.20 & 0.05 & 0.41 & 0.0635 & 0.32 & 0.11 & 0.27 & 5.0 \\
\hline $13 R-5,26-28$ & 455.36 & 0.34 & 2.80 & 0.0659 & 0.76 & 0.27 & 0.22 & 3.3 \\
\hline $13 R-5,78-80$ & 455.88 & 1.02 & 8.48 & 0.0515 & 1.29 & 0.21 & 0.27 & 5.2 \\
\hline 13R-5, 104-106 & 456.14 & 0.03 & 0.30 & 0.0711 & 0.53 & 0.32 & 0.50 & 7.0 \\
\hline $14 \mathrm{R}-2,17.5-19.5$ & 461.60 & 0.04 & 0.33 & 0.0636 & 0.30 & 0.12 & 0.26 & 4.7 \\
\hline $14 \mathrm{R}-4,0-2$ & 463.17 & 0.16 & 1.30 & 0.0562 & 0.59 & 0.58 & 0.44 & 9.0 \\
\hline $14 \mathrm{R}-5,45-47$ & 464.08 & 0.12 & 1.01 & 0.0318 & 0.27 & 0.22 & 0.15 & 5.6 \\
\hline $14 R-6,4-6$ & 465.09 & 0.08 & 0.67 & 0.0643 & 0.37 & 0.12 & 0.29 & 5.3 \\
\hline $15 R-1,103-105$ & 470.54 & 0.32 & 2.69 & 0.0612 & 0.67 & 7.1 & 0.35 & 6.6 \\
\hline $15 R-2,45-47$ & 471.33 & 0.03 & 0.24 & 0.0714 & 0.35 & 0.40 & 0.32 & 5.2 \\
\hline $15 R-2,111-113$ & 471.99 & 0.04 & 0.31 & 0.0671 & 0.32 & 0.22 & 0.28 & 4.9 \\
\hline $15 R-3,0-2$ & 471.98 & 0.03 & 0.29 & 0.0680 & 0.32 & 0.12 & 0.29 & 4.9 \\
\hline $15 R-4,117-119$ & 473.66 & 0.35 & 2.90 & 0.0879 & 1.10 & 0.46 & 0.75 & 10 \\
\hline $16 \mathrm{R}-1,103-105$ & 477.84 & 0.11 & 0.92 & 0.0360 & 0.26 & 0.21 & 0.15 & 4.7 \\
\hline $16 \mathrm{R}-2,0-2$ & 478.22 & 0.11 & 0.94 & 0.0325 & 0.25 & 0.21 & 0.14 & 4.9 \\
\hline $19 R-3,0-2$ & 492.61 & 0.36 & 2.97 & 0.0667 & 0.67 & 0.04 & 0.32 & 5.6 \\
\hline $19 R-4,20-22$ & 493.17 & 0.04 & 0.32 & 0.0710 & 0.31 & 0.10 & 0.27 & 4.5 \\
\hline $19 R-4,74-76$ & 493.71 & 0.33 & 2.71 & 0.0773 & 0.88 & 0.35 & 0.56 & 8.4 \\
\hline $19 R-5,32-34$ & 494.63 & 0.04 & 0.32 & 0.0698 & 0.31 & 0.05 & 0.27 & 4.5 \\
\hline
\end{tabular}


Table T23 (continued). (Continued on next page.)

\begin{tabular}{|c|c|c|c|c|c|c|c|c|}
\hline $\begin{array}{l}\text { Core, section, } \\
\text { interval }(\mathrm{cm})\end{array}$ & $\begin{array}{l}\text { Depth } \\
\text { CSF (m) }\end{array}$ & $\underset{\text { (wt } \%)}{\text { IC }}$ & $\begin{array}{l}\mathrm{CaCO}_{3} \\
\text { (wt\%) }\end{array}$ & $\begin{array}{c}\mathrm{TN} \\
\text { (wt\%) }\end{array}$ & $\begin{array}{c}\text { TC } \\
\text { (wt\%) }\end{array}$ & $\begin{array}{c}\text { TS } \\
\text { (wt } \%)\end{array}$ & $\begin{array}{l}\text { TOC } \\
\text { (wt\%) }\end{array}$ & TOC/TN \\
\hline 19R-5, 133-135 & 495.64 & 4.01 & 33.5 & 0.0400 & 4.37 & 0.03 & 0.35 & 10.2 \\
\hline 19R-6, 19-21 & 495.82 & 0.05 & 0.44 & 0.0709 & 0.34 & 0.10 & 0.29 & 4.8 \\
\hline 20R-1, 15-17 & 498.56 & 7.40 & 61.7 & 0.0252 & 7.68 & 0.01 & 0.28 & 12.8 \\
\hline $21 \mathrm{R}-2,0-2$ & 501.66 & 0.03 & 0.29 & 0.0988 & 0.31 & 0.06 & 0.27 & 3.2 \\
\hline $21 R-4,106-108$ & 504.74 & 0.03 & 0.28 & 0.0936 & 0.30 & 0.10 & 0.27 & 3.3 \\
\hline 21R-5, 130-132 & 506.39 & 0.07 & 0.55 & 0.0922 & 0.36 & 0.14 & 0.30 & 3.7 \\
\hline $23 \mathrm{R}-2,0-2$ & 521.16 & 0.11 & 0.91 & 0.0880 & 0.47 & 0.29 & 0.36 & 4.8 \\
\hline 23R-3, 117.5-119.5 & 522.75 & 0.03 & 0.27 & 0.0919 & 0.39 & 18.8 & 0.36 & 4.5 \\
\hline $23 R-4,30-32$ & 523.28 & 0.11 & 0.91 & 0.0907 & 0.42 & 0.28 & 0.31 & 4.0 \\
\hline 23R-7, 106-108 & 527.37 & 0.08 & 0.68 & 0.0878 & 0.40 & 0.16 & 0.32 & 4.3 \\
\hline $23 R-8,53-55$ & 528.25 & 0.09 & 0.75 & 0.0866 & 0.38 & 0.12 & 0.29 & 4.0 \\
\hline $24 \mathrm{R}-1,0-2$ & 529.91 & 0.23 & 1.91 & 0.0891 & 0.54 & 0.17 & 0.31 & 4.1 \\
\hline $24 \mathrm{R}-2,17-22$ & 530.67 & 0.42 & 3.50 & 0.0897 & 0.80 & 0.15 & 0.38 & 5.0 \\
\hline $25 \mathrm{R}-1,30-32$ & 539.71 & 0.23 & 1.93 & 0.0919 & 0.77 & 0.36 & 0.54 & 6.8 \\
\hline $25 \mathrm{R}-2,50-52$ & 540.37 & 0.09 & 0.71 & 0.0606 & 0.37 & 0.58 & 0.29 & 5.5 \\
\hline $25 \mathrm{R}-3,22-24$ & 540.72 & 0.04 & 0.37 & 0.0864 & 0.35 & 0.04 & 0.31 & 4.1 \\
\hline 26R-1, 112-114 & 550.13 & 0.57 & 4.73 & 0.0788 & 0.83 & 0.10 & 0.26 & 3.9 \\
\hline 26R-2, 67-69 & 550.90 & 0.14 & 1.13 & 0.0851 & 0.41 & 0.20 & 0.27 & 3.7 \\
\hline $26 \mathrm{R}-3,25-27$ & 551.28 & 0.32 & 2.67 & 0.0800 & 0.57 & 0.06 & 0.25 & 3.7 \\
\hline 26R-5, 104-106 & 554.73 & 0.12 & 1.02 & 0.0777 & 0.35 & 0.03 & 0.23 & 3.4 \\
\hline $26 \mathrm{R}-6,5-7$ & 555.15 & 0.05 & 0.43 & 0.0396 & 0.14 & 0.14 & 0.09 & 2.7 \\
\hline $27 \mathrm{R}-1,22-24$ & 558.73 & 0.37 & 3.10 & 0.0837 & 0.71 & 0.15 & 0.34 & 4.7 \\
\hline $27 R-2,48-56$ & 559.88 & 0.04 & 0.31 & 0.0806 & 0.34 & 0.08 & 0.30 & 4.4 \\
\hline $27 R-3,115-117$ & 561.08 & 0.24 & 1.96 & 0.0829 & 0.58 & 0.20 & 0.34 & 4.8 \\
\hline 27R-4, 108-110 & 562.39 & 0.04 & 0.37 & 0.0772 & 0.29 & 0.18 & 0.24 & 3.7 \\
\hline 27R-4, 138-140 & 562.69 & 0.37 & 3.05 & 0.0763 & 0.74 & 0.24 & 0.37 & 5.7 \\
\hline 27R-5, 110-112 & 563.82 & 0.03 & 0.22 & 0.0775 & 0.24 & 0.08 & 0.22 & 3.3 \\
\hline 28R-1, 17-19 & 568.18 & 0.18 & 1.49 & 0.0830 & 0.53 & 0.14 & 0.35 & 5.0 \\
\hline $28 \mathrm{R}-2,0-2$ & 569.47 & 0.23 & 1.92 & 0.0828 & 0.59 & 0.58 & 0.36 & 5.1 \\
\hline 28R-3, 18-20 & 570.18 & 0.03 & 0.24 & 0.0808 & 0.33 & 0.14 & 0.30 & 4.4 \\
\hline 30R-1, 30-32 & 580.71 & 0.11 & 0.91 & 0.0798 & 0.37 & 0.29 & 0.26 & 3.9 \\
\hline $30 \mathrm{R}-2,0-2$ & 581.79 & 0.25 & 2.10 & 0.0877 & 0.62 & 0.12 & 0.37 & 4.9 \\
\hline 31R-1, 108-110 & 587.59 & 0.05 & 0.38 & 0.0825 & 0.34 & 0.17 & 0.29 & 4.1 \\
\hline $31 \mathrm{R}-1,120-122$ & 587.71 & 7.08 & 59.0 & 0.0445 & 7.58 & 0.12 & 0.50 & 13.1 \\
\hline $31 \mathrm{R}-2,50-52$ & 588.37 & 0.11 & 0.94 & 0.0574 & 0.37 & 0.19 & 0.26 & 5.3 \\
\hline $31 \mathrm{R}-3,77-80$ & 589.19 & 0.06 & 0.46 & 0.0772 & 0.32 & 0.10 & 0.26 & 4.0 \\
\hline $32 R-2,95-98$ & 598.40 & 0.09 & 0.73 & 0.0794 & 0.35 & 0.37 & 0.26 & 3.8 \\
\hline $32 \mathrm{R}-5,0-2$ & 601.40 & 0.10 & 0.80 & 0.0816 & 0.40 & 0.38 & 0.30 & 4.3 \\
\hline $33 \mathrm{R}-1,22-24$ & 605.73 & 0.06 & 0.52 & 0.0749 & 0.35 & 0.21 & 0.28 & 4.4 \\
\hline $33 \mathrm{R}-2,0-3$ & 605.96 & 0.05 & 0.46 & 0.0766 & 0.37 & 0.15 & 0.31 & 4.8 \\
\hline 33R-3, 17-19 & 606.66 & 6.69 & 55.7 & 0.0358 & 6.96 & 0.00 & 0.27 & 8.8 \\
\hline $33 R-3,32-34$ & 606.81 & 0.84 & 7.01 & 0.0685 & 1.12 & 0.44 & 0.28 & 4.8 \\
\hline $35 \mathrm{R}-3,23-25$ & 627.41 & 0.27 & 2.24 & 0.0777 & 0.58 & 0.12 & 0.31 & 4.7 \\
\hline $35 \mathrm{R}-4,0-3$ & 628.16 & 0.06 & 0.49 & 0.0765 & 0.35 & 0.12 & 0.29 & 4.4 \\
\hline $35 R-5,87-89$ & 629.53 & 0.23 & 1.89 & 0.0677 & 0.53 & 0.19 & 0.31 & 5.3 \\
\hline $35 R-6,60-62$ & 630.59 & 0.05 & 0.46 & 0.0762 & 0.52 & 0.06 & 0.47 & 7.1 \\
\hline 35R-6, 115-117 & 631.14 & 0.14 & 1.14 & 0.0767 & 0.31 & 0.17 & 0.17 & 2.6 \\
\hline $35 R-7,94-96$ & 632.27 & 0.35 & 2.89 & 0.0815 & 0.72 & 0.32 & 0.38 & 5.4 \\
\hline $35 \mathrm{R}-8,44-46$ & 633.11 & 0.07 & 0.62 & 0.0734 & 0.33 & 0.23 & 0.25 & 4.0 \\
\hline $36 \mathrm{R}-2,50-52$ & 635.18 & 0.06 & 0.47 & 0.0756 & 0.35 & 0.07 & 0.29 & 4.5 \\
\hline $36 \mathrm{R}-3,96-98$ & 636.18 & 0.17 & 1.39 & 0.0482 & 0.36 & 0.44 & 0.20 & 4.8 \\
\hline $36 \mathrm{R}-4,127-129$ & 637.90 & 0.09 & 0.76 & 0.0769 & 0.42 & 0.12 & 0.33 & 5.0 \\
\hline 36R-5, 69-71 & 638.73 & 0.28 & 2.30 & 0.0775 & 0.62 & 0.35 & 0.35 & 5.2 \\
\hline $37 R-2,50-53$ & 645.22 & 0.25 & 2.07 & 0.0788 & 0.59 & 0.23 & 0.34 & 5.0 \\
\hline $37 R-4,9-11$ & 646.63 & 0.26 & 2.13 & 0.0690 & 0.57 & 0.16 & 0.31 & 5.2 \\
\hline 37R-5, 110-112 & 648.96 & 0.62 & 5.13 & 0.0656 & 0.99 & 0.19 & 0.38 & 6.7 \\
\hline $37 R-7,33-35$ & 650.84 & 0.12 & 0.97 & 0.0638 & 0.35 & 0.15 & 0.23 & 4.2 \\
\hline 38R-1, 72-74 & 653.73 & 0.53 & 4.43 & 0.0661 & 0.83 & 0.12 & 0.30 & 5.3 \\
\hline $38 \mathrm{R}-2,0-2$ & 654.40 & 0.30 & 2.54 & 0.0652 & 0.56 & 0.20 & 0.26 & 4.6 \\
\hline $38 R-4,64-66$ & 656.99 & 2.02 & 16.9 & 0.0568 & 2.26 & 0.05 & 0.24 & 5.0 \\
\hline 38R-6, 18-20 & 659.36 & 0.65 & 5.44 & 0.0558 & 0.92 & 0.18 & 0.27 & 5.6 \\
\hline 38R-7, 92-94 & 661.50 & 0.76 & 6.33 & 0.0610 & 0.99 & 0.29 & 0.23 & 4.4 \\
\hline $39 \mathrm{R}-1,23.5-25.5$ & 662.75 & 1.37 & 11.4 & 0.0586 & 1.61 & 0.10 & 0.23 & 4.7 \\
\hline $39 R-4,50-52$ & 667.25 & 0.25 & 2.08 & 0.0637 & 0.57 & 0.33 & 0.32 & 5.9 \\
\hline 39R-5, 108-110 & 668.42 & 0.25 & 2.05 & 0.0578 & 0.49 & 0.36 & 0.25 & 5.0 \\
\hline $39 R-6,25-27$ & 669.01 & 0.15 & 1.27 & 0.0594 & 0.38 & 0.15 & 0.23 & 4.5 \\
\hline $40 \mathrm{R}-1,30-32$ & 672.31 & 0.06 & 0.47 & 0.0623 & 0.28 & 0.15 & 0.23 & 4.3 \\
\hline 40R-2, 17-19 & 673.58 & 0.10 & 0.85 & 0.0615 & 0.36 & 0.41 & 0.26 & 4.8 \\
\hline $40 \mathrm{R}-3,0-2$ & 674.83 & 0.19 & 1.55 & 0.0604 & 0.50 & 0.21 & 0.31 & 6.1 \\
\hline
\end{tabular}


Table T23 (continued).

\begin{tabular}{|c|c|c|c|c|c|c|c|c|}
\hline $\begin{array}{l}\text { Core, section, } \\
\text { interval }(\mathrm{cm})\end{array}$ & $\begin{array}{l}\text { Depth } \\
\text { CSF }(m)\end{array}$ & $\begin{array}{c}\text { IC } \\
(w t \%)\end{array}$ & $\begin{array}{c}\mathrm{CaCO}_{3} \\
\text { (wt\%) }\end{array}$ & $\begin{array}{c}\mathrm{TN} \\
(\mathrm{wt} \%)\end{array}$ & $\begin{array}{c}\text { TC } \\
(w t \%)\end{array}$ & $\begin{array}{c}\text { TS } \\
(w t \%)\end{array}$ & $\begin{array}{c}\text { TOC } \\
\text { (wt\%) }\end{array}$ & $\mathrm{TOC} / \mathrm{TN}$ \\
\hline $42 \mathrm{R}-2,0-2$ & 681.89 & 0.24 & 1.99 & 0.0538 & 0.48 & 0.20 & 0.24 & 5.2 \\
\hline $43 R-2,40-42$ & 686.04 & 0.29 & 2.40 & 0.0516 & 0.49 & 0.09 & 0.21 & 4.7 \\
\hline $43 R-3,0-2$ & 685.88 & 0.40 & 3.30 & 0.0553 & 0.67 & 0.20 & 0.28 & 5.9 \\
\hline $43 R-4,56-58$ & 686.68 & 1.21 & 10.10 & 0.0490 & 1.47 & 0.05 & 0.26 & 6.1 \\
\hline 43R-5, 117-119 & 687.92 & 0.16 & 1.36 & 0.0547 & 0.45 & 0.24 & 0.29 & 6.2 \\
\hline $44 \mathrm{R}-2,0-3$ & 690.43 & 0.05 & 0.38 & 0.0495 & 0.26 & 0.15 & 0.22 & 5.1 \\
\hline $44 \mathrm{R}-3,0-2$ & 691.10 & 0.09 & 0.71 & 0.0534 & 0.30 & 0.25 & 0.21 & 4.6 \\
\hline $44 R-4,21-23$ & 691.91 & 0.21 & 1.79 & 0.0547 & 0.46 & 0.16 & 0.24 & 5.2 \\
\hline $44 R-7,65-67$ & 696.60 & 0.21 & 1.79 & 0.0547 & 0.46 & 0.16 & 0.24 & 5.2 \\
\hline 45R-1, 24-26 & 698.75 & 0.59 & 4.94 & 0.0696 & 1.10 & 0.39 & 0.51 & 8.5 \\
\hline $45 R-3,0-2$ & 700.29 & 0.14 & 1.18 & 0.0588 & 0.41 & 0.51 & 0.27 & 5.3 \\
\hline $45 R-4,36.5-38.5$ & 701.19 & 0.74 & 6.17 & 0.0625 & 1.16 & 0.32 & 0.42 & 7.9 \\
\hline $45 R-5,44-46$ & 702.69 & 0.19 & 1.56 & 0.0594 & 0.82 & 0.58 & 0.63 & 12.4 \\
\hline $45 R-8,12-15$ & 706.67 & 0.06 & 0.50 & 0.0619 & 0.37 & 0.35 & 0.31 & 5.8 \\
\hline 46R-1, 105-107 & 709.06 & 0.22 & 1.84 & 0.0400 & 0.48 & 0.91 & 0.26 & 7.5 \\
\hline $46 \mathrm{R}-2,25-27$ & 709.66 & 0.83 & 6.89 & 0.0485 & 1.22 & 0.28 & 0.39 & 9.4 \\
\hline $47 R-2,0-2$ & 712.62 & 0.16 & 1.34 & 0.0507 & 0.43 & 0.37 & 0.27 & 6.2 \\
\hline $47 R-4,60-62$ & 715.21 & 0.12 & 1.01 & 0.0640 & 0.66 & 2.43 & 0.53 & 9.7 \\
\hline $47 R-5,83-85$ & 716.86 & 0.09 & 0.76 & 0.0551 & 0.41 & 0.29 & 0.32 & 6.8 \\
\hline $47 R-5,113-115$ & 717.16 & 0.32 & 2.64 & 0.0531 & 0.67 & 0.43 & 0.35 & 7.7 \\
\hline 48R-2, 9-11 & 722.10 & 0.09 & 0.74 & 0.0547 & 0.43 & 0.07 & 0.34 & 7.3 \\
\hline $48 \mathrm{R}-3,25-27$ & 722.80 & 0.15 & 1.22 & 0.0752 & 0.93 & 0.32 & 0.78 & 12.2 \\
\hline $49 R-7,122-124$ & 736.15 & 0.31 & 2.57 & 0.0534 & 0.62 & 0.10 & 0.31 & 6.7 \\
\hline $50 R-2,31-33$ & 739.12 & 0.11 & 0.93 & 0.0505 & 0.38 & 0.13 & 0.27 & 6.3 \\
\hline 51R-1, 136-139 & 748.88 & 0.15 & 1.22 & 0.0471 & 0.35 & 0.09 & 0.21 & 5.1 \\
\hline $51 R-2,58-60$ & 749.38 & 0.08 & 0.67 & 0.0521 & 0.34 & 0.13 & 0.26 & 5.9 \\
\hline $51 \mathrm{R}-4,0-2$ & 750.52 & 0.07 & 0.62 & 0.0493 & 0.33 & 0.15 & 0.25 & 5.9 \\
\hline 51R-7, 135-137 & 755.05 & 0.06 & 0.51 & 0.0516 & 0.31 & 0.18 & 0.25 & 5.6 \\
\hline 52R-1, 112-114 & 758.13 & 0.07 & 0.58 & 0.0443 & 0.24 & 0.16 & 0.17 & 4.5 \\
\hline $52 R-1,60-62$ & 757.61 & 0.07 & 0.59 & 0.0484 & 0.28 & 0.25 & 0.21 & 5.0 \\
\hline $52 \mathrm{R}-2,11-13$ & 758.41 & 0.12 & 1.02 & 0.0187 & 0.23 & 0.19 & 0.11 & 6.7 \\
\hline $52 R-3,95.5-98$ & 760.58 & 0.25 & 2.08 & 0.0510 & 0.51 & 0.19 & 0.26 & 5.9 \\
\hline $52 R-5,82-84$ & 763.07 & 0.04 & 0.37 & 0.0537 & 0.28 & 0.31 & 0.24 & 5.2 \\
\hline $52 \mathrm{R}-6,0-2$ & 763.35 & 0.08 & 0.70 & 0.0626 & 0.58 & 0.44 & 0.50 & 9.2 \\
\hline $53 \mathrm{R}-1,82-84$ & 767.33 & 0.13 & 1.07 & 0.0567 & 0.37 & 0.58 & 0.24 & 5.0 \\
\hline 53R-1, 112-114 & 767.63 & 0.52 & 4.35 & 0.0537 & 0.75 & 0.64 & 0.23 & 5.0 \\
\hline $53 \mathrm{R}-2,0-2$ & 767.31 & 0.21 & 1.74 & 0.0635 & 0.67 & 0.56 & 0.46 & 8.5 \\
\hline $54 R-5,44-46$ & 774.69 & 0.06 & 0.54 & 0.0636 & 0.54 & 0.35 & 0.47 & 8.7 \\
\hline 54R-5, 70-72 & 774.95 & 0.05 & 0.38 & 0.0467 & 0.93 & 0.76 & 0.89 & 22.2 \\
\hline 54R-5, 110-112 & 775.35 & 0.03 & 0.25 & 0.0343 & 0.40 & 0.46 & 0.37 & 12.8 \\
\hline $55 \mathrm{R}-1,27-29$ & 779.28 & 0.03 & 0.22 & 0.0231 & 0.21 & 0.44 & 0.18 & 9.2 \\
\hline $55 \mathrm{R}-2,0-2$ & 779.51 & 0.01 & 0.09 & 0.0199 & 0.12 & 0.61 & 0.11 & 6.5 \\
\hline 55R-3, 77-79.5 & 780.88 & 0.01 & 0.08 & 0.0130 & 0.06 & 0.20 & 0.05 & 4.4 \\
\hline $55 R-5,23-25$ & 781.86 & 0.02 & 0.17 & 0.0202 & 0.15 & 0.30 & 0.13 & 7.5 \\
\hline $56 \mathrm{R}-2,0-2$ & 844.54 & 0.03 & 0.24 & 0.0730 & 0.78 & 0.37 & 0.75 & 12.0 \\
\hline 56R-3, 100-104 & 846.11 & 0.07 & 0.55 & 0.0540 & 0.36 & 0.18 & 0.29 & 6.3 \\
\hline 57R-2, 96-98 & 848.78 & 0.04 & 0.35 & 0.0444 & 0.24 & 0.09 & 0.20 & 5.3 \\
\hline $57 R-4,0-2$ & 850.46 & 0.06 & 0.47 & 0.0140 & 0.09 & 0.09 & 0.04 & 3.2 \\
\hline $57 R-5,120-123$ & 852.26 & 0.03 & 0.23 & 0.0367 & 0.11 & 0.23 & 0.08 & 2.6 \\
\hline 57R-6, 74-76.5 & 853.21 & 0.06 & 0.52 & 0.0217 & 0.08 & 0.18 & 0.02 & 1.1 \\
\hline 57R-6, 23-25 & 852.70 & 0.04 & 0.35 & 0.0444 & 0.24 & 0.09 & 0.20 & 1.0 \\
\hline $58 \mathrm{R}-1,48-50$ & 856.39 & 0.06 & 0.47 & 0.0140 & 0.09 & 0.09 & 0.04 & 2.5 \\
\hline 58R-1, 21-23 & 856.12 & 0.03 & 0.23 & 0.0367 & 0.11 & 0.23 & 0.08 & 5.6 \\
\hline 58R-2, 119-121 & 858.43 & 0.06 & 0.52 & 0.0217 & 0.08 & 0.18 & 0.02 & 5.9 \\
\hline $58 \mathrm{R}-3,0-2$ & 858.48 & 0.04 & 0.35 & 0.0238 & 0.11 & 0.46 & 0.07 & 11.2 \\
\hline $58 R-4,40-42$ & 859.45 & 0.46 & 3.85 & 0.0178 & 0.51 & 0.22 & 0.05 & 1.1 \\
\hline 58R-4, 100-102 & 860.05 & 0.10 & 0.79 & 0.0174 & 0.14 & 0.55 & 0.04 & 10.6 \\
\hline $58 \mathrm{R}-5,0-3$ & 860.47 & 0.04 & 0.35 & 0.0450 & 0.23 & 0.20 & 0.18 & 2.4 \\
\hline $58 R-5-72,74$ & 861.18 & 0.03 & 0.22 & 0.0464 & 0.20 & 0.10 & 0.17 & 1.4 \\
\hline $58 R-6,44.5-46.5$ & 862.19 & 0.01 & 0.12 & 0.0359 & 0.13 & 0.59 & 0.11 & 12.5 \\
\hline $59 R-3,0-2$ & 867.49 & 0.02 & 0.15 & 0.0381 & 0.13 & 0.08 & 0.11 & 1.7 \\
\hline $59 R-4,45-49$ & 868.46 & 0.02 & 0.13 & 0.0189 & 0.08 & 0.39 & 0.07 & 12.2 \\
\hline 60R-CC, 0-6 & 874.09 & 0.02 & 0.13 & 0.0385 & 0.12 & 0.08 & 0.10 & 1.8 \\
\hline
\end{tabular}

Note: IC = inorganic carbon, $\mathrm{TN}=$ total nitrogen, $\mathrm{TC}=$ total carbon, $\mathrm{TS}=$ total sulfur, $\mathrm{TOC}=$ total organic carbon. 
Table T24. Characterization of the type and maturity of organic matter, Hole C0011B. (See table notes.)

\begin{tabular}{|c|c|c|c|c|c|c|c|c|c|c|}
\hline $\begin{array}{l}\text { Core, section, } \\
\text { interval }(\mathrm{cm})\end{array}$ & $\begin{array}{l}\text { Depth } \\
\text { CSF (m) }\end{array}$ & $\begin{array}{c}\mathrm{S}_{1} \\
\text { (mg HC/g) }\end{array}$ & $\begin{array}{c}\mathrm{S}_{2} \\
(\mathrm{mg} \mathrm{HC} / \mathrm{g})\end{array}$ & $\begin{array}{c}\mathrm{S}_{3} \\
(\mathrm{mg} \mathrm{CO} / \mathrm{g})\end{array}$ & $\begin{array}{l}T_{\max } \\
\left({ }^{\circ} \mathrm{C}\right)\end{array}$ & $\begin{array}{c}\mathrm{HI} \\
\text { (mg HC/ } \\
\text { g TOC) }\end{array}$ & $\begin{array}{c}\mathrm{Ol} \\
\left(\mathrm{mg} \mathrm{CO}_{2} /\right. \\
\mathrm{g} \mathrm{TOC})\end{array}$ & $\mathrm{PI}$ & $\begin{array}{c}\text { PC } \\
\text { (wt\%) }\end{array}$ & $\begin{array}{c}\mathrm{RC} \\
(\mathrm{wt} \%)\end{array}$ \\
\hline \multicolumn{11}{|l|}{ 322-C0011B- } \\
\hline $1 \mathrm{R}-1,38-40$ & 340.39 & 0 & 0.08 & 1.43 & 405 & 17 & 298 & 0.01 & 0.05 & 0.43 \\
\hline $1 \mathrm{R}-2,26-26.5$ & 341.14 & 0 & 0.04 & 0.41 & 403 & 16 & 164 & 0 & 0.02 & 0.23 \\
\hline 2R-1, 59-61 & 350.10 & 0 & 0.04 & 0.38 & 410 & 15 & 146 & 0 & 0.02 & 0.24 \\
\hline $3 R-1,22-24$ & 359.23 & 0 & 0.04 & 0.91 & 425 & 13 & 294 & 0 & 0.03 & 0.28 \\
\hline $3 R-2,25-27$ & 359.85 & 0 & 0.02 & 0.48 & 422 & 7 & 166 & 0 & 0.02 & 0.27 \\
\hline $3 R-4,118.5-120.5$ & 362.64 & 0 & 0.02 & 0.36 & 425 & 11 & 200 & 0 & 0.01 & 0.17 \\
\hline $3 R-5,18.5-20.5$ & 362.99 & 0 & 0.18 & 1.11 & 404 & 35 & 218 & 0.02 & 0.05 & 0.46 \\
\hline $5 R-4,105-108$ & 378.03 & 0 & 0.02 & 0.6 & 417 & 10 & 300 & 0 & 0.02 & 0.18 \\
\hline $6 \mathrm{R}-1,128-130$ & 385.29 & 0 & 0.08 & 1.07 & 412 & 18 & 243 & 0 & 0.04 & 0.4 \\
\hline $6 \mathrm{R}-2,70-72$ & 386.09 & 0 & 0.03 & 1.14 & 408 & 6 & 211 & 0 & 0.04 & 0.5 \\
\hline $6 \mathrm{R}-3,105-107$ & 387.81 & 0 & 0.01 & 0.41 & 409 & 4 & 178 & 0 & 0.01 & 0.22 \\
\hline $6 \mathrm{R}-5,25-27$ & 388.59 & 0 & 0.01 & 0.84 & 408 & 4 & 350 & 0 & 0.03 & 0.21 \\
\hline $6 \mathrm{R}-8,15-17$ & 391.75 & 0 & 0.02 & 0.97 & 413 & 5 & 249 & 0 & 0.03 & 0.36 \\
\hline $7 R-1,38-40.5$ & 393.89 & 0 & 0.01 & 0.68 & 416 & 4 & 272 & 0 & 0.02 & 0.23 \\
\hline 7R-5, 101.5-103.5 & 397.86 & 0 & 0.09 & 1.11 & 410 & 23 & 285 & 0.01 & 0.05 & 0.34 \\
\hline $8 R-1,4-5$ & 403.05 & 0 & 0.02 & 0.28 & 409 & 12 & 165 & 0 & 0.01 & 0.16 \\
\hline $10 \mathrm{R}-3,0-2$ & 424.76 & 0.01 & 0.01 & 0.44 & 406 & 4 & 163 & 0.33 & 0.02 & 0.25 \\
\hline 11R-5, 107-109 & 436.32 & 0.01 & 0.08 & 0.61 & 434 & 38 & 290 & 0.11 & 0.03 & 0.18 \\
\hline $12 \mathrm{R}-6,0-2$ & 446.97 & 0.01 & 0.07 & 0.67 & 424 & 9 & 86 & 0.11 & 0.03 & 0.75 \\
\hline $13 R-3,30-35$ & 453.65 & 0 & 0.02 & 0.39 & 408 & 7 & 139 & 0 & 0.02 & 0.26 \\
\hline $14 R-6,4-6$ & 465.09 & 0 & 0.14 & 0.72 & 367 & 67 & 343 & 0.01 & 0.04 & 0.17 \\
\hline $15 R-3,0-2$ & 471.98 & 0.01 & 0.1 & 0.45 & 406 & 38 & 173 & 0.07 & 0.03 & 0.23 \\
\hline $16 \mathrm{R}-2,0-2$ & 478.22 & 0 & 0 & 0.31 & 435 & 0 & 221 & 0 & 0.01 & 0.13 \\
\hline $19 \mathrm{R}-3,0-2$ & 492.61 & 0 & 0.04 & 1.04 & 422 & 15 & 385 & 0.09 & 0.04 & 0.23 \\
\hline $21 \mathrm{R}-2,0-2$ & 501.66 & 0 & 0.04 & 0.55 & 425 & 21 & 289 & 0.01 & 0.02 & 0.17 \\
\hline 21R-4, 106-108 & 504.74 & 0 & 0.09 & 0.59 & 406 & 36 & 236 & 0.01 & 0.03 & 0.22 \\
\hline $23 \mathrm{R}-2,0-2$ & 521.16 & 0 & 0.1 & 0.57 & 414 & 31 & 178 & 0.05 & 0.03 & 0.29 \\
\hline $24 \mathrm{R}-2,17-22$ & 530.67 & 0.01 & 0.13 & 0.99 & 416 & 37 & 283 & 0.07 & 0.05 & 0.3 \\
\hline $25 \mathrm{R}-1,30-32$ & 539.71 & 0 & 0.15 & 0.87 & 419 & 37 & 212 & 0.01 & 0.04 & 0.37 \\
\hline $26 \mathrm{R}-1,112-114$ & 550.13 & 0 & 0.06 & 0.87 & 426 & 22 & 322 & 0.02 & 0.03 & 0.24 \\
\hline $26 \mathrm{R}-2,67-69$ & 550.90 & 0 & 0.04 & 0.59 & 423 & 27 & 393 & 0.01 & 0.02 & 0.13 \\
\hline $27 \mathrm{R}-1,22-24$ & 558.73 & 0 & 0.06 & 0.88 & 424 & 21 & 303 & 0.03 & 0.04 & 0.25 \\
\hline $27 \mathrm{R}-2,48-56$ & 559.88 & 0 & 0.07 & 0.51 & 418 & 28 & 204 & 0.01 & 0.02 & 0.23 \\
\hline $28 \mathrm{R}-1,17-19$ & 568.18 & 0 & 0.07 & 0.75 & 421 & 33 & 357 & 0 & 0.03 & 0.18 \\
\hline $28 \mathrm{R}-2,0-2$ & 569.47 & 0 & 0.07 & 0.77 & 422 & 28 & 308 & 0.02 & 0.03 & 0.22 \\
\hline $30 \mathrm{R}-2,0-2$ & 581.79 & 0 & 0.08 & 0.89 & 423 & 30 & 330 & 0.01 & 0.04 & 0.23 \\
\hline $32 \mathrm{R}-5,0-2$ & 601.40 & 0 & 0.04 & 0.65 & 425 & 17 & 283 & 0.04 & 0.03 & 0.2 \\
\hline $33 R-2,0-3$ & 605.96 & 0 & 0.06 & 0.53 & 427 & 30 & 265 & 0 & 0.03 & 0.17 \\
\hline $35 \mathrm{R}-3,23-25$ & 627.41 & 0 & 0.06 & 0.87 & 424 & 30 & 435 & 0 & 0.03 & 0.17 \\
\hline $35 R-4,0-3$ & 628.16 & 0 & 0.03 & 0.56 & 426 & 17 & 311 & 0 & 0.02 & 0.16 \\
\hline $36 \mathrm{R}-2,50-52$ & 635.18 & 0 & 0.03 & 0.68 & 427 & 20 & 453 & 0 & 0.03 & 0.12 \\
\hline $37 R-2,50-53$ & 645.22 & 0.01 & 0.11 & 0.98 & 419 & 33 & 297 & 0.08 & 0.04 & 0.29 \\
\hline $38 \mathrm{R}-2,0-2$ & 654.40 & 0 & 0.06 & 0.92 & 428 & 22 & 341 & 0.04 & 0.03 & 0.24 \\
\hline $39 R-4,50-52$ & 667.25 & 0 & 0.08 & 1.09 & 427 & 24 & 330 & 0.04 & 0.04 & 0.29 \\
\hline 40R-2, 17-19 & 673.58 & 0 & 0.06 & 0.51 & 427 & 24 & 204 & 0.03 & 0.02 & 0.23 \\
\hline 40R-3, 0-2 & 674.83 & 0 & 0.07 & 0.73 & 426 & 23 & 243 & 0.04 & 0.03 & 0.27 \\
\hline $42 \mathrm{R}-2,0-2$ & 681.89 & 0.01 & 0.05 & 0.83 & 428 & 24 & 395 & 0.1 & 0.03 & 0.18 \\
\hline $43 R-3,0-2$ & 685.88 & 0.01 & 0.09 & 1.01 & 421 & 36 & 404 & 0.08 & 0.04 & 0.21 \\
\hline $44 R-3,0-2$ & 691.10 & 0.01 & 0.08 & 0.65 & 428 & 47 & 382 & 0.1 & 0.03 & 0.14 \\
\hline $45 \mathrm{R}-3,0-2$ & 700.29 & 0.01 & 0.1 & 0.63 & 423 & 48 & 300 & 0.1 & 0.03 & 0.18 \\
\hline $45 R-4,36.5-38.5$ & 701.19 & 0.01 & 0.19 & 0.8 & 419 & 48 & 200 & 0.05 & 0.04 & 0.36 \\
\hline $46 \mathrm{R}-2,25-27$ & 709.66 & 0.02 & 0.13 & 0.85 & 421 & 35 & 230 & 0.1 & 0.04 & 0.33 \\
\hline $47 \mathrm{R}-2,0-2$ & 712.62 & 0.01 & 0.08 & 0.56 & 422 & 40 & 280 & 0.11 & 0.03 & 0.17 \\
\hline $48 \mathrm{R}-3,25-27$ & 722.80 & 0.02 & 0.5 & 0.63 & 426 & 83 & 105 & 0.03 & 0.07 & 0.53 \\
\hline $49 R-7,122-124$ & 736.15 & 0.01 & 0.1 & 0.6 & 435 & 33 & 200 & 0.1 & 0.03 & 0.27 \\
\hline $50 \mathrm{R}-2,31-33$ & 739.12 & 0 & 0.12 & 0.52 & 427 & 63 & 274 & 0.02 & 0.02 & 0.17 \\
\hline $51 \mathrm{R}-4,0-2$ & 750.52 & 0.01 & 0.09 & 0.58 & 430 & 38 & 242 & 0.06 & 0.03 & 0.21 \\
\hline $52 \mathrm{R}-6,0-2$ & 763.35 & 0 & 0.24 & 0.5 & 420 & 53 & 111 & 0.02 & 0.04 & 0.41 \\
\hline 54R-5, 110-112 & 775.35 & 0 & 0.22 & 0.24 & 431 & 67 & 73 & 0 & 0.03 & 0.3 \\
\hline $58 \mathrm{R}-3,0-2$ & 858.48 & 0 & 0.07 & 0.38 & 429 & 50 & 271 & 0.04 & 0.02 & 0.12 \\
\hline
\end{tabular}

Notes: Determined by Rock-Eval pyrolysis. $S_{1}=$ amount of free hydrocarbons, $S_{2}=$ amount of hydrocarbons generated through thermal cracking of nonvolatile organic matter, $\mathrm{S}_{3}=$ amount of $\mathrm{CO}_{2}$ produced during pyrolysis of kerogen, $T_{\max }=$ temperature at which the maximum release of hydrocarbons from cracking of kerogen occurs during pyrolysis, $\mathrm{HI}=$ hydrogen index, $\mathrm{Ol}=$ oxygen index, $\mathrm{PI}=$ production index, $\mathrm{PC}=$ pyrolyzable carbon, RC = residual organic carbon. 
Table T25. Depth and type distribution of sediment and interstitial water samples, Hole C0011B. (See table notes.)

\begin{tabular}{|c|c|c|c|c|c|c|}
\hline $\begin{array}{l}\text { Core, } \\
\text { section }\end{array}$ & $\begin{array}{l}\text { Top depth } \\
\text { CSF }(\mathrm{m})\end{array}$ & $\begin{array}{l}\text { Cultivation } \\
\text { studies }\end{array}$ & $\begin{array}{l}\text { Cell counting } \\
\text { and FISH } \\
\text { studies }\end{array}$ & $\begin{array}{c}\text { DNA/RNA } \\
\text { phylogeny } \\
\text { studies }\end{array}$ & RMS & $\begin{array}{c}\text { Interstitial } \\
\text { water } \\
\text { sample }\end{array}$ \\
\hline \multicolumn{7}{|c|}{ 322-C0011B- } \\
\hline $3 R-2$ & 359.6 & $5 \mathrm{~cm} \mathrm{WRC}$ & $2 \mathrm{~cm}^{3}$ slurry & $\begin{array}{l}10 \mathrm{~cm} \mathrm{WRC,} \\
10 \mathrm{~cm}^{3} \text { chip }\end{array}$ & & Yes \\
\hline $4 R-3$ & 400.0 & & & & & Yes \\
\hline $5 \mathrm{R}-2$ & 375.4 & & & & & Yes \\
\hline $6 \mathrm{R}-5$ & 388.3 & $5 \mathrm{~cm}$ WRC & $2 \mathrm{~cm}^{3}$ slurry & $10 \mathrm{~cm}$ WRC & & Yes \\
\hline $7 \mathrm{R}-3$ & 395.1 & & & & & Yes \\
\hline $8 \mathrm{R}-2$ & 404.3 & & & & & Yes \\
\hline 9R-2 & 413.6 & & & & Yes & Yes \\
\hline $10 \mathrm{R}-3$ & 424.7 & & & & & Yes \\
\hline $11 \mathrm{R}-4$ & 434.6 & $5 \mathrm{~cm}$ WRC & $2 \mathrm{~cm}^{3}$ slurry & $10 \mathrm{~cm}$ WRC & & Yes \\
\hline $12 \mathrm{R}-6$ & 447.0 & & & & & Yes \\
\hline $13 R-3$ & 453.3 & & & & & Yes \\
\hline $14 \mathrm{R}-4$ & 463.2 & & & & Yes & Yes \\
\hline $15 \mathrm{R}-2$ & 470.9 & & & & & Yes \\
\hline 16R-2 & 478.2 & & & & & Yes \\
\hline $19 \mathrm{R}-3$ & 492.7 & & & $10 \mathrm{~cm}^{3}$ chip & & Yes \\
\hline 20R-1 & 498.4 & & & & & No \\
\hline $21 \mathrm{R}-2$ & 501.7 & $5 \mathrm{~cm} \mathrm{WRC}$ & $2 \mathrm{~cm}^{3}$ slurry & $10 \mathrm{~cm}$ WRC & & Yes \\
\hline $23 R-2$ & 521.1 & & & & & Yes \\
\hline 24R-1 & 529.9 & & & $10 \mathrm{~cm}^{3}$ chip & & Yes \\
\hline $25 \mathrm{R}-2$ & 539.9 & & & $10 \mathrm{~cm}^{3}$ chip & & Yes \\
\hline $26 \mathrm{R}-2$ & 550.2 & $5 \mathrm{~cm}$ WRC & $2 \mathrm{~cm}^{3}$ slurry & $10 \mathrm{~cm}$ WRC & & Yes \\
\hline $27 \mathrm{R}-2$ & 559.4 & & & $10 \mathrm{~cm}^{3}$ chip & & Yes \\
\hline $28 \mathrm{R}-2$ & 569.5 & & & $10 \mathrm{~cm}^{3}$ chip & & Yes \\
\hline $30 \mathrm{R}-2$ & 581.8 & & & $10 \mathrm{~cm}^{3}$ chip & & Yes \\
\hline $31 \mathrm{R}-2$ & 587.9 & & & $10 \mathrm{~cm}^{3}$ chip & & Yes \\
\hline $32 \mathrm{R}-5$ & 601.4 & & & $10 \mathrm{~cm}^{3}$ chip & & Yes \\
\hline $33 R-2$ & 605.9 & & & $10 \mathrm{~cm}^{3}$ chip & & Yes \\
\hline 35R-1 & 625.0 & $5 \mathrm{~cm}$ WRC & $2 \mathrm{~cm}^{3}$ slurry & $10 \mathrm{~cm} \mathrm{WRC}$ & & No \\
\hline $35 \mathrm{R}-4$ & 628.2 & & & $10 \mathrm{~cm}^{3}$ chip & & Yes \\
\hline $36 \mathrm{R}-2$ & 634.7 & & & $10 \mathrm{~cm}^{3}$ chip & & Yes \\
\hline $37 \mathrm{R}-2$ & 644.8 & & & $10 \mathrm{~cm}^{3}$ chip & & Yes \\
\hline $38 \mathrm{R}-2$ & 654.4 & & & $10 \mathrm{~cm}^{3}$ chip & & Yes \\
\hline $39 \mathrm{R}-4$ & 666.7 & & $2 \mathrm{~cm}^{3}$ slurry & $5 \mathrm{~cm}$ WRC & & Yes \\
\hline $40 \mathrm{R}-3$ & 674.8 & & & $10 \mathrm{~cm}^{3}$ chip & & Yes \\
\hline $42 \mathrm{R}-2$ & 681.9 & & & $10 \mathrm{~cm}^{3}$ chip & & No \\
\hline $43 R-3$ & 686.9 & & & $10 \mathrm{~cm}^{3}$ chip & & Yes \\
\hline $44 \mathrm{R}-3$ & 691.1 & & & & & Yes \\
\hline $44 R-5$ & 693.6 & & & $10 \mathrm{~cm}^{3}$ chunk & & No \\
\hline $44 \mathrm{R}-6$ & 695.5 & & & $10 \mathrm{~cm}^{3}$ chunk & & No \\
\hline $45 \mathrm{R}-3$ & 700.3 & & & & & Yes \\
\hline $47 \mathrm{R}-2$ & 713.2 & & & $10 \mathrm{~cm}^{3}$ chip & & Yes \\
\hline $48 \mathrm{R}-3$ & 722.5 & $5 \mathrm{~cm}$ WRC & $2 \mathrm{~cm}^{3}$ slurry & $10 \mathrm{~cm}$ WRC & & Yes \\
\hline $51 \mathrm{R}-1$ & 748.5 & & & $10 \mathrm{~cm}^{3}$ chunk & & No \\
\hline 51R-1 & 748.5 & & & $10 \mathrm{~cm}^{3}$ chunk & & No \\
\hline $51 \mathrm{R}-4$ & 750.8 & & & & & Yes \\
\hline $52 \mathrm{R}-6$ & 763.8 & & & & & Yes \\
\hline $53 \mathrm{R}-2$ & 767.7 & & & $10 \mathrm{~cm}^{3}$ chip & & Yes \\
\hline $54 \mathrm{R}-3$ & 772.6 & $5 \mathrm{~cm}$ WRC & $2 \mathrm{~cm}^{3}$ slurry & $10 \mathrm{~cm}$ WRC & & No \\
\hline $55 R-2$ & 779.5 & & $2 \mathrm{~cm}^{3}$ slurry & $\begin{array}{l}10 \mathrm{~cm} \mathrm{WRC,} \\
10 \mathrm{~cm}^{3} \text { chip }\end{array}$ & & Yes \\
\hline $55 R-4$ & 781.5 & & & $10 \mathrm{~cm}$ WRC & & No \\
\hline $56 \mathrm{R}-2$ & 844.6 & & & $10 \mathrm{~cm}^{3}$ chip & & No \\
\hline $57 \mathrm{R}-4$ & 846.4 & & & $10 \mathrm{~cm}^{3}$ chip & & No \\
\hline $58 \mathrm{R}-3$ & 858.5 & & & & & Yes \\
\hline $58 \mathrm{R}-6$ & 862.4 & $5 \mathrm{~cm} \mathrm{WRC}$ & $2 \mathrm{~cm}^{3}$ slurry & $10 \mathrm{~cm}$ WRC & & No \\
\hline $59 \mathrm{R}-3$ & 865.4 & & & $10 \mathrm{~cm}^{3}$ chip & & Yes \\
\hline
\end{tabular}

Notes: $\mathrm{FISH}=$ fluorescence in situ hybridization. $\mathrm{RMS}=$ routine microbiology samples. $\mathrm{WRC}=$ whole-round core. 
Table T26. Event summary of SET-P tool Deployment 1, Hole C0011B, 8 September 2009. (See table note.)

\begin{tabular}{lcl}
\hline $\begin{array}{c}\text { Event } \\
\text { number }\end{array}$ & $\begin{array}{c}\text { Time* } \\
(\mathrm{h})\end{array}$ & \multicolumn{1}{c}{ Event description } \\
\hline 1 & 1423 & SET-P tool power on; data acquisition started \\
2 & 1430 & SET-P tool on rig floor \\
3 & 1502 & SET-P tool in drill pipe \\
4 & 1506 & SET-P tool connected to colleted delivery system \\
5 & 1515 & Start lowering SET-P tool downhole \\
6 & 1532 & Stop at 988 mbsl; pumps off \\
7 & 1534 & Start lowering SET-P tool downhole; pumps on \\
8 & 1543 & Stop at 1989 mbsl; pumps off \\
9 & 1546 & Start pulling SET-P tool uphole with wireline \\
10 & 1610 & Disconnect SET-P tool from wireline \\
11 & 1624 & Disconnect SET-P tool from colleted delivery system \\
12 & 1625 & Pulled SET-P tool out of drill pipe \\
13 & 1631 & Data acquisition stopped; data downloaded; SET-P tool power off \\
\hline
\end{tabular}

Note: ${ }^{*}=$ UTC +9 h. SET-P $=$ sediment temperature-pressure.

Table T27. Depth range of the five main logging units and their subunits. (See table note.)

\begin{tabular}{lrlr}
\hline $\begin{array}{c}\text { Logging } \\
\text { unit }\end{array}$ & $\begin{array}{c}\text { Depth } \\
\text { LSF }(\mathrm{m})\end{array}$ & $\begin{array}{c}\text { Logging } \\
\text { subunit }\end{array}$ & $\begin{array}{c}\text { Depth } \\
\text { LSF }(\mathrm{m})\end{array}$ \\
\hline 1 & $0-251.5$ & 1A & $0-100.0$ \\
& & 1B & $100.0-212.0$ \\
& & 1C & $212.0-251.5$ \\
2 & $251.5-478.5$ & 2A & $251.5-337.0$ \\
& & 2B & $337.0-478.5$ \\
3 & $478.5-736.0$ & 3A & $478.5-542.5$ \\
& & 3B & $542.5-649.0$ \\
4 & & 3C & $649.0-736.0$ \\
5 & $836.0-867.0$ & Four "packages" \\
& $867.0-950.5$ & 5A & $867.0-938.5$ \\
& & 5B & $938.5-950.5$ \\
\end{tabular}

Note: Logging units defined from gamma ray and ring resistivity. 